This report was supported in part, or whole, by funds from the Comprehensive Environmental Response, Compensation, and Liability Act trust fund by interagency agreement with the Agency for Toxic Substances and Disease Registry, United States Public Health Service.

\title{
Inhalation Developmental
}

Toxicology Studies: Teratology

Study of Acetone in

Mice and Rats

\section{Final Report}

T. J. Mast, Principal Investigator
J. J. Evanoff
R. J. Weigel
R. L. Rommereim
R. B. Westerberg
K. H. Stoney

November 1988

Prepared for the

National Institute of Environmental

Health Sciences, National Toxicology Program

under a Related Services Agreement

with the U.S. Department of Energy

Contract DE-AC06-76RLO 1830

Pacific Northwest Laboratory

Operated for the U.S. Department of Energy

by Battelle Memorial Institute 


\title{
DISCLAIMER
}

This report was prepared as an account of work sponsored by an agency of the United States Government. Neither the United States Government nor any agency thereof, nor Battelle Memorial Institute, nor any or their employees, makes any warranty, expressed or implied, or assumes any legal liability or responsibility for the accuracy, completeness, or usefulness of any information, apparatus, product, or process disclosed, or represents that its use would not infringe privately owned rights. Reference herein to any specific commercial product, process, or service by trade name, trademark, manufacturer, or otherwise does not necessarily constitute or imply its endorsement, recommendation, or favoring by the United States Government or any agency thereof, or Battelle Memorial Institute. The views and opinions of authors expressed herein do not necessarily state or reflect those of the United States Government or any agency thereof.

\author{
PACIFIC NORTHWEST LABORATORY \\ operated by \\ BATTELLE MEMORIAL INSTITUTE \\ for the \\ UNITED STATES DEPARTMENT OF ENERGY \\ under Contract DE-ACO6-76RLO 1830
}

\begin{tabular}{|c|c|}
\hline \multicolumn{2}{|c|}{ Printed in the United States of America } \\
\hline \multicolumn{2}{|c|}{ Available from } \\
\hline \multicolumn{2}{|c|}{ National Technical Information Service } \\
\hline \multicolumn{2}{|c|}{ United States Department of Commerce } \\
\hline \multicolumn{2}{|c|}{5285 Port Royal Road } \\
\hline \multicolumn{2}{|c|}{ Springfield, Virginia 22161} \\
\hline \multicolumn{2}{|c|}{ NTIS Price Codes } \\
\hline \multicolumn{2}{|c|}{ Microfiche A01 } \\
\hline \multicolumn{2}{|c|}{ Printed Copy } \\
\hline & Price \\
\hline Pages & Codes \\
\hline $001-025$ & $\mathrm{~A} 02$ \\
\hline $026-050$ & $\mathrm{~A} 03$ \\
\hline $051-075$ & $\mathrm{AO4}$ \\
\hline $076-100$ & A05 \\
\hline $101-125$ & $A O \infty$ \\
\hline $126-150$ & A07 \\
\hline 151.175 & AOS \\
\hline$\$ 76-200$ & $\mathrm{~A} 0 \mathrm{~g}$ \\
\hline $201-225$ & A10 \\
\hline $226-250$ & A11 \\
\hline $251-275$ & A 72 \\
\hline $276-300$ & A13 \\
\hline
\end{tabular}


"This report was supported in part, or whole, by funds from the Comprehensive Environmental Response, Compensation, and Liability Act trust fund by interagency agreement with the Agency for Toxic Substances and Disease Registry, United States Public Health Service."

INHALATION DEVELOPMENTAL TOXICOLOGY STUDIES: TERATOLOGY STUDY OF ACETONE

IN MICE AND RATS

Final Report

No. NIH-YOI-ES-70153

T.J. Mast - Principal Investigator

J.J. Evanoff

R. L. Rommereim

K.H. Stoney

R.J. Weigel

R.B. Westerberg

November 1988

Prepared for the

National Institute of Environmental Health Sciences, National Toxicology Program under a Related Services Agreement with the U.S. Department of Energy under Contract DE-AC06-76RLO 1830

Pacific Northwest Laboratory Richland, washington 99352 

Acetone, an aliphatic ketone, is a ubiquitous industrial solvent and chemical intermediate; consequently, the opportunity for human exposure is high. The potential for acetone to cause developmental toxicity was assessed in Sprague-Dawley rats exposed to 0,440, 2200, or 11000 ppm, and in Swiss (CD-1) mice exposed to 0,440,2200, and $6600 \mathrm{ppm}$ acetone vapors, $6 \mathrm{~h} / \mathrm{day}$, 7 days/week. Each of the four treatment groups consisted of 10 virgin females (for comparison), and $\approx 32$ positively mated rats or mice. Positively mated mice were exposed on days 6-17 of gestation (dg), and rats on 6-19 dg. The day of plug or sperm detection was designated as $0 \mathrm{dg}$. Body weights were obtained throughout the study period, and uterine and fetal body weights were obtained at sacrifice (rats, $20 \mathrm{dg}$; mice, $18 \mathrm{dg}$ ). Implants were enumerated and their status recorded. Live fetuses were sexed and examined for gross, visceral, skeletal, and soft-tissue craniofacial defects.

Pregnant ratg did not exhibit overt symptoms of toxicity other than statistically significant reductions for the 11000-ppm group in body weight $(14,17,20 \mathrm{dg})$, cumulative weight gain from $14 \mathrm{dg}$ onward, uterine weight and in extragestational weight gain. (EGWG = maternal body weight [20 dg] uterine weight - maternal body weight $[0 \mathrm{dg}]$.$) Mean body weights of treated$ virgin females were also reduced, but not significantly. There were no maternal deaths and the mean pregnancy rate was $\geq 938$ in all groups. No affect was observed in the mean liver or kidney weights of pregnant dams, the organ to body weight ratios, the number of implantations, the mean percent of live pups/litter, the mean percent of resorptions/litter, or the fetal sex ratio. However, fetal weights were significantly reduced for the 11000-ppm exposure group relative to the o-ppm group. The incidence of fetal malformations was not significantly increased by gestational exposure to acetone vapors, although the percent of litters with at least one pup exhibiting malformations was greater for the 11000-ppm group than for the 0-ppm group, 11.5 and 3.8 , respectively. The diversity of malformations observed in the 11000-ppm group was greater than that found in the lower dose groups or in the 0-ppm group. 
There was no increase in the incidence of fetal variations, reduced ossification sites, or in the mean incidence of fetal variations per litter.

Analysis of rat plasma samples 30 min post-exposure showed an increase in plasma acetone levels which correlated with increasing exposure concentration. Acetone levels dropped to control levels by $17 \mathrm{~h}$ pogt-exposure for all exposure groups except the 11000-ppm group. Plasma acetone levels for this group were still slightly elevated with respect to the controls at $17 \mathrm{~h}$ post-exposure. The concentration of plasma acetore levels at either $30 \mathrm{~min}$ or $17 \mathrm{~h}$ post exposure did not increase over gestation regardless of the exposure concentration. Neither exposure to acetone vapor, nor advancing gestation resulted in alterations of the plasma levels for the other two ketone bodies, acetoacetic acid and $\beta$-hydroxybutyric acid, with respect to control animals.

Swisg (CD-1) mice exhibited severe narcosis at the 11000-ppm acetone concentration; consequently, the high exposure corcentration was reduced to 6600 ppm acetone after one day of exposure. No further overt signs of toxicity were observed and there were no maternal deaths. No treatmentrelated effects on maternal or virgin body weight, maternal uterine weight, or on EGWG were noted in mice. There was a treatment-correlated increase in liver to body weight ratios in pregnant dams which may have been indicative of an induction of the $\mathrm{P}_{450}$-monooxygenase enzyme system.

The mean pregnancy rate for all mated mice was $\geq 85 \%$ in all groups. There was no effect on the number of implantations per dam, on any other reproductive indices, or on the fetal sex ratio. Developmental toxicity was observed in mice in the 6600 ppm exposure group as; 1) a statistically gignificant reduction in fetal weight, and 2) a gight, but gtatistically significant increase in the percent incidence of -ate resorptions. However, the increase in the incidence of late resorptions was not sufficient to cause a decrease in the nean number of live fetuseg per litter. The incidence of fetal malformations or variations in mice was not altered by exposure to acetone vapors at any of the levels employed. 
It may be concluded from the results of this study that the 2200-ppm acetone level was the no observable effect level (NOEL) in both the SpragueDawley (CD) rat and the Swiss (CD-1) mouse for developmental toxicity. Furthermore, since only minimal maternal toxicity was observed at 11000 ppm acetone for rats and $6600 \mathrm{ppm}$ acetone for mice, it is possible that the actual maternal NOEL is somewhat greater than $2200 \mathrm{ppm}$. 



\title{
ACKNOWLEDGMENTS
}

\author{
Responsibility \\ Name \\ Principal Investigator \\ T.J. Mast \\ Exposure System \\ R.J. Weigel \\ J.R. Decker \\ E.J. Rossignol \\ Monitoring/Analytical Chemistry \\ R.B, Westerberg \\ K.H. Stoney \\ Animal Regources Section \\ M.G. Brown \\ S.E. Rowe \\ A.E. Jarrel1 \\ Teratology Evaluations \\ T.J. Magt \\ R.L. Rommereim \\ health and Safety \\ M.L. Clark \\ Report Co-ordinator \\ J.J. Evanoff

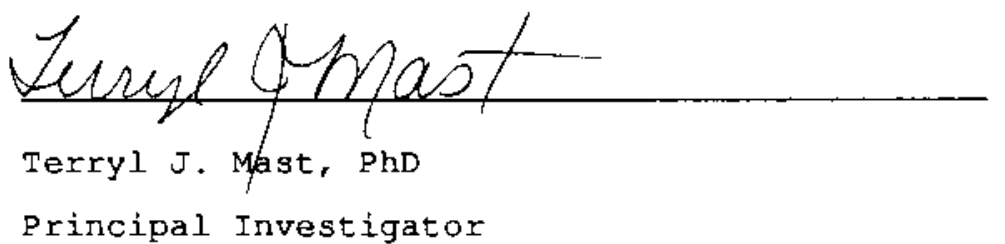

This work was supported by the National Institute of Environmental Health Sciences, National Toxicology Program under a Related Services Agreement with the U.S. Department of Energy under Contract DE-AC06-76RLO 1830 at the Pacific Northwest Laboratory operated for the U.S. Department of Energy by Battelle Memorial Institute.

The excellent technical support in the Developmental Toxicology Laboratory of B.J. Willemsen, H.W. Hill, and P.J. Boyd is much appreciated. 

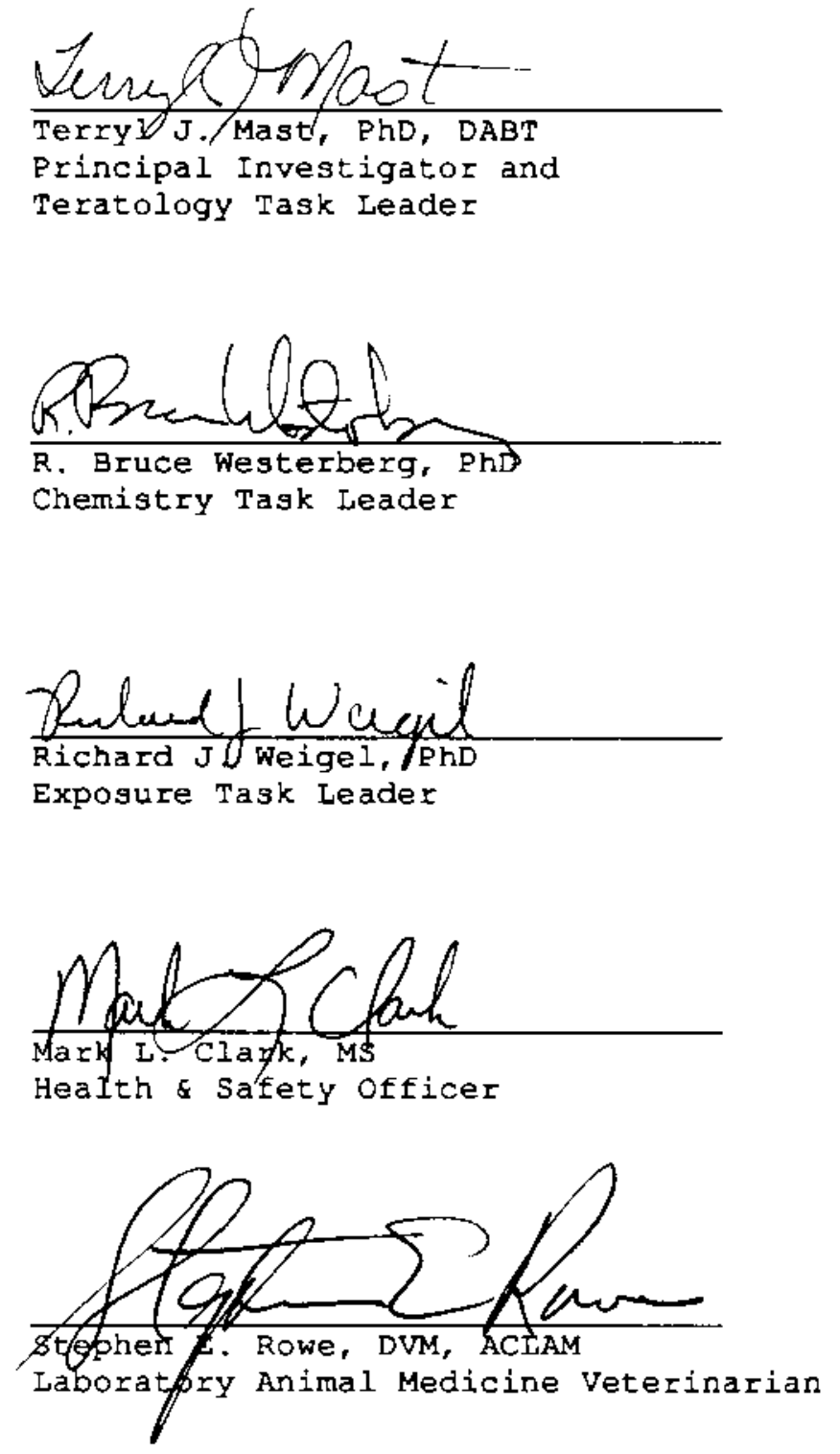
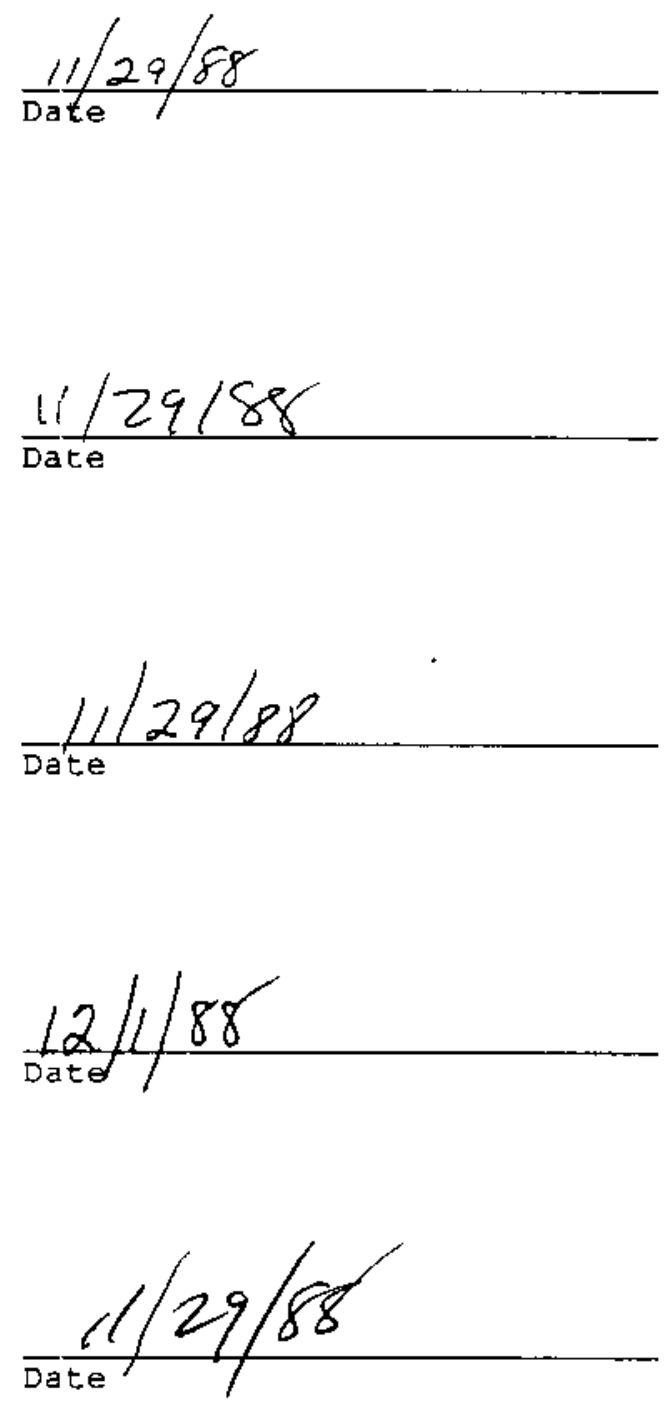


\section{CONTENTS}

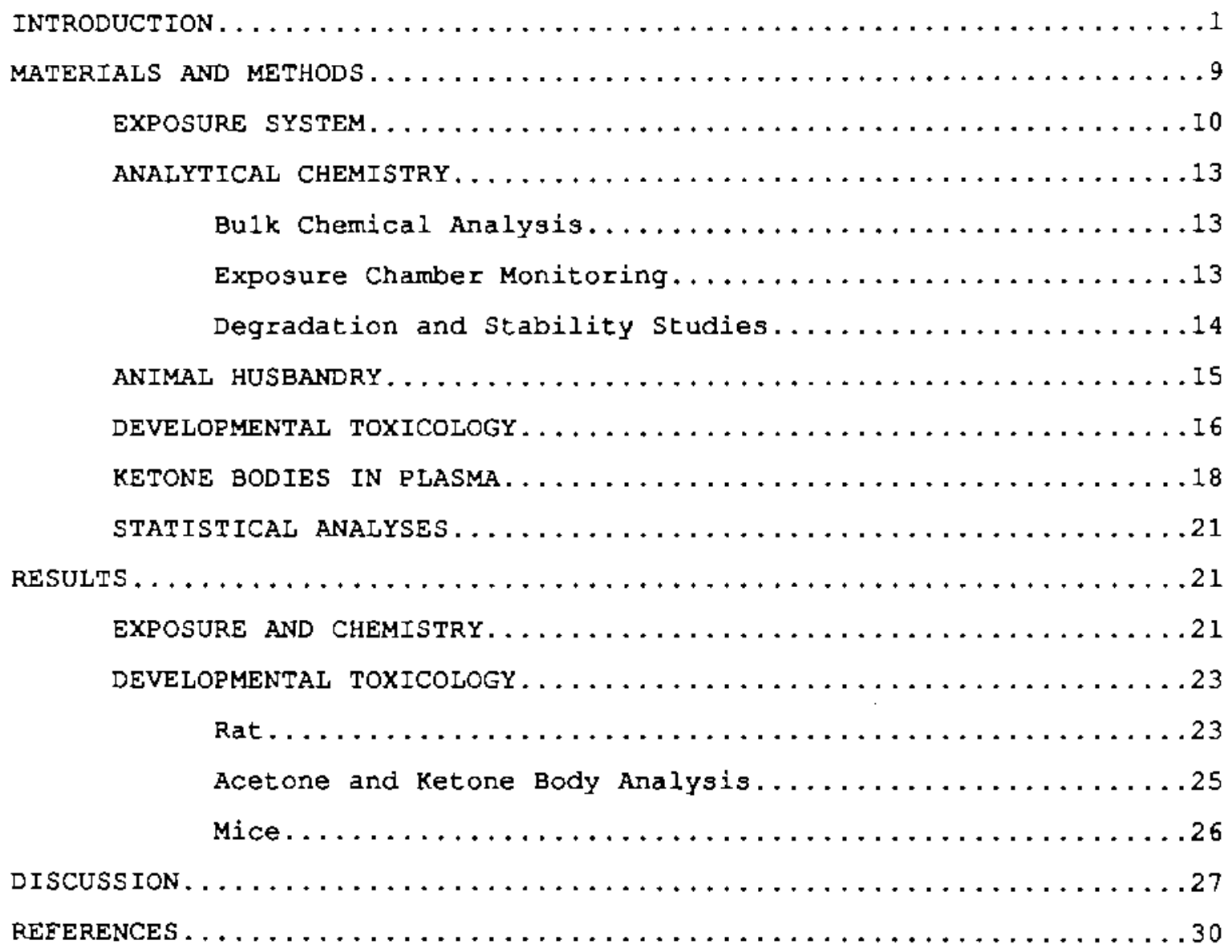


APPENDICES

APPENDIX A - ANALYTICAL CHEMISTRY NARRATIVE AND DATA............ 1 BULK CHEMICAL . ............................... 1

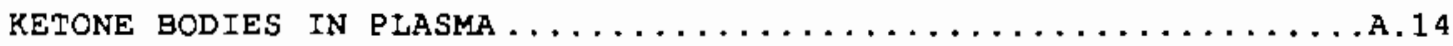
APPENDIX B - EXPOSURE NARRATIVE AND DATA.................. I NARRATIVE . ................................ 1 EXPOSURE CHAMBER CONCENTRATIONS (RATS) ......................

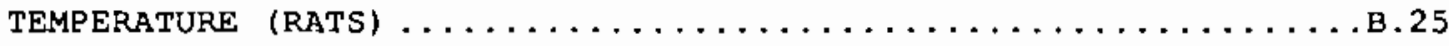

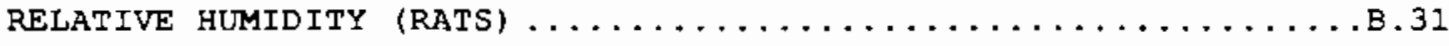

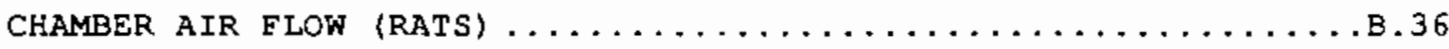

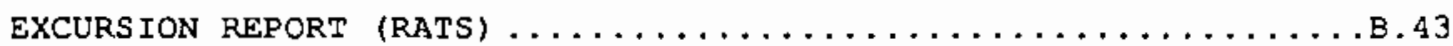

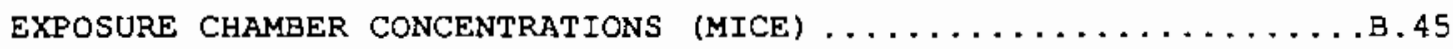

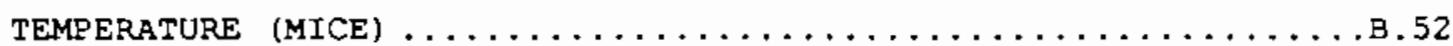
REIATIVE HUMIDITY (MICE) .......................

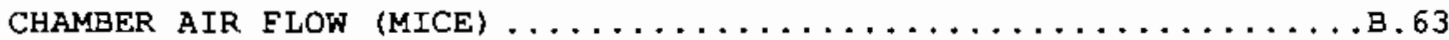

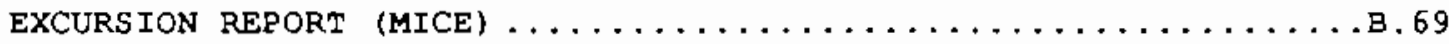

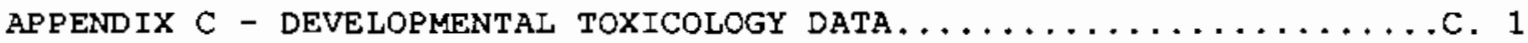
BODY WEIGHTS AND URINE PARAMETERS FOR VIRGIN FEMALES (RATS) ....C. 1 MATERNAL WEIGHT DATA AND URINE PARAMETERS (RATS) ............ 5 BODY WEIGHTS AND URINE PARAMETERS (KETONE RATS) ............... 13

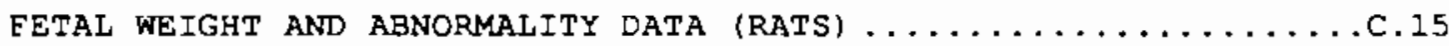
CODE SHEET FOR IDENTIFICATION OE EETAL ABNORMALITIES (RATS) ....C.54

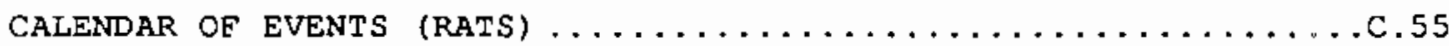

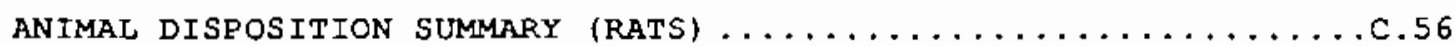

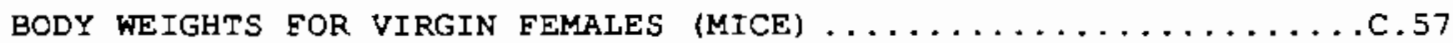

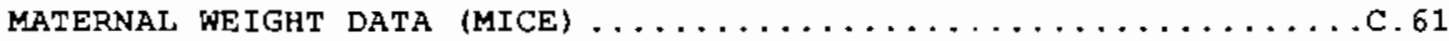
EETAL WEIGHT AND ABNORMALITY DATA (MICE) .............. 65 CODE SHEET FOR IDENTIFICATION OF FETAL ABNORMALITIES (MICE) ....C.65

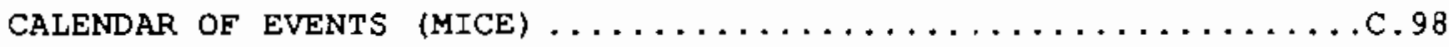

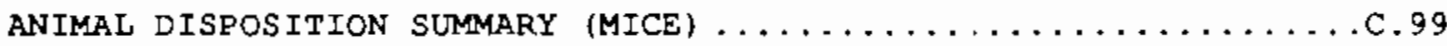

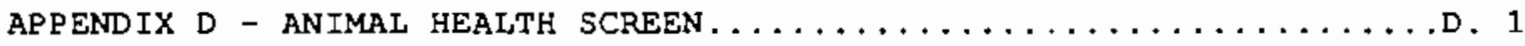
APPENDIX E - QUALITY ASSURANCE STATEMENT .................. 1 APPENDIX $F-$ PROTOCOL AND CAGE MAPS ................... 


\section{EIGURES}

EIGURE 1. Acetone Generation and Delivery System...............

FIGURE 2a. Buildup and Decay of Vapor Concentrations for Exposure of Rats to Acetone With and Without Arimals Present......35

EIGURE 2b. Buildup and Decay of Vapor Concentrations for Exposure of Mice to Acetone With and Without Animals Present. ...36

FIGURE 3. Acetone Rat Teratology: Cumulative weight Gain Graph....37

FIGURE 4. Acetone Rat Teratology: Acetone Plasma Levels.........38

FIGURE 5. Acetone Mouse Teratology: Cumulative Weight Gain

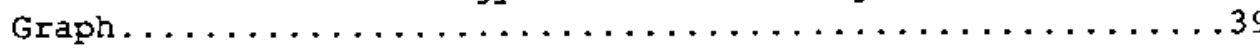

\section{TABLES}

TABLE 1. Teratology Study of Acetone in Mice and Rats: Sumary of Chamber Uniformity Data Obtained Before Exposure and During Exposure..........................40

TABLE 2. Acetone Teratology Study: Average Daily Expogure Chamber Concentrations for Rat Exposures...........41

TABLE 3. Acetone Teratology Study: Average Daily Exposure Chamber Concentrations for Mouse Exposures..........44

TABLE 4. Acetone Rat Teratology Study: Mean Body, Uterine, and Extra-gestational Weights of Pregnant Dams (g \pm SD) ....45

TABLE 5. Contemporary Control Data for Sprague Dawley Rats (N=80

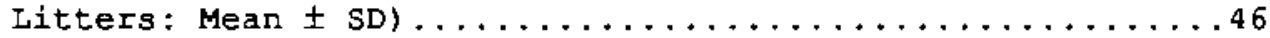

TABLE 6. Acetone Rat Teratology Study: Mean Body Weighto for

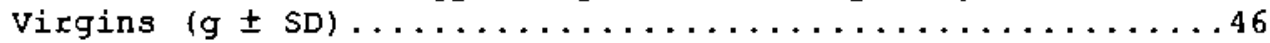

TABLE 7. Acetone Rat Teratology Study: Mean Organ Weights of

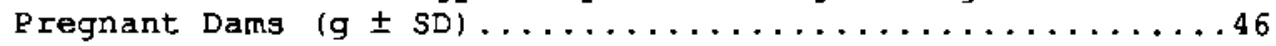

TABLE B. Acetone Rat Teratology Study: Reproductive Measures

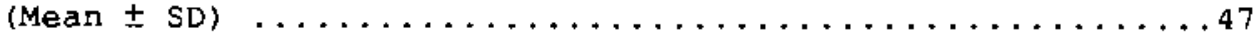

TABLE 9. Acetone Rat Teratology Study: Average Fetal weights (Means of Litter Means; $g \pm S D$ ), and Percent Male Eetuses..............................47 
TABLE 10. Acetone Rat Teratology Study: Malformations observed in Live Eetuses...........................48

TABLE 11. Acetone Rat Teratology Study: Mean Percent of Live Eetuses Affected per Litter (Mean $\pm s \supset$ ) ............49

TABLE 12. Contemporary Control Data on Rat Teratology Studies: Malformations............................. . . .

TABLE 13. Acetone Rat Teratology Study: Variations observed in Live Fetuses...........................51

TABLE 14. Contemporary Control Data on Rat Teratology Studies: Variations and Reduced Ossifications..............52

TABLE 15. Acetone Rat Teratology Study (Ketone): Mean Body, Uterine, and Extra-gestational Weights of Pregnant Dams

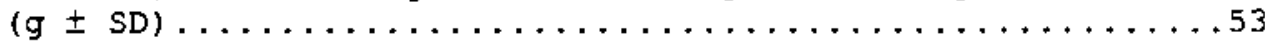

TABLE 16. Concentration of Ketone Bodies Found in the Plasma of Pregnant Rats Exposed to Acetone by Inhalation .......54

TABLE 17. Acetone Mouse Teratology Study: Mean Body, Uterine, and Extra-gestational Weights of Eregnant Dams ( $\pm \pm S D$ ) .....55

TABLE 18. Contemporary Control Data for Swiss (CD-1) Hice (N=83

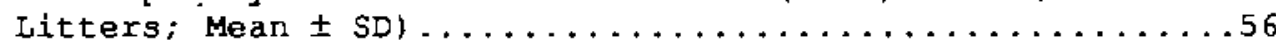

TABLE 19. Acetone Mouse Teratology Study: Mean Body Weights for

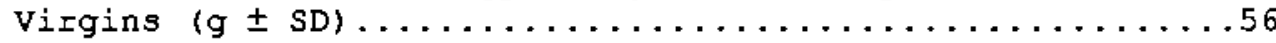

TABLE 20. Acetone Mouse Teratology Study: Mean Organ Weights of Eregnant Dams (Mean \pm SD) ....................

TABLE 21. Acetone Mouse Teratology Study: Reproductive Measures

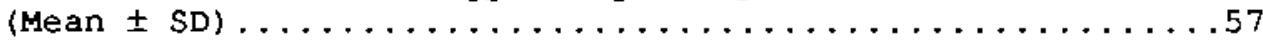

TABLE 22. Acetone Mouse Teratology Study: Average Eetal Weights (Mean of Litter Means; $g \pm S D$ ) and Percent Male Eetuses...57

TABLE 23. Acetone Mouse Teratology Study: Malformations observed in Live Eetuses..........................58

TABLE 24. Acetone Mouse Teratology Study: Mean Percent of Live Fetuses Affected per Litter (Mean \pm SD) ............59

TABLE 25. Contemporary Control Data on Swiss (CD-1) Mouse Teratology Studies: Malformations and variations.......66

TABLE 26. Acetone Mouse Teratology study: variations observed in Live Fetuses...........................61

TABLE 27. Comparison of Acetone plasma Levels with Literature Values...............................62 


\section{INTRODUCTION}

Acetone, an aliphatic ketone, is a ubiquitous industrial solvent and chemical intermediate; consequently, the opportunity for human exposure is high. Acetone production in the United states alone reached nearly one million metric tons in 1974 and world manufacturing capacity was predicted to be greater than 3 million metric tons per year by 1980 (Nelson and Webb 1978 ). The primary use for acetone is in the synthesis of methacrylates, followed by its use as a multi-purpose solvent or a chemical intermediate. The combination of its high volatility (bp $56.2^{\circ} \mathrm{C}$ ) and extengive use creates a significant possibility for human exposure to acetone via inhalation, especially in the industrial environment. Acetone is also present in many hazardous waste sites and may reach the groundwater.

The National Institute of Occupational Safety and Health (NIOSH 1978) recomnends an exposure limit of $250 \mathrm{ppm}\left(590 \mathrm{mg} / \mathrm{m}^{3}\right)$ for acetone. The osHa standard for acetone is 1000 ppm averaged over an 8-h work shift. The American Conference of Governmental Industrial Hygienists (ACGIH 1987) recommends a threshold limit value time-weighted-average (TIV-TWA) of 750 PPm $\left(1,780 \mathrm{mg} / \mathrm{m}^{3}\right)$ over each $8-\mathrm{h}$ period of a 40-h work week, and a short-term exposure Iimit (STEL) of $1000 \mathrm{ppm}\left(2,375 \mathrm{mg} / \mathrm{m}^{3}\right)$ for $15 \mathrm{minutes}$. The odor threshold is reported to be between 200 and 400 ppm.

Acetone is considered to be one of the least toxic organic solvents used in industry, both in terms of acute and of chronic toxicity. The inhaled vapor is absorbed into the blood stream; and is present in expired air and urine as the parent compound and/or metabolites. Although no permanent effects have been observed from short-term exposures to low concentrations of acetone vapors $(\approx 1000 \mathrm{ppm})$, subjects exposed to these levels have complained of slight eye, nose, and throat irritation. Inhalation of vaporg at higher concentrations (in excess of 10,000 ppm) is likely to produce central nervous system depression and narcosis (Clayton and Clayton 1982). Prolonged or repeated skin contact with the liquid may cause dryness or defatting of the skin followed by erythema and dermatitis. It has been reported that only a 
small amount of acetone is absorbed through the intact skin (Reynolds and Prasad 1982). However, these results are in contrast to those of another study where Fukabori et al. (1979) applied acetone to the skin and subsequently detected elevated concentrations of acetone in the blood, alveolar air and urine. The skin penetration of acetone was rapid and absorption of acetone increased directly with the frequency and the extent of exposure.

Male volunteers exposed to either 300 or $500 \mathrm{ppm}$ acetone under various regimens of exercise and rest demonstrated that about $45 \%$ of the acetone administered was absorbed regardless of the state of exercise or the exposure concentration; however, blood levels increased under a work load due to the increased ventilation rate (Wigeaus et al. 1981). There was no sign of attainment of an equilibrium between blood, alveo.ar air, and inspired air. The half-life of acetone in alveolar air, arteria: blood, and venous blood in the human was $4.3 \pm 1.1 \mathrm{~h}, 3.9 \pm 0.7 \mathrm{~h}$, and $6.1 \pm 0.7 \mathrm{~h}$, respectively.

In another study, male volunteers were exposed to 100 or $500 \mathrm{ppm}$ acetone vapor for either a single 2- or 4-h period (Divincenzo et al. 1973). Exposure to the vapor caused no untoward effects, nor were any changes noted in clinical chemistry or hematological values in the human subjects. In concurrence with wigeaus et al. (1981), exercise during exposure increased the amount of acetone absorbed and retained by the subject. Body burdens of acetone in this, as in the previously mentioned study, were not observed to approach steady state concentrations. Disappearance of acetone from blood appears to follow zero-order kinetics, i.e. the decline rate is not concentration dependent.

Studies in experimental animals have shown that exposure of rats to $52,000 \mathrm{ppm}$ acetone for $1 \mathrm{~h}$ produced narcosis, and that exposure to $126,000 \mathrm{ppm}$ for $1 \mathrm{~h}$ was fatal (Rowe 1963). The minimum lethaj. concentration for rats exposed to acetone vapors has been reported as 16,000 ppm for a 4-h exposure (Smyth et a1. 1962), and 46,000 ppr for mice exposed for $1 \mathrm{~h}$ (Flury and wirth 1934). Another report gave the minimum lethal concentration for rats as 126,000 ppm following a 2 h exposure period (Verschueren 1977). Rats exposed 
to $3,000,6,000,12,000$, and $16,000 \mathrm{ppm}$ of acetone, $4 \mathrm{~h} /$ day for 10 days, showed some behavioral changes, particularly at the higher levels, e.g., the inability to climb a pole within 2 seconds of receiving a stimulus (Goldberg et al. 1964). Tolerance developed after additional exposures. Rats exposed to $19,000 \mathrm{ppm}$ acetone, $3 \mathrm{~h} /$ day, 5 days/week for 8 weeks, and sacrificed at 2 , 4, 8, 10 weeks of exposure, exhibited no biochemical or histological evidence of toxic effects (Bruckner and Peterson 1981b). The $3-\mathrm{h} \quad \mathrm{LC}_{50}$ in rats was determined to be $55,700 \mathrm{ppm}$, approximately 6.5 times that of toluene (Bruckner et al. 1981a).

Subchronic exposure of rats to $19,000 \mathrm{ppm}$ acetone, $3 \mathrm{~h} /$ day, 5 days/week, for 8 weeks did not result in any statistically significant changes in the clinical chemistry parameters monitored, in gross pathology or histopathology, or in body weight gain over the course of the study (Bruckner and Peterson, 1981b). There was a slight elevation in serum glutamic-oxaloacetic transaminase (SGOT) levels in acetone-exposed animals at 2, 4, and 8 weeks; however, lactate dehydrogenase $(\mathrm{LDH})$ and blood urea nitrogen (BUN) levels were not significantly affected at any time during the study. Liver specimens showed little sign of lipid vacuolation and liver triglyceride levels were not different from controls. Brain and kidney weights were also reduced in animals with lowered body weights, however, liver weights remained comparable to controls. This finding is consistent with the known ability of acetone to induce the hepatic mixed-function oxidase system. [No female animals were included in this study.]

Single oral doses of acetone prior to the oral adrinistration of a halocarbon have been shown to potentiate the hepatotoxic action of several of these agents in rats, e.g. chloroform, dibromochloromethane (DBCM) and bromodichloromethane (BDCM; Hewitt, Brown and Plaa 1983; Traiger and Plaa 1972; Traiger and Plaa 1974). Acetone has also been shown to enhance the nephrotoxicity of chloroform (Hewitt et al. 1980); however, it did not enhance the nephrotoxic effects of either DBCM or BDCM (Hewitt, Brown and Plaa 1983). A later study, was designed to evaluate the relationship between blood acetone concentrations and the potentiation of chloroform toxicity following oral or 
inhalation exposure to the halocarbon (Charbonneau et al 1986). These workers found that blood acetone levels were indeed a major determinant in the potentiation of chloroform-induced hepatotoxicity.

The metabolism of acetone was well-characterized by the late 1950's (Mourkides et al. 1959; Sakami et al. 1950; Price and Rittenberg 1950; and Rudney 1950). Acetone was shown to be eliminated in expired air, mostly as carbon dioxide, but also as the parent compound if the initial dose exceeded the metabolic capacity of the test animal. Excretion of parent compound and metabolites into the urine was also determined to be a significant route of elimination. Acetone was found to be converted to acetate, formate, a threecarbon intermediate which entered the glycolytic cycle (later identified as the 1,2-diol), acetoacetic acid, and $\beta$-hydroxybutyrate in vivo.

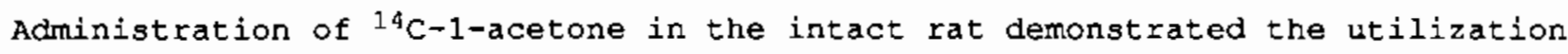
of the methyl group in the synthesis of cholesterol and several amino acids, i.e. serine and the methyl groups of choline and methionine (Sakami et al. 1950). Since this author had previously shown the same compounds to contain a methyl group derived from administexed formate (Sakami 1948) it is presumed that at least one metabolic pathway of acetone proceeds via formic acid.

Acetone administered to male rats in drinking water ( $1 \% \mathrm{v} / \mathrm{v}$ for 5 days) increased plasma free fatty acid concentrations from $408.0 \pm 40.9 \mu \mathrm{eq} / 1$ to $473.0 \pm 37.3 \mu \mathrm{eq} / 1$ (Furner et al. 1972). Measurements of hepatic MFo activity demonstrated no difference in the ability of microsomal preparations from treated animals to $\mathrm{N}$-demethylate ethylmorphine; however, the ability of preparations from treated animals to p-hydroxylate aniline or to o-deethylate p-ritroanisole was significantly increased as compared to controls. These changes were similar to MFO activity changes founc following starvation and physical stress.

When male Sprague-Dawley rats were exposed to $19,000 \mathrm{ppm}$ acetone via inhalation for a 3-h period, whole brain, liver ard blood were found to contain $2.7 \mathrm{mg} / \mathrm{g}, 2.5 \mathrm{mg} / \mathrm{g}$, and $3.3 \mathrm{mg} / \mathrm{ml}$ acetone, respectively (Bruckner and Peterson 1981b). Although this exposure is higher than would be used in a developmental toxicity study, the results demonstrate that acetone is 
distributed more or less homogeneously in the tissues examined and that blood levels are significantly elevated. Since acetone is one of the "ketone bodies" normaliy found in the blood, levels of this magnitude could result in ketosis and the symptoms concurrent with that metabolic disorder.

Furthermore, elevated ketone body levels are of significant impact where developmental studies are concerned since ketosis, a condition present in Diabetes mellitus, is known to have adverge effects on pregnancy.

The interactions of maternal metabolic disturbances with fetal development are extremely complex as evidenced by the fact that ketonemia during the embryonic period may regult in retarded development of the embryo while the same disturbance in late pregnancy results in excessive fetal growth, macrosomia (Freinkel 1985). The latter may be due in part to elevated insulin levels acting through growth factor receptors. Infusion of insulin into fetal baboons in utero recreates the metabolic and growth abnormalities typical of infants with diabetic mothers. Ketonemia during pregnancy may also result in alterations in normal development of the central nervous system and cause such abnormalities as open neural tube, faulty neural tube fusion, microcephaly, and pericardial edema. Offspring of diabetic mothers are at an increased risk for all of these defects. Other human abnormalities, all associated with the early organogenic period, are also linked to diabetic pregnancies and include transposition of the great vessels and sacral dysgenesis (Gabbe 1977).

Fasting has been shown to produce ketosis in rats during late pregnancy more rapidly than it does in nonpregnant animals, and primiparous rats developed a more severe ketosis after 1 day of fasting than multiparous dams did (Cheng and Yang 1970). Adrenal corticoid secretions were also found to be involved in the metabolic changes which subsequently increased the susceptibility to ketosis during pregnancy. Additionally, increased levels of progesterone or estrogen also contributed to these changes.

Several in vitro studies have been conducted in attempts to determine the teratogenic potential of acetone and have yielded negative results. No evidence of teratogenicity was found when 39 or $78 \mathrm{mg}$ of acetone was injected 
into the yolk sacs of fertile chick eggs prior to incubation (McLaughlin et al. 1964). Dipaolo et al. (1969) added 0.2 percent acetone to the growth medium of cultured Syrian hamster embryonic cells and detected no evidence of cellular transformation. Kitchin and Ebron (1984) reported normal growth in rat embryo in vitzo in the presence of 0.18 or $0.5 \%(v / v)$ acetone in the growth medium; however, when the level was raised to $2.5 \%$ the embryos failed to thrive. Guntakatta et al. (1984) assayed acetone for teratogenic potential in an in vitro mouse embryo $1 \mathrm{imb}$ bud cell culture system designed to detect perturbations in the synthesis of extracellular matrix components and found no effects attributable to acetone.

Acetone was not mutagenic in the salmonella/microsome test (McCann et al. 1975).

Although these in vitro studies did not indicate a significant teratogenic potential for acetone, such studies conducted on another ketone body, $\beta$-hydroxybutyrate $(\beta-\mathrm{HB})$, indicated an involvement in fetal abnormalities. Horton and Sadler (1983) exposed mouse embryos in vitro to $\beta-\mathrm{HB}$, the most common ketone body, at either the $3-4$ or the 4-5 somite stage. The concentrations of $\beta-\mathrm{HB}$ employed, $1-4 \mathrm{mg} / \mathrm{ml}$, encompassed ketone body levels in blood reported in cases of severe ketosis in the human. Embryos cultured in the presence of $\beta$-HB exhibited neural tube defects, the incidence of which were age- and dose-related, with the younger embryos being the more sensitive. The abnormalities were characterized by inhibition or delay of neural tube closure primarily involving the cranial region.

Acetone is listed as causing birth defects iSchardein 1985; Table 21-2, PP. 572-572), however, no reference source for this information is given nor is any specific abnormality mentioned. At a later point (p.650) the same author states that "reports of acetone testing in teratogenesis or reproductive toxicology apparently have not been published." However, this author does refer to a report in which sacral ageresis was associated with a history of exposure of women to fat solvents during pregnancy (Kucera 1968). In addition to acetone, these women were also exposed to xylene, trichloroethylene, methyl chloride and petrol. Arother report, by the same 
author (Kucera and Benasova 1962) was mentioned "in which a case of camptomelic syndrome $[s i c]$ in an infant was associated with close [maternal] contact with acetone (and other chemicals) during the fifth to eight gestational weeks of pregnancy."

The only other mention found in the published literature regarding the occupational hazards of acetone exposure to women of child-bearing age was an article translated from the Russian language (Nizyayeva 1982 [translator unknown]). The intent of this study was to statistically characterize the reproductive function of female factory workers chronically exposed to acetone at, or slightly above, the Russian $\mathrm{TLV}, 200 \mathrm{mg} / \mathrm{m}^{3}(85 \mathrm{ppm})$. They report a statistically significant increase in problem pregnancies among these workers including an increased threat of abortion $(p<0.001)$, toxicosis during the second half of pregnancy $(p<0.02)$, and diminished hemoglobin level and hypotengion $(p<0.001)$. A significant reduction in the birth weight and size of infants of the chemical fiber-factory workers relative to a control group was also reported $(p<0.001)$. They viewed these complications of pregnancy as being secondary to changes in general body function, notably "acidosis, disturbed carbohydrate and fat metabolism, and disturbed neuroendocrine regulation." Furthenmore, they associated these pathologic conditions directly with exposure to relatively low levels of acetone.

In addition to the human epidemiological data presented by Nizyayeva (1982), an inhalation teratology study was performed in an unidentified rodent species [rats?]. Animals were exposed to 30 and $300 \mathrm{mg} / \mathrm{m}^{3}$ acetone for either 1-13 days of gestation (dg) or $1-20 \mathrm{dg}$. [Details of the daily duration of exposure were not given.] A statistically significant, but not concentrationrelated, reduction in the percentage of live embryos was reported for both exposure concentrations in animals exposed from 1-20 dg. Percent embryonal deaths for the control, 30 and $300 \mathrm{mg} / \mathrm{m}^{3}$ groups were $11.3 \pm 1.3,28.4 \pm 5.9$, and $23.0 \pm 3.8$, respectively. Fetal weights were not given. They also reported "disorders of the placental barrier", apparently based on morphological changes. This reviewer believes that caution is required when considering the data presented in the report of Nizyayeva (1982) since 
experimental conditions, as well as results, were not clearly defined. However, the toxic effects referred to axe consistent with those which could be expected following exposure to a volatile ketone during pregnancy.

In sumarma:

- Acetone is a relatively non-toxic solvent whose only established hazard at relatively low exposure levelg is its ability to potentiate chlorinated hydrocarbon hepatotoxicity.

- Exposure to relatively high levels of acetone cesults in an increase in blood ketones and may therefore mimic deleterisus effects on pregnancy known to be caused by metabolic ketosis resulting from starvation or Diabetes mellitus.

- Acetone has been indirectly linked to several vases of human teratogenesis and one report presents human epidemiological evidence, as well as experimental evidence, that acetone exposure may have deleterious effects on pregnancy and the offspring (Nizyayeva, 1982).

In light of the known ability of acetone vapors to cause ketosis, the strongly suspected harmful effects of maternal ketosis during pregnancy on the offspring, and the ubiquitous nature of acetone, a two-species teratology study was performed with acetone vapors. Materna: organ to body weight ratios for maternal liver and kidneys were obtained, and maternal rat urine was monitored for evidence of metabolic imbalance(s) with respect to controls at the time of sacrifice. By testing acetone for its potential to cause developmental toxicity, the results obtained from these studies would aid in establishing the risk associated with exposure of women of child-bearing age to acetone vapors. The following teratology study was conducted in Swiss $\langle C D-1\rangle$ mice and Sprague-Dawley rats.

Acetone chamber concentrations, 0, 440, 2200, and 11000 ppm, were chosen with the goals of observing mild maternal toxicity at the highest exposure level and a no observable effect level at the lowest exposure concentration. The 440-ppm exposure concentration is also intermediate with respect to the 
NIOSH and ACGIH recommended TLVs $(250 \mathrm{ppm}$ and $750 \mathrm{ppm}$, respectively). The intermediate concentration was chosen with the expectation of obtaining a graded response.

\section{MATERIALS AND METHODS}

Four groups each of Sprague-Dawley rats (13 wk; Charles River, Raleigh, NC) were exposed to 0 (filtered air), 440, 2200, or $11000 \mathrm{ppm}$, and Swiss (CD-1) mice (11 wk; Charles River, Portage, MI) were exposed to 0, 440, 2200, or $6600 \mathrm{ppm}$ acetone vapors, $6 \mathrm{~h} /$ day, 7 days/week. Mice were exposed concurrently for 12 consecutive days $(6-17 \mathrm{dg}$ for mated mice), followed by the exposure of the rats for 14 consecutive days (6-19 dg for mated rats). Each of the four exposure groups consisted of 10 virgin females per species, $30-31$ sperm-positive rats and 33 plug-positive mice; all groups were randomly selected using body weight as the blocking variable. An additional 7 sperm-positive rats were included in each of the 4 exposure groups to be used for blood sampling. Developmental evaluations were conducted on pregnant mice killed on $18 \mathrm{dg}$, and on pregnant rats killed on $20 \mathrm{dg}$. Virgin females were killed on the day after the last day of exposure.

The highest exposure chamber concentration, $11000 \mathrm{ppm}$, was limited to 508 of the lower explosion limit $(22000 \mathrm{ppm})$ for safety considerations. The lowest exposure concentration was set to approximate recommended TLV levels and the mid-level was chosen to furnish a graded response. Although excessive maternal toxicity was not expected, virgin and positively-mated mice in the 11000-ppm chamber exhibited severe narcosis at the end of the first exposure day. Consequently, the highest exposure level for mice was lowered to $6600 \mathrm{ppm}$ acetone vapor for the duration of the mouse study. A new chamber concentration of $6600 \mathrm{ppm}$ was used for the mice because it was the only concentration possible on such short notice. (Since two test material delivery pumps had been used for $11000 \mathrm{ppm}$, it was possible to shut down one of those pumps in order to provide $6600 \mathrm{ppm}$ acetone vapor.)

In order to assess the effect of acetone exposure on the level of ketone bodies in the blood of rats, and to determine pre- and post-exposure blood 
levels of acetone, blood samples were analyzed for parent compound and two other ketone bodies, acetoacetic acid (AAA), and $\beta$-hydroxybutyrate $(\beta-H B)$. Urine from maternal and virgin animals was monitored at the time of sacrifice with a urine dip-stick for evidence of metabolic imbalance (e.g. an increase in ketone body level).

\section{EXPOSURE SYSTEM}

Inhalation exposures were conducted in Battelle-designed inhalation exposure chambers (Harford System; Lab Products, Inc., Aberdeen, MD). The $2.3-\mathrm{m}^{3}$ stainless-steel chamber $\left(1.7-\mathrm{m}^{3}\right.$ active mixing volume) contained three levels of caging, each of which was split into two offset tiers. The drawer-like stainless-steel cage units accommodated individual animal cages, feed troughs and automatic waterers. Stainless-steel catch pans designed to aid in maintaining a uniform concentration of vapor throughout the chamber, as well as for the collection of urine and feces, were suspended below each cage unit. Air (HEPA- and charcoal-filtered) contaizing a uniform mixture of the test article flowed through the chamber at approximately $15 \mathrm{ft}^{3} / \mathrm{min}$ (CEM) which was equivalent to approximately 15 air changes per hour. The uniform mixture was diverted along the inner surfaces of the chamber and a portion of the flow was "peeled off" by each catch pan, thus creating mixing eddies. Exhaust from each tier was cleared through the space between the tiers.

A schematic diagram of the acetone generation and delivery system is shown in Figure 1. The acetone to be vaporized was contained in a 19-Iiter stainless steel reservoir which was refilled every other day. During exposure the acetone was pumped from the stainless steel reservoir through an eductor tube to delivery tubes which supplied the vaporizers located at the fresh air inlet of each animal exposure chamber. Tegt mate:ial was pumped to the vaporizer by stable micrometering pumps with adjustable, drift-free pump rates. Acetone vapor in the highest exposure chamber was delivered to two vaporizers since the rate of delivery required to generate the desired exposure concentration exceeded the vaporization sapability of a single vaporizer. 
The vaporizer consigted of a stainless steel cylinder covered with a glass fiber wick. An 80-watt heater and a temperature sensing element were incorporated within the cylinder and connected to a remotely located temperature controller. A second temperature monitor was also incorporated in the vaporizer allowing the operating temperature to be recorded by the automated data acquisition system. The operating temperatures of the vaporizers $\left(93-137^{\circ} \mathrm{F}\right)$ were adjusted to completely vaporize supplied test material. All materials which came into contact with the acetone were either stainless-steel, glass, Teflon ${ }^{(\mathbb{2}}$ or viton ${ }^{(3)}$ All equipment contained in the vented generator cabinet was explosion proof.

Exposure chambers (without animals) and the exposure room, were monitored for particles during one day of test generation with a small particle detector (Gardner Associates, TYpe CN, Schnectedy, NY). Particle monitoring was also conducted once during the exposure with rats in the chambers. No particles were detected in the control chamber or in any of the exposure chambers during any of the tests. A count of approximately 200 particles $/ \mathrm{cm}^{3}$ was found in the room during generation; however, these particles were not considered to result from test material generation.

The time for the concentration to build up to 90 of the final, stable concentration following the start of generation $\left(T_{90}\right)$, and the time for the vapor concentration to decay to $10 \%$ of the stable concentration following the cessation of generation $\left(\mathrm{T}_{10}\right)$, were determined before and after animals were placed in the chambers (Figures $2 a$ and $2 b$ ). The experimental value for Tgo, with or without animals, was found to range from 10 to 12 minutes. At a chamber air flow rate of $15 \mathrm{CFM}$, the theoretical value for Tgo is approximately 12.5 minutes. Since there could have been variability in buildup times due to fluctuations in chamber flow rates and sampling accuracy, a T90 of 12 minutes was chosen for this study. The value of $T_{10}$ ranged from 10 to 13 without animals present, and from 9 to 13 minutes with animals present.

Uniformity of vapor concentration in the exposure chambers was verified prior to the start of, and once during the study. The vapor concentrations 
for these determinations were measured using the on-line GC with the automatic sampling valve disabled to allow continuous monitoring from a single input line. Prior to animal loading, 12 chamber positions were measured. The second set of vapor concentration measurenents was taken from the front and back positions of the chamber only where cage units contained animals.

The acetone exposures were conducted using an automated data acquisition and control system in an exposure suite. This system monitored and controlled the basic inhalation test system functions including chamber air flow, vacuum, temperature, relative humidity, and test chemical concentrations. Conditions which may have been a threat to the health of the animals or constituted an explosion hazard triggered alarms to personnel who were on call $24 \mathrm{~h} /$ day. All data acquisition and exposure control originated from an executive computer which contained the exposure protocols and controlled a multiplexing-interface system.

Chamber and room temperatures were measured by calibrated resistance temperature detectors (RTD) which were located at the measurement site, and were multiplexed to a digital thermometer interfaced to the computer. Chamber temperature was controlled primarily by adjusting the temperature of the exposure room.

Percent relative humidity ( $8 \mathrm{R} H$ ) was calculated with an accuracy of $68 \mathrm{gH}$ by pulling an air sample from the measurement location through a Teflon tube into a dew point hygrometex located in the control. center. Measurements were taken from different locations using a valving system which multiplexed the sampling tubes to the hygrometer. Values for of were calculated and maintained by the executive computer from temperature and dew point measurements.

Chamber air flow was calculated by measuring the pressure drop across calibrated orifices located at the inlet and exhaust of each chamber. Leaks in the chambers could be detected by comparison of the inlet flow rate with exhaust flow rate. Flow was maintained by a compter-controlled gate valve in the exhaust line of each chamber. Chamber vacuum, relative to the control 
center, was measured using the same pressure transducer system which measured chamber air flows. Chamber vacuum was maintained at approximately (-) 1 " $\mathrm{H}_{2} \mathrm{O}$ primarily by inlet resistance provided by the HEPA and charcoal filters.

\section{ANAIYTICAL CHEMISTRY}

\section{Bulk Analysis}

Identity of the bulk test material was confimed by infrared spectroscopy, and the initial percent purity was measured by determining the percent of the total peak area that was represented by the acetone peak. Gas chromatography was performed on a Hewlett Packard (HP) 5890 or $5830 \mathrm{~A}$ equipped with a glass column packed with Porapak $Q 80 / 100$. The purity of the bulk acetone used during the exposures was found to be $100.0 \%$ and was acceptable throughout the study.

\section{Exposure Chamber Monitoring}

Generation of acetone vapor concentrations utilized $\sim 5.2 \mathrm{~kg} / \mathrm{day}$ for the rat exposure, and $-3.4 \mathrm{~kg} / \mathrm{day}$ for mice. A total of approximately $216 \mathrm{~kg}$ of test material was consumed during the study. Prior to its use in generation, test material was maintained at room temperature in the LSL-II storage facility. All transfers of the acetone from the storage drum to the reservoir were performed under nitrogen to prevent possible oxidative degradation due to the introduction of air into the drum.

The concentrations of acetone vapor in the chambers were monitored with an HF5840 GC system (1/8" 0.d. x 1.0' nickel column, 18 SP-1000 on 60/80 mesh Carbopack $\mathrm{B}, 130^{\circ} \mathrm{C}$ ). This instrument was equipped with an 8 -port stream select valve, and measured acetone vapor levels in the three exposure chambers, the control chamber, the holding chamber, the exposure room, and the on-line standard, and also monitored a nitrogen blank. In order to confirm values generated by the on-line monitor, bubbler grab samples were collected from the chambers and analyzed with an HP5830 or HP5840 GC $(2$ or $4 \mathrm{~mm} i$.d. $x$ $1.8 \mathrm{~m}$ glass column, 108 Carbowax:20M TPA on Chromosorb WAw, $130^{\circ} \mathrm{C}$ ). An online, certified standard, $-2000 \mathrm{ppm}$ acetone in nitrogen (MG Industries 
Scientific Gases, Los Angeles, CA), was used to cieck instrument drift throughout the exposure day.

Precision of the on-line GC was estimated by taking a consecutive measurements of the on-line standard, one from every active sampling port. A 0.11 coefficient of variation was observed. Accuracy of the on-line GC was assured by calibrating it against a gravimetrically calibrated GC. (See Appendix A.) The minimum detectable limit of the GC was estimated from the decay profile for the 440 -ppm chamber and was found to be $=0.05$ ppm acetone.

Degradation and Stability Studies

Chemical stability of the acetone in the generator reservoir was determined by aging the test material in the stainless steel reservoir for 4 days at room temperature. The purity prior to, and after, aging was $>99.9 \%$. No impurity peaks representing greater than 0.018 total peak area were observed. These results indicated that acetone was stable in the generator reservoir for periods up to 4 days.

Acetone, a methyl ketone prone to polymerization, was handled in a manner designed to prevent chemical degradation during vapor generation; e.g. low generation temperatures, the use of inert materials, and the short residence time of acetone on the vaporizer. In order to confim chemical stability, the fiberglass wicks were removed from the vaporizer after several days of test generation and then extracted with methanol and sonification for approximately $30 \mathrm{~min}$. Gas chromatographic analysis of the methanol extract did not reveal any volatile degradation products.

Studies of the stability of acetone vapor ir the exposure chambers were conducted on samples taken after the exposure system was allowed to operate for at least 5 hours, and in the case of the highest concentration chamber, also taken at the beginning of vapor generation. Since individual vaporizers were used samples were taken from each of the three chambers.

Samples from the occupied chambers were taken by pulling a measured volume of gas through charcoal sampling tubes. One sample set was eluted with 
methanol for identification of compounds less volatile than acetone, and the second set was eluted with dimethylformamide (DMF) for identification of compounds more volatile than acetone. Sample size was adjusted to provide adequate sensitivity for impurities without producing substantial breakthrough of acetone. The amount of breakthrough was measured by analysis of secondary beds within the charcoal tubes. Good trapping efficiency for species such as polymers and dimers was assumed when good trapping efficiency was observed for acetone. Charcoal has previously been shown to produce good collection efficiency for numerous organic compounds. Satisfactory recovery of acetone and polymeric products of acetone was shown using a prepared standard containing microgram amounts of diacetone, mesityl oxide and isophorone.

Recoveries were detemined by placing 1-ml aliquots of spiked solvent on the charcoal packing used in the adsorption tubes and comparing the extracts to the original solution without charcoal treatment. The original solution contained amounts of possible degradation products at 0.1 to $0.2 \mathrm{w} / \mathrm{w}$ of acetone collected during sampling. Although less than 100 o recovery of several known impurities of acetone was shown using prepared standards, detection of impurities at $0.1 \% \mathrm{w} / \mathrm{w}$ acetone from the charcoal sampling tubes was possible. Thus an equivalent amount of degradation product collected on the chamber samples could be determined using the systems and solvents employed.

\section{ANIMAL HUSBANDBY}

Upon receipt, all animals were housed in quarantine rooms for at least 30 days prior to the start of exposure. Males and females were housed separately on stainless steel wire racks equipped with automatic waterers (10-11 mice per cage, 5-6 rats per cage). During the quarantine period at least five males and five females of each species were killed and examined for gross and microscopic lesions. (See Appendix D for details.) Nasopharyngeal washes from these animals were cultured for bacterial pathogens. Serum from each animal was tested for antibodieg to selected pathogens (Appendix D). Another check for antibodies to selected pathogens was performed on serum obtained from at least five females in the control group and from at least 
five females in the highest exposure group, for each species, at the final sacrifice. [Serum from an additional ten rats, not identified as to group, was also obtained at the end of sacrifice.] All results were negative for significant pathogens and lesions (see Appendix D for complete details). Animals were observed daily for mortality, morbidity, and overt signs of toxicity.

Food, pelleted NIH-07 diet (Zieglez Bros., Inc., Gardner, PA), was provided ad libitum during the entire time the animals were in the test facility except during the 6 -h exposure period when it was removed to prevent contamination with acetone and oral ingestion of the test material. Water was provided ad libitum with automatic waterers throughout the study. Room lighting was maintained on a $12-\mathrm{h}$ on-off cycle $(0600-1800 \mathrm{~h}$ for the light phase). During the quarantine period animal room temperature was maintained at $75 \pm 3^{\circ} \mathrm{F}$ and the percent relative humidity was maintained at $50 \pm 15 \%$.

Target chamber temperatures during the exposure periods were maintained within the limits of $75 \pm 3^{\circ} \mathrm{F}$. Chamber temperature means for all exposure days were within the specified limits. Mean percent relative humidity in all exposure chambers was within the specified limits of $55 \pm 15 \%$. The average air flow in all chambers for the study was within the specified limits of 12 to 18 CFM. A complete sumnary of the daily chamber environmental data can be found in Appendix B.

\section{DEVELORMENTAI TOXICOLOGY}

Female mice and rats were weighed and individually identified by eaz tags 1-2 weeks prior to mating. At this time 40 virgin females of each species were randomly selected using body weight as the blocking variable. The remaining females were bred by caging two to three females overnight with each male. Copulation was established on the fol.lowing morning by the presence of a vaginal plug in the case of the mice; or for rats, by a sperm-positive vaginal lavage smear. If evidence of mating was detected, this day was designated as $0 \mathrm{dg}$, and positively mated Eemales were weighed and randomly assigned to exposure groups using body wight as the blocking 
variable. Mating was conducted for five consecutive nights for each species to obtain 132 positively mated female mice (33/group), and 122 positively mated rats (30-31/group). ${ }^{1}$ Seven additional positively mated rats were assigned to each exposure group for monitoring of ketone body levels in rat plasma. In order to acclimate animals to exposure chambers, on 0 dg mated females were individually caged in exposure chambers with the doors open (chambers were in the breeding room). Virgin females were weighed and assigned to exposure groups 2 days prior to the start of exposure for mice and 4 days prior to exposure for rats.

Mice were exposed from $6-17 \mathrm{dg}$ and sacrificed on $18 \mathrm{dg}$. Rats were exposed from 6-19 dg and sacrificed on $20 \mathrm{dg}$. Virgin mice were exposed for 12 consecutive days and virgin rats for 14 consecutive days. Virgins were exposed concurrently with positively mated animals and were sacrificed on the day following the last day of exposure. Mated female mice were weighed on 0 , $6,9,12,15$ and $18 \mathrm{dg}$, and rats on $0,6,10,14,17$ and $20 \mathrm{dg}$. Virgin mice and rats were weighed 2 and 6 days prior to the start of exposure, respectively, and on exposure days 1,5 , and 10 , and at sacrifice.

On the morning of sacrifice, a urine sample was collected from each female rat, applied to a urine dip-stick and compared to the test color chart on the dip-stick container. The values were recorded for pH, protein, glucose, ketones, bilirubin, blood and urobilinogen.

At the time of sacrifice, rats and mice were euthanized with $\mathrm{CO}_{2}$, weighed and examined grossly for signs of maternal toxicity. Maternal liver and kidney weights were obtained, and both ovaries were saved for sectioning and quantitative follicle counts (performed by another laboratory designated by the sponsor; data will not be presented in this report). Apparently nongravid uteri from positively mated females were stained with $10 \%$ anmonium sulfide to detect possible implantation sites. The number, position and

I Positively mated females from the first breeding night were designated as Gestation Group A, those from the second night as Gestation Group B, etc. 
status of implants were recorded for each gravid uterus. Placentas were examined and discarded unless abnommal.

Live fetuses were weighed, examined for gross defects, and their sex was determined by internal examination of the gonads after euthanagia with an injection of Nembutal (sodium pentobarbital). Fifty percent of the live fetuses from each litter, (randomly selected) and any fetuses with gross external abnormalities were examined for visceral defects by dissection of fresh tissue. The heads of fifty percent of the live fetuses were removed and placed in Bouin's fixative. After fixation the heads were serially sectioned with a razor blade and examined for soft-tissue craniofacial abnormalities.

All fetal carcasses, with and without heads, were prepared for skeletal staining. Cartilage as well as ossified bone was visualized by double-staining with alcian blue and alizarin red $S$. The individual identity of each skeletal and head specimen was maintained throughout the study.

KETONE BODIES IN PLASMA

Plasma was collected from seven rats in each of the four exposure groups to assegs the effect of acetone exposure during pregnancy on the level of ketone bodies in the blood and to determine post-exposure blood levels of acetone. The plasma was analyzed for three ketone bodies: acetone, acetoacetic acid (AAA), and $\beta$-hydroxybutyrate ( $\beta$-HB). Blood was collected by retro-orbital puncture of $\mathrm{CO}_{2}$-anesthetized rats 30 minutes post-exposure on 7 , 14 and $19 \mathrm{dg}$, and again one hour prior to the start of exposure on the following day. The same seven animals in each exposure group were used for this purpose throughout the study. Blood was collected into iced, EDTA-coated

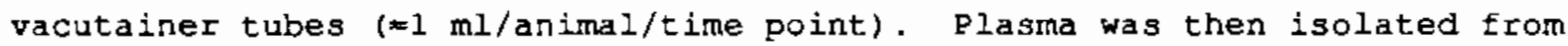
whole blood by centrifugation at $4^{\circ} \mathrm{C}$ for $20 \mathrm{~min}$, stored at $4^{\circ} \mathrm{C}$, and analyzed within $24 \mathrm{~h}$ of collection. At the time of sacrifice these animals were weighed, their gestational status recorded, uterine and fetal weights obtained and the status of the fetuses recorded. These fetuses were not subjected to a teratological evaluation except for a gross examination for external defects. (See Appendix A for further details.) 
An analytical method modified from Lopez-Soriano and Argiles (1985) was used to determine the levels of the three ketone bodies in plasma. In this procedure both $A A A$ and $\beta$-HB were decarboxylated and converted to acetone which was measured using a headspace-gas chromatographic technique. Each plasma sample was divided into three 125- 11 aliquots and placed in headspace analysis vials. In the first aliquot free acetone was determined following the addition of $25 \mu \mathrm{l}$ of $4 \mathrm{~N}$ sodium hydroxide to prevent spontaneous decarboxylation of AAA. The second aliquot was treated with $25 \mu l$ of $0.6 \mathrm{M}$ perchloric acid and heated at $-100^{\circ} \mathrm{C}$ for $90 \mathrm{~min}$ to enhance quantitative decarboxylation of AAA to acetone, and the third plasma aliquot was treated with $25 \mu \mathrm{\mu l}$ of axidative reagent $\left(0.2 \mathrm{M} \mathrm{K}_{2} \mathrm{Cr}_{2} \mathrm{O}_{7}\right.$ in $5 \mathrm{M}$ phosphoric acid) and heated at $100^{\circ} \mathrm{C}$ for $90 \mathrm{~min}$. The oxidative treatment of the third sample converts all ketone bodies present to acetone; thus, $\beta$-HB concentration was determined by subtracting the amount of acetone and AAA determined in the first two aliquots from the value obtained for the total ketone body level in the third aliquot.

Prepared plasma samples were subjected to headspace analysis by gas chromatography (HP $5890 \mathrm{GC}$ ) after a 15 -min equilibration period at $60^{\circ} \mathrm{C}$ (HP 19295 Headspace Analyzer), according to the methods of Lopez-Soriano and Argiles (1985). Aspirated headspace was analyzed on a $1 / 8$ " $0 . d$. $x$ ' nickel column packed with $3 \%$ Carbowax 1500 on Chromosorb WAW, 60/80 mesh, operated at $40^{\circ} \mathrm{C}$ with a short ramp to $45^{\circ} \mathrm{C}$ for column cleanup. The retention time of acetone was about 1.5 minutes.

The slope of the calibration curve observed for acetone was insensitive to preparation of standards in either saline or plasma. However, as reported by Lopez-Soriano and Argiles (1985), the acetone standards exhibited greater response when prepared in the caustic media. Calibrations for this study were performed using standards of acetone in saline and were prepared fresh every analysis day. The acetone standard concentrations bracketed the acetone concentrations expected in the samples. The relationship between GC peak area and acetone concentration for each reaction mixture was constructed from a 
composite of all calibration data and was linear with correlation coefficient of 1.0 .

A series of experiments was performed to optimize the recovery of AAA and $\beta-H B$ from the various reaction mixtures. Some decarboxylation of AAA occurred in the sodium hydroxide solution; consequently, less than a $100 \%$ recovery from the dichromate/phosphoric acid reaction mixture was observed for both carboxylic acids, $\beta-H B$ and AAA (See Appendix A for details). The recovery values were analyzed in a series of simutaneous linear equations to account for their deviation from the ideal recovery of either 0\% or $100 \%$.

Determination for AAA and $\beta-\mathrm{HB}$ in plasma recruired subtracting the acetone contribution; therefore, when the acetone level was high, and AAA and $\beta$-HB differed from the background by only a small amount, the effective sensitivity of the method for these ketone bodies was limited. The citation of different lower limits of detection for the different time points in Table.16 reflects this dependency of the lower limit of detection upon the acetone concentration encountered for a particulaz sample. The effective limit of detection was calculated for the determination of AAA and $\beta-H B$ from the standard deviation of the acetone concentration according to Mandel and Steihler (1964). Sensitivity, $\gamma$, is defined as the ratio of the slope to the standard deviation of the measurement:

$$
\gamma=\frac{d x / d C}{S x}=\frac{1}{S c}
$$

where $S x$ is the standard deviation of the measured value (peak area), $X$ is peak area, $C$ is concentration $(m M)$, yhas units of concentration-I, and Sc is the standard deviation of the concentration. The smallest concentration change that can be measured is then determined as $1 / \gamma$. Erom this statistic, a limit of detection (LD) can be defined by

$$
\mathrm{ID}=\frac{\mathrm{K}}{\gamma} \quad \text { where } \mathrm{K}=\frac{\mathrm{t}}{\sqrt{\mathrm{n}}}
$$

where 't' is the student 't' statistic for the required confidence level (998 was used for these calculations), and $\mathrm{n}$ is the number of determinations 
made. From this it follows that the limit of detection can also be defined as:

$$
L D=\frac{t(S c)}{\sqrt{n}}
$$

Thus, elevated acetone leve1s have the effect of producing an elevated lower limit of detection for $A A A$ and $\beta$-HB for those samples having elevated acetone levels. Values for ketone bodies determined as below the limit of detection are reported as "less than" the calculated limit of detection.

\section{STATISTICAL ANATYSES}

All meang and standard deviations for animal data were calculated with SAS statistical software on a VAX $11 / 780$ computer. Mean body weights lag a mean of litter means for fetal data) were analyzed using the sAs General Linear Models (GLM) Procedure (SAS, 1985) with an analysis of variance (ANOVA) model for unbalanced data. Response variables, either body weight or the arcsin transformations of proportional incidence data, were analyzed against the class variable, "treatment", in a one-way ANovA model. A Tukey's t-test (twotailed) was used to assess statistically significant differences between control and exposed groups. If appropriate, the dose-response relationship was determined by means of an orthogonal trend test (winer, 1971). In the case of proportional data the t-tests and trend analyses were performed on transformed variables. The litter was used as the basis for analysis of fetal variables.

\section{RESULTS}

\section{EXPOSURE AND CHEMISTRY}

Test material stability studies indicated that the materials and techniques used to generate acetone vapor for inhalation exposures did not affect its stability. The chemical stability of acetone was evaluated in both 
the generator reservoir and in the exposure chambers (with and without animals). Acetone was found to be stable in the generator reservoir for periods of up to 4 days, and there was no evidence of decomposition products greater than $1 \frac{8}{8}$ of the target acetone concentration present in the exposure chambers (with and without animals). Direct measurements of chamber concentrations of potential acetone degradation products, isophorone, mesityl oxide, and diacetone, demonstrated that none of these compounds were produced in significant amounts. The most prevalent impurity was acetic acid, analyzed as methyl acetate, which ranged from $0.02 \%$ (sample worked up immediately after

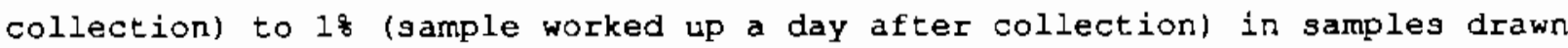
from occupied exposure chambers after 6 h test generation (Appendix A). Temperature-programed gas chromatography failed to show evidence of any other volatile degradation products.

The test material concentration uniformity data for each chamber during prestart testing, and after animals were in place, are sumarized in Table 1. Uniformity in all chambers was acceptable. To provide easier interpretation of the uniformity measurement results, the concentration readings for each port are expressed as a percentage of the mean value at all ports measured. The table includes analysis of Total port variability (Tgv), within port Variability (WPV) and Between Port Variability (BFV), all expressed as Percent Relative Standard Deviation ( 8 RSD). The possible variation of test chemical concentration measured from one sample port to ancther during the measurement procedure is termed the Total Port Variability anc consists of both spatial and temporal variations. Two factors contribute to the TPV. The first, the Between Port Variability (BPV), is the factor of interest as it represents the spatial variation of test chemical distribution within the chamber. The second factor, the within gort Variability (WPV), represents the temporal fluctuation of the average chemical concentration within the chamber during the time the measurements were taken. This temporal factor includes variations in vapor generation as well as variation of the measurement instrument itself. 
The grand means ${ }^{1}$ of chamber concentrations for the rat study were $100 \%$ of the target, with relative standard deviations in the range of 1 to $6 \%$ (Table 2). The daily mean concentrations for all chambers were between 95 and $102 \%$ of the target concentrations. At least $97 \%$ of individual concentration measurements at each target level were within $\pm 10 \%$ of the target levels. Except for 1 day, the sRSD's were less than 10\%. The maximum concentration observed in the control chamber was $0.26 \mathrm{ppm}$, and in the room was $1.06 \mathrm{ppm}$.

The grand means of the acetone concentrations in each chamber for the mouse study were between 99 and 1018 of the target, with relative standard deviations in the range of 3 to 8 (Table 3). Except for the last day of exposure, the daily mean concentrations ranged from 96 to 1028 of target and \&RSD's were less than $10 \%$. On the last day, one of the generators for the high dose chamber failed. When discovered, the exposure was discontinued after 5 hours and 9 minuteg. At least $98 \%$ of individual concentration measurements at each target level were within \pm 10 s of the target levels. The maximum concentration observed at any time in the control chamber was 3.8 ppm, and in the room was $16.6 \mathrm{ppm}$. The average room concentration was $0.21 \pm 1.04$ ppm acetone.

Chamber air flow, temperature and relative humidity data for both mouse and rat exposures were all within specified limits.

DEVELORMENTAL TOXICOLOGY: RAT

There were no maternal deaths. Pregnant females in the 11000-pprn group exhibited a significant reduction in body and uterine weight and in extragestational weight gain (EGWG; Table 4). The EGWG is the actual maternal body weight gained during pregnancy and is equal to the maternal body weight at sacrifice minus the gravid uterine weight minus the maternal body weight on 0 dg. No other overt symptoms of maternal toxicity were evident. The reductions in body weight, uterine weight and EGWG were also significantly

1 Grand mean = mean of all individual readings for the duration of the study. 
correlated with increasing exposure concentration. Mean maternal body weight at sacrifice, as well as uterine weight and EGWG for the 0-ppm group are consistent with values observed for the contemporary control group (Table 5). Mean body weights of virgin female rats were not significantly affected at any time during the 14-day exposure period or at sacrifice, although there was a 68 reduction in the mean body weight of animals in the 11000-ppm group relative to the 0 -ppm group (Table 6). This was the same relative reduction in whole body weight as for the pregnant animals, but data for the virgins lacked statistical significance due to the higher standard deviations relative to body weight. The rate of body weight gain for pregnant rats in the $11000-$ ppm group was adversely affected by $10 \mathrm{dg}$ (Figure 3). The mean liver and kidney weights of pregnant dams as well as organ to body weight ratios were not affected by expogure to acetone vapors (Table 7).

Maternal and virgin urine was assayed with urine dip-sticks just prior to sacrifice to deternine if acetone exposure altered nomal urine chemistry. Parameters measured included $\mathrm{pH}$, protein, ketone bodies (determined as acetoacetic acid), blood, glucose, bilirubin, and urobilinogen. No differences with respect to exposure group were noted for either the pregnant or the virgin rats. (See Appendix $C$ for details.)

Gestational exposure of rats to acetone vapors on 6-19 dg had no significant effect on the number of implantations, the mean percent of live pups per litter, or the mean percent of resorptions per litter. However, the percent of litters with resorptions was greater (not statistically significant) for the 11000-ppm group than for the 0-ppm group (50 versus $77 \%$, respectively; Table 8 ). The number of live fetuses per litter and the percent. intrauterine death per litter for all groups were within the range of the contemporary control data (Table 5). Male and female fetal weights (as means of litter means) were slightly, but significantly, reduced for the 11000-ppm exposure group when compared to the 0-ppm group (Table 9). Mean body weights for both male and female fetuses in the 11000-ppm group were $\approx 85 \%$ of the mean weights for the control fetuses; however, fetal weights for the 440- and 2200-ppm group were not noticeably affected. Fetal weight for the highest 
exposure group was also less than the mean fetal weight for the contemporary controls. The ratio of male to female fetuses in the litters was not altered by gestational exposure to acetone.

The incidence of fetal malformations was not significantly increased by gestational exposure to acetone vapors (Tables 10 and 11); however, the percent of litters with at least one pup exhibiting malformations was greater for the $11000-p p m$ group than for the 0 -ppm group, 11.5 and $3.8 \%$, respectively (Table 10). The percent of affected litters in the 11000-ppm group was also greater than the same value for contemporary control data (Tables 10 and 12), 11.5 and $6.3 \%$, respectively. The mean percent of live fetuses with malformations per litter was also greater for the 11000-ppn group than it was for either the 0-ppm group or for the contemporary control data (Table 11); however, the differences were not statistically significant. None of the major malformations observed in the highest exposure group (e.g. cleft sternum, ectopic heart, major vessel malformations, edema, unilateral arhinia, microstomia, vertebral agenesis, or a missing tail) had been observed in control litters and several fetuses had multiple malformations.

Gestational exposure to acetone did not increase the incidence of fetal variations or reduced ossification sites, nor was the mean incidence of fetal variations per litter increased (Tables 11 and 13). The types of variation observed as well as the incidence of variations was consistent with values for contemporary controls (Table 14).

\section{ACETONE AND KETONE BODY ANALYSES}

In general, maternal weights and reproductive data for these animalg were consistent with data for animals not used for blood collection although EGWG were less than for non-sampled animals (Table 15). (Complete raw data for these animals is contained in Appendix $C_{\text {.) }}$

Analysis of plasma samples $30 \mathrm{~min}$ post-exposure showed an increase in plasma acetone levels which correlated with increasing exposure concentration (Table 16 and Figure 4). Acetone plasma levels dropped to control levels by 
$17 \mathrm{~h}$ post-exposure for all exposure groups except the 11000-ppm group. Plasma acetone levels for this group were still slightly elevated with respect to the controls at $17 \mathrm{~h}$ post-exposure. The concentration of acetone $30 \mathrm{~min}$ or $17 \mathrm{~h}$ post exposure did not increase over gegtation regardiess of the exposure concentration, (i.e. samples taken on 19 dg were not significantly greater than samples taken on $7 \mathrm{dg}$ ). Neither exposure to acetone vapor nor advancing gestation, resulted in alterations of the plasma jevels for the other two ketone bodies, $A A A$ and $\beta-H B$, with respect to control animals. Since only three out of the seven females in the 440-ppm group were pregnant, values for this group are reported separately. Although the number of animals in each group is too small to perform statistical comparisons, there does not appear to be a significant difference between pregnant and non-pregnant females with respect to plasma levels of any of the three ketone bodies.

DEVELOPMENTAL TOXICOLQGY: MICE

Mice in the 11000-ppm chamber exhibited severe narcosis at the end of the firgt day of exposure; therefore, the acetone concentration in the highest exposure level was reduced to 6600 ppm for the remainder of the exposure period. Consequently, the 10 virgins and 5 dans from the first gestation group in the highest exposure level were exposed to 11000 ppm acetone on the first exposure day and to 6600 ppr for the remainder of the exposure days. The remaining three gestation groups in the highest exposure level were exposed to $6600 \mathrm{ppm}$ acetone on all exposure days. There were no maternal deaths and no overt symptoms of toxicity were evident in the plug-positive female or virgin mice after the highest exposure level was reduced to 6600 ppr.

Gestational exposure to acetone vapors did not affect maternal body or uterine weight or extragestational weight gain with respect to either the o-ppm group or contemporary controls (Figure 5; Tables 17 and 18). Mean body weights of virgin mice were not affected at any time during the 12-day exposure period or at sacrifice (Table 19). There were no significant differences in kidney weights between exposure groups; however, the liver 
weight and the liver to body weight ratio for the 6600-ppm group were significantly greater than for the 0-ppm group (Table 20).

Exposure of pregnant mice to acetone vapors on $6-17 \mathrm{dg}$ resulted in a slight, but significant, increase in the percent of late resorption for the 6600-ppm exposure group (Table 21). Other reproductive measures, the number of implantations per litter, the percent of live fetuses per litter and the percent of total intrauterine deaths, were not affected by gestational exposure to acetone vapors and were consistent with values for contemporary control data (Table 18). Male and female fetal weights (as means of litter means) were significantly reduced for the 6600-ppm exposure group when compared to the 0-ppm exposure group (Table 23). Mean body weights for this group were reduced by $\approx 8$ for both male and female fetuses with respect to the 0 -ppm group. The ratio of males to females in the litters was not affected.

The incidence of fetal malformations was not significantly increased by gestational exposure to acetone vapors and was consistent with data for contemporary controls (Tables 24,25 and 26). No fetal malformations were observed that had not previously been found in control fetuses. There was no increase in the incidence of fetal variations when all types were combined; however, when examined individually there was a statistically significant increase in the incidence of reduced sternebral ossifications (Tables 24 and 26). Data for the 0-ppm group and for the two lower exposure groups were consistent with contemporary control data on fetal variations (Table 25).

\section{DISCUSSION}

Exposure of pregnant rats to $0,440,2200$ or 11000 ppm acetone did not result in selective developmental toxicity, but did cause maternal toxicity as well as a significant decrease in fetal weight (both sexes) at the highest exposure level. The maternal toxicity was evident as exposure-correlated decreases in body and uterine weight and in extra-gestational weight gain when compared to the 0 -ppm group. These decreases were statistically significant for the 11000-ppm group. The body weights of virgin females were similarly affected, although the decreases were not statistically significant. There 
were no treatment-related effects upon reproductive indices for any exposure level nor was there a significant increase in the incidence of fetal malformations or variations. However, it is of interest to note that a greater diversity of malformations was observed in the 11000-ppm group than was found in the lower dose groups or in the 0-ppm group. This increase in diversity was attributable to three pups that had multiple malformations ${ }^{1}$, but since maternal toxicity was also present at the 11000-ppm level, this increase in the diversity of malfomations cannot be attrikuted solely to selective developmental toxicity.

The correlation of acetone levels in rat plasma measured 30 min. post-exposure with increasing exposure concentrations clearly demonstrates the biological uptake of acetone from the lung. Eurthemore, values obtained in this study are consistent with those obtained by Charbonneau, et al (1986) following inhalation exposure of rats to acetone vapor (Table 27). Fetal exposure can also be inferred since acetone, like other volatile organics, has been shown to cross the placenta (Dowty and Laseter 1976). The continued ability of the animals to clear acetone after 14 days of exposure indicates that maternal metabolic processes were not impaired by this compound. Although acetone has been reported to be an inducer of the $P_{450-m o n o o x y g e n a s e}$ system (Bruckrer and peterson 1981b), the fact that there was no treatmentrelated increase in the liver to body weight ratios in the dams suggests that this may not be the case in pregnant females, or, more likely, that such an induction was masked by the nomal increase in liver size seen during pregnancy. However, a significant increase in liver size was seen in mice.

The lack of a teratogenic responge following gestational exposure of rat fetuses to acetone vapors in this study is consistent with in vitro data demonstrating that 10.5 day rat embryos cultured in serum containing $\leq 0.58$ $(v / v)$ acetone grew nomally (Kitchin and Ebron 1984). Analygis of maternal plasma in this study showed that maximum plasma levels for dams in the high

\footnotetext{
1 Maternal body weights and gaing for the dams of these pups were not remarkably different from the rest of the group.
} 
exposure group, $11000 \mathrm{ppm}$ acetone, reached $2.15 \mathrm{mg} / \mathrm{ml}$ acetone or on $1 \mathrm{y} 0.22$ s $(v / v)$, a level lower than that allowing normal embryonic development in the Kitchin and Ebron study. Furthermore, although these exposures caused an increase in plasma acetone levels, circulating concentrations of the other two ketone bodies, $A A A$ and $\beta-\mathrm{HB}$, were not elevated following inhalation exposure to acetone. The lack of an increase in the $\beta$-HB concentration may be of toxicological significance since a previous study showed this compound to be teratogenic to rat embryos in vitro (Horton and Sadler, 1983).

Exposure of Swiss (CD-1) mice to 0, 440, 2200, or 6600 ppm acetone did not result in significant selective toxicity to the offspring. However, adult female mice were found to be more sensitive to the acute effects of acetone inhalation than were the rats. The original experimental design called for a high exposure concentration of 11,000 ppm as was used in the rat study; however, since this level produced severe narcosis in mice on the first day of exposure it was necessary to decrease the highest exposure concentration from $11000 \mathrm{ppm}$ to $6600 \mathrm{ppm}$. No treatment-related effects on maternal body weight, uterine weight, or on extra-gestational weight gain were noted in mice at any concentration employed, but there was a treatment-correlated increase in liver weights and in liver to body weight ratios with respect to controls in the pregnant dams .

Some developmental toxicity was observed in Swiss (CD-1) mice; 1) a slight, but statistically significant reduction in fetal weight for the highest exposure group, and 2) a slight, but statistically significant increase in the percent incidence of late resorptions in the 6600-ppm group. However, the increase in the incidence of late resorptions was not accompanied by an increase in the percent incidence of total intrauterine death (early plus late resorptions) nor by a decrease in the mean number of live fetuses per litter. The incidence of fetal malformations or variations was not significantly affected by exposure to acetone vapors at any of the levels employed with the exception of an increase in the percent of fetuses (on a litter basis) with reduced ossification of the sternebrae. This may not be biologically significant since the incidence was still <108 for the 6600-ppm 
group and was not accompanied by an increase in the incidence of any other abnormalities.

It may be concluded from the results of this study that the 2200-ppm acetone level was the no observable effect level (NOEI) in both the SpragueDawley (CD) rat and the swiss (CD-1) mouse for developmental toxicity. The NOEl for maternal toxicity in the rat study was 2200 pmo. Furthermore, since only minimal maternal effects were observed at 11000 ppm acetone for rats and at 6600 ppm acetone for mice, it is possible that the actual NosL is somewhat greater than 2200 ppm in both species.

\section{REFERENCES}

American Conference of Governmental Industrial Hygienists. 1987. Threshold Limit Values and Bielogical Exposure Indices fer 1987-1988. Cincinnati: ACGIH.

Bruckner, J. V., and R. G. Peterson. 1981a. "Evaluation of toluene and acetone inhalant abuse: pharmacology and phammacodynamics." Texicol. Appl. pharmacol, 61:27-38.

Bruckner, J. V., and R. G. Peterson. 1981b. "Evaluation of toluene and acetone inhalant abuge: model development and toxicology." Toxicel. Appl. pharmacol, 61:302-312.

Charbonneau, M., J. Brodeur, P. du Souich, and G. L. Plaa. 1986. "Correlation between acetone-potentiated $\mathrm{CCl}_{4}$-induced liver injury and blood concentrations after inhalation or oral administration." Toxicol. Appl. shannacele $84: 286-294$.

Cheng, K. K., and M. P. Yang. 1970. "Study of pregnancy ketosis in the rat." Q. J. Exp. Ehysiol. 55:83-92.

Clayton, G. D., and E. E. Clayton. 1982. Ratty's Industrial hygiene and Toxicology. 3rd Revised Edition. 2c:4720-4727.

Dipaolo, J. A., P. Donovan, and R. Nelson. 1969. "Quantitative studies of in vitro transformation by chemical carcinogens." J.Natl. Cancer Int. $42: 867-874$.

DiVincenzo, G. D., F. J. Yanno, and B. D. Astil1. 1973. "Exposure of man and dog to low concentrations of acetone vapor." Am. Ind. Hyg. Assec. I. $34: 329-336$. 
Dowty, B.J. and J.L. Laseter. 1976. "The transplacental migration and accumulation in blood of volatile organic constituents." Radiat. Res. $10: 696-701$.

Elury, F., and W. Wirth. 1934. Arch. Gewerbepathol, Gewerbehyo. 5:1.

Ereinkel, N. 1985. "Metabolic Changes in Pregnancy." In Textbook of Endocrinology, J. D. Wilgon, and D. W. Foster, Eds., ed 7, pp. 438-451, Saunders Co., Rhiladelphia.

Fukabori, S., K. Nakaaki, and O. Taga. 1979. "Cutaneous absorption of acetone." Bode Kagaku $55: 525-532$.

Furner, R. L., E. D. Neville, K. S. Talarico, and D. B. Feller. 1972. "A common modality of action of simulated space stresges on the oxidative metabolism of ethylmorphine, aniline and p-nitroanisole by male rat liver." Texicol. Appl... Pharmacol. 21:569-581.

Gabbe, S. G. 1977. "Congenital malformations in infants of diabetic mothers." obstet_Gynecol. Sury, 32:125-132.

Goldberg, M. E., H. E. Johnson, U. C. Pozzani, and H. F. Smyth. 1964. "Effect of repeated inhalation vapors of industrial solvents on animal behavior." Am. Ind. Hyg Assec. I. 25:369-375.

Guntakatta, M., E. J. Matthews, and J. O. Rundell. 1984. "Development of a mouse embryo limb bud cell culture system for the estimation of chemical teratogenic potential." Teratog, Carcinor. Mutagen. 4:349-364.

Hewitt, W. R., E. M. Brown, and G. L. Plaa. 1983. "Acetone-induced potentiation of trihalomethane toxicity in male rats." Toxicel. Iett. I $6: 285-296$.

Hewitt, W. R., H. Miyajima, M. G. Cote, and G. I. Plaa, I980. "Acute alteration of chloroform-induced hepato- and nephrotoxicity by n-hexane, methyl n-butylketone, and 2,5-hexanedione." Toxicel. Appl. Phandacol. $53: 230-248$.

Horton, W. E., and T. W. Sadler. 1983. "Effects of maternal diabetes on early embryogenesis: alteration in morphogenesis produced by the ketone body, B-hydroxybutyrate." Diabetes, 32:610-6I6.

Kitchin, K. T. and M. T. Ebron. 1984. "Eurther development of rodent whole embryo culture: Solvent toxicity and water insoluble compound delivery system." Toxicology $30(1): 45-57$.

Kucera, J. 1968. "Exposure to fat solvents: a possible cause of sacral agenegis in man." I. Pediat, $72: 857-859$.

Kucera, J., and D. Benasova. 1962. "Poruchy nitrodelozniho vyvoje cloveka zpusobene pokusem o potrat." Cesk. Pediat. 17:483-489. 
Lopez-Soriano, F. J., and J. M. Argiles. 1985. "Simultaneous determination of ketone bodies in biological samples by gas chromatographic headspace analysis." J.Chrom. Sci. 23:120-123.

Mandel, J. and R.D. Stiehler. 1964. I. Res, Natl_Eur. Std. A53:155.

McCann, J., E. Choi, E. Yamasaki, and B. N. Ames. 1975. "Detection of Carcinogens as mutagens in the Salmonella/microsome test: Assay of 300 chemicals." Proc. Nat. Acad. Sci. 72:5135-5139.

McLaughlin, J., J. P. Marliac, M. J. Verrett, M. K. Mutchler, and O. G. Fitzhugh. 1964. "Toxicity of 14 volatile chemicals as measured by the chick embryo method." Am. Ind. Hvg. Assoc. J. 25:282-284.

Mourkides, G. A., D. C. Hobbs, and R. E. Koeppe. 1959. "The metabolism of acetone-2-C ${ }^{14}$ by intact rats." J. Biel. Chem. 234:27-30.

Nelson, D. L., and B. P. Webb. 1978. "Acetone." In Kirk-Othmer Encyclopedia of chemical Technolegy, H. F. Mark, D. F. Othrer, C. G. Overberger, and G. T. Seaborg, Eds., ed 3, pp 1:179-191. Wiley and Sons, NY,

NIOSH, Criteria for a reconmended standard for occupational exposure to ketones. US Dept of Health, Education and Welfare, National Institute for eccupational Safety and Health DHEW_NIOSH) Publication No. 78-173, 1978.

Nizyayeva, 1. V. 1982. "On hygienic assessment of acetone." Gig.truda. prof zabel. (Russian) June, pp. 24-28.

Parkes, D. G., C. R. Ganz, A. Polinsky, and J. Schulze. 1976, "A simple gas chromatographic method for the analysis of trace organics in ambient air." Amer. Ind. Hyom Assoc. J. 36:165.

Price, T. D., and D. Rittenberg. 1950. "The metabolism of acetone: I. Gross aspects of catabolism and excretion." I. Biol_chem. 185:449-459.

Reynolds, J. E. F., and A. B. Prasad, Eds. 1982, Martindale: The Extra Rharmacopeia, $28^{\text {th }}$ Edition. The Pharmaceutical Press, London.

Rowe, V. K. 1963. Industrial Hygiene and Toxicelogy, 2nd Ed, Vol II, Interscience, NY.

Rudney, H. 1950. "The metabolism of 1,2-propanediol." Arch. Biochem. $29: 231-232$.

Sakami, W., and J. M. Lasaye. 1950. "Formation of formate and labile methyl groups from acetone in the intact rat." J.Biel. Chem. 187:369-378.

Sakami, พ. J. 1948. Biol, Chem, 176:995.

SAS Institute. 1985. SASQ User's Guide: Basics, Version 5 Edition SAS Institute, Cary, North Carolina, pp 434-506. 
Schardein, J. L. 1985. Chemically Induced Birth Defects. Marcel Dekker.

Smyth, H. F., C. P. Carpenter, C. S. Weil, and U. C. Pozzani. 1962. "Range finding toxicity data: list VI." Am. Ind. Hyg. Assoc. J. 23:95-107.

Traiger, G. J., and G. L. Plaa. 1972. "Relationship of alcohol metabolism to the potentiation of $\mathrm{CCl}_{4}$ hepatotoxicity induced by aliphatic alcohols." I. Pharmacol. Exp. Ther. 183:481-488.

Traiger, G. J. and G. L. Plaa. 1974. "Chlorinated hycrocarbon toxicity, Arch. Environ. Health, 28:276-278.

Verschueren, K. 1977. Handbook of Environmental Data on Organic Chemicals. Van Nostrand Reinhold, New York.

Wigeaus, E., A. Lof, and M. Nordqvist. 1982. "Distribution and elimination of $2-\left[{ }^{14} \mathrm{C}\right]$-acetone in mice after inhalation exposure." Scand. $J$. Work. Environ. Health. $8: 121-128$.

Wigeaus, E., S. Holm, and I. Astrand. 1981. "Exposure to acetone: uptake and elimination in man." Scand. J. Work. Environ. Health 7:84-94.

Winer, B. J. 1971. Statistical Principles in Experimental Design, McGrawHill Book Co., NY, pp 170-185. 


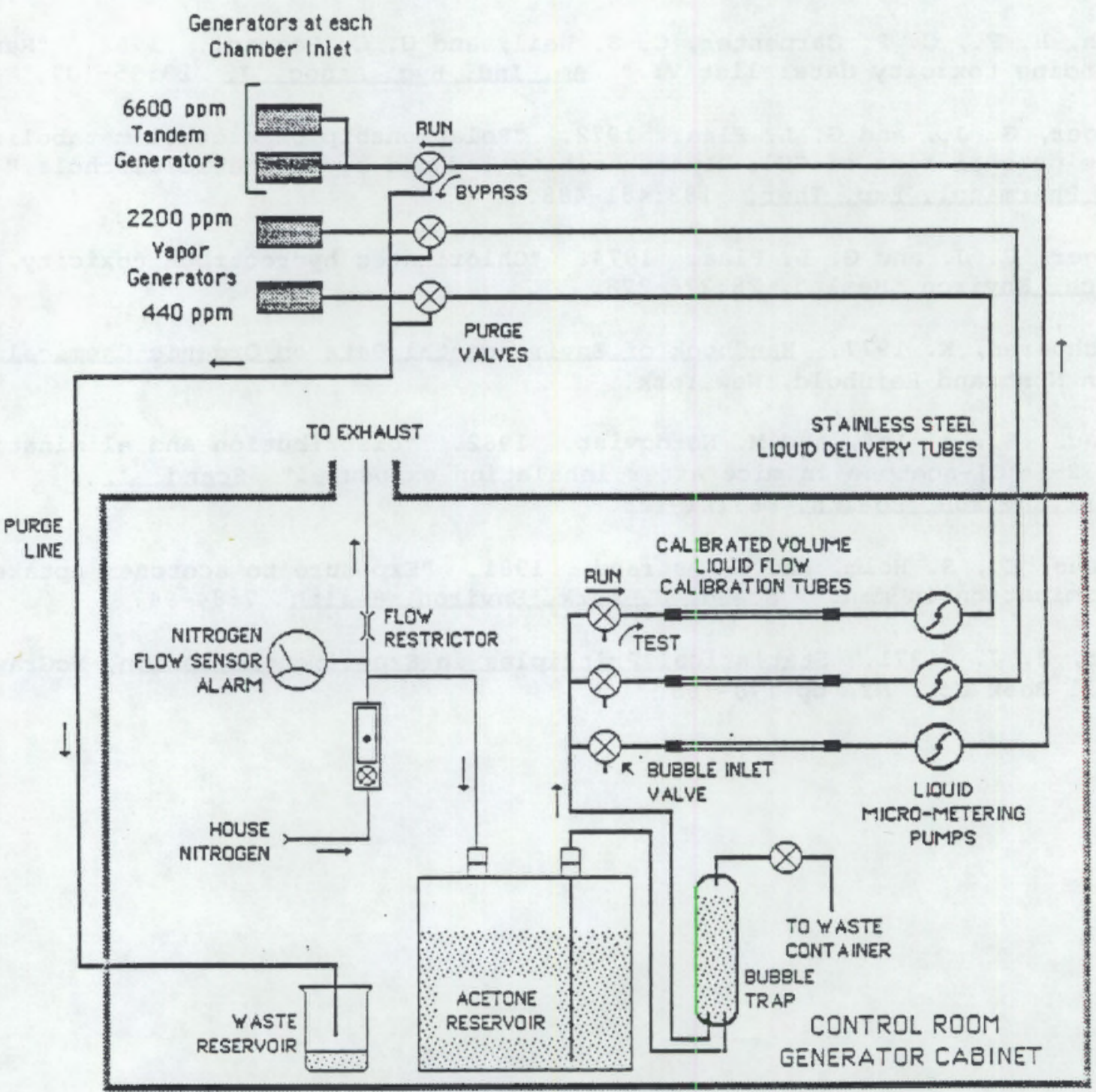

FlGURE 1. Acetone Generation and Delivery System 


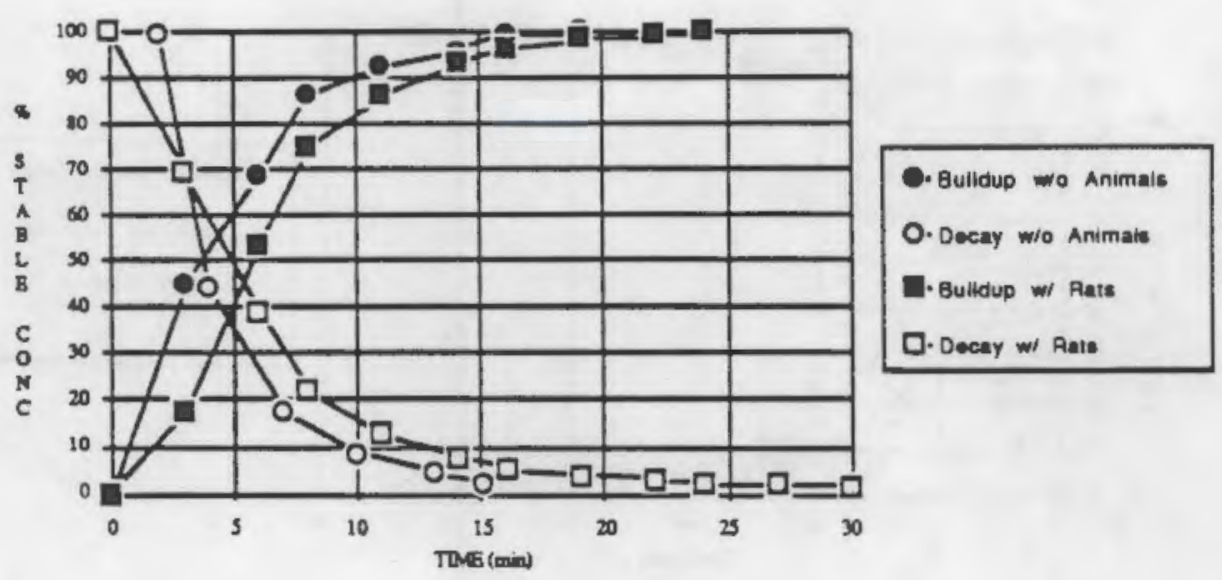

ACETONE: 2200 ppm Chamber

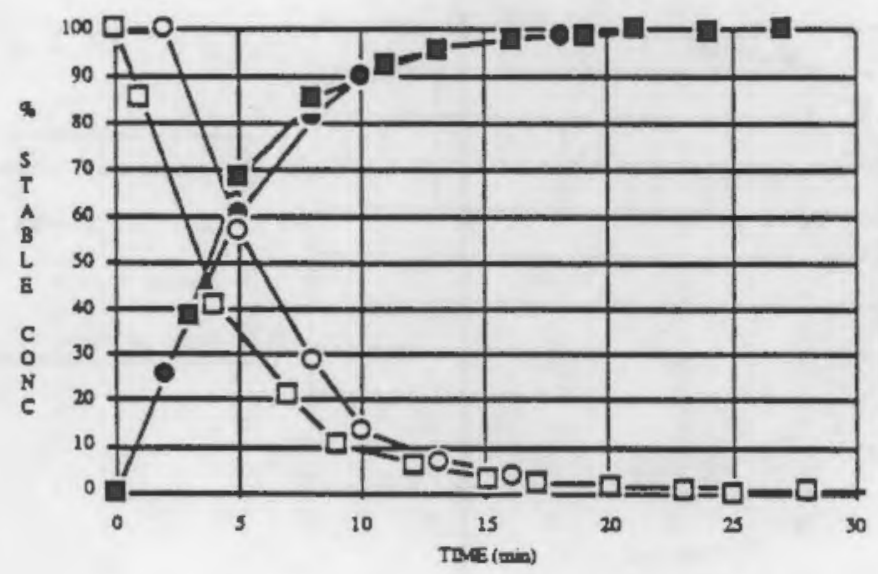

- Buildup wo Animais

O. Oecay wio Animals

2. Buildup wt Rats

D. Docay w/ Rats

ACETONE: $11,000 \mathrm{ppm}$ Chamber

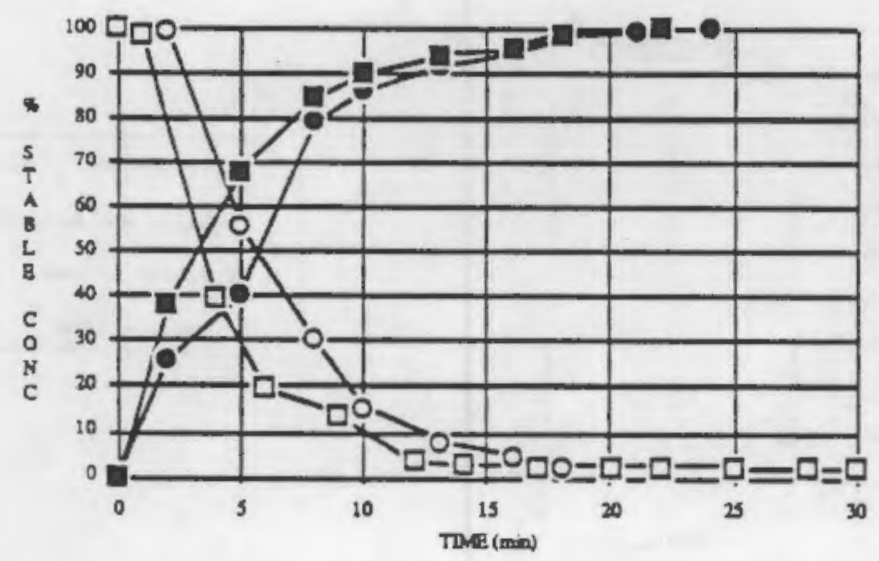

- Buildup w/o Animais

O. Decay w/o Animak

प. Bulldup w/ Rats

ㅁ. Decay wi Rais

FIGURE_2a. Buildup and Decay of Vapor Concentrations for

Exposure of Rats to Acetone With And Without Animais Present. 


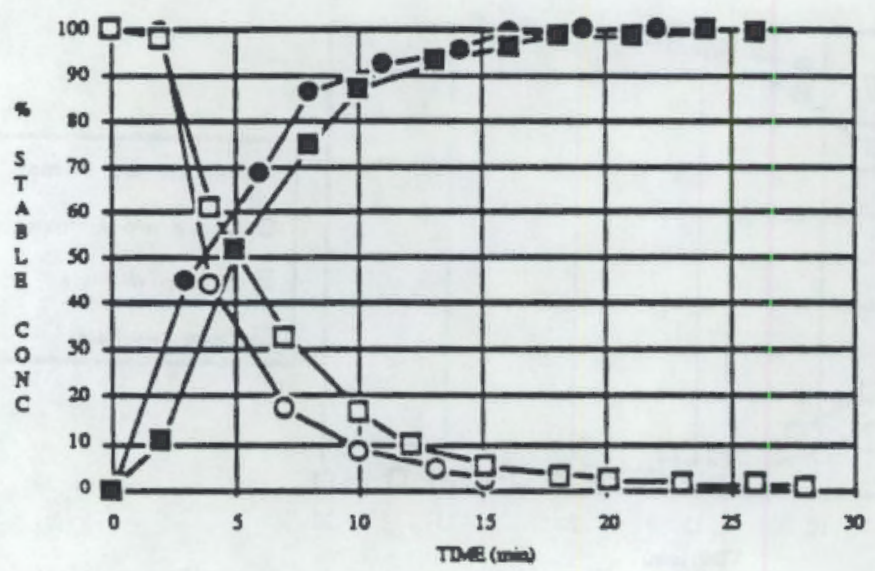

- Bulldup wo Animale O. Oecay wo Animan

E. Bulldup w/ Mice 口. Decay w/ Mico

ACETONE: 2200 ppm Chamber

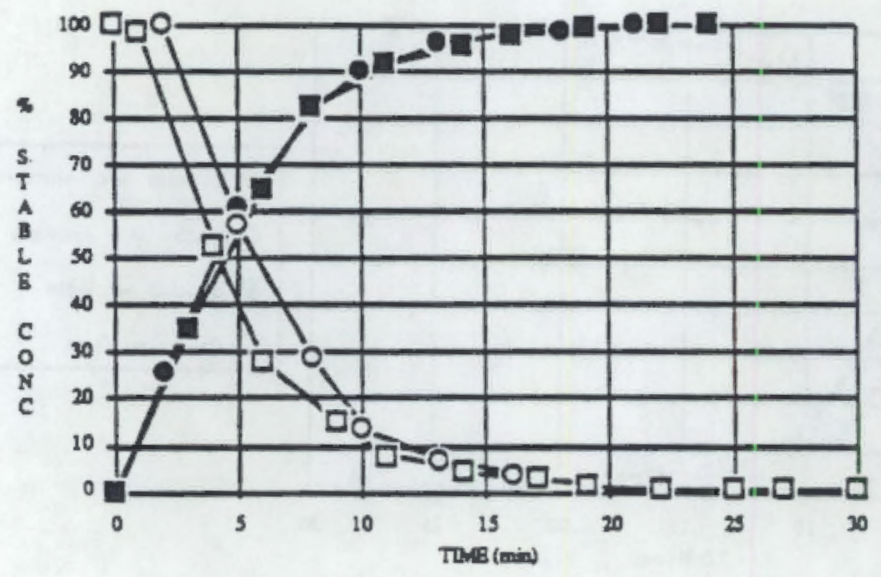

- Buildup wo Animals

O. Decay w/o Animais

E. Buildup w/ Mice

D. Decay w/ Mice

ACETONE: 6,600 ppm Chamber*

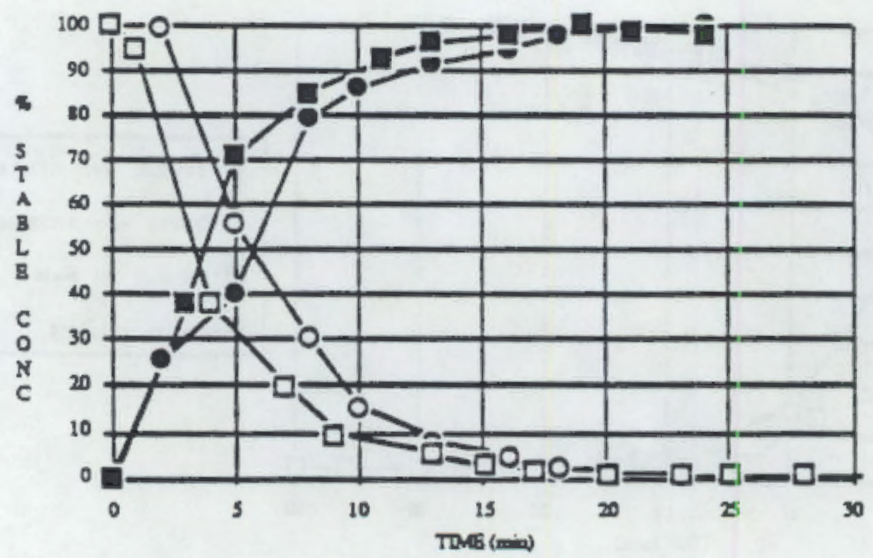

- Buildup wo Animals

O. Oecay w/o Animais

E. Bulldup w/ Mice

Q. Decay w/ Mice

FlGURE 2b. Buildup and Decay of Vapor Concentrations for Exposure of Mice to Acetone With And Without Animals Present.

* Buildup and decay without animais was conducted at 11,000 ppm Acetone for the highest exposure chamber. 


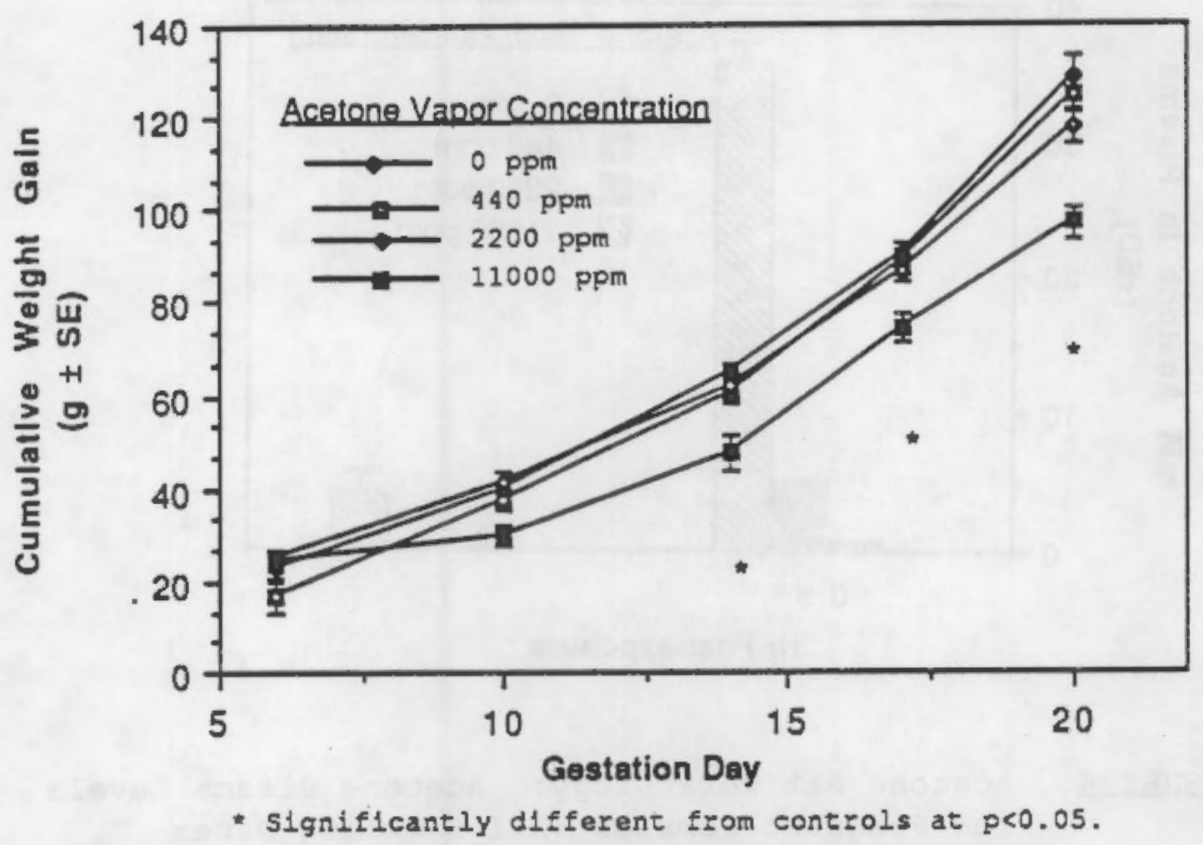

ElGURE3. Acetone Rat Teratology: Cumulative Weight Gain Graph 


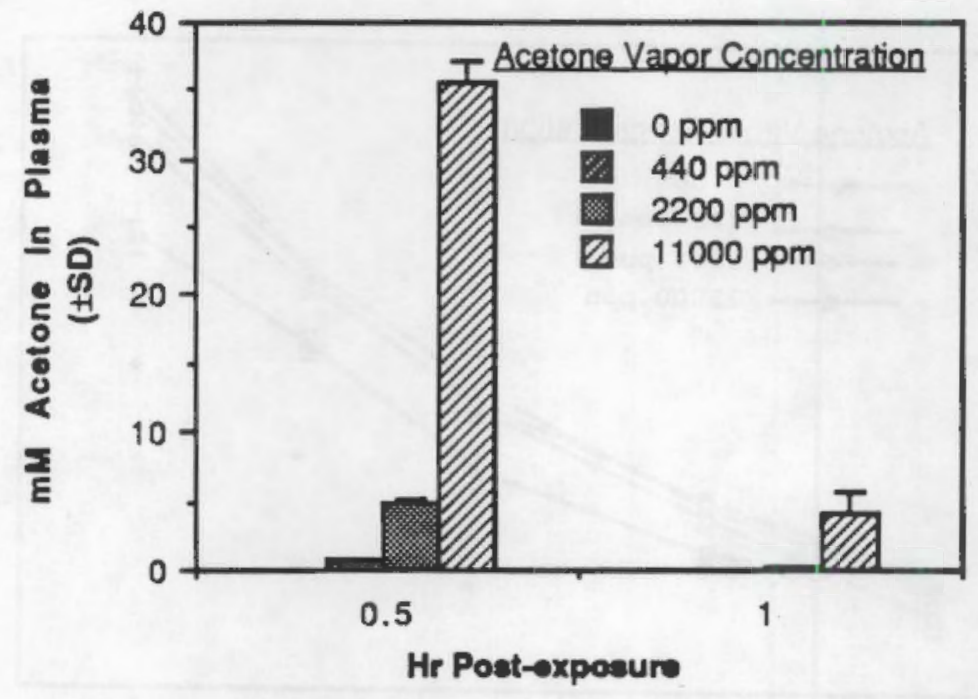

EIGURE 4. Acetone Rat Teratology: Acetone Plasma Levels for Pregnant Females (All Sarnpling Dates Combined) . 


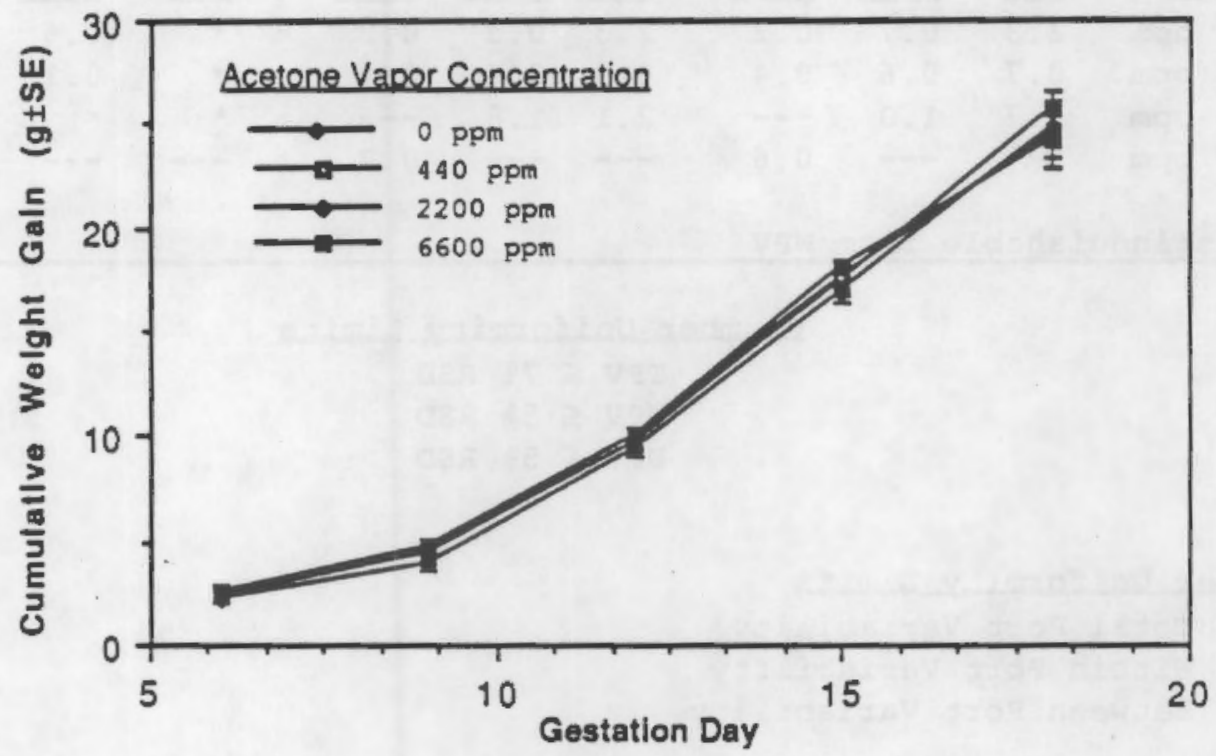

FlGURE 5. Acetone Mouse Teratology: Cumulative Weight Gain Graph 
TABLE 2. Teratology Study of Acetone in Mice and Rats: Summary of Chamber Uniformity Data Obtained Before Exposure and During Exposure.

\begin{tabular}{|c|c|c|c|c|c|c|c|c|c|}
\hline & \multicolumn{3}{|c|}{ TPV (8RSD) } & \multicolumn{3}{|c|}{ WPV (\%RSD) } & \multicolumn{3}{|c|}{ BPV (8RSD) } \\
\hline Chamber & Pre & Rats & Mice & Pre & Rats & Mice & Pre & Rats & Mice \\
\hline 440 ppm & 2.3 & 0.7 & 0.2 & 2.3 & 0.3 & 0.2 & * & 0.6 & * \\
\hline $2200 \mathrm{ppm}$ & 0.7 & 0.6 & 0.4 & 0.8 & 0.6 & 0.4 & * & 0.1 & * \\
\hline $11000 \mathrm{ppm}$ & 1.7 & 1.0 & --- & 2.1 & 1.8 & $-\infty$ & * & * & -- \\
\hline $6600 \mathrm{ppm}$ & -- & -- & 0.6 & -- & -- & 0.7 & $-\infty$ & $-\infty$ & * \\
\hline
\end{tabular}

Chamber Uniformity Limits

TPV $\leq 7 \%$ RSD

WPV $\leq 5 \%$ RSD

$\mathrm{BPV} \leq 5$ 용 RSD

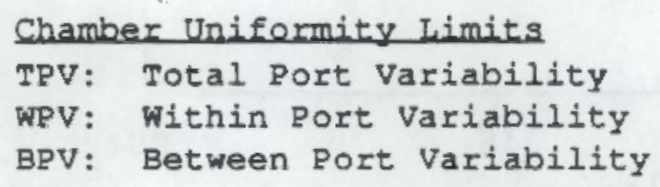


TABLE 2. Acetone Teratology Study: Average Daily Exposure Chamber Concentrations for Rat Exposures.

\begin{tabular}{|c|c|c|c|c|c|c|}
\hline \multicolumn{7}{|c|}{ O ppm Acetone Vapor } \\
\hline $\begin{array}{c}\text { Exposure } \\
\text { Day }\end{array}$ & $\begin{array}{c}\text { Mean } \pm S O \\
\text { (ppm) }\end{array}$ & $\begin{array}{c}\text { Max } \\
\text { (pom) }\end{array}$ & $\begin{array}{l}\mathrm{Min} \\
(\mathrm{ppm})\end{array}$ & $\begin{array}{l}\text { Number } \\
\text { Samples }\end{array}$ & $\begin{array}{c}\text { Number } \\
\text { in Pange (b) }\end{array}$ & $\begin{array}{l}\text { Percent } \\
\text { in Range }\end{array}$ \\
\hline 1 & $0.13 \pm 0.04$ & 0.17 & $<M D L(a)$ & 17 & 17 & 100 \\
\hline 2 & $0.14 \pm 0.02$ & 0.16 & 0.09 & 17 & 17 & 100 \\
\hline 3 & $0.14 \pm 0.05$ & 0.26 & 0.06 & 14 & 14 & 100 \\
\hline 4 & $0.12 \pm 0.04$ & 0.17 & $\angle M D L$ & 17 & 17 & $\$ 00$ \\
\hline 5 & $0.03 \pm 0.05$ & 0.12 & $<M D L$ & 54 & 54 & 100 \\
\hline 6 & $0.03 \pm 0.04$ & 0.11 & <MDL & 19 & 19 & 100 \\
\hline 7 & $0.11 \pm 0.01$ & 0.15 & 0.09 & 15 & 15 & 100 \\
\hline 8 & $0.09 \pm 0.03$ & 0.11 & $\angle M D L$ & 15 & 15 & 100 \\
\hline 9 & $0.08 \pm 0.03$ & 0.11 & $\angle M D L$ & 15 & 15 & 100 \\
\hline 10 & $0.09 \pm 0.03$ & 0.11 & $<M D L$ & 15 & 15 & 100 \\
\hline 11 & $0.08 \pm 0.03$ & 0.11 & $\angle M D L$ & 16 & 16 & 100 \\
\hline 12 & $0.08 \pm 0.03$ & 0.10 & $\angle M D L$ & 17 & 17 & 100 \\
\hline 13 & $0.06 \pm 0.04$ & 0.10 & $\angle M D L$ & 18 & 18 & 100 \\
\hline 14 & $0.07 \pm 0.03$ & 0.10 & $\angle M D L$ & 17 & 17 & 100 \\
\hline 15 & $0.07 \pm 0.04$ & 0.10 & $\angle M D L$ & 17 & 17 & 100 \\
\hline 16 & $0.07 \pm 0.04$ & 0.10 & $\angle M D L$ & 17 & 17 & 100 \\
\hline 17 & $0.07 \pm 0.03$ & 0.09 & $\angle M D L$ & 17 & 17 & 100 \\
\hline 18 & $0.08 \pm 0.01$ & 0.10 & 0.05 & 15 & 15 & 100 \\
\hline Summary & $0.08 \pm 0.05$ & 0.26 & $\angle M D L$ & 332 & 332 & 100 \\
\hline
\end{tabular}

(a) Minimum Detectable Limit (MDL) $=0.05$ ppm Acetone.

(b) Range-0-25 ppm Acetone.

\begin{tabular}{|c|l|c|c|c|c|c|}
\hline \multicolumn{7}{|c|}{40 ppm Acetone Vapor } \\
\hline $\begin{array}{c}\text { Exposure } \\
\text { Day }\end{array}$ & $\begin{array}{c}\text { Mean } \pm \text { (pD } \\
\text { (pom) }\end{array}$ & $\begin{array}{c}\text { Max } \\
\text { (pom) }\end{array}$ & $\begin{array}{c}\text { Min } \\
\text { (pom) }\end{array}$ & $\begin{array}{c}\text { Number } \\
\text { Samples }\end{array}$ & $\begin{array}{c}\text { Number } \\
\text { in Range (a) })\end{array}$ & $\begin{array}{c}\text { Percent } \\
\text { in Range }\end{array}$ \\
\hline 1 & $445 \pm 13$ & 464 & 422 & 16 & 16 & 100 \\
2 & $429 \pm 12$ & 440 & 396 & 16 & 15 & 94 \\
3 & $449 \pm 14$ & 480 & 434 & 13 & 13 & 100 \\
4 & $449 \pm 98$ & 797 & 386 & 15 & 12 & 80 \\
5 & $419 \pm 35$ & 445 & 322 & 16 & 14 & 88 \\
6 & $431 \pm 24$ & 474 & 398 & 11 & 11 & 100 \\
7 & $448 \pm 15$ & 494 & 434 & 15 & 14 & 93 \\
8 & $434 \pm 5$ & 443 & 424 & 15 & 15 & 100 \\
9 & $435 \pm 6$ & 443 & 422 & 15 & 15 & 100 \\
10 & $440 \pm 7$ & 448 & 421 & 14 & 14 & 100 \\
11 & $442 \pm 7$ & 464 & 435 & 16 & 16 & 100 \\
12 & $432 \pm 10$ & 455 & 414 & 17 & 17 & 100 \\
13 & $449 \pm 5$ & 456 & 436 & 17 & 17 & 100 \\
14 & $450 \pm 9$ & 468 & 435 & 16 & 16 & 100 \\
15 & $442 \pm 7$ & 463 & 434 & 16 & 16 & 100 \\
16 & $430 \pm 16$ & 451 & 389 & 16 & 15 & 94 \\
17 & $446 \pm 13$ & 464 & 412 & 16 & 16 & 100 \\
18 & $439 \pm 8$ & 452 & 428 & 14 & 14 & 100 \\
\hline Summary & $439 \pm 27$ & 797 & 322 & 274 & 266 & 97 \\
\hline
\end{tabular}

(a) Range $= \pm 10 \%$ target. 
TABLE 2. Acetone Teratology Study: Average Daily Exposure Chamber Concentrations for Rat Exposures. (comt.)

\begin{tabular}{|c|c|c|c|c|c|c|}
\hline \multicolumn{7}{|c|}{2200 ppm Acetone Vapor } \\
\hline $\begin{array}{c}\text { Exposure } \\
\text { Day }\end{array}$ & $\begin{array}{c}\text { Moan } \pm S D \\
\text { (ppm) }\end{array}$ & $\begin{array}{c}\text { Max } \\
\text { (ppm) }\end{array}$ & $\begin{array}{l}\text { Min } \\
\text { (pom) }\end{array}$ & $\begin{array}{l}\text { Number } \\
\text { Samples }\end{array}$ & $\begin{array}{c}\text { Number } \\
\text { in Range (a) }\end{array}$ & $\begin{array}{l}\text { Percent } \\
\text { in Range }\end{array}$ \\
\hline 1 & $2230 \pm 16$ & 2260 & 2200 & 16 & 16 & 100 \\
\hline 2 & $2200 \pm 22$ & 2230 & 2150 & 16 & 16 & 100 \\
\hline 3 & $2210 \pm 14$ & 2240 & 2190 & 13 & 13 & 100 \\
\hline 4 & $2220 \pm 19$ & 2270 & 2190 & 15 & 15 & 100 \\
\hline 5 & $2190 \pm 44$ & 2240 & 2070 & 16 & 16 & 100 \\
\hline 6 & $2200 \pm 10$ & 2220 & 2190 & 10 & 10 & 100 \\
\hline 7 & $2220 \pm 24$ & 2240 & $2+40$ & 15 & 15 & 100 \\
\hline 8 & $2210 \pm 11$ & 2240 & 2200 & 15 & 15 & 100 \\
\hline 9 & $2190 \pm 13$ & 2210 & 2160 & 15 & 15 & 100 \\
\hline 10 & $2200 \pm 18$ & 2250 & 2180 & 14 & 14 & 100 \\
\hline 11 & $2200 \pm 13$ & 2230 & 2180 & 15 & 15 & 100 \\
\hline 12 & $2210 \pm 39$ & 2340 & 2140 & 17 & 17 & 100 \\
\hline 13 & $2160 \pm 18$ & 2200 & 2140 & 17 & 17 & 100 \\
\hline 14 & $2190 \pm 17$ & 2210 & 2150 & 16 & 16 & 100 \\
\hline 15 & $2220 \pm 13$ & 2240 & 2190 & 16 & 16 & 100 \\
\hline 16 & $2210 \pm 15$ & 2240 & 2190 & 16 & 16 & 100 \\
\hline 17 & $2200 \pm 15$ & 2220 & 2170 & 16 & 16 & 100 \\
\hline 18 & $2210 \pm 13$ & 2230 & 2190 & 14 & 14 & 100 \\
\hline Summary & $2200 \pm 25$ & 2340 & 2070 & 272 & 272 & 100 \\
\hline
\end{tabular}

(a) Range $= \pm 10 \%$ target.

\begin{tabular}{|c|c|c|c|c|c|c|}
\hline \multicolumn{7}{|c|}{$11000 \mathrm{ppm}$ Acetone Vapor } \\
\hline $\begin{array}{l}\text { Exposure } \\
\text { Day }\end{array}$ & $\begin{array}{c}\text { Mean } \pm S D \\
\text { (pom) }\end{array}$ & $\begin{array}{c}\operatorname{Max} \\
(\operatorname{gom})\end{array}$ & $\begin{array}{l}\text { Min } \\
\text { (ppm) }\end{array}$ & $\begin{array}{l}\text { Number } \\
\text { Samples }\end{array}$ & $\begin{array}{c}\text { Number } \\
\text { in Range (a) }\end{array}$ & $\begin{array}{l}\text { Percent } \\
\text { in Range }\end{array}$ \\
\hline 1 & $15100 \pm 179$ & $1 \div 400$ & 10800 & 16 & 16 & 100 \\
\hline 2 & $11000 \pm 116$ & 11200 & 10800 & 16 & 16 & 100 \\
\hline 3 & $11100 \pm 122$ & 11200 & 10800 & 13 & 13 & 100 \\
\hline 4 & $11000 \pm t 04$ & $\uparrow 1100$ & 10800 & 16 & 16 & 100 \\
\hline 5 & $11000 \pm 113$ & 11100 & 10700 & 16 & 16 & 100 \\
\hline 6 & $11000 \pm 147$ & 11200 & 10700 & 10 & 10 & 100 \\
\hline 7 & $11100 \pm 190$ & 11300 & 10500 & 15 & 15 & 100 \\
\hline 8 & $11100 \pm 139$ & 11400 & 10900 & 14 & 14 & 100 \\
\hline 9 & $11100 \pm 136$ & 11300 & 10800 & 13 & 13 & 100 \\
\hline 10 & $11100 \pm 102$ & 11300 & 11000 & 14 & 14 & 100 \\
\hline 11 & $11000 \pm 108$ & 11200 & 10900 & 15 & 15 & 100 \\
\hline 12 & $11100 \pm 103$ & 11300 & 10900 & 16 & 16 & 100 \\
\hline 13 & $10900 \pm 118$ & 11100 & 10700 & 17 & 17 & 100 \\
\hline 14 & $11000 \pm 67$ & 11100 & 10900 & 16 & 16 & 100 \\
\hline 15 & $10900 \pm 63$ & 11100 & 10800 & 16 & 16 & 100 \\
\hline 16 & $10800 \pm 64$ & 11000 & 10700 & 16 & 16 & 100 \\
\hline 17 & $10900 \pm 88$ & 11100 & 10800 & 16 & 16 & 100 \\
\hline 18 & $11000 \pm 83$ & 11200 & 10900 & 14 & 14 & 100 \\
\hline Summary & $11000 \pm 137$ & 11400 & 10500 & 269 & 269 & 100 \\
\hline
\end{tabular}

(a) Flange $= \pm 10 \%$ target. 
IABLE_3 Acotone Teratology Study: Average Daity Exposure Chamber Concentrations for Mouse Exposures.

0 ppm Acetone Vapor

\begin{tabular}{|c|c|c|c|c|c|c|}
\hline $\begin{array}{c}\text { Exposure } \\
\text { Day }\end{array}$ & $\begin{array}{c}\text { Mean } \pm S D \\
\text { (gom) }\end{array}$ & $\begin{array}{l}\text { Max } \\
\text { (ppm) }\end{array}$ & $\begin{array}{c}\text { Min } \\
\text { (pgm) }\end{array}$ & $\begin{array}{l}\text { Number } \\
\text { Samples }\end{array}$ & $\begin{array}{c}\text { Number } \\
\text { in Range (b) }\end{array}$ & $\begin{array}{l}\text { Percent } \\
\text { in Range } \\
\end{array}$ \\
\hline 1 & $0.10 \pm 0.03$ & 0.12 & $<M D L$ (a) & 17 & 17 & 100 \\
\hline 2 & $0.06 \pm 0.03$ & 0.15 & $\angle M D L$ & 15 & 15 & 100 \\
\hline 3 & $0.04 \pm 0.03$ & 0.08 & $<M D L$ & 17 & 17 & 100 \\
\hline 4 & $0.03 \pm 0.03$ & 0.07 & $<M D L$ & 17 & 17 & 100 \\
\hline 5 & $0.29 \pm 0.96$ & 3.75 & $<M D L$ & 15 & 14 & 93 \\
\hline 6 & $0.06 \pm 0.03$ & 0.10 & $<M D L$ & 15 & 15 & 100 \\
\hline 7 & $0.05 \pm 0.03$ & 0.08 & $<M D L$ & 16 & 16 & 100 \\
\hline 8 & $0.04 \pm 0.04$ & 0.09 & $<M D L$ & 15 & 15 & 100 \\
\hline 9 & $0.04 \pm 0.04$ & 0.08 & $<M D L$ & 15 & 15 & 100 \\
\hline 10 & $0.01 \pm 0.03$ & 0.07 & $\angle M D L$ & 16 & 16 & 100 \\
\hline 11 & $0.01 \pm 0.03$ & 0.08 & <MDL & 17 & 17 & 100 \\
\hline 12 & $0.03 \pm 0.03$ & 0.08 & <MDL & 17 & 17 & 100 \\
\hline 13 & $0.02 \pm 0.03$ & 0.08 & $<M D L$ & 17 & 17 & 100 \\
\hline 14 & $0.01 \pm 0.02$ & 0.06 & $\angle M D L$ & $\$ 5$ & 15 & 100 \\
\hline 15 & $0.02 \pm 0.03$ & 0.08 & $\angle M D L$ & 17 & 17 & 100 \\
\hline 16 & $0.00 \pm 0.00$ & $\angle M D L$ & $\angle M D L$ & 11 & 11 & 100 \\
\hline $\mathrm{umm}$ & $0.05 \pm 0.24$ & 3.75 & $\langle\mathrm{MDL}$ & 252 & 251 & 100 \\
\hline
\end{tabular}

(a) Minimum Detectable Limit (MDL) $=0.05$ ppm Acetone.

(b) Range=0-25 pom Acetona.

\begin{tabular}{|c|l|c|c|c|c|c|}
\hline \multicolumn{7}{|c|}{440 ppm Acetone Vapor } \\
\hline $\begin{array}{c}\text { Exposure } \\
\text { Day }\end{array}$ & $\begin{array}{c}\text { Mean } \pm \text { SD } \\
\text { (pom) }\end{array}$ & $\begin{array}{c}\text { Max } \\
\text { (ppm) }\end{array}$ & $\begin{array}{c}\text { Min } \\
\text { (ppm) }\end{array}$ & $\begin{array}{c}\text { Number } \\
\text { Samples }\end{array}$ & $\begin{array}{c}\text { Number } \\
\text { Sange (a) }\end{array}$ & $\begin{array}{c}\text { Percent } \\
\text { in Range }\end{array}$ \\
\hline 1 & $442 \pm 23$ & 489 & 411 & 16 & 15 & 94 \\
2 & $429 \pm 29$ & 472 & 397 & 15 & 15 & 100 \\
3 & $434 \pm 13$ & 457 & 407 & 16 & 16 & 100 \\
4 & $442 \pm 21$ & 471 & 377 & 16 & 15 & 94 \\
5 & $450 \pm 12$ & 471 & 427 & 13 & 13 & 100 \\
6 & $445 \pm 7$ & 451 & 421 & 15 & 15 & 100 \\
7 & $424 \pm 15$ & 456 & 402 & 14 & 14 & 100 \\
8 & $440 \pm 15$ & 479 & 421 & 13 & 13 & 100 \\
9 & $439 \pm 8$ & 452 & 426 & 15 & 15 & 100 \\
10 & $440 \pm 7$ & 446 & 426 & 15 & 15 & 100 \\
11 & $446 \pm 3$ & 449 & 434 & 16 & 16 & 100 \\
12 & $444 \pm 4$ & 448 & 432 & 16 & 16 & 100 \\
13 & $433 \pm 6$ & 447 & 426 & 16 & 16 & 100 \\
14 & $439 \pm 5$ & 447 & 427 & 14 & 14 & 100 \\
15 & $435 \pm 8$ & 445 & 416 & 16 & 16 & 100 \\
16 & $376 \pm 136$ & 468 & 8 & 10 & 8 & 80 \\
\hline Summary & $436 \pm 33$ & 489 & 8 & 236 & 232 & 98 \\
\hline
\end{tabular}

(a) Range $= \pm 10 \%$ target. 
TABLE 3. Acetone Teratology Study: Average Daily Exposure

Chamber Concentrations for Mouse Exposures. (cont.)

\begin{tabular}{|c|c|c|c|c|c|c|}
\hline \multicolumn{7}{|c|}{2200 ppm Acetone Vapor } \\
\hline $\begin{array}{c}\text { Exposure } \\
\text { Day }\end{array}$ & $\begin{array}{c}\text { Mean } \pm \text { SD } \\
\text { (pom) }\end{array}$ & $\begin{array}{c}\text { Max } \\
\text { (pom) }\end{array}$ & $\begin{array}{c}\text { Min } \\
\text { (pom) }\end{array}$ & $\begin{array}{c}\text { Number } \\
\text { Samples }\end{array}$ & $\begin{array}{c}\text { Number } \\
\text { in Range (a) }\end{array}$ & $\begin{array}{c}\text { Percent } \\
\text { in Range }\end{array}$ \\
\hline 1 & $2250 \pm 69$ & 2450 & 2200 & 16 & 15 & 94 \\
2 & $2200 \pm 32$ & 2310 & 2180 & 15 & 15 & 100 \\
3 & $2190 \pm 16$ & 2220 & 2160 & 16 & 16 & 100 \\
4 & $2190 \pm 37$ & 2240 & 2080 & 16 & 16 & 100 \\
5 & $2210 \pm 18$ & 2240 & 2180 & 13 & 13 & 100 \\
6 & $2190 \pm 11$ & 2210 & 2170 & 15 & 15 & 100 \\
7 & $2170 \pm 16$ & 2190 & 2130 & 15 & 15 & 100 \\
8 & $2190 \pm 54$ & 2250 & 2040 & 13 & 13 & 100 \\
9 & $2180 \pm 12$ & 2210 & 2170 & 14 & 14 & 100 \\
10 & $2170 \pm 15$ & 2190 & 2140 & 15 & 15 & 100 \\
11 & $2170 \pm 16$ & 2210 & 2150 & 16 & 16 & 100 \\
12 & $2180 \pm 13$ & 2200 & 2160 & 16 & 16 & 100 \\
13 & $2180 \pm 12$ & 2190 & 2150 & 16 & 16 & 100 \\
14 & $2200 \pm 12$ & 2230 & 2190 & 14 & 14 & 100 \\
15 & $2200 \pm 9$ & 2220 & 2180 & 16 & 16 & 100 \\
16 & $1940 \pm 678$ & 2200 & 15 & 10 & 9 & 90 \\
\hline Summary & $2180 \pm 146$ & 2450 & 15 & 236 & 234 & 99 \\
\hline
\end{tabular}

(a) Range $= \pm 10 \%$ target.

\begin{tabular}{|c|c|c|c|c|c|c|}
\hline \multicolumn{7}{|c|}{} \\
\hline $\begin{array}{c}\text { Exposure } \\
\text { Oay }\end{array}$ & $\begin{array}{c}\text { Mean } \pm \text { SO } \\
\text { (ppm) }\end{array}$ & $\begin{array}{c}\text { Max } \\
(\text { ppm) }\end{array}$ & $\begin{array}{c}\text { Min } \\
\text { (ppm) }\end{array}$ & $\begin{array}{c}\text { Number } \\
\text { Samples }\end{array}$ & $\begin{array}{c}\text { Number } \\
\text { in Range (b) }\end{array}$ & $\begin{array}{c}\text { Percent } \\
\text { in Range }\end{array}$ \\
\hline 1 (a) & $11100 \pm 336$ & 11700 & 10700 & 16 & 16 & 100 \\
2 & $6590 \pm 83$ & 6770 & 6450 & 15 & 15 & 100 \\
3 & $6560 \pm 78$ & 6720 & 6440 & 16 & 16 & 100 \\
4 & $6510 \pm 98$ & 6730 & 6370 & 16 & 16 & 100 \\
5 & $6520 \pm 120$ & 6680 & 6320 & 14 & 14 & 100 \\
6 & $6610 \pm 61$ & 6690 & 6520 & 15 & 15 & 100 \\
7 & $6550 \pm 107$ & 6730 & 6380 & 14 & 14 & 100 \\
8 & $6520 \pm 201$ & 6680 & 5960 & 12 & 12 & 100 \\
9 & $6580 \pm 112$ & 6710 & 6290 & 14 & 14 & 100 \\
10 & $6560 \pm 82$ & 6760 & 6450 & 15 & 15 & 100 \\
11 & $6630 \pm 43$ & 6710 & 6570 & 16 & 16 & 100 \\
12 & $6630 \pm 45$ & 6710 & 6560 & 16 & 16 & 100 \\
13 & $6500 \pm 80$ & 6620 & 6380 & 16 & 16 & 100 \\
14 & $6630 \pm 47$ & 6700 & 6570 & 14 & 14 & 100 \\
15 & $6560 \pm 56$ & 6690 & 6500 & 16 & 16 & 100 \\
16 & $5850 \pm 2021$ & 6770 & 113 & 10 & 9 & 90 \\
\hline Summary & $6540 \pm 448$ & 6770 & 113 & 219 & 218 & 100 \\
\hline
\end{tabular}

(a) Changed from $11000 \mathrm{ppm}$ to $6600 \mathrm{ppm}$ Acetone vapor after the first day of exposure. See Text.

(b) Range $= \pm 10 \%$ target. 
TABLE 4. Acetone Rat Teratology Study: Mean Body, Uterine, and Extra-gestational Weights of Pregnant Dams ( $9 \pm$ SD).

\begin{tabular}{|l|c|c|c|c|}
\hline \multirow{2}{*}{$\begin{array}{c}\text { Acetone } \\
\text { (ppm) }\end{array}$} & \multicolumn{4}{|c|}{ Weight (g) } \\
\cline { 2 - 5 } & $0 \mathrm{ppm}$ & $440 \mathrm{ppm}$ & $2200 \mathrm{ppm}$ & $11000 \mathrm{ppm}$ \\
\hline $\mathrm{N}$ & 26 & 27 & 29 & 26 \\
Body Weight & & & & $274.5 \pm 19.9$ \\
$0 \mathrm{dg}$ & $272.6 \pm 17.7$ & $273.6 \pm 15.7$ & $273.1 \pm 18.6$ & $299.0 \pm 23.9$ \\
$6 \mathrm{dg}$ & $295.4 \pm 22.3$ & $290.5 \pm 28.5$ & $298.5 \pm 19.2$ & $304.4 \pm 24.9$ \\
$10 \mathrm{dg}$ & $312.5 \pm 18.8$ & $311.2 \pm 20.0$ & $314.7 \pm 21.1$ & $322.1 \pm 28.9$ \\
$14 \mathrm{dg}$ & $337.6 \pm 19.8$ & $333.8 \pm 21.5$ & $334.8 \pm 22.1$ & $348.7 \pm 26.1$ \\
$17 \mathrm{dg}$ & $362.8 \pm 21.5$ & $362.0 \pm 23.8$ & $359.8 \pm 24.5$ & $371.3 \pm 29.1$ (a) \\
$20 \mathrm{dg}$ (b) & $401.2 \pm 29.5$ & $398.5 \pm 27.9$ & $390.8 \pm 28.1$ & $67.1 \pm 13.9$ (a) \\
& $83.2 \pm 19.0$ & $79.7 \pm 14.5$ & $74.5 \pm 16.3$ & \\
Uterine (b) & & & & $29.7 \pm 14.4$ (a) \\
Extra-gestational & & & $43.2 \pm 15.2$ & \\
Wt. gain (b) & $45.3 \pm 16.7$ & $45.1 \pm 13.2$ & 43.2 & \\
\hline
\end{tabular}

(a) Significantly different from 0-ppm group, $p<0.05$.

(b) Significantly correlated with exposure concentration, $p<0.05$. 
TABLE 5, Contemporary Control Data for Sprague Dawley

Rats ( $\mathrm{N}=80$ Litters; Mean $\pm \mathrm{SD}$ ).

\begin{tabular}{|l|r|c|}
\hline & Number & Percent \\
\hline Maternal Weight; 20 dg & $404.8 \pm 29.0$ & - \\
Gravid Uterine Weight & $79.6 \pm 18.7$ & - \\
Extra-gestational Weight Gain & $48.2 \pm 15.0$ & - \\
& & \\
Implants & $15.7 \pm 2.9$ & - \\
Live Fetuses & $14.7 \pm 3.3$ & $92.5 \pm 9.0$ \\
Earty Resorptions & $0.9 \pm 1.1$ & $6.4 \pm 8.6$ \\
Late Resorptions & $0.2 \pm 0.5$ & $1.1 \pm 3.3$ \\
Dead Fetuses & $0.0 \pm 0.0$ & $0.0 \pm 0.0$ \\
Total Intrauterine Death & $1.1 \pm 1.1$ & $7.5 \pm 9.0$ \\
& & \\
Litters with Resorptions & 48 & 60 \\
& & \\
Fetal Weight & $3.55 \pm 0.33$ & - \\
Male & $3.64 \pm 0.39$ & - \\
Female & $3.45 \pm 0.32$ & - \\
\hline
\end{tabular}

TABLE 6. Acetone Rat Teratology Study: Mean Body Weights for Virgins $(g \pm S D)$.

\begin{tabular}{|l|ccccc|}
\hline $\begin{array}{c}\text { Exposure } \\
\begin{array}{c}\text { Concen- } \\
\text { tration }\end{array}\end{array}$ & $\mathrm{N}$ & $\begin{array}{c}\text { Exposure } \\
\text { Day 1 }\end{array}$ & $\begin{array}{c}\text { Exposure } \\
\text { Day 5 }\end{array}$ & $\begin{array}{c}\text { Exposure } \\
\text { Day 10 }\end{array}$ & Sacritice \\
\hline & & & & & \\
0 ppm & 10 & $280.1 \pm 16.6$ & $287.5 \pm 20.2$ & $290.0 \pm 20.1$ & $290.2 \pm 21.8$ \\
$440 \mathrm{pprm}$ & 10 & $277.0 \pm 20.1$ & $283.3 \pm 17.9$ & $290.6 \pm 18.5$ & $286.6 \pm 27.7$ \\
$2200 \mathrm{ppm}$ & 10 & $278.7 \pm 23.8$ & $297.1 \pm 19.9$ & $292.6 \pm 20.2$ & $292.0 \pm 16.6$ \\
11000 ppm & 10 & $279.0 \pm 24.2$ & $277.2 \pm 26.8$ & $276.7 \pm 26.0$ & $273.1 \pm 26.4$ \\
\hline
\end{tabular}

TABLE 7. Acetone Rat Teratology Study: Mean Organ Weights of Pregnant Dams ( \pm SD).

\begin{tabular}{|l|ccccc|}
\hline $\begin{array}{l}\text { Exposure } \\
\text { Concen- } \\
\text { tration }\end{array}$ & $\mathrm{N}$ & Liver & $\begin{array}{c}\text { Liver } \\
\text { \% LBWR (a) }\end{array}$ & Kidney & $\begin{array}{c}\text { Kidney } \\
\% \text { KBWR (b) }\end{array}$ \\
\hline $0 \mathrm{ppm}$ & 26 & $16.9 \pm 1.7$ & $\mathbf{4 . 2 2} \pm 0.31$ & $2.2 \pm 0.1$ & $0.56 \pm 0.04$ \\
$440 \mathrm{ppm}$ & 27 & $17.1 \pm 1.8$ & $\mathbf{4 . 2 9} \pm 0.27$ & $2.3 \pm 0.2$ & $0.57 \pm 0.05$ \\
$2200 \mathrm{ppm}$ & 29 & $16.5 \pm 1.6$ & $\mathbf{4 . 2 1} \pm 0.28$ & $2.2 \pm 0.2$ & $0.57 \pm 0.05$ \\
$11000 \mathrm{opm}$ & 26 & $16.8 \pm 2.2$ & $4.51 \pm 0.39$ & $2.4 \pm 0.2$ & $0.64 \pm 0.05$ \\
\hline
\end{tabular}

(a) \%LBWR $=$ Percent Liver to Body Weight Ratio, (at sacrifice).

(b) \%KBWR=Percent Kidney to Body Weight Ratio, (at sacrifice). 
IABLE 8. Acetone Rat Teratology Study: Reproductive Measures (Mean \pm SD).

\begin{tabular}{|c|c|c|c|c|}
\hline & \multicolumn{4}{|c|}{ Acetone Chamber Concentration (ppm) } \\
\hline & 0 & 440 & 2200 & 11000 \\
\hline $\begin{array}{l}\text { Sperm-positive Females } \\
\text { Number Pregnant } \\
\text { Pregnant (\%) } \\
\text { Pregnancies Examined } \\
\text { Implantations/Dam } \\
\text { Live Fetuses/Litter } \\
\text { Resorptions/Litter: Total } \\
\text { Earty } \\
\text { Late } \\
\text { Dead Fetuses/Litter } \\
\text { Litters with Resorptions }\end{array}$ & $\begin{array}{c}30 \\
28 \\
93 \\
26 \text { (a) } \\
15.9 \pm 2.3 \\
14.8 \pm 2.5 \\
1.0 \pm 1.3 \\
0.8 \pm 1.1 \\
0.2 \pm 0.7 \\
0 \\
13\end{array}$ & $\begin{array}{c}31 \\
29 \\
94 \\
27(b) \\
15.7 \pm 2.5 \\
14.6 \pm 2.8 \\
1.1 \pm 1.6 \\
0.9 \pm 1.2 \\
0.2 \pm 0.8 \\
0 \\
16\end{array}$ & $\begin{array}{c}31 \\
29 \\
94 \\
29 \\
15.7 \pm 2.2 \\
14.0 \pm 3.2 \\
1.6 \pm 2.1 \\
1.3 \pm 1.8 \\
0.3 \pm 1.1 \\
0 \\
20\end{array}$ & $\begin{array}{c}30 \\
29 \\
97 \\
26(c) \\
15.4 \pm 3.0 \\
14.1 \pm 2.8 \\
1.3 \pm 1.3 \\
1.0 \pm 1.0 \\
0.3 \pm 0.6 \\
0 \\
20\end{array}$ \\
\hline \multicolumn{5}{|l|}{ PERCENTAGE OF: } \\
\hline $\begin{array}{l}\text { Live Fetuses/Litter } \\
\text { Resorptions/Litter: Total } \\
\text { Early } \\
\text { Late } \\
\text { Dead Fetuses/Litter } \\
\text { Litters with Resorptions }\end{array}$ & $\begin{array}{l}93.4 \pm 8.5 \\
6.6 \pm 8.5 \\
5.0 \pm 7.3 \\
1.5 \pm 4.2 \\
0 \\
50 \\
\end{array}$ & $\begin{array}{l}92.7 \pm 9.6 \\
7.3 \pm 9.6 \\
5.9 \pm 7.3 \\
1.4 \pm 4.8 \\
0 \\
59\end{array}$ & $\begin{array}{r}89.3 \pm 14.6 \\
10.7 \pm 14.6 \\
8.6 \pm 12.3 \\
2.1 \pm 7.3 \\
0 \\
69 \\
\end{array}$ & $\begin{array}{l}92.1 \pm 7.7 \\
7.9 \pm 7.7 \\
6.3 \pm 6.1 \\
1.6 \pm 3.7 \\
0 \\
77 \\
\end{array}$ \\
\hline
\end{tabular}

(a) 2 dams removed from study; one with umbilical hernia and one with litter $\leq 2$ implants.

(b) 2 dams removed from study; one with dental problems and one with litter $\leq 2$ implants.

(c) 3 dams removed from study; two with litters $\leq 2$ implants and one with dental problems.

TABLE 9. Acetone Rat Teratology Study: Average Fetal Weights (Means of Litter Means; $g \pm S D$ ), and Percent Male Fetuses.

\begin{tabular}{|l|c|c|c|c|}
\hline \multirow{2}{*}{} & \multicolumn{4}{|c|}{ Acetone Chamber Concentration (ppm) } \\
\cline { 2 - 5 } & 0 & 440 & 2200 & 11000 \\
\hline Litter Exarnined & 26 & 27 & 28 & 26 \\
& & & & \\
Fetal Weight (c) & $3.6 \pm 0.4$ & $3.7 \pm 0.2$ & $3.5 \pm 0.3$ & $3.1 \pm 0.3(\mathrm{~b})$ \\
Male (c) & $3.7 \pm 0.4$ & $3.8 \pm 0.2$ & $3.6 \pm 0.3$ & $3.1 \pm 0.3(\mathrm{~b})$ \\
Fermale (c) & $3.5 \pm 0.3$ & $3.6 \pm 0.2$ & $3.4 \pm 0.3$ & $3.0 \pm 0.3(\mathrm{~b})$ \\
Percent Male Fetuses & $51.6 \pm 13.7$ & $49.9 \pm 14.4$ & $51.9 \pm 15.5$ (a) & $49.5 \pm 13.2$ \\
\hline
\end{tabular}

(a) $\mathrm{N}=29$ litters; one lifter was sexed but inadvertantly not weighed.

(b) Significantly different from 0-ppm group, $0<0.05$.

(c) Significantly correlated with exposure concentration, $p<0.05$. 
TABLE 10. Acatone Rat Teratology Study: Malformations Observed in Liva Fotuses.

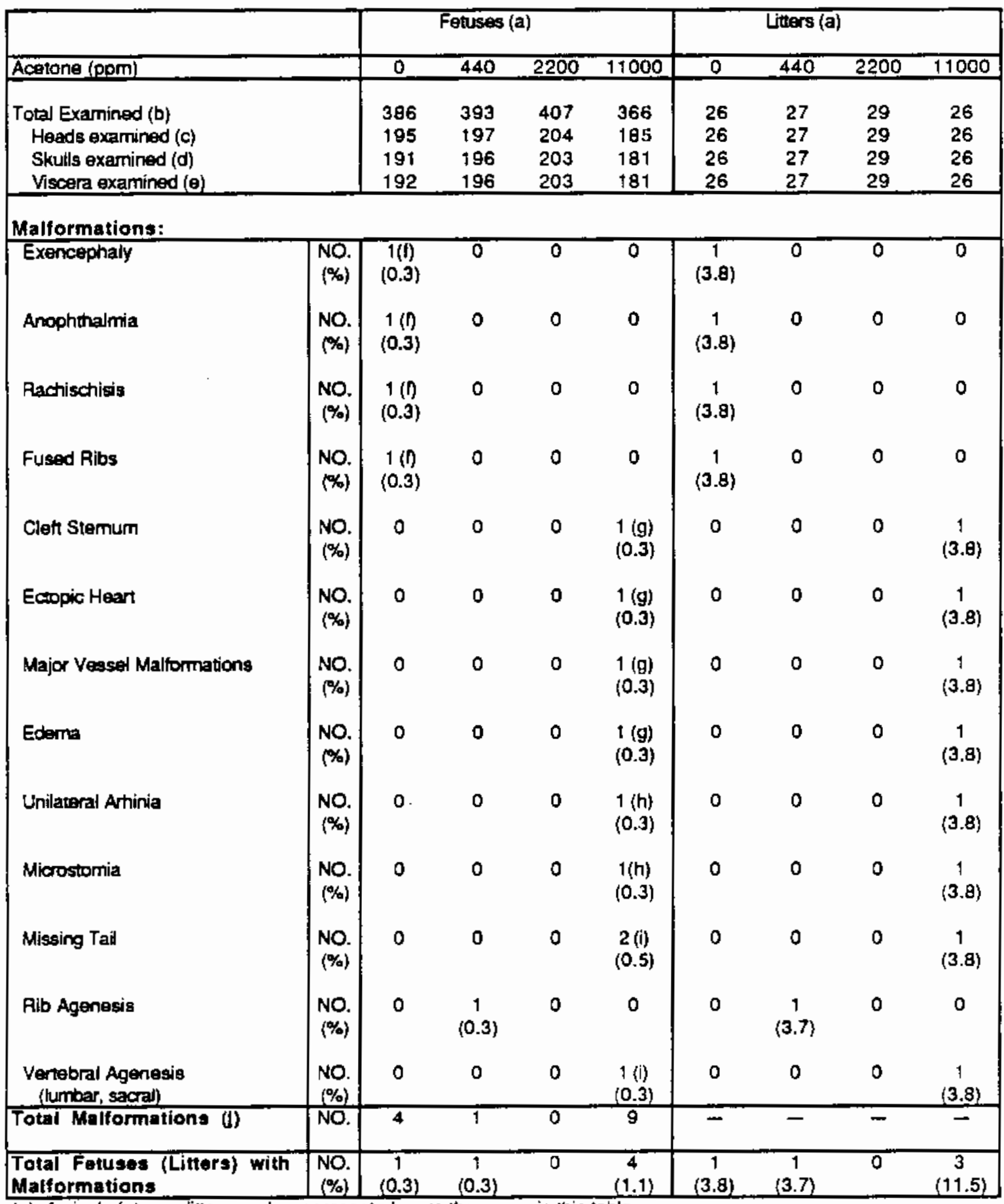

(a) A single fetus or litter may be represented more than once in this table.

(b) All fetuses examined for extemal and skeletal defects. One-half had heads removed prior to skeietal staining.

(c) Heads fixed in Bouin's solution for sott-tissue craniolacial evaluations.

(d) Heads remaining on the fetuser for skeletal examination; see (b).

(e) Viecerads pertomed on approx. 50\% of live tetuses and all fetuses with external delects.

(i) Three major malformations found in a single fetus.

(g) Four major malformations found in a single letus.

(h) Two major maltorrations found in a single ferus.

(i) Two major malformations found in a single fetus.

(j) There may be $>1$ malformation per tenss. 
TABLE 11. Acetone Rat Terablogy Sudy: Mean Percent of Livo Fetuses Alfected per Limar (Maen \pm SD).

\begin{tabular}{|c|c|c|c|c|}
\hline & \multicolumn{3}{|c|}{ Acetone Vapor Concentration (ppm) } & \multirow[b]{2}{*}{11000} \\
\hline & 0 & 440 & 2200 & \\
\hline $\begin{array}{l}\text { Number Lituers } \\
\text { Live Fetuses/Litter }\end{array}$ & $\begin{array}{c}26 \\
14.8 \pm 2.5\end{array}$ & $\begin{array}{c}27 \\
14.6 \pm 2.8\end{array}$ & $\begin{array}{c}29 \\
14.0 \pm 3.2\end{array}$ & $\begin{array}{c}26 \\
14.1 \pm 2.8\end{array}$ \\
\hline Malformeitons: & $\% \pm S O$ & $\% \pm \mathrm{SO}$ & $\% \pm$ SD & $\% \pm \mathrm{SD}$ \\
\hline Exencephaly & $0.3 \pm 1.5$ & 0 & 0 & 0 \\
\hline Anophthaimia & $0.3 \pm 1.5$ & 0 & 0 & 0 \\
\hline Rachischisis & $0.3 \pm 1.5$ & 0 & 0 & 0 \\
\hline Fused Rib & $0.3 \pm 1.5$ & 0 & 0 & 0 \\
\hline Clett Stemum & 0 & 0 & 0 & $0.2 \pm 1.0$ \\
\hline Ectopic Heart & 0 & 0 & 0 & $0.2 \pm 1.0$ \\
\hline Major Vessel Maiformation & 0 & 0 & 0 & $0.2 \pm 1.0$ \\
\hline Edema & 0 & 0 & 0 & $0.2 \pm 1.0$ \\
\hline Unilateral Athnia & 0 & 0 & 0 & $0.3 \pm 1.5$ \\
\hline Microstomia & 0 & 0 & 0 & $0.3 \pm 1.5$ \\
\hline Missing Tail & 0 & 0 & 0 & $0.7 \pm 3.6$ \\
\hline Aib Agenesis & 0 & $0.2 \pm 1.1$ & 0 & 0 \\
\hline $\begin{array}{l}\text { Vertebral Agenesis } \\
\text { (lumbar and sacral) }\end{array}$ & 0 & 0 & 0 & $0.3 \pm 1.8$ \\
\hline $\begin{array}{l}\text { \% Fotuses per Litter with at Least } \\
\text { One Malformation }\end{array}$ & $0.9 \pm 4.5$ & $0.2 \pm 1.1$ & 0 & $2.8 \pm 8.5$ \\
\hline \multicolumn{5}{|l|}{ Variations: } \\
\hline Dilated Ureter & $2.9 \pm 7.6$ & $3.4 \pm 10.9$ & $2.4 \pm 6.4$ & $3.8 \pm 7.3$ \\
\hline Misaligned Stemebra (b) & $0.6 \pm 2.0$ & $0.7 \pm 2.1$ & $0.5 \pm 2.0$ & $2.1 \pm 3.8$ \\
\hline Missing innominake & $0.5 \pm 2.5$ & $0.5 \pm 2.7$ & 0 & $0.5 \pm 2.8$ \\
\hline Supemumerary Rib & $6.6 \pm 12.9$ & $4.8 \pm 12.2$ & $5.0 \pm 12.2$ & $3.0 \pm 6.5$ \\
\hline Renal Polvic Cavitation & 0 & 0 & $0.4 \pm 2.3$ & 0 \\
\hline \multicolumn{5}{|l|}{ Reduced Ossiflcations: } \\
\hline Pelvis & $1.7 \pm 5.3$ & $0.4 \pm 2.1$ & $2.2 \pm 5.7$ & $0.7 \pm 3.6$ \\
\hline Phalanges & $1.4 \pm 5.2$ & 0 & $0.2 \pm 1.0$ & $1.2 \pm 3.8$ \\
\hline Phos(c) & 0 & 0 & $0.4 \pm 1.7$ & $0.5 \pm 1.8$ \\
\hline Skull & $1.0 \pm 4.9$ & 0 & $2.4 \pm 5.3$ & $4.3 \pm 9.7$ \\
\hline Stemebrae (b) & $6.1 \pm \$ 1.1$ & $4.6 \pm 5.8$ & $6.3 \pm 9.0$ & $11.5 \pm 14.1$ \\
\hline Vertabral Centra & $2.2 \pm 4.2$ & $1.9 \pm 3.5$ & $1.7 \pm 3.8$ & $1.4 \pm 3.1$ \\
\hline $\begin{array}{l}\text { \% Fetuses per Litter with at Least } \\
\text { One Variation or Reduced } \\
\text { Ossiflegtion }\end{array}$ & $15.4 \pm 13.9$ & $11.3 \pm 15.9$ & $15.0 \pm 17.2$ & $18.3 \pm 15.5$ \\
\hline
\end{tabular}

(a) Inctudes malformations, variations, and reduced ossifications.

(b) Mean percent incidence is linearly correlated with exposure concentration $(p<0.05)$.

(c) Ineludes thoracic rudimentary ribs. 
TABLE 12. Contemporary Control Daba on Rat Teratology Sucties: Malformations.

\begin{tabular}{|c|c|c|c|c|}
\hline & & $\begin{array}{l}\text { Fotuses (a) } \\
\text { Number } \\
\text { (Percent) }\end{array}$ & $\begin{array}{l}\text { Litter: } \\
\text { Number } \\
\text { (Percent) }\end{array}$ & $\begin{array}{c}\text { Mean Percent } \\
\text { per Liter } \\
( \pm S D)\end{array}$ \\
\hline $\begin{array}{l}\text { Total examined (b) } \\
\text { Heads examined (c) } \\
\text { Skulls examined (d) }\end{array}$ & & $\begin{array}{c}1172 \\
- \\
- \\
\end{array}$ & $\begin{array}{l}80 \\
- \\
- \\
\end{array}$ & - \\
\hline \multicolumn{5}{|l|}{ Melformatlons } \\
\hline Exencephaly & $\begin{array}{l}\text { No. } \\
(\%)\end{array}$ & $\begin{array}{c}1 \\
(0.1)\end{array}$ & $\begin{array}{c}1 \\
(1.3)\end{array}$ & $0.1 \pm 0.9$ \\
\hline Microphatmia & $\begin{array}{l}\text { No. } \\
\text { (\%) }\end{array}$ & $\begin{array}{c}1 \\
(0.1)\end{array}$ & $\stackrel{1}{(1.3)}$ & $0.1 \pm 0.7$ \\
\hline Anophthalmia & $\begin{array}{l}\text { No. } \\
\text { (\%) }\end{array}$ & $\stackrel{1}{1}(0.1)$ & $\begin{array}{c}1 \\
(1.3)\end{array}$ & $0.1 \pm 0.9$ \\
\hline Rachischisis & $\begin{array}{l}\text { No. } \\
\text { (\%) }\end{array}$ & $\stackrel{1}{1}$ & $\begin{array}{c}1 \\
(1.3)\end{array}$ & $0.1 \pm 0.9$ \\
\hline Ectopic Ovarios & $\begin{array}{l}\text { No. } \\
\text { (\%) }\end{array}$ & $\begin{array}{c}1 \\
(0.1)\end{array}$ & $\begin{array}{c}1 \\
(1.3)\end{array}$ & $0.1 \pm 0.6$ \\
\hline $\begin{array}{c}\text { Total Fetuses (Litters) } \\
\text { with Malformations }\end{array}$ & $\begin{array}{l}\text { No. } \\
\text { (\%) }\end{array}$ & $\begin{array}{c}3 \\
(0.2)\end{array}$ & $\begin{array}{c}5 \\
(6.3) \\
\end{array}$ & $0.2 \pm 1.3(\theta)$ \\
\hline
\end{tabular}

(a) A single feus or liter may be represented more than once in this table.

(b) Al teruses examined for external and skeletal delects. One-half had heads removed prior to skeletal staining.

(c) Heads fixed in Bouin's solution for soft-tissue craniofacial avaluations.

(d) Heads that remained on the fetuses had a skeletal examination; see (b)

(e) Mean percem of fetuses per liter with at least one maltomation. 
TABLE 13. Acotone Rat Teratology Study: Variations Observed in Live Fetuses.

\begin{tabular}{|c|c|c|c|c|c|c|c|c|c|}
\hline \multirow{2}{*}{\multicolumn{2}{|c|}{ Acetone (ppm) }} & \multicolumn{4}{|c|}{ Fotuses (a) } & \multicolumn{4}{|c|}{ Litters (a) } \\
\hline & & 0 & 440 & 2200 & 11000 & 0 & 440 & 2200 & 11000 \\
\hline $\begin{array}{l}\text { Total Examined (b) } \\
\text { Heads exarrined (c) } \\
\text { Skulls examined (d) } \\
\text { Viscera examined (e) }\end{array}$ & & $\begin{array}{l}386 \\
195 \\
191 \\
192 \\
\end{array}$ & $\begin{array}{l}393 \\
197 \\
196 \\
196 \\
\end{array}$ & $\begin{array}{l}407 \\
204 \\
203 \\
203\end{array}$ & $\begin{array}{l}366 \\
185 \\
181 \\
181 \\
\end{array}$ & $\begin{array}{l}26 \\
26 \\
26 \\
26 \\
\end{array}$ & $\begin{array}{l}27 \\
27 \\
27 \\
27\end{array}$ & $\begin{array}{l}29 \\
29 \\
29 \\
29 \\
\end{array}$ & $\begin{array}{l}26 \\
26 \\
26 \\
26\end{array}$ \\
\hline \multicolumn{10}{|l|}{ Variations: } \\
\hline Dílated Ureter & $\begin{array}{l}\text { NO. } \\
(\%)\end{array}$ & $\begin{array}{c}5 \\
(2.6)\end{array}$ & $\begin{array}{c}7 \\
(3.6)\end{array}$ & $\begin{array}{c}5 \\
(2.5)\end{array}$ & $\begin{array}{c}7 \\
(3.9)\end{array}$ & $\begin{array}{c}4 \\
(15.4)\end{array}$ & $\begin{array}{c}3 \\
(11.1)\end{array}$ & $\begin{array}{c}4 \\
(13.8)\end{array}$ & $\begin{array}{c}6 \\
(23.1)\end{array}$ \\
\hline Misaligned Sternebrae & $\begin{array}{l}\text { NO. } \\
(\%)\end{array}$ & $\begin{array}{c}2 \\
(0.5)\end{array}$ & $\begin{array}{c}3 \\
(0.8)\end{array}$ & $\stackrel{2}{(0.5)}$ & $\stackrel{g}{(2.2)}$ & $\stackrel{2}{2}$ & $\begin{array}{c}3 \\
(11.1)\end{array}$ & $\begin{array}{c}2 \\
(6.9)\end{array}$ & $\begin{array}{c}7 \\
(26.9)\end{array}$ \\
\hline Missing Innominate & $\begin{array}{l}\text { No. } \\
(\%)\end{array}$ & $\stackrel{1}{(0.5)}$ & ${ }^{1}$ & 0 & $\begin{array}{c}1 \\
(0.5)\end{array}$ & $\begin{array}{c}1 \\
(3.8)\end{array}$ & $\begin{array}{c}1 \\
(3.7)\end{array}$ & 0 & $\begin{array}{c}1 \\
(3.8)\end{array}$ \\
\hline Supernumerary Rib & $\begin{array}{l}\text { NO. } \\
(\%)\end{array}$ & $\begin{array}{c}27 \\
(7.0)\end{array}$ & $\begin{array}{c}17 \\
(4.3)\end{array}$ & $\begin{array}{c}17 \\
(4.2)\end{array}$ & $\begin{array}{c}12 \\
(3.3)\end{array}$ & $\begin{array}{c}9 \\
(34.6)\end{array}$ & $\begin{array}{c}5 \\
(18.5)\end{array}$ & $\begin{array}{c}7 \\
(24.1)\end{array}$ & $\begin{array}{c}9 \\
(34.6)\end{array}$ \\
\hline Renal Pelvic Cavitation & $\begin{array}{l}\text { NO. } \\
(\%)\end{array}$ & 0 & 0 & $\begin{array}{c}1 \\
(0.5) \\
\end{array}$ & 0 & 0 & 0 & $\begin{array}{c}1 \\
(3.4)\end{array}$ & 0 \\
\hline \multicolumn{10}{|l|}{ Reduced Ossifications: } \\
\hline Pelvis & $\begin{array}{l}\text { NO. } \\
(\%)\end{array}$ & $\begin{array}{c}5 \\
(1.3)\end{array}$ & $\begin{array}{c}1 \\
(0.2)\end{array}$ & $\begin{array}{c}7 \\
(1.7)\end{array}$ & $\begin{array}{c}2 \\
(0.5)\end{array}$ & $\begin{array}{c}3 \\
(11.5)\end{array}$ & $\begin{array}{c}1 \\
(3.7)\end{array}$ & $\begin{array}{c}5 \\
(17.2)\end{array}$ & $\begin{array}{c}\ddagger \\
(3.8)\end{array}$ \\
\hline Phalanges & $\begin{array}{l}\text { NO. } \\
(\%)\end{array}$ & $\begin{array}{c}4 \\
(1.0)\end{array}$ & 0 & $\begin{array}{c}1 \\
(0.2)\end{array}$ & $4^{4}$ & $\stackrel{2}{(7.7)}$ & 0 & $\begin{array}{c}1 \\
(3.4)\end{array}$ & ${ }^{3}$ \\
\hline Ribs (I) & $\begin{array}{l}\text { NO. } \\
(\%)\end{array}$ & 0 & 0 & $\begin{array}{c}2 \\
(0.5)\end{array}$ & $\stackrel{2}{2}$ & 0 & 0 & $\begin{array}{c}2 \\
\{6.9\}\end{array}$ & $\stackrel{2}{(7.7)}$ \\
\hline Skul & $\begin{array}{l}\text { NO. } \\
(\%)\end{array}$ & $\begin{array}{c}1 \\
(0.5)\end{array}$ & 0 & $\begin{array}{c}5 \\
(2.5)\end{array}$ & $\begin{array}{c}8 \\
(4.4)\end{array}$ & $\begin{array}{c}1 \\
\text { (3.8) }\end{array}$ & 0 & $\begin{array}{c}\mathbf{S} \\
(17.2)\end{array}$ & $\begin{array}{c}6 \\
(23.1)\end{array}$ \\
\hline Stemebrae & $\begin{array}{l}\text { NO. } \\
(\%)\end{array}$ & $\begin{array}{c}21 \\
(5.4)\end{array}$ & $\begin{array}{c}18 \\
(4.6)\end{array}$ & $\begin{array}{c}23 \\
(5.6)\end{array}$ & $\begin{array}{c}44 \\
(12.0)\end{array}$ & $\begin{array}{c}11 \\
(42.3)\end{array}$ & $\begin{array}{c}13 \\
(48.1)\end{array}$ & $\begin{array}{c}16 \\
(55.2)\end{array}$ & $\begin{array}{c}15 \\
(57.7)\end{array}$ \\
\hline Vertebral Centra & $\begin{array}{l}\text { NO. } \\
(\%)\end{array}$ & $\begin{array}{c}9 \\
(2.3)\end{array}$ & $\begin{array}{c}5 \\
(1.3)\end{array}$ & $\begin{array}{c}7 \\
(1.7)\end{array}$ & $\begin{array}{c}5 \\
(1,4)\end{array}$ & $\begin{array}{c}7 \\
(26.9)\end{array}$ & $\begin{array}{c}3 \\
(11.1)\end{array}$ & $\begin{array}{c}6 \\
(20.7)\end{array}$ & $\begin{array}{c}5 \\
(99.2)\end{array}$ \\
\hline $\begin{array}{l}\text { Total Variations and } \\
\text { Reduced Ossifications ig }\end{array}$ & NO. & 75 & 52 & 70 & 93 & - & - & - & $\overline{-}$ \\
\hline $\begin{array}{l}\text { Total Fotuses (Litters) with } \\
\text { Variations or Red.Ossif. }\end{array}$ & $\begin{array}{l}\text { NO. } \\
(\%)\end{array}$ & $\begin{array}{c}58 \\
(15.0) \\
(15)\end{array}$ & $\begin{array}{c}43 \\
(10.9) \\
\end{array}$ & $\begin{array}{c}55 \\
(13.5) \\
(13.5)\end{array}$ & $\begin{array}{c}70 \\
(19.1) \\
\end{array}$ & $\begin{array}{c}24 \\
292.3 \\
\end{array}$ & $\begin{array}{c}16 \\
(59.3) \\
\end{array}$ & $\begin{array}{c}22 \\
(75.9)\end{array}$ & $\begin{array}{c}21 \\
(80.8)\end{array}$ \\
\hline
\end{tabular}
(a) A single tetus or litter may be represented more then once in this table.
(b) All feuses examined for external and skeletal delects. One-half hed heads removed prior to skeletal staining.
(c) Heads fixed in Bouin's solution for soft-tissue craniofacial avatuations.
(d) Heads remaining on the fetuses for skeletal examination; see (b).
(e) Viscerals pertormed on approx. $50 \%$ of live fetuses and all fetuses with external defects.
(i) Includes nudimentary thoracic ribs.
(9) There may be $>1$ variation of reduced ossification site per fetus. 
TABLE 14. Contemporary Control Data on Rat Teratology Studies: Variations and Reduced Ossifications.

\begin{tabular}{|c|c|c|c|c|}
\hline & & $\begin{array}{c}\text { Fetuses (a) } \\
\text { Number } \\
\text { (Percent) }\end{array}$ & $\begin{array}{l}\text { Litters } \\
\text { Number } \\
\text { (Percent) }\end{array}$ & $\begin{array}{c}\text { Mean Percent } \\
\text { per Utter } \\
( \pm S D)\end{array}$ \\
\hline $\begin{array}{l}\text { Total examined (b) } \\
\text { Heads examined (c) } \\
\text { Skulls examined (d) }\end{array}$ & & $\begin{array}{c}1172 \\
- \\
- \\
\end{array}$ & $\begin{array}{l}80 \\
- \\
-\end{array}$ & - \\
\hline \multicolumn{5}{|l|}{ Variations } \\
\hline Supernumerary Rib & $\begin{array}{l}\text { No. } \\
(\%)\end{array}$ & $\begin{array}{l}38 \\
(3.2)\end{array}$ & $\begin{array}{c}\$ 7 \\
(21.3)\end{array}$ & $3.2 \pm 8.4$ \\
\hline Missing Innominate & $\begin{array}{l}\text { No. } \\
\text { (\%) }\end{array}$ & $\stackrel{2}{(0.2)}$ & $\stackrel{2}{(2.5)}$ & $0.2 \pm 1.1$ \\
\hline Dilated Ureter & $\begin{array}{l}\text { No. } \\
(\%)\end{array}$ & $\begin{array}{c}32 \\
(2.7)\end{array}$ & $\begin{array}{c}15 \\
(18.8)\end{array}$ & $2.9 \pm 8.7$ \\
\hline Rudimentary Rib & $\begin{array}{l}\text { No. } \\
\text { (\%) }\end{array}$ & $\begin{array}{c}1 \\
(0.1)\end{array}$ & $\begin{array}{c}1 \\
(1.3)\end{array}$ & $0.1 \pm 0.7$ \\
\hline $\begin{array}{c}\text { Renal Petvic } \\
\text { Canitation }\end{array}$ & $\begin{array}{l}\text { No. } \\
(\%)\end{array}$ & $\begin{array}{c}8 \\
(0.7)\end{array}$ & $\stackrel{4}{(5.0)}$ & $0.7 \pm 3.4$ \\
\hline $\begin{array}{l}\text { Misseligned } \\
\text { Siemabrae }\end{array}$ & $\begin{array}{l}\text { No. } \\
(\%)\end{array}$ & $\stackrel{4}{(0.3)}$ & $\begin{array}{c}4 \\
(5.0)\end{array}$ & $0.3 \pm 1.5$ \\
\hline \multicolumn{5}{|l|}{ Reduced Ossifications: } \\
\hline Stemebrae & $\begin{array}{l}\text { No. } \\
(\%)\end{array}$ & $\begin{array}{c}95 \\
(8.1)\end{array}$ & $\begin{array}{c}38 \\
(47.5)\end{array}$ & $8.5 \pm 15.0$ \\
\hline Vertebrae & $\begin{array}{l}\text { No. } \\
(\%)\end{array}$ & $\begin{array}{c}53 \\
(4.5)\end{array}$ & $\begin{array}{c}29 \\
(36.3)\end{array}$ & $4.7 \pm 10.2$ \\
\hline Phalanges & $\begin{array}{l}\text { No. } \\
\text { (\%) }\end{array}$ & $\begin{array}{c}9 \\
(0.8)\end{array}$ & $\begin{array}{c}6 \\
(7.5)\end{array}$ & $1.0 \pm 4.0$ \\
\hline Peivic & $\begin{array}{l}\text { No. } \\
(\%)\end{array}$ & $\begin{array}{c}21 \\
(1.8)\end{array}$ & $\begin{array}{c}10 \\
(12.5)\end{array}$ & $2.3 \pm 9.8$ \\
\hline Skull & $\begin{array}{l}\text { No. } \\
(\%)\end{array}$ & $\begin{array}{r}15 \\
(1.3) \\
\end{array}$ & $\begin{array}{c}7 \\
(8.8) \\
\end{array}$ & $1.5 \pm 6.1$ \\
\hline $\begin{array}{l}\text { Total Fetuses (Litters) with } \\
\text { Vaptations or Red. Oasif. }\end{array}$ & $\begin{array}{l}\text { No. } \\
(\%)\end{array}$ & $\begin{array}{c}205 \\
(17.4) \\
\end{array}$ & $\begin{array}{c}69 \\
(86.3) \\
\end{array}$ & $18.0 \pm 18.3(\theta)$ \\
\hline
\end{tabular}
(a) A singie tews or liter mey be represented more than once in this table.
(b) Alt fetuses examined for external and skeletal defects. One-half had heads removed prior o skeletal staining.
(c) Heads fixed in Bouin's solution for soft-issue craniofacial evaluations.
(d) Heads that remained on the foluses had a skeleal examination; see (b).
(e) Maan percent of feruses per litter with at least one veriation or reduced ossification.. 
TABLE 15. Acetone Rat Teratology Study (Ketone): Mean Body, Uterine, and Extra-gestational Weights of Pregnant Dams $(g \pm S D)$.

\begin{tabular}{|l|c|c|c|c|}
\hline & \multicolumn{4}{|c|}{ Weights (g) } \\
\cline { 2 - 5 } & 0 ppm & $440 \mathrm{ppm}$ & $2200 \mathrm{ppm}$ & $11000 \mathrm{ppm}$ \\
\hline $\mathrm{N}$ & 7 & 3 & 7 & 7 \\
Body Weights & & & & \\
$0 \mathrm{dg}$ & $274.8 \pm 20.9$ & $278.1 \pm 18.2$ & $275.5 \pm 15.0$ & $280.3 \pm 18.6$ \\
$6 \mathrm{dg}$ & $304.5 \pm 23.0$ & $299.1 \pm 17.9$ & $298.3 \pm 13.6$ & $302.3 \pm 21.5$ \\
$10 \mathrm{dg}$ & $309.0 \pm 27.6$ & $313.6 \pm 17.1$ & $317.0 \pm 15.1$ & $305.6 \pm 20.4$ \\
$14 \mathrm{dg}$ & $333.4 \pm 23.1$ & $337.0 \pm 19.4$ & $339.4 \pm 14.4$ & $326.6 \pm 23.7$ \\
$17 \mathrm{dg}$ & $357.6 \pm 29.0$ & $355.3 \pm 18.8$ & $361.1 \pm 16.8$ & $345.0 \pm 28.3$ \\
$20 \mathrm{dg}$ & $393.6 \pm 38.7$ & $381.2 \pm 24.5$ & $396.0 \pm 24.9$ & $366.1 \pm 33.9$ \\
& & & & \\
Uterine & $81.9 \pm 23.8$ & $65.1 \pm 21.4$ & $76.4 \pm 10.0$ & $71.2 \pm 8.7$ \\
& & & & \\
Extra-gestational & & & & \\
Wt. gain & $37.0 \pm 17.2$ & $37.9 \pm 12.7$ & $44.1 \pm 29.4$ & $14.6 \pm 25.7$ \\
\hline
\end{tabular}


TABLE 16. Concentration of Ketone Bodies Found in the Plagma of Pregnant Rats (except where noted) Exposed to Acetone by Inhalation.

\begin{tabular}{|c|c|c|c|c|c|c|c|c|c|c|c|}
\hline $\begin{array}{l}\text { Exposure } \\
\text { Group }\end{array}$ & $\begin{array}{l}\text { Time of } \\
\text { Sampling }\end{array}$ & $\begin{array}{l}\text { Day of } \\
\text { Gescation }\end{array}$ & $\begin{array}{r}\text { Aceto } \\
\text { Mean } \pm\end{array}$ & $\begin{array}{l}\mathrm{SD}(\mathrm{m} \\
\mathrm{SD}\end{array}$ & $N$ & $\begin{array}{c}\text { Acetoace } \\
\text { Mean } \pm\end{array}$ & $\begin{array}{l}\text { tic } A \\
\text { SD }\end{array}$ & $\mathrm{N}^{(\mathrm{mM})}$ & $\begin{array}{r}\text { B-Hydro } \\
\text { Mean }\end{array}$ & $\begin{array}{l}\text { butyric } \\
\text { SD }\end{array}$ & $\begin{array}{l}\text { Acid }(\mathrm{mH}) \\
\mathrm{N}\end{array}$ \\
\hline Control & $\begin{array}{l}30 \mathrm{~min} \\
\text { Post- } \\
\text { exposure }\end{array}$ & $\begin{array}{r}7 \\
19 \\
\quad 19\end{array}$ & $\begin{array}{r}<0.01 \\
<0.01 \\
0.03\end{array}$ & 0.02 & $\begin{array}{l}7 \\
7 \\
7\end{array}$ & $\begin{array}{l}0.05 \\
0.03 \\
0.02\end{array}$ & $\begin{array}{l}0.01 \\
0.02 \\
0.01\end{array}$ & $\begin{array}{l}7 \\
7 \\
7\end{array}$ & $\begin{array}{l}1.0 \\
0.9 \\
1.1\end{array}$ & $\begin{array}{l}0.1 \\
0.1 \\
0.2\end{array}$ & $\begin{array}{l}7 \\
7 \\
7\end{array}$ \\
\hline $\begin{array}{l}440 \text { pprn } \\
\text { (Pregnant) }\end{array}$ & $\begin{array}{l}30 \mathrm{~min} \\
\text { Post- } \\
\text { Exposure }\end{array}$ & $\begin{array}{r}7 \\
14 \\
\text { e } 19\end{array}$ & $\begin{array}{l}0.66 \\
0.74 \\
0.91\end{array}$ & $\begin{array}{l}0.07 \\
0.03 \\
0.08\end{array}$ & $\begin{array}{l}4 \\
9 \\
4\end{array}$ & $\begin{array}{r}<0.02 \\
0.39 \\
<0.20\end{array}$ & $\begin{array}{c}-- \\
0.07 \\
--\end{array}$ & $\begin{array}{l}4 \\
4 \\
4\end{array}$ & $\begin{array}{r}<1.5 \\
2.6 \\
1.4\end{array}$ & $\begin{array}{l}-- \\
0.3 \\
0.2\end{array}$ & $\begin{array}{l}4 \\
4 \\
4\end{array}$ \\
\hline $\begin{array}{l}440 \text { pprn } \\
\text { (Non-pregnant) }\end{array}$ & $\begin{array}{l}30 \mathrm{~min} \\
\text { Post- } \\
\text { exposure }\end{array}$ & $\begin{array}{r}7 \\
14 \\
+\quad 19\end{array}$ & $\begin{array}{l}0.58 \\
0.59 \\
0.66\end{array}$ & $\begin{array}{l}0.01 \\
0.06 \\
0.06\end{array}$ & $\begin{array}{l}3 \\
3 \\
3\end{array}$ & $\begin{array}{l}0.16 \\
<0.4 \\
<0.4\end{array}$ & $\begin{array}{c}0.05 \\
-- \\
--\end{array}$ & $\begin{array}{l}3 \\
3 \\
3\end{array}$ & $\begin{array}{l}0.8 \\
2.0 \\
1.1\end{array}$ & $\begin{array}{l}0.2 \\
0.4 \\
0.4\end{array}$ & $\begin{array}{l}3 \\
3 \\
3\end{array}$ \\
\hline $2,220 \mathrm{ppm}$ & $\begin{array}{l}30 \mathrm{~min} \\
\text { Post- } \\
\text { exposure }\end{array}$ & $\begin{array}{r}7 \\
14 \\
\quad 19\end{array}$ & $\begin{array}{l}5.1 \\
4.7 \\
5.1\end{array}$ & $\begin{array}{l}0.3 \\
0.5 \\
0.4\end{array}$ & $\begin{array}{l}7 \\
7 \\
7\end{array}$ & $\begin{array}{l}<0.5 \\
<0.7 \\
<0.5\end{array}$ & $\begin{array}{l}-- \\
-- \\
--\end{array}$ & $\begin{array}{l}7 \\
7 \\
7\end{array}$ & $\begin{array}{c}<0.5 \\
<1.6 \\
9\end{array}$ & $\begin{array}{l}-- \\
-- \\
3\end{array}$ & $\begin{array}{l}7 \\
7 \\
7\end{array}$ \\
\hline $11,000 \mathrm{ppm}$ & $\begin{array}{l}30 \mathrm{~min} \\
\text { Post- } \\
\text { exposure }\end{array}$ & $\begin{array}{r}7 \\
19 \\
0 \quad 19\end{array}$ & $\begin{array}{l}37 \\
36 \\
34\end{array}$ & $\begin{array}{l}2 \\
4 \\
5\end{array}$ & $\begin{array}{l}7 \\
7 \\
7\end{array}$ & $\begin{array}{l}<3 \\
<5 \\
<7\end{array}$ & $\begin{array}{l}-- \\
-- \\
--\end{array}$ & $\begin{array}{l}7 \\
7 \\
7\end{array}$ & $\begin{array}{l}<3 \\
<5 \\
<7\end{array}$ & $\begin{array}{l}-- \\
-- \\
--\end{array}$ & $\begin{array}{l}7 \\
7 \\
7\end{array}$ \\
\hline Control & $\begin{array}{l}17 \mathrm{~h} \\
\text { Post - } \\
\text { exposure }\end{array}$ & $\begin{array}{r}7 \\
14 \\
e \quad 19\end{array}$ & $\begin{array}{l}<0.01 \\
<0.01 \\
<0.01\end{array}$ & $\begin{array}{l}-- \\
-- \\
--\end{array}$ & $\begin{array}{l}7 \\
7 \\
5\end{array}$ & $\begin{array}{l}0.06 \\
0.03 \\
0.03\end{array}$ & $\begin{array}{l}0.03 \\
0.01 \\
0.02\end{array}$ & $\begin{array}{l}7 \\
7 \\
7\end{array}$ & $\begin{array}{l}1.2 \\
1.2 \\
1.2\end{array}$ & $\begin{array}{l}0.3 \\
0.1 \\
0.1\end{array}$ & $\begin{array}{l}7 \\
7 \\
7\end{array}$ \\
\hline $\begin{array}{l}440 \text { ppm } \\
\text { (Pregnant) }\end{array}$ & $\begin{array}{l}17 \mathrm{~h} \\
\text { Post- } \\
\text { exposure }\end{array}$ & $\begin{array}{r}7 \\
14 \\
+\quad 19\end{array}$ & $\begin{array}{l}<0.07 \\
<0.01 \\
<0.03\end{array}$ & $\begin{array}{l}-- \\
-- \\
--\end{array}$ & $\begin{array}{l}4 \\
4 \\
3\end{array}$ & $\begin{array}{r}<0.60 \\
0.03 \\
<0.03\end{array}$ & $\begin{array}{c}0.01 \\
--\end{array}$ & $\begin{array}{l}4 \\
4 \\
3\end{array}$ & $\begin{array}{l}0.7 \\
1.6 \\
1.6\end{array}$ & $\begin{array}{l}0.4 \\
0.1 \\
0.4\end{array}$ & $\begin{array}{l}4 \\
4 \\
3\end{array}$ \\
\hline $\begin{array}{l}440 \text { ppm } \\
\text { (Non-pregnant) }\end{array}$ & $\begin{array}{l}17 \mathrm{~h} \\
\text { Post- } \\
\text { exposure }\end{array}$ & $\begin{array}{r}7 \\
14 \\
\text { e } 19\end{array}$ & $\begin{array}{l}<0.01 \\
<0.02 \\
<0.01\end{array}$ & $\begin{array}{l}-- \\
-- \\
--\end{array}$ & $\begin{array}{l}3 \\
3 \\
2\end{array}$ & $\begin{array}{l}0.06 \\
0.09 \\
0.06\end{array}$ & $\begin{array}{c}0.03 \\
0.02 \\
--\end{array}$ & $\begin{array}{l}3 \\
3 \\
2\end{array}$ & $\begin{array}{l}0.9 \\
1.4 \\
1.1\end{array}$ & $\begin{array}{l}0.2 \\
0.1 \\
0.1\end{array}$ & $\begin{array}{l}3 \\
3 \\
2\end{array}$ \\
\hline $2,200 \mathrm{ppm}$ & $\begin{array}{l}17 \mathrm{~h} \\
\text { Post- } \\
\text { exposure }\end{array}$ & $\begin{array}{r}7 \\
14 \\
\quad 19\end{array}$ & $\begin{array}{r}<0.01 \\
0.01 \\
0.40\end{array}$ & $\begin{array}{l}-- \\
0.01 \\
0.20\end{array}$ & $\begin{array}{l}7 \\
7 \\
7\end{array}$ & $\begin{array}{l}<0.20 \\
<0.02 \\
<0.06\end{array}$ & $\begin{array}{l}-- \\
-- \\
--\end{array}$ & $\begin{array}{l}7 \\
7 \\
7\end{array}$ & $\begin{array}{l}1.0 \\
0.9 \\
1.4\end{array}$ & $\begin{array}{l}0.4 \\
0.1 \\
0.3\end{array}$ & $\begin{array}{l}7 \\
7 \\
7\end{array}$ \\
\hline $11,000 \mathrm{ppm}$ & $\begin{array}{l}17 \mathrm{~h} \\
\text { Post- } \\
\text { exposure }\end{array}$ & $\begin{array}{r}7 \\
14 \\
e \quad 19\end{array}$ & $\begin{array}{r}3 \\
<3 \\
6\end{array}$ & $\begin{array}{r}1 \\
-- \\
2\end{array}$ & $\begin{array}{l}7 \\
6 \\
7\end{array}$ & $\begin{array}{l}<2 \\
<2 \\
<2\end{array}$ & $\begin{array}{l}-- \\
-- \\
--\end{array}$ & $\begin{array}{l}7 \\
6 \\
7\end{array}$ & $\begin{array}{r}2 \\
<2 \\
5.2\end{array}$ & $\begin{array}{l}1 \\
-- \\
0.7\end{array}$ & $\begin{array}{l}7 \\
6 \\
7\end{array}$ \\
\hline
\end{tabular}


TABLE 17. Acetone Mouse Teratology Study: Mean Body, Uterine, and Extra-gestational Weights of Pregnant Dams $(g \pm S D)$.

\begin{tabular}{|l|c|c|c|c|}
\hline \multirow{2}{*}{$\begin{array}{l}\text { Acetone } \\
\text { (ppm) }\end{array}$} & $0 \mathrm{ppm}$ & $440 \mathrm{ppm}$ & $2200 \mathrm{ppm}$ & $6600 \mathrm{ppm}$ \\
\cline { 2 - 5 } $\mathrm{N}$ & 26 & 28 & 29 & 31 \\
Body Weight & & & & \\
$0 \mathrm{dg}$ & $27.7 \pm 2.6$ & $27.3 \pm 2.7$ & $27.5 \pm 3.3$ & $27.5 \pm 2.5$ \\
$6 \mathrm{dg}$ & $29.9 \pm 2.6$ & $29.7 \pm 2.7$ & $30.0 \pm 3.6$ & $30.0 \pm 2.7$ \\
$9 \mathrm{dg}$ & $31.5 \pm 2.7$ & $31.8 \pm 2.6$ & $32.2 \pm 3.5$ & $32.2 \pm 2.7$ \\
$12 \mathrm{dg}$ & $37.1 \pm 3.1$ & $37.1 \pm 3.1$ & $37.5 \pm 4.1$ & $37.6 \pm 3.3$ \\
$15 \mathrm{dg}$ & $44.6 \pm 3.9$ & $44.7 \pm 4.2$ & $45.1 \pm 5.0$ & $45.5 \pm 3.7$ \\
$18 \mathrm{dg}$ & $52.5 \pm 5.0$ & $53.0 \pm 5.9$ & $52.1 \pm 8.4$ & $53.0 \pm 6.6$ (a) \\
& $18.7 \pm 3.4$ & $18.4 \pm 3.9$ & $17.9 \pm 3.5$ & $17.6 \pm 2.7$ \\
Uterine & & & & \\
Extra-gestational & & & & \\
Wh. gain & $6.1 \pm 2.1$ & $7.3 \pm 2.8$ & $6.7 \pm 4.9$ & $7.7 \pm 3.0$ (a) \\
\hline
\end{tabular}

(a) One dam was weighed incorrectly, therefore the weight was entered as -1 and the $n \pm 30$. 
TABLE 18. Contermporary Control Data for Swiss (CD-1) Mice ( $N=83$ Litters; Mean \pm SD).

\begin{tabular}{|l|r|c|}
\hline & Number & Percent \\
\hline Matemal Weight; 18 dg & $54.4 \pm 5.6$ & - \\
Gravid Uterine Weight & $20.2 \pm 3.6$ & - \\
Extra-gestational Weight Gain & $6.6 \pm 3.0$ & - \\
& $12.6 \pm 2.1$ & - \\
Implants & $11.7 \pm 2.2$ & $93.5 \pm 7.3$ \\
Live Fetuses & $0.6 \pm 0.8$ & $4.6 \pm 6.3$ \\
Early Resorptions & $0.2 \pm 0.5$ & $1.9 \pm 3.7$ \\
Late Resorptions & $0.0 \pm 0.0$ & $0.0 \pm 0.0$ \\
Dead Fetuses & $0.8 \pm 1.0$ & $6.5 \pm 7.3$ \\
Total Intrauterine Death & 35 & \\
& & 42.2 \\
Litters with Resorptions & $1.4 \pm 0.1$ & - \\
Fetal Weight & $1.4 \pm 0.1$ & - \\
Male & $1.3 \pm 0.1$ & - \\
Female & & \\
\hline
\end{tabular}

TABLE 19. Acetone Mouse Teratology Study: Mean Body Weights for Virgins ( $\pm \pm S D$ ).

\begin{tabular}{|l|ccccc|}
\hline $\begin{array}{c}\text { Exposure } \\
\text { Concen- } \\
\text { tration }\end{array}$ & $\mathrm{N}$ & $\begin{array}{c}\text { Exposure } \\
\text { Day 1 }\end{array}$ & $\begin{array}{c}\text { Exposure } \\
\text { Day5 }\end{array}$ & $\begin{array}{c}\text { Exposure } \\
\text { Day 10 }\end{array}$ & Sacrifice \\
\hline & & & & & \\
0 ppm & 10 & $26.6 \pm 2.4$ & $27.2 \pm 2.2$ & $28.1 \pm 2.4$ & $28.3 \pm 2.5$ \\
$440 \mathrm{ppm}$ & 10 & $26.8 \pm 2.7$ & $27.4 \pm 3.3$ & $27.4 \pm 2.5$ & $28.1 \pm 2.2$ \\
$2200 \mathrm{ppm}$ & 10 & $26.9 \pm 3.4$ & $27.4 \pm 3.3$ & $27.3 \pm 3.4$ & $28.3 \pm 3.4$ \\
$6600 \mathrm{ppm}$ & 10 & $26.6 \pm 2.4$ & $27.3 \pm 2.1$ & $28.6 \pm 2.2$ & $29.2 \pm 2.5$ \\
\hline
\end{tabular}

TABLE 20. Acetone Mouse Teratology Study: Mean Organ Weights of Pregnant Dams (Moan \pm SD).

\begin{tabular}{|l|lllll|}
\hline $\begin{array}{c}\text { Exposure } \\
\text { Concen- } \\
\text { tration }\end{array}$ & $\mathrm{N}$ & Liver (d) & $\begin{array}{c}\text { Percent } \\
\text { LBWR (a.d) }\end{array}$ & Kidney & $\begin{array}{c}\text { Percent } \\
\text { KBWR (b) }\end{array}$ \\
\hline $0 \mathrm{ppm}$ & 26 & $2.8 \pm 0.6$ & $5.36 \pm 1.03$ & $0.5 \pm 0.1$ & $0.90 \pm 0.21$ \\
$440 \mathrm{ppm}$ & 28 & $2.8 \pm 0.6$ & $5.32 \pm 1.04$ & $0.6 \pm 0.5$ & $1.07 \pm 0.89$ \\
$2200 \mathrm{ppm}$ & 29 & $3.0 \pm 0.3$ & $5.85 \pm 1.21$ & $0.5 \pm 0.1$ & $0.98 \pm 0.20$ \\
$6600 \mathrm{ppm}$ & 31 & $3.4 \pm 0.5(\mathrm{c})$ & $6.53 \pm 0.67(\mathrm{c})$ & $0.6 \pm 0.5$ & $1.28 \pm 1.77$ \\
\hline
\end{tabular}

(a) Percent LBWR=Percent Liver to Body Weight Ratio, (at sacrifice).

(b) Percent KBWR=Percent Kidney to Body Weight Ratio, (at sacrifice) .

(c) Significantly different from 0-ppm group, p<0.05.

(d) Significantly correlated with exposure concentration, $p<0.05$. 
IABLE 21 Acetone Mouse Teratology Study: Reproductive Measures (Mean \pm SD).

\begin{tabular}{|c|c|c|c|c|}
\hline & \multicolumn{4}{|c|}{ Acetone Chamber Concentration (ppm) } \\
\hline & 0 & 440 & 2200 & 6600 \\
\hline $\begin{array}{l}\text { Plug-positive Females } \\
\text { Number Pregnam } \\
\text { Pregnant (\%) } \\
\text { Pregnancies Examined } \\
\text { implantations/Dam } \\
\text { Live Fetuses/Litter } \\
\text { Resorptions/Litter } \\
\text { Earty } \\
\quad \text { Late } \\
\text { Dead Fetuses/Litter } \\
\text { Litters with Resorotions }\end{array}$ & $\begin{array}{c}33 \\
28 \\
85 \\
26(a) \\
122 \pm 2.0 \\
11.2 \pm 1.9 \\
1.0 \pm 1.0 \\
0.6 \pm 0.7 \\
0.4 \pm 0.6 \\
0 \\
17 \\
\end{array}$ & $\begin{array}{c}33 \\
28 \\
85 \\
28 \\
120 \pm 2.2 \\
+1.0 \pm 2.1 \\
1.1 \pm 1.2 \\
0.7 \pm 1.1 \\
0.3 \pm 0.7 \\
0 \\
17 \\
\end{array}$ & $\begin{array}{c}33 \\
29 \\
88 \\
29 \\
11.8 \pm 1.8 \\
10.9 \pm 2.2 \\
0.9 \pm 0.8 \\
0.5 \pm 0.7 \\
0.3 \pm 0.5 \\
0.0 \pm 0.2 \\
17 \\
\end{array}$ & $\begin{array}{c}33 \\
31 \\
94 \\
31 \\
12.5 \pm 2.0 \\
11.1 \pm 2.1 \\
1.5 \pm 1.1 \\
0.6 \pm 0.8 \\
1.0 \pm 1.0 \\
0 \\
25 \\
\end{array}$ \\
\hline \multicolumn{5}{|l|}{ PERCENTAGE OF: } \\
\hline $\begin{array}{c}\text { Live Fetuses/Litter } \\
\text { Resorptions/Litter } \\
\text { Early } \\
\text { Late (b) } \\
\text { Dead Fetuses/Litter } \\
\text { Litters with Resorptions }\end{array}$ & $\begin{array}{c}91.9 \pm 7.6 \\
8.1 \pm 7.6 \\
4.8 \pm 5.8 \\
3.2 \pm 4.8 \\
0 \\
65\end{array}$ & $\begin{array}{c}91.4 \pm 9.7 \\
8.6 \pm 9.7 \\
6.1 \pm 9.5 \\
25 \pm 4.8 \\
0 \\
61\end{array}$ & $\begin{array}{r}91.8 \pm 8.3 \\
7.9 \pm 8.0 \\
4.7 \pm 6.9 \\
3.2 \pm 5.1 \\
0.3 \pm 1.7 \\
59\end{array}$ & $\begin{array}{l}87.7 \pm 9.2 \\
12.3 \pm 9.2 \\
4.5 \pm 5.6 \\
7.8 \pm 7.9(c) \\
0 \\
81\end{array}$ \\
\hline
\end{tabular}

(a) Two darns removed from study. Premature delivery of litters; not treatment related.

(b) Significamly correlated with exposure concentration $(p<0.05$ ).

(c) Significant different than 0 -ppm after arcsin transtormation of proportional data $(p<0.05)$.

TABLE_22. Acetone Mouse Teratology Study: Average Fetal Weights (Mean of Litter Means; g \pm SD) and Percent Male Fetuses.

\begin{tabular}{|c|c|c|c|c|}
\hline & & Acetone Chamber & Concentration (ppm) & \\
\hline & 0 & 440 & 2200 & 6600 \\
\hline $\begin{array}{l}\text { Litters Examined } \\
\text { Live Fetuses Examined }\end{array}$ & $\begin{array}{c}26 \\
292\end{array}$ & $\begin{array}{c}28 \\
307\end{array}$ & $\begin{array}{l}29 \\
316\end{array}$ & 34 \\
\hline $\begin{array}{l}\text { Fetal Weight (b) } \\
\text { Male (b) } \\
\text { Female (b) }\end{array}$ & $\begin{array}{l}1.3 \pm 0.1 \\
1.4 \pm 0.1 \\
1.3 \pm 0.1\end{array}$ & $\begin{array}{l}1.4 \pm 0.1 \\
1.4 \pm 0.1 \\
1.3 \pm 0.1\end{array}$ & $\begin{array}{l}1.3 \pm 0.1 \\
1.3 \pm 0.1 \\
1.3 \pm 0.1\end{array}$ & $\begin{array}{l}1.2 \pm 0.1(a) \\
1.2 \pm 0.1(a) \\
1.2 \pm 0.1(a)\end{array}$ \\
\hline Percent Male Fetuses & $46.5 \pm 13.5$ & $47.3 \pm 11.3$ & $47.7 \pm 16.9$ & $50.9 \pm 16.0$ \\
\hline
\end{tabular}

(a) Significantly different from 0-ppm group, $p<0.05$.

(b) Significantly correlated with exposure concentration, $0<0.05$. 
TABLE 23. Acetone Mouse Teratology Study: Malformations Observed in Live Fetuses.

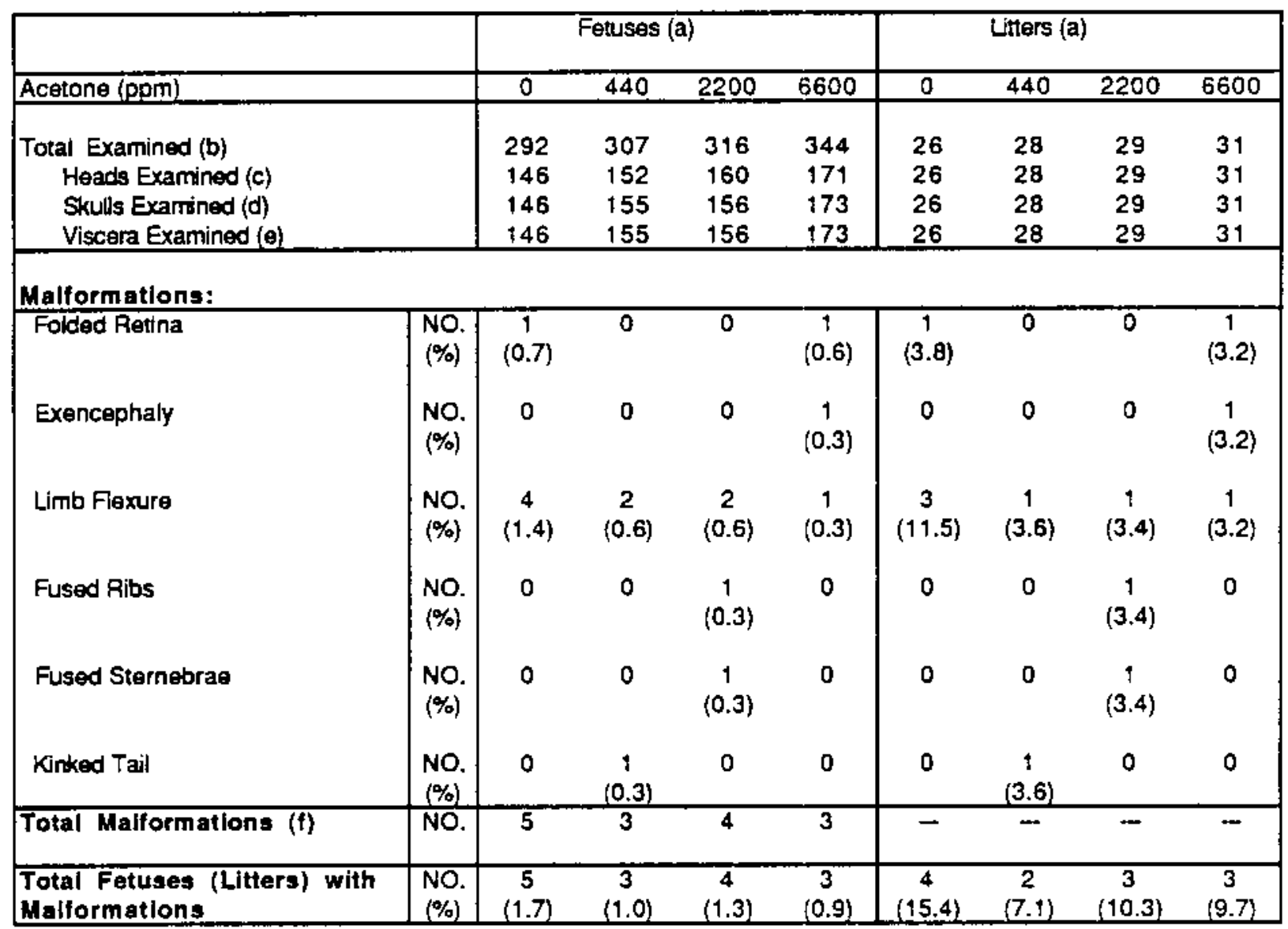
(a) A single fetus or litter may be represented more than once in this table.
(b) All feruses examined for external and skeletal defects. One-hath had heads removed prior to skeletal staining.
(c) Heads fixed in Bouin's solution for soft-tissue craniofacial evaluations.
(d) Heads remaining on the fetuses for skeletal examination; see (b).
(e) Viscerais pertormed on approx. $50 \%$ of live fetuses and all feruses with external defects.
(i) There may be >1 maltomation per ferus. 
IABLE 24. Acetone Mouse Teratology Study: Mean Percent of Live Fetuses Affected per Litter (Man $\pm S D$ ).

\begin{tabular}{|c|c|c|c|c|}
\hline & \multicolumn{4}{|c|}{ Acetone Concentration (ppm) } \\
\hline & 0 & 440 & 2200 & 6600 \\
\hline $\begin{array}{l}\text { Number Litters } \\
\text { Live Fetuses/Litter }\end{array}$ & $\begin{array}{r}26 \\
11.2 \pm 1.9\end{array}$ & $\begin{array}{r}28 \\
11.0 \pm 2.1\end{array}$ & $\begin{array}{r}29 \\
10.9 \pm 2.2 \\
\end{array}$ & $\begin{array}{l}31 \\
11.1 \pm 2.1 \\
\end{array}$ \\
\hline \multicolumn{5}{|l|}{ Malformatlons: } \\
\hline Folded Retina & $0.6 \pm 3.3$ & $\overline{0}$ & 0 & $0.5 \pm 3.0$ \\
\hline Exencephaiy & 0 & 0 & 0 & $0.4 \pm 2.2$ \\
\hline Limb Flexure & $1.3 \pm 3.9$ & $0.6 \pm 3.4$ & $0.5 \pm 2.7$ & $0.2 \pm 1.4$ \\
\hline Fused Fibs & 0 & 0 & $0.3 \pm 1.9$ & 0 \\
\hline Fused Sternebrae & 0 & 0 & $0.3 \pm 1.5$ & 0 \\
\hline Kinked Tail & 0 & $0.3 \pm 1.5$ & 0 & 0 \\
\hline $\begin{array}{l}\text { \% Fetuses per Litter with at } \\
\text { Least One Malformation }\end{array}$ & $1.6 \pm 4.7$ & $0.9 \pm 3.7$ & $1.1 \pm 3.5$ & $0.9 \pm 2.9$ \\
\hline \multicolumn{5}{|l|}{ Variations: } \\
\hline Supernumerary Ribs & $23.3 \pm 27.3$ & $29.5 \pm 26.0$ & $20.7 \pm 21.8$ & $12.9 \pm 17.1$ \\
\hline Misaligned Stemebrae & $5.1 \pm 10.0$ & $8.2 \pm 12.2$ & $5.0 \pm 7.7$ & $9.4 \pm 14.5$ \\
\hline $\begin{array}{l}\text { Extra Stemebral } \\
\text { Ossification Sites }\end{array}$ & $0.4 \pm 2.0$ & $3.2 \pm 16.8$ & $0.2 \pm 1.3$ & 0 \\
\hline Dilated Ureter & 0 & 0 & 0 & $1.2 \pm 4.6$ \\
\hline \multicolumn{5}{|l|}{ Reduced Ossification (a) } \\
\hline Sternebrae(b) & $1.5 \pm 4.0$ & $2.4 \pm 4.9$ & $2.7 \pm 6.6$ & $9.9 \pm 17.6(c)$ \\
\hline $\begin{array}{l}\text { \% Fetuses per Lifter with at } \\
\text { Least One Variatlon or } \\
\text { Reduced Ossiflcation }\end{array}$ & $28.2 \pm 28.6$ & $38.1 \pm 29.4$ & $26.5 \pm 24.3$ & $25.4 \pm 27.7$ \\
\hline
\end{tabular}

(a) Other sites examined included pelvis, phalanges, ribs, skull and vertebrae. There was no reduction in the ossification of these areas.

(b) Significantly correlated with exposure concentration, $p \leq 0.05$.

(c) Significantly different from control after arcsin transtormation (pso.05). 
TABLE 25. Contemporary Controd Data on CD-1 Mouse Teratology Studies: Malformations and Variations.

\begin{tabular}{|c|c|c|c|c|}
\hline & & $\begin{array}{l}\text { Fetuses (a) } \\
\text { Number } \\
\text { (Percent) } \\
\end{array}$ & $\begin{array}{l}\text { Litters } \\
\text { Number } \\
\text { Percent) }\end{array}$ & $\begin{array}{c}\text { Mean Percent } \\
\text { per LلUtter } \\
( \pm \mathrm{SO})\end{array}$ \\
\hline $\begin{array}{l}\text { Total examined (b) } \\
\text { Heads axamined (c) } \\
\text { Stculls examined (d) }\end{array}$ & & $\begin{array}{l}975 \\
- \\
- \\
\end{array}$ & $\begin{array}{l}83 \\
- \\
- \\
\end{array}$ & - \\
\hline \multicolumn{5}{|l|}{ Variatjane } \\
\hline Supernumerary Rib & $\begin{array}{l}\text { No. } \\
(\%)\end{array}$ & $\begin{array}{c}175 \\
(17.9)\end{array}$ & $\begin{array}{l}52 \\
162.7\end{array}$ & $18.5 \pm 24.4$ \\
\hline $\begin{array}{l}\text { Misaligned } \\
\text { Sternabrae }\end{array}$ & $\begin{array}{l}\text { No. } \\
\text { (\%) }\end{array}$ & $\begin{array}{r}23 \\
(2.4) \\
\end{array}$ & $\begin{array}{c}14 \\
16.9)\end{array}$ & $2.3 \pm 6.3$ \\
\hline \multicolumn{5}{|l|}{ Reduced Ossifications } \\
\hline Sternebrae & $\begin{array}{l}\text { No. } \\
\text { (\%) }\end{array}$ & $\begin{array}{l}36 \\
(3.7)\end{array}$ & 25 & $3.7 \pm 6.4$ \\
\hline الئالs' & $\begin{array}{l}\text { No. } \\
(\%)\end{array}$ & $\begin{array}{c}10 \\
(1.0)\end{array}$ & $\begin{array}{c}5 \\
(6.0) \\
\end{array}$ & $1.1 \pm 4.8$ \\
\hline $\begin{array}{l}\text { Total Fotusese (Lltters) with } \\
\text { Variatlont or Reduced } \\
\text { Ossificatlons } \\
\end{array}$ & $\begin{array}{l}\text { No. } \\
\text { (\%) }\end{array}$ & $\begin{array}{r}230 \\
(23.6) \\
\end{array}$ & $\begin{array}{c}67 \\
80.7 \\
\end{array}$ & $24.0 \pm 24.5(\theta)$ \\
\hline \multicolumn{5}{|l|}{ Malformations } \\
\hline Exencephaly & $\begin{array}{l}\text { No. } \\
\text { (\%) }\end{array}$ & $\begin{array}{c}1 \\
(0.1)\end{array}$ & $\begin{array}{c}1 \\
(1.2)\end{array}$ & $0.1 \pm 1.2$ \\
\hline Folded Retina & $\begin{array}{l}\text { No. } \\
\text { (\%) }\end{array}$ & $\begin{array}{c}2 \\
(0.2)\end{array}$ & $\begin{array}{c}2 \\
(2.4)\end{array}$ & $0.2 \pm 1.5$ \\
\hline Limb Flexure & $\begin{array}{l}\text { No. } \\
(\%)\end{array}$ & $\begin{array}{c}12 \\
(1.2)\end{array}$ & $\begin{array}{c}8 \\
(9.6)\end{array}$ & $1.1 \pm 3.8$ \\
\hline $\begin{array}{l}\text { Total Fotumes (Litiers) with } \\
\text { Malformatlone }\end{array}$ & $\begin{array}{l}\text { No. } \\
(\%)\end{array}$ & $\begin{array}{c}14 \\
(1.4)\end{array}$ & $\begin{array}{c}10 \\
(12.0)\end{array}$ & $1.3 \pm 4.0(f)$ \\
\hline
\end{tabular}

(a) A single feus may be represented more than once in this table.

(b) All feusers examined for extemal, visceral and skeletal delects. All feusess stained with alcian blue and alizarin red S, one-hall had heads removed prior to staining.

(c) Heads removed from fetuses and fixed in Bouin's solution then examined tor soft-tissue cranio-tacial malfomations.

(d) Heads remained on the feluses that were stained for skeletal examination: see a) above.

(e) Mean percent of feluses per litter with at least one variation or reduced ossification

(f) Mean percent of fetuses por litter wich at least one malformation. 
TABLE 26. Acetone Mouse Teratology Study: Variations Observed in Live Fetuses.

\begin{tabular}{|c|c|c|c|c|c|c|c|c|c|}
\hline \multirow{2}{*}{ Acetone (ppm) } & & \multicolumn{4}{|c|}{ Fetuses (a) } & \multicolumn{4}{|c|}{ Litters (a) } \\
\hline & & 0 & 440 & 2200 & 6600 & 0 & 440 & 2200 & 6600 \\
\hline $\begin{array}{l}\text { Total Examined (b) } \\
\text { Heads Examined (c) } \\
\text { Slulls Examined (d) } \\
\text { Viscera Examined (e) }\end{array}$ & & $\begin{array}{l}292 \\
146 \\
146 \\
146\end{array}$ & $\begin{array}{l}307 \\
152 \\
155 \\
155\end{array}$ & $\begin{array}{l}316 \\
160 \\
156 \\
156\end{array}$ & $\begin{array}{l}344 \\
171 \\
173 \\
173 \\
\end{array}$ & $\begin{array}{l}26 \\
26 \\
26 \\
26\end{array}$ & $\begin{array}{l}28 \\
28 \\
28 \\
28\end{array}$ & $\begin{array}{l}29 \\
29 \\
29 \\
29\end{array}$ & $\begin{array}{l}31 \\
31 \\
31 \\
31\end{array}$ \\
\hline \multicolumn{10}{|l|}{ Variatlons: } \\
\hline Supemumerary Fibs & $\begin{array}{l}\text { NO. } \\
(\%)\end{array}$ & $\begin{array}{c}67 \\
(23.0)\end{array}$ & $\begin{array}{c}93 \\
(30.3)\end{array}$ & $\begin{array}{c}64 \\
(20.3)\end{array}$ & $\begin{array}{c}44 \\
(12.8)\end{array}$ & $\begin{array}{c}19 \\
(69.2)\end{array}$ & $\begin{array}{c}22 \\
(78.6)\end{array}$ & $\begin{array}{c}19 \\
(65.5)\end{array}$ & $\begin{array}{c}19 \\
(61.3)\end{array}$ \\
\hline Misaligned Sternebra & $\begin{array}{l}\text { NO. } \\
(\%)\end{array}$ & $\begin{array}{c}16 \\
(5.5)\end{array}$ & $\begin{array}{c}27 \\
(8.8)\end{array}$ & $\begin{array}{c}16 \\
(5.1)\end{array}$ & $\begin{array}{c}29 \\
(8.4)\end{array}$ & $\begin{array}{c}B \\
(30.8)\end{array}$ & $\begin{array}{c}10 \\
(35.7)\end{array}$ & $\begin{array}{c}10 \\
(34.5)\end{array}$ & $\begin{array}{c}12 \\
(38.7)\end{array}$ \\
\hline $\begin{array}{l}\text { Extra Ossification Site(s) } \\
\text { Stemum }\end{array}$ & $\begin{array}{l}\text { NO. } \\
(\%)\end{array}$ & $\begin{array}{c}1 \\
(0.3)\end{array}$ & $\begin{array}{c}8 \\
(2.6)\end{array}$ & $\begin{array}{c}1 \\
(0.3)\end{array}$ & 0 & $\begin{array}{c}1 \\
(3.8)\end{array}$ & $\stackrel{1}{(3.6)}$ & $\begin{array}{c}1 \\
(3.4)\end{array}$ & 0 \\
\hline Dilated Ureter & $\begin{array}{l}\text { NO. } \\
(\%)\end{array}$ & 0 & 0 & 0 & $\begin{array}{c}2 \\
(1.2)\end{array}$ & 0 & 0 & 0 & $\begin{array}{c}2 \\
(6.4) \\
\end{array}$ \\
\hline \multicolumn{10}{|l|}{ Reduced Osglfications: } \\
\hline Sternebrae $(\mathrm{f})$ & $\begin{array}{l}\text { NO. } \\
(\%)\end{array}$ & $\begin{array}{c}5 \\
(1.7)\end{array}$ & $\begin{array}{c}8 \\
(2.6)\end{array}$ & $\begin{array}{c}7 \\
(2.2)\end{array}$ & $\begin{array}{c}32 \\
(9.3)\end{array}$ & $\begin{array}{c}4 \\
(15.4)\end{array}$ & $\begin{array}{c}6 \\
(21.4)\end{array}$ & $\begin{array}{c}5 \\
(17.2)\end{array}$ & $\begin{array}{c}10 \\
(32.2)\end{array}$ \\
\hline $\begin{array}{l}\text { Total Variations and } \\
\text { Reduced Ossifications (g) }\end{array}$ & NO. & 89 & 136 & 88 & 107 & - & $\cdots$ & - & - \\
\hline $\begin{array}{c}\text { Total Fetuses (Litters) with } \\
\text { Varfations or Red. Ossif. }\end{array}$ & $\begin{array}{l}\text { NO. } \\
(\%)\end{array}$ & $\begin{array}{c}82 \\
(28.1)\end{array}$ & $\begin{array}{c}120 \\
(39.1)\end{array}$ & $\begin{array}{c}81 \\
(25.6)\end{array}$ & $\begin{array}{c}83 \\
(24,1)\end{array}$ & $\begin{array}{c}21 \\
(80.8)\end{array}$ & $\begin{array}{c}24 \\
(85.7)\end{array}$ & $\begin{array}{c}23 \\
(79.3)\end{array}$ & $\begin{array}{c}23 \\
(74.2)\end{array}$ \\
\hline
\end{tabular}

(a) A single fetus or litter may be represented more than once in this table.

(b) All fetuses examined tor external and skeletal defects. One-half had heads removed prior to skeletal staining.

(c) Heads fixed in Bouin's solution for sott-tissue craniofacial evaluations.

(d) Heads temaining on the feruses for skeletal examination; see (b).

(e) Viscerais performed on approx. $50 \%$ of live fetuses and all fetuses with extemal defects.

(f) Other sites examined included peivis, phaianges, ribs, skull, and vertebrae.

Thore was no reduced oseiflcation noted in these areas.

(g) There may be $>1$ variation or reduced ossification per ferus. 
TABLE 27. Comparison of Acetone Plasma Levels with Literature Values.

\begin{tabular}{|c|c|c|c|c|}
\hline \multirow[b]{2}{*}{$\begin{array}{l}\text { Acetone Vapor } \\
\text { Concentration }\end{array}$} & \multicolumn{2}{|c|}{$\begin{array}{l}30 \text { min Post- } \\
\text { Exposure }\end{array}$} & \multicolumn{2}{|c|}{$\begin{array}{l}17 \text { hr Post- } \\
\text { Exposure }\end{array}$} \\
\hline & This Study (a) & $\begin{array}{l}\text { Charbonreau } \\
\text { et al. (1986) (b) }\end{array}$ & This Study & $\begin{array}{l}\text { Charbonneau } \\
\text { et al. (1986) }\end{array}$ \\
\hline $\begin{array}{l}2200-2500 \text { ppm } \\
10000-11000 \text { ppm }\end{array}$ & $\begin{array}{l}5.0 \mathrm{mM} \\
36 \mathrm{mM}\end{array}$ & $\begin{array}{l}5.2 \mathrm{mM} \\
40 \mathrm{mM}\end{array}$ & $\begin{aligned} \approx & 0.1 \mathrm{mM} \\
& 4.5 \mathrm{mM}\end{aligned}$ & $\begin{array}{l}0.4 \mathrm{mM} \\
2.6 \mathrm{mM}\end{array}$ \\
\hline
\end{tabular}

(a) Exposures $7 \mathrm{hr} / \mathrm{day}, 2200$ and $11000 \mathrm{ppm}$ acetone.

(b) Exposures $4 \mathrm{hr} / \mathrm{day}, 2500$ and $10000 \mathrm{ppm}$ acetone. 


\section{APPENDIX A}

ANAIYTICAI CHEMISTRY NARRATIVE AND DATA FOR ACETONE 
CHEMISTRY

BULK CHEMICAL

Teat Material Receipt, Storage and Usage

Receipt and Inventory

Acetone, manufactured by Ashland Chemical Company (Columbus, OH), was shipped from Research Triangle Park, to Battelle Northwest (BNW). Ten gallons of test material (BNW Lot No. 52446-6, Manufacturer's Lot No. 06/88/7E) were received $9 / 8 / 87$. Test material was packaged in one-gallon amber glass bottles. An additional 100 gallons of acetone packaged in two metal drums (BNW Lot No. 52446-32, Manufacturer's Lot No. 06/88/7E) were received 10/12/87.

\section{Storage Conditions}

The bulk chemical was stored in its original shipping containers at room temperature in a flammable storage facility near the LSI-II building.

\section{Usage}

Approximately $216 \mathrm{~kg}$ were consumed for the Inhalation Reproductive Toxicology studies. BNW Lot Nos. 52446-6 and 52446-32 were used for test generation. Animal exposures were performed using acetone from BNW Lot No. 52446-32 only. An average of $5.2 \mathrm{~kg} /$ day was consumed during the exposures of rats $(10 / 26 / 87$ to $11 / 12 / 87)$, and $=3.4 \mathrm{~kg} /$ day were used for the exposure of mice $(12 / 2 / 87$ to $12 / 17 / 87)$.

\section{Transfer Procedures}

Bulk chemical was transferred to the generator reservoir under a nitrogen blanket to avoid the introduction of air.

\section{Waste Disposal}

Acetone waste material was transferred to waste bottles and allowed to evaporate in an exhaust hood.

\section{Surplus Disposal}

Residual test material was returned to Research Triangle Institute at the direction of the Inhalation Reproductive Toxicology Program after completion of the acetone studies at BNW.

\section{Chemical Analysis}

\section{Analysis at Research Triangle Institute}

The test material was analyzed at Research Triangle Institute (RTI) prior to shipment to BNW. Battelle did not receive the RTI analytical report. 


\section{Reanalysis at Battelle Pacific Northuest zaboratories}

Bulk analysis procedure was implemented as BNW SOP $B \mathrm{~B}-\mathrm{AC}-3 \mathrm{AlH}$. Identity of bulk chemical was confirmed during initial analysis by infrared spectroscopy. Initial purity was determined by percent total peak area using gas chromatography (GC) with a glass column packed with Porapak 0 80/100. BNW Lot No. 52446-32 was found to be 100.08 pure by area percent upon receipt and again on $12 / 2 / 87$.

\section{Test Article Concentration Monitoring}

\section{Description of Nonitoring system}

An HP5840 gas chromatographic system monitored the acetone concentration in the exposure chamberg. This ingtrument was equipped with an 8-position stream select valve and employed a $1 / 8^{n} 0 . \mathrm{d}$., one-foot nickel column packed with 1 \% SP-1000 on 60/80 mesh Carbopack B. The oven temperature was operated at $130^{\circ} \mathrm{C}$.

As described in the section that follows (Calibration of the Monitoring System), the monitor was calibrated againgt gravimetrically prepared standards. These standards were related to the on-line monitor through quantitative analysis of grab samples taken from the chambers.

Additionally, the operation of the chamber monitor was checked daily against an on-line compressed gas standard of acetone in nitrogen. This check provided a measure of day-to-day instrument drift. Additional calibration checks by grab sampling were made when drift of the on-line standard response factor was detected. Daily operating procedures for the concentration monitoring system were contained in SOP $\$ 98-A C-3 B 26$.

\section{Calibration of the Honitoring system}

The calibration of the on-line chamber monitor was based on a quantitative analysis of bubbler grab samples. This procedure tied the calibration of the on-line monitor to gravimetrically prepared standard solutions in dimethylformamide (DMF) through a second off-line GC. The gravimetrically calibrated GC was used to measure the quantity of acetone collected from the exposure chambers in DMF-filled bubblers. The relationship between the peak area observed with the on-line GC and the concencration of acetone in the chamber was defined by comparison with the chamber concentrations determined by the gravimetrically calibrated GC.

Since the accuracy of the on-line GC calibration depended on accurate analysis of bubbler grab samples, several quality control steps were imposed on the analysis of grab samples. A set of five standards were run for each analysis session. The concentration range of the standards bracketed the concentration range of interest. The breakthrough for the higi chamber was measured using a second DMF-filled bubbler. This correction for breakthrough was applied to the chamber measurements.

The analysis of bubbler grab samples was performed using a HP5830 Or HPSB40 gas chromatograph with a 2 or $4 \mathrm{~mm}$ by $1.8 \mathrm{~m}$ glass column packed with 10 s. Carbowax 20M TPA on Chromsorb wAW with an oven temperature of $130^{\circ} \mathrm{C}$. The calibration curve over the concentration range of interest was linear. 


\section{Sensitivity and Specificity}

The minimum detectable limit (MDL) estimated from the decay profile of the 440 ppm chamber was 0.05 ppm. A measure of chromatograph specificity is defined by determination of the analytes partition coefficient. The retention time of methane, assumed to be non-retained, was $0.26 \mathrm{~min}$; the retention time for acetone was $0.62 \mathrm{~min}$. Thus, the partition ratio for acetone on this system was 1. 4 .

\section{Precision, Iinearity, and Absolute Recovery}

Precision for the on-line GC was estimated from 8 measurements of an on-line standard using every active sampling port; a 0.11 o coefficient of variation (CV) was observed. Linearity of the on-line GC was assured by calibrating it against a gravimetrically calibrated GC (see coments in the "Calibration of the Monitor System" section). A series of bubbler grab samples were acquired during the exposure from the chambers. These samples were analyzed and the results compared to those from gravimetrically prepared standards. The appropriate on-line GC calibration curve was then applied to the data acquisition and control system.

Achievement of linearity for the on-line monitor was therefore dependent upon defining a linear method for analysis of bubbler samples. The calibration curve for this analysis showed good linearity over an extended range. Routine analysis of bubblers was performed using midrange, high, and low level

standards in order to assure adequate linearity.

Accuracy depended upon good characterization of the absolute recovery demonstrated by the grab sampling methods used to measure chamber concentration (on-line and bubbler grab). Backup bubblers were installed for the high exposure chamber and were used to correct the measured chamber concentration at all exposure levels for breakthrough encountered during grab sampling. Breakthrough was typically 2-3항 with 3-1iter samples.

\section{Detection of Drift using on-Iine standard}

An on-line compressed gas standard, $2000 \pm 2 \% \mathrm{ppm}$ acetone in nitrogen was used to check instrument drift throughout the exposure day. The standard was checked before the start of each exposure day, then monitored every 8th sample throughout the exposure day by the on-line GC. The measured concentration for the standard had to be within $\pm 10 \%$ of the assigned target value before any exposure could begin without consultation with the Exposure Control Task Leader. During the course of the exposure, if the on-line standard was within 5 of the target value, no change in calibration was required. If the on-line standard was between $5 \%$ and $10 \%$ of its asgigned target, the calibration could be updated by an Exposure or Chemistry Specialist. Such a correction was based upon the on-line standard. If the cumulative drift exceeded 15\%, then the calibration was checked by quantitative analysis of grab samples. 


\section{CHEMICAI STABIIITY FOR ACETONE INHALATION STUDIES}

The stability of acetone vapor in the exposure chamberg and reservoir was examined. The expected degradation products, diacetone, mesityl oxide, and isophorone, were measured in the chambers using gas chromatography. Stability in the generator reservoir was evaluated by gas chromatographic analysis.

\section{Chemical Reservoir stability}

The stability and purity of acetone in the 5-gelion stainless steel reservoir were evaluated. On $9 / 25 / 87$ the reservoir was filled with acetone from bottles BNW Lot No. 52446-6-6, 7, $9 \& 10$. Samples for analysis were taken directly from the bottle prior to filling the reservoir and from the reservoir immediately after filling, following one day's test generation, and after 4-days' residence in the reservoir (on 9/29/87). These samples were analyzed by gas chromatography with a flame ionization detector using a system ghown to identify the known degradation products of acetone (Table 3 , system 1). The results of these analyses are shown in Table 1 . No impurities greater than 0.01 \% were observed. A compound having the retention time of diacetone (4-hydroxy-4-methyl-2-pentanone) at a concentration of $\$ 0.006$ was only impurity detected. No degradation or contamination products were found. There was no change in the acetone after 4-days' residence in the reservoir; this was the maximum period of time the tegt material was allowed to remain in the generator during the study.

Table 1. Stability of Acetone in the Reservoir

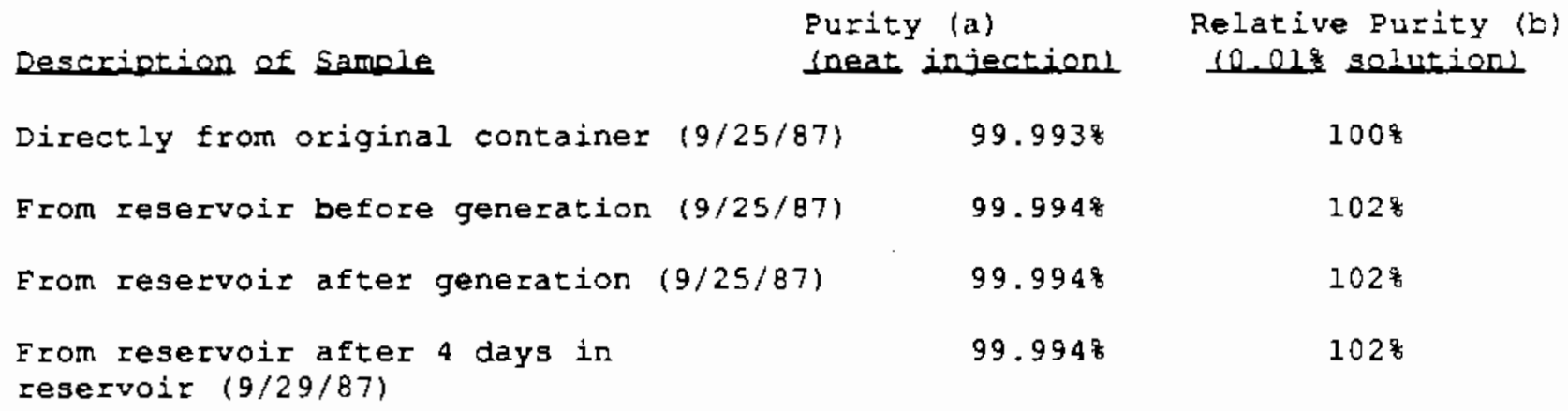

(a) Determined by area percent.

(b) Determined by peak comparison against a reference standard.

\section{Generator stability}

The acetone vapor used for exposure was generated by evaporating acetone from a fiberglass wick on a stainless steel heater. Acetone is a methyl ketone and prone to polymerization. The low generation temperatures (below and near the boiling point of acetone), use of inert materials, and low regidence time of acetone on the heater minimized any degradation of acetone. The fiberglass wicks were removed after test generation and then extracted with methanol and $=30$ minutes of ultrasonic treatment. GC analysis of the methanol extract failed to indicate any volatile degradation products.

$$
\text { A. } 4
$$




\section{Stability with the Chemical Delivery system}

Acetone liquid was transferred from the 5-gallon stainless steel reservoir to the pump through a 1/8" Teflon@ line. A positive pressure nitrogen headspace was maintained over the acetone to prevent the introduction of air to the system. The acetone was distributed in the $1 / 8^{*}$ stainless steel lines to the heaters at each chamber using a FMI micrometering pump. The pump piston and cylinder assemblies were constructed of stainless steel. None of these materials of construction are incompatible with acetone.

\section{Chamber stability}

Stability of acetone in the exposure chambers was evaluated at least five hours after the initiation of the exposure using gas sampling tubes. Samples were drawn so as to collect $>4500 \mu \mathrm{g}$ of acetone. Since three individual generation systems were used, samples were collected from each chamber. In addition, samples from the high concentration chamber were taken at the beginning of the exposure period to determine the stability of the acetone under initial generating conditions. These samples were analyzed by the gas chromatography and the results compared to those obtained from analysis of the bulk test material (Table 1 ).

The chambers were sampled by pulling measured volumes of chamber atmospheres through gas-sampling charcoal tubes containing a secondary charcoal bed which trapped breakthrough of acetone or its polymeric products. We assumed that good trapping efficiency for species such as polymers and dimers was achieved when good trapping efficiency was observed for acetone. Organic compounds are retained on the charcoal by the same type of of partitioning mechanism encountered in gas-solid chromatography. Thus, in agreement with basic chromatographic principles, the less volatile polymer products would be strongly adsorbed to the organic matrix of the gas sampling tube. The porous polymer packings have been shown to have good collection efficiency for numerous organic compounds (D.G. Parkes, C.R. Ganz, A. Polinsky, J. Schulse: Am. Ind, Bygiene Assoc. J. March 1976 pl65-173). Sample size was adjusted to provide adequate sensitivity for polymeric products without substantial breakthrough of acetone.

\section{Method Validation}

Experiments were performed to demonstrate satisfactory recovery of acetone and its polymeric products from the charcoal sorbent in the gas sampling tubes. Standards containing microgram amounts of diacetone, mesityl oxide and isophorone (Table 2) were spiked onto charcoal sorbent in a series of GC autosampling vials. To identify compounds less volatile than acetone, one set of samples was eluted using methanol with $=30$ minutes of ultrasonic treatment. Eor compounds more volatile than acetone, second set of samples was eluted with dimethylformamide $(D M F)$ and $=30$ minutes of ultrasonic treatment. Acetone and its polymeric products were quantitated using the chromatographic systems described in Table 3. Results of these analyses are given in Table 2 . Standards of acetone polymerization products were prepared at the $=9$ $\mu \mathrm{g} / \mathrm{sample}$ level. Although recovery varied, all compounds were detected in the standards. The concentration of these contaiminant standards were about $0.3 \%$ of the acetone collected by the grab samples. Thus, all of the potential contaiminants could be detected well below 1 s of the chamber target concentration. 
Table 2. Recovery of Acetone, Isophorone, Mesityl oxide, and Diacetone

\begin{tabular}{lccc} 
& \multicolumn{3}{c}{ Solvent } \\
Sample & Methanol & Dimethylformamide \\
Acetone & $\approx 9000 \mu \mathrm{g} / \mathrm{ml}$ & 87.08 & 97.08 \\
Isophorone & $\approx 9 \mu \mathrm{Hg} / \mathrm{ml}$ & 158 & $(\mathrm{~b})$ \\
Mesityl Oxide & $=8.6 \mu \mathrm{Hg} / \mathrm{ml}$ & 68 & 47.48 \\
Diacetone (c) & $=9 \mu \mathrm{gg} / \mathrm{ml}$ & 148 & 37.68
\end{tabular}
(a) Percent recovery was based on comparison tc untreated samples.
(b) Solvent peak prevented measurement.
(c) 4-Hydroxy-4-methyl-2-pentanone.

Table 3. GC Parameters Used for Acetone Stability Study

Chromsorb $80 / 100$

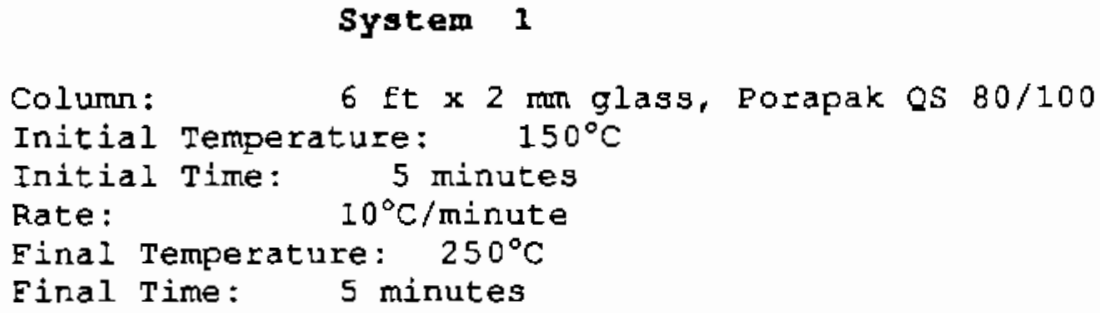

\section{Syatem 2}

Column: $\quad$ \& ft $\times 2$ mm glass, 10 \&arbowax 20 on

Initial Temperature: $\quad 70^{\circ} \mathrm{C}$

Initial Time: $\quad 10$ minutes

Rate: $\quad 10^{\circ} \mathrm{C} /$ minute

Final Temperature: $200^{\circ} \mathrm{C}$

Final Time: 5 minutes

\section{System 3}

Column: $\quad 6$ ft $\times 2$ mum glass, $0.1 \%$ SP-1000 on $80 / 100$

Carbopack

Initial Temperature: $\quad 70^{\circ} \mathrm{C}$
Initial Time: 10 minutes
Rate: $\quad 10^{\circ} \mathrm{C} /$ minute
Einal Temperature: $200^{\circ} \mathrm{C}$
Final Time: 10 minutes




\section{Analysis of Chamber Samples}

The charcoal sorbent from gas sampling tubes used to collect chamber samples was transferred to a GC autosampler vial and desorbed using either methanol or DMF with $=30$ minutes of ultrasonic treatment. Samples were then analyzed by gas chromatographic systems 1 and 2 (Table 3) to separate and identify the compounds present. A flame ionization detector was used with both systems. Chamber samples desorbed with DMF and analyzed on these systems showed acetone to be $=100 \%$ as a percent of the background corrected peak area. The chamber samples desorbed with methanol and analyzed on systems 1 and 2 showed a single impurity which was analyzed by GC/MS and found to be methyl acetate. This impurity was $\leq 0.28$ for the set of samples drawn $11 / 05 / 87$ and analyzed $11 / 06 / 87$ but its concentration increased to $\approx 2 \%$ when samples were drawn $11 / 05 / 87$ and analyzed 11/10/87. The concentration of methyl acteate appeared to increase when samples were not eluted from the charcoal and analyzed soon after collection. Thus, the methyl acetate was assumed to result from the esterification of acetic acid with the methanol used to desorb the samples. The acetic acid may have been collected from the chamber or formed during the collection process by air oxidation of acetone on charcoal. Since acetic acid is a common metabolite in animals and only small concentrations were found, no further investigation was done.

\section{Conclusion}

Studies at BNW indicate that the materials and techniques used to generate acetone vapor for inhalation exposures did not affect its stability. Analysis of neat samples of acetone taken from the reservoir and generator showed purities of $>99.9 \%$. Acetone was stable in the reservoir for a period of 4 days. In both occupied and unoccupied chambers, no degradation products were identified in samples which were drawn from the chambers after five hours of test exposure, then desorbed with DMF and analyzed on three GC systems. However, when similar samples were desorbed with methanol and analyzed on a GC system employing Systems 1 and 2, a $0.2-28$ impurity was observed. The impurity was assumed to be methyl acetate, the ester of acetic acid which may have been formed during sample collection and/or workup.

Thus, we conclude that the condensation products normally encountered in acetone as impurities (isophorone, mesityl oxide, and diacetone) were not produced in significant amounts. The impurity assumed to be methyl acetate did not warrant further investigation since its level was low and acetic acid is a common metabolite in animals. 
COMPOUND:

\section{CAS\#}

LOT\#

APPEARANCE:

RECEIPT DATE:

ANALYSIS PERIOD:

STORAGE TEMPERATURE:

SAMPLE SUBMITTAL DATE:

SAMPLE ANALYSIS DATE:

ANALYSIS PROCEDURE:

NOTESOOK RETERENCE:

\section{ACETONE}

67-64-1

BNW\# 52446-32 Drum \#1

Coioriess liquid

10-12-87

Initial

Room temperature

10/13/87

$10 / 19,28 / 87$

ØB-AC-3A1H

BNW 52446-51

IDENTITY: Infrared spectroscopy, using a $10 \mathrm{~cm}$ gas cell with silver chloride windows and $10 / 87$

Instrument: Beckman Acculab 8 Intrared Spectrometer

ASSAY: $\quad$ Gas chromatography using $4 \mathrm{ft} \times 2 \mathrm{~mm}$ glass column packed with porapak $\mathrm{O}$ $80 / 100$ for purity by area $\%$.

Instrument: HP 5890

RESULTS: Bulk\% Purity

$10 / 87$

100.0

100.0

100.0

Average

$100.0 \% S D= \pm 0.0$

Acetone eluted at $\sim 2.85$ minutes.

No impurities were observed.

ASSAY: Gas chromatography using $4 \mathrm{ft} \times 2 \mathrm{~mm}$ glass column packed with porapak $\mathrm{Q}$

$10 / 87$

$80 / 100$ for purity by area $\%$.

instrument: HP 5890

RESULTS: impurity Profile

A major peak of $100.0 \%$ area was observed at a retention time of $\sim 2.06$ minutes for the neat test material. No impurity peaks were observed.

Conclusion: Infrared spectroscopy confirms the gross purity and identity of BNW Lot No. 52446-32. Gas chromatography shows lot BNW52446-32-Drum \#1 to be $100.0 \%$ pure by area percent and acceptable by suggested SOP\#OB-AC-3A1H purity limit of $>99 \%$. The impurity profile shows a major peak of $100.0 \%$ area. No impurities were observed.

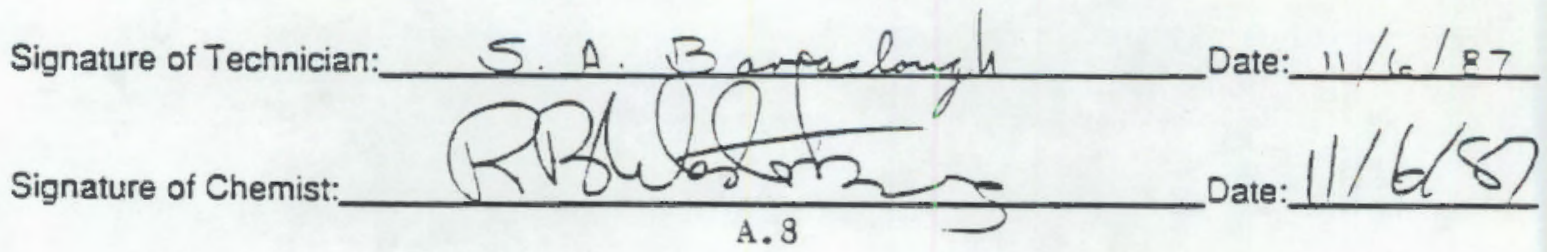


COMPOUND:

CAS*

LOT\#

APPEARANCE:

RECEIPT DATE:

STORAGE TEMPERATURE.

SAMPLE SUBMITTAL DATE:

SAMPLE ANALYSIS DATE:

ANALYSIS PROCEDURE:

NOTEOOKREFERCE:

\author{
ACETONE \\ 67-64-1 \\ BNW\# 52446-32 Drum \#1 \\ Coloriess liquid \\ 10-12-87 \\ Room temperature \\ $12 / 2 / 87$ \\ $12 / 2887$ \\ OB-AC-3A1H-OO \\ BNW 52446-129
}

IDENTITY: Infrared spectroscopy is performed using a $10 \mathrm{~cm}$ gas cell with silver chioride windows and scanning from $4000 \mathrm{~cm}-1$ to $600 \mathrm{~cm}-1$.

Instrument: Beckman Acculab 8 Infrared Spectrometer

RESULTS: The spectrum was similar to that found during previous BNW analyses.

ASSAY: $\quad$ Gas chromatography using a $4 \mathrm{ft} \times 2 \mathrm{~mm}$ glass column packed with Porapak 0 $80 / 100$ is used to determine the purity of a solution of $1 \%$ acetone in methanol by major peak area $\%$. Instrument: HP 5830A

RESULTS: Bulk\% Puritx 99.99

100.0 Average

100.0 $100.0 S D= \pm 0.01$

No impurities greater than $0.01 \%$ of the total test material sample area were observed. Acetone eluted at -3.1 minutes.

ASSAY: $\quad$ Gas chromatography using a $4 \mathrm{f} \times 2 \mathrm{~mm}$ glass column packed with Porapak $Q$ $80 / 100$ is used to determine the purity of the neat buk chemical by major peak area \%.

instrument: HP 5830A

RESULTS: Impurity Profile

A major peak of $99.98 \%$ area was observed at a relention time of -2.18 minutes for neat injections of both test and reierence material. No inpurity peaks with areas greater than $0.01 \%$ of the major peak were observed.

Conclusion: Intrared spectroscopy comfirms the gross purity and identity of BNW Lot No. 52446-32. Gas chromatography shows Lot BNW52446-32 Drum \#1 to be $100.0 \%$ pure by area percent. SOPHOB-AC-3A1HEO defines the acceptabie purity limit as $>95 \%$. Gas chromatography of the neal chemical shows a major peak of $99.98 \%$ by area. No impurities greater than $0.01 \%$ relative to the major peak were obsened.

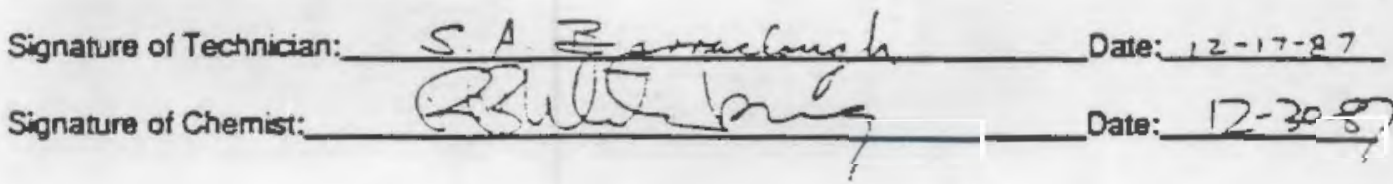




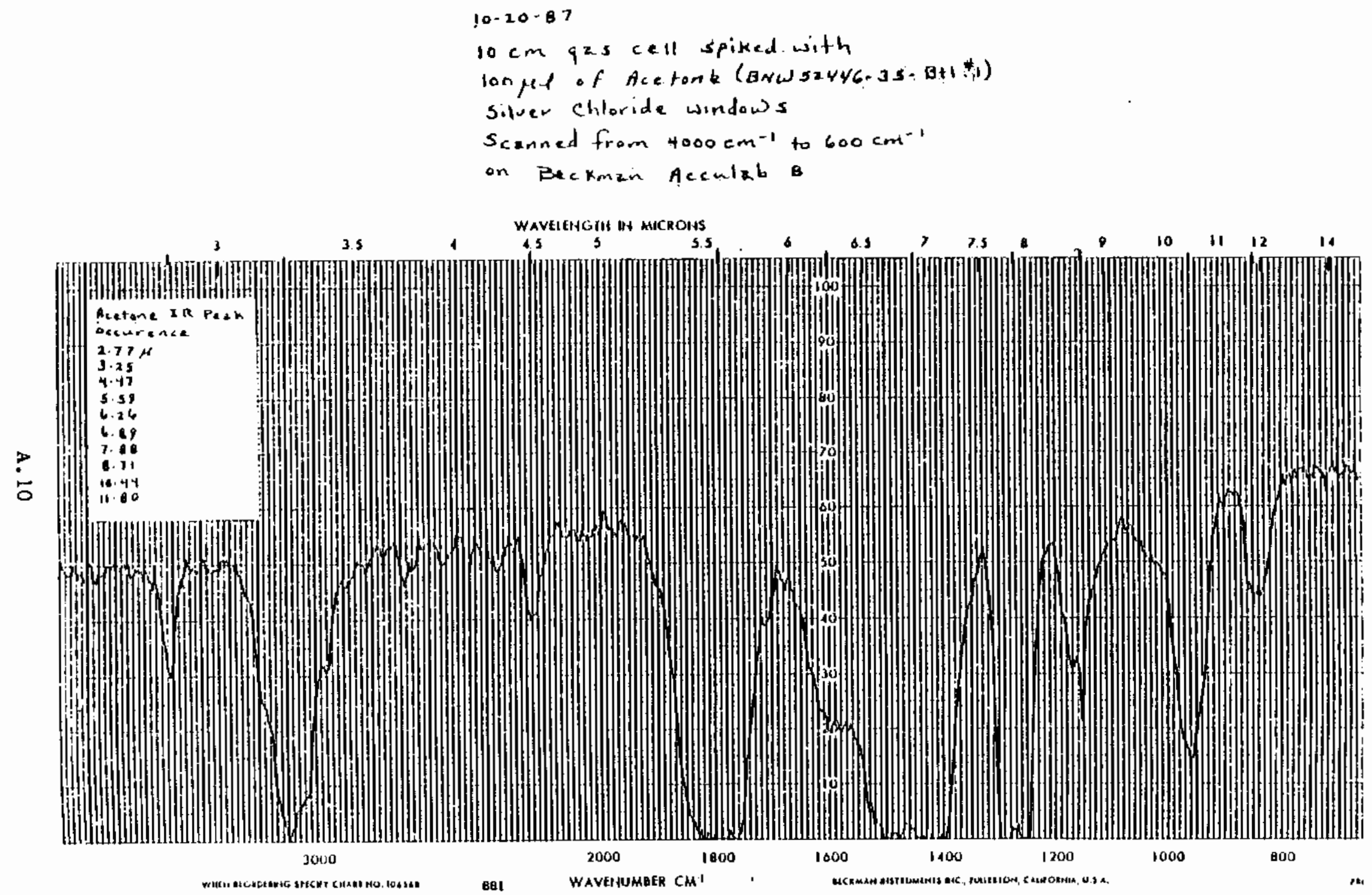


Punity Anvlysis of Acetome by G.C. Methon: $\varnothing B-A C \cdot 3 A \mid H$

G.C. Run Date: $10.28-87$

G.C.: HPS890 N813541

Column: 4 ft. $\times 2 \mathrm{~mm}$ glass, $\bar{c}$ Porapack $Q 80 / 100$ (TRT)

Acetme: BNW $52446-32-* 1$

Methronel: Burdick $\$$ Jacks on, Lot Arsty

NoTx: This purity was done to

LIST: METH $\&$ replace the original

G.C. Run of 10-19.87 duc

RUN PRKTRS

ZERO $=10$

ATT $2 T=8$

CHT $S P=8.5$

PK LD $=0.40$

THRSH $=11$

AR REJ $=8$

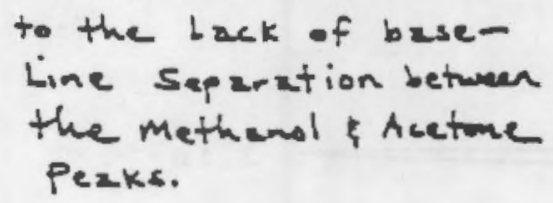

$B N \omega \leq 2.446=51$

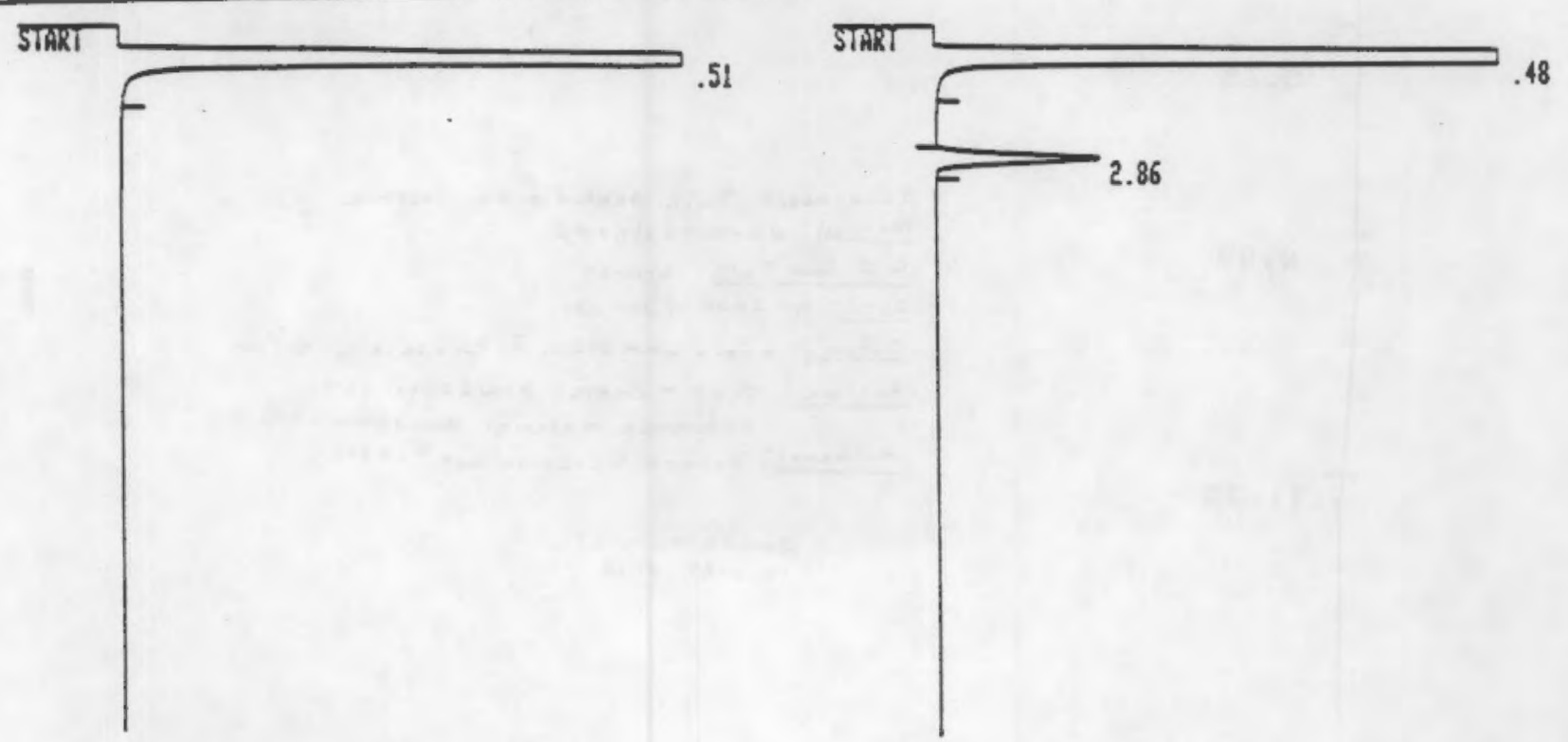

RUN +7

HORKFILE ID: C

HORKFILE HAIIE:

SAMPLE: 1 Methrmol BLANK

AREA\%

RT

0.51
AREA TYPE

1. $4948 E+88+58 B$
AR/TT

0. 385
AREA\% 188.080
RUN +8

MORKFILE ID: C

HORKFILE HAIE:

SAMPLE $20.5 \%$ Soln.

AREA\%

F

AREA TYPE

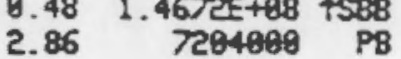

AR/HT

0. 298

8. 223

AREA*

95.320

4.680 

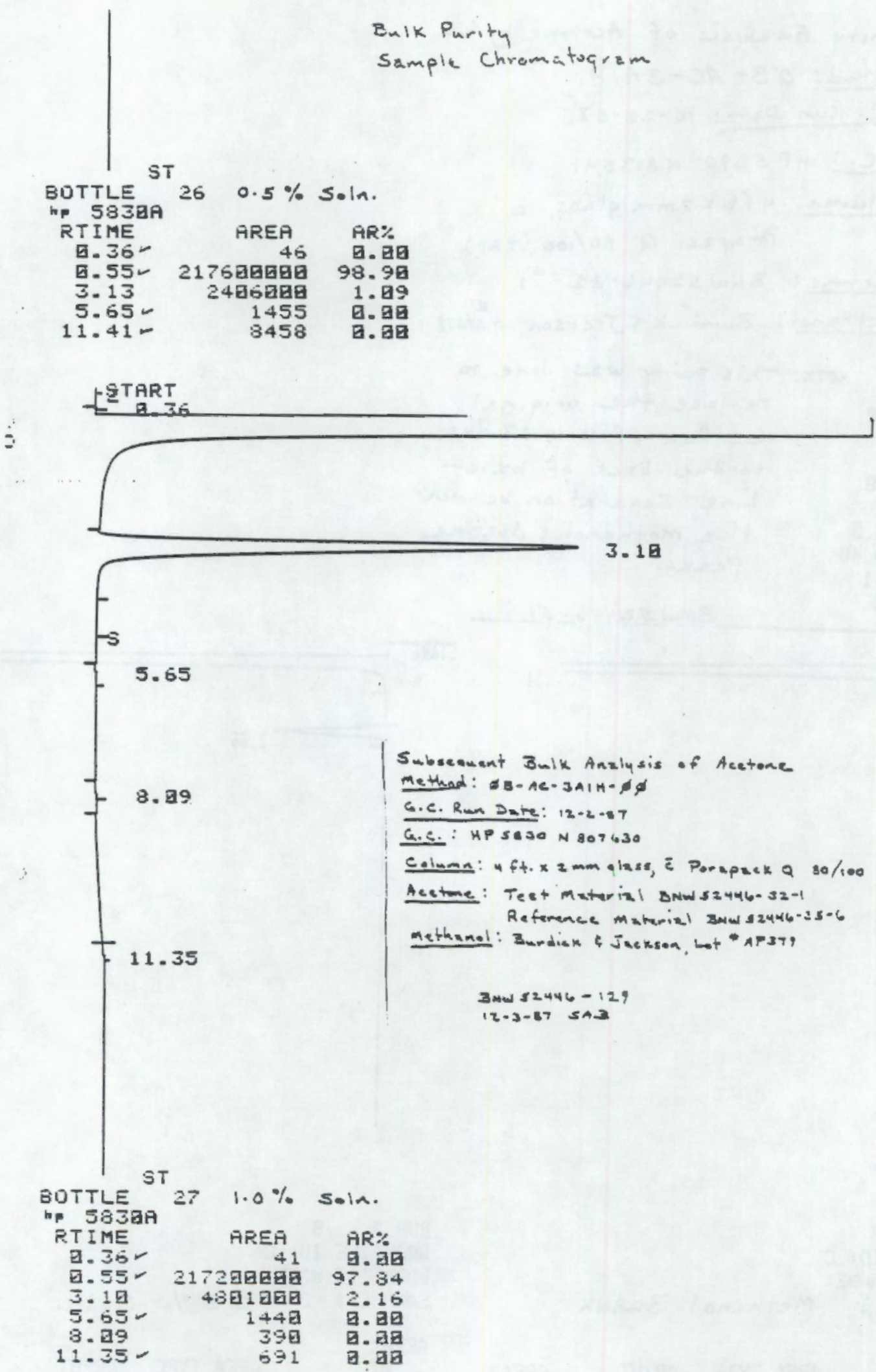

A. 12 


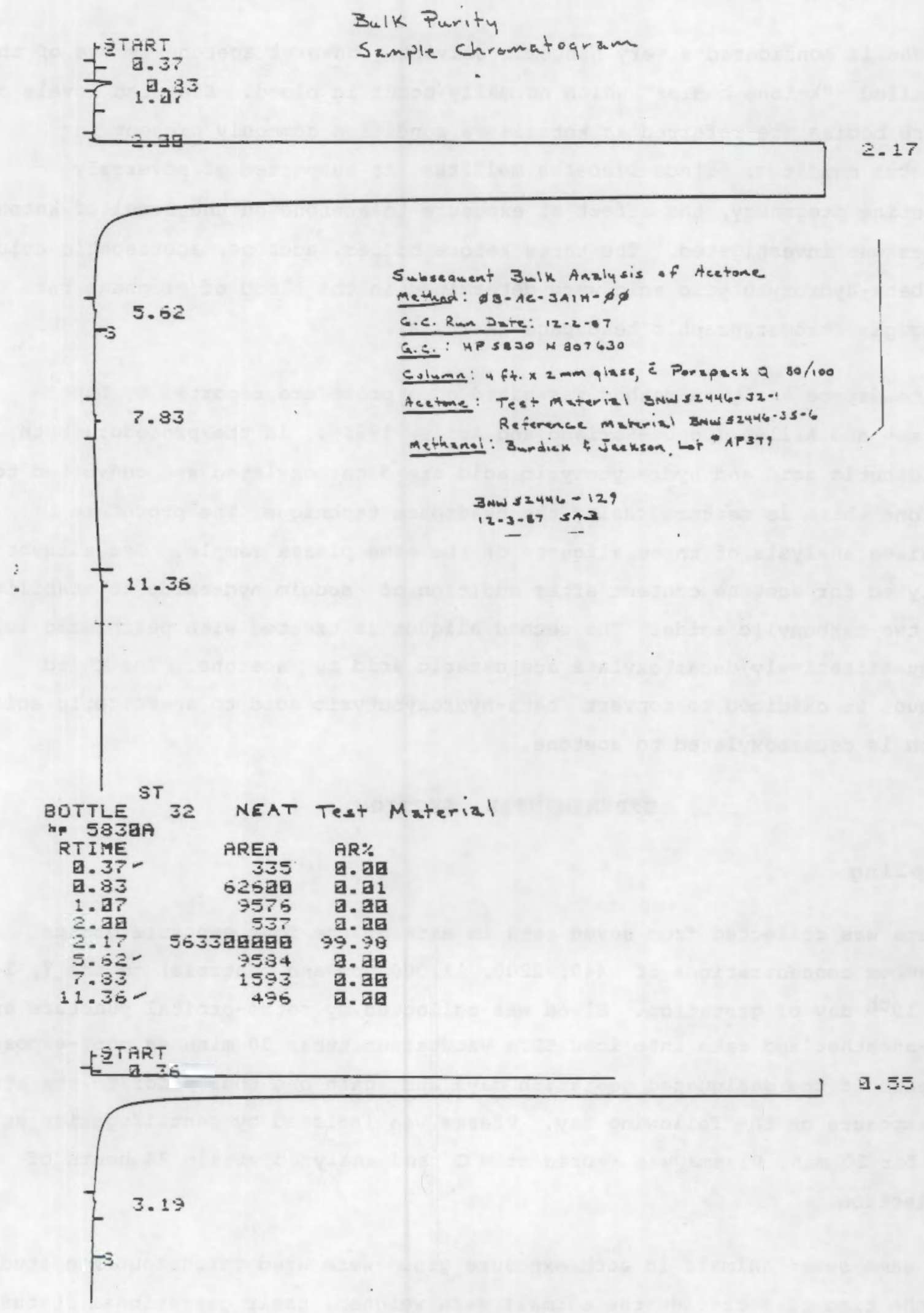

A. 13 


\section{DETERMINATION OF KETONE BODIFS IN RAT PIASMA}

Acetone is considered a very nontoxic solvent, however acetone is one of the so called "ketone bodies" which normally occur in blood. Elevated levels of ketone bodies are referred as ketosis a condition commonly present in Diabetes mellitus. Since Diabetes mellitus is suspected of adversely affecting pregnancy, the effect of exposure to acetone on the level of ketone bodies was investigated. The three ketone bodies, acetone, acetoacetic acid, and beta-hydroxybutyric acid were determined in the blood of pregnant rats using gas chromatographic headspace analysis.

The headspace analysis method was based on a procedure reported by LopezSoriano and Ariles (Lopez-Soriano and Ariles 1985). In the procedure both acetoacetic acid and hydroxybutyric acid are decarboxylated and converted to acetone which is measured using the headspace technique. The procedure requires analysis of three aliquots of the same plasma sample. one aliquot is analyzed for acetone content after addition of soduim hydroxide to stabilize the two carboxylic acids. The second aliquot is treated with perchloric acid to quantitatively decarboxylate acetoacetic acid to acetone. The third aliquot is oxidized to convert beta-hydroxybutyric acid to acetoacetic acid which is decarboxylated to acetone.

\section{EXPERIMENTAL SECTION}

\section{Sampling}

Plasma was collected from seven rats in each of the four exposure groups (chamber concentrations of $440,2200,11,000$ ppm and controls) on the 7, 14, and $19^{\text {th }}$ day of gestation. Blood was collected by retro-orbital puncture of $\mathrm{CO}_{2}$-anesthetized rats 1 to iced EDTA vacutainer tubes 30 minutes post-exposure on each of the designated gestation days and again one hour prior to the start of exposure on the following day. Plasma was 1solated by centrifugation at $4^{\circ} \mathrm{C}$ for 20 min. Plasma was stored at $4^{\circ} \mathrm{C}$ and analyzed within 24 hours of collection.

The same seven animals in each exposure group were used throughout the study. At the time of sacrifice the animals were weighed, their gestational status

$$
\text { A. } 14
$$


recorded, uterine and fetal weights obtained and the status of the fetuses recorded. These fetuses were not subjected to a teratological evaluation except for a gross examination.

\section{Headspace Analysis}

Three 125 ul aliquots were placed in each of three $20 \mathrm{ml}$ headspace-analysis vials, one for each of the three ketone bodies. Plasma samples were subjected to headspace analysis (HP 19295 headspace analyzer) by gas chromatography (HP $5890 \mathrm{GC}$ with a HP 3392 or 3393 integrator and HP $9114 \mathrm{~B}$ disk drive) according to the methods of Lopez-Soriano and Argiles (1985). All samples were quantified by headspace gas chromatographic analysis using a $15 \mathrm{~min}$ equilibration in the analyzer at $60^{\circ} \mathrm{C}$. Gas chromatography was performed on a 1/8" o.d. x 9' nickel column packed with $3 \%$ Carbowax 1500 on Chromosorb WAW, $60 / 80$ mesh, operated at $40^{\circ} \mathrm{C}$ with a short ramp to $45^{\circ} \mathrm{C}$ for column cleanup. The retention time of acetone on this system was about 1.5 minutes.

Free acetone was determined after the addition of 25 ul of $4 \mathrm{~N}$ sodium hydroxide to one of the 125 ul aliquots to prevent spontaneous decarboxylation of acetoacetic acid. The second and third allquots were kept in a $100^{\circ} \mathrm{C}$ sand bath for 90 minutes after addition of reaction solutions. The second aliquot was treated with $25 \mathrm{ul}$ of $0.6 \mathrm{M}$ perchloric acid to enhance quantitative decarboxylation of acetoacetic acid to acetone and the third plasma aliquot was treated with $25 \mathrm{ul}$ of an oxidative reagent $10.2 \mathrm{M} \mathrm{K}_{2} \mathrm{Cr}_{2} \mathrm{O}_{7}$ in $5 \mathrm{M}$ phosphoric acid). The oxidative treatment of the third sample converts all ketone bodies to acetone; thus, beta-hydroxybutyric acid was determined by subtracting the amount of acetone and acetoacetic acid from the value obtained for the total ketone body level.

\section{Headspace Calibration}

The slope of the calibration curve observed for acetone was insensitive to standard preparation in either saline or plasma. As reported by Lopez-5oriano and Argiles, the acetone standards exhibited greater response when prepared in the caustic media.

Calibration was performed using standards of acetone in saline. For each set of analyses, standards were prepared in each reaction mixture every analysis A. 15 
day. The acetone concentration bracketed the amount of acetone expected in the samples. Figure 1 shows the relationship between GC peak area and acetone quantity for each reaction mixture constructed from a composite of all calibration data. As shown in the figure the response relationship was linear with correlation coefficients of 1.000 .

A series of experiments was performed to optimize the recovery of acetoacetic acid and beta-hydroxybutyric acid from the various reaction mixtures. The recovery values established for the optimized procedure are shown in Table 1. As shown in the table some decarboxylation of acetoacetic acid occurred in the sodium hydroxide solution. Less than the desired $100 \%$ recovery was observed for both carboxylic acids from the dichromate/phosphoric acid reaction mixture. The recovery of hydroxybutyric acid from the dichromate/phosphoric acid reaction medium was substaintially less than the desired $100 \%$. The recovery values shown in the table were employed in a series of simultaneous linear equations to account for the deviation from the ideal recoveries of either $0 \%$ or $100 \%$.

\section{RESULTS AND DISCUSSION}

As shown in Table 2 the plasma concentration of acetone found immediately following exposure is dependent upon the exposure concentration. The plasma concentration is not dependent upon the gestation day. An average plasma concentration of $0.7 \mathrm{mM}, 5 \mathrm{mM}$, and $36 \mathrm{mM}$ was observed for the 440,2200 , and $11000 \mathrm{ppm}$ dose groups. At 7 and 14 days of gestation the control acetone concentrations were below the limit of detection. At 19 days of gestation an average acetone concentration of $0.03 \mathrm{mM}$ was observed for the pre-exposure samples acquired from the control group.

The acetone levels in plasma samples acquired immediately before the start of exposures were very low for all exposure groups. Since acetone is metabolized and excreted unchanged both in urine and expired air it is not surprizing that the compound would be cleared from the test animals after 17 hours off exposure. Pre-exposure samples for all but the 11,000 ppm exposure group are indistinguishable from control values. This group shows elevation of plasma 
acetone following 17 hours off exposure. Plasma acetone for the 2,200 group is slightly elevated following 17 hours off exposure.

Determinations for acetoacetic acid and beta-hydroxybutyric acid require subtracting the acetone contributions. When the acetone level is high acetoacetic acid and beta-hydroxybutyric acid are determined by small differences against the acetone background. In such instances the effective sensitivity of the method is limited by the uncertainty of determining the high background acetone concentrations. An effective limit of detection has been calculated for the determination of acetoacetic acid and betahydroxybutyric acid from the standard deviation of the acetone concentration. The citation of different lower limits of detection in Table 2 reflects the dependency of the lower limit of detection upon acetone concentration encountered for a particular sample. The data conclusively demonstrates that concentrations of acetoacetic acid and beta-hydroxybutyric acid are not elevated to the values observed for acetone for exposed animals.

\section{CONCLUSIONS}

Plasma levels of acetone are markedly elevated relative to normal physiological levels in pregnant rats exposed by route of inhalation to concentrations ranging from 440 to $11,000 \mathrm{ppm}$ acetone. Elevation of acetoacetic acid and beta-hydroxybutyric acid does not occur. Thus, exposure to acetone should not produce acidosis, a condition which commonly accompanies ketosis.

\section{IITERATURE CITED}

Lopez-Soriano, FJ and JM Argiles. Simultaneous Determination of Ketone Bodies in Biological Samples By Gas Chromatogrphic Headspace Analysis. J. Chrom. Sci. 23:120-123, 1986. 
Table 1

Recoveries for Acetoacetic Acid and Hydroxybutyric Acid from Reaction Media

Ketone Reaction Medium

$\mathrm{NaOH}$

AAA

AAA

AAA

HBA

HBA

HBA

dichromate/phosphoric

perchloric

dichromate/phosphoric

$\mathrm{NaOH}$

perchloric

0 \%

$100 \%$
Observed Recovery

$10.8 \%$

$100 \frac{\%}{5}$

$70.1 \%$

$0 \%$

$0 \%$

$26.7 \%$

AAA: acetoacetic acid

HBA: beta-hydroxybutyric acid 


\section{Calibration Curve for Acetone Determinations}

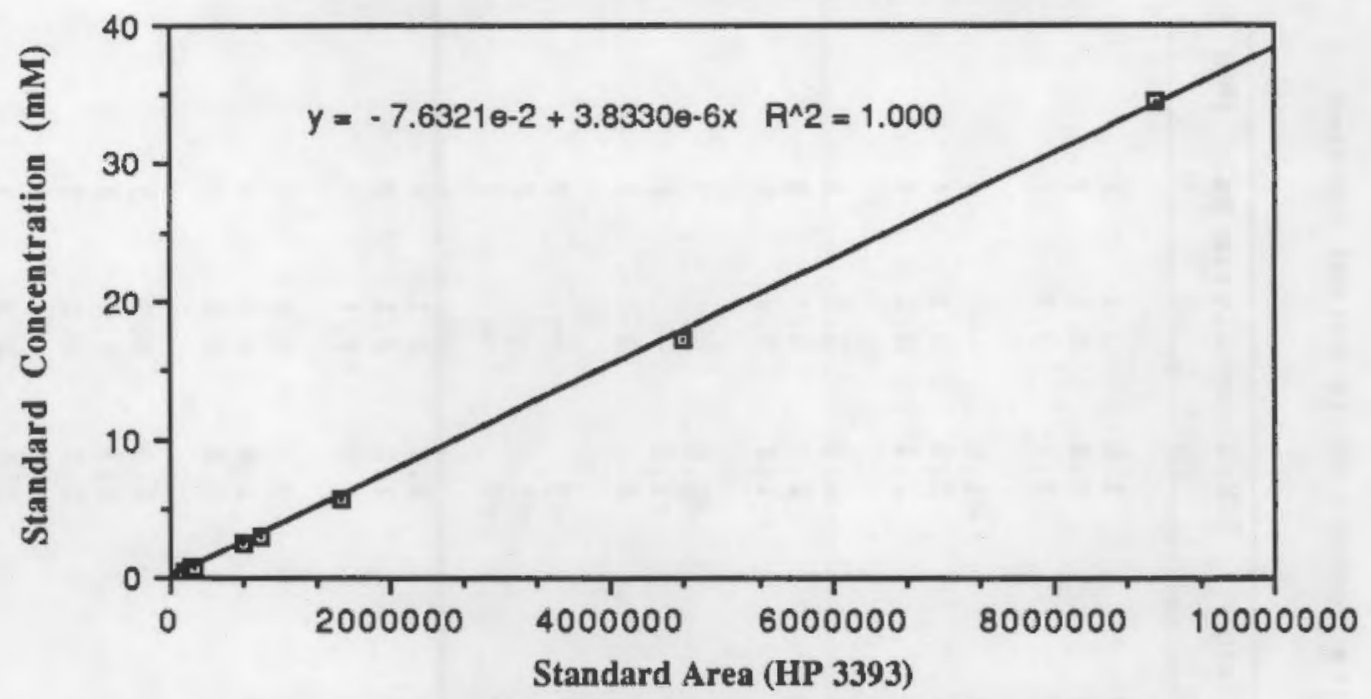

Calibration Curve for Acetoacetic Acid Determinations

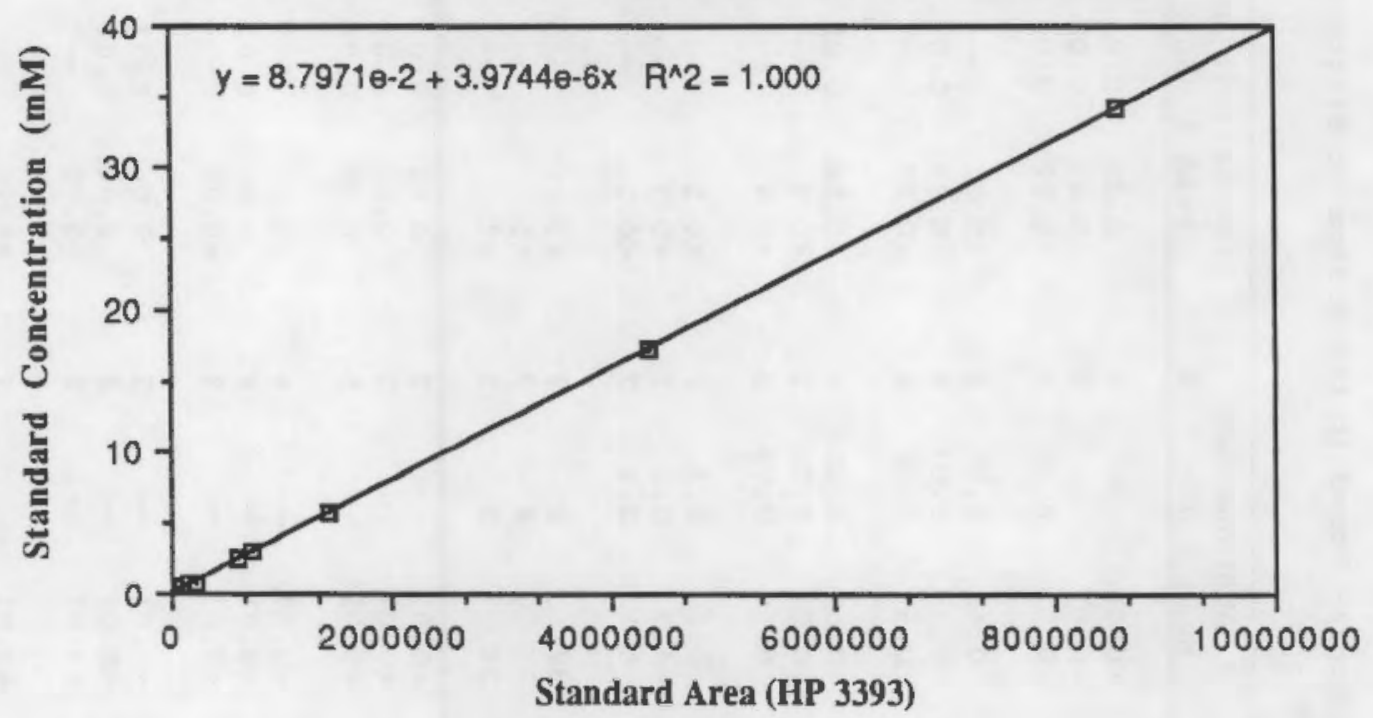

Calibration Curve for beta-Hydroxybutyric Acid Determinations

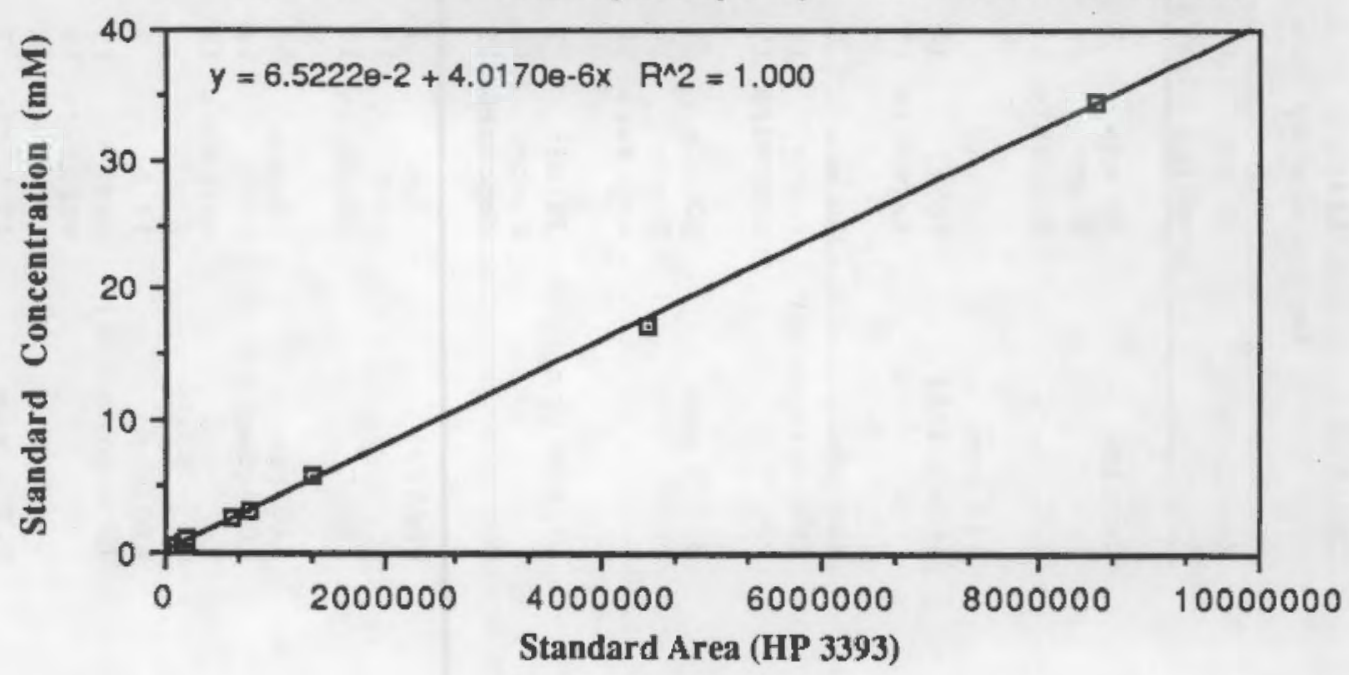

A. 19 
TABLE 2. Concentration of Ketone Bodies Found in the Plasma of Pregnant Rats (except where noted) Exposed to Acetone by Inhalation.

\begin{tabular}{|c|c|c|c|c|c|c|c|c|c|c|c|}
\hline $\begin{array}{l}\text { Exposure } \\
\text { Group }\end{array}$ & $\begin{array}{ll}\text { Time of } & D \\
\text { Sampling } & G \\
\end{array}$ & $\begin{array}{l}\text { Day of } \\
\text { Gestation }\end{array}$ & $\begin{array}{l}\text { Aceto } \\
\text { Mean } \pm \\
\end{array}$ & SD & $\mathbf{N}$ & $\begin{array}{c}\text { Acetoace } \\
\text { Mean } \pm \\
\end{array}$ & $\begin{array}{l}\text { tic Ac } \\
\text { SD }\end{array}$ & $\mathrm{N}_{\mathrm{N}}^{(\mathrm{mM})}$ & $\begin{array}{r}\text { B-Hydroxy } \\
\text { Mean } \pm\end{array}$ & $\begin{array}{l}\text { butyric } \\
\text { SD } \\
\end{array}$ & $\begin{array}{l}\text { Acid }(\mathrm{mM}) \\
\mathrm{N}\end{array}$ \\
\hline Control & $\begin{array}{l}30 \mathrm{~min} \\
\text { Post- } \\
\text { exposure }\end{array}$ & $\begin{array}{r}7 \\
14 \\
\quad 19\end{array}$ & $\begin{array}{r}<0.01 \\
<0.01 \\
0.03\end{array}$ & $\begin{array}{l}-- \\
-- \\
0.02\end{array}$ & $\begin{array}{l}7 \\
7 \\
7\end{array}$ & $\begin{array}{l}0.05 \\
0.03 \\
0.02\end{array}$ & $\begin{array}{l}0.01 \\
0.02 \\
0.01\end{array}$ & $\begin{array}{l}7 \\
7 \\
7\end{array}$ & $\begin{array}{l}1.0 \\
0.9 \\
1.1\end{array}$ & $\begin{array}{l}0.1 \\
0.1 \\
0.2\end{array}$ & $\begin{array}{l}7 \\
7 \\
7\end{array}$ \\
\hline $\begin{array}{l}440 \text { ppm } \\
\text { (Pregnant) }\end{array}$ & $\begin{array}{l}30 \mathrm{~min} \\
\text { Post- } \\
\text { Exposure }\end{array}$ & $\begin{array}{r}7 \\
14 \\
e \quad 19\end{array}$ & $\begin{array}{l}0.66 \\
0.74 \\
0.91\end{array}$ & $\begin{array}{l}0.07 \\
0.03 \\
0.08\end{array}$ & $\begin{array}{l}4 \\
4 \\
4\end{array}$ & $\begin{array}{r}<0.02 \\
0.39 \\
<0.20\end{array}$ & $\begin{array}{c}-- \\
0.07 \\
--\end{array}$ & $\begin{array}{l}4 \\
4 \\
4\end{array}$ & $\begin{array}{r}<1.5 \\
2.6 \\
1.4\end{array}$ & $\begin{array}{l}-- \\
0.3 \\
0.2\end{array}$ & $\begin{array}{l}4 \\
4 \\
4\end{array}$ \\
\hline $\begin{array}{l}440 \mathrm{ppm} \\
\text { (Non-pregnant) }\end{array}$ & $\begin{array}{l}30 \mathrm{~min} \\
\text { Post- } \\
\text { exposure }\end{array}$ & $\begin{array}{r}7 \\
14 \\
e \quad 19\end{array}$ & $\begin{array}{l}0.58 \\
0.59 \\
0.66\end{array}$ & $\begin{array}{l}0.01 \\
0.06 \\
0.06\end{array}$ & $\begin{array}{l}3 \\
3 \\
3\end{array}$ & $\begin{aligned} & 0.16 \\
< & 0.4 \\
< & 0.4\end{aligned}$ & $\begin{array}{c}0.05 \\
-- \\
--\end{array}$ & $\begin{array}{l}3 \\
3 \\
3\end{array}$ & $\begin{array}{l}0.8 \\
2.0 \\
1.1\end{array}$ & $\begin{array}{l}0.2 \\
0.4 \\
0.4\end{array}$ & $\begin{array}{l}3 \\
3 \\
3\end{array}$ \\
\hline $2,220 \mathrm{ppm}$ & $\begin{array}{l}30 \mathrm{~min} \\
\text { Post- } \\
\text { exposure }\end{array}$ & $\begin{array}{r}7 \\
14 \\
e \quad 19\end{array}$ & $\begin{array}{l}5.1 \\
4.7 \\
5.1\end{array}$ & $\begin{array}{l}0.3 \\
0.5 \\
0.4\end{array}$ & $\begin{array}{l}7 \\
7 \\
7\end{array}$ & $\begin{array}{l}<0.5 \\
<0.7 \\
<0.5\end{array}$ & $\begin{array}{l}-- \\
--\end{array}$ & $\begin{array}{l}7 \\
7 \\
7\end{array}$ & $\begin{array}{c}<0.5 \\
<1.6 \\
4\end{array}$ & $\begin{array}{l}-- \\
-- \\
3\end{array}$ & $\begin{array}{l}7 \\
7 \\
7\end{array}$ \\
\hline $11,000 \mathrm{ppm}$ & $\begin{array}{l}30 \mathrm{~min} \\
\text { Post- } \\
\text { exposure }\end{array}$ & $\begin{array}{r}7 \\
14 \\
+\quad 19\end{array}$ & $\begin{array}{l}37 \\
36 \\
34\end{array}$ & $\begin{array}{l}2 \\
4 \\
5\end{array}$ & $\begin{array}{l}7 \\
7 \\
7\end{array}$ & $\begin{array}{l}<3 \\
<5 \\
<7\end{array}$ & $\begin{array}{l}-- \\
--\end{array}$ & $\begin{array}{l}7 \\
7 \\
7\end{array}$ & $\begin{array}{l}<3 \\
<5 \\
<7\end{array}$ & $\begin{array}{l}-- \\
--\end{array}$ & $\begin{array}{l}7 \\
7 \\
7\end{array}$ \\
\hline Control & $\begin{array}{l}17 \mathrm{~h} \\
\text { Post- } \\
\text { exposure }\end{array}$ & $\begin{array}{r}7 \\
14 \\
\quad 19\end{array}$ & $\begin{array}{l}<0.01 \\
<0.01 \\
<0.01\end{array}$ & $\begin{array}{l}-- \\
-- \\
--\end{array}$ & $\begin{array}{l}7 \\
7 \\
5\end{array}$ & $\begin{array}{l}0.06 \\
0.03 \\
0.03\end{array}$ & $\begin{array}{l}0.03 \\
0.01 \\
0.02\end{array}$ & $\begin{array}{l}7 \\
7 \\
7\end{array}$ & $\begin{array}{l}1.2 \\
1.2 \\
1.2\end{array}$ & $\begin{array}{l}0.1 \\
0.1 \\
0.1\end{array}$ & $\begin{array}{l}7 \\
7 \\
7\end{array}$ \\
\hline $\begin{array}{l}440 \text { ppm } \\
\text { (Pregnant) }\end{array}$ & $\begin{array}{l}17 \mathrm{~h} \\
\text { Post- } \\
\text { exposure }\end{array}$ & $\begin{array}{r}7 \\
14 \\
e \quad 19\end{array}$ & $\begin{array}{l}<0.07 \\
<0.01 \\
<0.03\end{array}$ & $\begin{array}{l}-- \\
-- \\
--\end{array}$ & $\begin{array}{l}4 \\
4 \\
3\end{array}$ & $\begin{array}{r}<0.60 \\
0.03 \\
<0.03\end{array}$ & $\begin{array}{c}0.01 \\
--\end{array}$ & $\begin{array}{l}4 \\
4 \\
3\end{array}$ & $\begin{array}{l}0.7 \\
1.6 \\
1.6\end{array}$ & $\begin{array}{l}0.4 \\
0.1 \\
0.4\end{array}$ & $\begin{array}{l}4 \\
4 \\
3\end{array}$ \\
\hline $\begin{array}{l}440 \mathrm{ppm} \\
\text { (Non-pregnant) }\end{array}$ & $\begin{array}{l}17 \mathrm{~h} \\
\text { Post- } \\
\text { exposure }\end{array}$ & $\begin{array}{r}7 \\
14 \\
\text { e } 19\end{array}$ & $\begin{array}{l}<0.01 \\
<0.02 \\
<0.01\end{array}$ & -- & $\begin{array}{l}3 \\
3 \\
2\end{array}$ & $\begin{array}{l}0.06 \\
0.04 \\
0.06\end{array}$ & $\begin{array}{c}0.03 \\
0.02 \\
--\end{array}$ & $\begin{array}{l}3 \\
3 \\
2\end{array}$ & $\begin{array}{l}0.9 \\
1.4 \\
1.1\end{array}$ & $\begin{array}{l}0.2 \\
0.1 \\
0.1\end{array}$ & $\begin{array}{l}3 \\
3 \\
2\end{array}$ \\
\hline 2,200 ppm & $\begin{array}{l}17 \mathrm{~h} \\
\text { Post- } \\
\text { exposure }\end{array}$ & $\begin{array}{r}7 \\
14 \\
\quad 19\end{array}$ & $\begin{array}{r}<0.01 \\
0.01 \\
0.40\end{array}$ & $\begin{array}{l}-- \\
0.01 \\
0.20\end{array}$ & $\begin{array}{l}7 \\
7 \\
7\end{array}$ & $\begin{array}{l}<0.20 \\
<0.02 \\
<0.06\end{array}$ & -- & $\begin{array}{l}7 \\
7 \\
7\end{array}$ & $\begin{array}{l}1.0 \\
0.9 \\
1.4\end{array}$ & $\begin{array}{l}0.4 \\
0.1 \\
0.3\end{array}$ & $\begin{array}{l}7 \\
7 \\
7\end{array}$ \\
\hline $11,000 \mathrm{ppm}$ & $\begin{array}{l}17 \mathrm{~h} \\
\text { Post- } \\
\text { exposure }\end{array}$ & $\begin{array}{r}7 \\
14 \\
\quad 19\end{array}$ & $\begin{array}{r}3 \\
<3 \\
6\end{array}$ & $-\frac{1}{2}$ & $\begin{array}{l}7 \\
6 \\
7\end{array}$ & $\begin{array}{l}<2 \\
<2 \\
<2\end{array}$ & $\begin{array}{l}-- \\
-- \\
--\end{array}$ & $\begin{array}{l}7 \\
6 \\
7\end{array}$ & $\begin{array}{r}2 \\
<2 \\
5.2\end{array}$ & $\begin{array}{l}1 \\
-- \\
0.7\end{array}$ & $\begin{array}{l}7 \\
6 \\
7\end{array}$ \\
\hline
\end{tabular}


APPENDIX B

EXPOSURE NARRATIVE AND DATA

FOR ACETONE 


\section{EXPOSURE DATA AND NARRATIVE FOR ACETONE}

\section{Animal sxposure Chamber}

The Battelle-designed inhalation exposure chamber (commercially available from Harford Systems/Lab Products, Inc., Aberdeen, MD) was used for the inhalation exposures. The $2.3 \mathrm{~m}^{3}\left(1.7 \mathrm{~m}^{3}\right.$ active mixing volume) stainless steel chamber contained three levels of caging, each level split into two offset tiers (Eigure B.1a). The drawer-like stainless steel cage units were comprised of individual animal cages, feed troughs and automatic watering. Stainless steel catch pans for the collection of urine and feces were suspended below each cage unit.

The catch pans, which remained in the chamber during exposure, were designed to aid in maintaining uniform concentrations of aerosol, dust or vapors throughout the chamber (Figure B.1b). Incoming air was HEPA and charcoal filtered before addition of the test article. Following the addition of the test article the uniform mixture was diverted along the inner surfaces of the chamber. A portion of the flow was "peeled off" by each catch pan thus creating mixing eddies. Exhaust from each tier was cleared through the space between the tiers.

\section{Exposure Suite System Description}

The acetone exposures were conducted using an automated data acquisition and control system in an exposure suite (Figures B.2 and B.3). This system monitored and controlled the basic inhalation test system functions including chamber air flow, vacuum, temperature, relative humidity and test chemical concentration. The system computers, printers, magnetic data storage devices, interface equipment, and monitoring instruments were located in a central control room and interfaced with monitoring and control elements in three exposure rooms. All data acquisition and control originated from an executive computer which controlled a multiplexing interface system. All experimental protocols related to data acquisition and control resided in this computer and were entered into software tables accessed by menus.

Data from each exposure was stored in the exposure control center on separate magnetic media micro-floppy diskettes. Data and comments from each exposure room were printed on separate printers. Data was printed and stored immediately upon completion of the measurement. At the end of the 24 hour period, the daily data was analyzed and summary and data outlier reports were printed.

A dual point alazm system with user-defined set points was available for each parameter measured. Action taken upon alarm depended on the cause and severity of the alarm and ranged from audio/visual alert to automatic shutoff of the exposure generator. Alarm conditions which might be a threat to the health of the animals alerted a building power operator who was on duty 24 hours per day. 

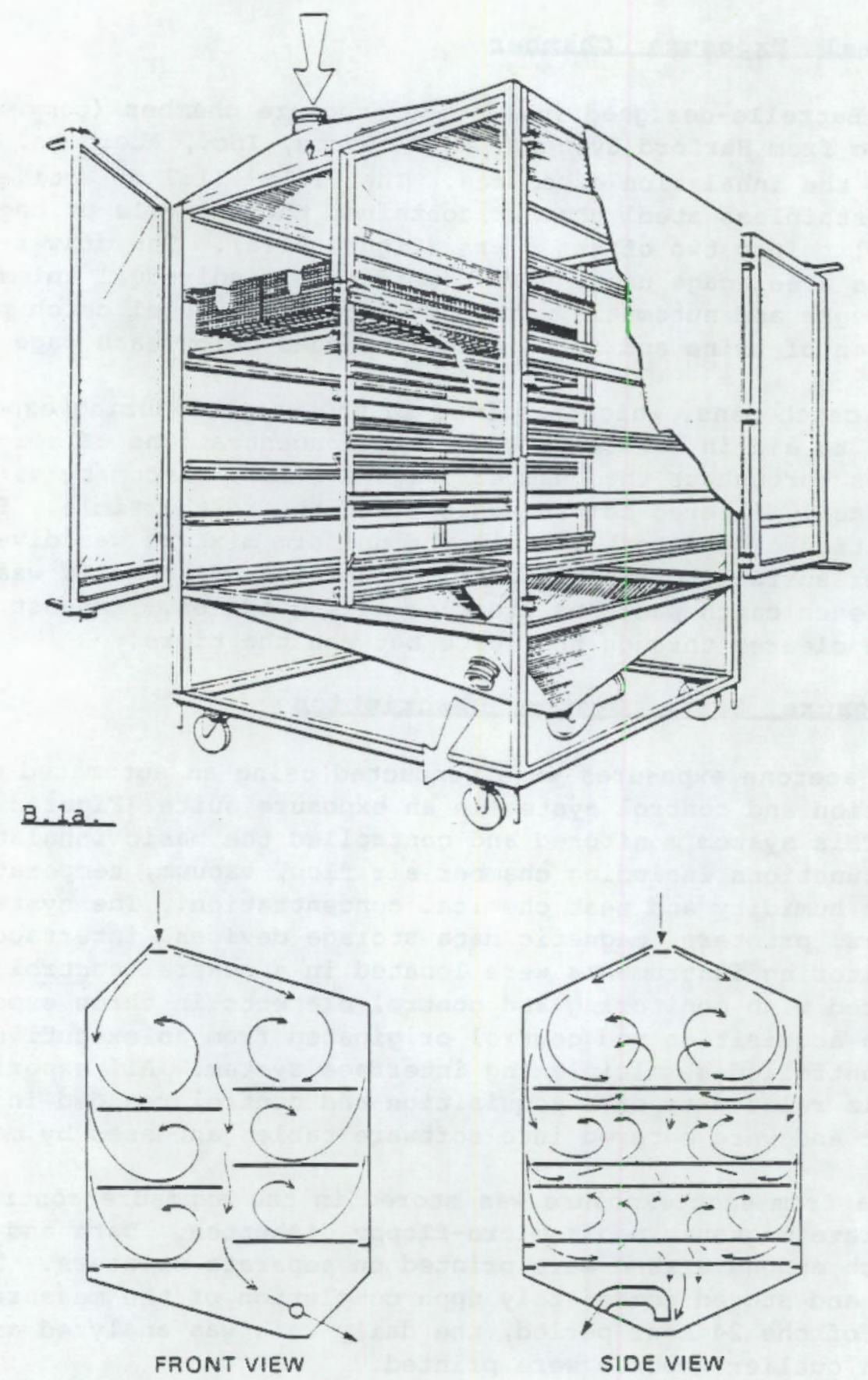

3.16 .

EIGURES B.1a and B.1b. Inhalation Exposure Chamber 


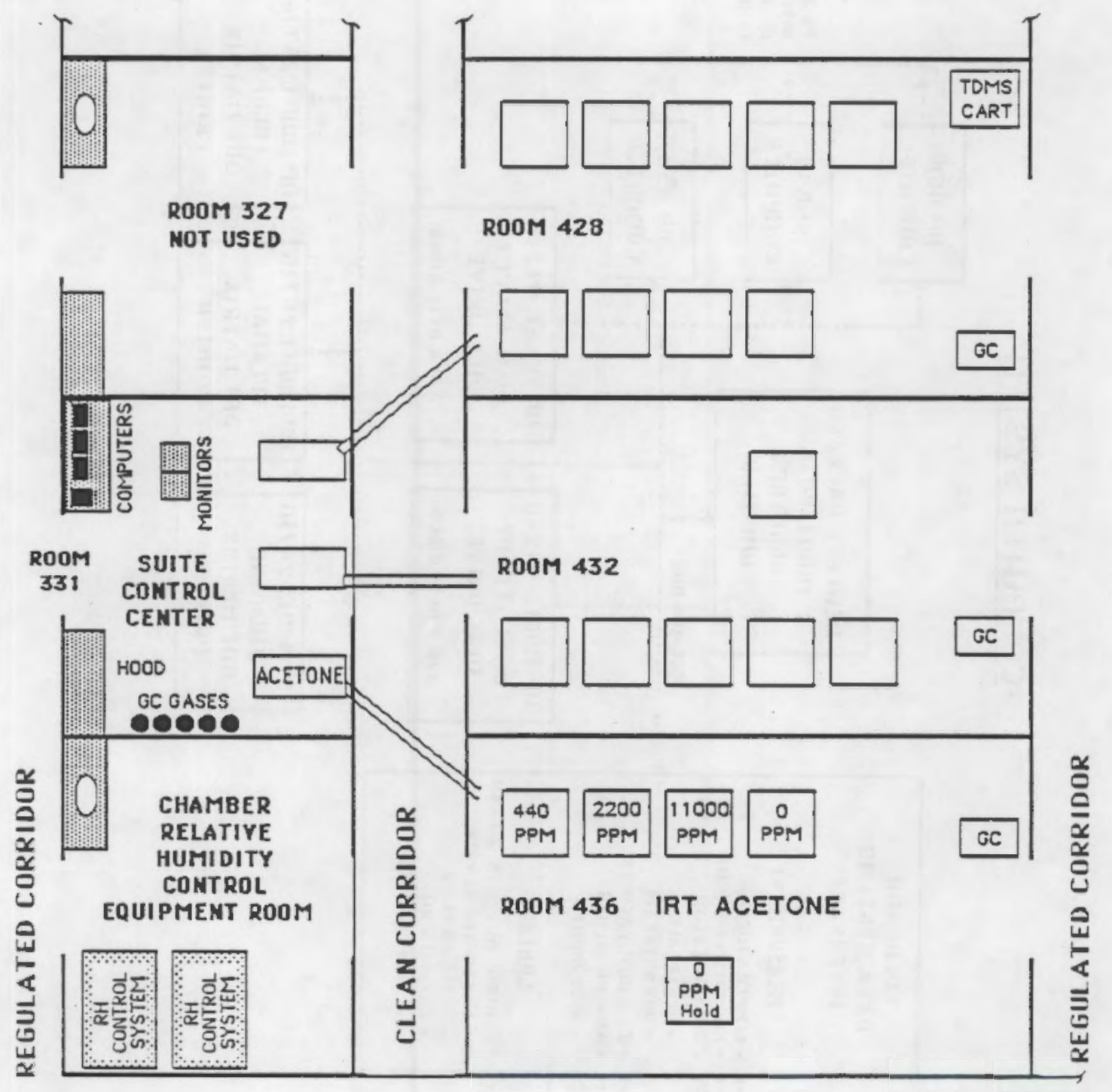

EIGURE B.2. Acetone Exposure Suite

B.3 


\section{COMPUTER SYSTEM}

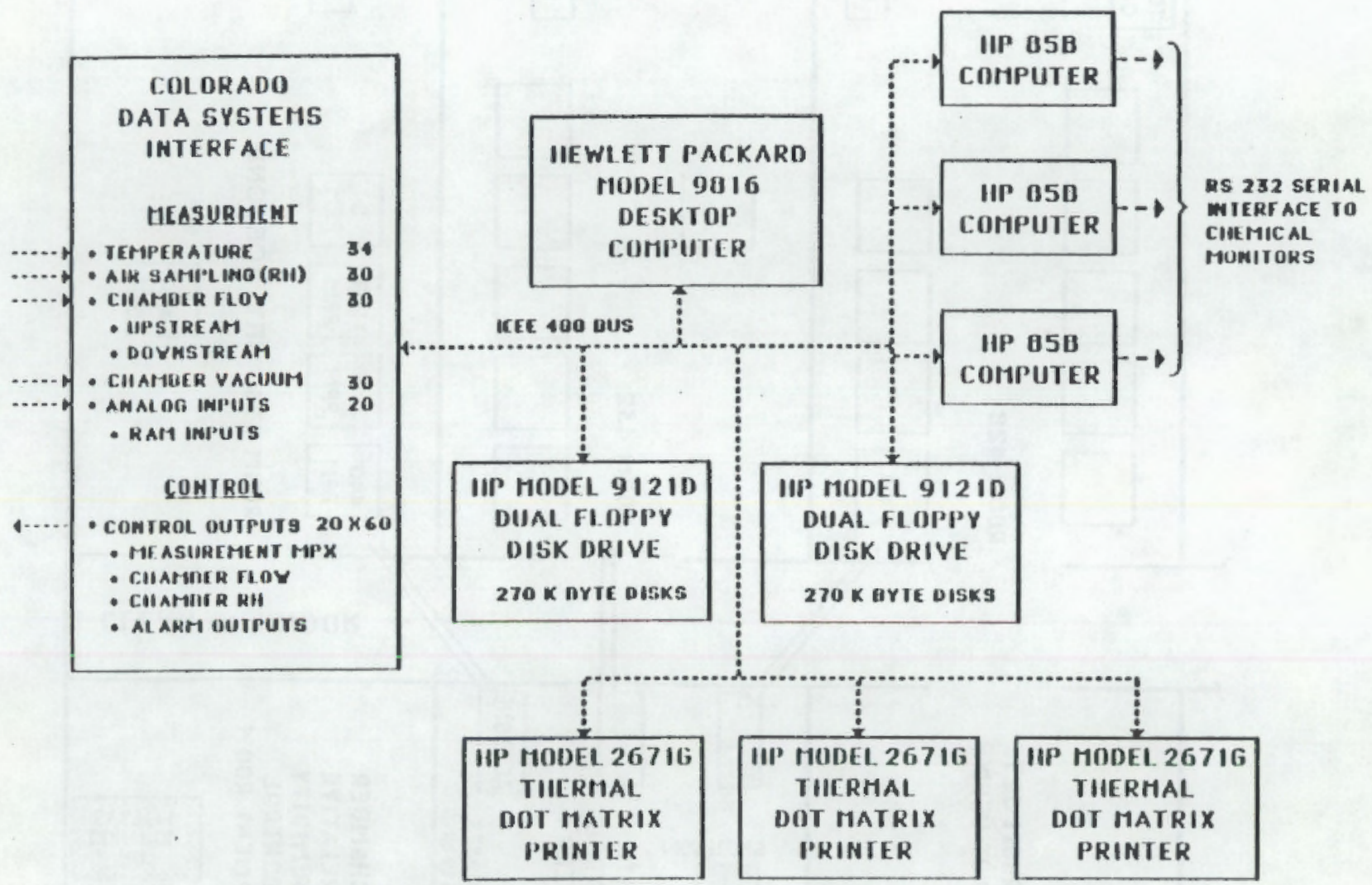


Chamber and room temperatures were measured by Resistance Temperature Detectors (RTDs) located at the measurement site. The RTD's were multiplexed to a digital thermometer which was interfaced to the computer. Chamber temperature was controlled primarily by controlling the temperature of the room housing the chambers. Prior to the start of the study RTD'S were calibrated to within $\pm 0.5^{\circ} \mathrm{F}$ of a certified mercury thermometer in a temperature controlled water bath.

Relative humidity (RH) was calculated with an accuracy of $\pm 6 \%$ by pulling a sample from the measurement location through a Teflon tube into a dewpoint hygrometer located in the control center. Measurements were made from different locations by a valving system which multiplexed the tubes to the hygrometer. Percent RH was calculated by the executive computer from temperature and dewpoint measurements. Chamber orH was maintained by a "wet/dry" air source supplied to each chamber. The ratio of "wet" to "dry" air, determined by a computer-controlled mixing valve, determined the chamber ofRH.

Chamber air flow was calculated with an accuracy of $\pm 151 / \mathrm{min}$ by measurement of the pressure drop across calibrated orifices located at the inlet and exhaust of each chamber. The desired flow orifice was attached by means of a multiplexed valve system to a calibrated pressure transducer located in the control center. Leaks in the chambers could be detected by comparison of the measurement of inlet flow with that of the exhaust. Flow was maintained by a computer-controlled gate valve in the exhaust line of each chamber.

Chamber vacuum, relative to the control center, was measured with

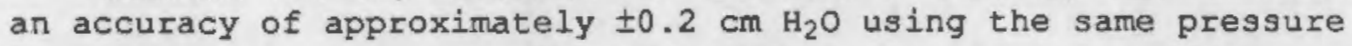
transducer system which measured chamber air flows. Chamber vacuum was maintained at approximately $(-) 1^{\prime \prime} \mathrm{H}_{2} \mathrm{O}$ primarily by inlet resistance provided by the HEPA and charcoal filters.

\section{Acetone Generation System}

A schematic diagram of the acetone generation and delivery system is shown in Figure B.4. The acetone generator was housed in a vented cabinet located in the Suite Control Center. The acetone to be vaporized was contained in a 19 liter stainless steel reservoir. This reservoir was filled from the original shipping container by the following method which was designed to prevent explosion during transfer. All oxygen in the reservoir was displaced with nitrogen through a purge port. The nitrogen pressure in the shipping container forced acetone through a filter and into the reservoir. All metal containers were grounded. The filled reservoir was then transferred to, and installed into, the generator cabinet. The reservoir was refilled every other day.

During exposure the acetone was pumped from the stainless steel reservoir through an eductor tube and delivery tubes to vaporizers located at the fresh air inlet of each animal exposure chamber. On the high chamber, the chemical was delivered to two vaporizers since the rate of delivery exceeded the vaporization capability of a single vaporizer. Stable micrometering pumps with adjustable drift-free pump 
rates ranging from less than $1 \times 10^{-3}$ to greater than $20 \mathrm{ml}$ per minute were used.

The vaporizer comprised a stainless steel cylinder covered with a glass fiber wick from which the liquid was vaporized. The wick could be easily and inexpensively replaced if residue buildup occurred. An 80-watt heater and a temperature sensing element were incorporated within the cylinder and connected to a remotely located temperature controller. A second temperature monitor was incorporated in the vaporizer allowing the operating temperature to be recorded by the automated data acquisition system. The operating temperature of the vaporizer was maintained below $135^{\circ} \mathrm{F}$.

A clear Tefion ${ }^{\circledR}$ tube of measured volume, preceded by a three-way valve was attached just upstream of the pump to facilitate measurement of the flow rate of the vapor generator. Measurement was accomplished by momentarily switching the three-way valve from the run position to the test position. A small bubble of air was pulled by the pump from the cabinet through the valve and into the clear tube. The progress of this bubble from one end of the tube to the other (a calibrated volume) was timed with a stop watch. Flow rate was calculated by dividing the volume by the time. The concentration in the exposure chamber could be calculated from the flow measurements of liquid and dilution air and was used as a check on chamber concentrations in addition to GC measurements. A three-way valve at the output of the liquid reservoir allowed the liquid to be pumped either to the vaporizer or to a sample vial. In this way, samples could be taken from the reservoir for periodic purity assays, or for calibration of the monitoring equipment.

All generation equipment which came in contact with the acetone was stainless-steel, Teflon ${ }^{(1)}$ or Viton ${ }^{\circledR}$. All equipment contained in the vented generator cabinet was explosion proof. 


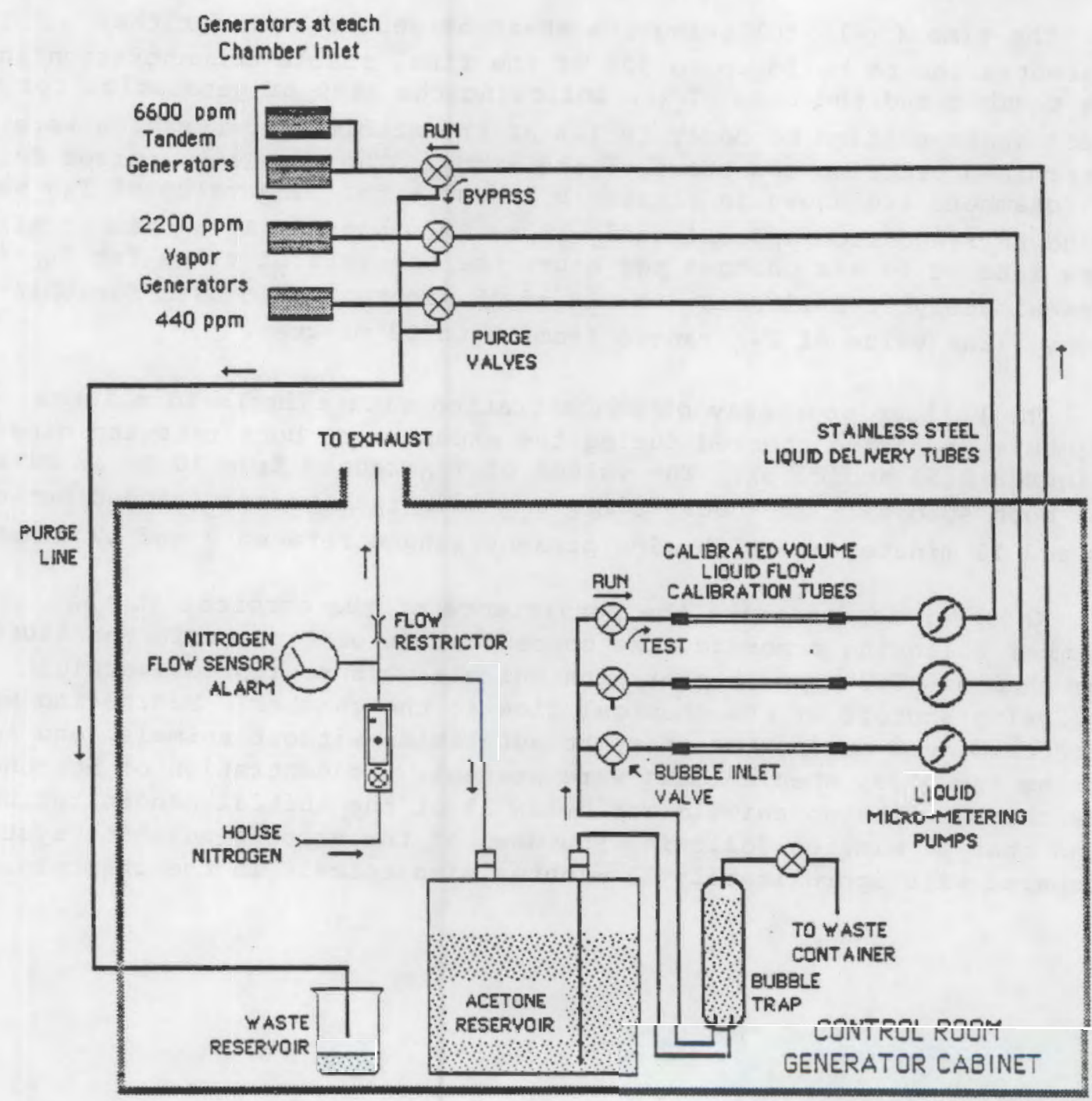

EIGURE B.4. Acetone Generation and Delivery System B. 7 
A condensation nuclei counter, Gardner Inc. type $\mathrm{CN}$, was used to check the chambers and the room for particles during generation before animals were placed in the chambers and once with rats in the chambers. No particles were found in the control chamber or any of the exposure chambers. A count of approximately 200 particles $/ \mathrm{cm}^{3}$ was found in the room during generation.

The time $\left(T_{90}\right)$, following the start of generation, for the concentration to build up to $90 \%$ of the final stable concentration in the chamber and the time $\left(T_{10}\right)$, following the stop of generation for the vapor concentration to decay to $10 \%$ of the stable concentration were determined prior to the start of the study. The resulting curves for all chambers are shown in Figures B.5a and B.5b. The value of T90 was found to range from approximately 10 to 12 minutes. At a chamber air flow rate of 15 air changes per hour, the theoretical value for $T_{90}$ is approximately 12.5 minutes. A T90 of 12 minutes was chosen for this study. The value of $\mathrm{T}_{10}$ ranged from 10 to 13 minutes.

The buildup and decay of concentration with animals in all the chambers were also checked during the exposure of both rats and mice (Eigures B.5a and B.5b). The values of $\mathrm{T}_{90}$ ranged from 10 to 12 minutes for both species. The decay time, $T_{10}$ with rats present ranged between 10 and 13 minutes and with mice present ranged between 9 and 13 minutes.

In order to determine the persistence of the chemical in the chamber following exposure, the concentration of acetone in the 11000 ppm chamber ( $6600 \mathrm{ppm}$ chamber with animals) was monitored overnight following shutoff of the chemical flow to the chamber. Monitoring was performed once during the prestart activities without animals, and again during the study when animals were present. Concentration of acetone in the chamber without animals was below 18 of the initial concentration in less than 17 minutes following shutdown of the vapor generation system compared with approximately 23 minutes with animals in the chambers. 


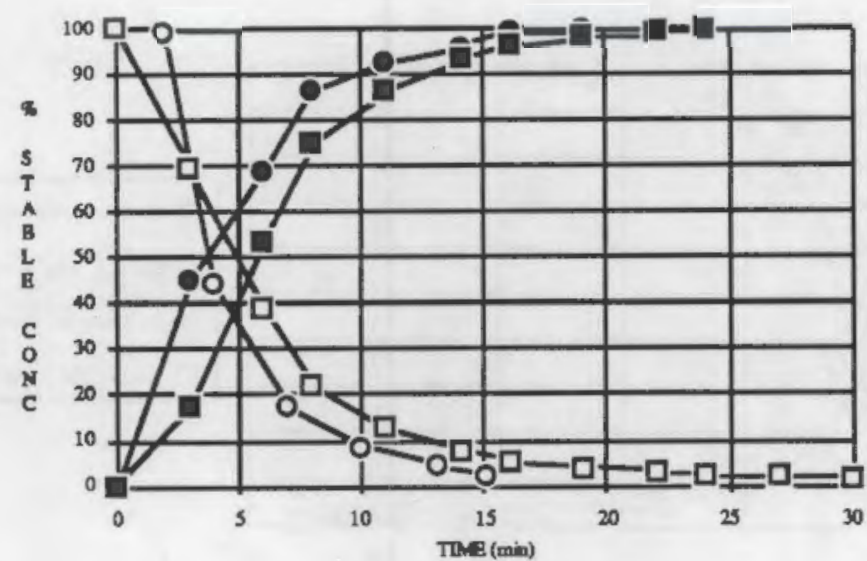

- Buildup wo Animais

O. Decay w/o Animals

D. Buildup w/ Rats

口. Decay w/ Rats

ACETONE: 2200 ppm Chamber

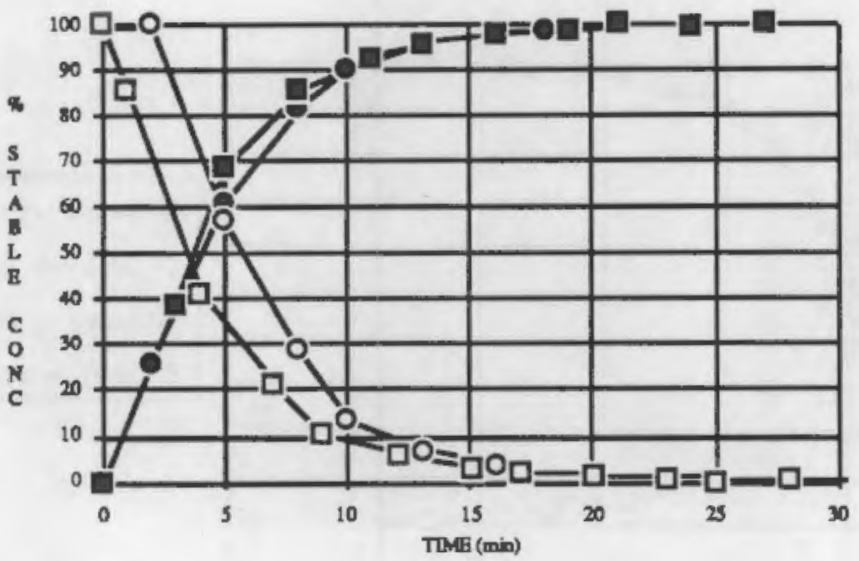

- Buildup wo Animals

O. Decay w/o Animals

D. Buildup w/ Rats

D. Decay w/ Rats

ACETONE: 11,000 ppm Chamber
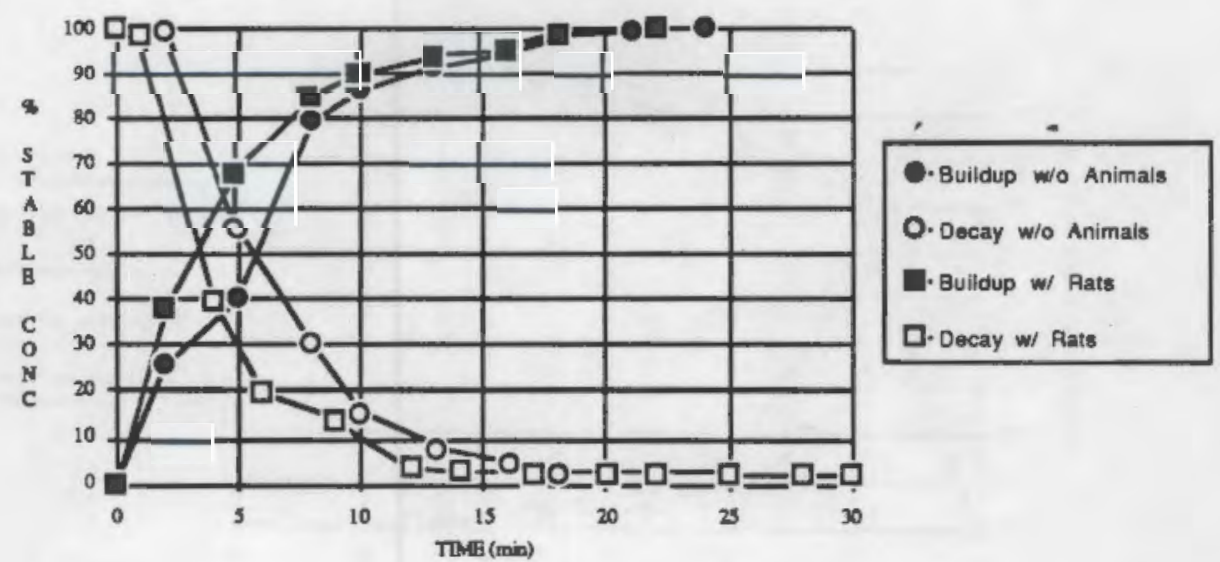

EIGURE B.5a. Buildup and Decay of Vapor Concentrations for Exposure of Rats to Acetone With and without Animals Present. 


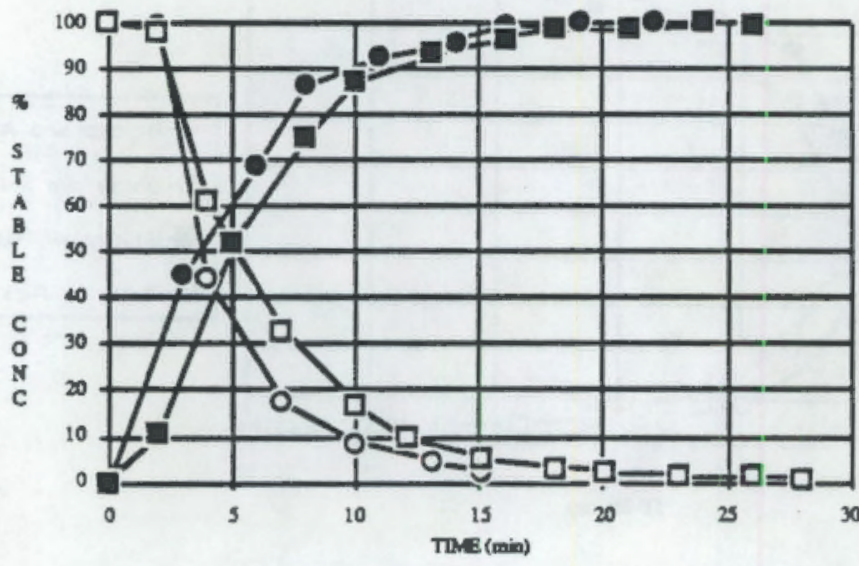

Q.Buildup wo Animais

O- Decay w/o Animais

- Buildup wice

口. Decay w/ Mice

ACETONE: 2200 ppm Chamber

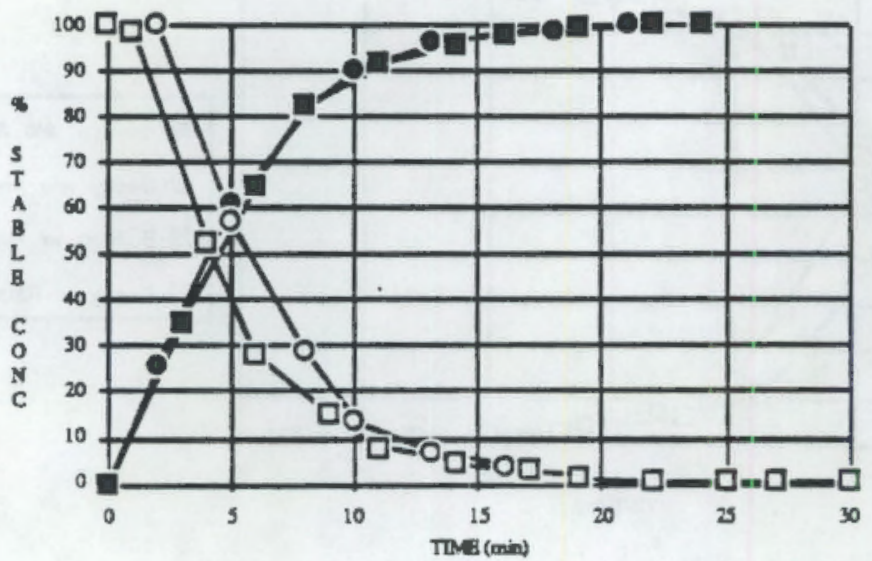

- Buildup w/o Animais

O. Decay w/o Animais

D. Buildup w/ Mice

口. Decay w/ Mice

ACETONE: 6,600 ppm Chamber*

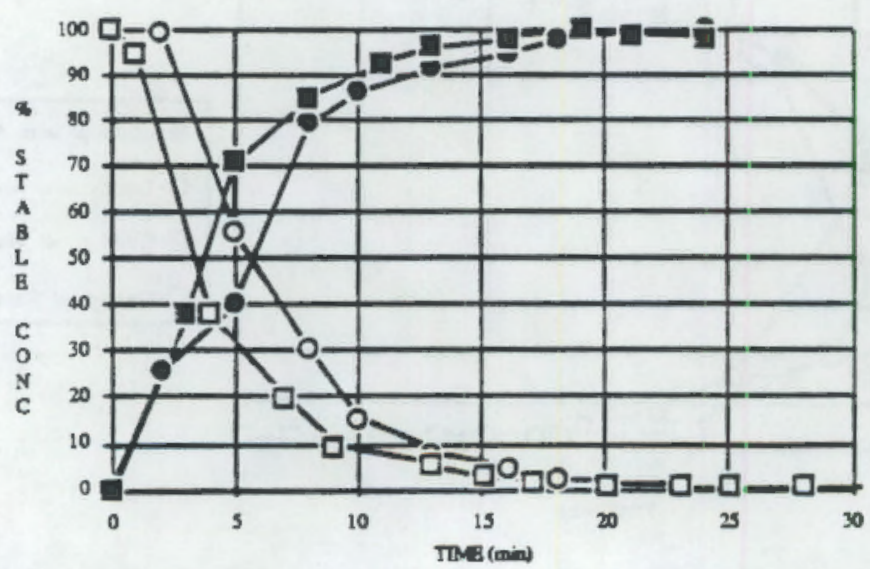

- Buildup wo Animais

O. Decay w/o Animals

D. Buildup wi Mice

口. Decay wi Mice

EIGURE B.5b. Buildup and Decay of Vapor Concentrations for Exposure of Mice to Acetone With and Without Animals present. 


\section{Vapor Concentration Uniformity in Chambers}

Uniformity of vapor concentration in the exposure chambers was measured prior to the start of and once during the study. The vapor concentration was measured using the on-line GC with the automatic 8-port sample valve disabled to allow continuous monitoring from a single input line. Prior to animal loading, 12 chamber positions (one in front and one in back, for each of the six possible animal cage unit positions per chamber) were measured. The second set of gas concentration measurements was taken from the front and back positions of the chamber only where cage units contained animals.

The sample point was just above and about $10 \mathrm{~cm}$ in from the front or back center of each cage unit. The uniformity data for each chamber during prestart testing, and after animals were in place in the chambers, are summarized in Table B.1. Complete data are found later in this Appendix. Uniformity in all chambers was found acceptable. To provide easier interpretation of the uniformity measurement results, the concentration readings in Table IV-3 for each port are expressed as a percentage of the mean value at all ports measured. The tables include analysis of Total Port Variability (TPV), Within Port Variability (WPV) and Between Port Variability (BPV), all expressed as of Relative Standard Deviation (zRSD). These terms are described in detail below. The uniformity criteria listed below were easily met for all chambers.

\section{Chamber Uniformity Limits:}

$$
\text { WPV } \leq 5 \% \text { RSD } \quad \text { BPV } \leq 5 \% \text { RSD TPV } \leq 7 \% \text { RSD }
$$

The possible variation of test chemical concentration measured from one sample port to another during the measurement procedure is termed the Total Port Variability (TPV) and consists of both spatial and temporal variations. Two factors contribute to the TPV. The first, the Between Port Variability (BPV), is the factor of interest as it represents the spatial variation of test chemical distribution within the chamber. The second factor, the within port variability (WPV), represents the temporal fluctuation of the average chemical concentration within the chamber during the time the measurements were taken. This temportal factor includes variations in vapor generation as well as variation of the measurement instrument itself.

The WPV is determined from a minimum of three measurements taken at the on-line monitor port ( $1 \mathrm{~B}$ or $2 \mathrm{~B}$ ) before, during and after all other ports are measured. The TPV is determined from measurements from, at the minimum, the front and back ports at each level on which animals are housed as well as one measurement from the on-line monitor port (whether or not animals are housed on that level). The BPV is determined by applying the following equation:

$$
\mathrm{BPV}=\sqrt{(\mathrm{TPV})^{2}-(\mathrm{WPV})^{2}}
$$


Since the WPV is often determined from fewer measurements than the TPV, statistically it is possible for the WPV to be greater than the TPV. In these cases, the BPV is very small, but it cannot be distinguished from the WPV. The BPV can't be determined using the above equation as it yields the square root of a negative number. In this case, it is reported as indistinguishable from the WPV.

IABLE B.1. Teratology Study of Acetone in Mice and Rats - Summary of Chamber Uniformity Data Obtained Before Exposure (PRE) and During Exposure (Rats and Mice).

TPV (

WPV (Rㅗ)

BPV (\%RSD)

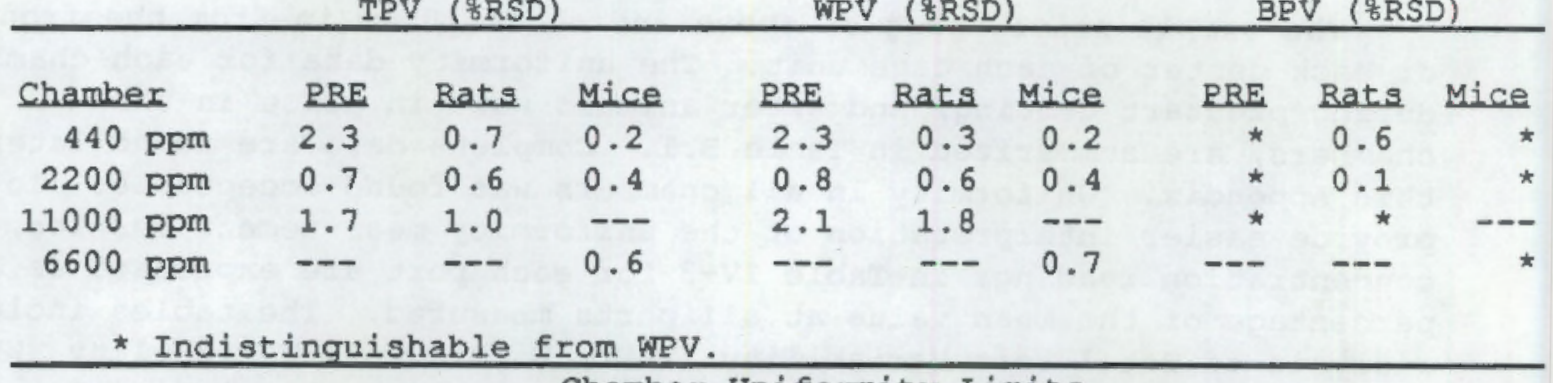

Chamber Uniformity Limits

WPV $\leq 5 \%$ RSD

BPV $\leq 5 \%$ RSD

TPV $\leq 78$ RSD 


\section{Envirenmental Data During Exposure}

Summations of chamber air flow, temperature and relative humidity data for the studies in mice and rats are shown in Tables B2 and B3. These tables include the mean, standard deviation, mean expressed as a percentage of the target, the percent relative standard deviation (SD/Mean), maximum, minimum readings, number of readings and the percent of readings for which the value was within the specified operating range.

For the mouse study (Table B.2), the mean values of temperature in all chambers for the entire study were between 73.8 and $75.7^{\circ} \mathrm{F}$, all within the specified limits of 72 to $78^{\circ} \mathrm{F}$. Temperature extremes ranged from 71.6 to $77.3^{\circ} \mathrm{E}$. The percent of temperature readings within the operating range for all chambers were greater than 978 .

The mean values of relative humidity in all chambers for the mouse study were between 51.7 and $55.1 \%$, all within the specified limits of 40 to $70 \%$. Relative humidity extremes (considering all chambers) ranged from 40 to $64 \%$. All readings were within the operating range.

The mean values of chamber air flow in all chambers for the mouse study were between 15.1 and $16.0 \mathrm{CFM}$ ( $1 \mathrm{CFM}=1$ air change per hour), all within the specified limits of 12 to 18 CFM. Flow extremes (considering all chambers) ranged from 13.9 to $17.0 \mathrm{CFM}$; all readings were within normal operating limits.

For the rat study (Table B.3), the mean values of temperature in all chambers for the entire study were between 74.2 and $75.7^{\circ} \mathrm{F}$, all within the specified limits of 72 to $78^{\circ} \mathrm{F}$. Temperature extremes ranged from 70.2 to $78.2^{\circ} \mathrm{F}$. The percent of temperature readings within the operating range for all chambers were greater than $90 \%$.

The mean values of relative humidity in all chambers for the rat study were between 54.4 and $57.1 \%$, all within the specified limits of 40 to 708 . Relative humidity extremes (considering all chambers) ranged from 36 to $79 \%$. All chambers were above the $90 \%$ target for readings within operating range.

The mean values of chamber air flow in all chambers for the rat study were between 14.4 and 15.4 CFM ( 1 CFM = 1 air change per hour), all within the specified limits of 12 to 18 CFM. Air flow extremes (considering all chambers) ranged from 12.8 to $17.5 \mathrm{CFM}$; all readings were within normal operating limits.

A complete sumary of the daily chamber environmental data and notations on any readings which exceeded critical limits is included in this appendix. 
TABLE B.2. Inhalation Teratology Study of Acetone in Mice-Summation of Environmental Data for the Period when Animals were Housed in the Exposure Chambers. Acceptable ranges are also shown.

\begin{tabular}{|c|c|c|c|c|c|c|}
\hline $\begin{array}{l}\text { Target Chamber } \\
\text { conc. (00m) }\end{array}$ & Mean \pm SD & $\begin{array}{l}\text { Percent of } \\
\text { Target } \pm \text { t RSD }\end{array}$ & Maximun & Minimum & $\begin{array}{l}\text { Number of } \\
\text { Samples }\end{array}$ & $\begin{array}{l}\text { \% Sample } \\
\text { in Bane }\end{array}$ \\
\hline 0 & $74.9 \pm 0.7$ & $100 \pm 1$ t & 76.6 & 73.2 & 128 & 100 \\
\hline Hold & $75.0 \pm 0.8$ & $100 \pm 1$ * & 76.2 & 73.3 & 71 & 100 \\
\hline 440 & $74.2 \pm 0.6$ & $99 \pm 1$ 8 & 75.4 & 72.3 & 128 & 100 \\
\hline 2200 & $73.8 \pm 0.7$ & $98 \pm 1$ t & 75.0 & 71.6 & 128 & 98 \\
\hline 11000 & $75.7 \pm 0.9$ & $101 \pm 1$ 항 & 77.3 & 72.9 & 128 & 100 \\
\hline
\end{tabular}

Relative Humidity (\% RH) Acceptable Range $=40$ to $70 \% \mathrm{RH}$

Target Chamber cenc. (pom)

0

Hold

440

2200

11000

\begin{tabular}{cc} 
Maximum & Minimum \\
\hline 61 & 42 \\
62 & 47 \\
62 & 45 \\
61 & 45 \\
64 & 40
\end{tabular}

Air Flow (Cry)

Target Chamber conc. (opml

0

Hold

440

2200

11000

Mean $\pm S D$
$51.7 \pm 4.6$
$55.1 \pm 3.7$
$54.4 \pm 4.0$
$53.6 \pm 4.4$
$52.8 \pm 5.5$

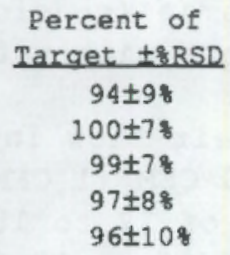

\begin{tabular}{cc} 
Maximum & Minimum \\
\cline { 2 - 2 } 15.3 & 15.0 \\
15.9 & 14.7 \\
16.9 & 13.9 \\
16.3 & 15.3 \\
17.0 & 15.2
\end{tabular}

\begin{tabular}{|c|c|}
\hline $\begin{array}{l}\text { Number of } \\
\text { Samples }\end{array}$ & $\begin{array}{l}\text { * Samples } \\
\text { in Bange }\end{array}$ \\
\hline 128 & 100 \\
\hline 57 & 100 \\
\hline 128 & 100 \\
\hline 128 & 100 \\
\hline 128 & 100 \\
\hline
\end{tabular}

Number of 8 Samples Sameles in Bange 100 100 100 100 100 
TABLE B.3. Inhalation Teratology Study of Acetone in Rats-Summation of Environmental Data for the Period when Animals were Housed in the Exposure Chambers. Acceptable ranges are also shown.

\begin{tabular}{|c|c|c|c|c|c|c|}
\hline $\begin{array}{l}\text { Target Chamber } \\
\text { cone. (opm) }\end{array}$ & Mean \pm SD & $\begin{array}{l}\text { Percent of } \\
\text { Target } \pm \text { RSD }\end{array}$ & Maximum & Minimum & $\begin{array}{l}\text { Number of } \\
\text { Samoles }\end{array}$ & $\begin{array}{l}\text { of Samples } \\
\text { In Bange }\end{array}$ \\
\hline 0 & $75.2 \pm 1.3$ & $100 \pm 28$ & 78.2 & 72.1 & 161 & 99 \\
\hline Hold & $74.2 \pm 1.6$ & $99 \pm 28$ & 78.0 & 71.4 & 53 & 91 \\
\hline 440 & $74.3 \pm 1.0$ & $99 \pm 1 \%$ & 77.1 & 70.7 & 138 & 99 \\
\hline 2200 & $75.3 \pm 1.5$ & $100 \pm 2 z$ & 77.8 & 70.2 & 138 & 99 \\
\hline 11000 & $75.7 \pm 1.4$ & $101 \pm 28$ & 78.1 & 70.5 & 138 & 99 \\
\hline
\end{tabular}

Relative Humidity (\% RH) Acceptable Range $=40$ to 70 sRH

Target Chamber cenc. corml.

$\begin{array}{ll}0 & 54.8 \pm 7.2 \\ \text { Hold } & 56.7 \pm 4.7 \\ 440 & 57.1 \pm 7.0 \\ 2200 & 54.6 \pm 4.8 \\ 11000 & 54.4 \pm 4.5\end{array}$

\begin{tabular}{l} 
Percent of \\
Target \pm 8 SD \\
\hline $100 \pm 13 t$ \\
$103 \pm 8 \%$ \\
$104 \pm 128$ \\
$99 \pm 98$ \\
$99 \pm 8 \%$
\end{tabular}

\begin{tabular}{l} 
Maximum \\
\hline 79 \\
65 \\
75 \\
70 \\
68
\end{tabular}

西

Minimum

45

47

37

36

38
Al工 Flow (CEM)

Acceptable Range $=12$ to $18 \mathrm{CFM}$

Target Chamber conc.enem) 0

Hold

440

2200

11000
Mean $\pm S D$

$14.9 \pm 0.1$

$14.4 \pm 0.1$

$15.4 \pm 1.0$

$15.1 \pm 0.1$

$15.4 \pm 0.1$

\begin{tabular}{c} 
Percent of \\
Target \pm RSD \\
\hline $99 \pm 0 \%$ \\
$96 \pm 0$ : \\
$103 \pm 7$ \\
$100 \pm 1 \%$ \\
$103 \pm 1 \%$
\end{tabular}

$\begin{array}{cc}\text { Maximum } & \text { Minimum } \\ 15.0 & 14.5 \\ 14.5 & 14.1 \\ 17.5 & 12.8 \\ 15.2 & 14.5 \\ 15.6 & 15.0\end{array}$

\begin{tabular}{cc} 
Number of & Samples \\
Samples & in Range \\
\hline 163 & 96 \\
54 & 100 \\
140 & 95 \\
140 & 98 \\
139 & 99
\end{tabular}

\begin{tabular}{|c|c|}
\hline $\begin{array}{l}\text { Number of } \\
\text { Samoles }\end{array}$ & $\begin{array}{l}\text { \% Samples } \\
\text { in Bange }\end{array}$ \\
\hline 156 & 100 \\
\hline 51 & 100 \\
\hline 135 & 100 \\
\hline 133 & 100 \\
\hline 133 & 100 \\
\hline
\end{tabular}




\section{Exposure Data}

Summaries of the concentration data for both the mouse and rat studies for all chambers and the exposure room are included in Tables B.4 and B.5. Summaries of concentration by exposure day follow in this Appendix along with graphic illustrations of the daily mean and standard deviation for each chamber. Note that the target concentration was reduced to $6600 \mathrm{ppm}$ from $11000 \mathrm{ppm}$ for the mice high dose chamber after 1 day of exposure. To maintain consistency within the data analysis program, however, the notations describing the high dose chamber were kept at $11000 \mathrm{ppm}$ in the tables and graphs.

For the mouse study (Table B.4), the grand means of the concentrations in each chamber for the entire study were between 99 and $101 \%$ of the target, with relative standard deviations in the range of 3 to 8 옥. Except for the last day of exposure, the daily mean concentrations ranged from 96 to $102 \%$ of target (the protocol required the daily means to be within $\pm 10 \%$ of the target concentrations) and 8 RSD's were less than $10 \%$. On the last day, one of the generators for the high dose chamber failed. When discovered, the exposure was discontinued after 5 hours and 9 minutes. At least 988 of individual concentration measurements at each target level were within $\pm 10 \%$ of the target levels, the specified operating limits. The maximum concentration observed in the control chamber was $3.8 \mathrm{ppm}$ and $0.1 \mathrm{ppm}$ in the hold chamber. The maximum concentration observed in the room was $16.6 \mathrm{ppm}$. The high readings were apparently a result of opening a chamber before the concentration level had decayed following shutdown. The next highest readings during the study were $0.3 \mathrm{ppm}$ in the room and $0.15 \mathrm{ppm}$ in the control chamber. Carryover of acetone in the sample lines had been observed, resulting in most of these small residual readings .

For the rat study (Table B.5), the grand means of concentrations in all chambers for the entire study were $100 \%$ of the target, with relative standard deviations in the range of 1 to $6 \%$. The daily mean concentrations for all chambers were between 95 and $102 \%$ of the target concentrations (the daily protocol required the daily means to be within \pm 10 용 of the target concentrations). At least $97 \%$ of individual

concentration measurements at each target level were within \pm 10 \% of the target levels, the specified operating limits. Except for 1 day, the sRSD's were less than $10 \%$. The maximum concentration in the control chamber was $0.26 \mathrm{ppm}$ and in the holding chamber, $0.34 \mathrm{ppm}$. Again, carryover in the sample lines gave readings of the same level. The maximum concentration observed in the room was $1.06 \mathrm{ppm}$.

A complete discussion of all concentration excursions is included in this appendix. 


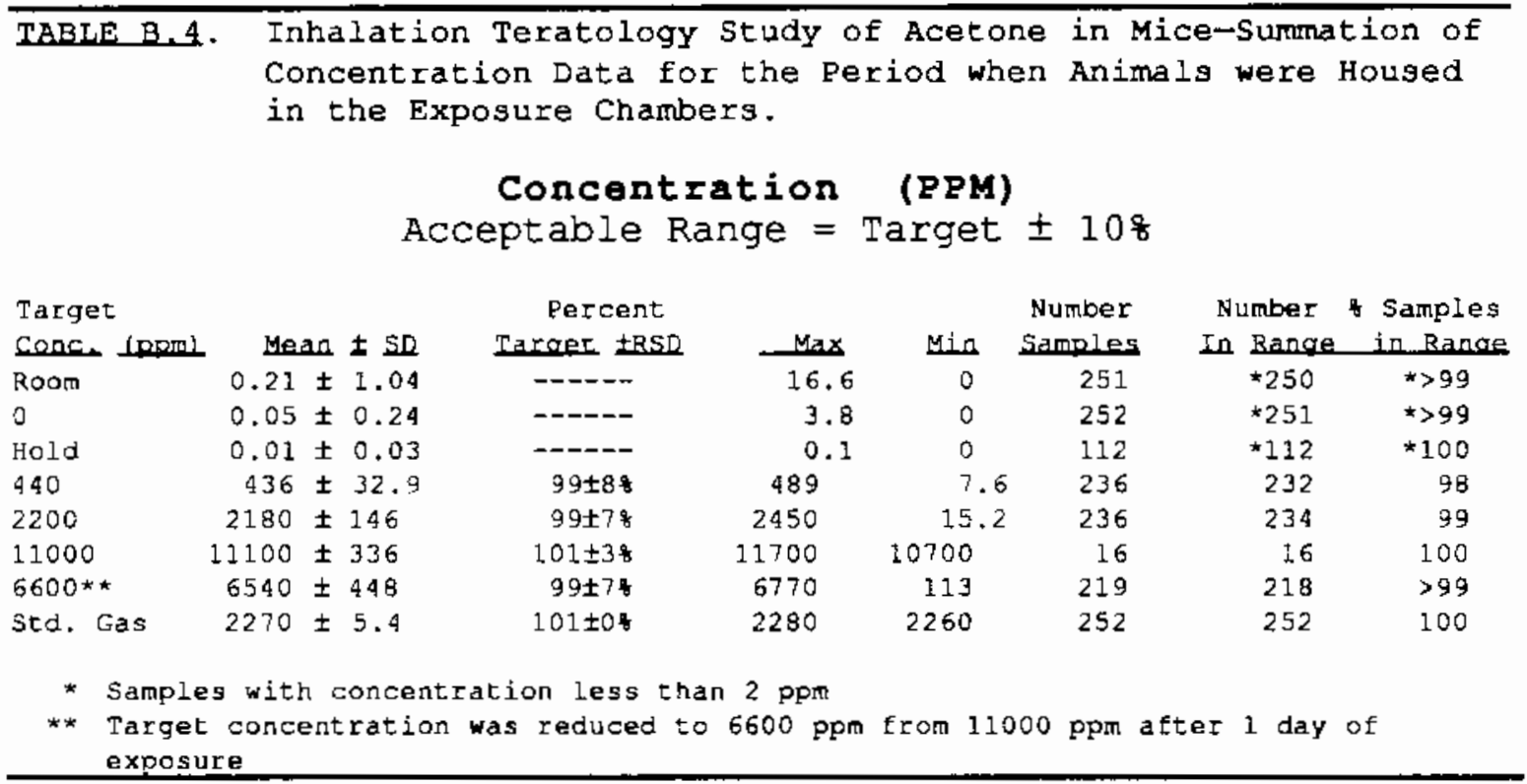

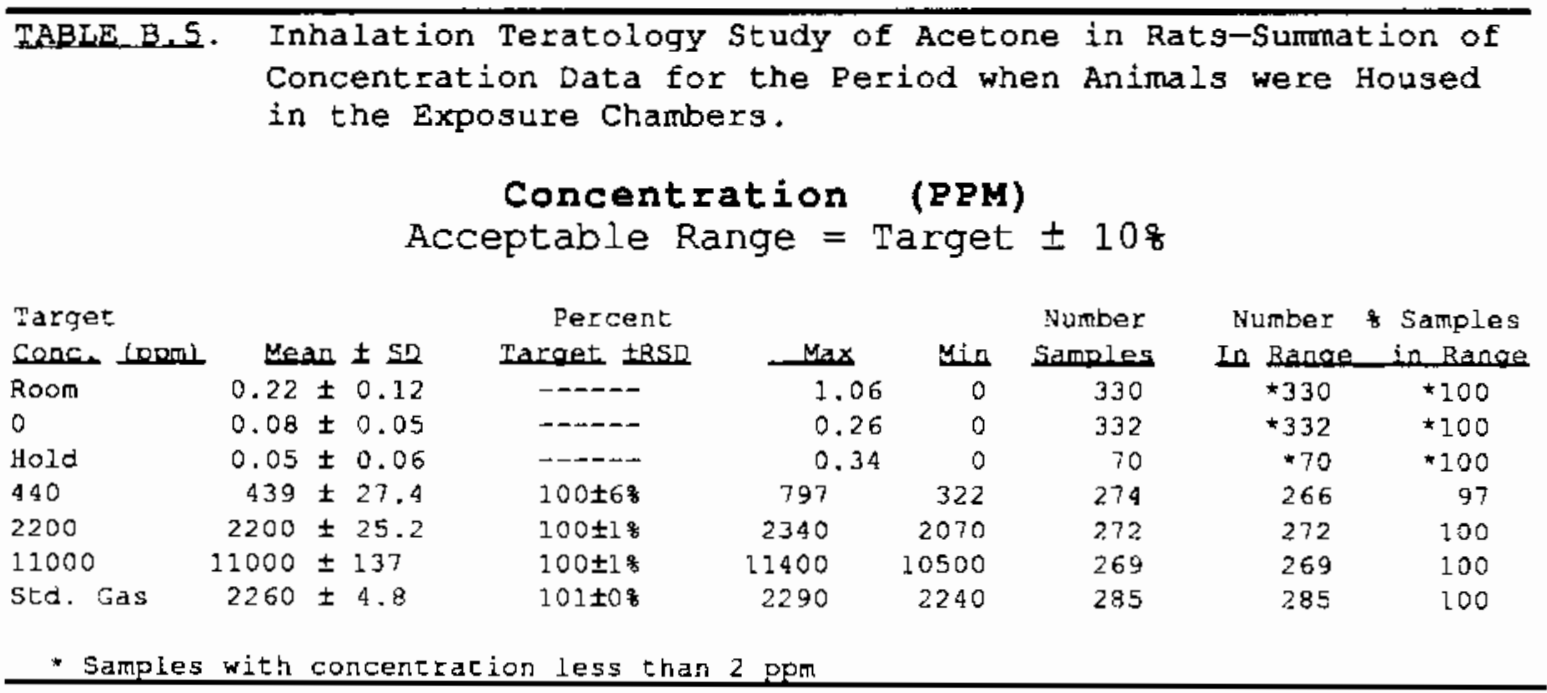


Qaily Summation For Acetone- IRT (Rats) From 26 Oct 1987 through 12 Nov 1987

\begin{tabular}{|c|c|c|c|c|c|c|c|c|c|}
\hline Summary Data & for: Acet & & Room/Conce & ration & & & & $0.00 E$ & to $2.00 \mathrm{E}$ \\
\hline Date & Mean. & $y$ Target & Std Oev & $\%$ RSD & Maximum & Minimum & $\mathrm{N}$ & $N$ in & $\% N$ in \\
\hline 26 oct 1987 & $2.52 \mathrm{E}-1$ & $25 \%$ & $1.476 E-2$ & $6 \%$ & $2.76 \mathrm{E}-1$ & $2.26 \mathrm{E}-1$ & 16. & 16. & $100 \%$ \\
\hline 27 oct 1987 & $2.63 \mathrm{E}-1$ & $26 \%$ & $2.763 \mathrm{E}-2$ & $10 \%$ & $2.95 \mathrm{E}-1$ & $1.77 £-1$ & 17. & 17. & $i 00 \%$ \\
\hline 28 oct 1987 & $3.10 \mathrm{E}-1$ & $31 \%$ & $6.057 \mathrm{E}-2$ & $20 \%$ & $4.26 \varepsilon-1$ & $2.30 E-1$ & 14. & 14. & $100 \%$ \\
\hline 29 oct 1987 & $2.26 E-1$ & $23 \%$ & $5.545 \mathrm{E}-2$ & $25 \%$ & 3. $02 \mathrm{E}-1$ & $1.03 E-1$ & 17. & 17. & $100 \%$ \\
\hline 30 oct 1987 & 1. $08 E-1$ & $11 \%$ & 1. $898 \mathrm{E}-1$ & $176 \%$ & 1. $.06 \mathrm{E}+0$ & $0.00 \equiv+0$ & 54. & 54. & $100 \%$ \\
\hline 31 oct 1987 & 1. $63 \mathrm{E}-1$ & $16 \%$ & $1.451 \mathrm{E}-1$ & $89 \%$ & $3.63 E-1$ & $0.00 \Xi+0$ & 18. & 18. & $100 \%$ \\
\hline 1 Nov 1987 & $3.15 E-1$ & $31 \%$ & $3.040 \mathrm{E}-2$ & $10 \%$ & $3.59 E-1$ & $2.72 \xi-1$ & 15. & 15. & $100 \%$ \\
\hline 2 Nov 1987 & $2.82 E-1$ & $28 \%$ & $4.979 E-2$ & $18 \%$ & $3.65 \mathrm{E}-1$ & $2.15 E-1$ & 15. & 15. & $100 \%$ \\
\hline 3 Nov 1987 & $2.45 \mathrm{E}-1$ & $24 \%$ & $3.304 \mathrm{E}-2$ & $13 \%$ & $3.02 \mathrm{E}-1$ & 1. $56 \mathrm{E}-1$ & 15. & 15. & $100 \%$ \\
\hline 4 Nov 1987 & $2.47 \mathrm{E}-1$ & $25 \%$ & $3.591 E-2$ & $15 \%$ & $3.12 E-1$ & $2.00 \mathrm{E}-1$ & 15. & 15. & $100 x$ \\
\hline 5 Nov 1987 & $2.41 E-1$ & $24 \%$ & $4.657 E-2$ & $19 \%$ & $2.81 E-1$ & $9.71 E-2$ & 16. & 16. & $100 \%$ \\
\hline 6 Nov 1987 & $2.39 E-1$ & $24 \%$ & $3.459 E-2$ & $14 \%$ & $3.38 \mathrm{E}-1$ & $1.75 t^{\circ}-1$ & 17. & 17. & $100 \%$ \\
\hline 7 Hov 1987 & $2.13 \mathrm{E}-1$ & $21 \%$ & $5.843 \mathrm{E}-2$ & $27 \%$ & $2.53 \mathrm{E}-1$ & $0.00 \mathrm{E}+0$ & 18. & 18. & $100 \%$ \\
\hline 8 Nov 1987 & $2.26 \mathrm{E}-1$ & $23 \%$ & $2.968 \varepsilon-2$ & $13 \%$ & $2.66 \varepsilon-1$ & 1. $43 \mathrm{E}-1$ & 17. & 17. & $100 \%$ \\
\hline 9 Nov 1987 & $2.22 \mathrm{E}-\mathrm{I}$ & $22 \%$ & $4.714 \mathrm{E}-2$ & $21 \%$ & $2.91 E-1$ & $9.71 E-2$ & 17. & 17 . & $100 \%$ \\
\hline 10 Nov 1987 & $2.37 \varepsilon-1$ & $24 \%$ & $4.832 E-2$ & $20 \%$ & $2.89 \mathrm{E}=1$ & $9.50 \mathrm{E}-2$ & 17. & 17. & $100 \%$ \\
\hline 11 Nov 1987 & $2.26 \mathrm{E}-1$ & $23 \%$ & $3.528 \mathrm{E}-2$ & $16 \%$ & $2.60 \mathrm{E}-1$ & $1.16 \mathrm{E}-1$ & 17 . & 17. & $100 \%$ \\
\hline 12 Nov 1987 & $2.84 \mathrm{E}-1$ & $28 \%$ & $1,988 \mathrm{E}-1$ & $70 \%$ & $9.96 E-1$ & $1.92 E-1$ & 15. & 15. & $100 \%$ \\
\hline Summary & $2.22 E-1$ & $22 \%$ & $1.159 E-1$ & $52 \%$ & $1.06 \mathrm{E}+0$ & $0.00 \mathrm{E}+0$ & 330. & 330. & $100 \%$ \\
\hline
\end{tabular}

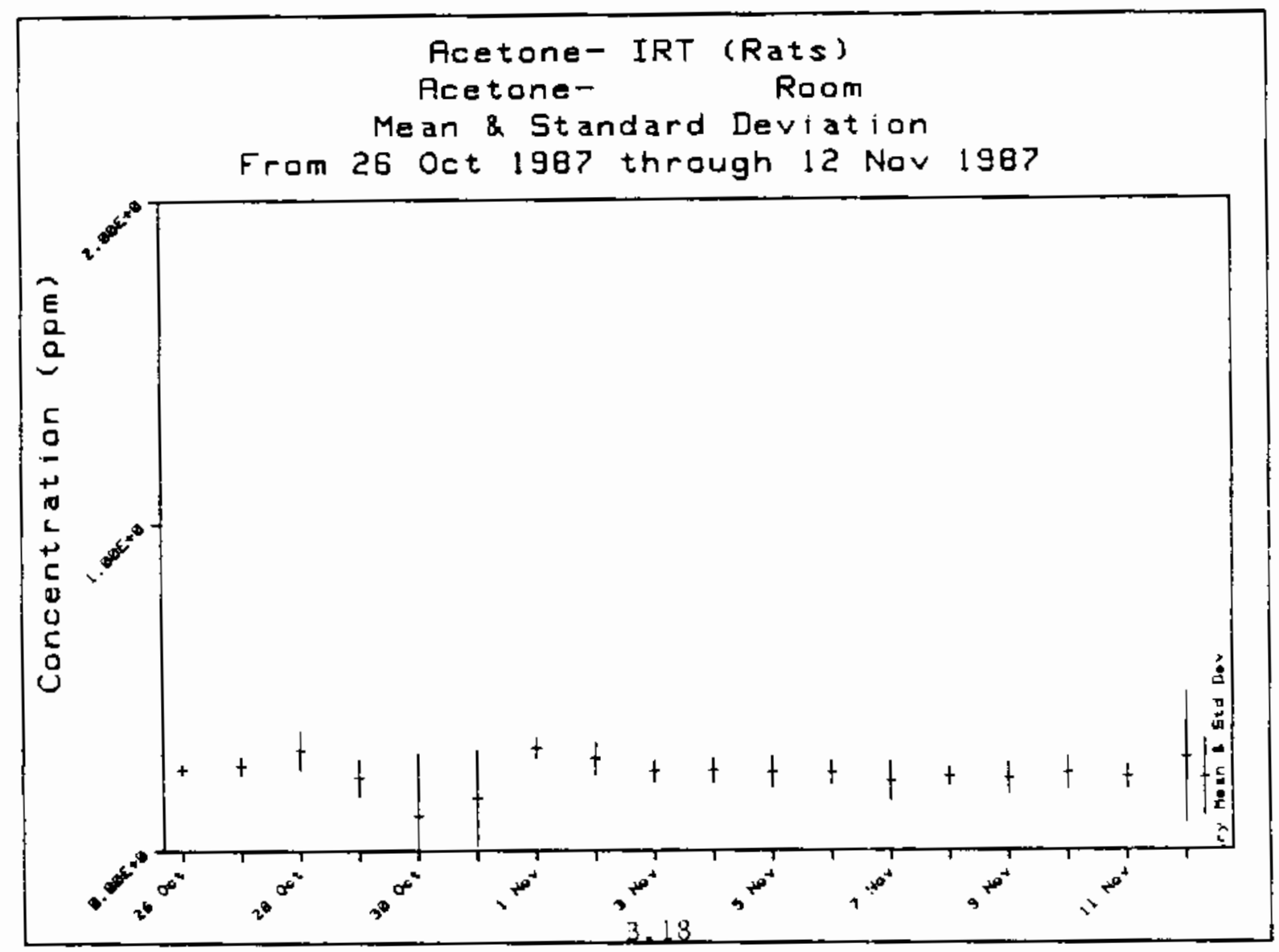


Daily Sumation For Acetone- IRT (Rats) From 26 Oct 1987 through 12 Nov 1987

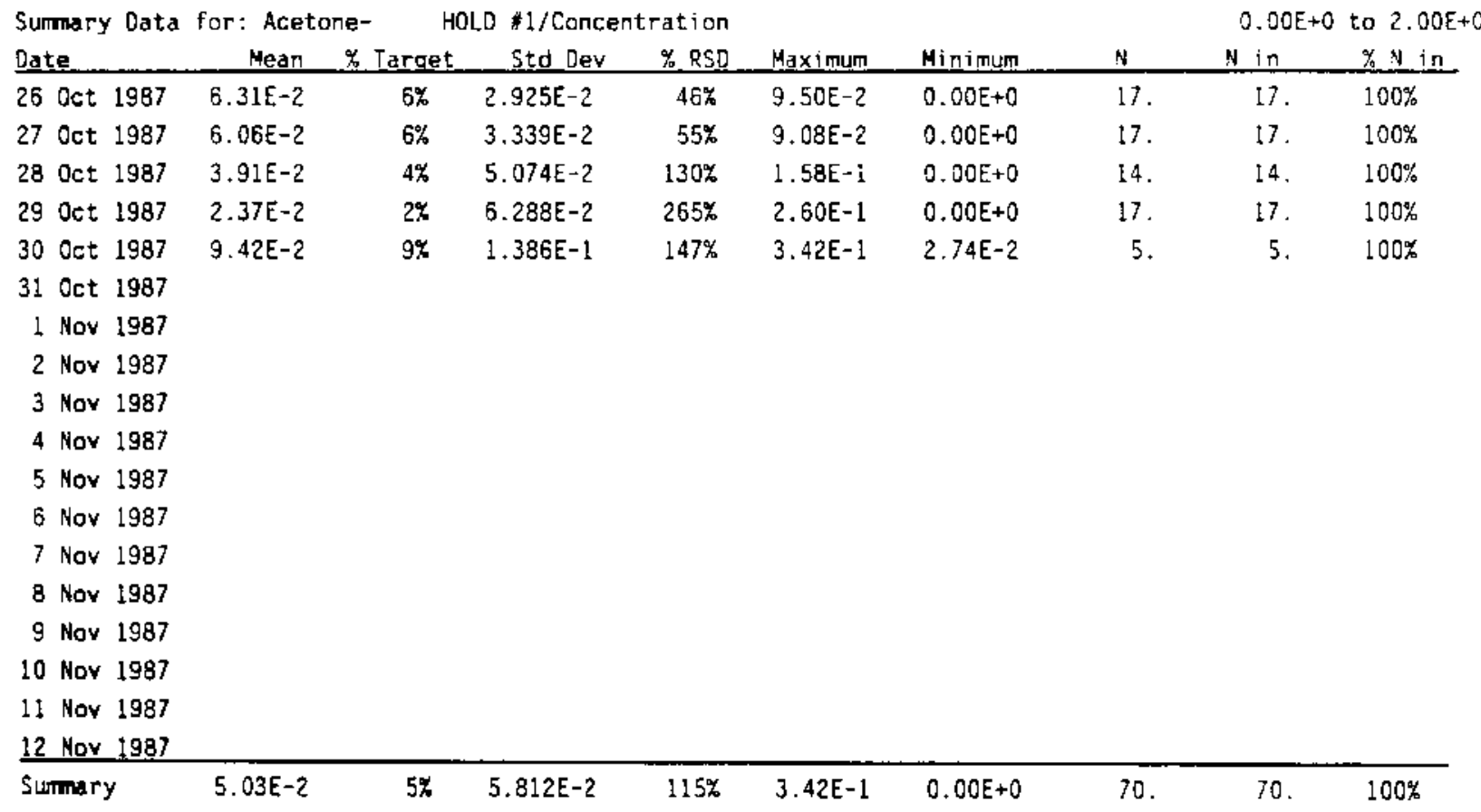

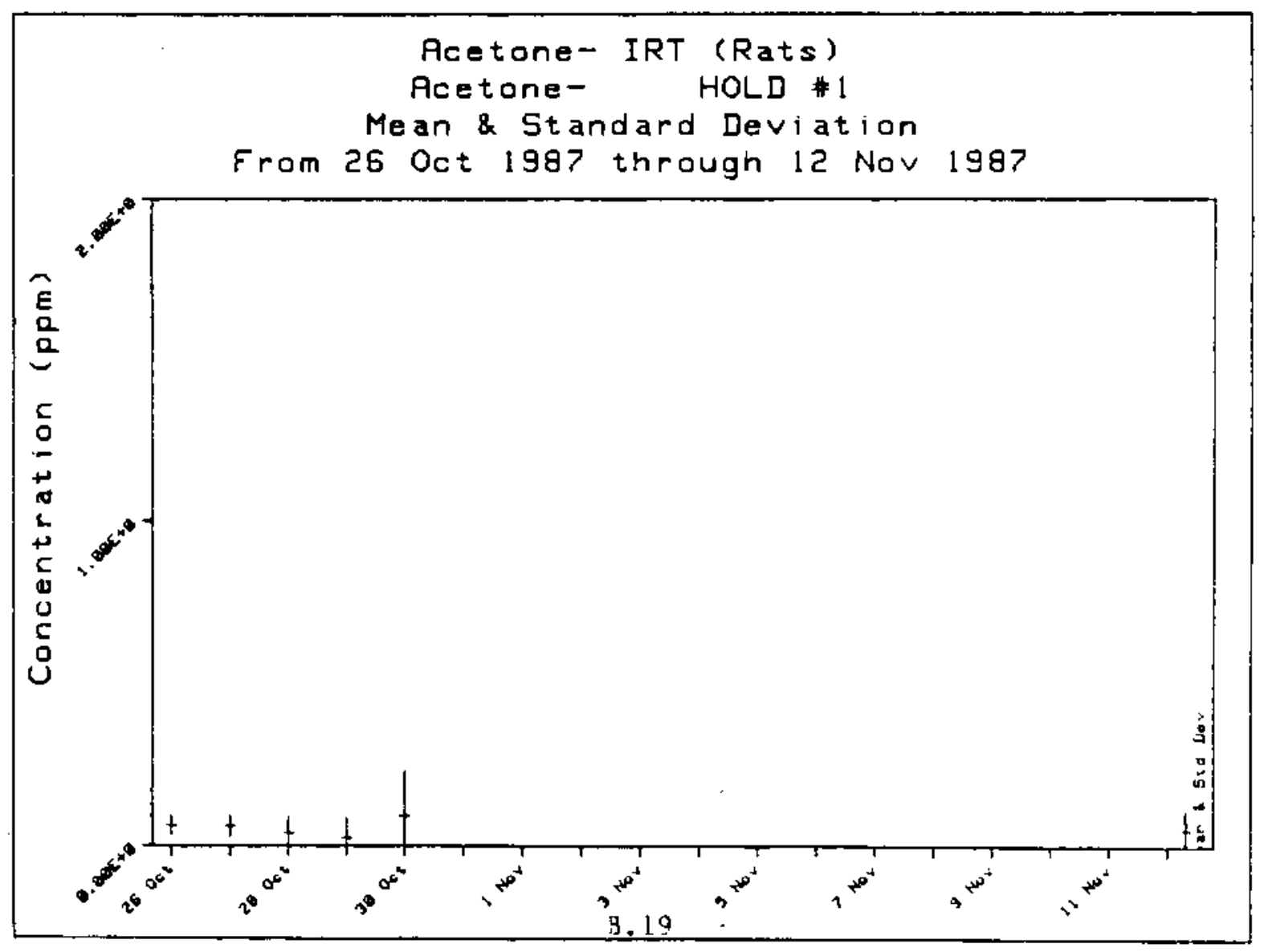


Daily Sumation For Acetone- IRT (Rats) From 26 Oct 1987 througr 12. Nov 1987

\begin{tabular}{|c|c|c|c|c|c|c|c|c|c|}
\hline \multicolumn{3}{|c|}{ Sumary Data for: Acetone- } & \multicolumn{2}{|c|}{$0 \mathrm{ppm} /$ Concentration } & \multirow[b]{2}{*}{ Maximum } & \multirow[b]{2}{*}{ Minimum } & \multicolumn{3}{|c|}{$0.00 \mathrm{E}+0$ to $2.00 \mathrm{E}$} \\
\hline Date & Mean & $\%$ Tarqet & Std Dev & $\%$ RSD & & & $\mathrm{N}$ & $\mathrm{N}$ in & $\% \mathbb{N}$ i \\
\hline 26 oct 1987 & $1.31 \mathrm{E}-1$ & $13 \%$ & $3.611 E-2$ & $28 x$ & $1.67 \mathrm{E}-1$ & $0.00 E+0$ & 17 & 17. & $100 \%$ \\
\hline 27 oct 1987 & $1.37 \mathrm{E}-1$ & $14 \%$ & $1.857 \mathrm{E}-2$ & $.14 x$ & 1. $60 \mathrm{E}-1$ & 8. $87 \mathrm{E}-2$ & 17 & 17. & $100 \%$ \\
\hline 28 Det 1987 & $1.41 E-1$ & $14 \%$ & $4.618 \mathrm{E}-2$ & $33 \%$ & $2.57 \mathrm{E}-1$ & $5.70 \mathrm{E}-2$ & I4. & 14. & $100 \%$ \\
\hline 29 oct 1987 & $1.16 \mathrm{E}-1$ & $12 \%$ & $3.551 E-2$ & $31 x$ & 1. $67 \mathrm{E}-1$ & $0.00 \mathrm{E}+0$ & 17 & 17. & $100 \%$ \\
\hline 30 oct 1987 & $3.10 \mathrm{E}-2$ & $3 \%$ & 4. $697 \mathrm{E}-2$ & $151 x$ & $1.18 E-1$ & $0.00 \mathrm{E}+0$ & 54 & 54. & $100 \%$ \\
\hline 31 0ct 1987 & $3.29 E-2$ & $3 \%$ & $4.474 \mathrm{E}-2$ & $136 \%$ & 1. $.06 \mathrm{E}-1$ & $0.00 E+0$ & 19 & 19. & $100 \%$ \\
\hline I Nov 1987 & $1.09 \mathrm{E}-1$ & $11 \%$ & $1.356 \mathrm{E}-2$ & $12 \%$ & $1.48 \mathrm{E}-1$ & $9.29 \mathrm{E}-2$ & 15. & 15. & $100 \%$ \\
\hline 2 Nov 1987 & $8.91 \mathrm{E}-2$ & $9 \%$ & $2.713 \mathrm{E}-2$ & $30 x$ & $1.10 \mathrm{E}-1$ & $0.00 \mathrm{E}+0$ & 15. & 15. & $100 \%$ \\
\hline 3 Nov 1987 & $8.47 E-2$ & $8 \%$ & $2.620 \mathrm{E}-2$ & $31 \%$ & $1.08 \mathrm{E}-1$ & $0.00 \mathrm{E}+0$ & 15. & 15. & $100 \%$ \\
\hline 4 Hov 1987 & $8.77 E-2$ & $9 \%$ & $2.779 \mathrm{E}-2$ & $32 \%$ & $1.12 \mathrm{E}-1$ & $0.00 \mathrm{E}+0$ & 15. & 15. & $100 \%$ \\
\hline 5 Nov 1987 & $7.71 E-2$ & $8 \%$ & $3.430 \mathrm{E}-2$ & $45 \%$ & $1.12 \mathrm{E}-1$ & $0.00 \mathrm{E}+0$ & 16. & 16. & $100 \%$ \\
\hline 6 Nov 1987 & $7.96 E-2$ & $8 \%$ & $2.744 \mathrm{E}-2$ & $34 \%$ & $1.01 E-1$ & $0.00 \mathrm{E}+0$ & 17 & 17 . & $100 \%$ \\
\hline 7 Nov 1987 & $5.20 \mathrm{E}-2$ & $6 \%$ & $4.023 E-2$ & $65 \%$ & $1.03 \mathrm{E}-1$ & $0.00 E+0$ & 18. & 18. & $100 \%$ \\
\hline 8 Nov 1987 & $7,31 \mathrm{E}-2$ & $7 \%$ & $3.105 E-2$ & $42 \%$ & $9.92 E-2$ & $0.00 E+0$ & 17 & 17. & $100 \%$ \\
\hline 9 Nov 1987 & $6.56 \mathrm{E}-2$ & $7 \%$ & $3.500 E=2$ & $53 \%$ & $9.71 E-2$ & $0.00 E+0$ & 17 & 17. & $100 \%$ \\
\hline 10 Nov 1987 & $7.18 \mathrm{E}-2$ & $7 \%$ & $3.515 E-2$ & $49 \%$ & $1.01 \mathrm{E}-1$ & $0.00 \mathrm{E}+0$ & 17 & 17. & $100 \%$ \\
\hline 11 Nov 1987 & $7.12 \mathrm{E}-2$ & $7 \%$ & $2.732 E-2$ & $38 x$ & $8.65 E-2$ & $0.00 \mathrm{E}+0$ & 17. & 17. & $100 \%$ \\
\hline 12 Nov 1987 & $7.61 \mathrm{E}-2$ & $8 x$ & 1.399E-2 & $18 \%$ & $9.71 \mathrm{E}-2$ & $4.64 \mathrm{E}-2$ & 15 & 15. & $100 \%$ \\
\hline Surmary & $7.83 \mathrm{E}-2$ & $8 \%$ & $4.794 \mathrm{E}-2$ & $61 \%$ & $2.57 \mathrm{E}-1$ & $0.00 \mathrm{E}+0$ & 332. & 332. & $100 \%$ \\
\hline
\end{tabular}

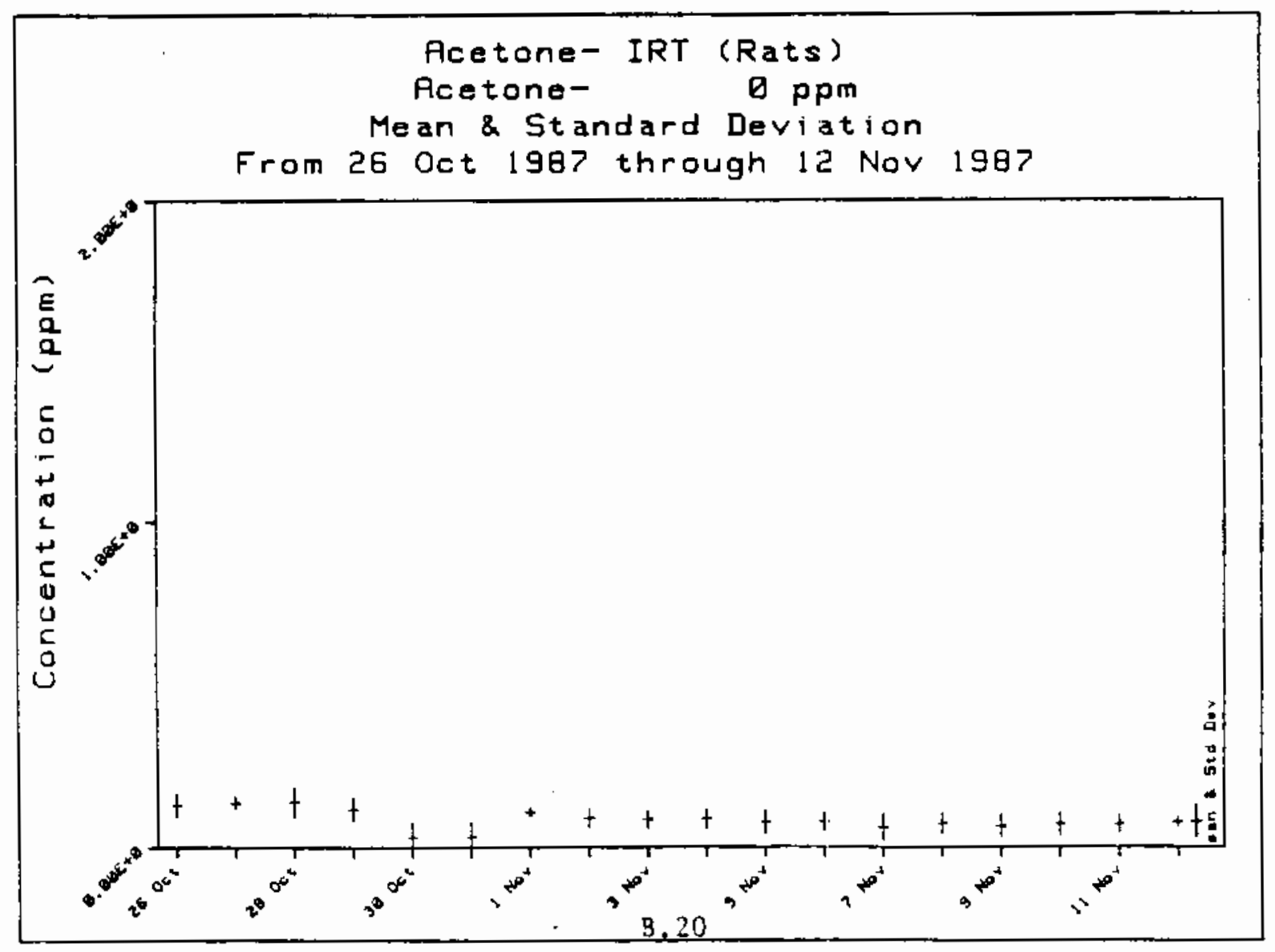


Daily Summation For Acetone- IRT (Rats) From 26 Oct 1987 through 12 Nov 1987

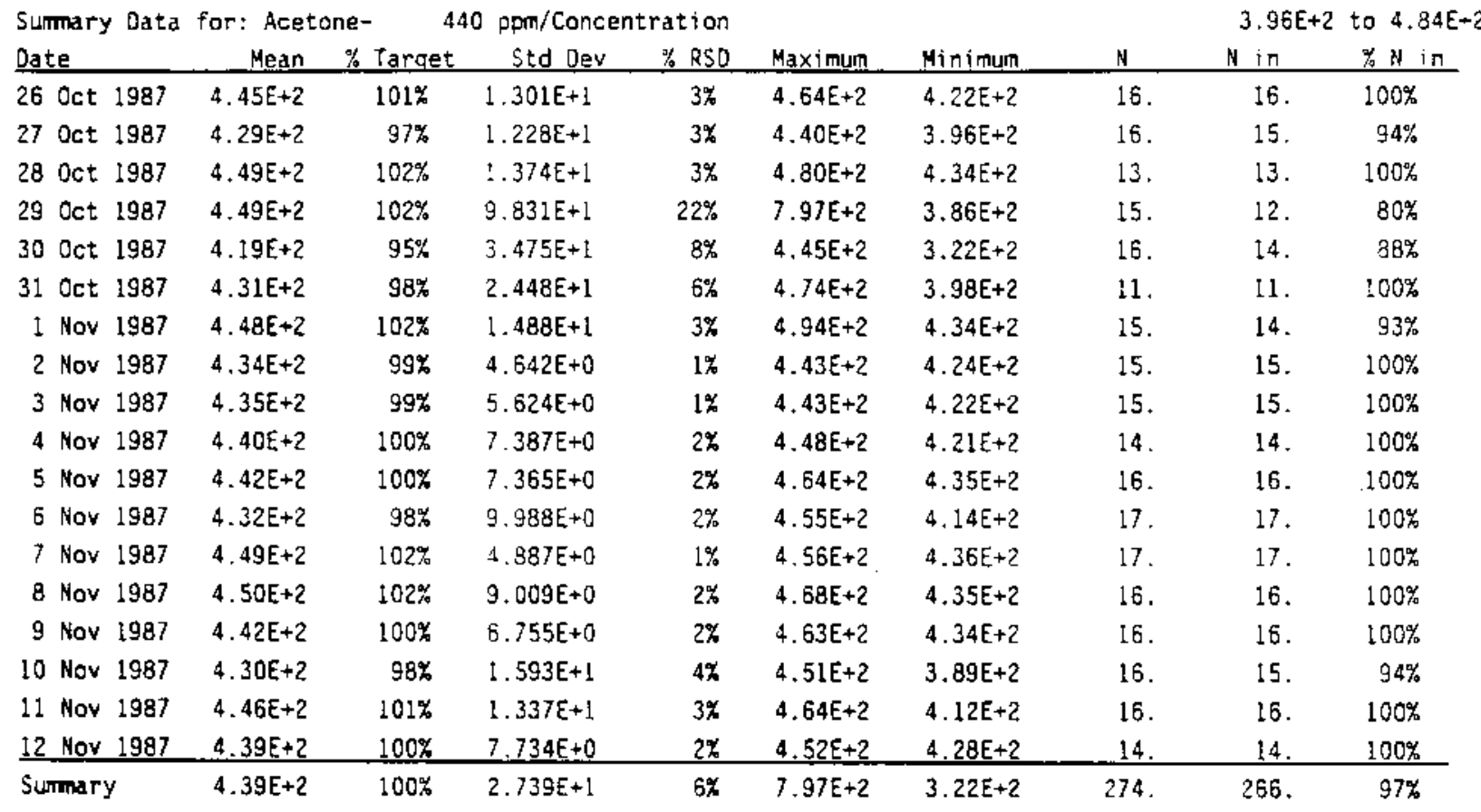

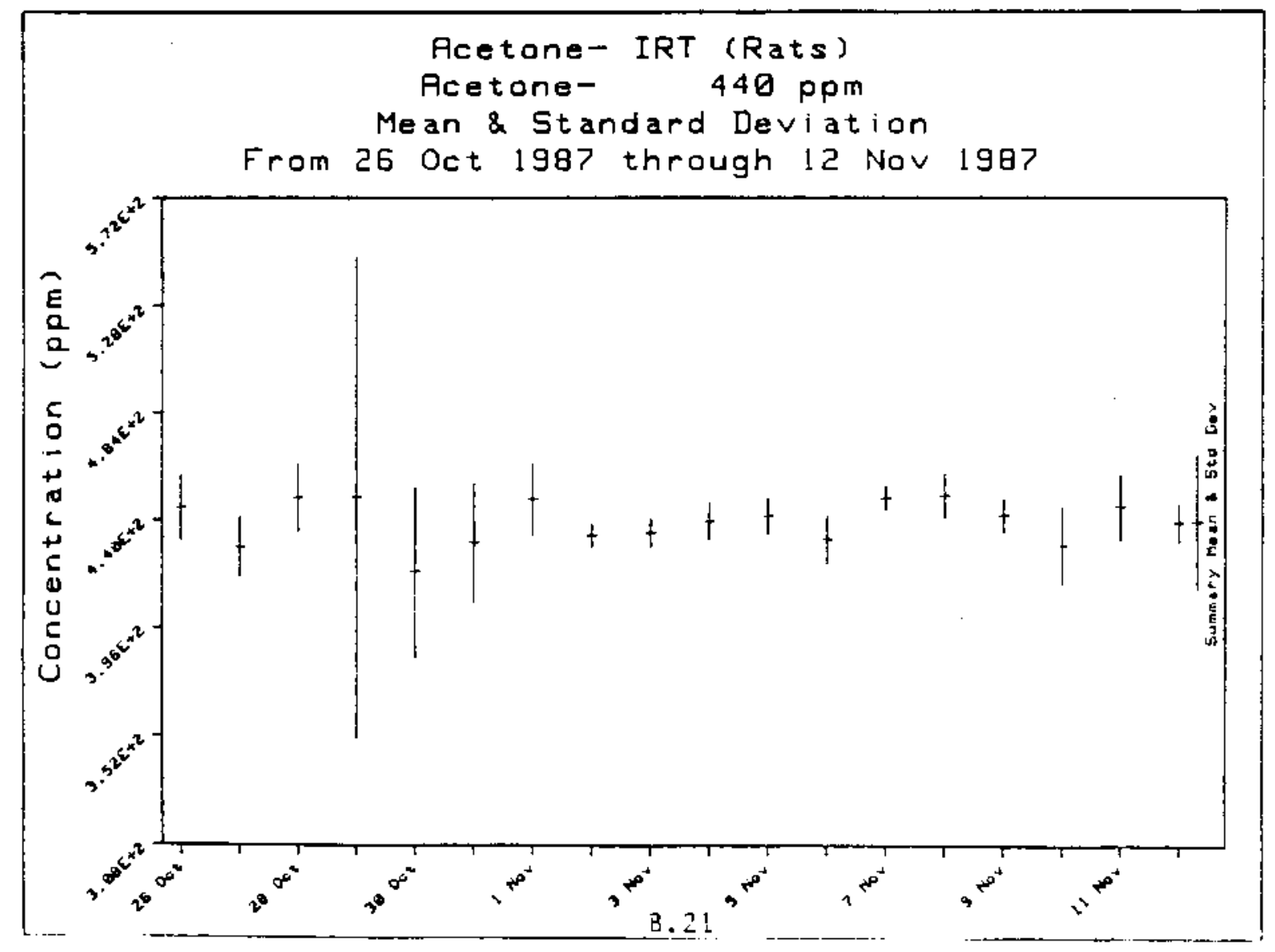


Oaily Summation For Acetone- IRT (Rats) From 26 Oct 1987 through 12 Nov 1987

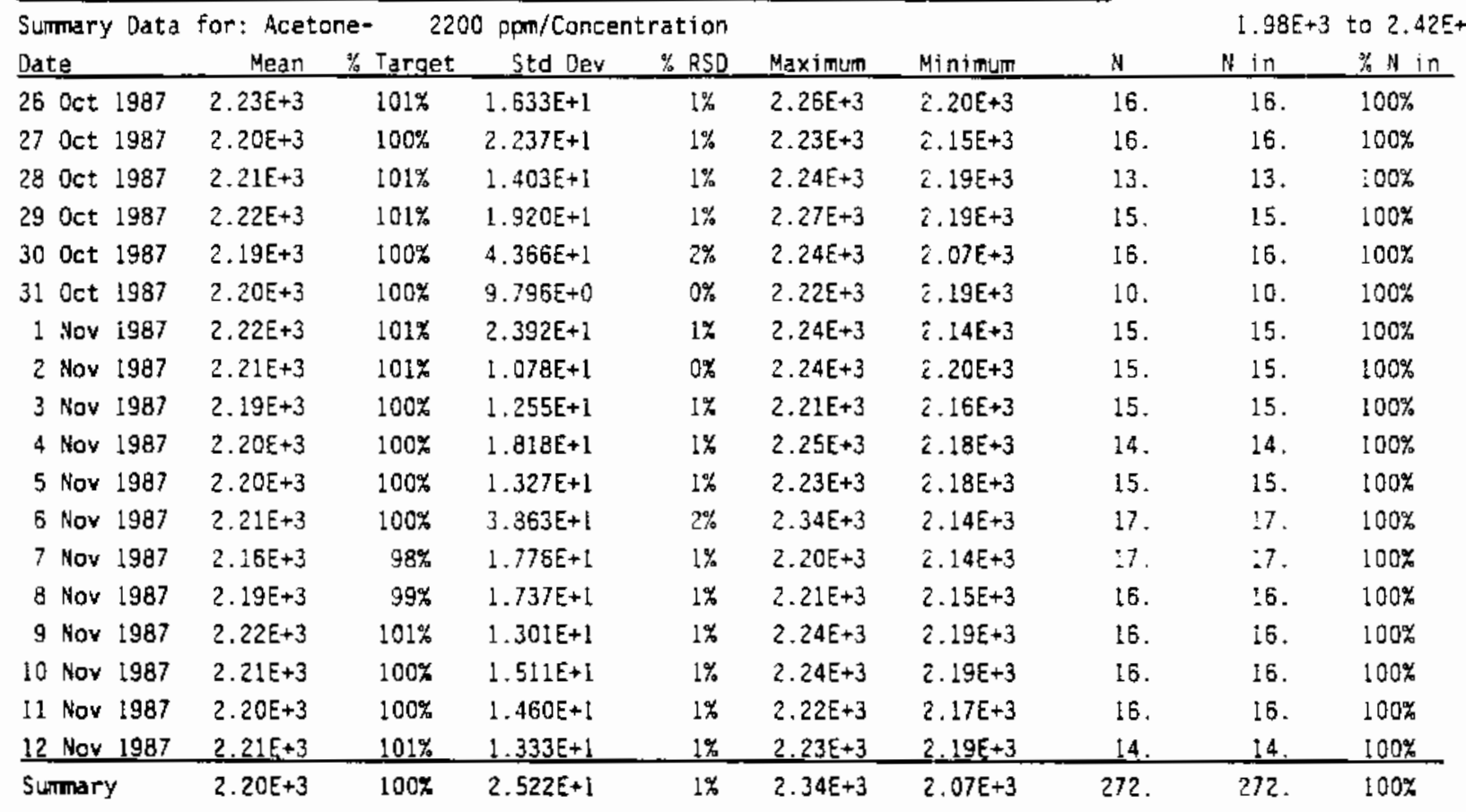

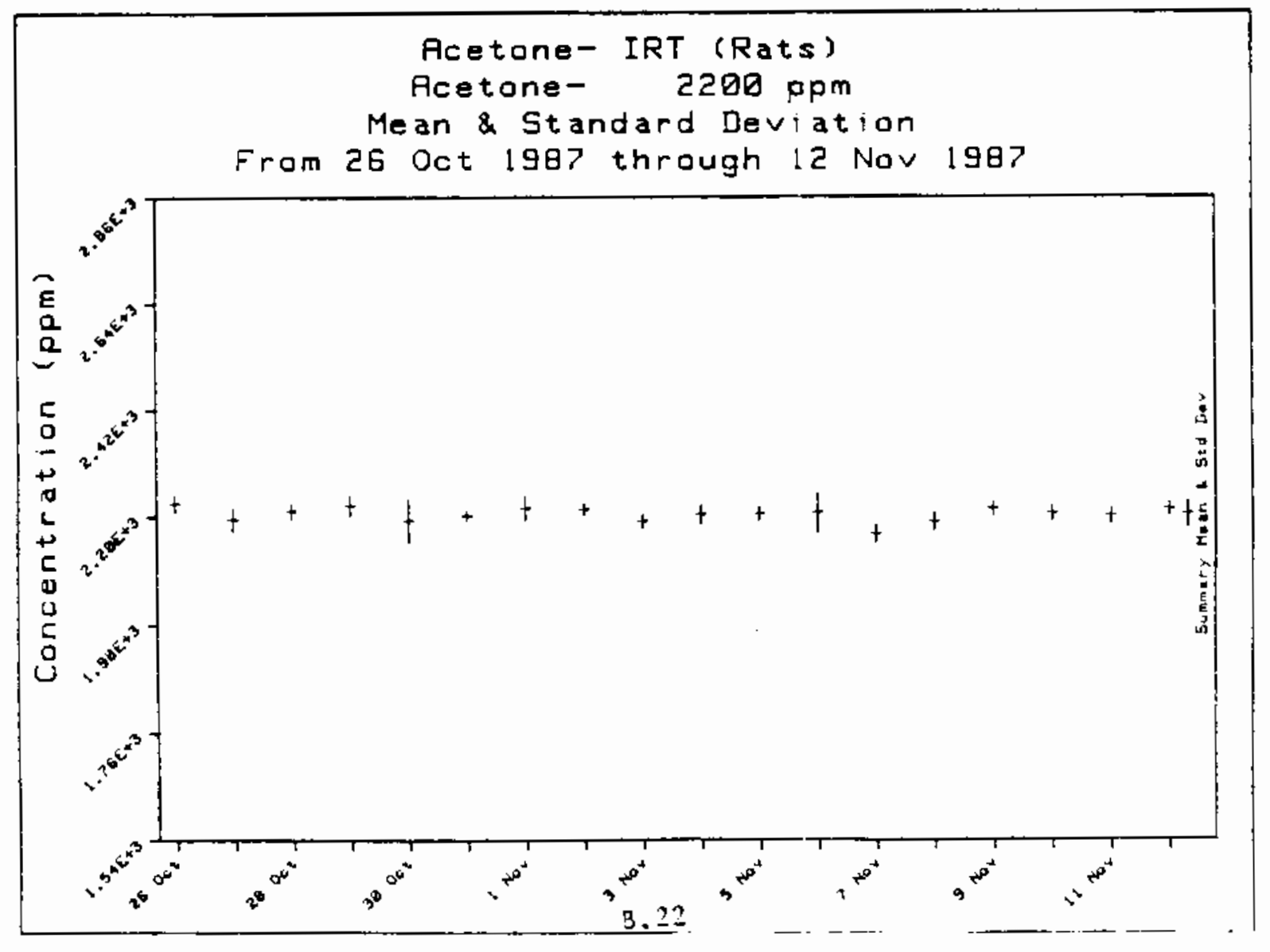




\begin{tabular}{|c|c|c|c|c|c|c|c|c|c|}
\hline \multicolumn{8}{|c|}{ Summary Data for: Acetone- $11000 \mathrm{ppm} /$ Concentration } & \multicolumn{2}{|c|}{$9.90 \mathrm{E}+3$ to $1.21 \mathrm{E}+c$} \\
\hline Date & Mean & $\%$ Tarqet & Std Dev & $\%$ RSD & Maximum & Hinimum & $\mathrm{N}$ & $\mathrm{N}$ in & $\approx N$ in \\
\hline 26 oct 1987 & $1.11 E+4$ & $101 \%$ & $1.790 \mathrm{E}+2$ & $2 \%$ & $1.14 \mathrm{E}+4$ & $1.08 E+4$ & 16. & 16. & $100 \%$ \\
\hline 27 Oct 1987 & $1.10 \mathrm{E}+4$ & $100 \%$ & 1. $163 E+2$ & $1 \%$ & 1. $12 \mathrm{E}+4$ & $1.08 \mathrm{E}+4$ & 16. & 16. & $100 \%$ \\
\hline 28 oct 1987 & $1.11 E+4$ & $101 \%$ & $1.219 \mathrm{E}+2$ & $1 \%$ & $1.12 \mathrm{E}+4$ & 1. $.08 \mathrm{E}+4$ & 13. & 13. & $100 \%$ \\
\hline 29 Oct 1987 & $1.10 E+4$ & $100 \%$ & $1.037 E+2$ & $1 \%$ & $1.11 E+4$ & $1.08 \mathrm{E}+4$ & 16. & 16. & $100 \%$ \\
\hline 30 oct 1987 & $1.10 \mathrm{E}+4$ & $100 \%$ & $1.129 E+2$ & $1 \%$ & $1.11 \mathrm{E}+4$ & $1.07 \mathrm{E}+4$ & 16. & 16. & $100 \%$ \\
\hline 31 Oct 1987 & $1.10 \mathrm{E}+4$ & $100 \%$ & $1.471 \mathrm{E}+2$ & $1 \%$ & 1. $12 \mathrm{E}+4$ & $1.07 \mathrm{E}+4$ & 10 . & 10. & $100 \%$ \\
\hline 1 Nov 1987 & $1.11 \mathrm{E}+4$ & $101 \%$ & $1.903 E+2$ & $2 \%$ & $1.13 E+4$ & $1.05 \mathrm{E}+4$ & 15. & 15. & $100 \%$ \\
\hline 2 Nov 1987 & $1.11 E+4$ & $101 \%$ & $1.392 \mathrm{E}+2$ & $1 \%$ & $1.14 \mathrm{E}+4$ & $1.09 E+4$ & 14. & 14. & $100 \%$ \\
\hline 3 Nov 1987 & $1.11 \mathrm{E}+4$ & $101 \%$ & $1.364 \mathrm{E}+2$ & $1 \%$ & $1.13 \mathrm{E}+4$ & $1.08 E+4$ & 13. & 13. & $100 \%$ \\
\hline 4 Nov 1987 & $1.11 \mathrm{E}+4$ & $101 \%$ & $1.017 \mathrm{E}+2$ & $1 \%$ & $1.13 E+4$ & $1.10 E+4$ & 14. & 14. & $100 \%$ \\
\hline 5 Nov 1987 & $1.10 \mathrm{E}+4$ & $100 \%$ & $1.079 E+2$ & $1 \%$ & $1.12 E+4$ & $1.09 E+4$ & 15. & 15. & $100 \%$ \\
\hline 6 Nov 1987 & $1.11 \mathrm{E}+4$ & $101 \%$ & $1.026 E+2$ & $1 \%$ & $1.13 \mathrm{E}+4$ & $1.09 \mathrm{E}+4$ & 16. & 16. & $100 \%$ \\
\hline 7 Nov 1987 & $1.09 E+4$ & $99 \%$ & $1.178 \mathrm{E}+2$ & $1 \%$ & $1.11 E+4$ & $1.07 E+4$ & 17. & 17. & $100 \%$ \\
\hline 8 Nov 1987 & $1.10 \mathrm{E}+4$ & $100 \%$ & $6.728 \mathrm{E}+1$ & $1 \%$ & $1.11 E+4$ & $1.09 \mathrm{E}+4$ & 16. & 16. & $100 \%$ \\
\hline 9 Nov 1987 & $1.09 \mathrm{E}+4$ & $99 \%$ & $6.253 \mathrm{E}+1$ & $1 \%$ & $1.11 E+4$ & $1.08 \mathrm{E}+4$ & 16. & 16. & $100 \%$ \\
\hline 10 Nov 1987 & $1.08 \mathrm{E}+4$ & $98 \%$ & $6.386 \mathrm{E}+1$ & $1 \%$ & $1.10 E+4$ & $1.07 \varepsilon+4$ & 16. & 16. & $100 \%$ \\
\hline 11 Nov 1987 & $1.09 \mathrm{E}+4$ & $100 \%$ & $8.799 \mathrm{E}+1$ & $1 \%$ & $1.11 \mathrm{E}+4$ & $1.08 E+4$ & 16. & 16. & $100 \%$ \\
\hline 12 Hov 1987 & $1.10 E+4$ & $100 \%$ & 8.269E+1 & $1 \%$ & $1.12 E+4$ & $1.09 E+4$ & 14. & 14. & $100 \%$ \\
\hline Sumary & $1.10 \mathrm{E}+4$ & $100 \%$ & $1.369 E+2$ & $1 x$ & $1.14 E+4$ & $1.05 E+4$ & 269. & 269. & $100 \%$ \\
\hline
\end{tabular}

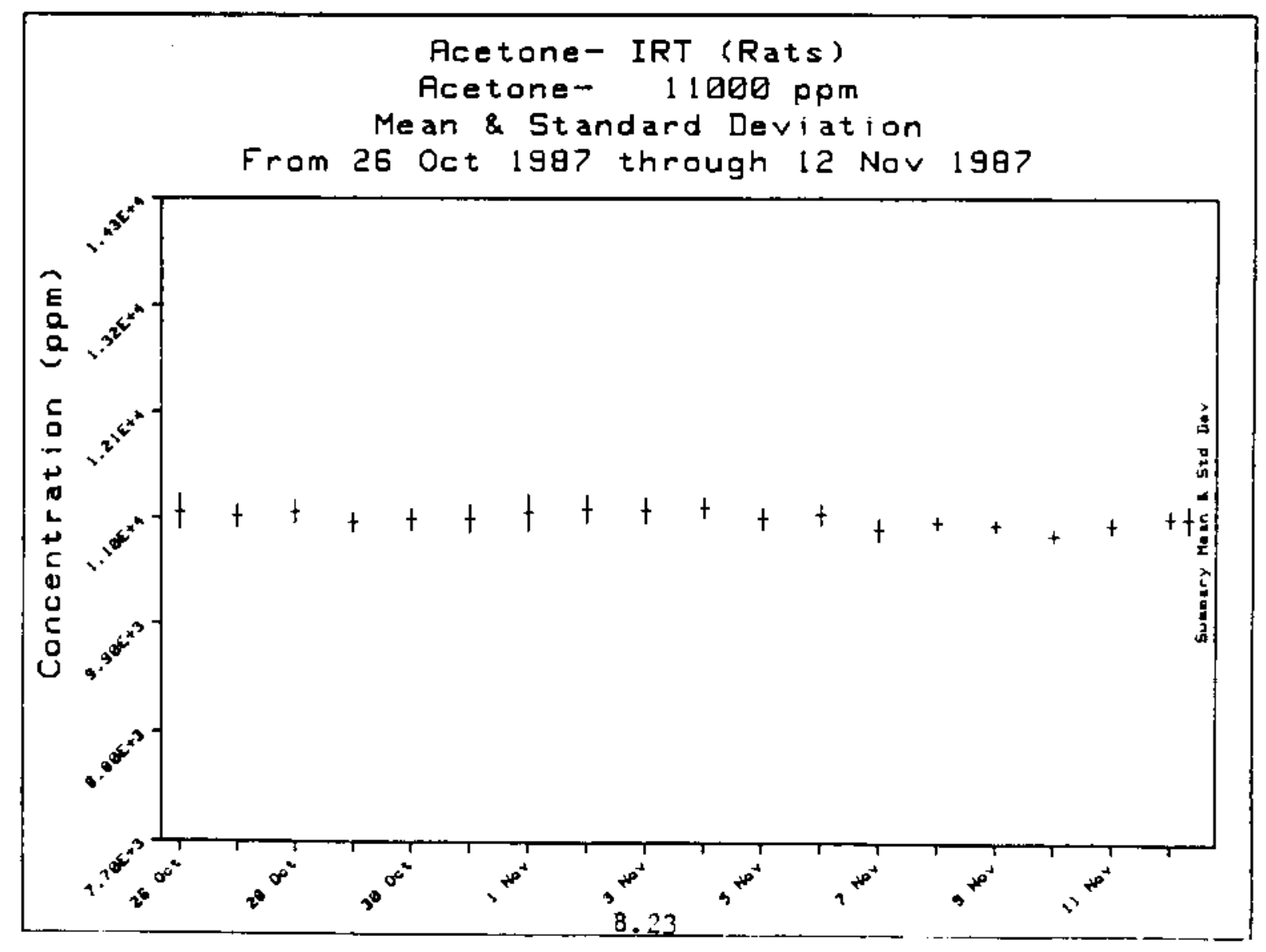


Daily Sumation For Acetone- IRT (Rats)___ From 26 Oct 1987 through 12 Nov 1987

\begin{tabular}{|c|c|c|c|c|c|c|c|c|c|}
\hline Date & Mean & $\%$ Tarqet & Std Dev & $\approx$ RSD & Haximum & Minimum & $\mathbb{M}$ & $\mathrm{N}$ in & $\%$ in \\
\hline 26 oct 1987 & $2.26 \mathrm{E}+3$ & $101 \%$ & $6.997 E+0$ & $0 \%$ & $2.27 E+3$ & $2.24 E+3$ & 16. & 16. & $100 \%$ \\
\hline 27 Oct 1987 & $2.26 \mathrm{E}+3$ & $101 \%$ & $2.633 E+0$ & $0 \%$ & $2.27 E+3$ & $2.26 E+3$ & 16. & 16. & $100 \%$ \\
\hline 28 oct 1997 & $2.26 \mathrm{E}+3$ & $101 \%$ & $4.830 E+0$ & $0 \%$ & $2.27 E+3$ & $2.25 E+3$ & 14 & 14. & $100 \%$ \\
\hline 290 ct 1987 & $2.26 \mathrm{E}+3$ & $101 \%$ & $5.503 \mathrm{E}+0$ & $0 \%$ & $2.27 E+3$ & $2.25 E+3$ & 17. & 17. & $100 \%$ \\
\hline 30 oet 1987 & $2.27 \mathrm{E}+3$ & $101 \%$ & $3.746 \mathrm{E}+0$ & $0 \%$ & $2.27 E+3$ & $2.26 E+3$ & 17. & 17 & $100 \%$ \\
\hline 31 oct 1987 & $2.26 E+3$ & $100 \%$ & $3.129 E+0$ & $0 \%$ & $2.27 \mathrm{E}+3$ & $2.26 \mathrm{E}+3$ & 12 & 12. & $100 \%$ \\
\hline 1 Nov 1987 & $2.26 E+3$ & $101 \%$ & $2.808 E+0$ & $O_{n}^{*}$ & $2.27 \mathrm{E}+3$ & $2.26 \mathrm{E}+3$ & 15. & 15. & $100 \%$ \\
\hline 2 Nov 1987 & $2.26 E+3$ & $100 \%$ & $2.306 E+0$ & $0 \%$ & $2.27 \mathrm{E}+3$ & $2.26 \mathrm{E}+3$ & 16. & 16. & $100 x$ \\
\hline 3 Nor 1987 & $2.26 E+3$ & $101 x$ & $2.673 \mathrm{E}+0$ & $0 x$ & $2.27 \mathrm{E}+3$ & $2.26 \mathrm{E}+3$ & 14. & 14. & $100 \%$ \\
\hline 4 Nor 1987 & $2.26 E+3$ & $101 \%$ & $2.690 \mathrm{E}+0$ & $0 x$ & $2.27 \mathrm{E}+3$ & $2.26 \mathrm{E}+3$ & 15. & 15. & $100 \%$ \\
\hline 5 Hov 1987 & $2.26 E+3$ & $101 x$ & $1.981 \mathrm{E}+0$ & $0 x$ & $2.27 \mathrm{E}+3$ & $2.26 \mathrm{E}+3$ & 15. & 15. & $100 \%$ \\
\hline 6 Nov 1987 & $2.26 E+3$ & $101 \%$ & $8.268 E+0$ & $\alpha x$ & $2.29 \mathrm{E}+3$ & $2.25 \mathrm{E}+3$ & 18. & 18. & $100 \%$ \\
\hline 7 Nov 1987 & $2.26 E+3$ & $101 \%$ & $2.093 E+0$ & $0 \%$ & $2.27 \mathrm{E}+3$ & $2.26 \mathrm{E}+3$ & 17. & 17. & $100 \%$ \\
\hline 8 Nov 1987 & $2.26 \mathrm{E}+3$ & $101 \%$ & $2.107 E+0$ & $0 \%$ & $2.27 \mathrm{E}+3$ & $2.26 \mathrm{E}+3$ & 17. & 17. & $100 \%$ \\
\hline 9 Nor 1987 & $2.26 E+3$ & $101 \%$ & $2.936 E+0$ & $0 x$ & $2.27 \mathrm{E}+3$ & $2.26 \mathrm{E}+3$ & 17. & 17. & $100 \%$ \\
\hline 10 Nor 1997 & $2.25 \mathrm{E}+3$ & $100 x$ & $2.984 E+0$ & $O x$ & $2.26 \mathrm{E}+3$ & $2.25 \mathrm{E}+3$ & 17. & 17. & $100 \%$ \\
\hline 11 Nov 1997 & $2.26 \mathrm{E}+3$ & $100 x$ & $1.976 E+0$ & $O x$ & $2.26 E+3$ & $2.25 E+3$ & 17. & 17. & $100 \%$ \\
\hline 12 Nor 1987 & $2.26 E+3$ & $100 x$ & $3.869 E+0$ & ox. & $2.27 E+3$ & $2.26 E+3$ & 15. & 15. & $100 \%$ \\
\hline Sumury & $2.26 \mathrm{E}+3$ & $101 x$ & $4.803 E+0$ & $0 x$ & $2.29 E+3$ & $2.24 E+3$ & 285 & 285. & $100 x$ \\
\hline
\end{tabular}

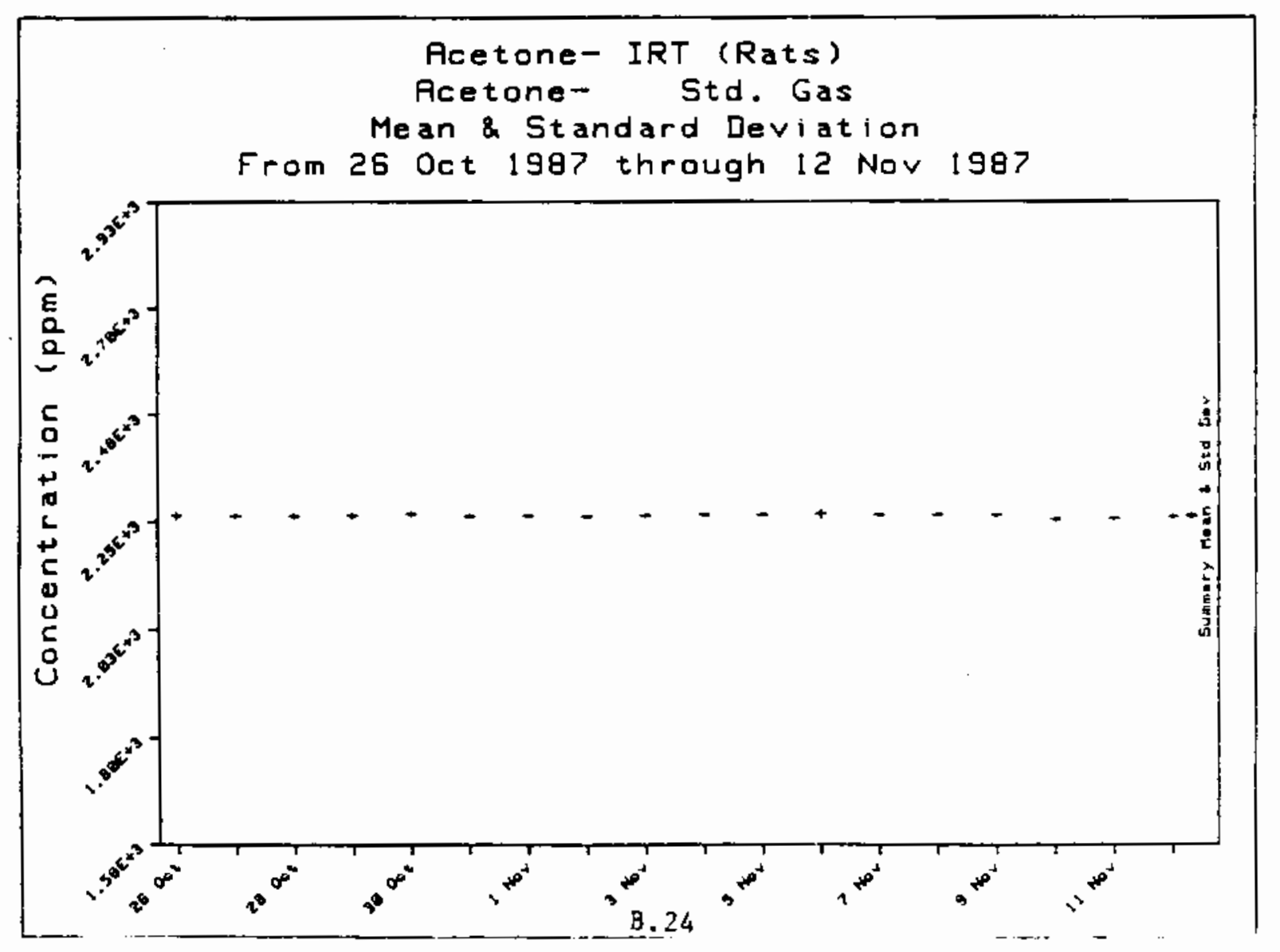


Dajly Summation For Acetone-. IRT (Rats) From 23 Oct 1987 through 13 Nov 1987

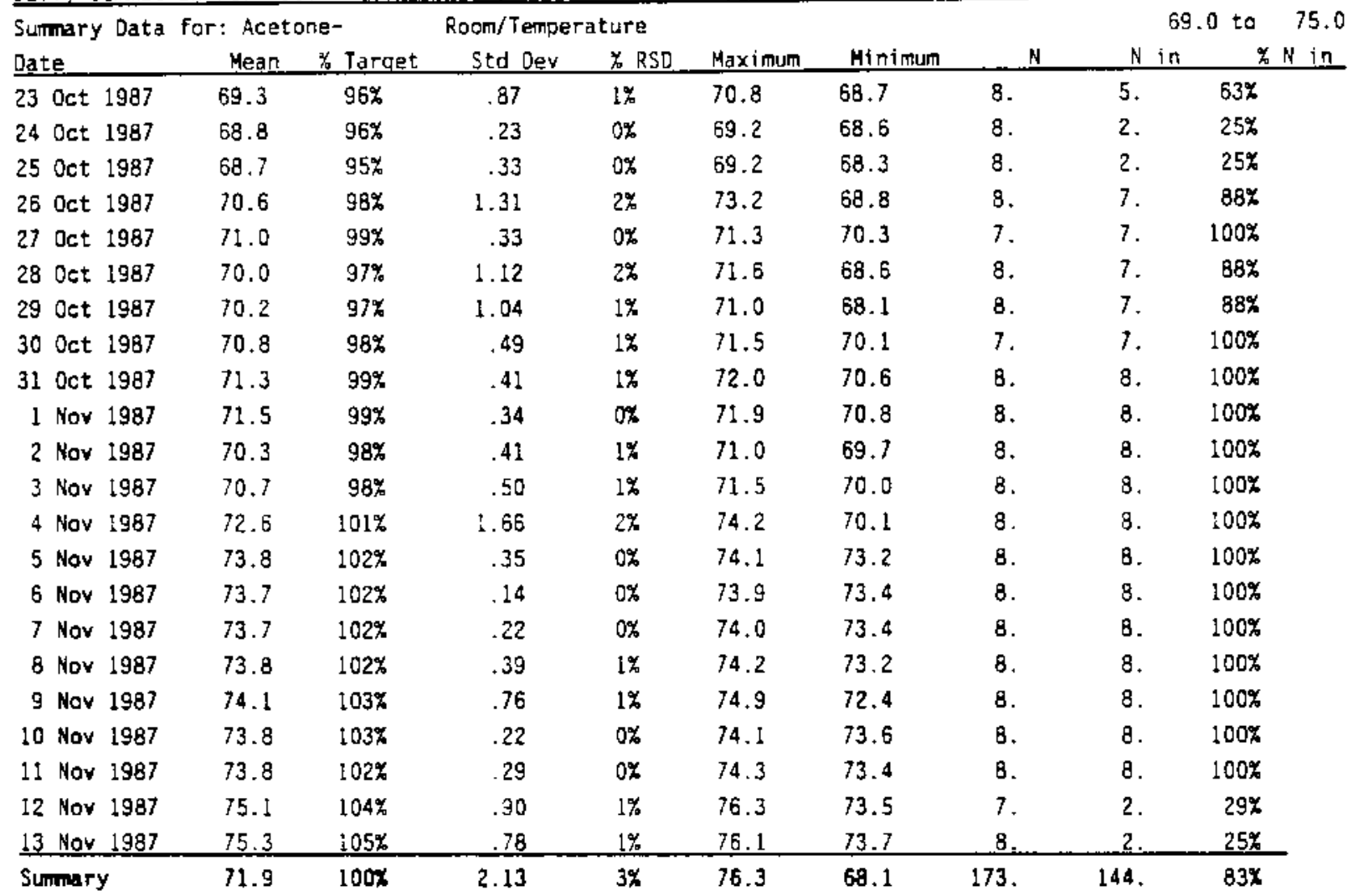

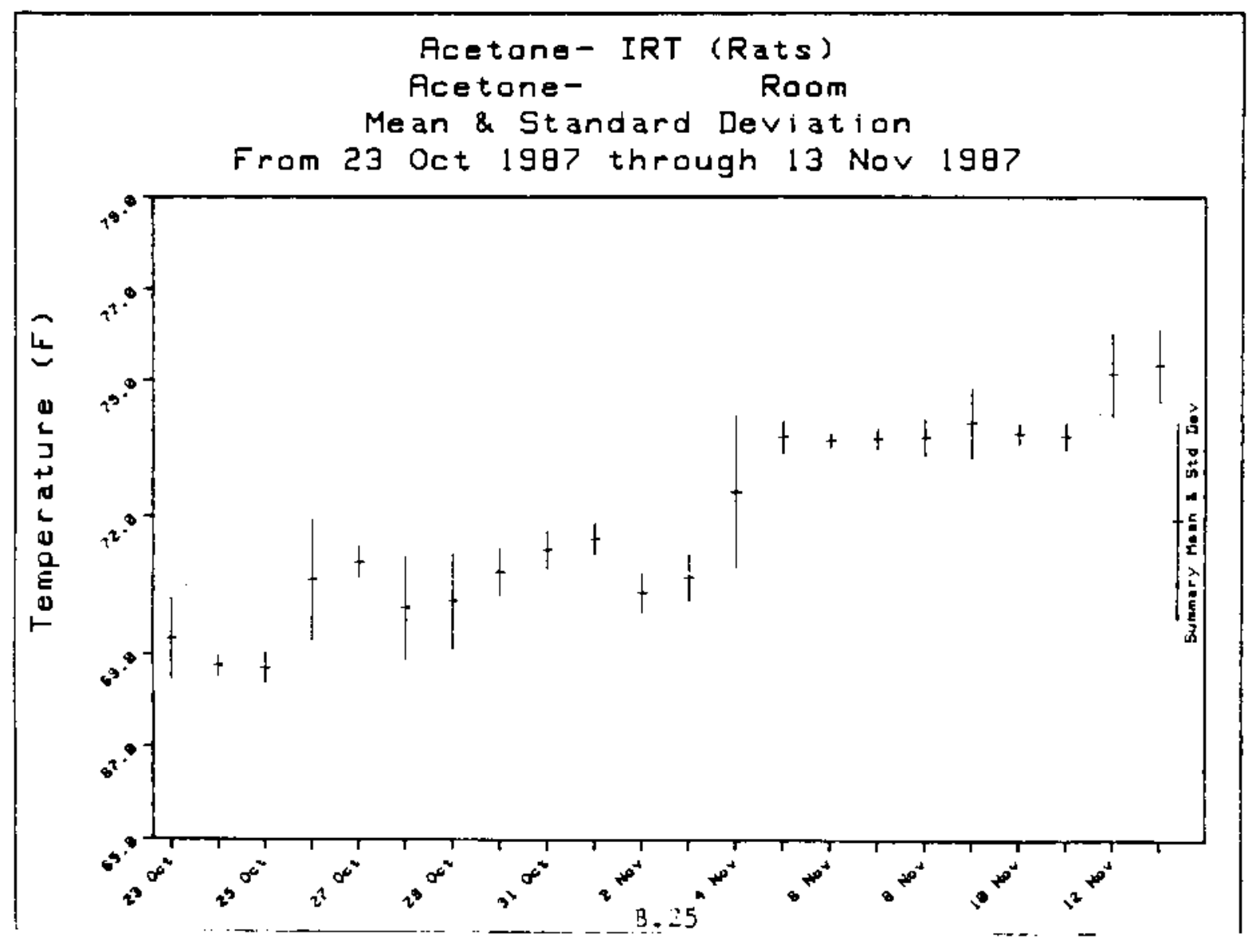


Daily Summation For Acetone- IRT (Rats) From 23 Oct 1987 through 13 Nov 1987

\begin{tabular}{|c|c|c|c|c|c|c|c|c|c|}
\hline \multirow{2}{*}{$\begin{array}{l}\text { Summary } \\
\text { Date }\end{array}$} & \multicolumn{2}{|c|}{ or: Acetone- } & \multicolumn{2}{|c|}{ ppm/Temperature } & \multirow[b]{2}{*}{ Maximum } & \multirow[b]{2}{*}{ Minimum } & \multirow[b]{2}{*}{ H } & \multicolumn{2}{|c|}{72.0 to 78.0} \\
\hline & Mean & \% Target & Std Dev & $\approx$ RSO & & & & $\mathrm{N}$ in & $\% N$ in \\
\hline 23 oet 1987 & 76.7 & $102 \%$ & .55 & $1 \%$ & 77.5 & 76.0 & 6. & 6. & $100 \%$ \\
\hline 24 Oct 1987 & 76.4 & $102 \%$ & .54 & $1 \%$ & 77.2 & 75.9 & 8. & 8. & $100 \%$ \\
\hline 25 oc 1987 & 76.5 & $102 \%$ & .70 & $1 \%$ & 77.8 & 75.8 & 8. & 8. & $100 \%$ \\
\hline 26 oet 1987 & 76.0 & $101 \%$ & 1.47 & $2 \%$ & 77.7 & 73.0 & 8. & 8. & $100 \%$ \\
\hline 27 Oct 1987 & 77.1 & $103 \%$ & .66 & $1 \%$ & 78.2 & 76.4 & 7 & 6. & $86 \%$ \\
\hline 28 Oct 1987 & 77.2 & $103 \%$ & .76 & $1 \%$ & 78.1 & 76.3 & 5 & 4. & $80 \%$ \\
\hline 29 oct 1987 & 75.0 & $100 \%$ & 1.03 & $1 \%$ & 77.5 & 74.3 & 8. & 8 & $100 \%$ \\
\hline 30 Oct 1987 & 75.2 & $100 \%$ & .64 & $1 \%$ & 76.0 & 74.4 & 7. & 7. & $100 \%$ \\
\hline 31 oct 1987 & 75.7 & $101 \%$ & .41 & $1 \%$ & 76.2 & 75.1 & 8. & 8. & $100 \%$ \\
\hline 1 Nov 1987 & 76.1 & $101 \%$ & .43 & $1 \%$ & 76.7 & 75.5 & 8. & 8. & $100 \%$ \\
\hline 2 Nov 1987 & 75.0 & $100 x$ & .45 & $1 \%$ & 75.9 & 74.3 & 8. & 8. & $100 \%$ \\
\hline 3 Nov 1987 & 75.1 & $100 \%$ & .25 & $\alpha x$ & 75.7 & 74.9 & 8. & 8. & $100 \%$ \\
\hline 4 Nov 1987 & 75.4 & $101 \%$ & .46 & $1 \%$ & 76.1 & 74.7 & 8. & 8. & $100 \%$ \\
\hline 5 Nov 1987 & 75.5 & $101 \%$ & .51 & $1 \%$ & 76.2 & 74.7 & B. & $B$. & $100 \%$ \\
\hline 6 Noy 1987 & 74.4 & $99 \%$ & 1.15 & $2 \%$ & 76.0 & 32.1 & 8. & 8. & $100 \%$ \\
\hline 7 Hov 1987 & 74.8 & $100 \%$ & .50 & $1 \%$ & 75.3 & 74.1 & 8. & 8. & $100 \%$ \\
\hline 8 Kov 1987 & 75.0 & $100 \%$ & .51 & $1 \%$ & 75.7 & 74.1 & 8. & 8. & $100 \%$ \\
\hline g Nov 1987 & 74.1 & $99 \%$ & .54 & $1 \%$ & 75.3 & 73.6 & 8. & 8. & $100 \%$ \\
\hline 10 Nov 1987 & 73.5 & $98 \%$ & .47 & $1 \%$ & 74.1 & 72.6 & 8. & 8. & $100 \%$ \\
\hline 11 Nor 1987 & 72.9 & $97 \%$ & .38 & $1 \%$ & 73.8 & 32.5 & 8. & 8. & $100 \%$ \\
\hline 12 Nov 1987 & 73.0 & $97 \%$ & .59 & $1 \%$ & 74.0 & 72.2 & 7. & 7. & $100 \%$ \\
\hline 13 Nor 1987 & 73.2 & $98 \%$ & 0.00 & $0 \%$ & 73.2 & 33.2 & 1. & 1. & $100 \%$ \\
\hline Summary & 75.2 & $100 \%$ & 1.33 & $2 \%$ & 78.2 & 72.1 & 61 & 59. & $99 \%$ \\
\hline
\end{tabular}

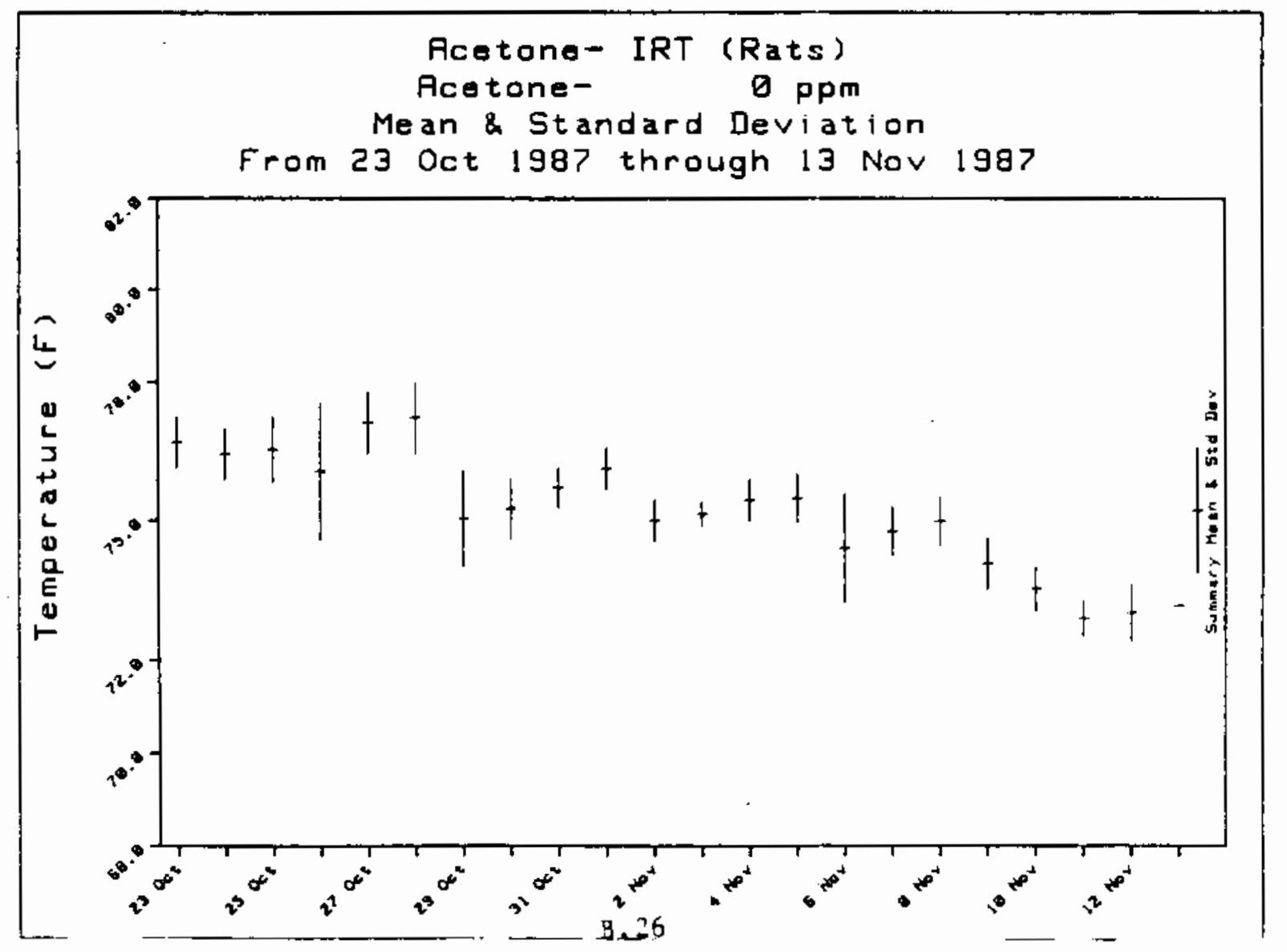


Daily Sumation For Acetone- IRT (Rats) From 23 Oct 1987 through 13 Nov 1987

\begin{tabular}{|c|c|c|c|c|c|c|c|c|c|}
\hline Sumary Data & or: Acet & ne- & \#1/Tempe & ture & & & & & 0 to \\
\hline Qate & Mean & $\%$ Tarqet & Std Dev & $\%$ RSD & Maximum & Minimum & $\mathrm{N}$ & N in & $\% \mathrm{~N}$ in \\
\hline 23 Oct 1987 & 74.1 & $99 \%$ & .31 & $0 \%$ & 74.5 & 73.5 & 6. & 6. & $100 \%$ \\
\hline 24 Oet 1987 & 73.9 & $99 \%$ & .24 & $0 \%$ & 74.3 & 73.5 & 8. & 8. & $100 \%$ \\
\hline 25 Oct 1987 & 73.8 & $98 \%$ & .37 & $1 \%$ & 74.4 & 73.3 & 8. & 8. & $100 \%$ \\
\hline 26 oet 1987 & 75.6 & $101 \%$ & 1.37 & $2 \%$ & 78.0 & 73.5 & 8. & 8. & $100 \%$ \\
\hline 27 Oct 1987 & 76.8 & $102 \%$ & .58 & $1 \%$ & 77.6 & 76.2 & 7. & 7. & $100 \%$ \\
\hline 28 oct 1987 & 73.1 & $98 \%$ & 2.09 & $3 \%$ & 76.8 & 71.8 & 5. & 3. & $60 \%$ \\
\hline 29 oct 1987 & 72.9 & $97 \%$ & .53 & $1 \%$ & 73.5 & 71.9 & 8. & 7. & $88 \%$ \\
\hline 30 oct 1987 & 72.0 & $96 \%$ & .82 & $1 \%$ & 72.9 & 71.4 & 3. & 1. & $33 \%$ \\
\hline 31 oct 1987 & & & & & & & & & \\
\hline 1 Nov 1987 & & & & & & & & & \\
\hline 2 Nov 1987 & & & & & & & & & \\
\hline 3 Nov 1987 & & & & & & & & & \\
\hline 4 Nov 1987 & & & & & & & & & \\
\hline 5 Nov 1987 & & & & & & & & & \\
\hline 6 Nov 1987 & & & & & & & & & \\
\hline 7 Nov 1987 & & & & & ' & & & & \\
\hline 8 Nov 1987 & & & & & & & & & \\
\hline 9 Nov 1987 & & & & & & & & & \\
\hline 10 Nov 1987 & & & & & & & & & \\
\hline 11 Nov 1987 & & & & & & & & & \\
\hline 12 Nov 1987 & & & & & & & & & \\
\hline 13 Nov 1987 & & & & & & & & & \\
\hline Sunmary & 74.2 & $99 x$ & 1.61 & $2 x$ & 78.0 & 71.4 & 53. & 48. & $91 \%$ \\
\hline
\end{tabular}

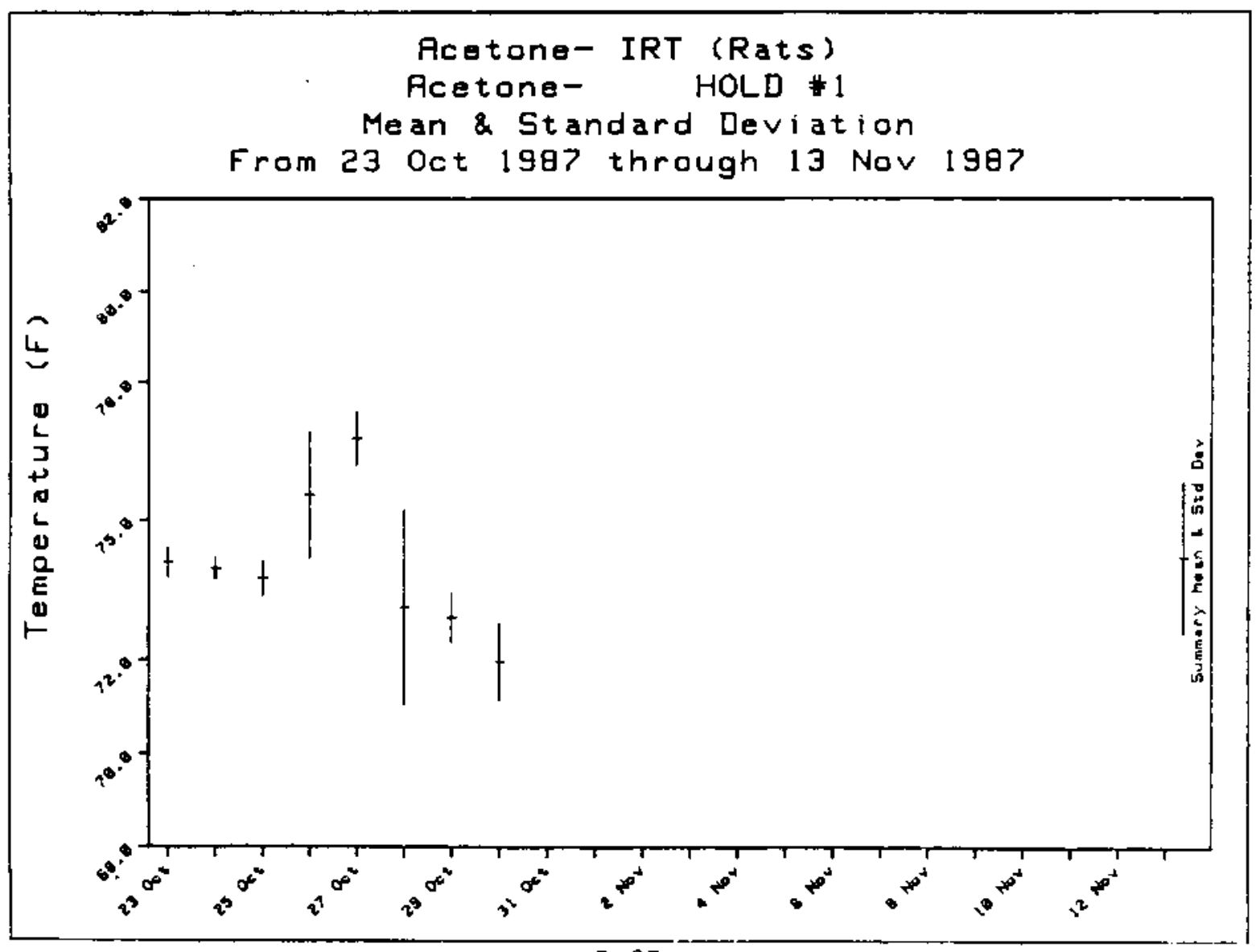


Qaily Summation For Acetone- IRT (Rats) From 23 Oct 1987 thrcugh 13 Nov 1987

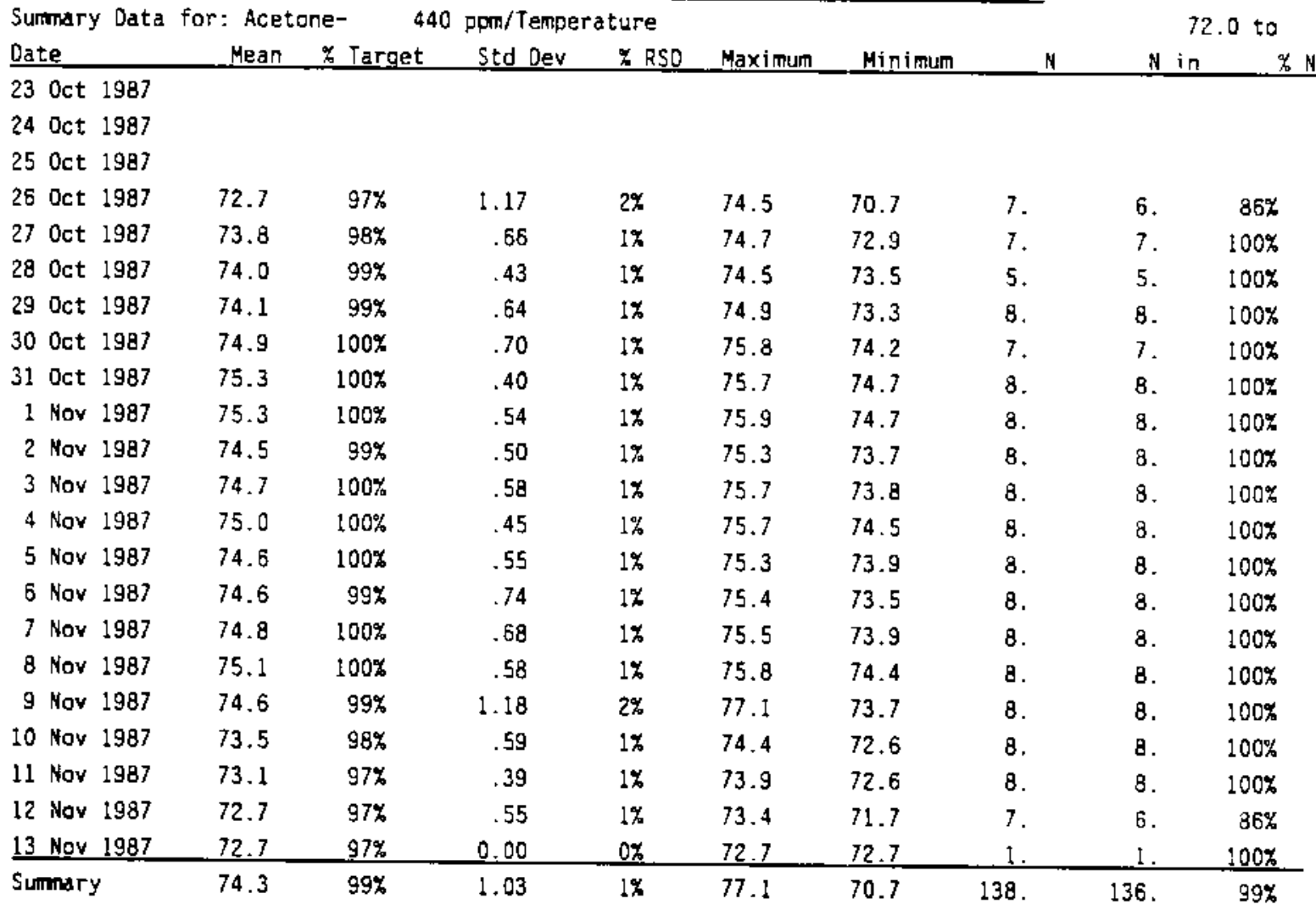

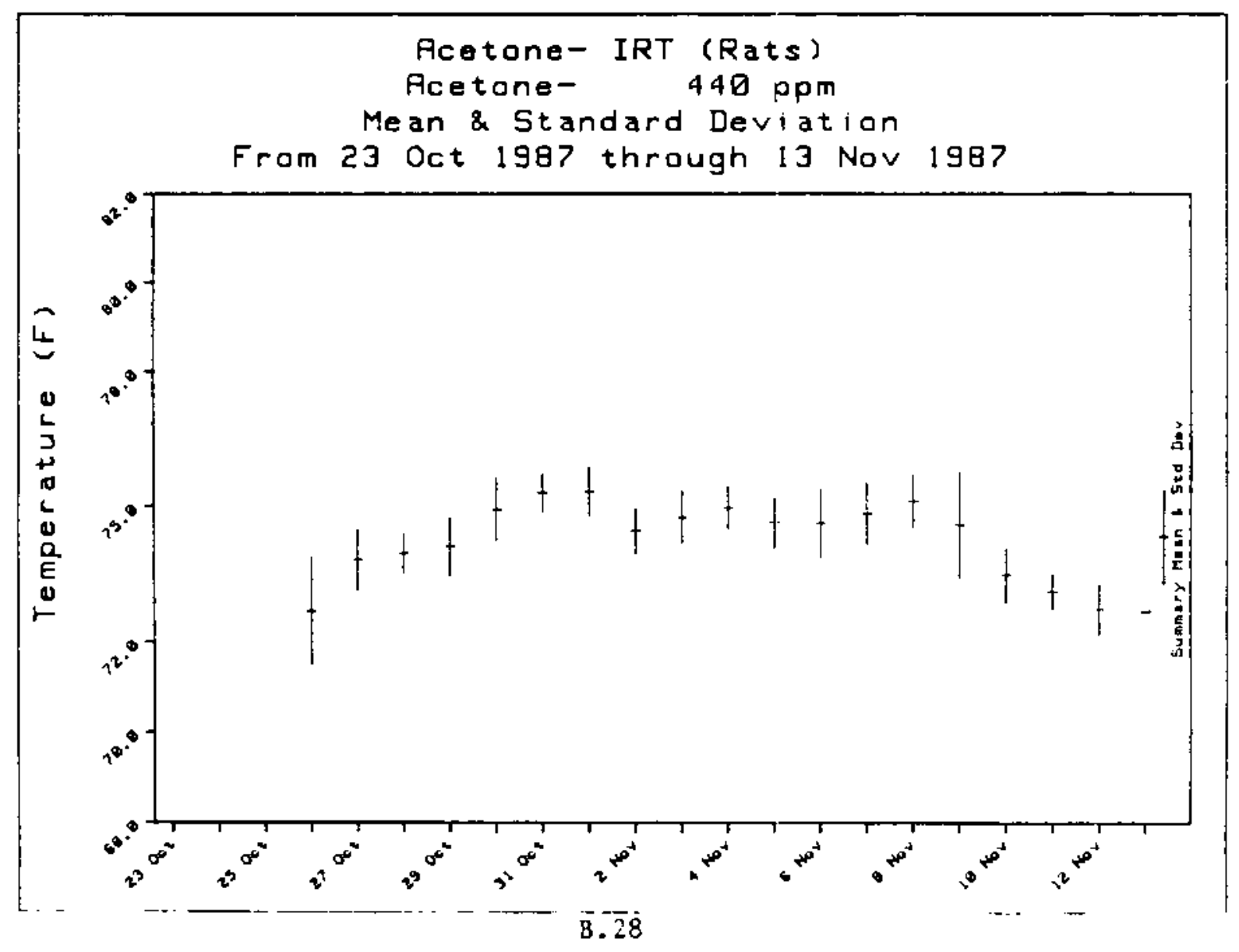


Oaily Summation For Acetone- IRT (Rats). From 23 Oct 1987 through 13 Nov 1987

\begin{tabular}{|c|c|c|c|c|c|c|c|c|c|}
\hline \multicolumn{5}{|c|}{ Sumary Data for: Acetone- $2200 \mathrm{ppm} /$ Temperature } & \multirow[b]{2}{*}{ Maximum } & \multirow[b]{2}{*}{ Minimum } & & \multicolumn{2}{|c|}{72.0 to } \\
\hline Date & Mean & $\%$ Taroet & Std Dev & $\%$ RSD & & & $\mathrm{N}$ & $\mathrm{N}$ & $\% \mathrm{~N}$ \\
\hline 23 oct 1987 & & & & & & & & & \\
\hline 24 Oct 1987 & & & & & & & & & \\
\hline 25 oct 1987 & & & & & & & & & \\
\hline 26 Oct 1987 & 72.9 & $97 \%$ & 1.58 & $2 \%$ & 75.0 & 70.2 & 7. & 6. & $86 \%$ \\
\hline 27 Oct 1987 & 73.7 & $98 \%$ & .76 & $I \%$ & 74.9 & 72.8 & 7. & 7 . & $100 \%$ \\
\hline 28 oct 1987 & 74.2 & $99 \%$ & .28 & $0 \%$ & 74.6 & 73.9 & 5. & 5. & $100 \%$ \\
\hline 29 oct 1987 & 74.7 & $100 \%$ & .85 & $1 \%$ & 75.5 & 73.4 & 8. & 8. & $100 \%$ \\
\hline 30 oct 1987 & 75.8 & $101 \%$ & .92 & $1 \%$ & 77.2 & 74.9 & 7. & 7. & $100 \%$ \\
\hline 31 oct 1987 & 76.5 & $102 \%$ & .88 & $1 \%$ & 77.5 & 75.3 & 8. & 8. & $100 \%$ \\
\hline 1 Nov 1987 & 76.7 & $102 \%$ & .93 & $1 \%$ & 77.8 & 75.6 & 8. & 8. & $100 \%$ \\
\hline 2 Nov 1987 & 76.1 & $: 01 \%$ & .67 & $1 \%$ & 76.9 & 75.1 & 8. & 8. & $100 \%$ \\
\hline 3 Nov 1987 & 76.1 & $101 \%$ & .57 & $\$ \%$ & 76.9 & 75.3 & 3. & 3. & $100 \%$ \\
\hline 4 Nov 1987 & 76.0 & $101 \%$ & .87 & $1 \%$ & 77.1 & 75.0 & 8. & 8. & $100 \%$ \\
\hline 5 Nov 1987 & 76.3 & $102 \%$ & .84 & $1 \%$ & 77.3 & 75.0 & 8. & 8. & $: 00 \%$ \\
\hline 6 Nov 1987 & 75.9 & $101 \%$ & .90 & $1 \%$ & 77.1 & 74.7 & 8. & 8. & $100 \%$ \\
\hline 7 Nov 1987 & 75.9 & $101 \%$ & .92 & $1 \%$ & 76.9 & 74.7 & 8. & 8. & $100 \%$ \\
\hline 8 Nov 1987 & 76.1 & $101 \%$ & .88 & $1 \%$ & 77.3 & 75.0 & 8. & 8. & $100 \%$ \\
\hline 9 Nov 1987 & 75.8 & $101 \%$ & 1.03 & $1 \%$ & 77.6 & 74.7 & 8. & 8. & $100 \%$ \\
\hline 10 Nov 1987 & 75.1 & $100 \%$ & .70 & $1 \%$ & 76.1 & 74.4 & 8. & 8. & $100 \%$ \\
\hline 11 Nov 1987 & 73.1 & $97 \%$ & 1.12 & $2 \%$ & 75.8 & 72.2 & 8. & 8. & $100 \%$ \\
\hline 12 Nov 1987 & 72.8 & $97 \%$ & .66 & $1 \%$ & 73.5 & 71.4 & 7. & $\overline{0 .}$ & $86 \%$ \\
\hline 13 Nov 1987 & 73.0 & $97 \%$ & 0.00 & $0 \%$ & 73.0 & 73.0 & 1. & 1. & $100 \%$ \\
\hline Summary & 75.3 & $100 \%$ & 1.52 & $2 \%$ & 77.8 & 70.2 & 138. & 136. & $99 \%$ \\
\hline
\end{tabular}

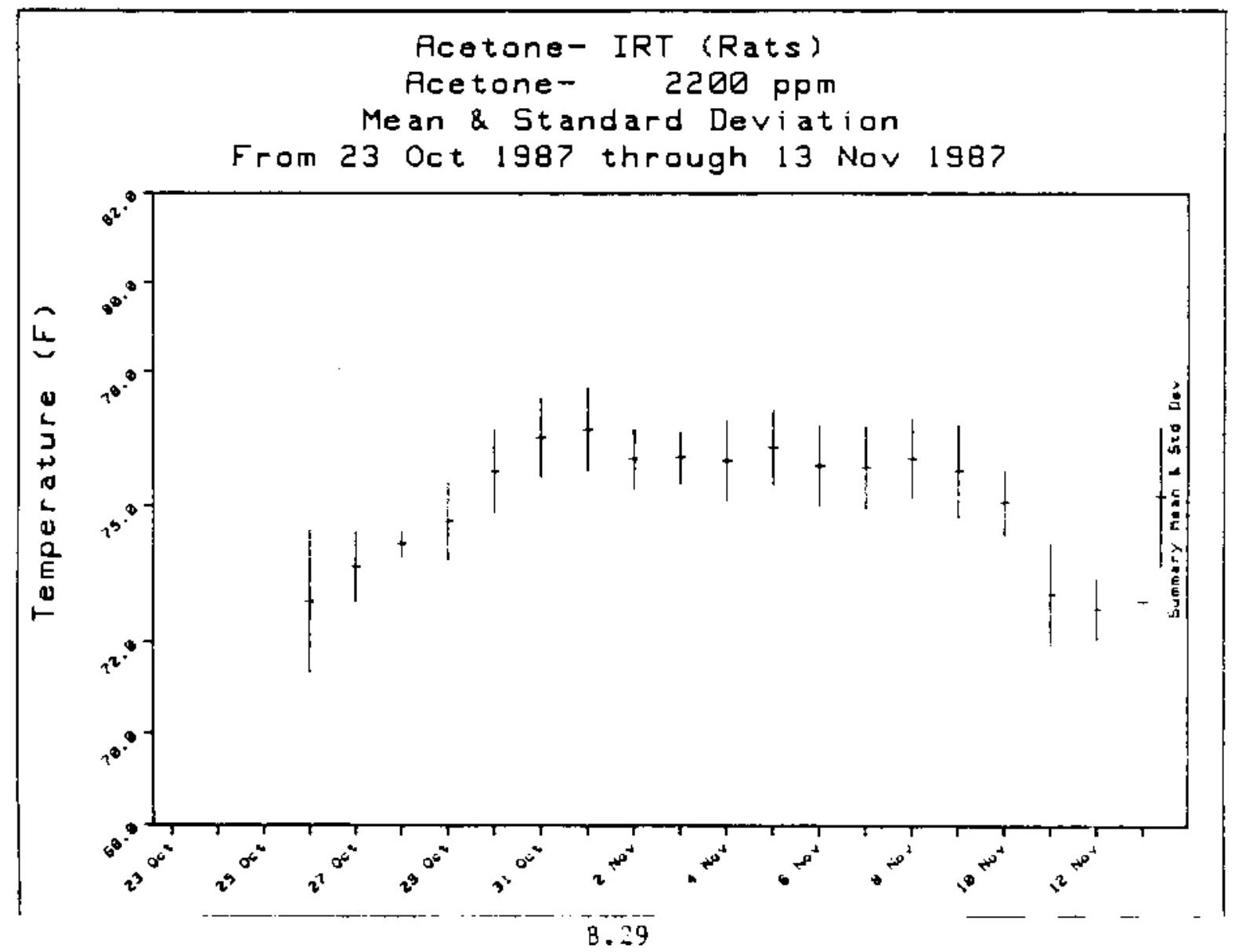


Daily Summation For Acetone- IRT (Rats) From 23 Oct 1987 through 13 Nov 1987

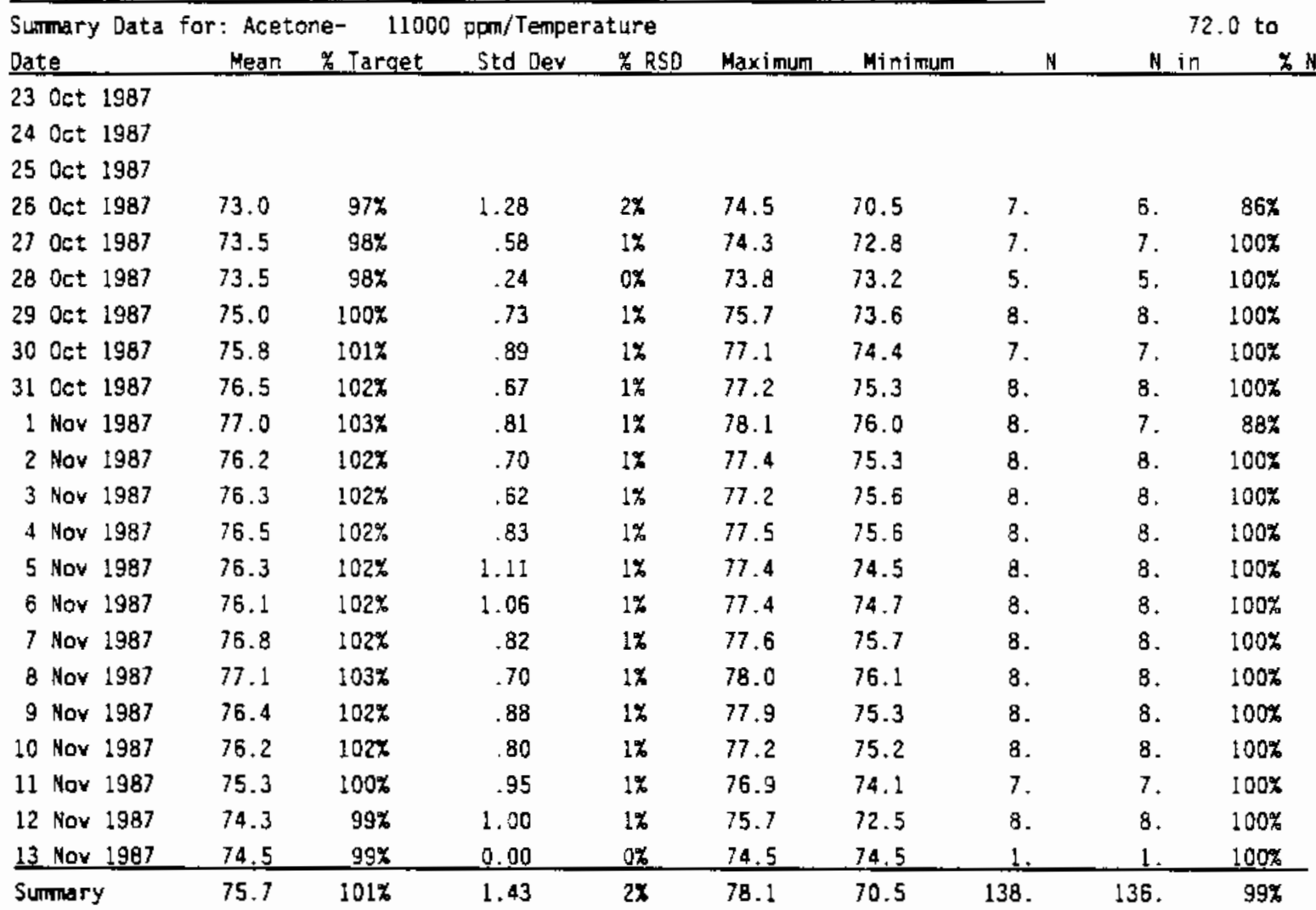

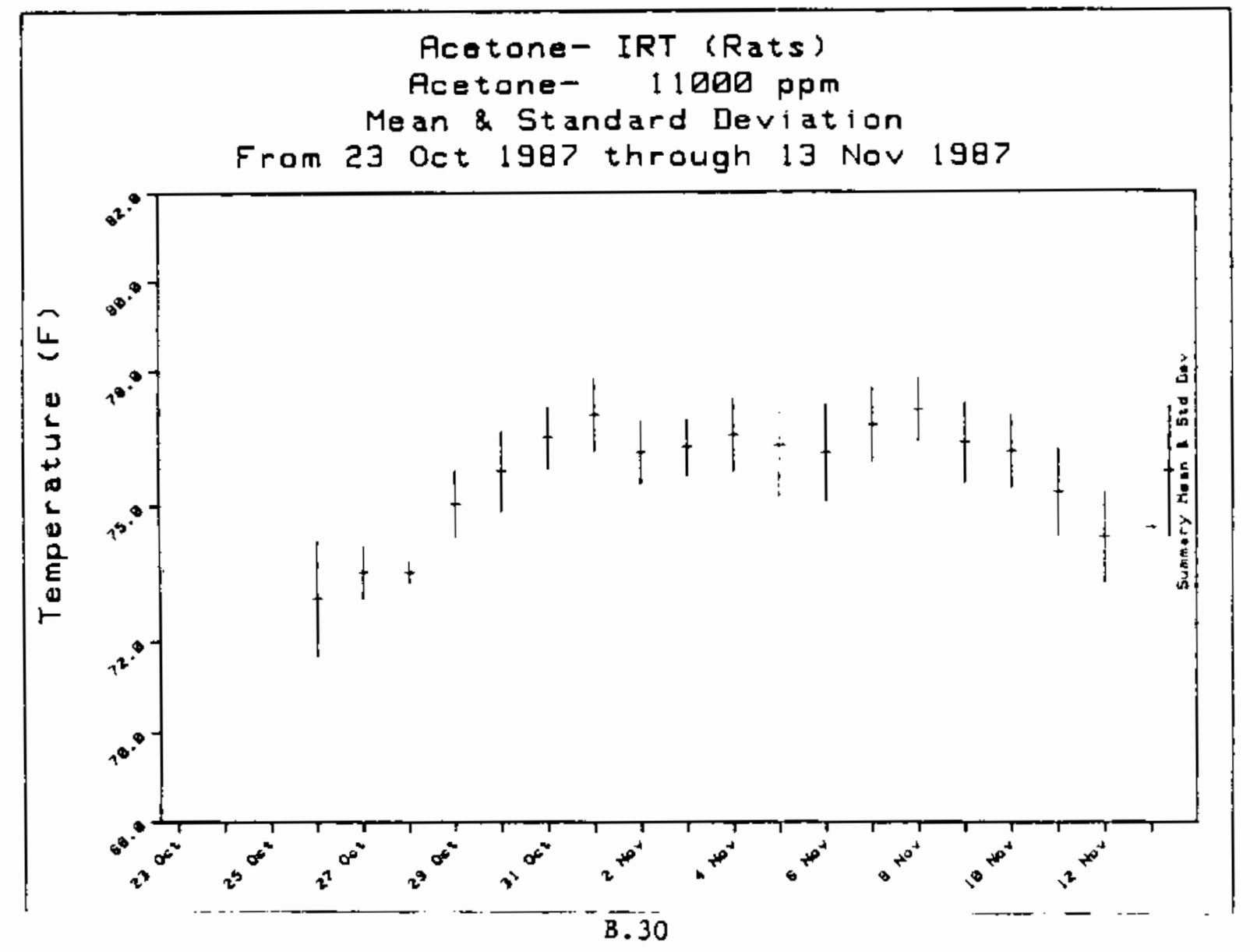


Daily Sumation For Acetone- IRI (Rats). From 23 0ct 1987 through 13 Nov 1987

\begin{tabular}{|c|c|c|c|c|c|c|c|c|c|}
\hline \multicolumn{3}{|c|}{ Summary Data for: Acetone- } & \multicolumn{5}{|c|}{$0 \mathrm{ppm} /$ Relative Humidity } & \multicolumn{2}{|c|}{40.0 to 70.0} \\
\hline Date & Mean & \% Tarqet & Std Dev & $\%$ RSO & Maximum & Minimum & N & $\mathrm{M}$ in & $\% N$ in \\
\hline 23 Oct 1987 & 66.2 & $120 \%$ & 4.07 & $6 \%$ & 70.0 & 59.0 & 6. & 5. & $100 \%$ \\
\hline 24 Oct 1987 & 61.6 & $112 \%$ & 5.26 & $9 \%$ & 68.0 & 54.0 & 8. & 8. & $100 \%$ \\
\hline 25 oct 1987 & 60.6 & $110 \%$ & 3.93 & $6 \%$ & 65.0 & 55.0 & 8. & 8. & $100 \%$ \\
\hline 26 oct 1987 & 67.9 & $\$ 23 \%$ & 7.54 & $11 \%$ & 79.0 & 59.0 & 7. & 5. & $71 \%$ \\
\hline 27 Oct 1987 & 60.3 & $110 \%$ & .95 & $2 \%$ & 62.0 & 59.0 & 7 & 7. & $100 \%$ \\
\hline 28 Oct 1987 & 60.4 & $110 \%$ & 9.43 & $16 \%$ & 74.0 & 49.0 & 7. & 5. & $71 \%$ \\
\hline 29 oct 1987 & 64.0 & $116 \%$ & 9.10 & $14 \%$ & 75.0 & 53.0 & 8. & 5. & $63 \%$ \\
\hline 30 oct 1997 & 51.9 & $94 x$ & 4.56 & $9 \%$ & 60.0 & 47.0 & 7 & 7. & $100 \%$ \\
\hline 31 oct 1987 & 54.7 & $100 \%$ & 5.06 & $9 \%$ & 63.0 & 48.0 & 8. & 8. & $100 \%$ \\
\hline 1 Nov 1987 & 57.3 & $104 \%$ & 2.55 & $4 \%$ & 62.0 & 53.0 & 8. & 8. & $100 \%$ \\
\hline 2 Nov 1987 & 53.1 & $97 \%$ & 2.36 & $4 \%$ & 58.0 & 50.0 & 8. & 8. & $100 \%$ \\
\hline 3 Nov 1987 & 50.6 & $92 \%$ & 1.85 & $4 \%$ & 54.0 & 48.0 & 8. & 8. & $100 \%$ \\
\hline 4 Nov 1997 & 50.5 & $92 \%$ & 1.31 & $3 \%$ & 52.0 & 48.0 & 8. & 8. & $100 \%$ \\
\hline 5 Nov 1987 & 50.8 & $92 \%$ & 1.49 & $3 x$ & 53.0 & 49.0 & 8. & 8. & $100 x$ \\
\hline 6 Nov 1987 & 51.6 & $94 \%$ & 1.92 & $4 \%$ & 54.0 & 49.0 & 8. & 8. & $100 \%$ \\
\hline 7 Nov 1987 & 50.8 & $92 \%$ & 1.91 & $4 \%$ & 54.0 & 49.0 & 8. & 8. & $100 \%$ \\
\hline 8 Nov 1987 & 49.0 & $89 \%$ & 1.85 & $4 x$ & 51.0 & 46.0 & 8. & 8. & $100 \%$ \\
\hline 9 Nov 1987 & 50.5 & $92 \%$ & 2.07 & $4 x$ & 53.0 & 46.0 & 8. & 8. & $100 \%$ \\
\hline 10 Nov 1987 & 49.7 & $90 \%$ & 1.91 & $4 \%$ & 53.0 & 47.0 & 8. & 8. & $100 \%$ \\
\hline 11 Hov 1987 & 49.6 & $90 \%$ & 2.88 & $6 x$ & 53.0 & 45.0 & 8. & 8. & $100 \%$ \\
\hline 12 Nov 1987 & 47.0 & $85 \%$ & 2.45 & $5 \%$ & 52.0 & 45.0 & 8. & 8. & $100 \%$ \\
\hline $13 \mathrm{Nav} 1987$ & 45.0 & $82 \%$ & 0.00 & $0 x$ & 45.0 & 45.0 & 1. & 1. & $100 \%$ \\
\hline Summary & 54.8 & $100 \%$ & 7.21 & $13 \%$ & 79.0 & 45.0 & 63. & 156 & $96 \%$ \\
\hline
\end{tabular}

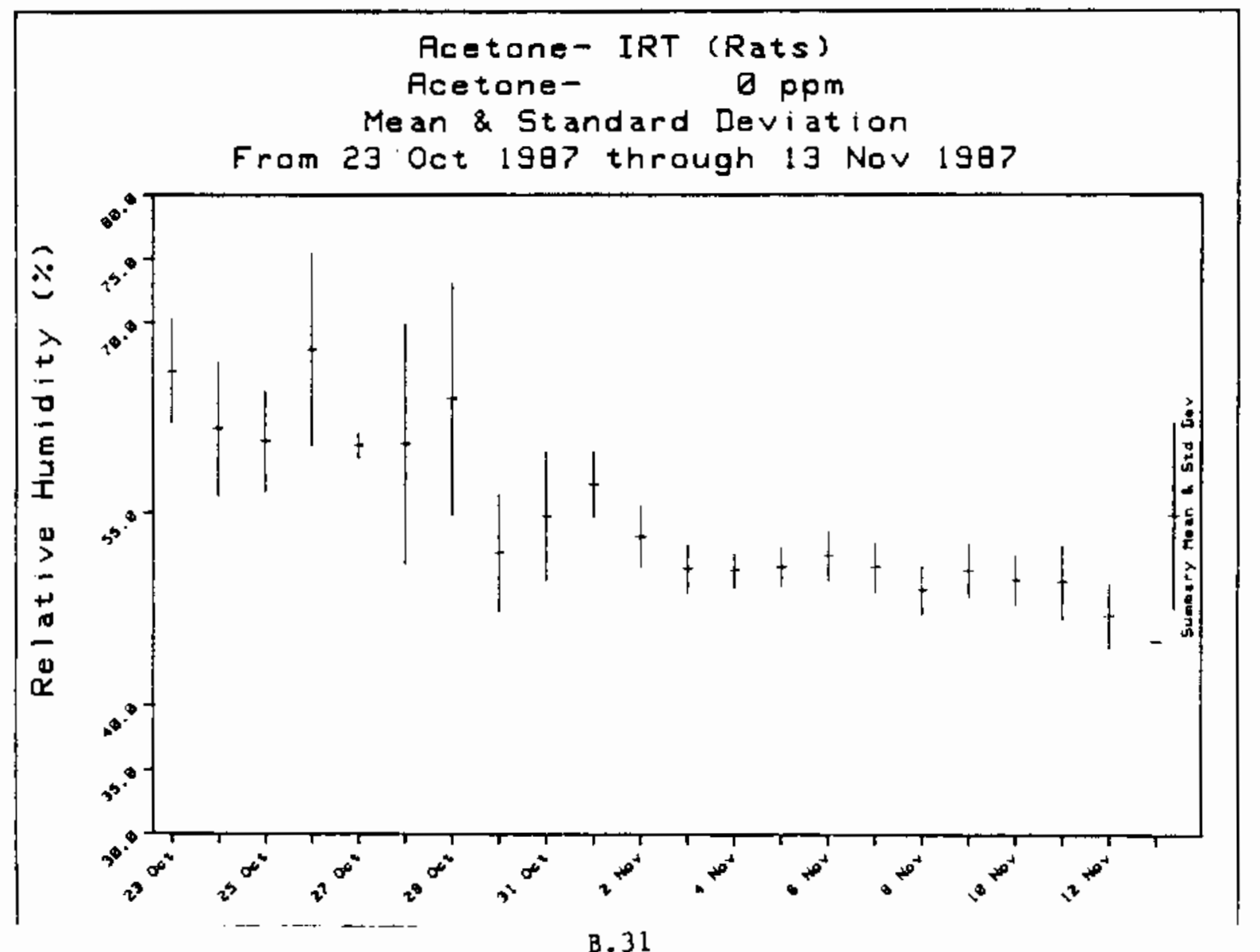


Daily Sumation For Acetone- IRT (Rats) From 23 Oct 1987 through 13 Nor 1987

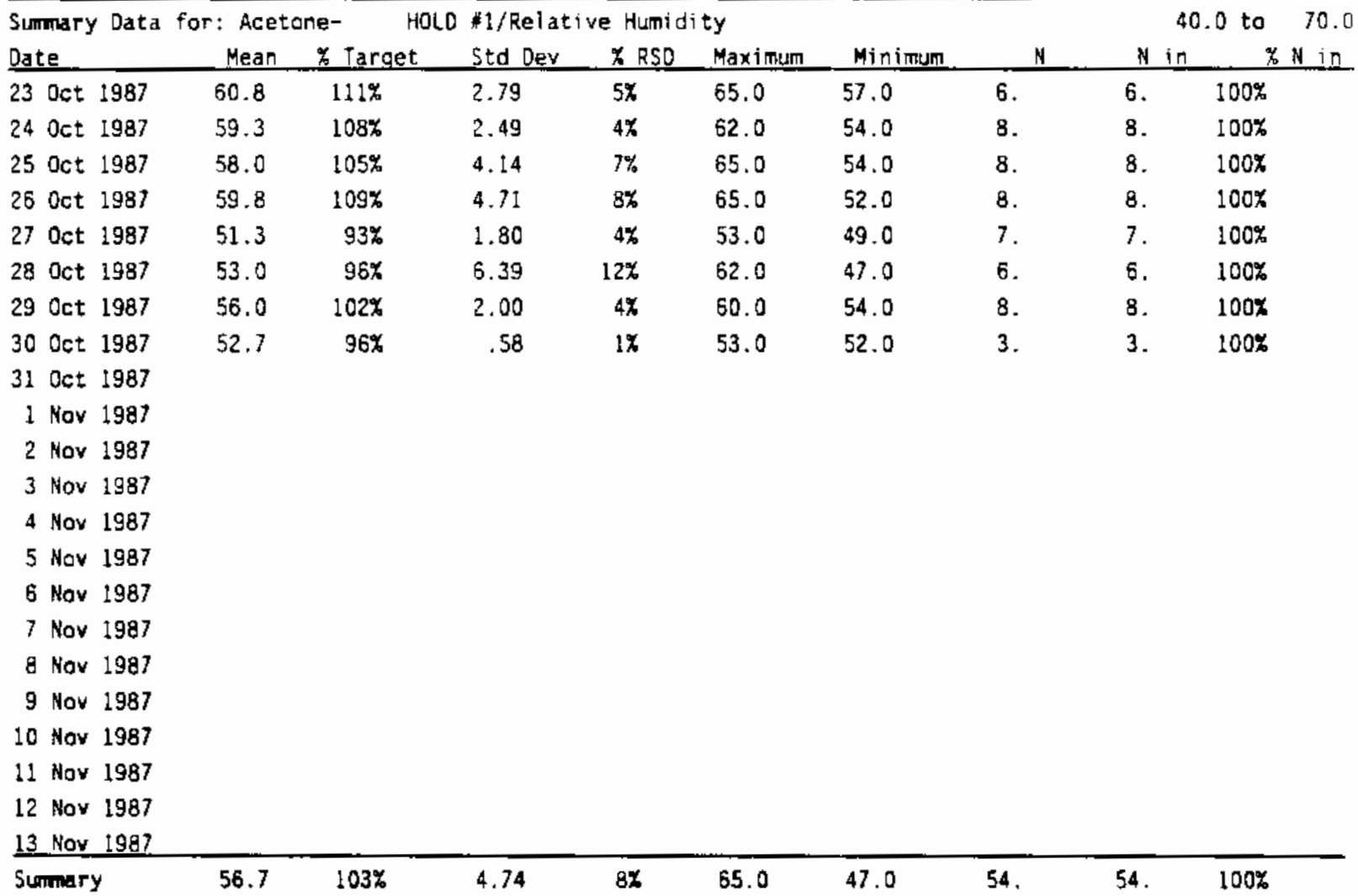

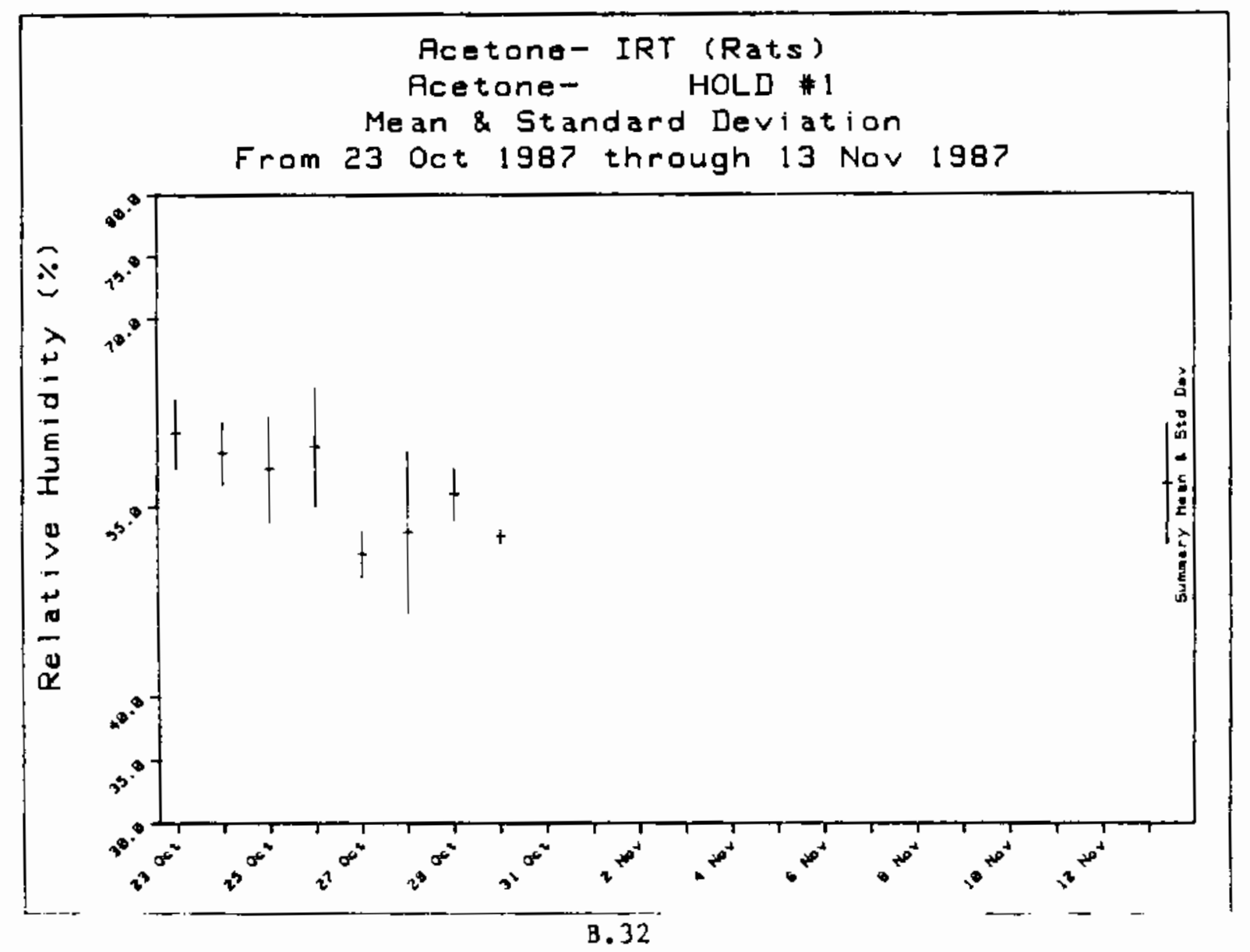


Daily Summation For Acetone-. IRT (Rats) From 23 Oct 1987 through 13 Nov 1987

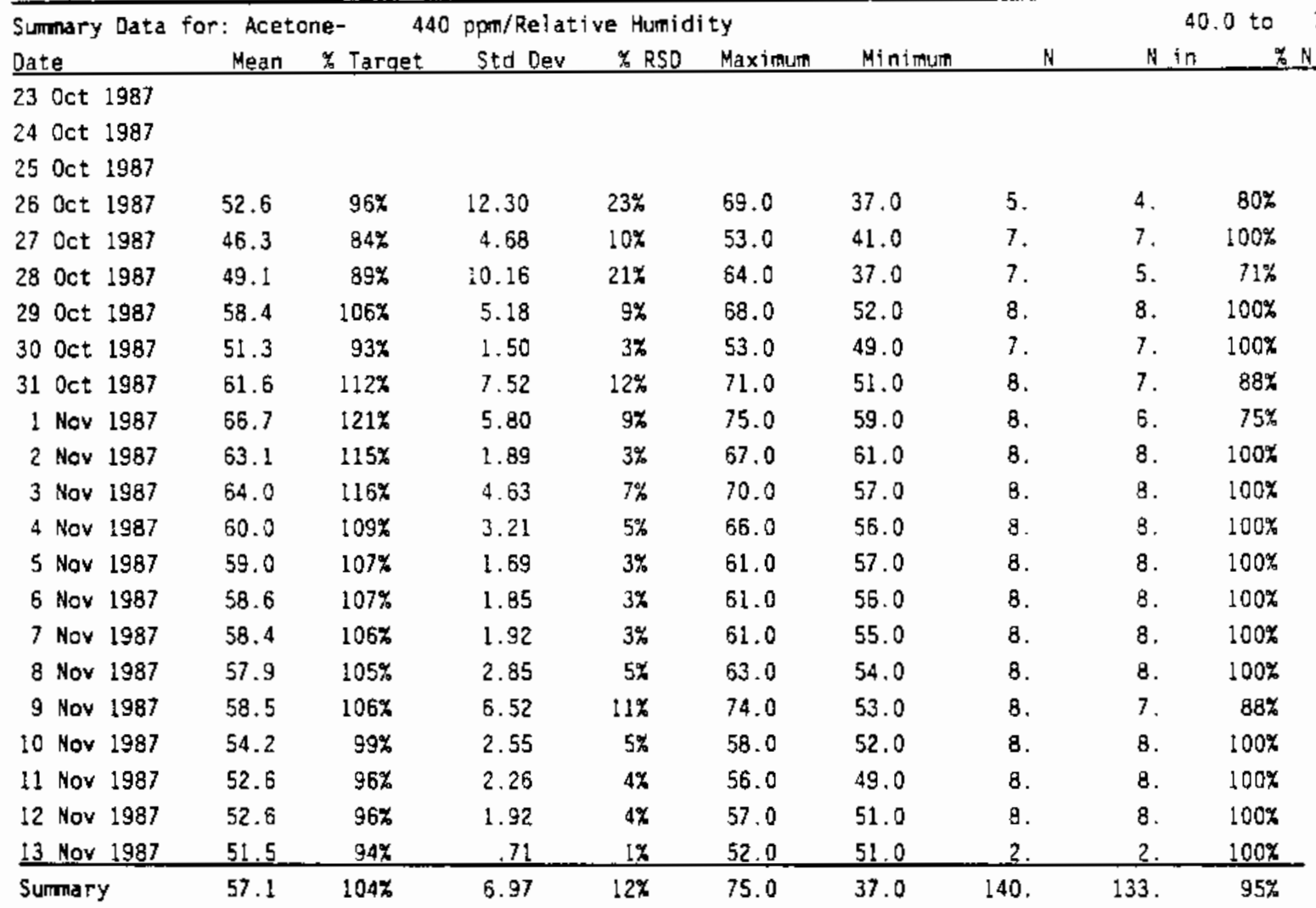

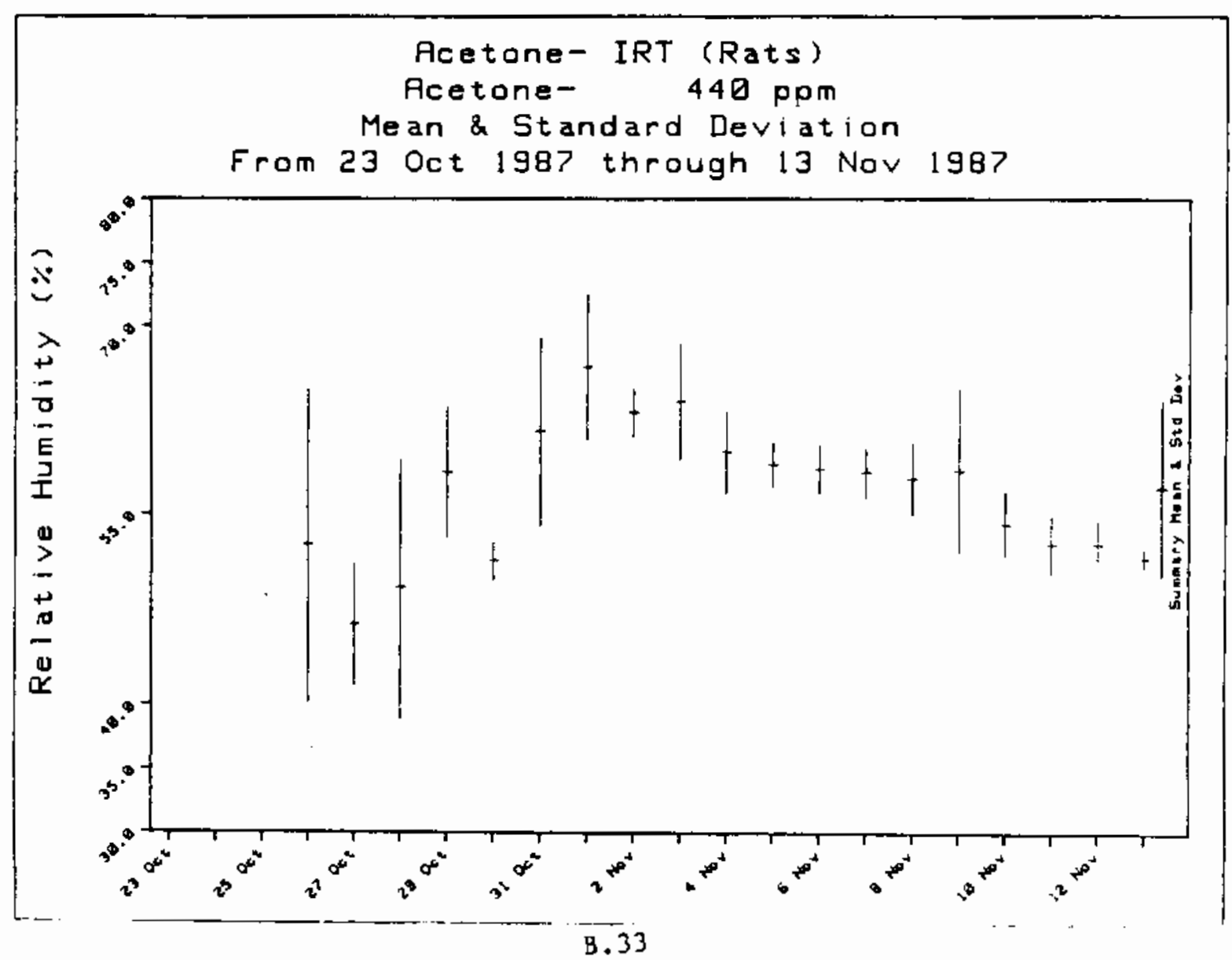


Daily Sumation For Acetone- IRT (Rats) From 23 Oct 1987 through 13 Nov 1987

\begin{tabular}{|c|c|c|c|c|c|c|c|c|c|}
\hline \multicolumn{8}{|c|}{ Summary Data for: Acetone- $2200 \mathrm{ppm} /$ Relative Humidity } & \multicolumn{2}{|c|}{40.0 to } \\
\hline Date. & Mean & \%. Tarqet & Std Dev & $\%$ RSD & Maximum & Minimum & Nㅗ & $\mathrm{N}$ in & $\%$ \\
\hline \multicolumn{10}{|l|}{23 oct 1987} \\
\hline \multicolumn{10}{|l|}{24 oct 1987} \\
\hline \multicolumn{10}{|l|}{25 oct 1987} \\
\hline 26 oct 1987 & 51.8 & $94 \%$ & 9.36 & $18 \%$ & 51.0 & 38.0 & 5. & 4. & $80 \%$ \\
\hline 27 oct 1987 & 46.9 & $85 \%$ & 4.10 & $9 \%$ & 53.0 & 42.0 & 7. & 7. & $100 \%$ \\
\hline 28 Oct 1987 & 48.1 & $88 \%$ & 9.89 & $21 \%$ & 61.0 & 36.0 & 7. & 5. & $71 \%$ \\
\hline 29 Oet 1987 & 62.5 & $114 \%$ & 3.82 & $6 \%$ & 70.0 & 58.0 & 8. & 8. & $100 \%$ \\
\hline 30 Oct 1987 & 55.1 & $100 \%$ & 4.45 & $8 \%$ & 62.0 & 48.0 & 7. & 7. & $100 \%$ \\
\hline 31 Oct 1987 & 56.5 & $103 \%$ & 3.78 & $7 \%$ & 64.0 & 53.0 & 8. & 8. & $100 \%$ \\
\hline 1 Nov 1987 & 59.4 & $108 \%$ & 3.16 & $5 \%$ & 65.0 & 56.0 & 8. & 8. & $100 \%$ \\
\hline 2 Nov 1987 & 55.7 & $101 \%$ & 2.05 & $4 \%$ & 60.0 & 53.0 & 8. & 8. & $100 \%$ \\
\hline 3 Nov 1987 & 54.7 & $100 \%$ & 1.16 & $2 \%$ & 57.0 & 53.0 & 8. & 8. & $100 \%$ \\
\hline 4 Nov 1987 & 56.0 & $102 \%$ & 1.20 & $2 \%$ & 58.0 & 54.0 & 8. & 8. & $: 00 \%$ \\
\hline 5 Nov 1987 & 55.6 & $101 \%$ & 1.77 & $3 \%$ & 58.0 & 52.0 & 8. & 8. & $: 00 \%$ \\
\hline 6 Nov 1987 & 54.2 & $99 \%$ & 1.83 & $3 \%$ & 57.0 & 52.0 & 8. & 8. & $100 \%$ \\
\hline 7 Nov 1987 & 54.7 & $100 \%$ & 1.28 & $2 \%$ & 57.0 & 53.0 & 8. & 8. & $\mathrm{i} 00 \%$ \\
\hline 8 Nov 1987 & 54.5 & $99 \%$ & 2.14 & $4 \%$ & 57.0 & 51.0 & 8. & 8. & $100 \%$ \\
\hline 9 Nov 1987 & 53.7 & $98 \%$ & 1.28 & $2 \%$ & 55.0 & 52.0 & 8. & 8. & $100 \%$ \\
\hline 10 Nov 1987 & 53.5 & $97 \%$ & 2.00 & $4 \%$ & 57.0 & 52.0 & 8. & 8. & $100 \%$ \\
\hline 11 Nov 1987 & 54.0 & $98 \%$ & 2.20 & $4 \%$ & 58.0 & 51.0 & 8. & 8. & $100 \%$ \\
\hline 12 Nov 1987 & 53.5 & $97 \%$ & 2.33 & $4 \%$ & 58.0 & 51.0 & 8. & 8. & $100 \%$ \\
\hline $13 \mathrm{Nov} 1987$ & 52.5 & $95 \%$ & .71 & $1 \%$ & 53.0 & 52.0 & 2. & 2. & $100 \%$ \\
\hline Summary & 54.6 & $99 \%$ & 4.81 & $9 \%$ & 70.0 & 36.0 & 140. & 137. & $98 \%$ \\
\hline
\end{tabular}

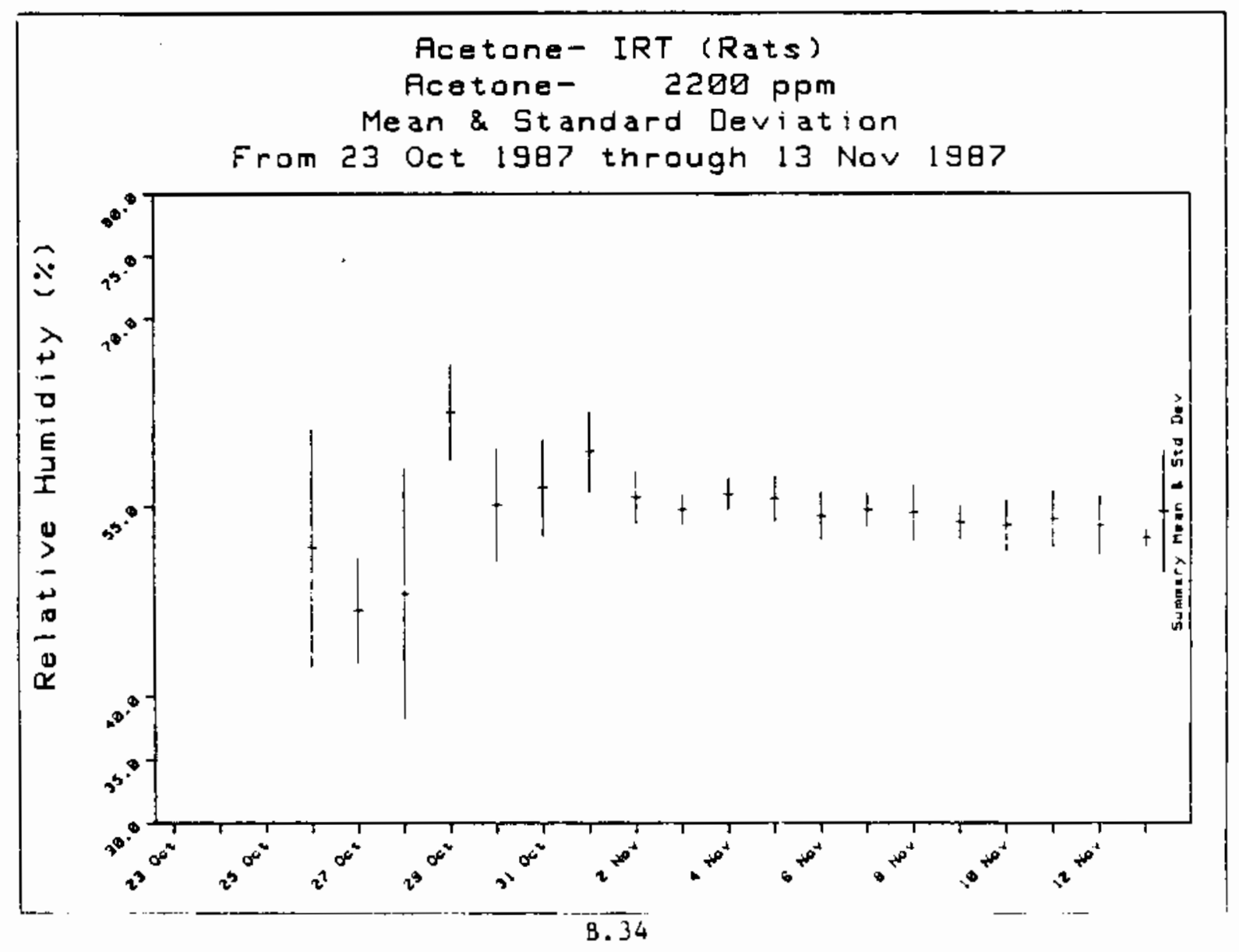


Daily Summation For Acetone- IRT (Rats) From 23 Oct 1987 through 13 Nov 1987

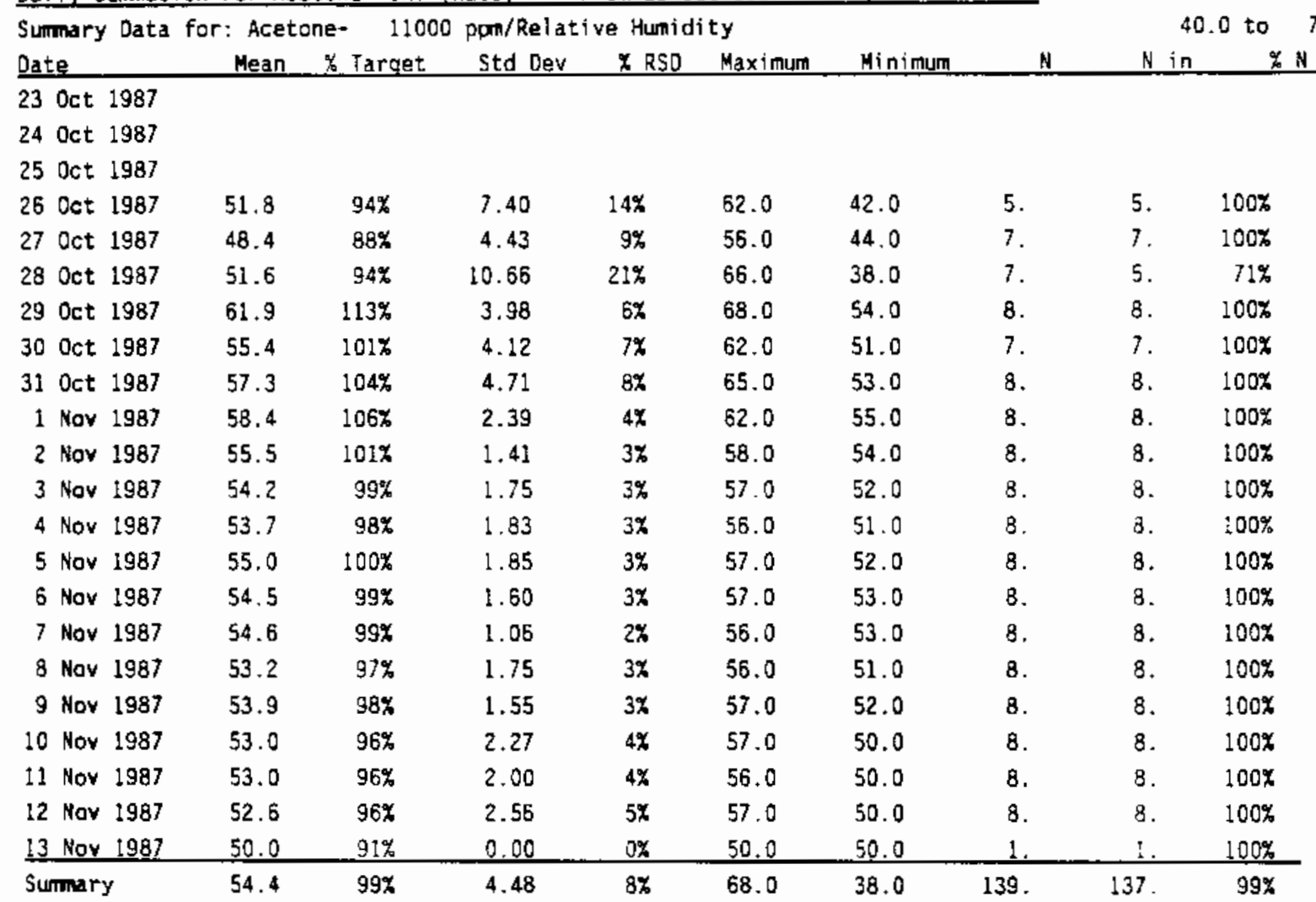

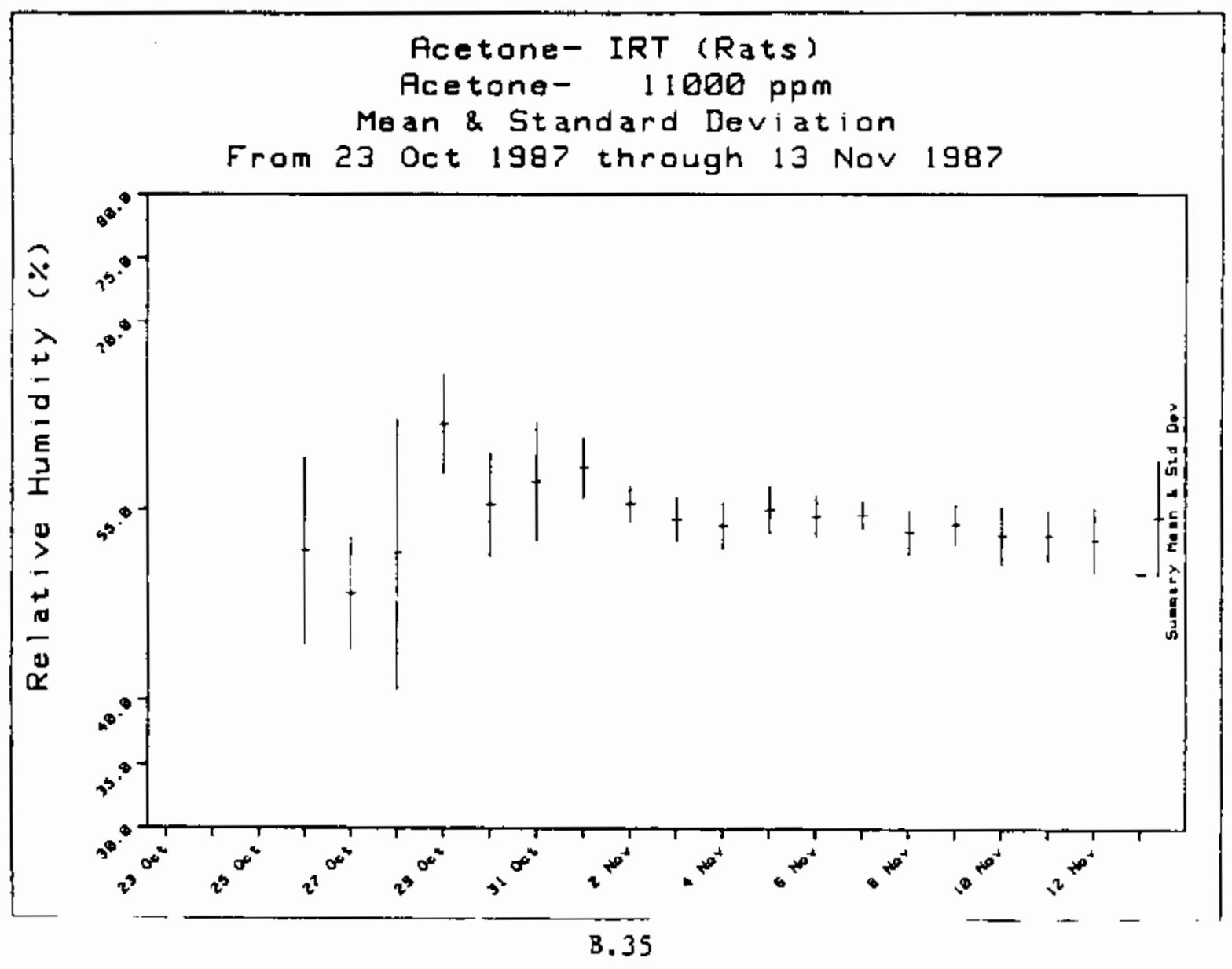


Dafiy Summation For Acetone- IRT (Rats)__ From 23 Oct 1987 through 13 Nor 1987

\begin{tabular}{|c|c|c|c|c|c|c|c|c|c|}
\hline Surmary Data & Ir: Acet & e- & $\mathrm{pm} /$ Exhau & Air Fl & & & & & 0 to \\
\hline Date & Mean & $\%$ Tarqet & Std Dev & $x$ RSD & Maximum & Minimum & $\mathrm{N}$ & $\mathrm{Nin}$ & $\% \mathrm{Nin}$ \\
\hline 23 oct 1987 & 14.9 & $99 x$ & .03 & $0 \%$ & 15.0 & 14.9 & 7. & 7. & $100 \%$ \\
\hline 24 Oct 1987 & 14.9 & $99 \%$ & .02 & $0 \%$ & 14.9 & 14.9 & 8. & 8. & $100 \%$ \\
\hline 25 oct 1987 & 14.9 & $99 \%$ & .01 & $0 \%$ & 14.9 & 14.9 & 8. & 8. & $100 \%$ \\
\hline 26 oct 1987 & 14.8 & $99 \%$ & .16 & $1 \%$ & 14.9 & 14.5 & 7. & 7. & $100 \%$ \\
\hline 27 Det 1987 & 14.9 & $99 \%$ & .02 & $0 x$ & 14.9 & 14.9 & 7. & 7. & $100 \%$ \\
\hline 28 oct 1987 & 14.9 & $99 \%$ & .04 & $0 \%$ & 14.9 & 14.8 & 4. & 4. & $100 \%$ \\
\hline 29 Oct 1987 & 14.9 & $99 x$ & .05 & $0 x$ & 15.0 & 14.8 & 8. & 8. & $100 \%$ \\
\hline 30 oct 1987 & 15.0 & $100 \%$ & .02 & $0 x$ & 15.0 & 14.9 & 8. & 8. & $100 \%$ \\
\hline 31 Oct 1987 & 14.9 & $99 \%$ & .05 & $0 \%$ & 15.0 & 14.8 & 8. & 8. & $100 \%$ \\
\hline 1 Nov 1987 & 14.8 & $99 x$ & .04 & $0 \%$ & 14.9 & 14.7 & 8. & 8. & $100 \%$ \\
\hline 2 Nov 1987 & 14.8 & $99 \%$ & .04 & $0 x$ & 14.9 & 14.8 & 8. & 8. & $100 \%$ \\
\hline 3 Nov 1987 & 14.9 & $99 \%$ & .03 & $0 \%$ & 14.9 & 14.8 & 7. & 7. & $100 \%$ \\
\hline 4 Nov 1987 & 14.9 & $99 z$ & .03 & $O \%$ & 14.9 & 14.8 & 8. & 8. & $100 \%$ \\
\hline 5 Nov 1987 & 14.8 & $99 \%$ & .03 & $0 \%$ & 14.9 & 14.8 & 8. & 8. & $100 \%$ \\
\hline 6 Nor 1987 & 14.9 & $99 \%$ & .02 & $0 x$ & 14.9 & 14.8 & 7. & 7. & $100 \%$ \\
\hline 7 Nov 1987 & 14.9 & $99 \%$ & .02 & $0 \%$ & 14.9 & 14.8 & 7. & 7. & $100 \%$ \\
\hline 8 Nov 1987 & 14.8 & $99 \%$ & .03 & $0 \%$ & 14.9 & 14.8 & 8. & 8. & $100 \%$ \\
\hline 9 Nov 1987 & 14.8 & $99 x$ & .14 & $1 \%$ & 14.9 & 14.5 & 7. & 7. & $100 \%$ \\
\hline 10 Nor 1987 & 14.8 & $99 \%$ & .02 & $0 \%$ & 14.8 & 14.8 & 8. & 8. & $100 \%$ \\
\hline 11 Nov 1987 & 14.8 & $99 \%$ & .01 & $0 \%$ & 14.8 & 14.8 & 7. & 7. & $100 \%$ \\
\hline 12 Nov 1987 & 14.8 & $98 \%$ & .02 & $0 x$ & 14.8 & 14.7 & 7. & 7. & $100 \%$ \\
\hline 13 Nor 1987 & 14.7 & $98 \%$ & 0.00 & $a \%$ & 14.7 & 14.7 & 1. & 1. & $100 \%$ \\
\hline Simmary & 14.9 & $99 x$ & .07 & $0 \%$ & 15.0 & 14.5 & 156. & 156. & $100 \%$ \\
\hline
\end{tabular}

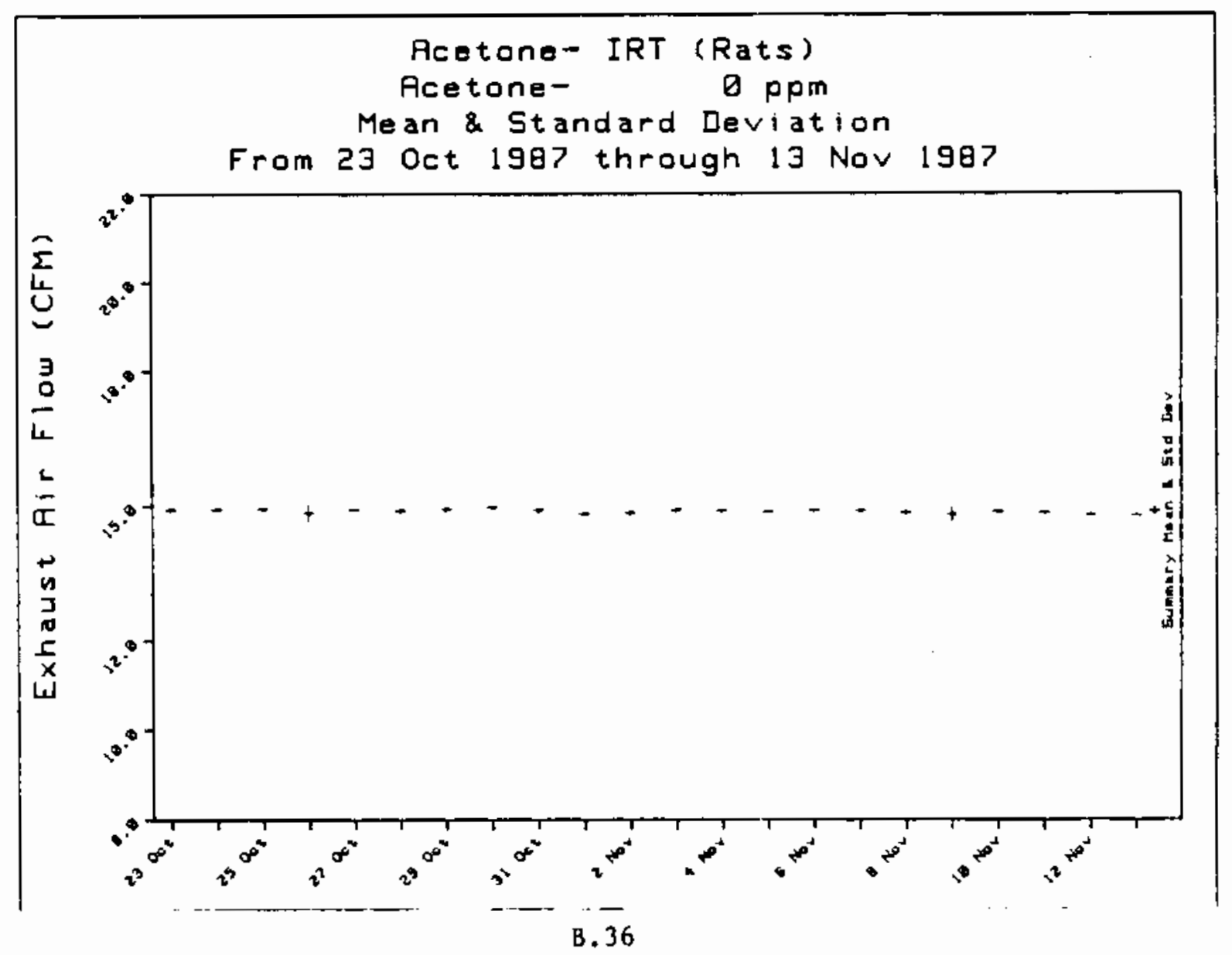


Daily Summation For Acetone- IRT (Rats)

From 23 Oct 1987 through 30 Oct 1987

Sumary Data for: Acetone- HOLD \#1/Exhaust Air Flow Range= 12.0 to 18.0

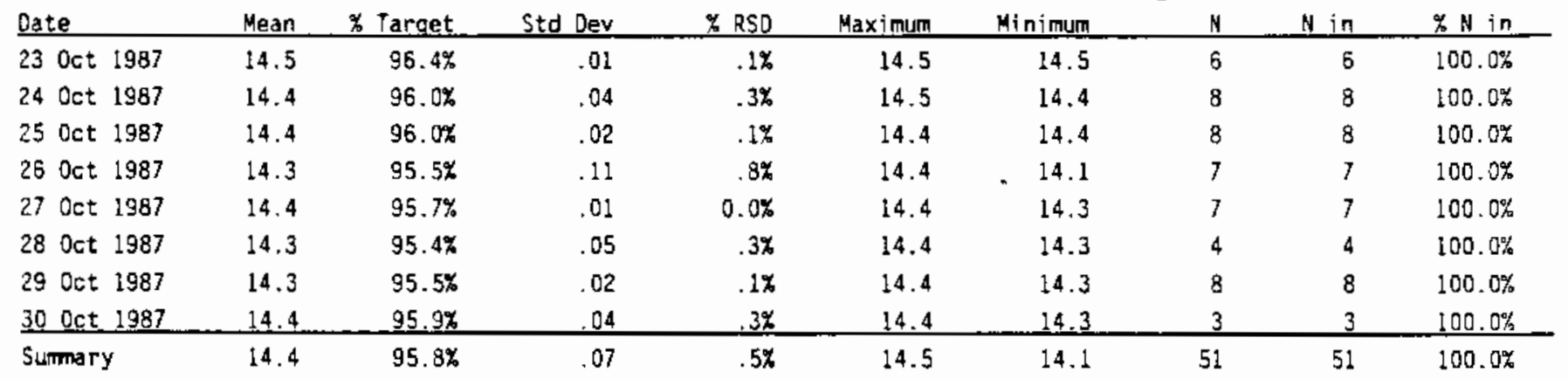

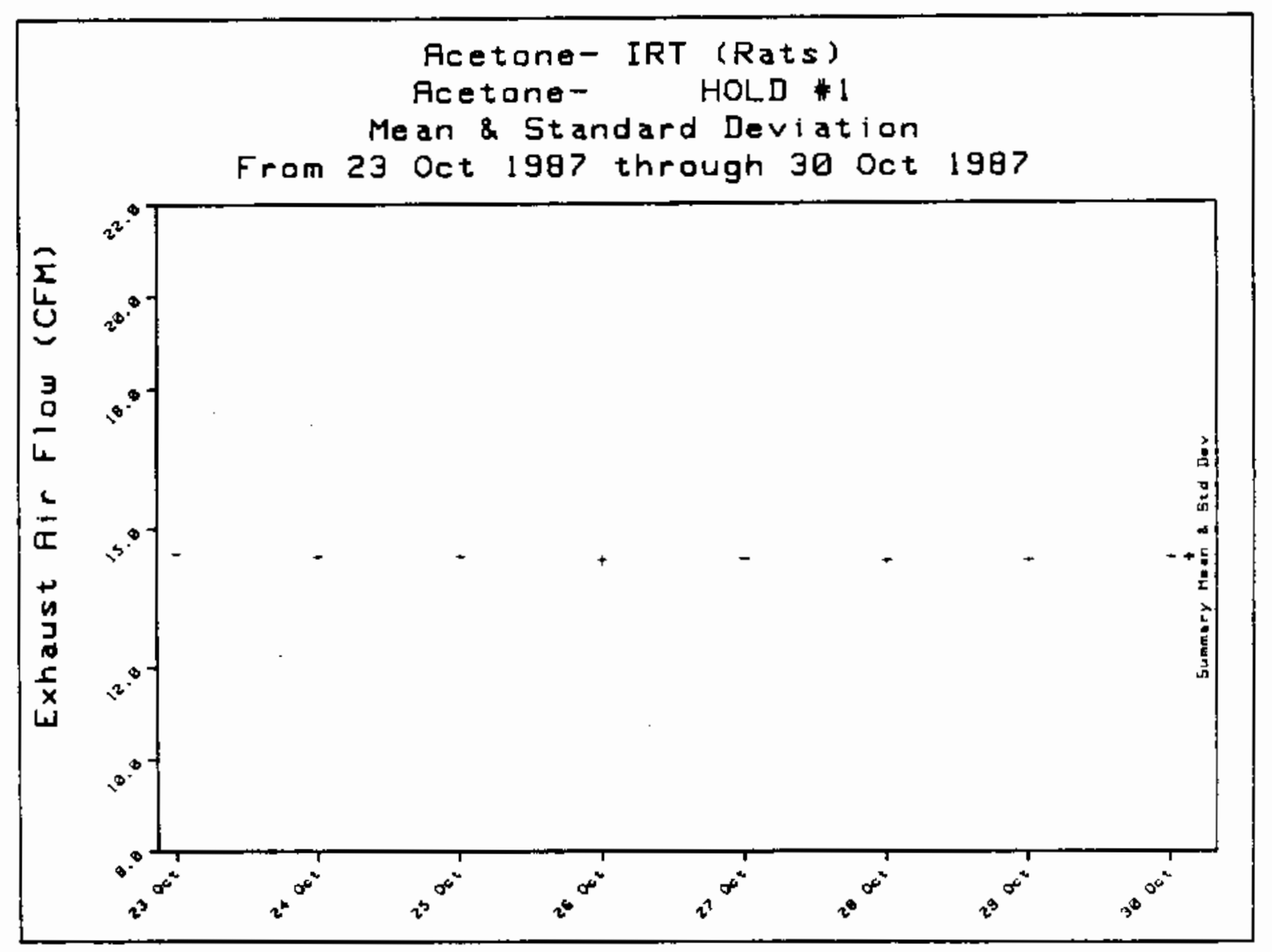


Daily Summation For Acetone- IRT (Rats) From 23 Oct 1987 through 13 Nov 1987

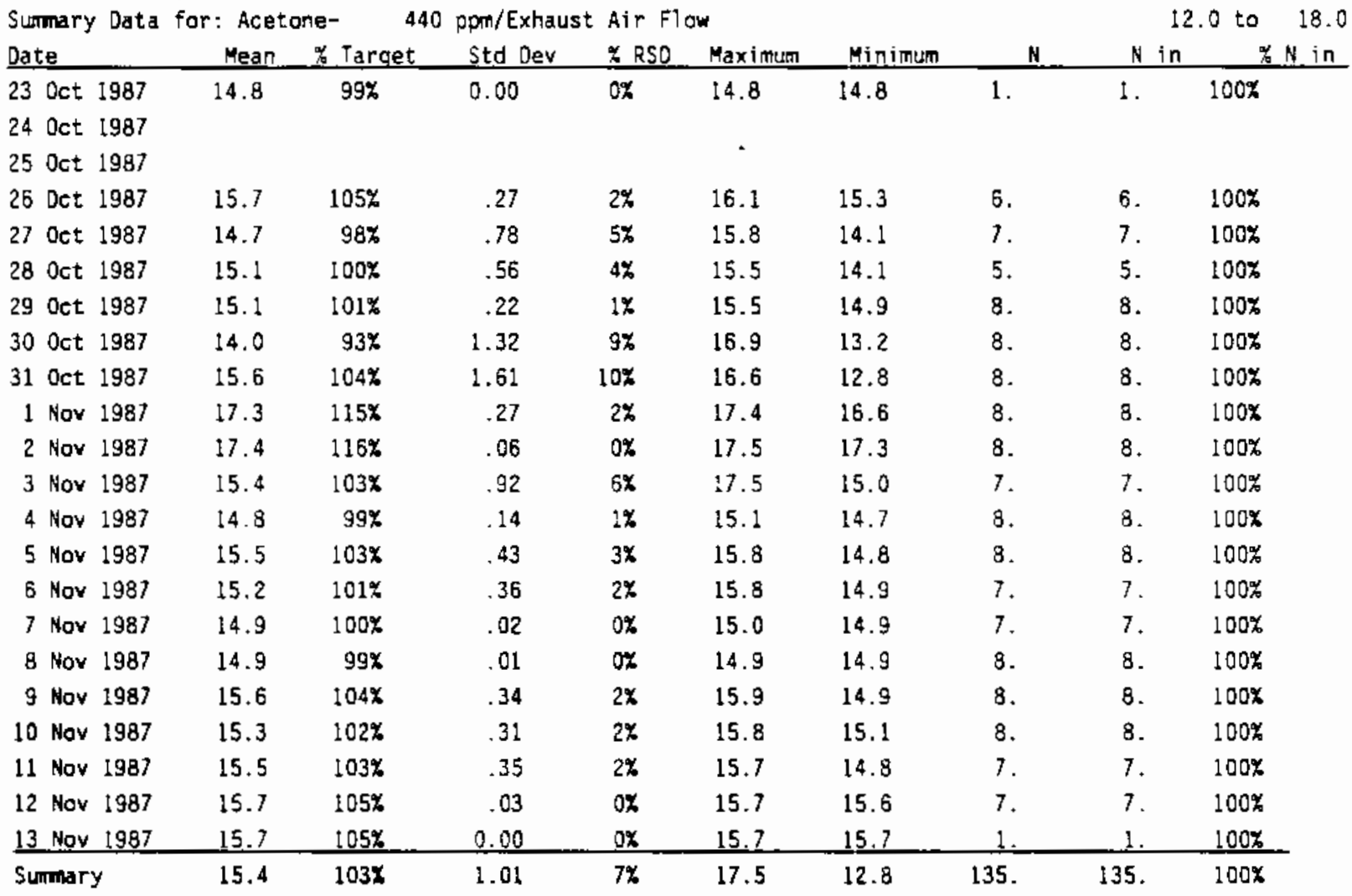

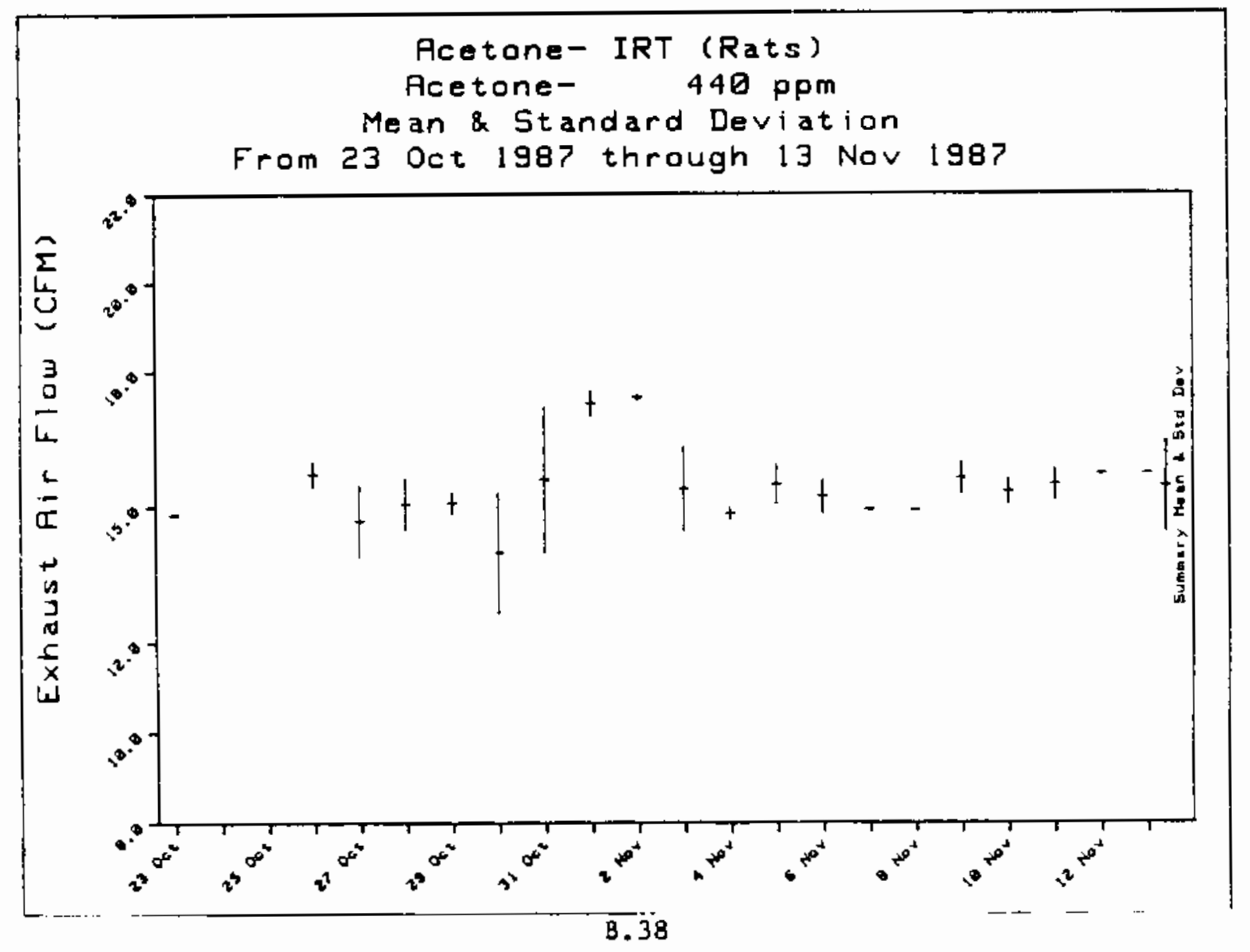


Daily Summation For Acetone- IRT (Rats) From 23 Oct 1987 through 13 Nov 1987

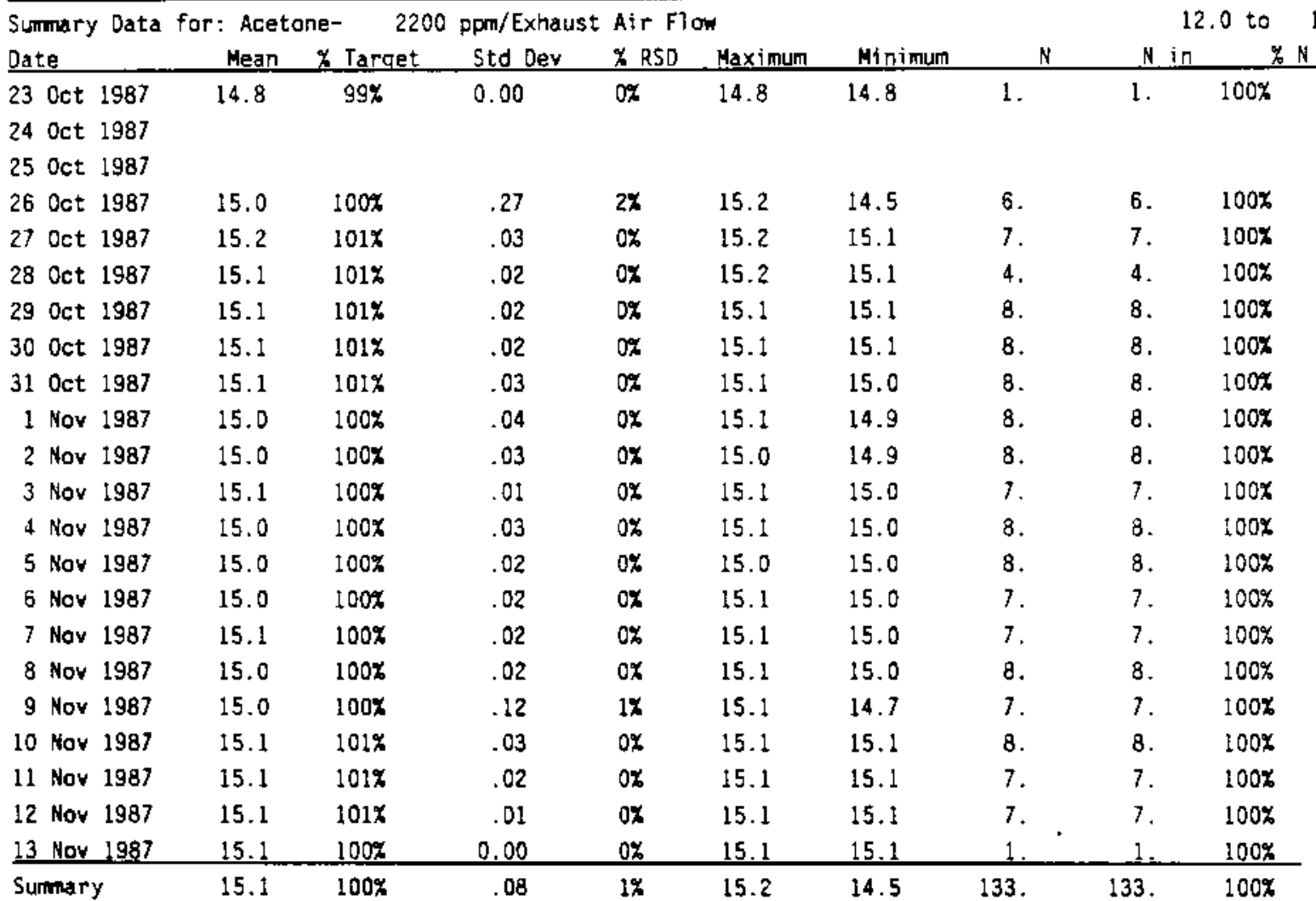

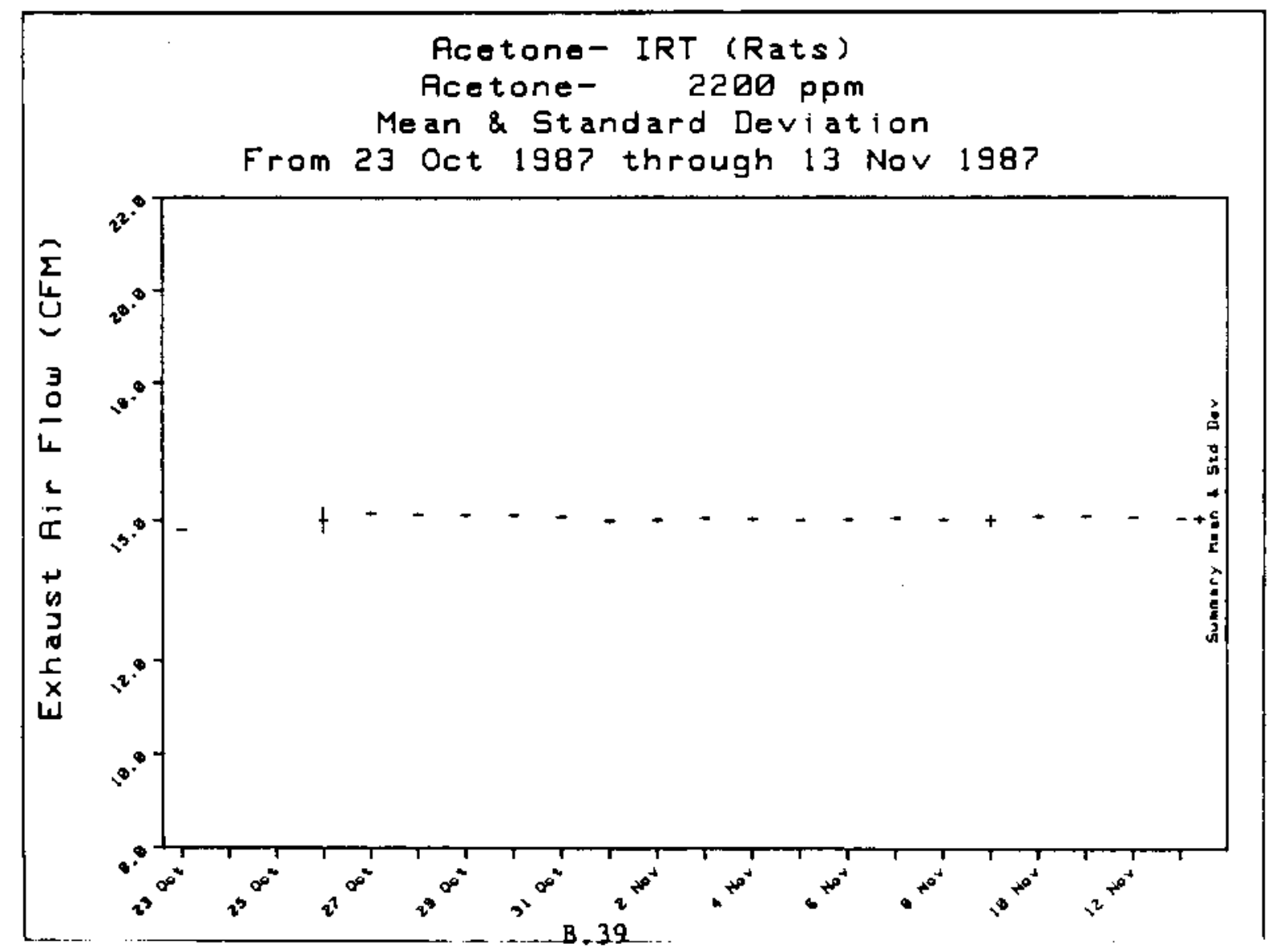


Daily Summation For Acetone- IRT (Rats). From 23 Oct 1987 through 13 Nov 1987

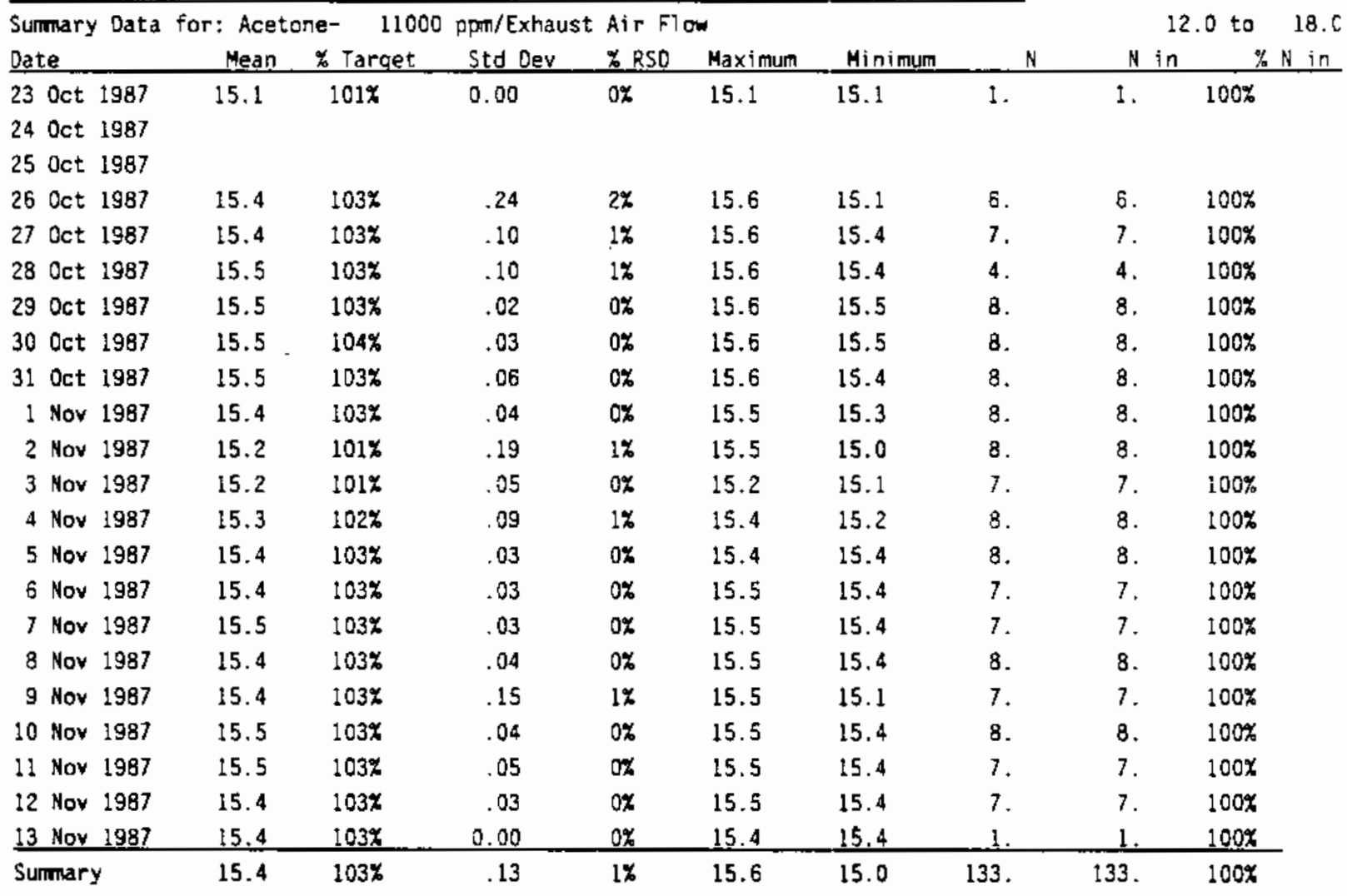

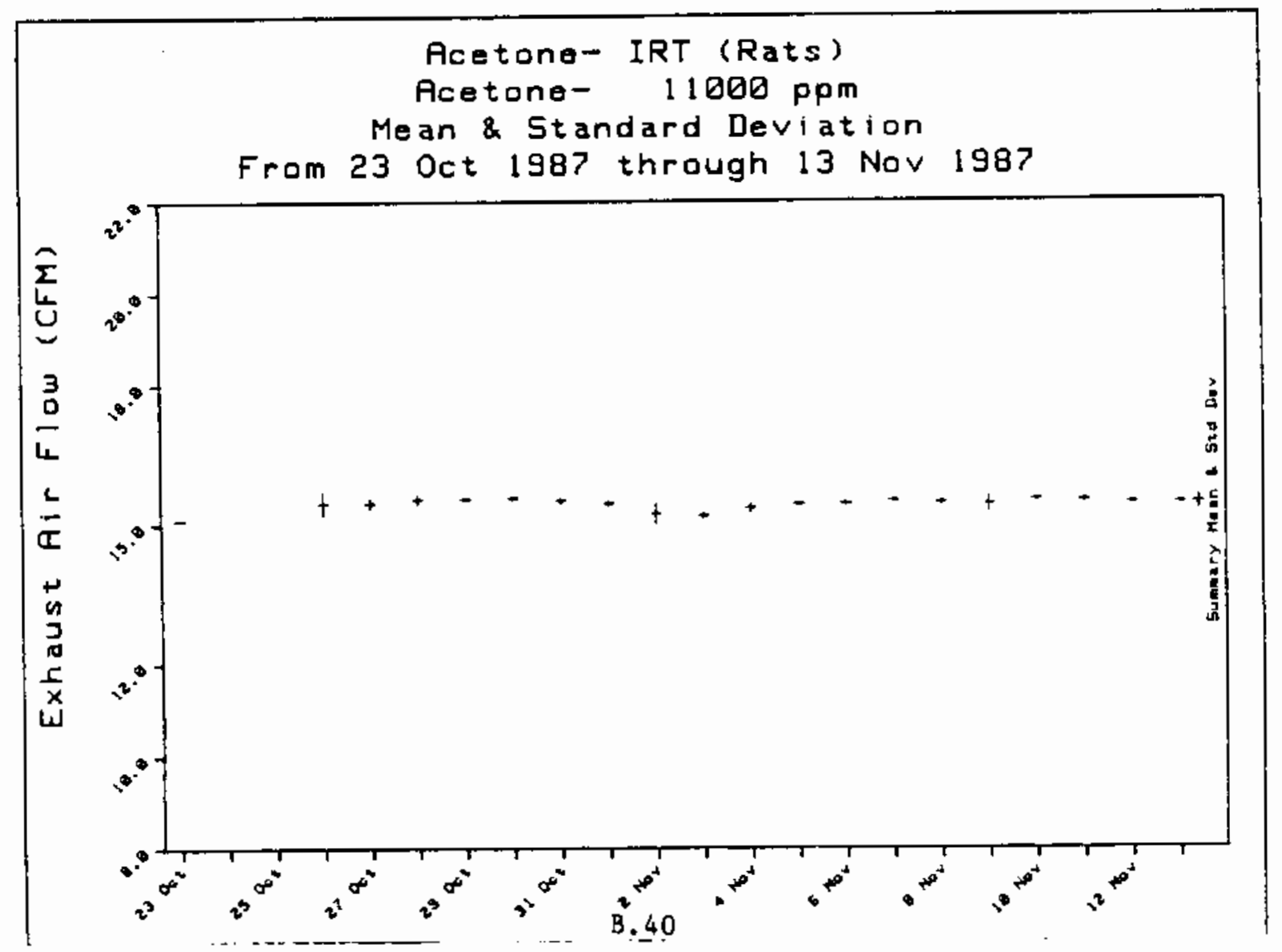


CHAMBER UNIFORMITY DATA SIIEET

COMPOUND: Acetone IRT

EXPOSURE ROOM NUMBER: 436

\begin{tabular}{|c|c|c|c|c|c|c|c|c|c|c|c|}
\hline \multicolumn{2}{|c|}{$\begin{array}{r}\text { CHAMBER: } \\
\text { DATE: }\end{array}$} & $\begin{array}{c}7 / 2200 \mathrm{ppm} \\
9 / 18 / 87 \\
\text { MONITOR } \\
\text { READING }\end{array}$ & $\mathscr{6}$ of Mean & $\begin{array}{c}\text { 9/22/87 } \\
\text { MONTOR } \\
\text { READING }\end{array}$ & $\%$ of Mean & $\begin{array}{c}\# 6 / 440 \mathrm{ppm} \\
9 / 22 / 87 \\
\text { MONITOR } \\
\text { READING }\end{array}$ & \% of Mean & & \multicolumn{2}{|l|}{$\begin{array}{l}\text { MONITOR } \\
\text { READING }\end{array}$} \\
\hline \multirow[t]{6}{*}{ BACK: } & $1 \mathrm{~B}$ & 1240000.0 & $100.1 \%$ & 3071000.0 & $97.5 \%$ & 250600.0 & $96.7 \%$ & & & & \\
\hline & $2 B$ & 1244000.0 & $100.4 \%$ & 3195000.0 & $101.4 \%$ & 268800.0 & $103.7 \%$ & & & & \\
\hline & $3 B$ & 1247000.0 & $100.7 \%$ & 3079000.0 & $97.8 \%$ & 256300.0 & $98.9 \%$ & & & & \\
\hline & $4 \mathrm{~B}$ & 1261000.0 & $101.8 \%$ & 3155000.0 & $100.2 \%$ & 255800.0 & $98.7 \%$ & & & & \\
\hline & $5 \mathrm{~B}$ & 1237000.0 & $99.9 \%$ & 3142000.0 & $99.8 \%$ & 258200.0 & $99.6 \%$ & & & & \\
\hline & $6 \mathrm{~B}$ & 1236000.0 & $99.8 \%$ & 3188000.0 & $101.2 \%$ & $265 B 00.0$ & $102.5 \%$ & & & & \\
\hline \multirow[t]{9}{*}{ FRONT: } & $1 F$ & 1229000.0 & $99.2 \%$ & 3249000.0 & $103.1 \%$ & 267100.0 & $103.0 \%$ & & & & \\
\hline & $2 F$ & 1229000.0 & $99.2 \%$ & 3181000.0 & $101.0 \%$ & 264700.0 & $102.1 \%$ & & & & \\
\hline & $3 F$ & 1235000.0 & $99.7 \%$ & 3136000.0 & $99.6 \%$ & 255500.0 & $98.6 \%$ & & & & \\
\hline & $4 F$ & 1236000.0 & $99.8 \%$ & 3098000.0 & $98.4 \%$ & 258200.0 & $99.6 \%$ & & & & \\
\hline & $5 \mathrm{~F}$ & $1243000: 0$ & $100.3 \%$ & 3119000.0 & $99.0 \%$ & 254600.0 & $98.2 \%$ & & & & \\
\hline & $6 \mathrm{~F}$ & 1229000.0 & $99.2 \%$ & 3185000.0 & $101.1 \%$ & 255300.0 & $98.5 \%$ & & & & \\
\hline & $\mathrm{AN}:$ & 1238833.3 & $100.0 \%$ & 3149833.3 & $100.0 \%$ & 259241.7 & $100.0 \%$ & & & & \\
\hline & V: & 9183.32 & $0.7 \%$ & 52818.44 & $1.7 \%$ & 5833.67 & $2.3 \%$ & & & & \\
\hline & $\mathrm{V}: 1$ & 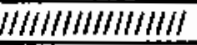 & $\leq 0 \%$ & 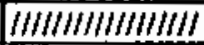 & $\leq 0 \%$ & 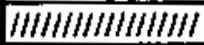 & $\leq 0 \%$ & IIIIIIIIIIIIIIII & & 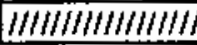 & \\
\hline
\end{tabular}

WPV MEASUREMENTS

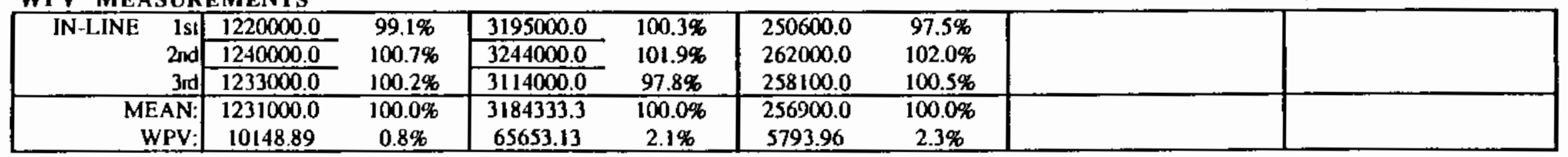

MONITOR TYPE: GC

SERIAL : N809422

MONITOR DATA LOCATION: 2B

COMMENTS: Pre-Exposure Chamber balance. No Animals Present

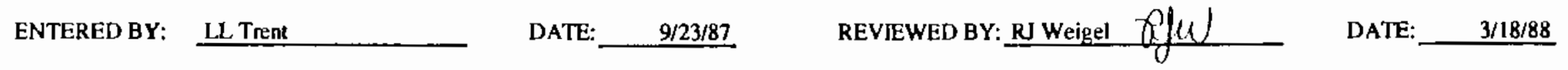


CHAMBER UNIFORMITY DATA SHEET

COMPOUND: Acetone IRT

EXPOSURE ROOM NUMBER: 436

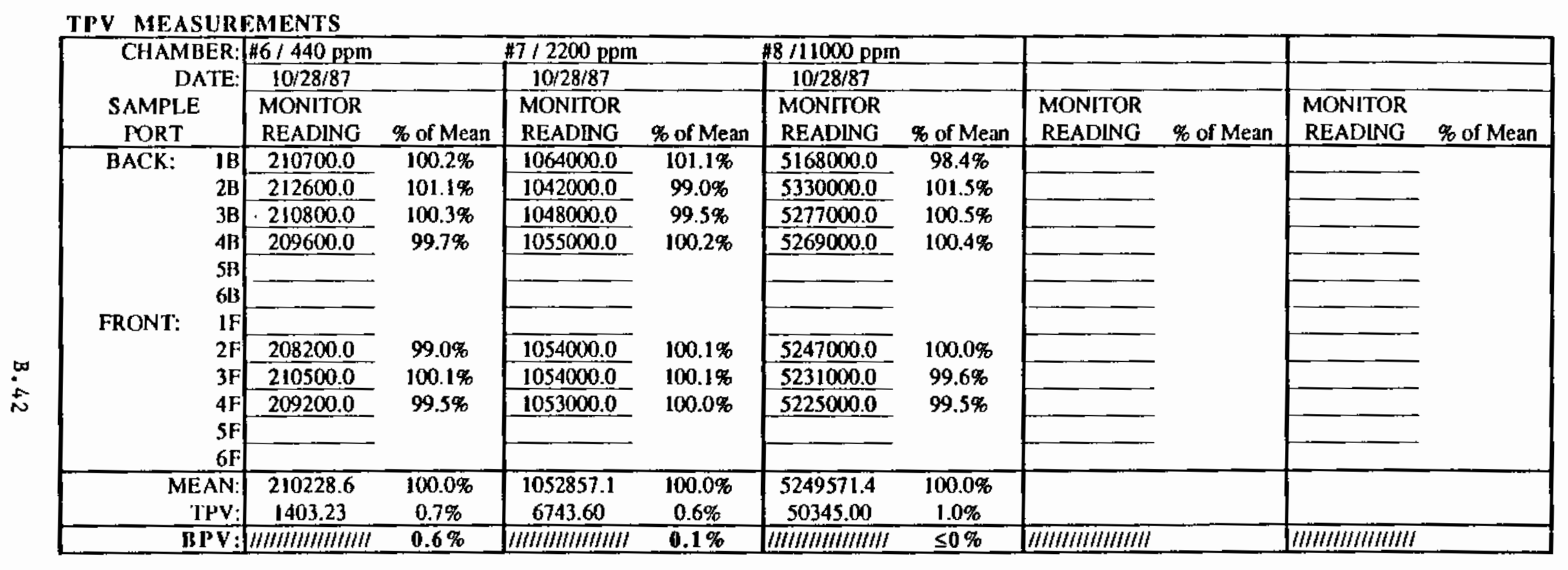

WPY MEASUREMENTS

\begin{tabular}{|c|c|c|c|c|c|c|c|c|}
\hline IN-LINE r \begin{tabular}{r|}
$1 \mathrm{st}$ \\
\\
\end{tabular} & $\frac{210700.0}{211400.0}$ & $\begin{array}{l}100.0 \% \\
100.3 \% \\
99.7 \%\end{array}$ & $\begin{array}{r}1064000.0 \\
1055000.0 \\
1051000.0\end{array}$ & $\begin{array}{l}100.7 \% \\
99.8 \% \\
99.5 \%\end{array}$ & $\frac{5168000.0}{5261000.0}$ & $\begin{array}{l}98.2 \% \\
100.0 \%\end{array}$ & & - \\
\hline $\begin{array}{r}\text { MEAN: } \\
\text { WPV: }\end{array}$ & $\begin{array}{c}210766.7 \\
602.77\end{array}$ & $\begin{array}{c}100.0 \% \\
0.3 \%\end{array}$ & $\begin{array}{c}1056666.7 \\
6658.33\end{array}$ & $\begin{array}{c}100.0 \% \\
0.6 \%\end{array}$ & $\begin{array}{c}5262333.3 \\
95007.02\end{array}$ & $\begin{array}{c}100.0 \% \\
1.8 \%\end{array}$ & & \\
\hline
\end{tabular}

MONITOR TYPE: GC

MONITOR DATA LOCATION: $2 B$

SERIAL \#: N809422

COMMENTS: $\quad$ BNW 52369 Page 36

Study with Rals

\begin{tabular}{|c|c|c|c|c|c|}
\hline GNIERED BY: & LL Trert & DAT & $10 / 28 / 87$ & REVIEWED BY: RJ Weigel & $3 / 18 / 88$ \\
\hline
\end{tabular}




\section{EXPOSURE OPERATION DISCUSSION SHEET}

INCLUDES DISCUSSIONS AND/OR EXPLANATTONS OF PROBLEMS AFFECTING ANIMAL ENYIRONMENT AND EXPOSURES. EXPLANATIONS ARE INCLUDED FOR DATA IN WHICH THERE WERE EXCURSIONS OF DALY MEAN OR STANDARD DEVIATION BEYOND ALLOWABLE OPERATING LIMITS OR EXCURSIONS OF INDIVIDUAL DATUM BEYOND CRITICAL LIMITS.

STUDY: IRT Acetone Inhalation Reproductive Teratology Study

REPORTING PERIOD: October 23.31, 1987

NOTE: 24 Hour Data Collection Period extends from $-5: 00 \mathrm{a} . \mathrm{m}$ to $-5: 00 \mathrm{am}$.

COMPILED BY:

R.I. Weigel Thlu)

DATE: $11 / 9 / 87$

\section{CHAMBER CONCENTRATION}

\section{DATE}

$10 / 29 / 87$

DISCUSSION OR EXPLANATION

Concentration in the $440 \mathrm{ppm}$ chamber ( $797 \mathrm{ppm}$ ) exceeded the critical high operating limit ( $528 \mathrm{ppm}$ ) ar 14:44. The excursion was caused by an overadjustment of the chemical delivery pump following a low reading the previous time. The operaror adjusted the pump downward and continued exposures for the remaining 17 minutes of the exposure day. Exceeding the critical high resulted in automatic shutdown of exposure, but it was restarted immediately. Due to the high reading, \% relative standard deviation exceeded the $10 \%$ limit for the 440 ppm chamber.

10/30/87 Following the misadjustment of the pump at the end of the previous day's exposure, the $440 \mathrm{ppm}$ chemical pump setting was intentionally set low and slowly brought to target over three successive readings. As a result, the concentration in the $440 \mathrm{ppm}$ chamber exceeded the critical low operating limit ( $352 \mathrm{ppm}$ ) twice. The readings were

$$
\begin{array}{ll}
342 \mathrm{ppm} & \text { at 09:19 } \\
322 \mathrm{ppm} & \text { at } 09: 42
\end{array}
$$

At 10:04, the concentration in the 440 pprn chamber was $431 \mathrm{ppm}$. Daily mean concentration and \%RSD remained within the normal limits.

\section{TEMPERATURE \& RELATIVE HUMIDITY}

\section{DATE DISCUSSION OR EXPLANATION}

10/26/87 Relative humidity (79\%) in the 0 ppm chamber exceeded the upper critical operating level (75\%) at 15:46, soon after animal care had resealed the chambers. No adjusuments were made and normal levels were maintained thereafter.

10/28/87 At 15:30, environmental monitoring switch was off for animal observations and was left off until 02:04. Data was manually taken as that time and normal environmental monitoring was resurned

\section{CHAMBER FLOW \& VACUUM}

\section{RATE DISCUSSIONQR EXPLANATION}

10/28/87 At 15:30, environmental monitoring switch was off for animal observations and was left off until 02:04. Data was manually taken at that time and normal environmental monitoring was resumed 


\section{EXPOSURE OPERATION DISCUSSION SHEET}

INCLUDES DISCUSSIONS AND/OR EXPLANATIONS OF PROBLEMS AFFECTING ANIMAL ENVIRONMENT AND EXPOSURES. EXPLANATIONS ARE INCLUDED FOR DATA IN WHICH THERE WERE EXCURSIONS OF DAIL Y MEAN OR STANDARD DEVLATION BEYOND ALLOWABLE OPERATING LIMITS OR EXCURSIONS OF INDIVIDUAL DATUM BEYOND CRITICAL LIMITS.

STUDY: IRT Acetone Inhaladion Reproductive Teratology Study

REPORTING PERIOD: November 1-30, 1987 NOTE: 24 Hour Data Collecrion Period extends from -5:00 am. to -5:00 a.m. COMPILED BY

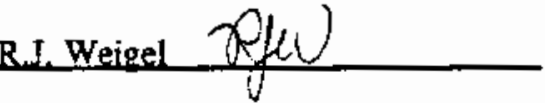

DATE: $12 / 9 / 87$

CHAMBER CONCENTRATION

DATE DISCUSSION OR EXPLANATTON

No problems or excursions to report during this period.

TEMPERATURE \& RELATIVE HUMIDITY

DATE_DISCUSSION OR EXPLANATION

No problems or excursions to report during this period.

CHAMBER FLOW \& VACUUM

DATE___ DISCUSSION OREXPLANATION

No problems or excursions to report during this period. 
Daily Summation For Acetone- IRT (Mice) From 2 Dec 1987 through 17 Dec 1987

\begin{tabular}{|c|c|c|c|c|c|c|c|c|c|}
\hline Surmary Data & for: Acet & & Room/Conce & ration & & & & $0.00 \mathrm{E}$ & to $2.00 \mathrm{E}$ \\
\hline Date & Mean & $\%$ Tarqet & Std Dev & $\%$ RSD & Maximum & Minimum & $\mathrm{N}$ & N in & $\% \mathrm{~N}$ in \\
\hline 2 Dec 1987 & $2.33 \mathrm{E}-1$ & $23 x$ & $3.145 E-2$ & $13 \%$ & $3.04 E-1$ & $1.37 \mathrm{E}-1$ & 17. & 17. & $100 \%$ \\
\hline 3 Dec 1987 & $1.80 \mathrm{E}-1$ & $18 \%$ & $3.377 \mathrm{E}-2$ & $19 \%$ & $2.70 E-1$ & $1.06 \mathrm{E}-1$ & 15. & 15. & $100 \%$ \\
\hline 4 Oec 1987 & $1.54 \mathrm{E}-1$ & $15 \%$ & $2.597 \mathrm{E}-2$ & $17 \%$ & $1.86 \mathrm{E}-1$ & $7.39 \mathrm{E}-2$ & 17. & 17. & $100 \%$ \\
\hline 5 Dec 1987 & $1.49 \mathrm{E}-1$ & $15 \%$ & $2.135 \mathrm{E}-2$ & $14 \%$ & $1.73 \varepsilon-1$ & $8.87 \mathrm{E}-2$ & 17. & 17. & $100 \%$ \\
\hline 6 Dec 1987 & $1.25 \mathrm{E}+0$ & $125 \%$ & $4.233 \mathrm{E}+0$ & $338 x$ & $1.66 E+1$ & $0.00 E+0$ & 15. & 14. & $93 \%$ \\
\hline 7 Oec 1987 & $1.50 \mathrm{E}-1$ & $15 \%$ & $2.129 E-2$ & $14 \%$ & $2.24 \varepsilon-1$ & $1.29 \mathrm{E}-1$ & 15. & 15. & $100 \%$ \\
\hline 8 Dec 1987 & $1.40 \mathrm{E}-1$ & $14 x$ & $1.074 \mathrm{E}-2$ & $8 x$ & $1.54 \varepsilon-1$ & $1.20 \mathrm{E}-1$ & 15. & 15. & $100 \%$ \\
\hline 9 Dec 1987 & $1.51 E-1$ & $15 \%$ & $4.818 \mathrm{E}-2$ & $32 x$ & $1.86 \mathrm{E}-1$ & $0.00 \mathrm{E}+0$ & 15. & 15. & $100 \%$ \\
\hline 10 Oec 1987 & $1.32 \varepsilon-1$ & $13 \%$ & $3.940 \mathrm{E}-2$ & $30 \%$ & $1.67 \mathrm{E}-1$ & $0.00 \mathrm{E}+0$ & 15. & 15. & $100 \%$ \\
\hline 11 Dec 1987 & $1.26 E-1$ & $13 x$ & $3.605 E-2$ & $29 \%$ & $1.62 \mathrm{E}-1$ & $0.00 E+0$ & 16. & 16. & $100 \%$ \\
\hline 12 Dec 1987 & $1.28 \mathrm{E}-1$ & $13 x$ & $3.639 \mathrm{E}-2$ & $29 \%$ & 1. $58 \mathrm{E}-1$ & $0.00 \mathrm{E}+0$ & 17. & 17. & $100 \%$ \\
\hline 13 Dec 1987 & $1.24 E-1$ & $12 \%$ & $3.385 \mathrm{E}-2$ & $27 \%$ & $1.48 \mathrm{E}-1$ & $0.00 \mathrm{E}+0$ & 17. & 17. & $100 x$ \\
\hline 14 Dec 1987 & 1.17E-1 & $12 \%$ & $3.263 E-2$ & $28 \%$ & $1.54 \mathrm{E}-1$ & $0.00 \mathrm{E}+0$ & 17. & 17. & $100 \%$ \\
\hline 15 Dec $19 B 7$ & $1.27 \mathrm{E}-1$ & $13 \%$ & $3.631 \mathrm{E}-2$ & $29 x$ & $1.50 \mathrm{E}-1$ & $0.00 \mathrm{E}+0$ & 15. & 15. & $100 \%$ \\
\hline 16 Dec 1987 & $1.27 E-1$ & $13 \%$ & $3.490 \mathrm{E}-2$ & $28 \%$ & $1.50 \mathrm{E}-1$ & $0.00 E+0$ & 17. & 17. & $100 \%$ \\
\hline 17 Dec 1987 & $9.79 E-2$ & $10 \%$ & $5.017 E-2$ & $51 x$ & $1.39 E-1$ & $0.00 E+0$ & 11. & 11. & $100 \%$ \\
\hline Sulnary & $2.10 E-1$ & $21 \%$ & $1.037 \varepsilon+0$ & $494 x$ & $1.66 E+1$ & $0.00 E+0$ & 251. & 250. & $100 \%$ \\
\hline
\end{tabular}

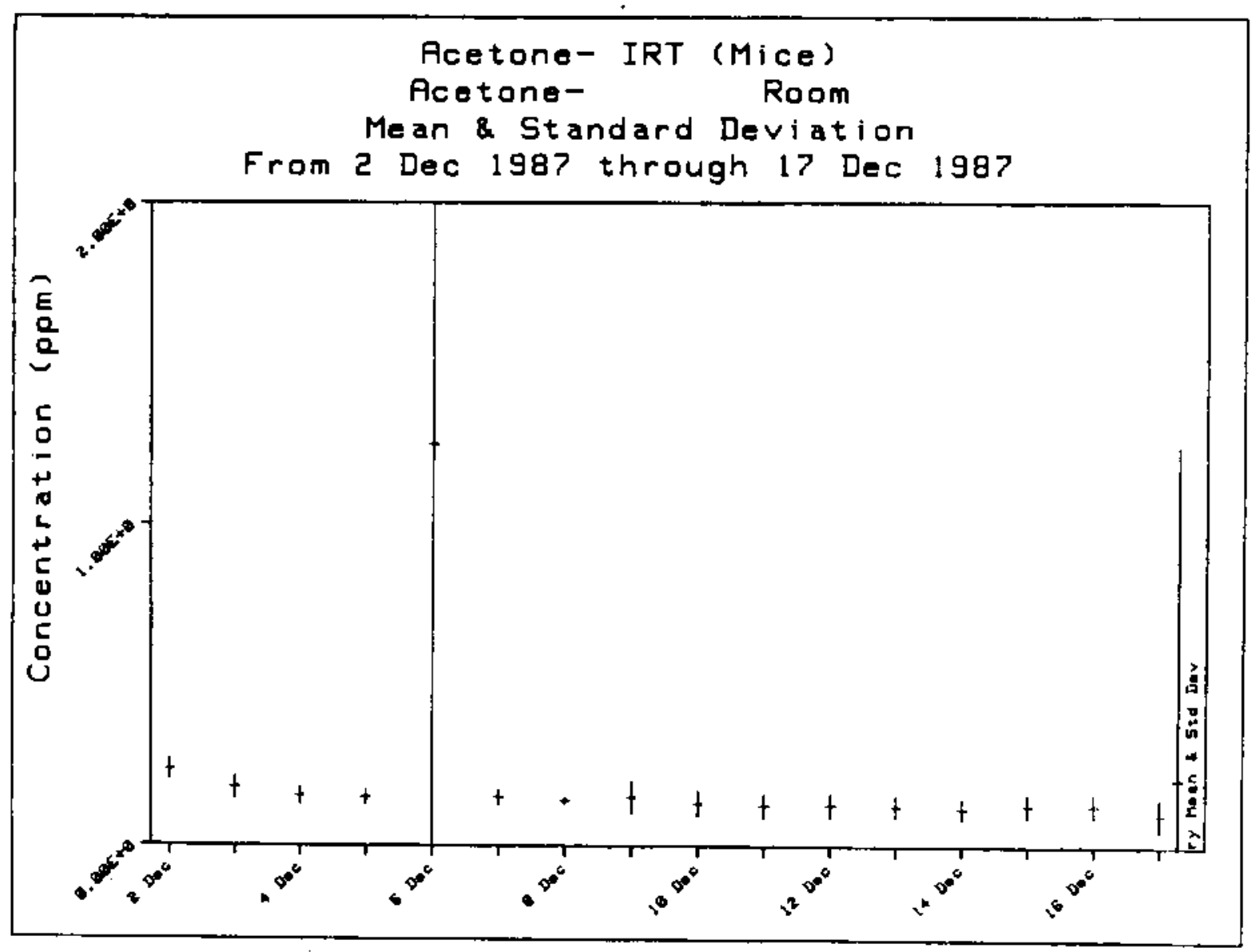


Daily Summation For Acetone- IRT (Mice) From 2 Dec 1987 through 17 Dec 1987

\begin{tabular}{|c|c|c|c|c|c|c|c|c|c|}
\hline Summary Data & for: Acet & & $0 \mathrm{ppm} /$ Conce & ration & & & & $0.00 \mathrm{E}$ & to $2.00 \mathrm{E}$ \\
\hline Date & Mean & $\%$ Farget & Std Oev & $\%$ RSO & Maximum & Minimum & $\mathrm{N}$ & $\mathrm{N}$ in & $\% N_{\text {in }}$ \\
\hline 2 Dec 1987 & $9.93 \mathrm{E}-2$ & $10 \%$ & $2.677 \mathrm{E}-2$ & $27 \%$ & $1.20 \varepsilon-1$ & $0.00 \varepsilon+0$ & 17 & 17. & $100 \%$ \\
\hline 3 Dec 1987 & $5.98 \mathrm{E}-2$ & $6 \%$ & $3.367 \mathrm{E}-2$ & $56 \%$ & $1.46 E-1$ & $0.00 E+0$ & 15 & 15. & $100 \%$ \\
\hline 4 Dec 1987 & $3.60 \mathrm{E}-2$ & $4 \%$ & $3.001 E-2$ & $83 \%$ & $7.60 \mathrm{E}-2$ & $0.00 E+0$ & 17. & 17. & $100 \%$ \\
\hline 5 Dec 1987 & $3.08 \mathrm{E}-2$ & $3 \%$ & $3.179 \mathrm{E}-2$ & $103 \%$ & $7.39 \mathrm{E}-2$ & $0.00 \mathrm{E}+0$ & 17 & 17. & $100 \%$ \\
\hline 6 Dec 1987 & $2.90 \mathrm{E}-1$ & $29 \%$ & $9.589 \mathrm{E}-1$ & $330 x$ & $3.75 \mathrm{E}+0$ & $0.00 \mathrm{E}+0$ & 15 & 14. & $93 \%$ \\
\hline 7 Dec 1987 & $5.59 \mathrm{E}-2$ & $6 x$ & $3.144 \mathrm{E}-2$ & $56 \%$ & $9.50 E-2$ & $0.00 \mathrm{E}+0$ & 15. & 15. & $100 \%$ \\
\hline 8 Dec 1987 & $5.26 \mathrm{E}-2$ & $5 \%$ & $3.195 \mathrm{E}-2$ & $61 \%$ & $8.02 E-2$ & $0.00 \mathrm{E}+0$ & 16. & 16. & $100 \%$ \\
\hline 9 Dec 1987 & $4.46 E-2$ & $4 x$ & $3.828 \mathrm{E}-2$ & $86 \%$ & 8. $65 \mathrm{E}-2$ & $0.00 \mathrm{E}+0$ & 15. & 15. & $100 \%$ \\
\hline 10 Dec 1987 & $3.90 \mathrm{E}-2$ & $4 \%$ & $3.811 \mathrm{E}-2$ & $98 \%$ & $8.23 E-2$ & $0.00 E+0$ & 15. & 15. & $100 \%$ \\
\hline 11 Dec 1987 & $1.19 E-2$ & $1 \%$ & $2.589 E-2$ & $218 \%$ & $7.39 E=2$ & $0.00 E+0$ & 16. & 16 & $100 \%$ \\
\hline 12 Dec 1987 & $1.27 \mathrm{E}-2$ & I\% & $2.823 E-2$ & $223 \%$ & $7.60 \mathrm{E}-2$ & $0.00 E+0$ & 17. & 17. & $100 \%$ \\
\hline 13 Dec 1987 & $2.74 \mathrm{E}-2$ & $3 \%$ & $3.410 \mathrm{E}-2$ & $124 X$ & $7.60 \mathrm{E}-2$ & $0.00 E+0$ & 17. & 17 & $100 \%$ \\
\hline 14 Dec 1987 & $1.92 \mathrm{E}-2$ & $2 x$ & $2.778 \mathrm{E}-2$ & {$[44 \%$} & $7.18 \mathrm{E}-2$ & $0.00 \mathrm{E}+0$ & 17 . & 17 & $100 \%$ \\
\hline 15 Dec 1987 & $9.01 \mathrm{E}-3$ & $1 \%$ & $1.939 E-2$ & $215 \%$ & $6.12 E-2$ & $0.00 \mathrm{E}+0$ & 15. & 15. & $100 \%$ \\
\hline 16 Dec 1987 & 3.54E-2 & $2 \%$ & $2.909 \mathrm{E}-2$ & $189 \%$ & $8.02 E-2$ & $0.00 E+0$ & 17. & 17. & $100 \%$ \\
\hline 17 Dec 1987 & $0.00 E+0$ & $0 \%$ & $0.000 E+0$ & $0 \%$ & $0.00 E+0$ & $0.00 E+0$ & 11. & 11. & $100 \%$ \\
\hline Summary & $5.00 E-2$ & $5 x$ & $2.373 E-1$ & $474 \%$ & $3.75 E+0$ & $0.00 E+0$ & 252. & 251. & $100 \%$ \\
\hline
\end{tabular}

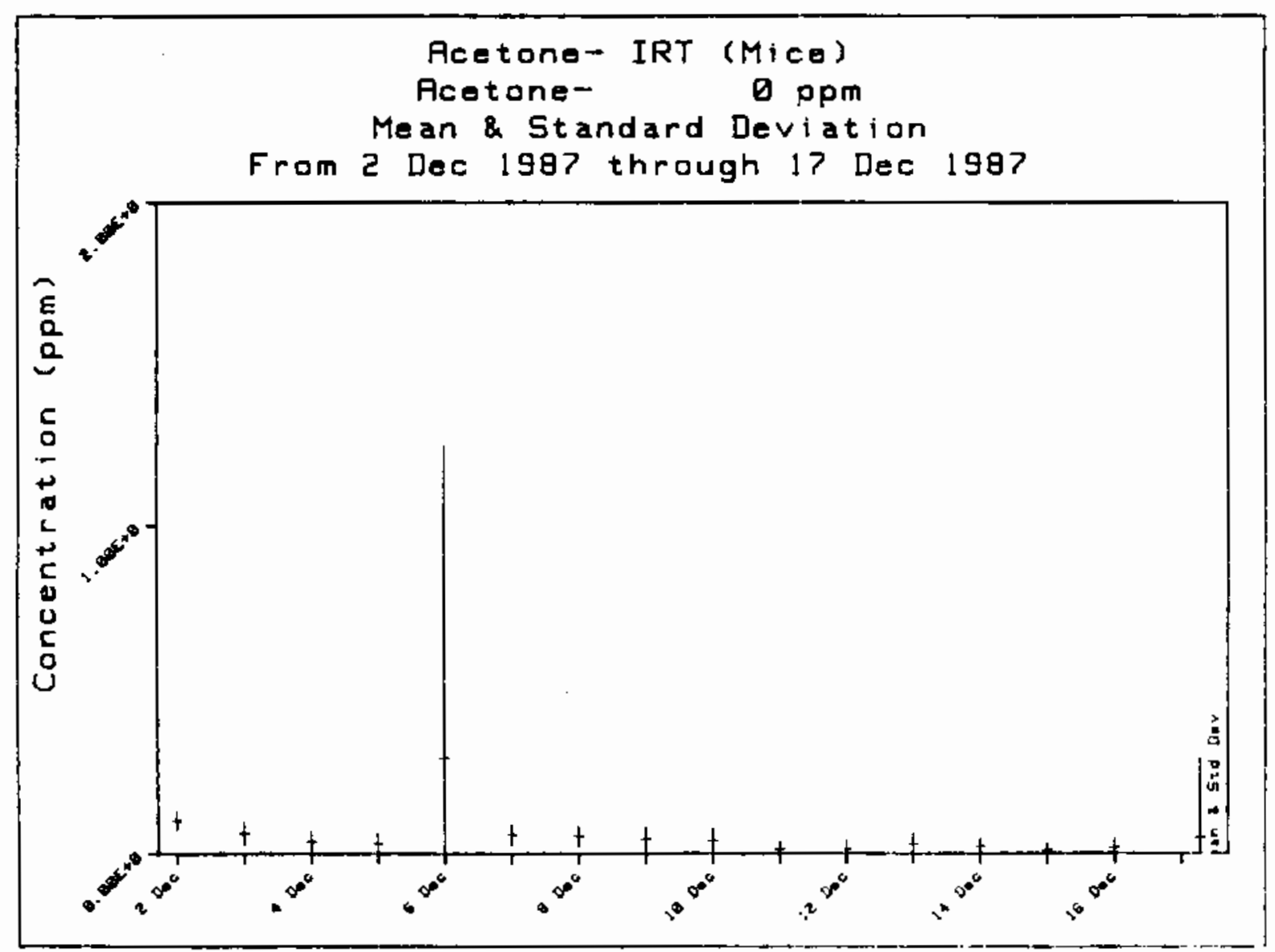


Daily Summation For Acetone- IRT (Mice) From 2 Dec 1987 through 17 Dec 1987

\begin{tabular}{|c|c|c|c|c|c|c|c|c|c|}
\hline Summary Data & for: Acet & & LD $* 1 /$ Conce & ration & & & & 0.00 & to 2.00 \\
\hline Date & Mean & \& Tarqet & Std Dev & $\approx \mathrm{RSD}$ & Maximum & Minimum & $\mathrm{N}$ & $\mathrm{N}$ in & $\% \mathrm{~N}$ in \\
\hline 2 Dec 1987 & $6.53 \mathrm{E}-2$ & $7 \%$ & $2.839 \mathrm{E}-2$ & $43 \%$ & $9.50 \mathrm{E}-2$ & $0.00 \mathrm{E}+0$ & 17 . & 17 . & $100 \%$ \\
\hline 3 Dec 1987 & $6.89 \mathrm{E}-3$ & 17 & $2.670 \mathrm{E}-2$ & $387 \%$ & $1.03 E-1$ & $0.00 \mathrm{E}+0$ & 15. & 15. & $100 \%$ \\
\hline 4 Dec 1987 & $0.00 \mathrm{E}+0$ & $0 x$ & $0.000 \mathrm{E}+0$ & $0 x$ & $0.00 E+0$ & $0.00 E+0$ & 17. & 17. & $100 x$ \\
\hline 5 Dec 1987 & $0.00 \mathrm{E}+0$ & $0 x$ & $0.000 E+0$ & $\alpha x$ & $0.00 E+0$ & $0.00 E+0$ & 17. & 17. & $100 x$ \\
\hline 6 Dec 1987 & $9.99 E-3$ & 18 & $2.637 \mathrm{E}-2$ & $264 x$ & $7.60 \mathrm{E}-2$ & $0.00 \mathrm{E}+0$ & 15. & 15. & $100 \%$ \\
\hline 7 Dec 1987 & $5.07 E-3$ & $\pm x$ & $1.962 \mathrm{E}-2$ & $387 \%$ & $7.60 \mathrm{E}-2$ & $0.00 E+0$ & 15. & 15. & $100 \%$ \\
\hline 8 Dec 1987 & $0.00 \mathrm{E}+0$ & $0 \%$ & $0.000 E+0$ & $0 \%$ & $0.00 \mathrm{E}+0$ & $0.00 E+0$ & 16. & 16. & $100 \%$ \\
\hline 9 Dec 1987 & & & & & & & & & \\
\hline 10 Dec 1987 & & & & & & & & & \\
\hline 11 Dec 1987 & & & & & & & & & \\
\hline 12 Dec 1987 & & & & & & & & & \\
\hline 13 Dec 1987 & & & & & & & & & \\
\hline 14 Dec 1987 & & & & & & & & & \\
\hline 15 Dec 1987 & & & & & & & & & \\
\hline 16 Dec 1987 & & & & & & & & & \\
\hline 17 Dec 1987 & & & & & & & & & \\
\hline Summary & $1.29 E-2$ & $1 x$ & $2.920 E-2$ & $227 x$ & $1.03 \mathrm{E}-1$ & $0.00 E+0$ & 112. & 112. & $100 \%$ \\
\hline
\end{tabular}

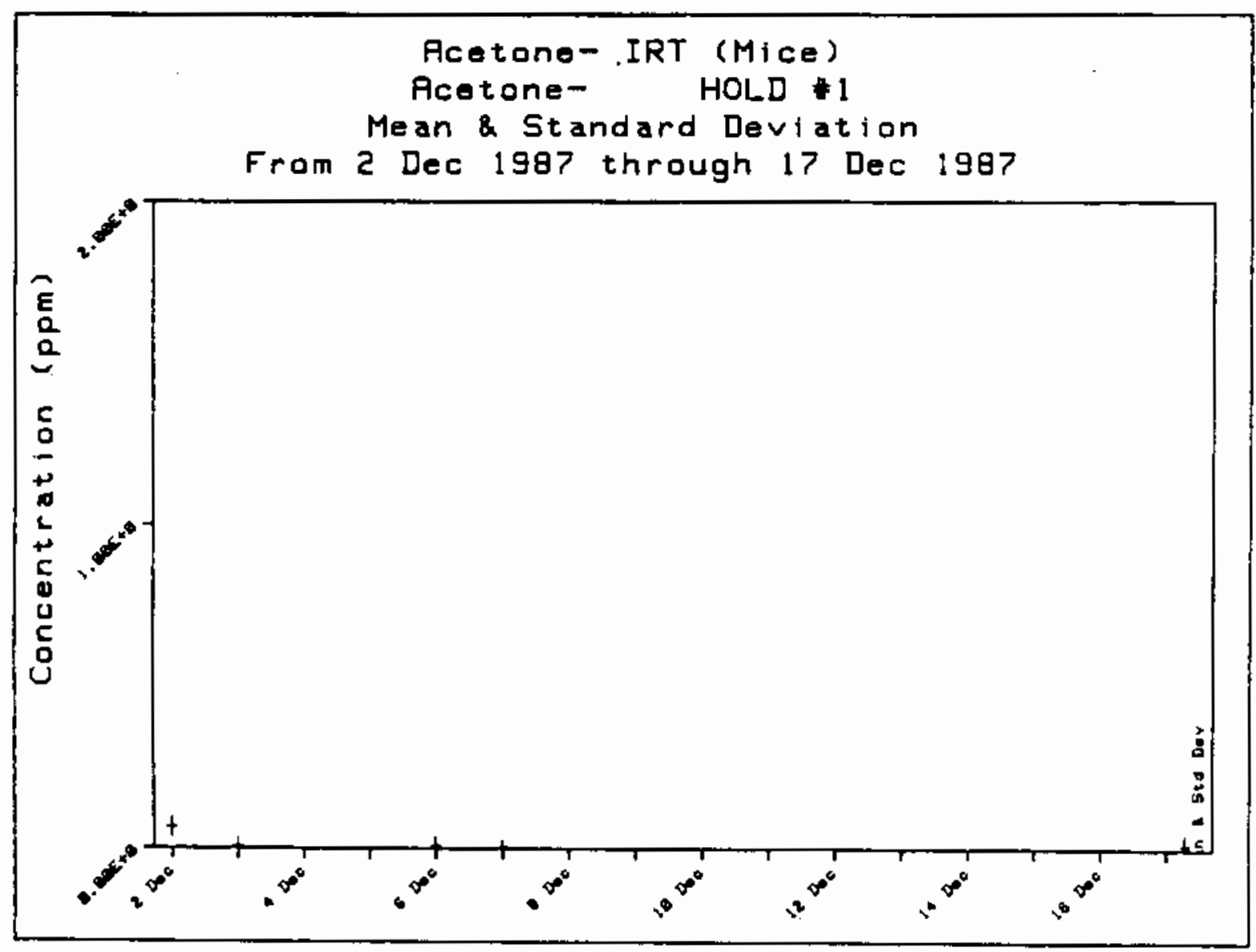

B. 47 
Daily Sumbation For Acetone- IRT (Mice). From 2 Dec 1987 through 17 Dec 1987

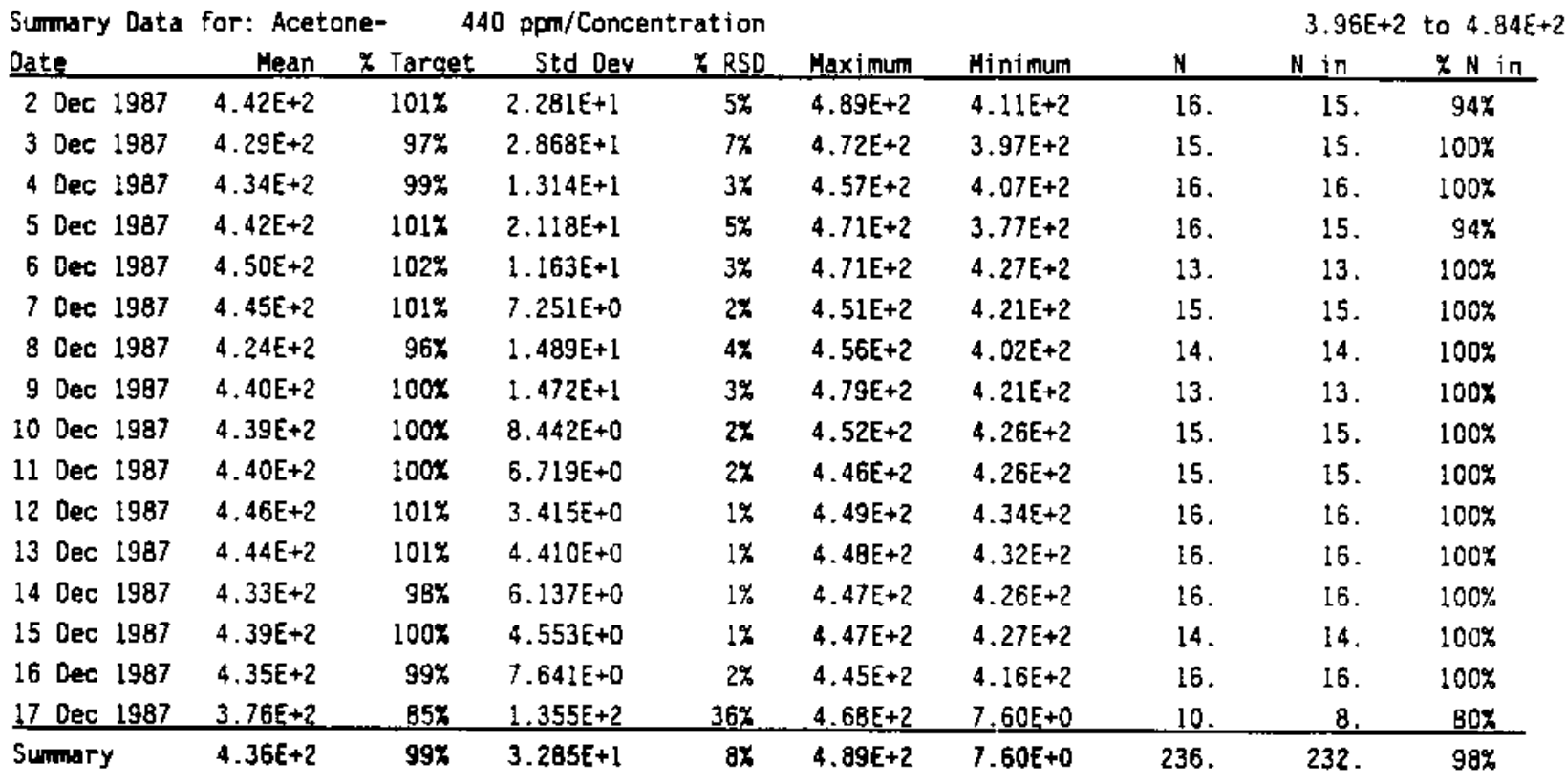

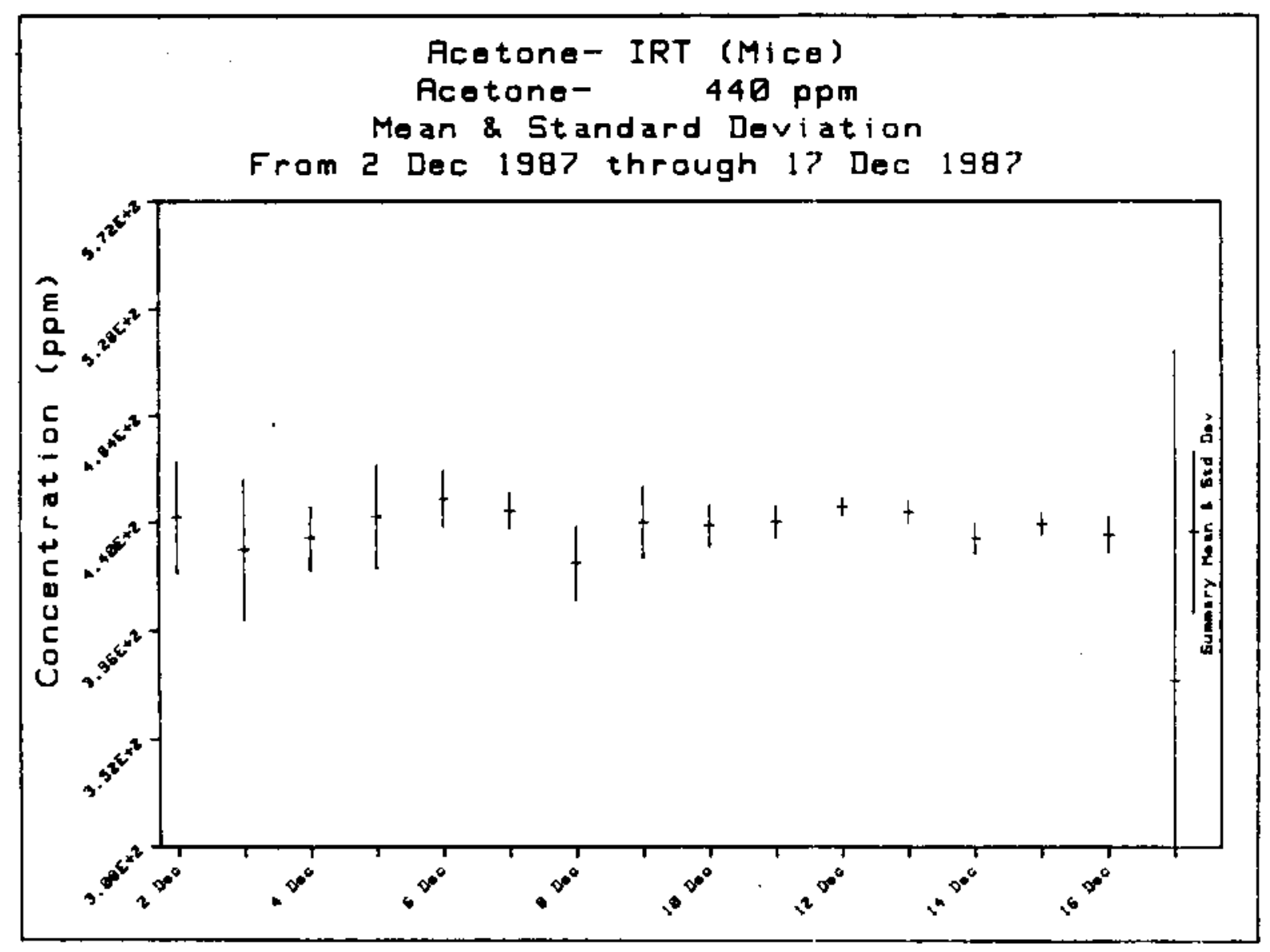

B. 48 
Qaily Summation For Acetone- IRT (Mice) From_20ec_1987 through 17 Dec 1987

\begin{tabular}{|c|c|c|c|c|c|c|c|c|c|}
\hline Summary Data & for: Ace & 220 & $\mathrm{ppmin} /$ Con & tion & & & & 1.98 & to $2.42 \mathrm{E}$ \\
\hline Date & Mean & $\%$ Tarqet & Std Dey & $\%$ RSD & Maximum & Minimum & N & $\mathrm{N}$ in & $x \times$ in \\
\hline 2 Dec 1987 & $2.25 \mathrm{E}+3$ & $102 x$ & $6.862 \mathrm{E}+1$ & $3 \%$ & $2.45 \mathrm{E}+3$ & $2.20 E+3$ & 16. & 15 & $94 \%$ \\
\hline 3 Dec 1987 & $2.20 \mathrm{E}+3$ & $100 \%$ & $3.171 \mathrm{E}+1$ & $1 x$ & $2.31 E+3$ & $2.18 \mathrm{E}+3$ & 15. & 15. & $100 x$ \\
\hline 4 Dec 1987 & $2.19 E+3$ & $99 x$ & $1.573 \mathrm{E}+1$ & 17 & $2.22 E+3$ & $2.16 E+3$ & 16. & 16. & $100 x$ \\
\hline 5 Dec 1987 & $2.19 \mathrm{E}+3$ & $100 x$ & $3.650 E+1$ & $2 x$ & $2.24 E+3$ & $2.08 E+3$ & 16. & 16. & $100 x$ \\
\hline 6 Dec 1987 & $2.21 E+3$ & $101 x$ & $1.845 E+1$ & $1 x$ & $2.24 E+3$ & $2.18 E+3$ & 13. & 13. & $100 x$ \\
\hline 7 Dec 1987 & $2.19 E+3$ & $100 x$ & $1.091 E+1$ & $0 x$ & $2.21 \varepsilon+3$ & $2.17 E+3$ & 15. & 15. & $100 x$ \\
\hline 8 Dec 1987 & $2.17 E+3$ & $98 x$ & $1.642 E+1$ & $1 x$ & $2.19 E+3$ & $2.13 E+3$ & 15. & 15. & $100 x$ \\
\hline 9 Dec 1987 & $2.19 E+3$ & $100 x$ & $5.362 \mathrm{E}+1$ & $2 x$ & $2.25 E+3$ & $2.04 E+3$ & 13. & 13. & $100 x$ \\
\hline 10 Dec 1987 & $2.18 \mathrm{E}+3$ & $99 \%$ & $1.164 E+1$ & $1 x$ & $2.21 E+3$ & $2.17 \varepsilon+3$ & 14. & 14. & $100 \%$ \\
\hline 11 Dec 1987 & $2.17 E+3$ & $98 x$ & $1.473 E+1$ & $1 \%$ & $2.19 \mathrm{E}+3$ & $2.14 E+3$ & 15. & 15. & $100 x$ \\
\hline 12 Oec 1987 & $2.17 \mathrm{E}+3$ & $99 x$ & $1.567 E+1$ & $1 x$ & $2.21 E+3$ & $2.15 E+3$ & 16. & 16. & $100 x$ \\
\hline 13 Oec 1987 & $2.18 E+3$ & $99 \%$ & $1.330 E+1$ & $1 x$ & $2.20 E+3$ & $2.16 E+3$ & 16. & 16. & $100 x$ \\
\hline 14 Dec 1987 & $2.18 E+3$ & $99 \%$ & $1.162 \mathrm{E}+1$ & $1 x$ & $2.19 \mathrm{E}+3$ & $2.15 E+3$ & 16. & 16. & $100 \%$ \\
\hline 15 Dec 1987 & $2.20 \mathrm{E}+3$ & $100 x$ & $1.162 E+1$ & $1 \%$ & $2.23 \mathrm{E}+3$ & $2.19 E+3$ & 14. & 14. & $100 x$ \\
\hline 16 Dec 1987 & $2.20 \mathrm{E}+3$ & 1007 & $9.381 E+0$ & $0 x$ & $2.22 \mathrm{E}+3$ & $2.18 \mathrm{E}+3$ & 16. & 16. & $100 x$ \\
\hline 17 Dec 1987 & $1.94 \mathrm{E}+3$ & $88 \%$ & $6.775 E+2$ & $35 \%$ & $2.20 \mathrm{E}+3$ & $1.52 \mathrm{E}+1$ & 10. & 9. & $90 x$ \\
\hline Sumary & $2.18 \mathrm{E}+3$ & $99 x$ & $1.458 E+2$ & $7 x$ & $2.45 E+3$ & $1.52 \mathrm{E}+1$ & 236 . & 234. & $99 \%$ \\
\hline
\end{tabular}

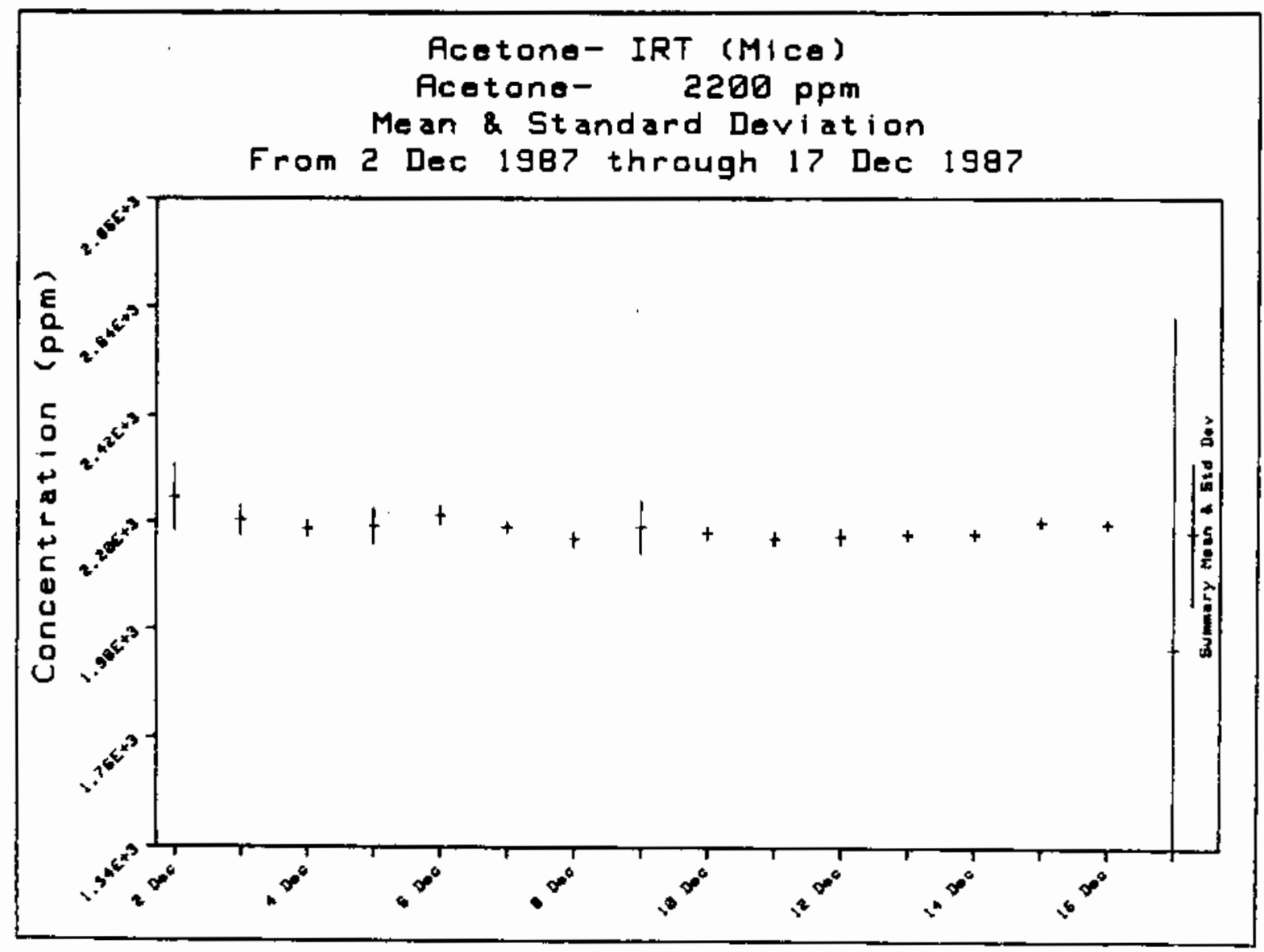


Daily Sumation For Acetone- IRT (Mice) From 2 Dec 1987 through 2. Dec 1987

\begin{tabular}{|c|c|c|c|c|c|c|c|c|c|}
\hline Sumary Data & for: Acet & 1100 & $0 \mathrm{ppm} /$ Cance & ration & & & & 9.90 & to 1.21 \\
\hline Date & Mean & $\%$ Target & Std Dev & X RSO & Maximum & Minimum & $N$ & $N$ in & $\% \mathrm{~N}$ in \\
\hline 2 Dec 1987 & $1.11 \mathrm{E}+4$ & $101 \%$ & $3.362 E+2$ & $3 x$ & $1.17 E+4$ & $1.07 E+4$ & 16. & 16. & $100 \%$ \\
\hline Summary & $1.11 E+4$ & $101 x$ & $3.362 \mathrm{E}+2$ & $3 x$ & $1.17 \mathrm{E}+4$ & $1.07 E+4$ & 16. & 16. & $100 x$ \\
\hline
\end{tabular}

Daily Summation, For Acetone- IRT (Mice) From 3 Dec, 1987 through 17 Dec 1987

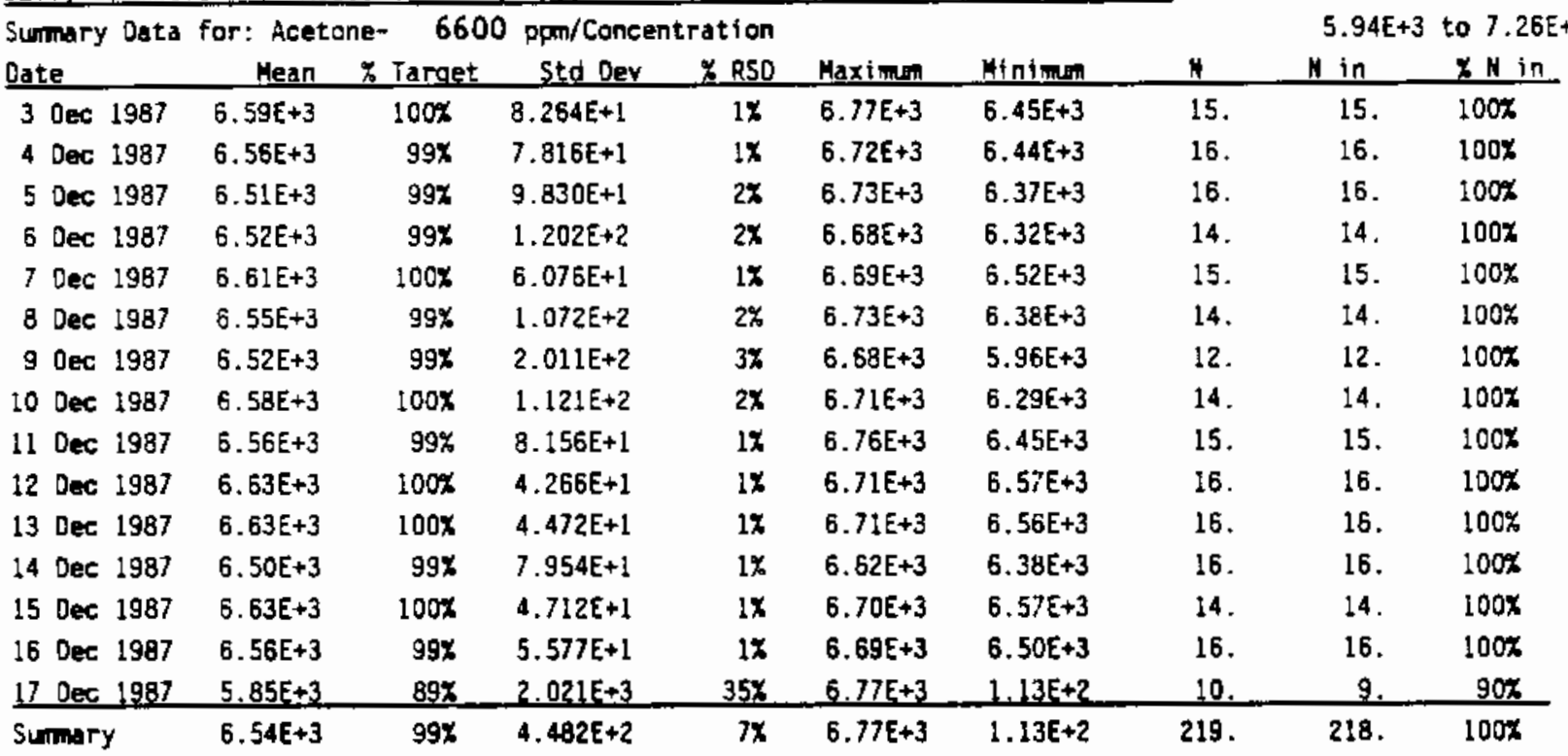

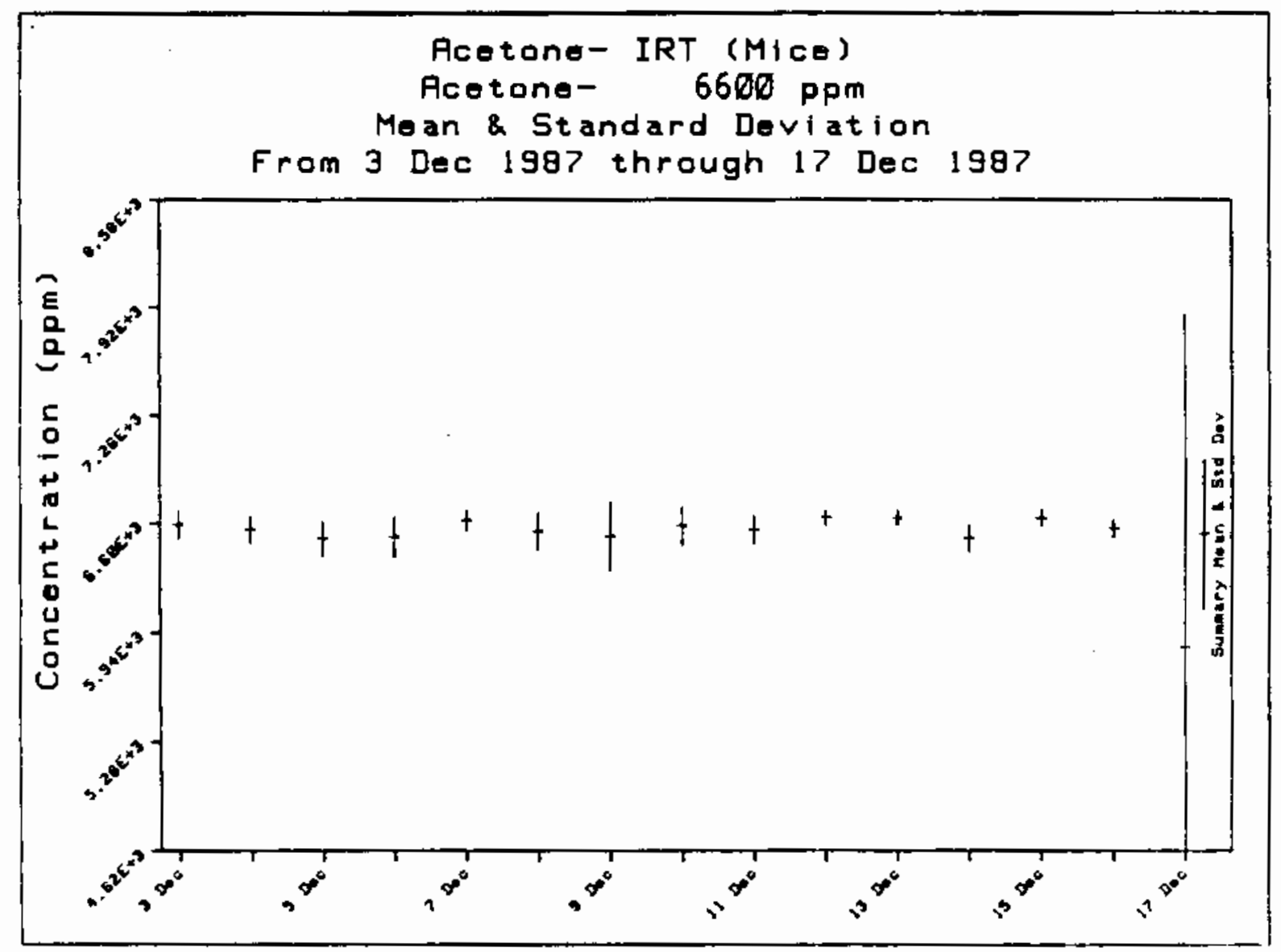


Dajly Sumation For Acetone- IRT (Mice). From 2 Oec 1987 through 17 Dec. 1987

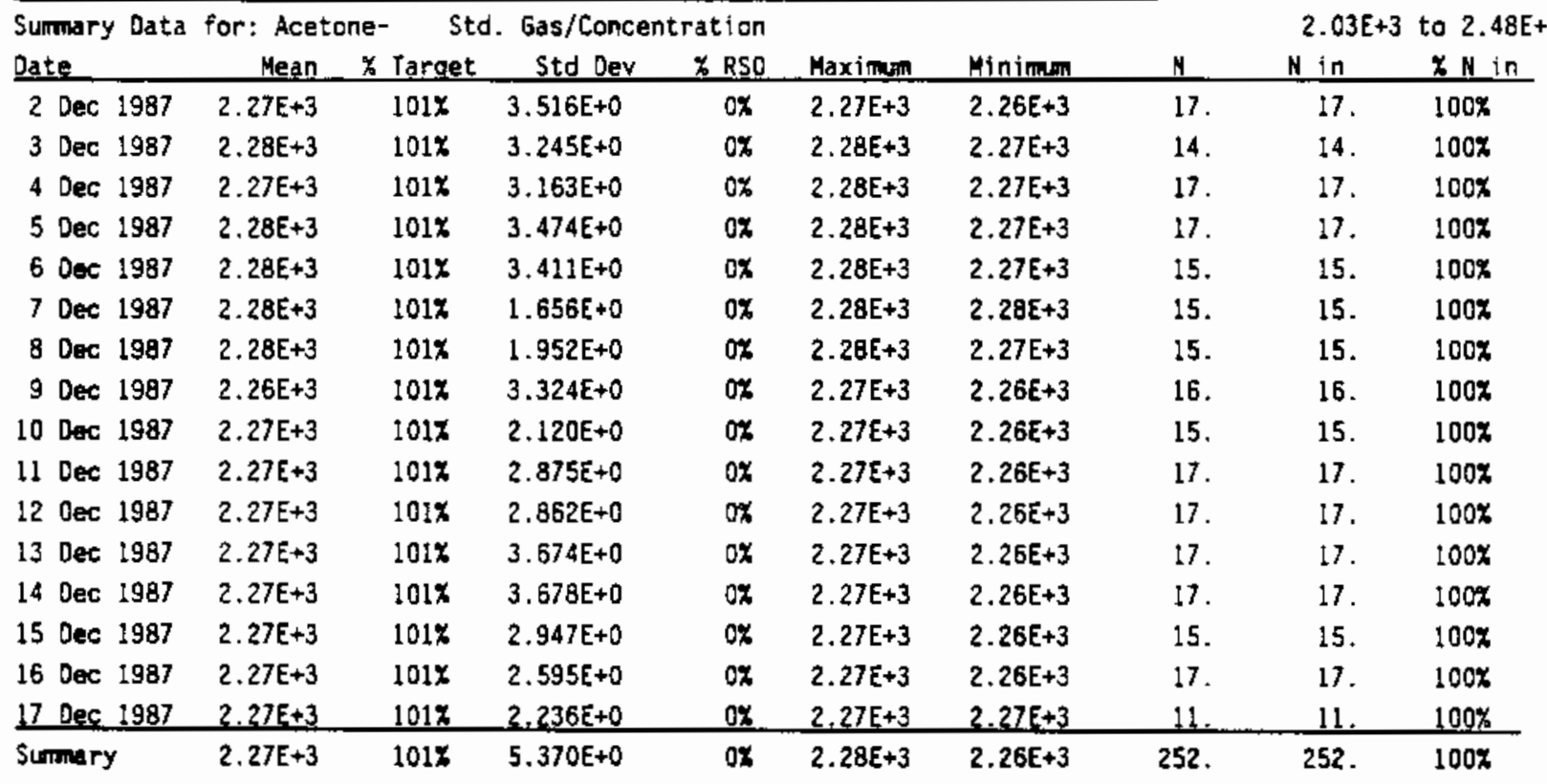

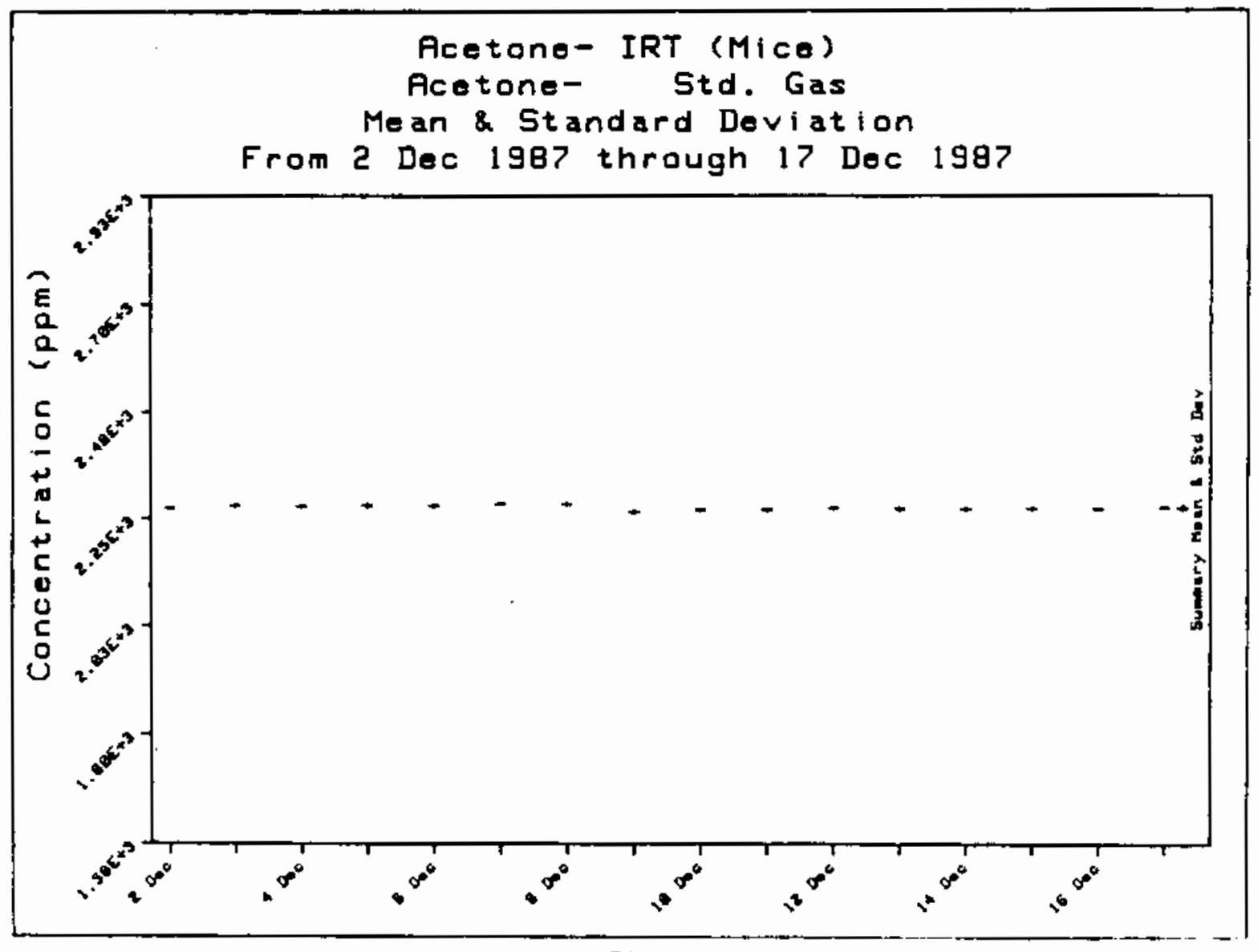

8. 51 
Qaily Sumbation For Acetone- IRT (Hicel_ From 2 Dec 1987 through 18 Dec 1987

\begin{tabular}{|c|c|c|c|c|c|c|c|c|c|}
\hline Sumary Data & : Acet & & Jan/Tempe & ture & & & & & 0 to 75.0 \\
\hline Date & Mean & $\%$ Target & Std Dev & $\approx$ RSD & Maximum & Minimum & N & $\mathrm{N}$ in & \& $N$ in \\
\hline 2 Dec 1987 & 75.8 & $105 \%$ & .78 & $1 x$ & 77.1 & 74.7 & 7. & 1. & $14 \%$ \\
\hline 3 Dec 1987 & 75.0 & $104 x$ & .78 & $1 x$ & 75.0 & 74.0 & 8. & 5. & $63 x$ \\
\hline 4 Dec 1987 & 74.5 & $103 \%$ & .38 & $1 \%$ & 74.9 & 73.9 & 8. & 8. & $100 \%$ \\
\hline 5 Dec 1987 & 74.7 & $104 x$ & .21 & $0 x$ & 75.0 & 74.3 & 8. & 8. & $100 x$ \\
\hline 6 Dec 1987 & 74.6 & $104 \%$ & .22 & $0 \%$ & 75.1 & 74.4 & 8. & 7. & $88 x$ \\
\hline 7 Dec 1987 & 74.1 & $103 x$ & .67 & $1 x$ & 74.9 & 73.4 & 8. & 8. & $100 \%$ \\
\hline 8 Dec 1987 & 73.5 & $102 x$ & .24 & $0 *$ & 73.8 & 73.1 & 8. & 8. & $100 \%$ \\
\hline 9 Dec 1987 & 73.5 & $102 x$ & .20 & $0 x$ & 73.7 & 73.1 & 8. & 8. & $100 \%$ \\
\hline 10 Dec 1987 & 73.6 & $102 x$ & .31 & $0 x$ & 74.1 & 73.2 & 8. & 8. & $100 x$ \\
\hline 11 Oec 1987 & 73.4 & $102 \%$ & .31 & $0 x$ & 73.8 & 72.8 & 8. & 8. & $100 \%$ \\
\hline 12 Dec 1987 & 73.3 & $102 x$ & .20 & $\alpha x$ & 73.7 & 73.1 & 8. & 8. & $100 \%$ \\
\hline 13 Dec 1987 & 73.4 & $102 x$ & .26 & $0 \%$ & 73.8 & 73.2 & 8. & 8. & $100 \%$ \\
\hline 14 Dec 1987 & 73.3 & $102 x$ & .26 & 07 & 73.6 & 72.8 & 8. & 8. & $100 \%$ \\
\hline 15 Dec 1987 & 73.3 & $102 x$ & .26 & $0 \mathbf{x}$ & 73.8 & 73.0 & 8. & 8. & $100 \%$ \\
\hline 16 Dec 1987 & 72.6 & $101 x$ & 2.16 & 37 & 73.7 & 66.9 & 9. & 8. & $89 \%$ \\
\hline 17 Dec 1987 & 73.2 & $102 x$ & .32 & $0 x$ & 73.6 & 72.5 & 8. & 8. & $100 \%$ \\
\hline 18 Dec 1987 & 73.4 & $102 \%$ & .13 & Ox & 73.6 & 73.3 & 3. & 3. & $100 \%$ \\
\hline Summary & 73.8 & $103 x$ & 1.02 & $1 x$ & 77.1 & 66.9 & 131. & 120. & $92 x$ \\
\hline
\end{tabular}

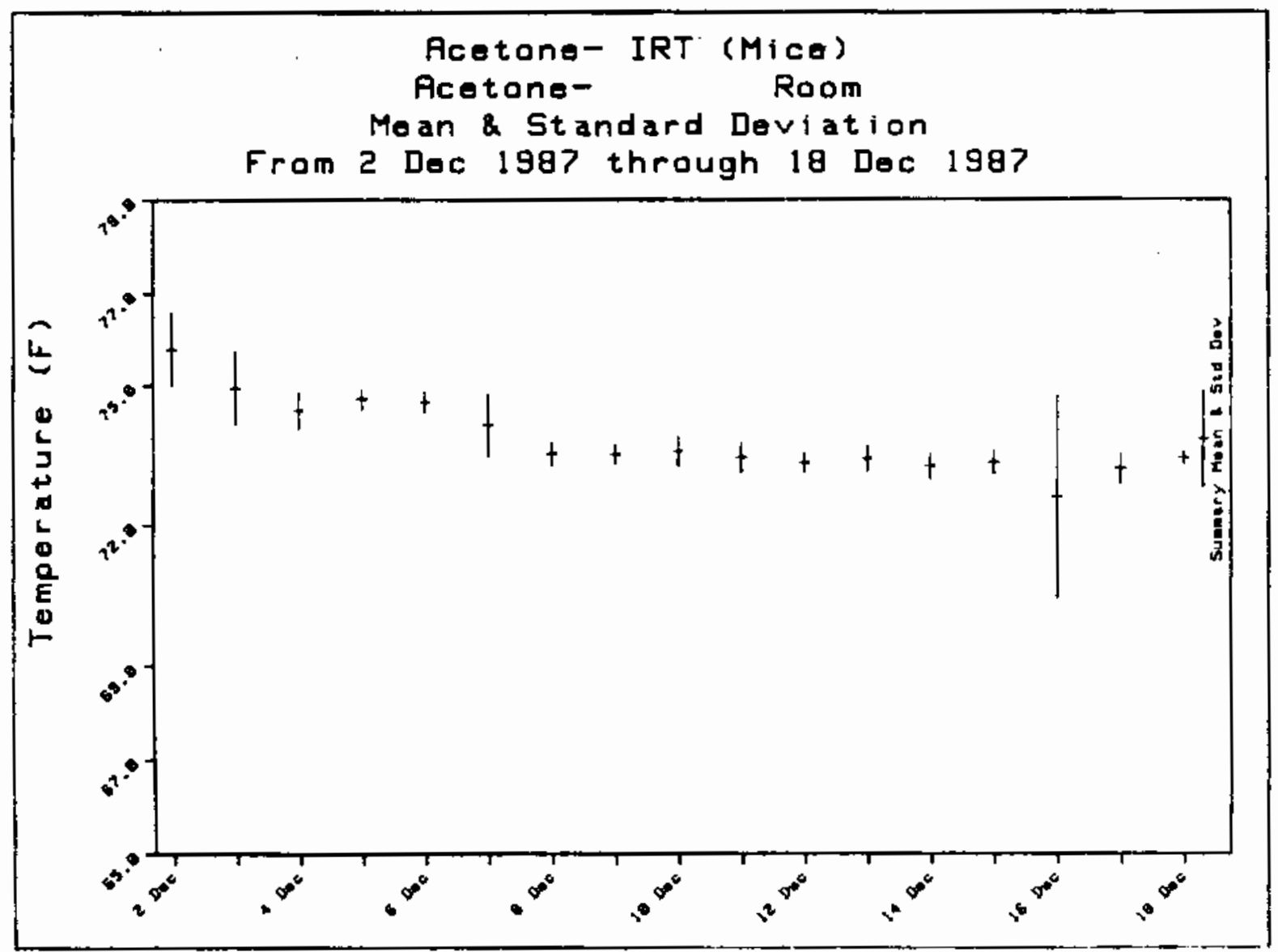


Daily Sunmation for Acetone- IRT (Mice)_. Fron? Dec 1987 through 18 Dec 1987

\begin{tabular}{|c|c|c|c|c|c|c|c|c|c|}
\hline Sumary Data & $r$ : Acet & & $\mathrm{ppm} /$ Tempe & Eure & & & & & 0 to \\
\hline Date & Mean & $\%$ Tarqet & Std Der & $\approx \mathrm{RSO}$ & Maximum & Minimun & $N$ & $N$ in & $\%$ in \\
\hline $2 \operatorname{Dec} 1987$ & 73.6 & $98 x$ & .22 & $0 x$ & 73.9 & 73.2 & 7. & 7. & $100 \%$ \\
\hline 3 Dec 1987 & 75.0 & $100 \%$ & .66 & $1 x$ & 75.6 & 73.9 & 8. & 8. & $100 \%$ \\
\hline 4 Dec 1987 & 75.3 & $100 \%$ & .23 & $0 x$ & 75.6 & 74.8 & 8. & 8. & $100 x$ \\
\hline 5 Dec 1987 & 75.7 & $101 \%$ & .31 & $\alpha x$ & 76.2 & 75.3 & 8. & 8. & $100 \%$ \\
\hline 6 Dec 1987 & 75.8 & $101 \%$ & .34 & $0 \%$ & 76.4 & 75.4 & 8. & 8. & $100 \%$ \\
\hline 7 Dec 1987 & 75.7 & $101 x$ & .66 & $1 \%$ & 76.6 & 75.1 & 8. & 8. & $100 x$ \\
\hline 8 Dec 1987 & 75.3 & $100 x$ & .35 & $0 x$ & 75.9 & 74.9 & 8. & 8. & $100 \%$ \\
\hline 9 Dec 1987 & 75.0 & $100 x$ & .32 & $0 x$ & 75.4 & 74.5 & 8. & 8. & $100 x$ \\
\hline 10 Dec 1987 & 75.0 & $100 \%$ & .38 & $1 x$ & 75.7 & 74.4 & 8. & 8. & $100 x$ \\
\hline 11 Dec 1987 & 75.1 & $100 \%$ & .29 & $0 x$ & 75.8 & 74.9 & 8. & 8. & $100 x$ \\
\hline 12 Dec 1987 & 75.2 & $100 \%$ & .33 & $0 x$ & 75.7 & 74.8 & 8. & 8. & $100 x$ \\
\hline 13 Dec 1987 & 75.0 & $100 \%$ & .35 & $0 x$ & 75.5 & 74.4 & 8. & 8. & $100 x$ \\
\hline 14 Dec 1987 & 74.7 & $100 x$ & .19 & $0 x$ & 75.0 & 74.5 & a. & 8. & $100 x$ \\
\hline 15 Dec 1987 & 74.4 & $99 x$ & .26 & $\alpha x$ & 74.9 & 74.2 & a. & 8. & $100 x$ \\
\hline 16 Dec 1987 & 74.1 & $99 x$ & .29 & $0 \%$ & 74.5 & 73.7 & 8. & 8. & $100 \%$ \\
\hline 17 Dec 1987 & 73.9 & $99 x$ & .23 & $0 x$ & 74.3 & 73.7 & 8. & a. & $100 \%$ \\
\hline 18 Dec 1987 & 74.1 & $99 x$ & 0.00 & $0 x$ & 74.1 & 74.1 & 1. & 1. & $100 x$ \\
\hline Summary & 74.9 & $100 x$ & .70 & $1 x$ & 76.6 & 73.2 & 128. & 128. & $100 \%$ \\
\hline
\end{tabular}

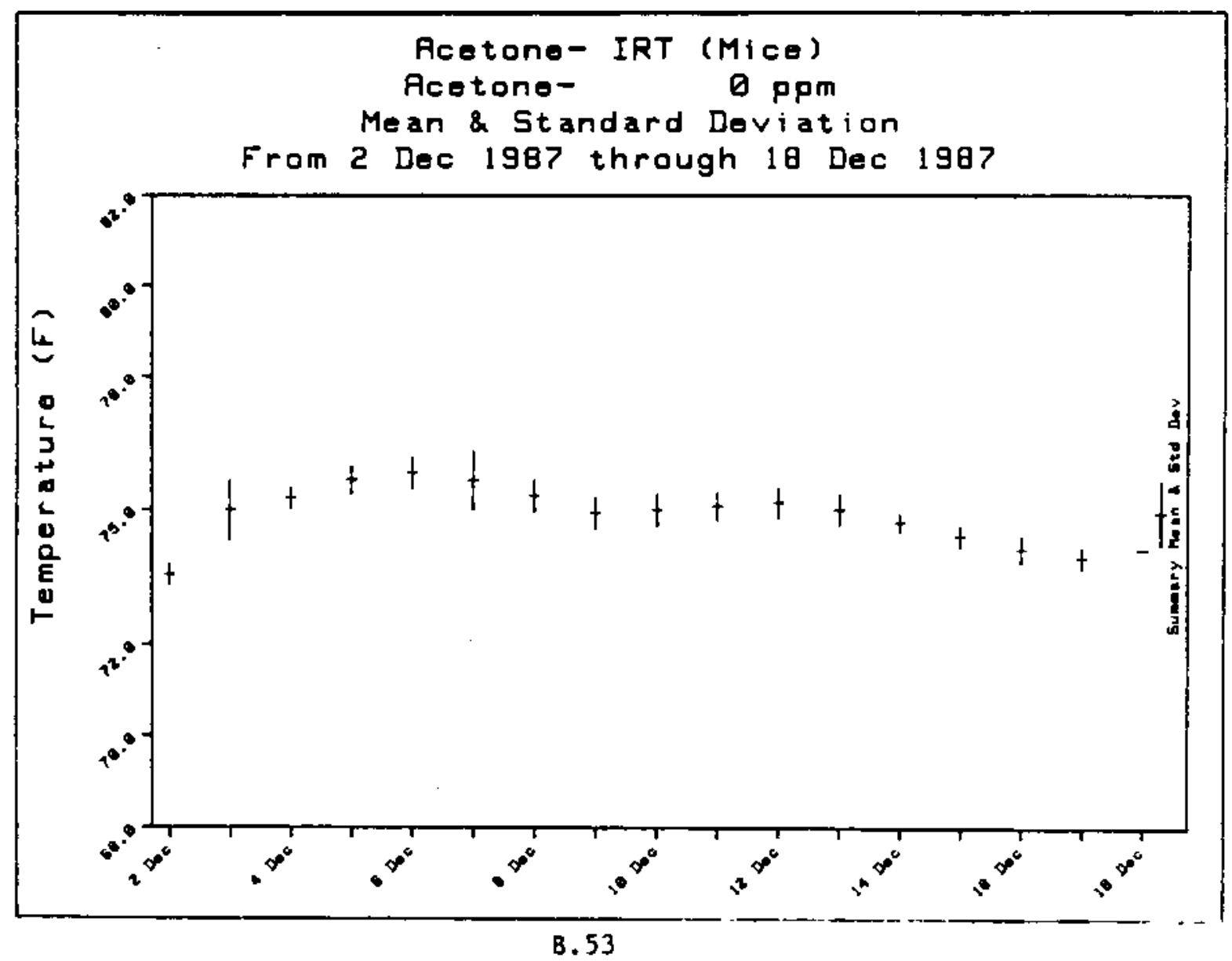


Daily Summation For Acetone- IRT (Mice) Fram 30 Nov 1987 through 18 Dec 1987

\begin{tabular}{|c|c|c|c|c|c|c|c|c|c|}
\hline Sumary Data & r: Acet & & $11 /$ Tempe & ture & & & & & .0 to 78.0 \\
\hline Oate & Mean & * Tarqet & Std Dev & $x$ RSD & Maximum & Mi nimum & H & $\mathrm{N}$ in & $\times N$ in \\
\hline 30 Nov 1987 & 75.8 & $101 x$ & .14 & $0 \%$ & 76.0 & 75.7 & 5. & 5. & $100 x$ \\
\hline 1 Dec 1987 & 75.7 & $101 \%$ & .31 & $0 x$ & 76.2 & 75.2 & 8. & 8. & $100 x$ \\
\hline 2 Oec 1987 & 75.2 & $100 x$ & .43 & $\pm x$ & 75.8 & 74.6 & 8. & 8. & $100 \%$ \\
\hline 3 Dec 1987 & 75.4 & $100 \%$ & .59 & 17 & 75.9 & 74.1 & 8. & 8. & $100 x$ \\
\hline 4 Dec 1987 & 75.2 & $100 \%$ & .42 & $3 \mathbf{x}$ & 75.8 & 74.5 & 8. & 8. & $100 x$ \\
\hline 5 Dec 1987 & 75.3 & $100 \%$ & .12 & $0 x$ & 75.5 & 75.2 & 8. & 8. & $100 x$ \\
\hline 6 Dec 1987 & 74.7 & $100 \%$ & .27 & $0 x$ & 75.2 & 74.4 & 8. & 8. & $100 \%$ \\
\hline 7 Dec 1987 & 74.1 & $99 \%$ & .73 & $1 \%$ & 75.0 & 73.3 & 8. & 8. & $100 x$ \\
\hline 8 Dec 1987 & 73.8 & $98 \%$ & .26 & $0 x$ & 74.2 & 73.3 & 8. & 8. & $100 x$ \\
\hline 9 Dec 1987 & 73.6 & $98 x$ & .26 & $0 \%$ & 73.8 & 73.4 & 2. & 2. & $100 x$ \\
\hline 10 Dec 1987 & & & & & & & & & \\
\hline 11 Dec 1987 & & & & & & & & & \\
\hline 12 Dec 1987 & & & & & & & & & \\
\hline 13 Dec 1987 & & & & & & & & & \\
\hline 14 Dec 1987 & & & & & & & & & \\
\hline $15 \mathrm{Dec} 1987$ & & & & & & & & & \\
\hline 16 Dec 1987 & & & & & & & & & \\
\hline 17 Dec 1987 & & & & & & & & & \\
\hline 18_Dec 1987 & & & & & & & & & \\
\hline Summary & 75.0 & $100 x$ & .79 & $1 x$ & 76.2 & 73.3 & 71. & 71. & $100 x$ \\
\hline
\end{tabular}

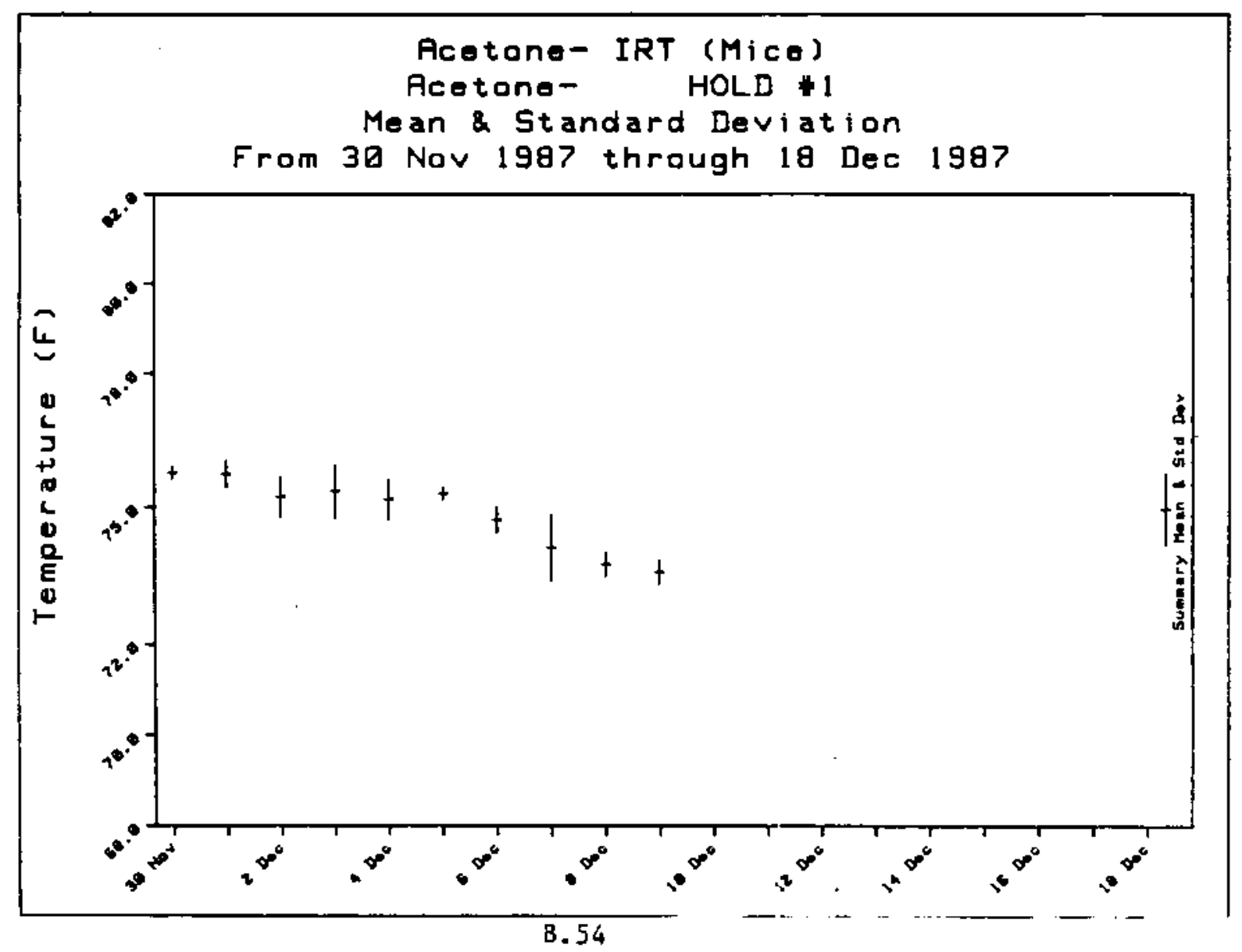


Daily Summation For Acetone- IRT (Mice). From 2 Dec 1987 through 18 Dec 1987

\begin{tabular}{|c|c|c|c|c|c|c|c|c|c|}
\hline Summary Data & $r$ : Aceto & ne- & $\mathrm{ppm} /$ Termpe & ture & & & & & 0 to 78.0 \\
\hline Date & Mean & \% Target & Std Oev & $\%$ RSD & Maximum & Minimem & $N$ & $\mathrm{~N}$ in & $\% \mathrm{~N}$ in \\
\hline 2 Dec 1987 & 72.9 & $97 \%$ & .39 & $1 \%$ & 73.4 & 72.3 & 7. & 7. & $100 x$ \\
\hline 3 Dec 1987 & 74.2 & $99 \%$ & .69 & 17 & 74.8 & 73.0 & 8. & 8. & $100 x$ \\
\hline 4 Dec 1987 & 74.6 & $100 x$ & .32 & ox & 75.1 & 74.1 & 8. & 8. & $100 x$ \\
\hline 5 Dec 1987 & 75.0 & $100 x$ & .11 & $0 x$ & 75.1 & 74.8 & 8. & 8. & $100 x$ \\
\hline 6 Dec 1987 & 75.0 & $100 x$ & .17 & $0 x$ & 75.4 & 74.9 & 8. & 8. & $100 x$ \\
\hline 7 Dec 1987 & 74.8 & $100 x$ & .58 & $\pm x$ & 75.4 & 74.2 & 8. & 8. & $100 x$ \\
\hline 8 Oec 1987 & 74.4 & $99 \%$ & .35 & $0 x$ & 75.0 & 73.8 & 8. & 8. & $100 x$ \\
\hline 9 Dec 1987 & 74.2 & $99 \%$ & .38 & 17 & 74.7 & 73.6 & 8. & 8. & $100 x$ \\
\hline 10 Dec 1987 & 74.2 & $99 \%$ & .36 & $\alpha x$ & 75.0 & 73.6 & 8. & 8. & $100 x$ \\
\hline 11 Dec 1987 & 74.3 & $99 x$ & .21 & Ox & 74.8 & 74.1 & 8. & 8. & $100 x$ \\
\hline 12 Dec 1987 & 74.2 & $99 x$ & .30 & $0 x$ & 74.7 & 73.7 & 8. & 8. & $100 x$ \\
\hline 13 Dec 1987 & 74.4 & $99 \%$ & .37 & $0 \%$ & 75.0 & 74.0 & 8. & 8. & $100 \%$ \\
\hline 14 Dec 1987 & 74.0 & $99 \%$ & .22 & $0 x$ & 74.4 & 73.7 & 8. & 8. & $100 x$ \\
\hline 15 Oec 1987 & 74.1 & $99 x$ & .36 & $0 x$ & 74.5 & 73.5 & 8. & 8. & $100 x$ \\
\hline 16 Dec 1987 & 73.5 & $98 x$ & .37 & $1 x$ & 74.3 & 73.1 & 8. & 8. & $100 x$ \\
\hline 17 Dec 1987 & 73.4 & $98 x$ & .26 & $\alpha x$ & 73.6 & 72.9 & 8. & 8. & $100 x$ \\
\hline 18. Dec 1987 & 73.6 & $98 x$ & 0.00 & $\alpha x$ & 73.6 & 73.6 & 1. & 1. & $100 x$ \\
\hline Summary & 74.2 & $99 \%$ & .64 & $1 \times$ & 75.4 & 72.3 & 128. & 128. & $100 x$ \\
\hline
\end{tabular}

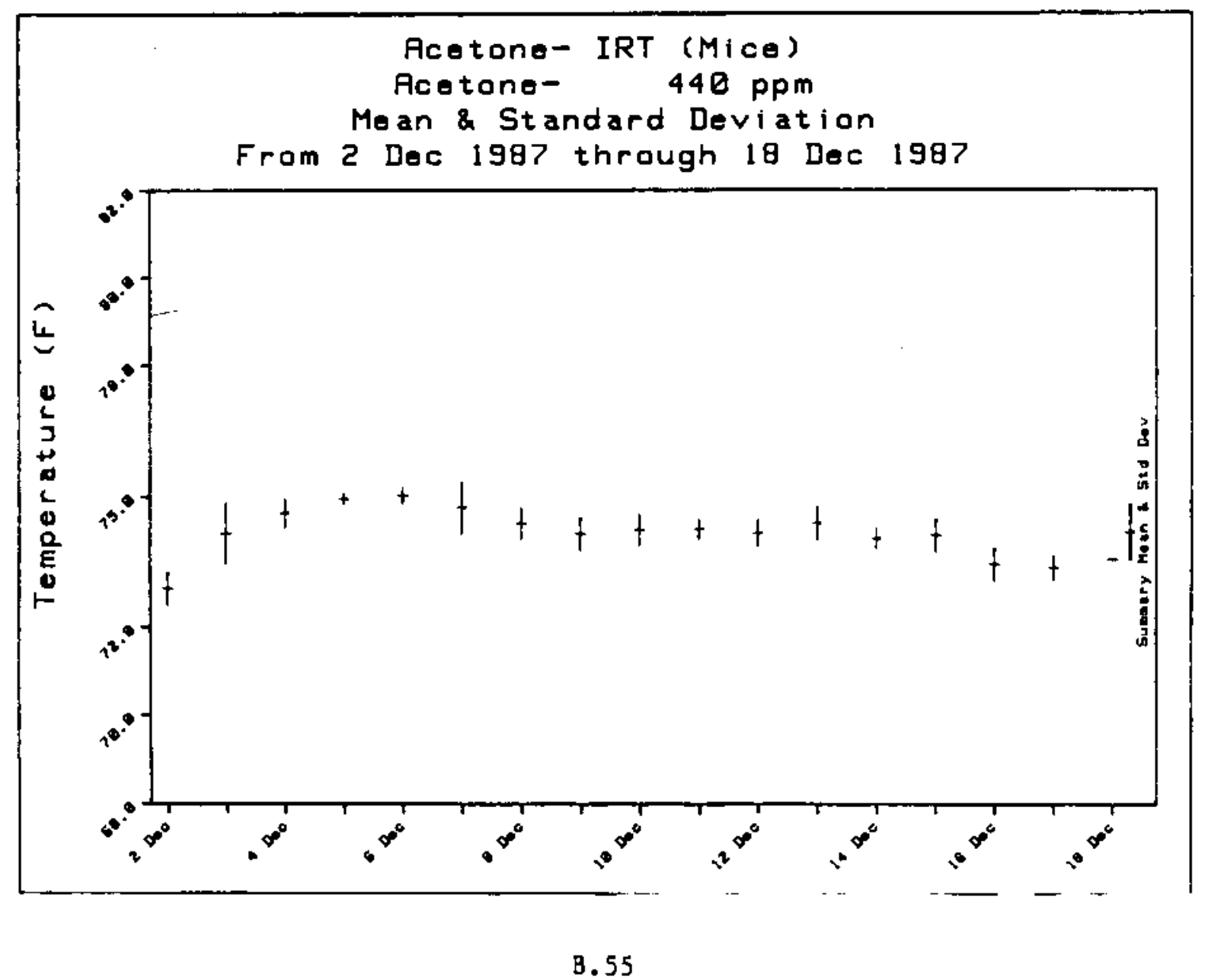


Daily Sumation For Acetone- IRT (Mice). From 2 Dec 1987 through 18 Dec 1987

\begin{tabular}{|c|c|c|c|c|c|c|c|c|c|}
\hline Summary Data & $r:$ Acet & 220 & ppm/Tempe & ture & & & & & 0 to \\
\hline Date & Mean & $\approx$ Target & Std Dev & $x R S D$ & Maximum & Minimum & $\mathrm{N}$ & $N$ in & $\% \mathrm{~N}$ in \\
\hline 2 Dec 1987 & 72.0 & $96 \%$ & .32 & $0 \%$ & 72.4 & 71.6 & 7. & 4. & $57 x$ \\
\hline 3 Dec 1987 & 73.2 & $98 \%$ & .69 & $1 x$ & 73.9 & 72.0 & 8. & 8. & $100 x$ \\
\hline 4 Dec 1987 & 73.9 & $99 \%$ & $.42{ }^{\circ}$ & $1 x$ & 74.5 & 73.5 & 8 . & 8. & $100 x$ \\
\hline 5 Dec 1987 & 74.6 & $99 x$ & .18 & $0 x$ & 74.9 & 74.4 & 8. & 8. & $100 x$ \\
\hline 6 Dec 1987 & 74.6 & $99 x$ & .28 & $\mathbf{0}$ & 75.0 & 74.2 & 8. & 8. & $100 \%$ \\
\hline 7 Dec 1987 & 74.3 & $99 x$ & .50 & $1 x$ & 74.9 & 73.8 & 8. & 8. & $100 \%$ \\
\hline 8 Dec 1987 & 73.7 & $98 \%$ & .42 & $2 x$ & 74.3 & 72.8 & 8. & 8. & $100 \%$ \\
\hline 9 Dec 1987 & 73.9 & $99 \%$ & .38 & $1 x$ & 74.4 & 73.2 & 8. & 8. & $100 \%$ \\
\hline 10 Dec 1987 & 74.1 & $99 x$ & .32 & $0 x$ & 74.4 & 73.4 & 8. & 8. & $100 x$ \\
\hline 11 Dec 1987 & 74.1 & $99 \%$ & .16 & $\mathbf{\alpha}$ & 74.3 & 73.9 & 8. & 8. & $100 x$ \\
\hline 12 Dec 1987 & 74.1 & $99 x$ & .21 & $\mathbf{\alpha}$ & 74.4 & 73.7 & 8. & 8. & $100 x$ \\
\hline 13 Dec 1987 & 74.2 & $99 \%$ & .21 & $0 \%$ & 74.5 & 73.9 & 8. & 8. & $100 \%$ \\
\hline 14 Dec 1987 & 73.9 & 987 & .11 & $0 x$ & 74.0 & 73.7 & 8. & 8. & $100 \%$ \\
\hline 15 Dec 1987 & 73.8 & $98 x$ & .24 & $0 x$ & 74.0 & 73.3 & 8. & 8. & $100 x$ \\
\hline 16 Dec 1987 & 73.3 & $98 x$ & .31 & $0 x$ & 74.0 & 33.1 & 8. & 8. & $100 x$ \\
\hline 17 Dec 1987 & 73.1 & $98 \%$ & .13 & $\mathbf{\alpha}$ & 73.3 & 73.0 & 8. & 8. & $100 x$ \\
\hline 18 Dec 1987 & 73.2 & $98 \%$ & 0.00 & $0 \%$ & 73.2 & 73.2 & 1. & 1. & $100 \%$ \\
\hline Sumary & 73.8 & $98 x$ & .69 & $1 x$ & 75.0 & 71.6 & 128. & 125. & $98 \%$ \\
\hline
\end{tabular}

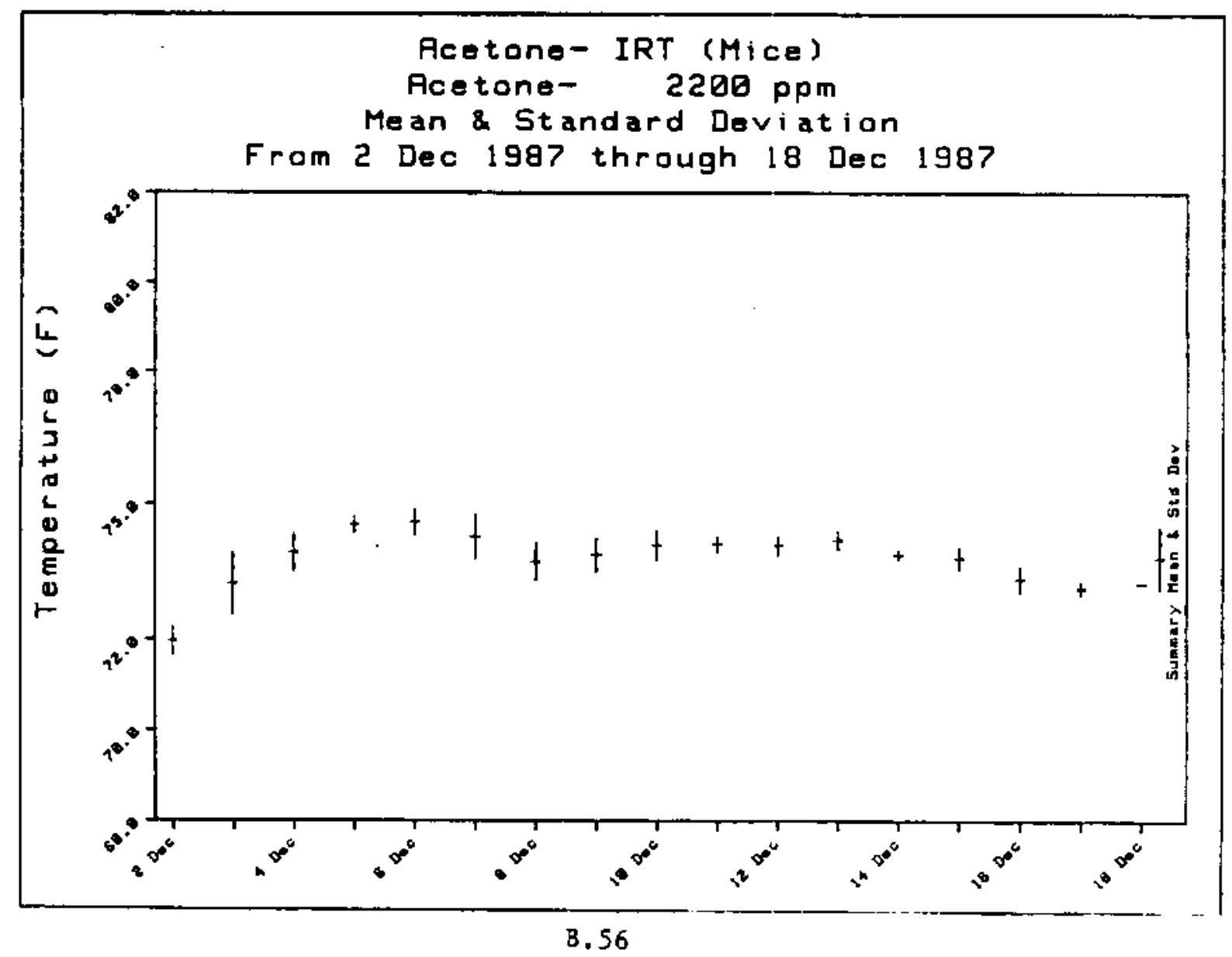


Daily Summation For Acetone- IRT (Hice) From 2 Dec 1987 through 18 Dec 1987

\begin{tabular}{|c|c|c|c|c|c|c|c|c|c|}
\hline Summary Data & : Acet & 66 & $\mathrm{pm} /$ Temp & ure & & & & & .0 to \\
\hline Qate & Mean & $\%$ Tarqet & Std Dev. & $\approx$ RSD & Maximum & Minimum & N & $\mathrm{N}$ in & $\% \mathrm{~N}$ in \\
\hline 2 Dec 1987 & 74.1 & $99 \%$ & .45 & $1 x$ & 74.7 & 73.5 & 7. & 7. & $100 x$ \\
\hline 3 Dec 1987 & 75.6 & $101 x$ & .77 & $1 \%$ & 76.3 & 74.3 & 8. & 8. & $100 x$ \\
\hline 4 Oec 1987 & 76.2 & $102 x$ & .43 & $1 x$ & 76.9 & 75.7 & 8. & 8. & $100 \%$ \\
\hline 5 Dec 1987 & 76.7 & $102 x$ & .17 & $0 x$ & 76.9 & 76.4 & 8. & 8. & $100 x$ \\
\hline 6 Dec 1987 & 76.7 & $102 x$ & .39 & $1 x$ & 77.3 & 76.0 & 8. & 8. & 1007 \\
\hline 7 Dec 1987 & 76.3 & $102 \%$ & .50 & 17 & 77.0 & 75.8 & 8. & 8. & $100 x$ \\
\hline 8 Dec 1987 & 75.9 & $101 x$ & .38 & $1 x$ & 76.4 & 75.1 & 8. & 8. & $100 x$ \\
\hline 9 Dec 1987 & 75.9 & $101 x$ & .35 & $0 x$ & 76.3 & 75.4 & 8. & 8. & $100 x$ \\
\hline 10 Dec 1987 & 76.1 & $102 x$ & .33 & $0 x$ & 76.5 & 75.5 & 8. & 8. & $100 x$ \\
\hline 11 Dec 1987 & 75.9 & $101 x$ & .13 & $0 x$ & 76.1 & 75.7 & 8. & 8. & $100 \%$ \\
\hline 12 Oec 1987 & 75.8 & $101 x$ & .22 & $a x$ & 76.2 & 75.6 & 8. & 8. & $100 x$ \\
\hline 13 Dec 1987 & 75.9 & $101 x$ & .27 & $\alpha x$ & 76.3 & 75.4 & 8. & 8. & $100 \%$ \\
\hline 14 Dec 1987 & 75.5 & $101 \%$ & .15 & $\alpha x$ & 75.8 & 75.4 & B. & 8. & $100 x$ \\
\hline 15 Dec 1987 & 75.5 & $101 x$ & .14 & $0 x$ & 75.6 & 75.3 & 8. & 8. & $100 x$ \\
\hline 16 Dec 1987 & 75.0 & $100 x$ & .32 & $0 x$ & 75.6 & 74.7 & 8. & 8. & $100 \%$ \\
\hline 17 Dec 1987 & 73.9 & $99 x$ & .80 & $1 x$ & 75.0 & 72.9 & 8. & 8. & $100 x$ \\
\hline 18 Dec 1987 & 73.7 & $98 x$ & 0.00 & $0 x$ & 73.7 & 73.7 & 1. & 1. & $100 x$ \\
\hline Summary & 75.7 & $101 x$ & .85 & $1 x$ & 77.3 & 72.9 & 128. & 128. & $100 x$ \\
\hline
\end{tabular}

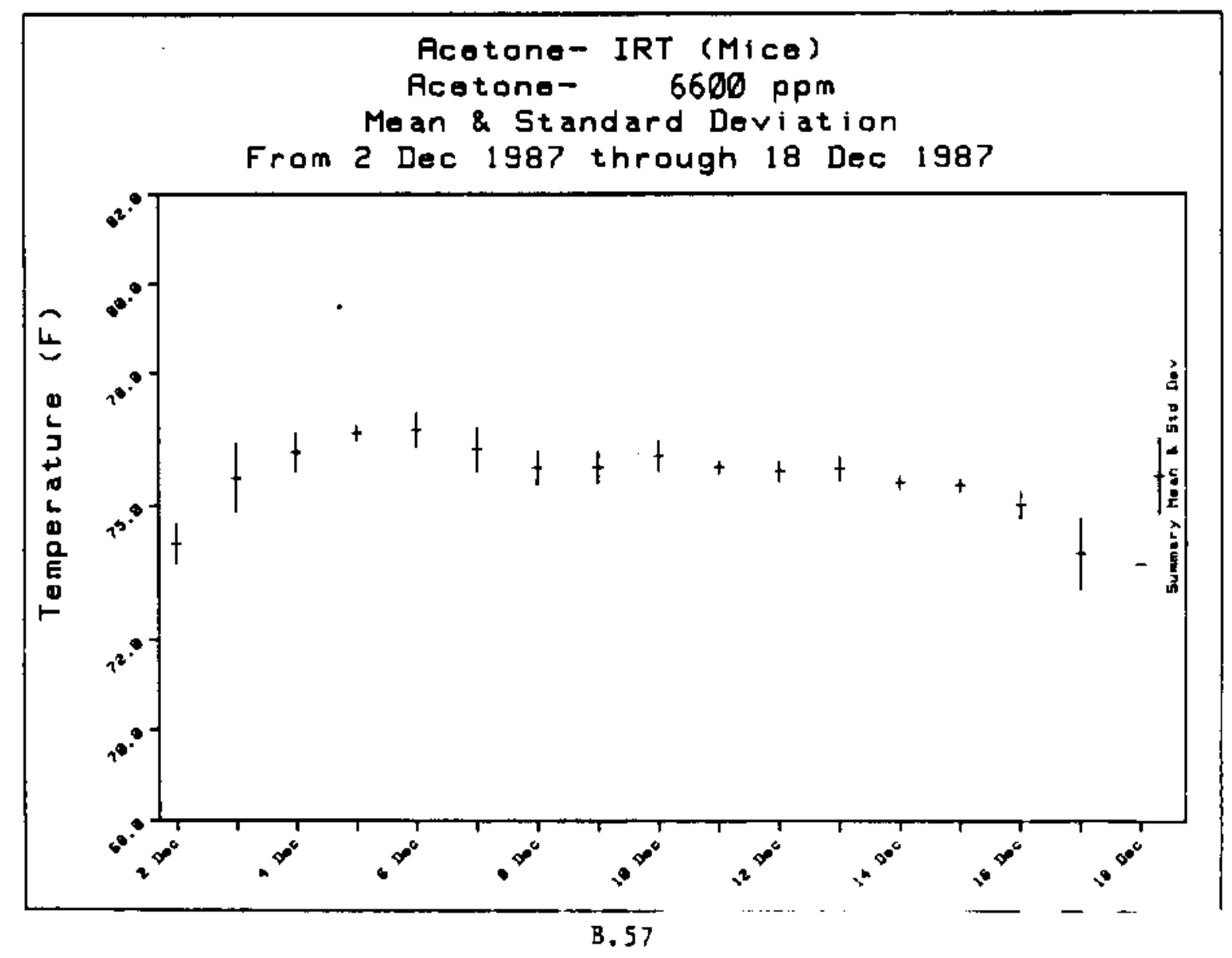


Daily Sumbation For Acetone- IRT (Mice)_ From 2 Dec 1987 through 18 Dec 1987

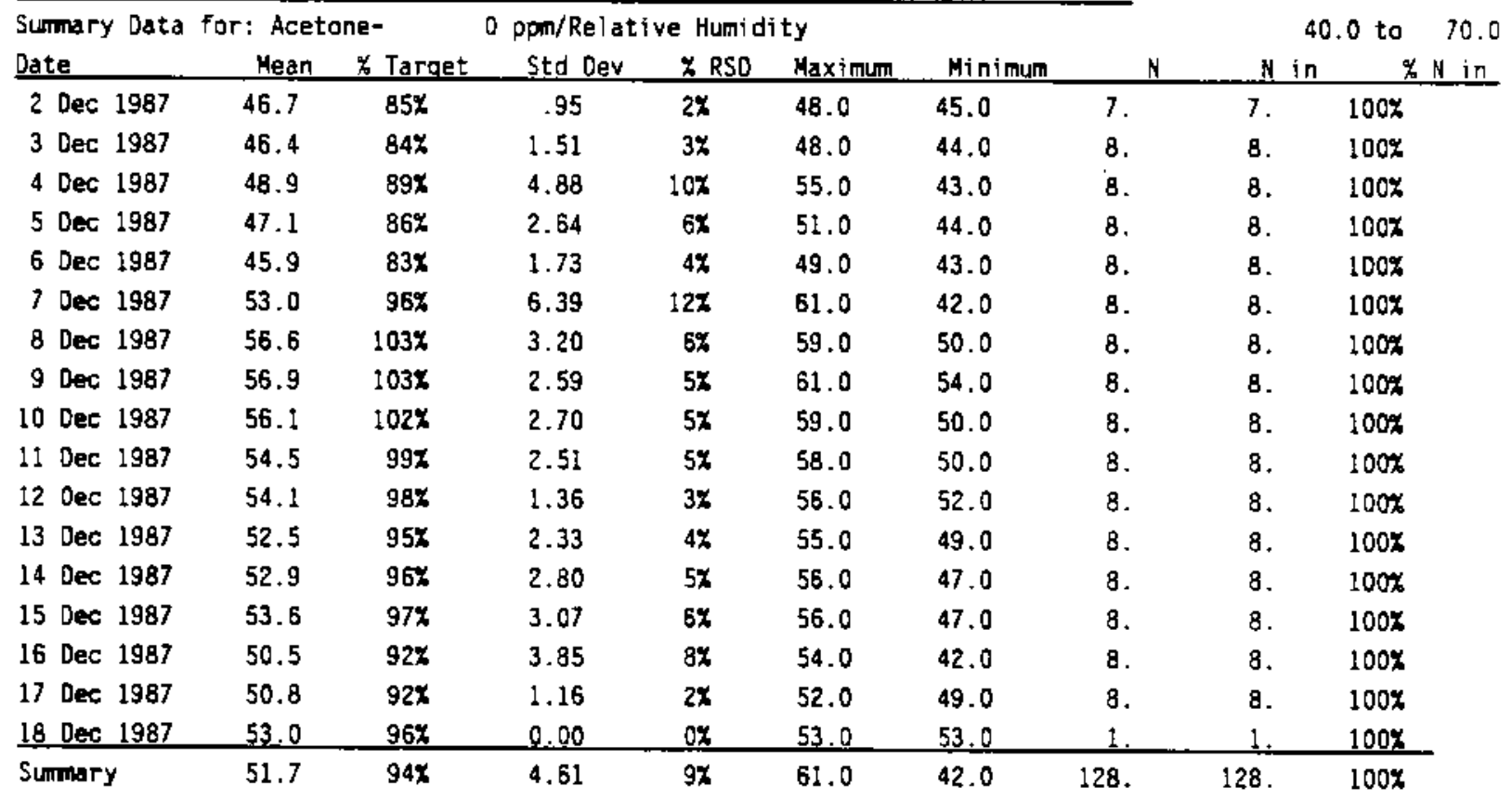

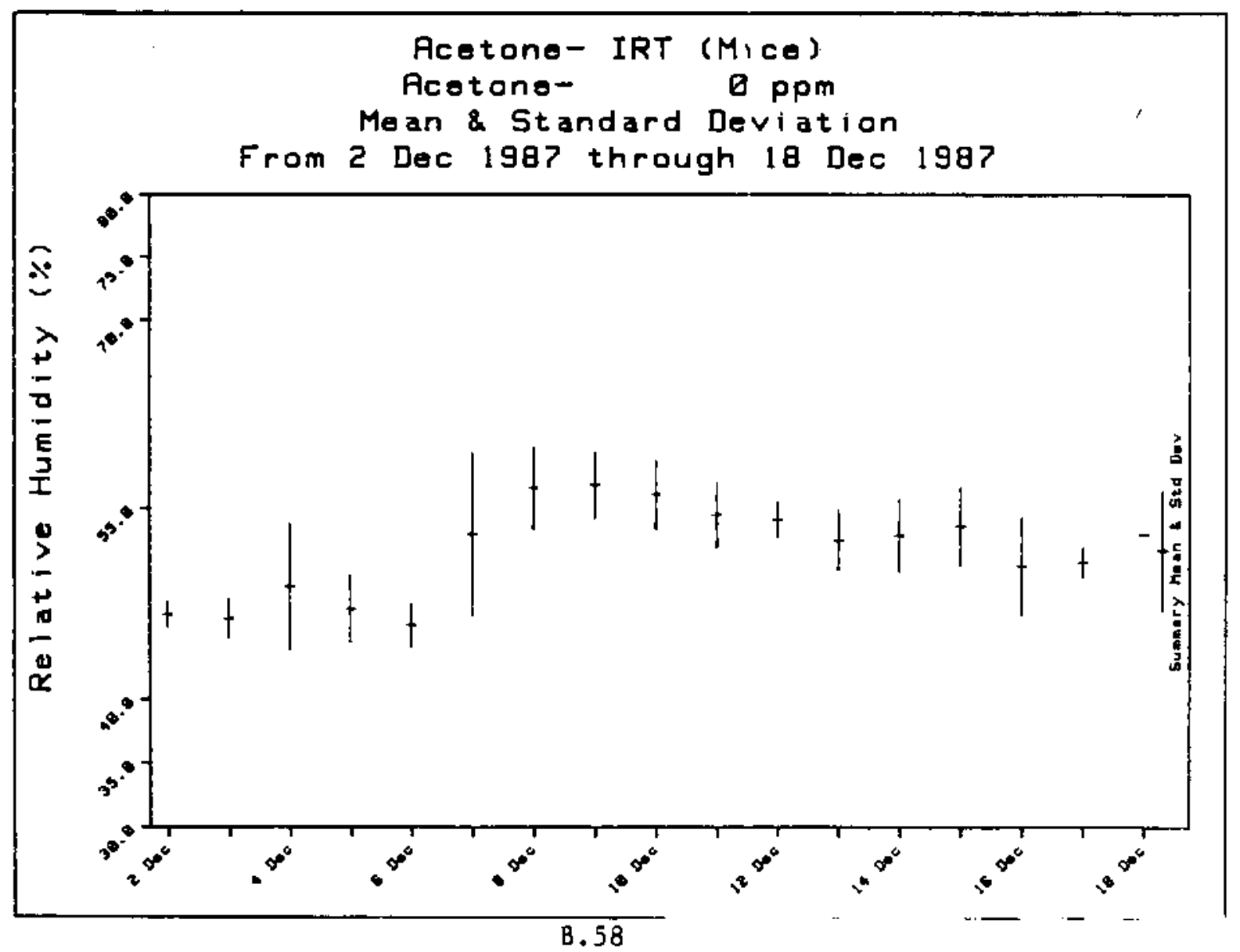


Daily Sumbation For Acetone- IRT (Mice) From 30 Nov 1987 through 18 Dec 1987

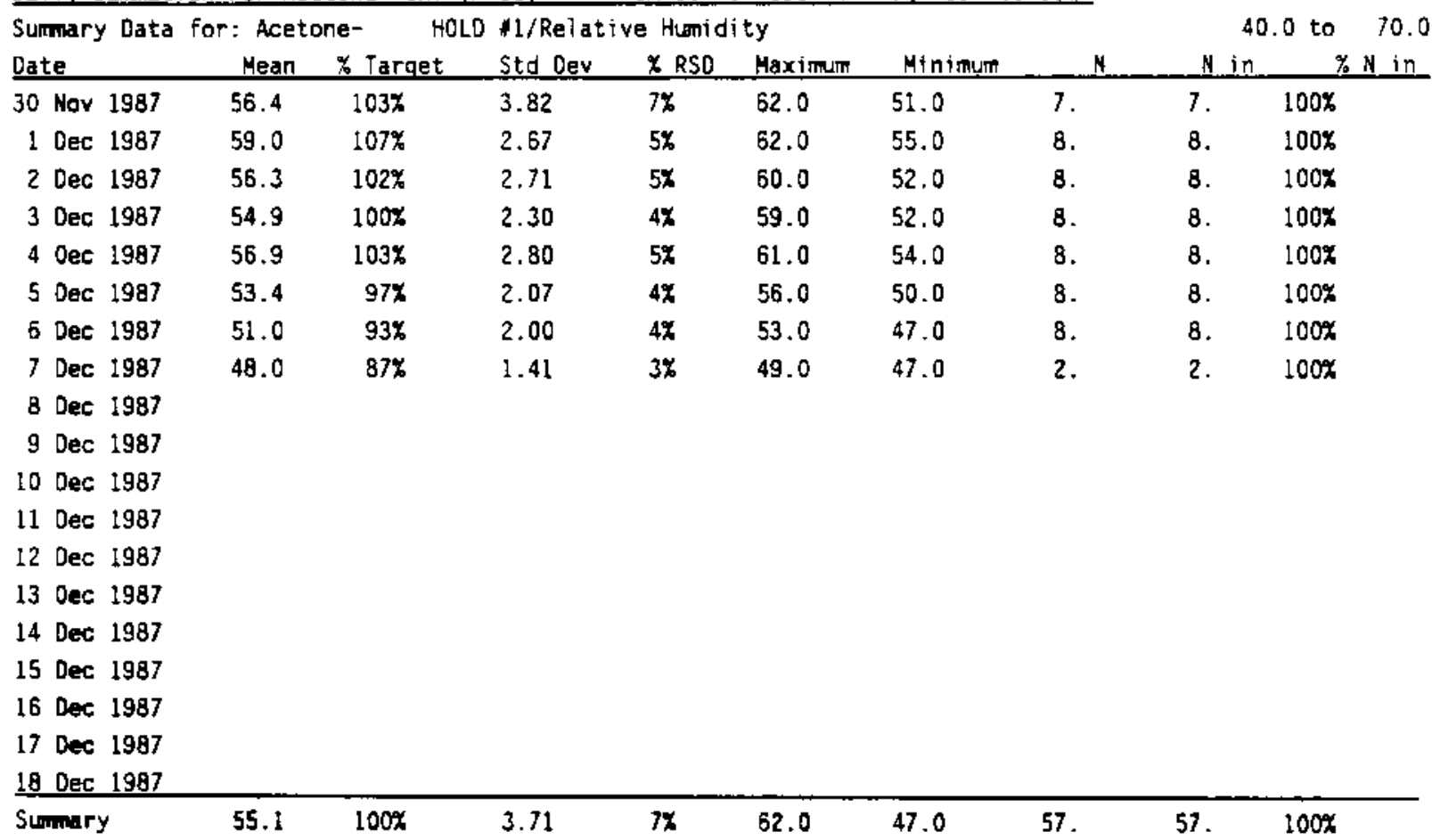

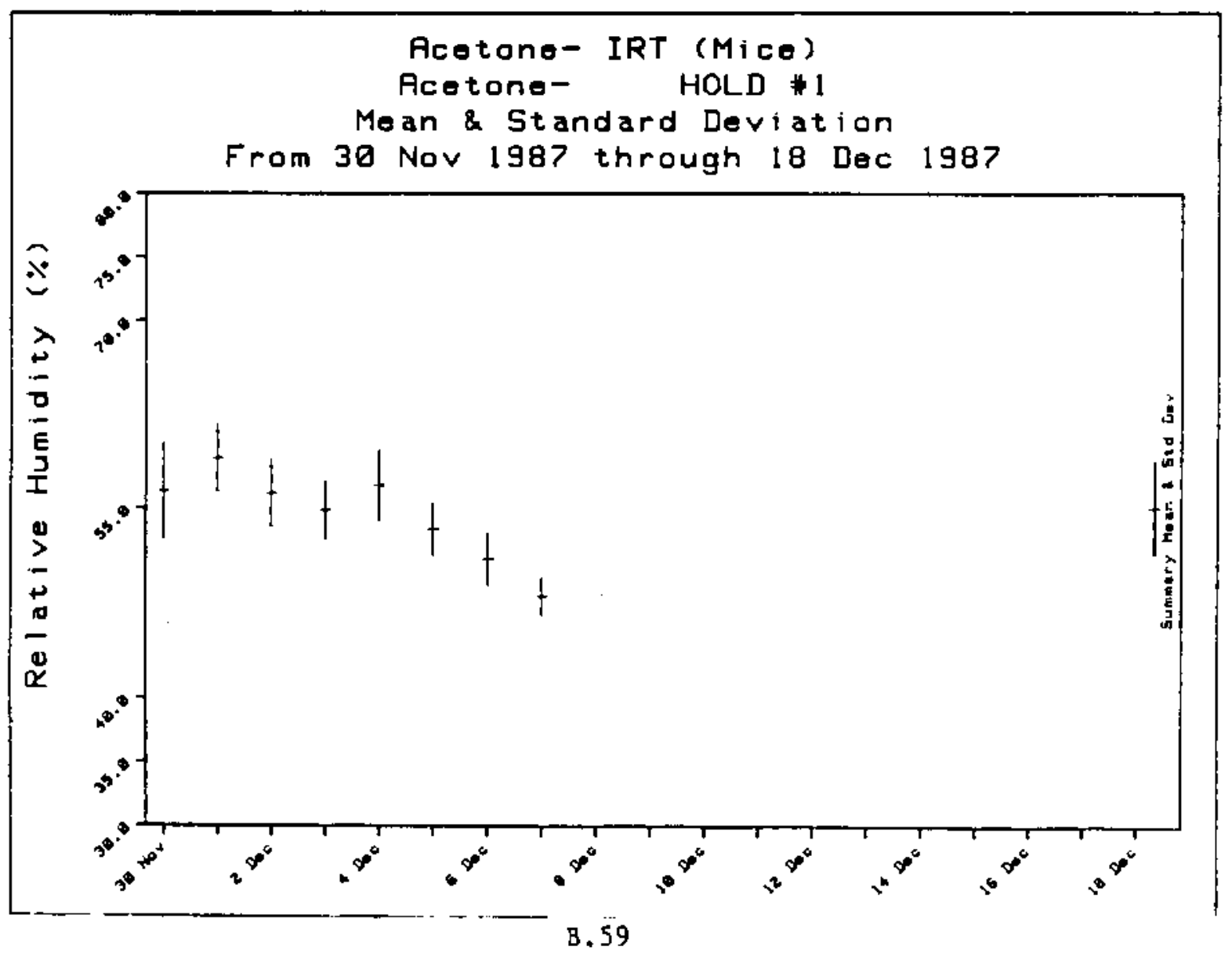


Daily Summation For Acetone- IRT (Mice) From 2 Dec 1987 through 18 Dec 1987

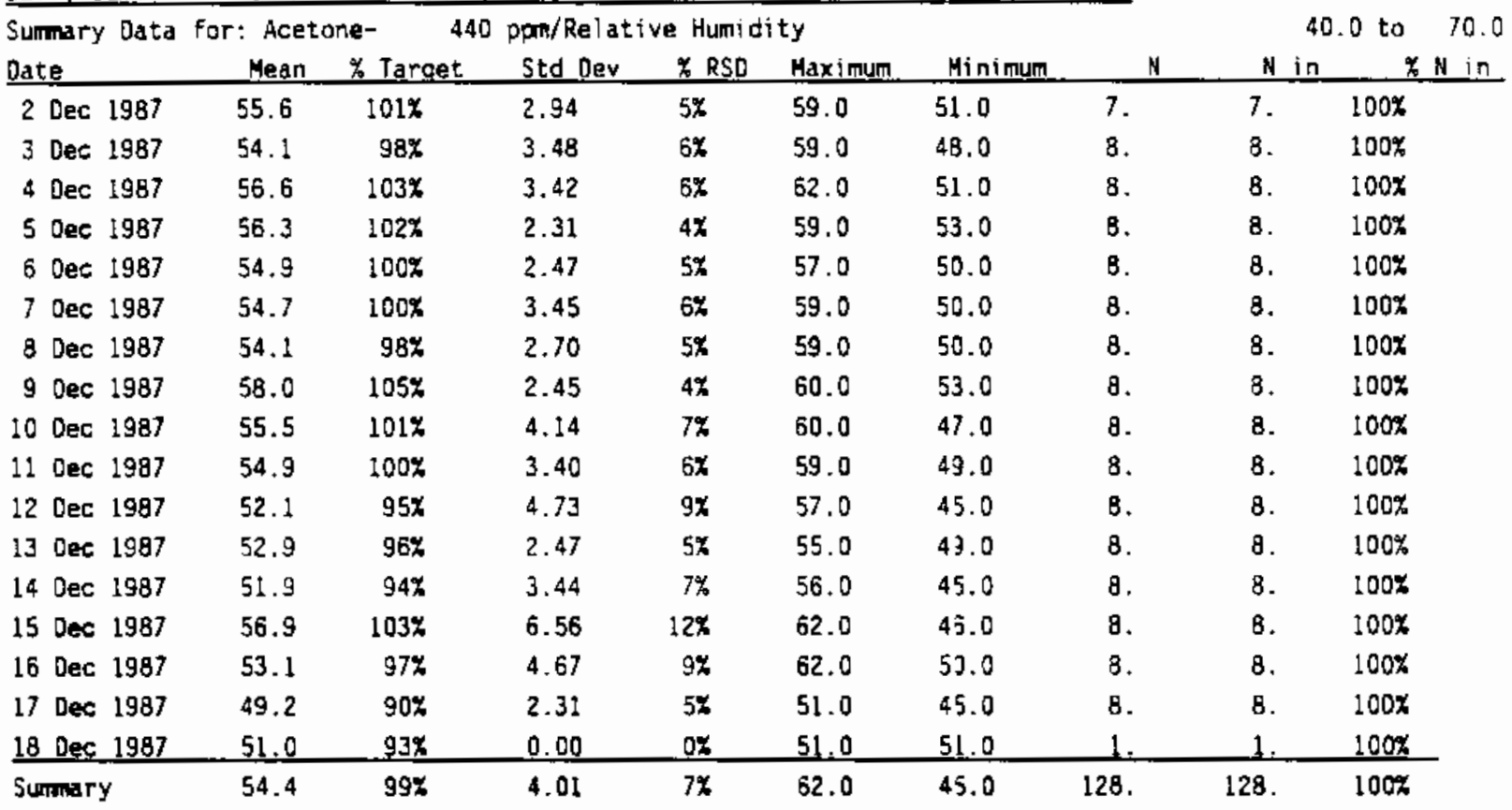

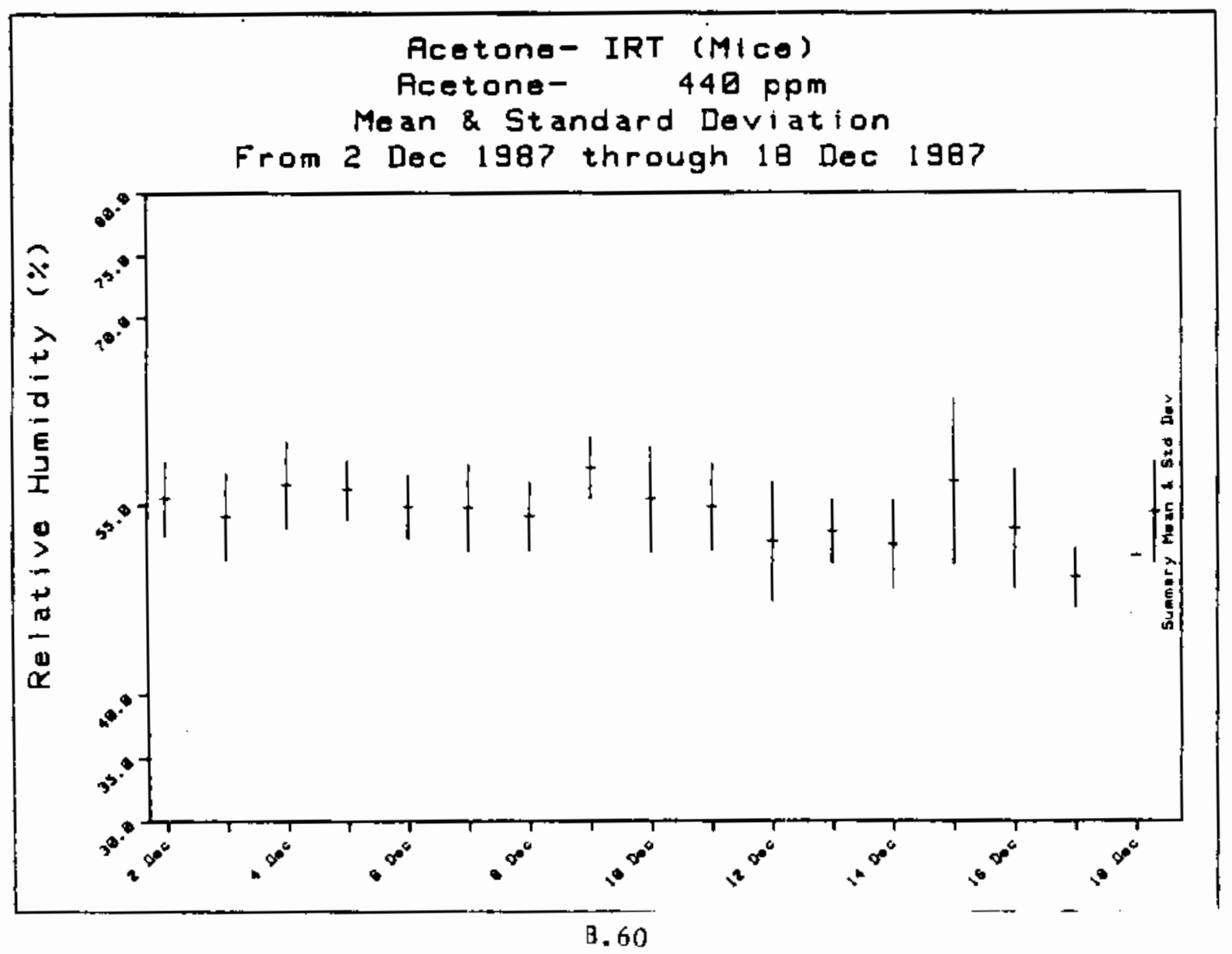


Daily Sumation For Acetone-_IRT (Mice) From.2 Dec 1987 through 18 Dec 1987

\begin{tabular}{|c|c|c|c|c|c|c|c|c|c|}
\hline Summary Data & $\because$ Acet & ne- & $\mathrm{ppm} / \mathrm{Re}$ t & e Hum & & & & & .0 to \\
\hline Date. & Hean & $\%$ Tarqet & Std Dev & $\approx$ RSD & Maximum & Minimim & N & $\mathrm{N}$ in & $X N$ in \\
\hline 2 Dec 1987 & 52.3 & $95 \%$ & 5.82 & $11 \%$ & 61.0 & 47.0 & 7. & 7. & $100 x$ \\
\hline 3 Dec 1987 & 47.6 & $87 \%$ & 1.77 & $4 x$ & 50.0 & 45.0 & 8. & 8. & $100 x$ \\
\hline 4 Dec 1987 & 54.6 & $99 x$ & 4.87 & $9 x$ & 60.0 & 48.0 & 8. & 8. & $100 x$ \\
\hline 5 Dec 1987 & 57.1 & $104 \%$ & 2.70 & $5 x$ & 60.0 & 53.0 & 8. & 8. & $100 x$ \\
\hline 6 Dec 1997 & 57.4 & $104 \%$ & 2.20 & $4 x$ & 61.0 & 54.0 & g. & 8. & $100 \%$ \\
\hline 7 Dec 1987 & 56.9 & $103 x$ & 2.23 & $4 x$ & 59.0 & 54.0 & 8. & 8. & $100 x$ \\
\hline 8 Dec 1987 & 57.8 & $105 x$ & 2.66 & $5 x$ & 60.0 & 52.0 & 8. & 8. & $100 x$ \\
\hline 9 Dec 1987 & 58.8 & $107 x$ & 2.25 & $4 \%$ & 61.0 & 54.0 & 8. & B. & $100 x$ \\
\hline 10 Dec 1987 & 55.0 & $100 \pi$ & 4.11 & $7 x$ & 59.0 & 46.0 & 8. & 8. & $100 x$ \\
\hline 11 Dec 1987 & 53.7 & $98 x$ & 1.58 & 37 & 57.0 & 52.0 & 8. & 8. & $100 \%$ \\
\hline 12 Dec 1987 & 52.5 & $95 \%$ & 2.51 & $5 x$ & 56.0 & 49.0 & 8. & 8. & $100 \%$ \\
\hline 13 Dec 1987 & 52.5 & $95 \%$ & 2.20 & $4 x$ & 55.0 & 48.0 & 8. & 8. & $100 x$ \\
\hline 14 Dec 1987 & 51.5 & $94 \%$ & 3.34 & $6 x$ & 56.0 & 45.0 & 8. & 8. & $100 x$ \\
\hline 15 Dec 1987 & 51.6 & $94 x$ & 2.50 & $5 \%$ & 54.0 & 46.0 & 8. & 8. & $100 x$ \\
\hline 16 DeC 1997 & 51.6 & $94 x$ & .74 & $1 \%$ & 52.0 & 50.0 & 8. & 8. & $100 x$ \\
\hline 17 Dec 1987 & 47.1 & $86 \%$ & 1.96 & $4 x$ & 50.0 & 45.0 & 8. & 8. & $100 x$ \\
\hline 18 Dec 1987 & 48.0 & $87 \%$ & 0.00 & $\alpha x$ & 48.0 & 49.0 & 1. & 1. & $100 x$ \\
\hline Sumary & 53.6 & $97 \%$ & 4.36 & $8 x$ & 61.0 & 45.0 & 128. & 128. & $100 \%$ \\
\hline
\end{tabular}

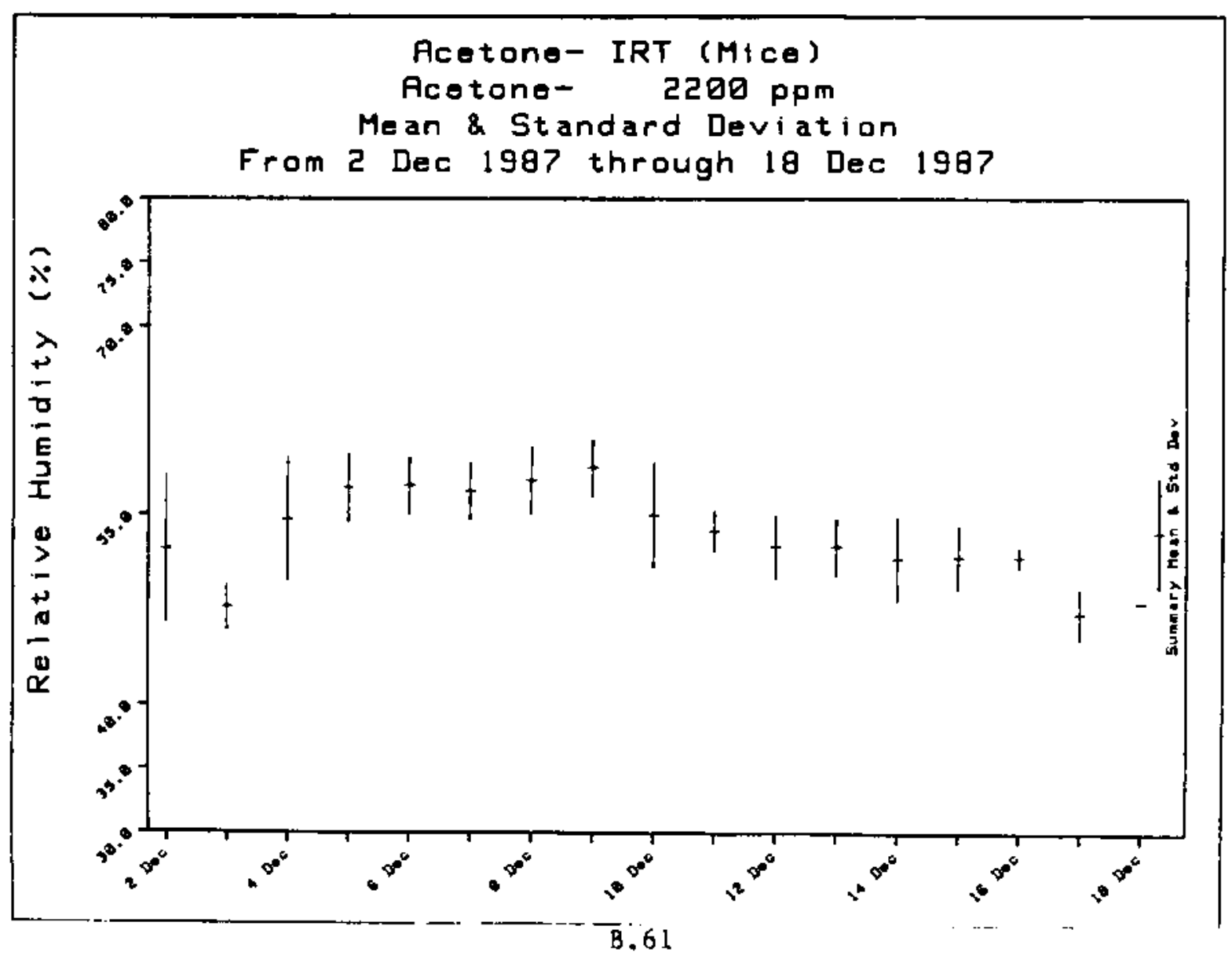


Daily Summation For Acetone- IRT (Mice) From 2 Dec 1987 through 18 Dec 1987

\begin{tabular}{|c|c|c|c|c|c|c|c|c|c|}
\hline Summary Data & Ace & & $\mathrm{ppm} / \mathrm{Rel}$ & e Hur & & & & & 0 to \\
\hline Date & Mean & \% Tarqet & Stdd Dev & $\approx$ RSD & Maximum & Minimum & $\mathrm{N}$ & $N$ in & $\% \mathrm{~N}$ in \\
\hline 2 Dec 1987 & 54.6 & $99 \%$ & 5.88 & $11 \%$ & 64.0 & 49.0 & 7. & 7. & $100 \%$ \\
\hline 3 Dec 1987 & 49.2 & $90 x$ & 3.28 & $7 x$ & 52.0 & 43.0 & 8. & 8. & $100 x$ \\
\hline 4 Dec 1987 & 52.9 & $96 \%$ & 5.22 & $10 x$ & 60.0 & 47.0 & 8. & 8. & $100 \%$ \\
\hline 5 Dec 1987 & 53.7 & $98 \%$ & 3.62 & $7 x$ & 58.0 & 47.0 & 8. & 8. & $100 x$ \\
\hline 6 Dec 1987 & 56.5 & $103 x$ & 3.42 & $6 x$ & 60.0 & 50.0 & 8. & 8. & $100 x$ \\
\hline 7 Dec 1987 & 58.5 & $106 \%$ & 1.85 & $3 x$ & 61.0 & 56.0 & 8. & 8. & $100 \%$ \\
\hline 8 Dec 1987 & 58.6 & $107 x$ & 3.62 & $6 \%$ & 62.0 & 51.0 & 8. & 8. & $100 x$ \\
\hline 9 Dec 1987 & 58.1 & $105 \%$ & 3.23 & $6 x$ & 63.0 & $\$ 2.0$ & g. & 8. & $100 x$ \\
\hline 10 Dec 1997 & 59.9 & $109 x$ & .64 & $1 \%$ & 61.0 & 59.0 & 8. & 8. & $100 \%$ \\
\hline 11 Dec 1987 & 50.6 & $92 \%$ & 5.83 & $12 \%$ & 61.0 & 47.0 & 8. & B. & $100 \%$ \\
\hline 12 Dec 1987 & 47.9 & $87 \%$ & 2.23 & $5 \%$ & 50.0 & 43.0 & 8. & 8. & $100 \%$ \\
\hline 13 Dec 1987 & 47.6 & $87 \%$ & 1.51 & 37 & 50.0 & 45.0 & 8. & 8. & $100 \%$ \\
\hline 14 Dec 1987 & 46.6 & $85 x$ & 2.50 & $5 \%$ & 49.0 & 41.0 & 8. & 8. & $100 \%$ \\
\hline 15 Dec 1987 & 51.0 & $93 \%$ & 5.15 & $10 x$ & 58.0 & 40.0 & 8. & 8. & $100 \%$ \\
\hline 16 Dec 1987 & 51.2 & $93 \%$ & 1.04 & $2 \%$ & 52.0 & 49.0 & 8. & 8. & $100 x$ \\
\hline 17 Dec 1987 & 47.9 & $87 \%$ & 1.81 & 47 & 50.0 & 45.0 & 8. & 8. & $100 x$ \\
\hline 18 Dec 1987 & 48.0 & $87 \%$ & 0.00 & $0 \%$ & 48.0 & 48.0 & 1. & 1. & $100 x$ \\
\hline Summary & 52.8 & $96 \%$ & 5.47 & $10 x$ & 64.0 & 40.0 & 128. & 128. & $100 x$ \\
\hline
\end{tabular}

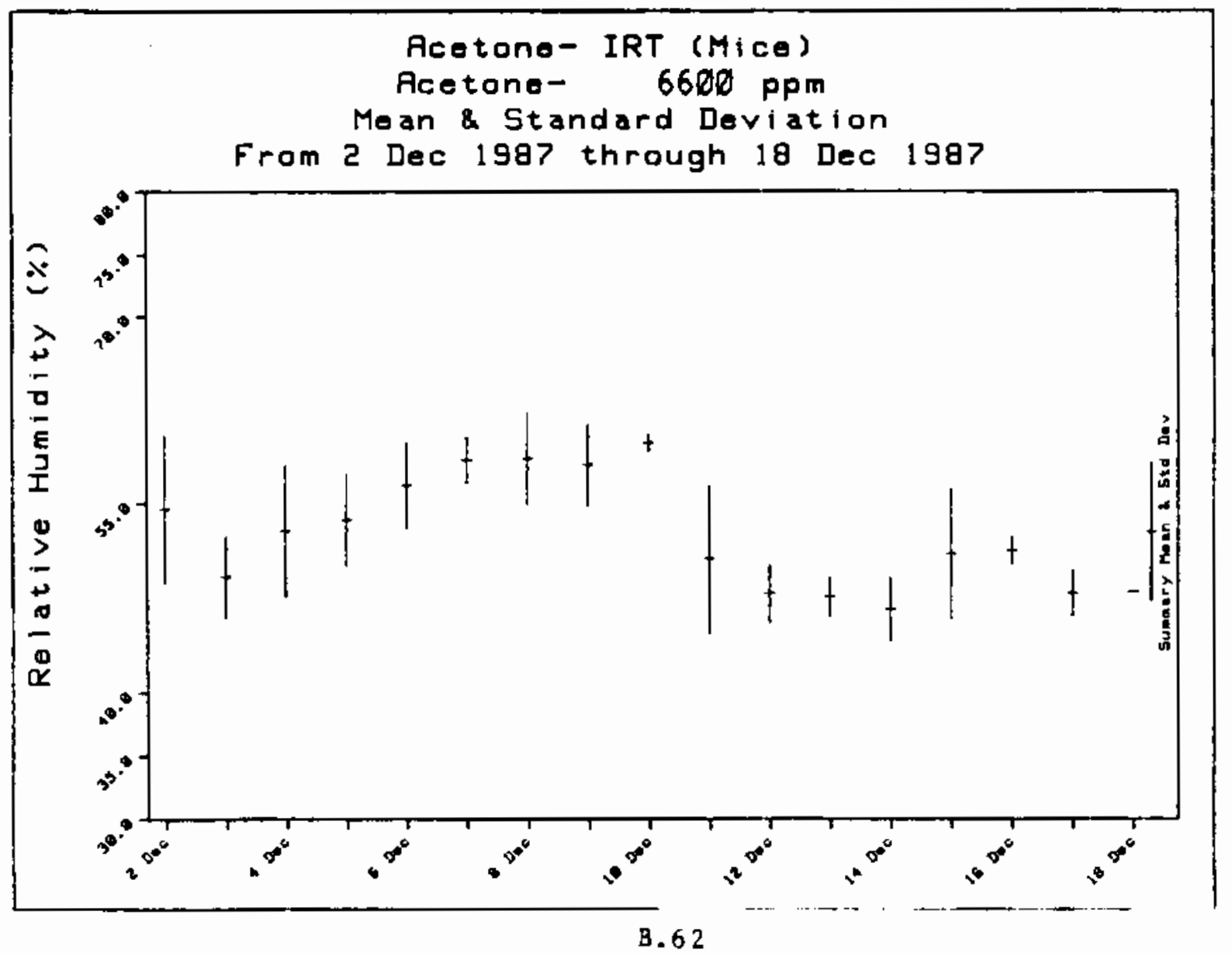


Qaily Sumation For Acetone- IRT (Mice) From 30 Nov 1987 through 18 Dec I987

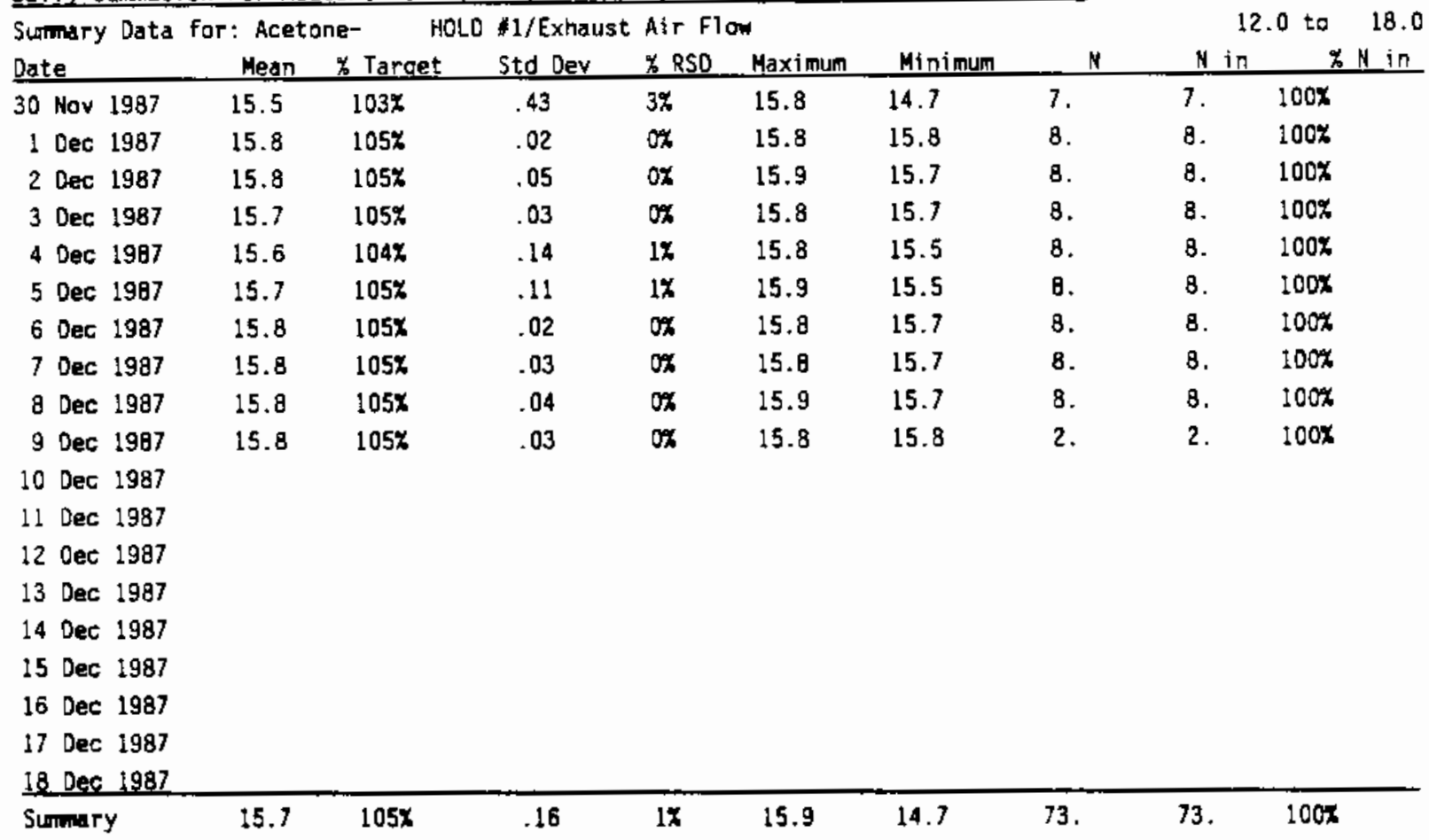

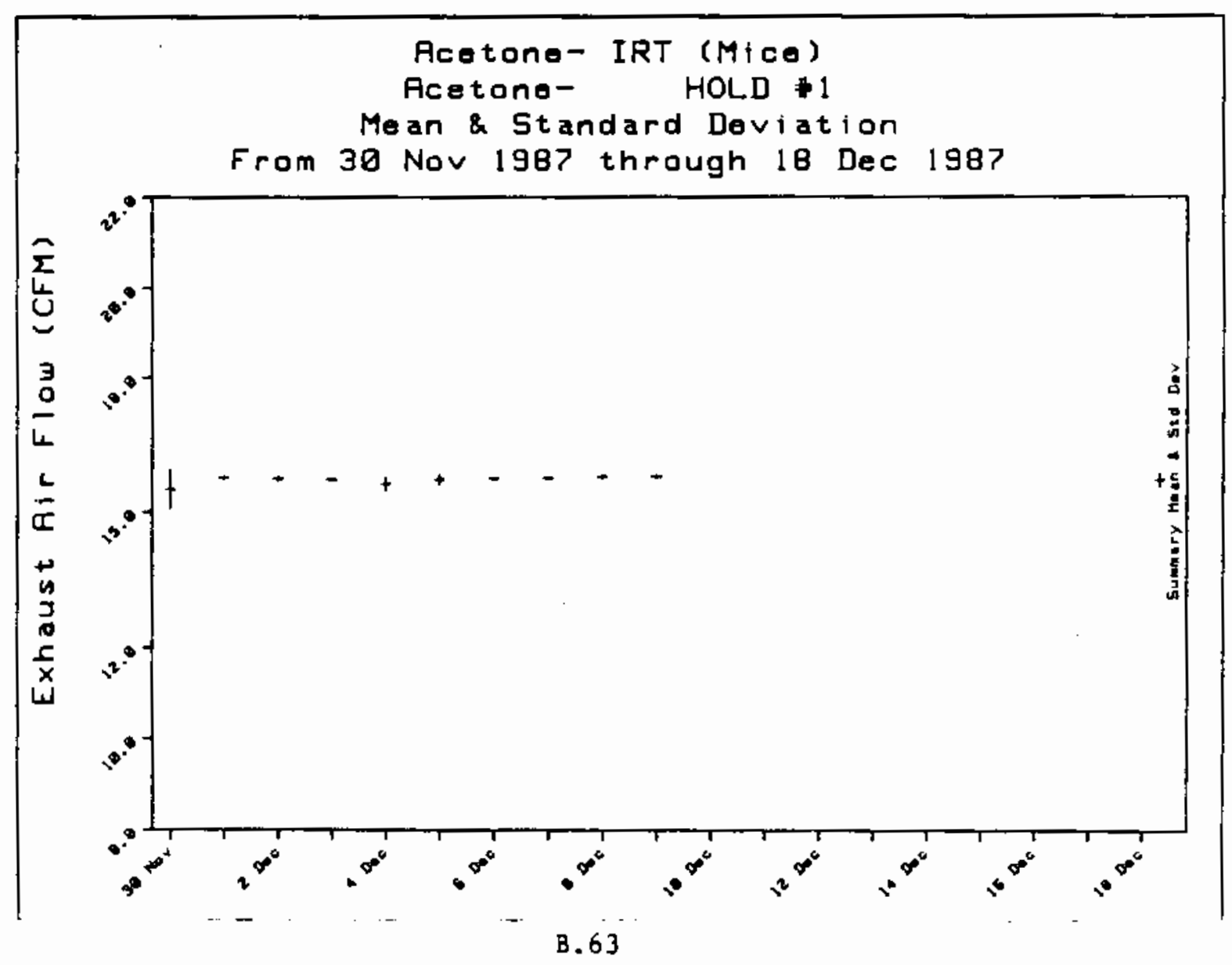


Daily Summation For Acetone- IRT (Mice)

From 2 Dec 1987 throuch 18 Dec 1987

\begin{tabular}{|c|c|c|c|c|c|c|c|c|c|}
\hline Summary Data & Acet & ne- & apm/Exhau & Air Fl & & & & & .0 to \\
\hline Date & Mean & $\%$ Tarcet & Std Dey & DSD & Maximm & Minimim & N & $N$ in & $\% N$ in \\
\hline $2 \operatorname{Dec} 1987$ & 15.2 & $101 \%$ & .05 & $0 \%$ & 15.3 & 15.1 & 7. & 7. & $100 x$ \\
\hline 3 Dec 1987 & 15.1 & $101 \%$ & .02 & $0 \%$ & 15.1 & $\$ 5.1$ & 8. & 8. & $100 x$ \\
\hline 4 Dec 1987 & 15.1 & $101 \%$ & .05 & $0 x$ & 15.2 & $\$ 5.1$ & 8. & 8. & $100 x$ \\
\hline 5 Des 1987 & 15.1 & $101 x$ & .02 & $0 \%$ & 15.2 & 15.1 & 8. & 8. & $100 x$ \\
\hline 6 Dec 1987 & 15.1 & $101 x$ & .04 & $0 x$ & 15.2 & 15.1 & 8. & 8. & $100 \%$ \\
\hline 7 Dec 1987 & 15.2 & $101 \%$ & .03 & $0 \%$ & 15.2 & 15.1 & 8. & 8. & $100 x$ \\
\hline 8 Dec 1987 & 15.2 & $101 \%$ & .04 & $0 x$ & 15.2 & 15.1 & 8. & 8. & $100 x$ \\
\hline 9 Dec 1987 & 15.1 & $101 \%$ & .07 & $0 \%$ & 15.2 & 15.0 & B. & 8. & $100 \%$ \\
\hline 10 Dec 1987 & 15.2 & $101 \%$ & .04 & $0 x$ & 15.2 & 15.1 & 8. & 8. & $100 \%$ \\
\hline 11 Dec 1987 & 15.2 & $101 \%$ & .02 & $0 \%$ & 15.2 & 15.1 & 8. & 8. & $100 \%$ \\
\hline 12 Dec 1987 & 15.2 & 1017 & .02 & $O \%$ & 15.2 & 15.1 & 8. & 8. & $100 \%$ \\
\hline 13 Dec 1987 & 15.1 & $101 \%$ & .02 & $\alpha x$ & 15.2 & 15.1 & 8. & 8. & $100 x$ \\
\hline 14 Dec 1987 & 15.1 & $101 \%$ & .02 & $0 x$ & 15.2 & 15.1 & 8. & 8. & $100 \%$ \\
\hline 15 dec 1987 & 15.1 & $101 x$ & .02 & $D x$ & 15.1 & 15.1 & 8. & 8. & $100 \%$ \\
\hline 16 Dec 1987 & 15.1 & $101 \%$ & .01 & $0 \%$ & 15.1 & 15.1 & 8. & 8. & $100 x$ \\
\hline 17 Dec 1987 & 15.2 & $101 x$ & .05 & $0 x$ & 15.2 & 15.1 & 8. & 8. & $100 x$ \\
\hline 18 Dec 1987 & 15.2 & $101 x$ & 0.00 & $0 x$ & 15.2 & 15.2 & 1. & 1. & $100 \%$ \\
\hline Sumary & 15.1 & $101 \%$ & .05 & $\alpha \%$ & 15.3 & 15.0 & 128. & 128. & $100 x$ \\
\hline
\end{tabular}

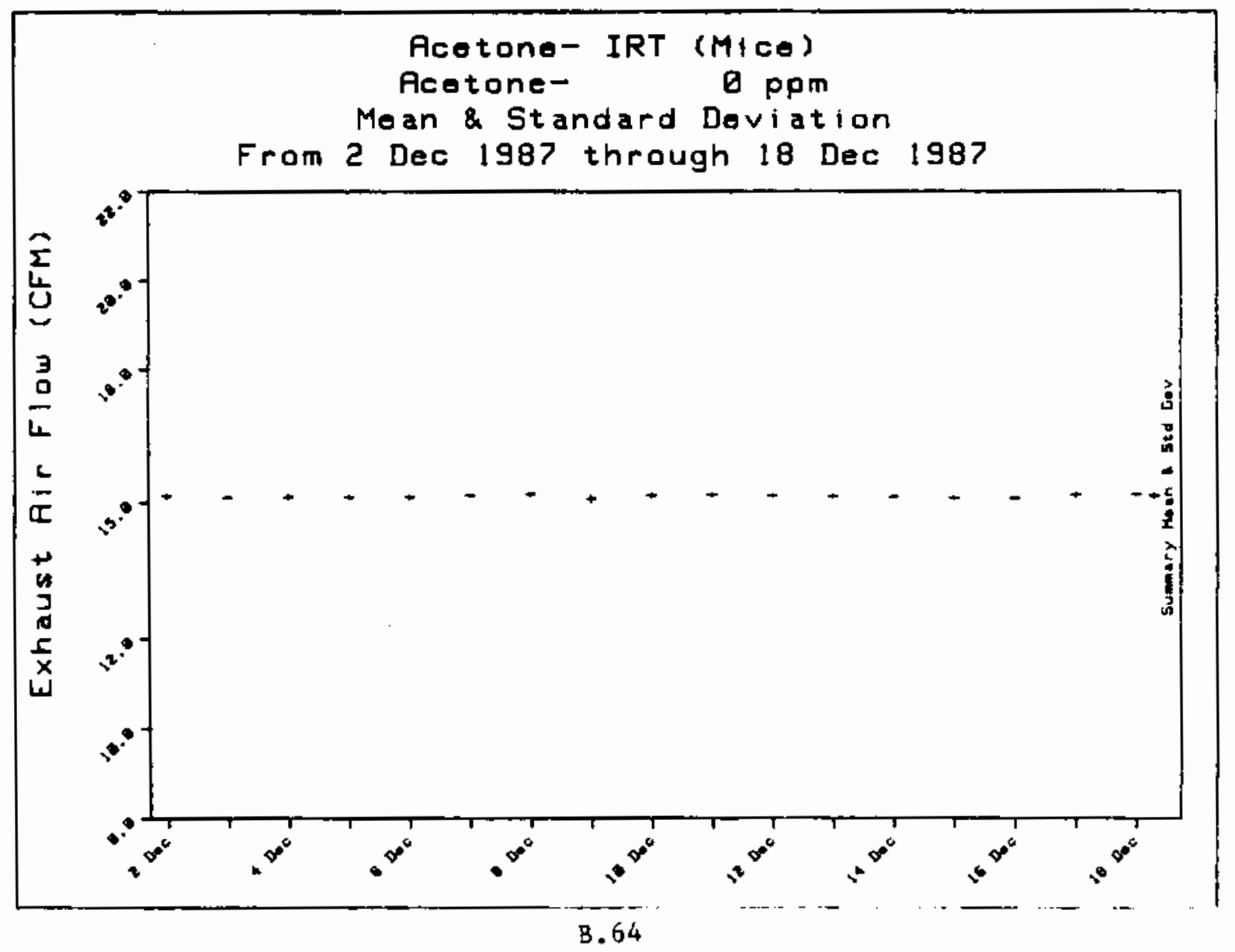


Daily Summation For Acetone- IRT (Hice) From 2 Dec 1987 through 18 Dec 1987

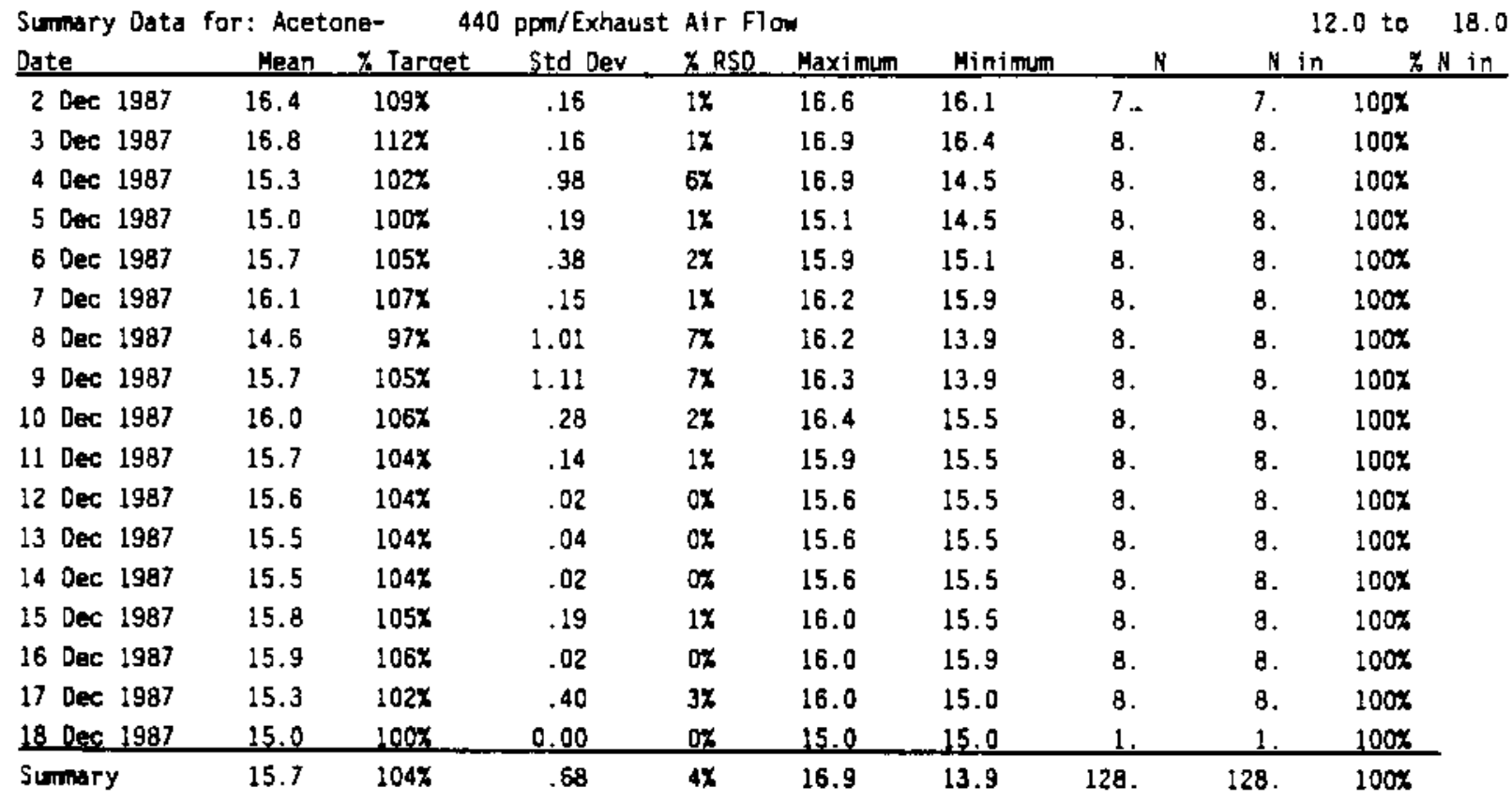

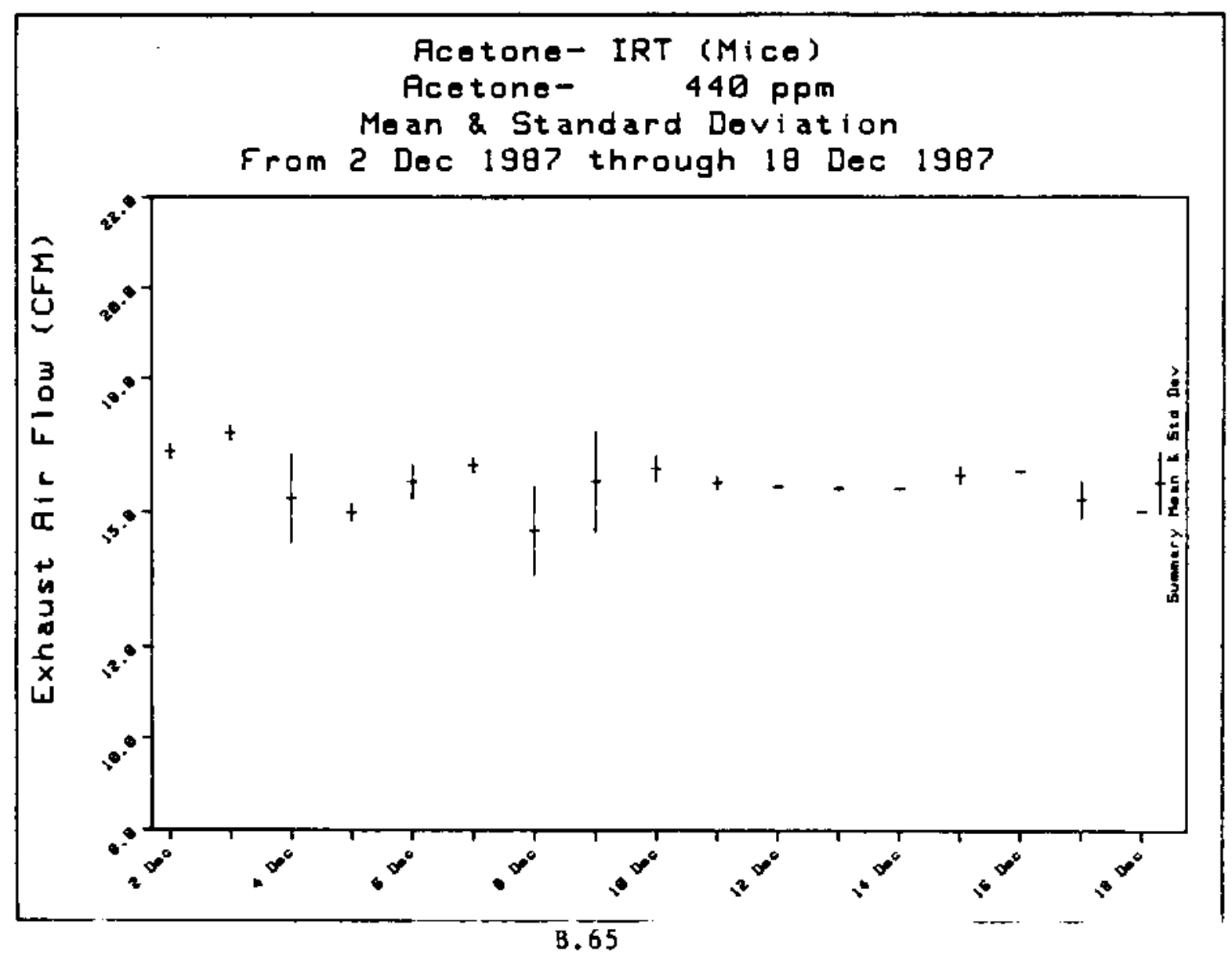


Daily Sumation For Acetone- IRT (Mice). From 2 Dec 1997 through 18 Dec 1987

\begin{tabular}{|c|c|c|c|c|c|c|c|c|c|}
\hline Surmary Data & for: Acet & 220 & ppm/Exhau & Air Fl & & & & & 0 to \\
\hline Date & Mean & D Target & Std Dev & $x$ RSO & Maximum & Mínimum & $\mathbf{N}$ & $\mathrm{N}$ in & $\not N$ in \\
\hline 2 Dec 1997 & 15.9 & $106 x$ & .29 & $2 x$ & 16.3 & 15.3 & 7. & 7. & $100 x$ \\
\hline 3 Des 1997 & 16.0 & $107 \%$ & .03 & $0 x$ & 16.0 & 16.0 & 8. & g. & $100 \%$ \\
\hline 4 Dec 1987 & 15.9 & $106 x$ & .19 & $1 x$ & 16.1 & 15.7 & 8. & 8. & $100 x$ \\
\hline 5 Dec 1987 & 15.9 & $106 x$ & .09 & $1 x$ & 16.0 & 15.7 & 8. & 8. & $100 x$ \\
\hline 6 Dec 1987 & 15.9 & $106 \%$ & .03 & $0 x$ & 16.0 & 15.9 & g. & 8. & $100 x$ \\
\hline 7 Dec 1987 & 15.9 & $106 x$ & .03 & $\alpha x$ & 16.0 & 15.9 & g. & 8. & $100 x$ \\
\hline $8 \mathrm{Dec} 1987$ & 16.0 & $106 x$ & .04 & $0 x$ & 16.0 & 15.9 & 8. & 8. & $100 x$ \\
\hline 9 Dec 1987 & 15.7 & $105 \%$ & .14 & $1 x$ & 16.0 & 15.6 & 8. & 8. & $100 \%$ \\
\hline 10 Dec 1987 & 15.8 & $105 x$ & .03 & $0 x$ & 15.8 & 15.7 & 8. & 8. & $100 x$ \\
\hline 11 Dec 1987 & 15.7 & $105 \%$ & .05 & $0 x$ & 15.8 & 15.6 & 8. & 8. & $100 x$ \\
\hline 12 Dec 1987 & 15.7 & $104 x$ & .02 & $0 x$ & 15.7 & 15.6 & 8. & 8. & $100 x$ \\
\hline 13 Dec 1987 & 15.6 & $104 x$ & .04 & $0 x$ & 15.7 & 15.6 & 8. & 8. & $100 x$ \\
\hline 14 Dec 1987 & 15.6 & $104 x$ & .02 & $0 x$ & 15.6 & 15.6 & 8. & 8. & $100 x$ \\
\hline 15 Dec 1987 & 15.6 & $104 x$ & .03 & $0 x$ & 15.6 & 15.5 & 8. & 8. & $100 x$ \\
\hline 16 Dec 1987 & 15.6 & $104 x$ & .03 & $0 x$ & 15.6 & 15.5 & g. & 8. & $100 x$ \\
\hline 17 Dec 1987 & 15.5 & $104 x$ & .04 & $0 x$ & 15.6 & 15.5 & 8. & 8. & $100 x$ \\
\hline 18 Dec 1987 & 15.5 & $103 \%$ & 0.00 & ox & 15.5 & 15.5 & 1. & 1. & $100 x$ \\
\hline Stmary & 15.8 & $105 x$ & .18 & $1 x$ & 16.3 & 15.3 & 128. & 128. & $100 x$ \\
\hline
\end{tabular}

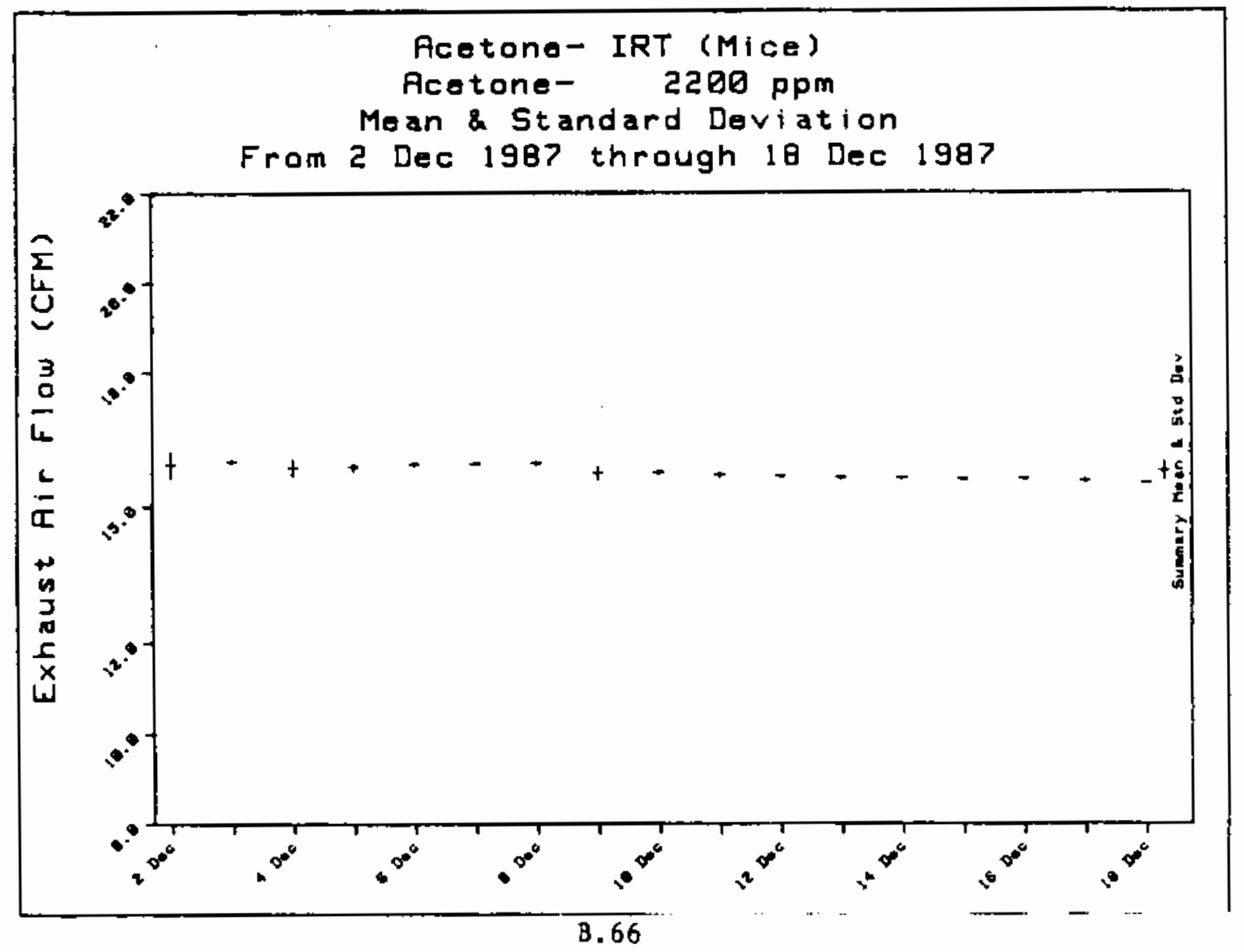


Qajily Summation For Acetone- IRT (Mice) From 2 Dec 1987 through 18 Dec 1987

\begin{tabular}{|c|c|c|c|c|c|c|c|c|c|}
\hline Sumary Data & IF: Acet & 660 & $\mathrm{ppm} /$ Exhau & Air Fl & & & & & .0 to 18.0 \\
\hline Date & Mean & $z$ Tarqet & Stcd Dev & $\%$ RSD & Maximm & Minimin & $N$ & $N$ in & $\%$ in \\
\hline $2 \operatorname{Dec} 1987$ & 16.4 & $109 \%$ & .43 & 37 & 16.6 & 15.4 & 7. & 7 & $100 x$ \\
\hline 3 Dec 1987 & 16.2 & $108 x$ & .15 & $1 x$ & 16.6 & 16.1 & 8. & 8. & $100 x$ \\
\hline $4 \operatorname{Dec} 1987$ & 16.0 & $107 x$ & .28 & $2 x$ & 16.5 & 15.8 & 8. & 8. & $100 x$ \\
\hline 5 Dec 1987 & 16.6 & $111 x$ & .47 & $3 x$ & 17.0 & 15.8 & 8. & 8. & $100 \%$ \\
\hline 6 Dec 1987 & 16.4 & $110 x$ & .30 & $2 x$ & 16.9 & 16.3 & 8. & 8. & $100 x$ \\
\hline 7 Dec 1987 & 16.3 & $109 \%$ & .04 & $0 x$ & 16.4 & 16.2 & 8. & 8. & $100 \%$ \\
\hline 8 Cec 1987 & 15.2 & $108 \%$ & .03 & $0 x$ & 16.2 & 16.1 & 8. & 8. & $100 x$ \\
\hline 9 Dec 1987 & 16.0 & $107 x$ & .10 & $1 x$ & 16.2 & 15.9 & 8. & 8. & $100 \%$ \\
\hline 10 Dec 1987 & 15.8 & $105 x$ & .15 & $1 x$ & 16.0 & 15.7 & 8. & 8. & $100 \%$ \\
\hline 11 Dec 1987 & 15.7 & $105 \%$ & .10 & $1 x$ & 16.0 & 15.7 & 8. & 8. & $100 \%$ \\
\hline 12 Dec 1987 & 15.7 & $104 \%$ & .02 & $0 x$ & 15.7 & 15.6 & 8. & 8. & $100 \%$ \\
\hline 13 Dec 1987 & 15.6 & $104 \%$ & .03 & $0 x$ & 15.7 & 15.6 & 8. & 8. & $100 \%$ \\
\hline 14 Dec 1987 & 15.5 & $104 \%$ & .02 & $0 x$ & 15.7 & 15.6 & 8. & 8. & $100 x$ \\
\hline 15 Dec 1987 & 15.7 & $105 \%$ & .06 & $0 \%$ & 15.8 & 15.6 & 8. & 8. & $100 \%$ \\
\hline 16 Dec 1987 & 15.8 & $105 \%$ & .07 & $0 x$ & 15.9 & 15.7 & 8. & 8. & $100 x$ \\
\hline 17 Dec 1987 & 15.5 & $103 x$ & .22 & $1 x$ & 15.9 & 15.2 & 8. & 8. & $100 x$ \\
\hline 18 Dec 1987 & 15.4 & $103 \%$ & 0.00 & $0 x$ & 15.4 & 15.4 & 1. & 1. & $100 \%$ \\
\hline Summary & 16.0 & $106 \%$ & .39 & $2 x$ & 17.0 & 15.2 & 128. & 128. & $100 \pi$ \\
\hline
\end{tabular}

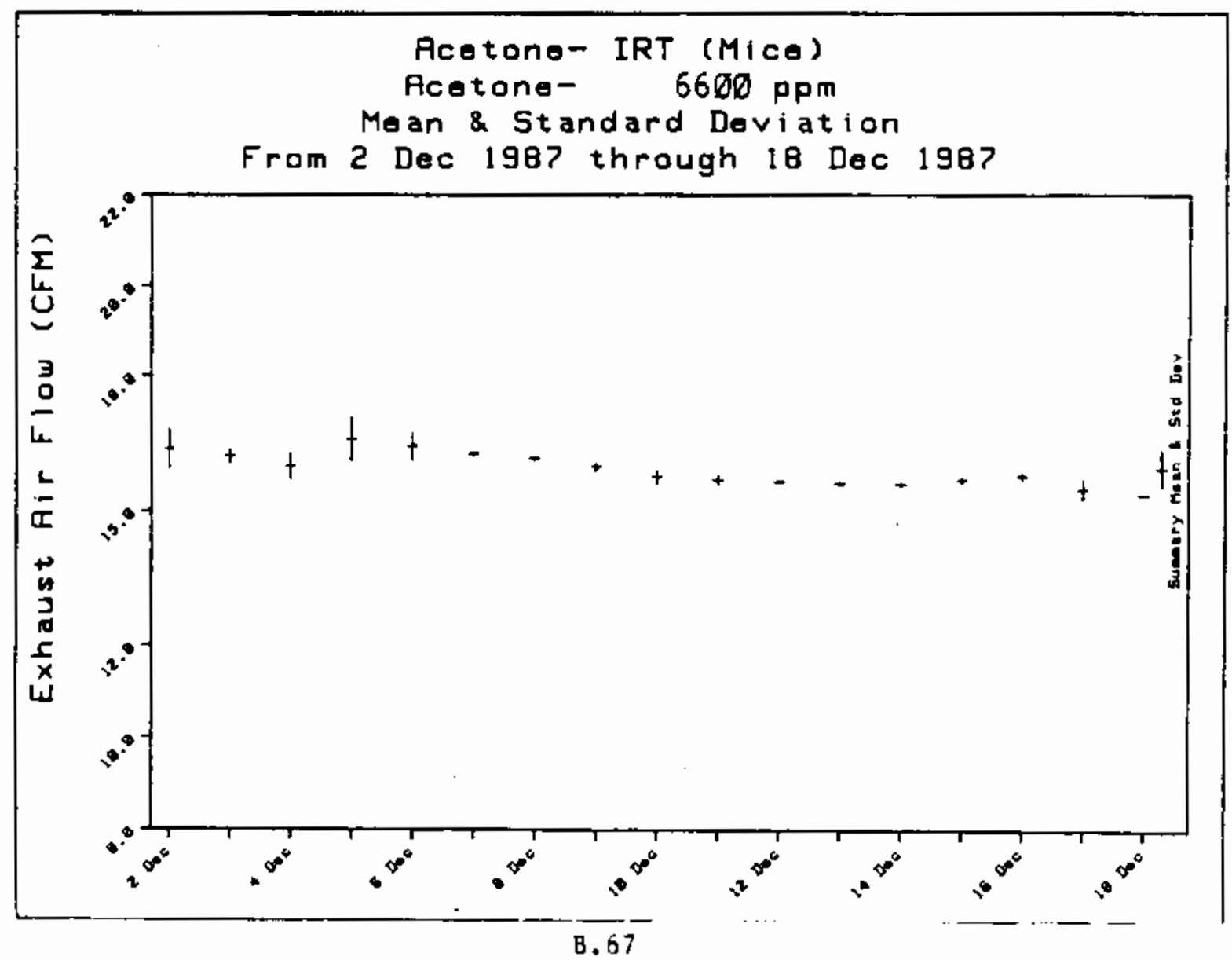


CHAMBER UNIFORMITY DATA SHEET

COMPOUND: Acetone IRT

EXPOSURE ROOM NUMBER: 436

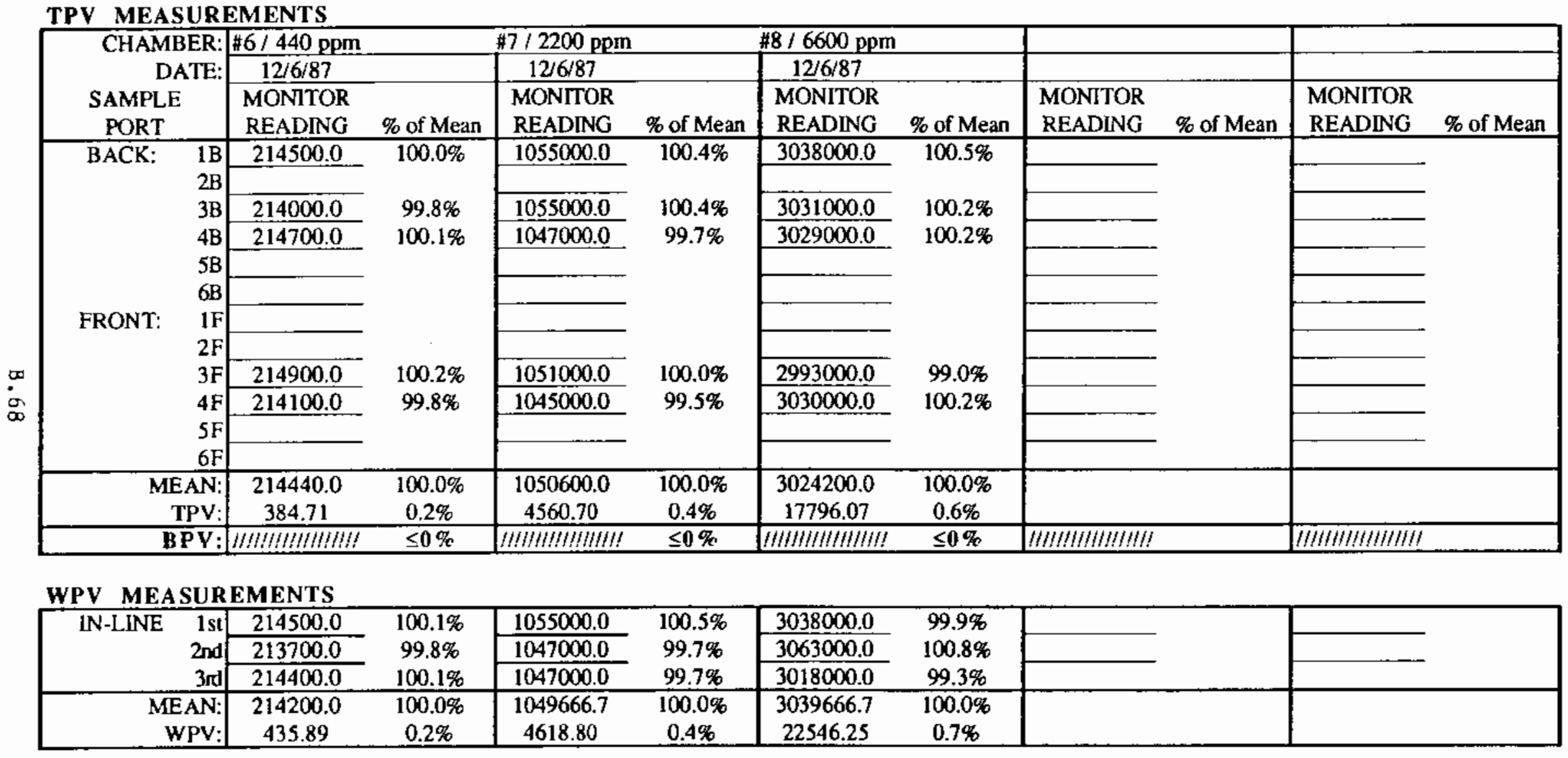

MONITOR TYPE: GC

SERIAL \# :

MONITOR DATA LOCATION: 2B

COMMENTS: $\quad$ Note change in dose in chamber \#8

Study with Mice

ENTERED BY: $\quad \underline{\text { LL Trent }}$

DATE: $\quad 12 / 10 / 87$

REVIEWED BY: RU Weigel

Rlu

DATE: $3 / 18 / 88$ 


\section{EXPOSURE OPERATION DISCUSSION SHEET}

INCLUDES DISCUSSIONS AND/OR EXPLANATIONS OF PROBLEMS AFFECTING ANIMAL ENVIRONMENT AND EXPOSURES. EXPLANATIONS ARE INCLUDED FOR DATA IN WHICH THERE WERE EXCURSIONS OF DAILY MEAN OR STANDARD DEVIATION BEYOND ALLOWABLE OPERATING LIMITS OR EXCURSIONNS OF INDIVIDUAL DATUM BEYOND CRITICAL LIMITS.

STUDY: IRT Acetone Inhalation Reproductive Teratology Study

REPORTING PERIOD: December 1-30, 1987 NOTE: 24 Hour Data Collection Period extends from 5:00 a.m. to $-5: 00$ a.m.

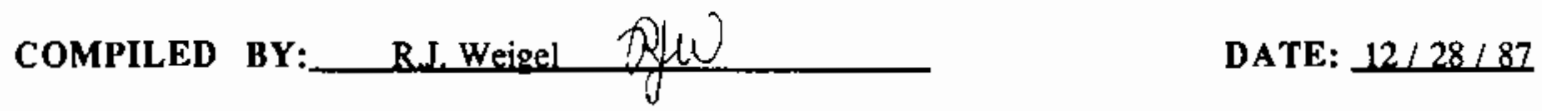

\section{CHAMBER CONCENTRATION}

\section{DATE____ DISCUSSION OR EXPLANATION}

12/3/87 Target concentration for the high chamber was changed from $11000 \mathrm{ppm}$ to $6600 \mathrm{ppm}$. This

12/6/87 Exposure ended at 15:14. At 15:22, concentration in the Room was measured at $16.6 \mathrm{ppm}$; at 15:25, concentration in the 0 ppm chamber was measured at $3.8 \mathrm{ppm}$. Readings before and after these showed no unusual levels in either chamber. The reason for these readings are not known. Animal care personnel have been reminded to wait the appropriate period before opening exposure chambers at the end of exposure days.

12/9/87 Exposures were interrupted at 9:12 after 23 minutes (11 minutes after T90 was reached) because food had been left in the exposure chambers. Following decay of concentration levels in the chambers, the food was removed and exposures were reinitiated at 10:12. The second

exposure period ran for 5: 36 after $T_{90}$ was reached ( 6 hrs - 23 minutes of prior exposure).

12/17/87 Exposures were terminated early on this last day of testing after 5:09 when the heater element burned out in one of the high chamber generators. Initial shutdown of the exposure occurred at 13:43, causing levels in all three chambers to fall below the critical low limits. At 14:16, the exposure was teminated when the problem was diagnosed and reported to the principal investigator. The readings below the critical levels were:

\begin{tabular}{lccccc} 
Time & Chamber & Concentration & \% Target(Daily Avel & \%RSD \\
\cline { 2 - 4 } $13: 46$ & $440 \mathrm{ppm}$ & $316 \mathrm{ppm}$ & & \\
$14: 08$ & $440 \mathrm{ppm}$ & $7.6 \mathrm{ppm}$ & $85 \%$ & $36 \%$ \\
$14: 06$ & $2200 \mathrm{ppm}$ & $15.2 \mathrm{ppm}$ & $88 \%$ & $35 \%$ \\
$14: 03$ & $11000 \mathrm{ppm}$ & $113 \mathrm{ppm}$ & $89 \%$ & $35 \%$
\end{tabular}

TEMPERATURE \& RELATIVE HUMIDITY

DATE_DISCUSSION OR EXPLANATION

$12 / 6 / 87 \quad$ Room temperature $\left(66.9^{\circ} \mathrm{F}\right)$ exceeded the lower alarm limit $\left(67^{\circ} \mathrm{F}\right)$ at $08: 16$. Animal care personnel were cleaning the floor at this time and may have sprayed the sensor with water. A manual reading at $09: 35$ showed a room temperature of $73.7^{\circ} \mathrm{F}$.

CHAMBER FLOW \& VACUUM

DATE_____LISCUSSION OR EXPLANATION

No problems or excursions to report during this period. 
APRENDIX C

DEVELOPMENTAT TOXICOLOGY DATA 
Acetone Rat Toratology Study: Body Weighte and Urine Paramoterg for Virgin Femalea

\begin{tabular}{|c|c|c|c|c|c|c|c|c|c|c|c|c|}
\hline Metno & $\begin{array}{l}\operatorname{Pre-study} \\
\text { wt }(\theta)\end{array}$ & $\begin{array}{c}\text { Exposure } \\
\text { Doyl (g) }\end{array}$ & $\begin{array}{l}\text { Exposure } \\
\text { Day }(g)\end{array}$ & $\begin{array}{l}\text { Exposure } \\
\text { Dey } 10(g)\end{array}$ & $\begin{array}{c}\text { Socrifice } \\
W t(g)\end{array}$ & PH & $\begin{array}{l}\text { Protein } \\
\text { (mg/dL) }\end{array}$ & $\begin{array}{l}\text { Glucose } \\
(\mathrm{mg} / \mathrm{dL})\end{array}$ & $\begin{array}{l}\text { Ketone } \\
(\mathrm{mg} / d L)\end{array}$ & $\begin{array}{c}\text { Bilirubin } \\
(0-3)\end{array}$ & $\begin{array}{c}B \operatorname{lood} \\
(0-4)\end{array}$ & $\begin{array}{l}\text { Urobilinogøn } \\
\text { (Ehrijich units/dL) }\end{array}$ \\
\hline 676 & 280.8 & 286.3 & 312.3 & 305.6 & 316.0 & $\theta .0$ & 300 & $D$ & $\theta$ & o & $\boldsymbol{D}$ & $D$ \\
\hline 740 & 272.8 & 294.3 & 283.8 & 294.0 & 299.2 & 8.0 & 30 & $D$ & $B$ & 0 & 1 & $D$ \\
\hline 753 & 285.1 & 295.6 & 304,1 & 300.0 & 307.7 & 8.0 & $1 \varnothing \varnothing$ & $B$ & 5 & $\boldsymbol{a}$ & b & $\varnothing$ \\
\hline 770 & 286.3 & 288.4 & 286.9 & 292.1 & 287.1 & 7.0 & 30 & $b$ & $\emptyset$ & 0 & D & 6 \\
\hline 775 & 294.9 & 297.7 & 312.8 & 316.6 & 316.1 & 8.5 & 30 & 8 & D & ต & $\boldsymbol{b}$ & $\boldsymbol{D}$ \\
\hline 788 & 278.0 & 282.3 & $3 \varnothing \varnothing .6$ & 302.6 & 299.0 & 8.5 & 30 & $\theta$ & 0 & $\emptyset$ & 1 & $\emptyset$ \\
\hline 835 & 260.3 & 285.4 & 273.8 & 276.0 & 274.9 & $8 . \varnothing$ & 36 & 6 & D & 6 & D & $\boldsymbol{D}$ \\
\hline 851 & 232.7 & 243.6 & 249.7 & 243.2 & 247.3 & 8. 5 & 106 & $\boldsymbol{D}$ & 6 & $\boldsymbol{b}$ & 6 & 0 \\
\hline 852 & 282.5 & 275.6 & 278.8 & 288.8 & 282.9 & 9.5 & 100 & $\boldsymbol{\sigma}$ & 0 & $\theta$ & $\boldsymbol{\theta}$ & b \\
\hline 658 & 269.9 & 272.8 & 272.3 & 281.6 & 271.4 & 9.ळ & 30 & $\theta$ & $\boldsymbol{D}$ & $\theta$ & 3 & $\boldsymbol{b}$ \\
\hline
\end{tabular}


Acetone Rat Teratology Study: Body Weights and Urine Parameters for Virgin Fomeles

440 ppm Acetone

\begin{tabular}{|c|c|c|c|c|c|c|c|c|c|c|c|c|}
\hline Matno & $\begin{array}{l}\text { Pre-atudy } \\
W t(g)\end{array}$ & $\begin{array}{l}\text { Exposure } \\
\text { Day } 1 \text { (g) }\end{array}$ & $\begin{array}{l}\text { Exposure } \\
\text { Day5 }(g)\end{array}$ & $\begin{array}{l}\text { Exposure } \\
\text { Day 10 (g) }\end{array}$ & $\begin{array}{c}\text { Sacrifice } \\
\text { Wt(g) }\end{array}$ & $\mathbf{P H}$ & $\begin{array}{l}\text { Protein } \\
(\mathrm{mg} / \mathrm{dL})\end{array}$ & $\begin{array}{l}\text { Glucoso } \\
(\mathrm{mg} / \mathrm{dL})\end{array}$ & $\begin{array}{l}\text { Ketone } \\
(m g / d L)\end{array}$ & Bilirubin & $\begin{array}{c}\text { Blood } \\
(0-4)\end{array}$ & $\begin{array}{l}\text { Urobilinogen } \\
\text { (Ehrilch units/dL) }\end{array}$ \\
\hline 669 & 293.6 & 301.7 & 309.2 & 311.7 & 316.8 & B. $B$ & 6 & $\boldsymbol{D}$ & $B$ & $\theta$ & $\boldsymbol{\sigma}$ & $\theta$ \\
\hline 744 & 276.4 & 282.8 & 285.2 & 304.8 & 367.6 & 8.6 & $B$ & B & b & D & D & $\theta$ \\
\hline 790 & 252.8 & 278.4 & 276.2 & 275.4 & 278.9 & 7.5 & 0 & $\theta$ & 0 & $B$ & $\theta$ & $B$ \\
\hline 803 & 271.4 & 273.0 & 277.0 & 271.3 & 234.3 & 6.5 & 300 & $\boldsymbol{\theta}$ & 16 & $\theta$ & 1 & $\varnothing$ \\
\hline 810 & 282.5 & 292.2 & 360.2 & 304.2 & 300.8 & B. 0 & 30 & $\theta$ & 0 & $\theta$ & $B$ & $\theta$ \\
\hline 837 & 291.8 & 301.0 & 309.2 & 320.3 & 327.4 & 8.6 & 100 & $\boldsymbol{\theta}$ & $\theta$ & $\theta$ & 0 & $\sigma$ \\
\hline 838 & 150.7 & 234.0 & $252 . \theta$ & 266.4 & 284.4 & 8.0 & 100 & 0 & $\theta$ & $\theta$ & 6 & $\sigma$ \\
\hline 861 & 259.4 & 250.2 & 271.1 & 288.6 & 272.2 & B. & 30 & $\boldsymbol{\theta}$ & $\boldsymbol{\sigma}$ & 0 & 1 & D \\
\hline 882 & 271.1 & 274.0 & 277.8 & 281.7 & 270.0 & 8.6 & 30 & $\theta$ & $\theta$ & 0 & 0 & 0 \\
\hline 905 & 278.3 & 275.8 & 275.8 & 281.8 & 292.3 & 8.6 & 100 & $\theta$ & 0 & $\theta$ & 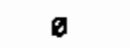 & $\boldsymbol{\sigma}$ \\
\hline
\end{tabular}

$\stackrel{n}{i}$ 
Acetone Rat Toratology Study: Bady Weighte end Urino Paramoters for Virgin Fomoles

\begin{tabular}{|c|c|c|c|c|c|c|c|c|c|c|c|c|}
\hline Motno & $\begin{array}{c}\text { Pre-study } \\
\text { wt (g) }\end{array}$ & $\begin{array}{l}\text { Exposure } \\
\text { Day } 1 \text { (g) }\end{array}$ & $\begin{array}{l}\text { Exposuro } \\
\text { Day } 5 \text { (g) }\end{array}$ & $\begin{array}{l}\text { Exposure } \\
\text { Day } 10(9)\end{array}$ & $\begin{array}{c}\text { Sacrifice } \\
W t(g)\end{array}$ & $\mathbf{P H}$ & $\begin{array}{l}\text { Protoin } \\
\text { (mg/dL) }\end{array}$ & $\underset{(\mathrm{mg} / \mathrm{dL})}{\mathrm{g}(\mathrm{ucose}}$ & $\begin{array}{l}\text { Kotone } \\
\text { (mg/dL) }\end{array}$ & $\underset{(B-3)}{\text { Qilirubin }}$ & $\begin{array}{l}\text { Blood } \\
(\theta-4)\end{array}$ & $\begin{array}{l}\text { Urobilinogon } \\
\text { (Ehrlich units/dL) }\end{array}$ \\
\hline 724 & 260.3 & 259.9 & 276.9 & 282.5 & 286.4 & 8.6 & 36 & $\boldsymbol{\theta}$ & $b$ & 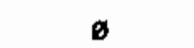 & b & $\varnothing$ \\
\hline 737 & 246.9 & 259.1 & 277.3 & 293.4 & 273.1 & 8.6 & 30 & $\theta$ & $b$ & D & $\theta$ & B \\
\hline 754 & 274.6 & 269.6 & 286.3 & 279.6 & 287.8 & 8.6 & 300 & $\theta$ & $\theta$ & $B$ & $\theta$ & $B$ \\
\hline 768 & 284.6 & 283.1 & 280.1 & 292.6 & 297.5 & 8.6 & 30 & $\boldsymbol{0}$ & 0 & $B$ & $D$ & 6 \\
\hline 796 & 281.0 & 299.4 & 294.8 & 300.9 & 317.2 & 8.0 & 36 & 0 & 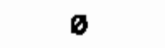 & $B$ & $\theta$ & $\varnothing$ \\
\hline 826 & 272.2 & 272.8 & 278.2 & 277.7 & 280.7 & 8.6 & 100 & 0 & $\boldsymbol{\sigma}$ & 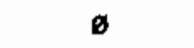 & $\theta$ & $\boldsymbol{b}$ \\
\hline 840 & 306.8 & 331.3 & 338.8 & 346.4 & 323.1 & 8.0 & 100 & $\theta$ & $b$ & $B$ & $\theta$ & $\boldsymbol{0}$ \\
\hline 841 & 283.2 & 274.1 & 284.3 & 265.2 & 276.5 & 7.6 & 38 & $\boldsymbol{\theta}$ & $b$ & $\theta$ & 0 & $\boldsymbol{\sigma}$ \\
\hline 969 & $28 \theta .8$ & 288.7 & 294.7 & 381.8 & 295.6 & 0.6 & $3 \varnothing \varnothing$ & $\theta$ & 5 & D & $\boldsymbol{\theta}$ & a \\
\hline 918 & 189.6 & 248.6 & 273.4 & 292.6 & 284.1 & 0.5 & $10 \theta$ & 6 & 0 & $\theta$ & $\theta$ & 0 \\
\hline
\end{tabular}


Acetone Rat Teratology Study: Body Weights end Urine Perameters for Virgin Females

\begin{tabular}{|c|c|c|c|c|c|c|c|c|c|c|c|c|}
\hline Matno & $\begin{array}{l}\text { Pre-study } \\
W t(g)\end{array}$ & $\begin{array}{l}\text { Exposuro } \\
\text { Dayl (g) }\end{array}$ & $\begin{array}{l}\text { Exposure } \\
\text { Day } 5(g)\end{array}$ & $\begin{array}{l}\text { Exposure } \\
\text { Doy1ø (g) }\end{array}$ & $\begin{array}{c}\text { Socrifice } \\
W t(g)\end{array}$ & PH & $\begin{array}{l}\text { Protein } \\
\text { (mg/dL) }\end{array}$ & $\begin{array}{l}\text { G I ucoso } \\
(\mathrm{mg} / \mathrm{dL})\end{array}$ & $\begin{array}{l}\text { Ketono } \\
(\mathrm{mg} / \mathrm{dL})\end{array}$ & $\underset{(0-3)}{\text { Bilirubin }}$ & $\begin{array}{c}8 \operatorname{lood} \\
(\theta-4)\end{array}$ & $\begin{array}{l}\text { Urobilinogen } \\
\text { (Ehrlich units/dL) }\end{array}$ \\
\hline 687 & 283.7 & 311.4 & 318.6 & 318.9 & 316.4 & 8.0 & $\theta$ & $\theta$ & 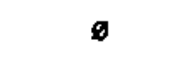 & ø & $B$ & 0 \\
\hline 692 & 280.3 & 276.2 & 270.4 & 275.3 & 270.6 & 6.6 & 100 & $\theta$ & $\theta$ & D & 4 & b \\
\hline $7 \boxminus 2$ & 268.5 & 285.6 & 257.3 & 254.6 & 257.7 & Q.D & 30 & 0 & 0 & $\boldsymbol{D}$ & 1 & 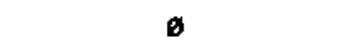 \\
\hline 713 & 294.5 & 299.4 & 290.7 & 289.2 & 283.3 & 8.0 & 30 & $\boldsymbol{D}$ & $\boldsymbol{0}$ & - & 0 & 6 \\
\hline 733 & 239.3 & $250 . \theta$ & 253.7 & 257.2 & 257.2 & 7.5 & 36 & D & 0 & 0 & $\theta$ & 0 \\
\hline 743 & 271.8 & 286.6 & 290.3 & 281.4 & 281.3 & 8.0 & 100 & $\theta$ & 5 & $\theta$ & $\boldsymbol{\sigma}$ & $\theta$ \\
\hline 759 & $263 . \theta$ & 276.2 & 277.2 & 283.3 & 273.0 & 8.0 & 15 & 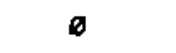 & $D$ & $\sigma$ & $B$ & 0 \\
\hline 782 & 274.3 & 295.6 & 285.6 & 287.0 & 291.2 & 7.0 & 30 & 0 & 40 & $\boldsymbol{\theta}$ & 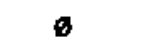 & ø \\
\hline 883 & 223.6 & 228.8 & 225,6 & 223.9 & 216.5 & B. 0 & 30 & $\theta$ & 6 & $\boldsymbol{D}$ & 0 & 0 \\
\hline$\theta 15$ & 292.3 & 296.6 & 303.2 & 298.6 & 206.7 & B.6 & 30 & 0 & 0 & $\theta$ & $\theta$ & $\boldsymbol{D}$ \\
\hline
\end{tabular}


Acotone Rot Toratology: Weight: (g) and Urine Parametera for Sperm Positive Fomales

\begin{tabular}{|c|c|c|c|c|c|c|c|c|c|c|}
\hline & Watno & Prognant & $\begin{array}{c}\operatorname{Pr}-s t u d y \\
w t(g)\end{array}$ & $\begin{array}{l}g d g \\
w t(g)\end{array}$ & $\begin{array}{l}\text { e dg } \\
w_{t}(g)\end{array}$ & $\begin{array}{l}16 d g \\
W t(g)\end{array}$ & ${ }_{w t(g)} d g$ & $\begin{array}{l}17 \mathrm{dg} \\
W t(g)\end{array}$ & $\begin{array}{l}2 \sigma d g \\
w t(g)\end{array}$ & $\begin{array}{l}\text { Uter } \\
\text { Wt (g) }\end{array}$ \\
\hline in & $\begin{array}{l}862 \\
666 \\
681 \\
686 \\
694 \\
761 \\
763 \\
766 \\
716 \\
736 \\
731 \\
732 \\
741 \\
746 \\
748 \\
784 \\
772 \\
778 \\
797 \\
866 \\
865 \\
869 \\
813 \\
833 \\
874 \\
896 \\
892 \\
896\end{array}$ & $\begin{array}{l}0 \\
1 \\
1 \\
1 \\
1 \\
1 \\
1 \\
1 \\
1 \\
1 \\
1 \\
1 \\
1 \\
1 \\
1 \\
1 \\
1 \\
1 \\
1 \\
1 \\
1 \\
1 \\
1 \\
0 \\
1 \\
1 \\
1 \\
1\end{array}$ & $\begin{array}{l}248.5 \\
243.2 \\
253.4 \\
246.8 \\
227.1 \\
238.7 \\
228.9 \\
238.4 \\
248.7 \\
237.1 \\
234.8 \\
238.3 \\
232.3 \\
238.2 \\
227.2 \\
228.7 \\
253.3 \\
232.8 \\
248.4 \\
248.8 \\
254.4 \\
233.4 \\
247.8 \\
218.8 \\
222.4 \\
232.6 \\
242.8 \\
258.7\end{array}$ & $\begin{array}{l}361.2 \\
276.9 \\
286.4 \\
285.8 \\
286.9 \\
277.1 \\
271.8 \\
272.8 \\
278.9 \\
292.3 \\
268.5 \\
246.7 \\
262.2 \\
264.7 \\
266.3 \\
267.2 \\
288.7 \\
267.7 \\
278.8 \\
396.3 \\
311.7 \\
262.1 \\
269.4 \\
264.2 \\
239.1 \\
262.8 \\
271.8 \\
287.5\end{array}$ & $\begin{array}{l}304.1 \\
292.1 \\
305.8 \\
316.4 \\
290.1 \\
297.6 \\
293.8 \\
295.8 \\
302.8 \\
314.6 \\
293.8 \\
293.8 \\
279.8 \\
293.6 \\
279.8 \\
272.7 \\
311.6 \\
286.8 \\
395.8 \\
332.8 \\
333.7 \\
236.8 \\
369.8 \\
288.8 \\
266.8 \\
262.7 \\
364.6 \\
323.6\end{array}$ & $\begin{array}{l}314.0 \\
296.6 \\
321.8 \\
328.6 \\
364.5 \\
308.6 \\
326.7 \\
389.1 \\
318.6 \\
328.8 \\
316.4 \\
311.3 \\
283.8 \\
369.7 \\
306.6 \\
288.8 \\
324.1 \\
364.8 \\
313.4 \\
346.8 \\
365.8 \\
298.8 \\
318.9 \\
361.8 \\
286.6 \\
273.8 \\
322.8 \\
336.5\end{array}$ & $\begin{array}{l}322.8 \\
324.3 \\
339.3 \\
347.8 \\
322.8 \\
337.3 \\
338.7 \\
330.3 \\
347.8 \\
347.6 \\
343.9 \\
323.7 \\
316.8 \\
336.3 \\
331.8 \\
308.3 \\
353.6 \\
327.3 \\
343.9 \\
378.7 \\
396.3 \\
336.2 \\
362.2 \\
363.1 \\
369.3 \\
361.6 \\
343.1 \\
369.8\end{array}$ & $\begin{array}{l}329.7 \\
351.2 \\
369.1 \\
374.5 \\
343.6 \\
357.3 \\
354.2 \\
354.3 \\
378.8 \\
367.1 \\
361.3 \\
366.1 \\
346.2 \\
364.6 \\
366.7 \\
328.8 \\
391.8 \\
349.8 \\
376.0 \\
469.6 \\
424.9 \\
367.8 \\
373.4 \\
288.6 \\
332.0 \\
327.4 \\
364.6 \\
374.2\end{array}$ & $\begin{array}{l}323.8 \\
395.6 \\
372.9 \\
464.3 \\
372.2 \\
393.8 \\
394.2 \\
437.8 \\
467.3 \\
463.2 \\
403.9 \\
461.6 \\
369.7 \\
369.2 \\
468.5 \\
331.6 \\
466.6 \\
406.6 \\
469.6 \\
441.6 \\
474.6 \\
399.8 \\
412.4 \\
268.6 \\
374.6 \\
372.6 \\
466.8 \\
466.1\end{array}$ & $\begin{array}{r}0.14 \\
90.76 \\
84.76 \\
67.61 \\
74.72 \\
79.31 \\
61.86 \\
139.24 \\
87.69 \\
80.90 \\
69.81 \\
87.37 \\
78.41 \\
84.73 \\
93.06 \\
48.14 \\
199.86 \\
166.19 \\
91.44 \\
110.06 \\
99.66 \\
80.60 \\
76.81 \\
6.72 \\
75.29 \\
84.96 \\
94.47 \\
48.39\end{array}$ \\
\hline
\end{tabular}


Acetone Ret Teratology Study: Weight: (g) end Urino Poremoters for Sperm-positive Femeles

\begin{tabular}{|c|c|c|c|c|c|c|c|c|c|c|}
\hline & Matno & $\begin{array}{l}\text { Liver } \\
\text { Wt(g) }\end{array}$ & $\begin{array}{l}\text { Kidney } \\
\text { Wt (g) }\end{array}$ & $\mathrm{pH}$ & $\begin{array}{l}\text { Protoin } \\
\text { (mg/dL) }\end{array}$ & $\underset{(\mathrm{mg} / \mathrm{dL})}{\mathrm{Glucose}}$ & $\begin{array}{l}\text { Kotone } \\
(\mathrm{mg} / \mathrm{dL})\end{array}$ & $\underset{(0-3)}{\text { Bilirubin }}$ & $\begin{array}{c}81000 \\
(\theta-4)\end{array}$ & $\begin{array}{l}\text { Urobilinogon } \\
\text { (Ehri ich units/dL) }\end{array}$ \\
\hline in & $\begin{array}{l}652 \\
680 \\
681 \\
668 \\
694 \\
701 \\
703 \\
706 \\
718 \\
730 \\
731 \\
732 \\
741 \\
748 \\
749 \\
764 \\
772 \\
778 \\
797 \\
800 \\
605 \\
609 \\
813 \\
833 \\
874 \\
896 \\
892 \\
698\end{array}$ & $\begin{array}{l}12.03 \\
16.93 \\
14.44 \\
18.36 \\
16.46 \\
16.95 \\
18.63 \\
18.35 \\
17.69 \\
18.46 \\
18.98 \\
17.69 \\
14.48 \\
14.98 \\
16.64 \\
13.52 \\
28.34 \\
16.62 \\
18.26 \\
17.53 \\
19.67 \\
16.48 \\
16.68 \\
11.36 \\
16.03 \\
16.97 \\
16.47 \\
19.28\end{array}$ & $\begin{array}{l}2.68 \\
2.13 \\
2.38 \\
2.68 \\
2.18 \\
2.60 \\
2.28 \\
2.34 \\
2.42 \\
2.16 \\
2.36 \\
2.23 \\
2.12 \\
2.13 \\
2.24 \\
2.61 \\
2.62 \\
2.14 \\
2.29 \\
2.18 \\
2.38 \\
2.44 \\
2.23 \\
1.96 \\
1.98 \\
2.23 \\
2.16 \\
2.21\end{array}$ & 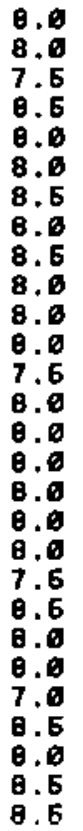 & $\begin{array}{r}30 \\
0 \\
100 \\
0 \\
16 \\
16 \\
30 \\
16 \\
30 \\
16 \\
0 \\
16 \\
0 \\
6 \\
0 \\
6 \\
30 \\
16 \\
36 \\
100 \\
16 \\
16 \\
16 \\
160 \\
100 \\
16 \\
36 \\
300\end{array}$ & $\begin{array}{l}0 \\
0 \\
0 \\
0 \\
0 \\
0 \\
0 \\
0 \\
0 \\
0 \\
0 \\
0 \\
0 \\
0 \\
0 \\
0 \\
0 \\
0 \\
0 \\
0 \\
0 \\
0 \\
0 \\
0 \\
0 \\
0 \\
0 \\
0\end{array}$ & $\begin{array}{l}0 \\
0 \\
5 \\
0 \\
0 \\
0 \\
0 \\
0 \\
0 \\
0 \\
0 \\
0 \\
0 \\
0 \\
0 \\
0 \\
0 \\
0 \\
5 \\
0 \\
0 \\
0 \\
0 \\
0 \\
0 \\
0 \\
0 \\
0\end{array}$ & $\begin{array}{l}0 \\
0 \\
0 \\
0 \\
0 \\
0 \\
0 \\
0 \\
0 \\
0 \\
0 \\
0 \\
0 \\
0 \\
0 \\
0 \\
0 \\
0 \\
0 \\
0 \\
0 \\
6 \\
0 \\
\dot{0} \\
0 \\
0 \\
0\end{array}$ & $\begin{array}{l}0 \\
2 \\
3 \\
0 \\
0 \\
0 \\
0 \\
3 \\
4 \\
1 \\
0 \\
0 \\
1 \\
0 \\
0 \\
0 \\
4 \\
0 \\
0 \\
4 \\
0 \\
0 \\
0 \\
\dot{2} \\
0 \\
1 \\
0\end{array}$ & $\begin{array}{l}0 \\
0 \\
0 \\
0 \\
0 \\
0 \\
0 \\
0 \\
0 \\
0 \\
0 \\
0 \\
0 \\
0 \\
0 \\
0 \\
0 \\
0 \\
0 \\
1 \\
0 \\
0 \\
0 \\
\dot{0} \\
0 \\
0 \\
0\end{array}$ \\
\hline
\end{tabular}


Acetone Rat Teratology: Weights (g) and Urine Parameters for Sparm Positive Fomalos

440 ррา Acetone

\begin{tabular}{|c|c|c|c|c|c|c|c|c|c|c|}
\hline & Watno & Pregnent & $\begin{array}{c}\text { Pre-study } \\
\text { Wt (g) }\end{array}$ & $\begin{array}{l}g d g \\
W t(g)\end{array}$ & $\begin{array}{l}a d g \\
W t(g)\end{array}$ & $\begin{array}{l}10 d g \\
w t(g)\end{array}$ & $\underset{w t}{14} d g$ & $\begin{array}{l}17 d g \\
\text { Wt }(g)\end{array}$ & $\begin{array}{l}20 d g \\
w t(g)\end{array}$ & $\begin{array}{l}\text { Uter } \\
\text { Wt }(g)\end{array}$ \\
\hline 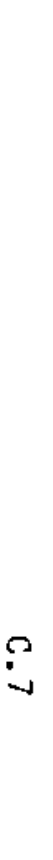 & $\begin{array}{l}682 \\
683 \\
684 \\
675 \\
681 \\
726 \\
723 \\
726 \\
728 \\
747 \\
748 \\
758 \\
781 \\
783 \\
861 \\
804 \\
814 \\
819 \\
829 \\
632 \\
848 \\
849 \\
865 \\
864 \\
879 \\
877 \\
881 \\
912 \\
913\end{array}$ & $\begin{array}{l}1 \\
1 \\
1 \\
1 \\
0 \\
1 \\
1 \\
0 \\
1 \\
1 \\
1 \\
1 \\
1 \\
1 \\
1 \\
1 \\
1 \\
1 \\
1 \\
1 \\
1 \\
1 \\
1 \\
1 \\
1 \\
1 \\
1 \\
1 \\
1\end{array}$ & $\begin{array}{l}282.2 \\
264.5 \\
245.4 \\
253.8 \\
247.2 \\
229.8 \\
238.2 \\
224.9 \\
236.8 \\
239.7 \\
239.4 \\
281.4 \\
232.8 \\
252.8 \\
268.8 \\
241.4 \\
243.8 \\
234.4 \\
246.1 \\
216.9 \\
244.8 \\
231.4 \\
241.4 \\
248.4 \\
237.2 \\
247.7 \\
232.7 \\
244.6 \\
239.9\end{array}$ & $\begin{array}{l}298.0 \\
292.1 \\
288.2 \\
283.8 \\
261.2 \\
238.8 \\
283.6 \\
272.0 \\
257.5 \\
278.4 \\
289.9 \\
286.7 \\
244.3 \\
286.9 \\
294.6 \\
289.9 \\
282.2 \\
256.5 \\
278.3 \\
252.8 \\
272.2 \\
258.2 \\
272.6 \\
293.7 \\
268.7 \\
272.8 \\
274.6 \\
288.9 \\
282.0\end{array}$ & 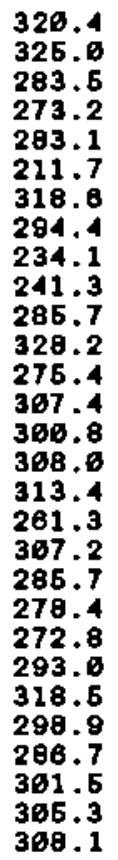 & $\begin{array}{l}329.4 \\
327.9 \\
281.7 \\
311.4 \\
292.6 \\
280.1 \\
335.7 \\
293.9 \\
300.3 \\
367.3 \\
294.5 \\
338.6 \\
265.9 \\
337.9 \\
313.6 \\
309.8 \\
339.9 \\
267.3 \\
335.7 \\
297.3 \\
303.9 \\
293.6 \\
310.6 \\
332.9 \\
313.4 \\
362.5 \\
315.3 \\
318.9 \\
322.1\end{array}$ & $\begin{array}{l}358.9 \\
362.9 \\
310.5 \\
344.2 \\
282.3 \\
278.5 \\
364.3 \\
292.5 \\
322.5 \\
320.6 \\
316.1 \\
383.6 \\
365.9 \\
365.4 \\
336.6 \\
339.1 \\
360.3 \\
369.5 \\
382.4 \\
307.7 \\
336.5 \\
314.8 \\
336.6 \\
341.6 \\
339.2 \\
324.3 \\
338.6 \\
331.4 \\
358.6\end{array}$ & $\begin{array}{l}399.4 \\
373.5 \\
332.5 \\
372.3 \\
284.9 \\
306.5 \\
382.1 \\
292.7 \\
345.8 \\
368.5 \\
346.6 \\
399.3 \\
333.3 \\
381.9 \\
365.9 \\
376.7 \\
396.1 \\
339.4 \\
393.8 \\
324.2 \\
367.2 \\
346.2 \\
368.8 \\
376.5 \\
368.7 \\
362.7 \\
371.2 \\
368.4 \\
378.8\end{array}$ & $\begin{array}{l}434.5 \\
414.1 \\
377.8 \\
468.9 \\
278.6 \\
332.5 \\
416.2 \\
283.6 \\
372.8 \\
364.3 \\
387.3 \\
418.4 \\
355.1 \\
438.5 \\
413.7 \\
395.2 \\
442.4 \\
385.7 \\
431.4 \\
346.1 \\
469.8 \\
383.5 \\
393.9 \\
406.1 \\
406.9 \\
410.3 \\
466.8 \\
419.2 \\
420.7\end{array}$ & $\begin{array}{l}96.31 \\
71.40 \\
76.86 \\
93.31 \\
6.62 \\
65.02 \\
76.47 \\
6.37 \\
79.85 \\
76.19 \\
79.96 \\
57.33 \\
67.87 \\
82.27 \\
89.82 \\
88.74 \\
91.16 \\
96.88 \\
95.44 \\
38.44 \\
69.38 \\
92.83 \\
72.67 \\
52.67 \\
65.63 \\
87.91 \\
81.97 \\
89.83 \\
84.78\end{array}$ \\
\hline
\end{tabular}


Acotone Ret Teretology Study: Woighte (g) and Urine Perameters for Sperm-positive Females

\begin{tabular}{|c|c|c|c|c|c|c|c|c|c|c|}
\hline & Matno & $\begin{array}{l}\text { Liver } \\
\text { Wt (g) }\end{array}$ & $\begin{array}{l}\text { Kidney } \\
\text { wt (g) }\end{array}$ & pH & $\begin{array}{l}\text { Proto in } \\
\text { (mg/dL) }\end{array}$ & $\begin{array}{l}\text { Glucose } \\
\text { (mg/dL) }\end{array}$ & $\begin{array}{l}\text { Kotone } \\
\text { (mg/dL) }\end{array}$ & $\underset{(B-3)}{\text { Bilirubin }}$ & $\begin{array}{l}\text { B lood } \\
(0-4)\end{array}$ & $\begin{array}{l}\text { Urobilinogon } \\
\text { (Ehrlich units/dL) }\end{array}$ \\
\hline$\infty$ & $\begin{array}{l}682 \\
683 \\
884 \\
676 \\
681 \\
726 \\
723 \\
728 \\
728 \\
747 \\
748 \\
758 \\
781 \\
763 \\
861 \\
864 \\
814 \\
819 \\
829 \\
832 \\
846 \\
649 \\
866 \\
884 \\
676 \\
977 \\
681 \\
812 \\
913\end{array}$ & $\begin{array}{r}19.16 \\
18.96 \\
16.68 \\
17.09 \\
9.76 \\
13.65 \\
18.36 \\
12.13 \\
14.91 \\
16.96 \\
16.28 \\
19.93 \\
14.78 \\
17.67 \\
19.67 \\
16.98 \\
28.22 \\
15.87 \\
17.88 \\
16.49 \\
16.56 \\
16.98 \\
17.06 \\
18.17 \\
17.36 \\
18.76 \\
14.81 \\
19.14 \\
17.82\end{array}$ & $\begin{array}{l}2.31 \\
2.35 \\
2.00 \\
2.61 \\
2.02 \\
1.83 \\
2.62 \\
1.97 \\
1.82 \\
2.32 \\
2.02 \\
2.69 \\
2.22 \\
2.43 \\
2.31 \\
2.33 \\
2.31 \\
2.32 \\
2.53 \\
2.34 \\
2.30 \\
2.29 \\
2.28 \\
2.64 \\
2.23 \\
2.66 \\
2.28 \\
2.23 \\
2.24\end{array}$ & 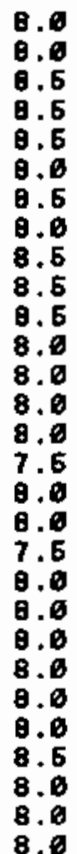 & $\begin{array}{r}0 \\
30 \\
300 \\
15 \\
16 \\
0 \\
0 \\
30 \\
6 \\
100 \\
0 \\
0 \\
6 \\
30 \\
6 \\
0 \\
15 \\
15 \\
0 \\
15 \\
30 \\
15 \\
15 \\
100 \\
16 \\
36 \\
160 \\
30 \\
16\end{array}$ & $\begin{array}{r}0 \\
0 \\
0 \\
0 \\
0 \\
250 \\
100 \\
0 \\
0 \\
0 \\
0 \\
0 \\
0 \\
0 \\
0 \\
0 \\
0 \\
0 \\
0 \\
0 \\
0 \\
0 \\
0 \\
0 \\
0 \\
0 \\
0 \\
0 \\
0\end{array}$ & $\begin{array}{l}0 \\
0 \\
0 \\
0 \\
0 \\
6 \\
0 \\
5 \\
0 \\
0 \\
0 \\
0 \\
0 \\
0 \\
0 \\
0 \\
0 \\
0 \\
0 \\
0 \\
5 \\
0 \\
0 \\
0 \\
0 \\
0 \\
0 \\
0 \\
0 \\
0\end{array}$ & $\begin{array}{l}0 \\
0 \\
0 \\
0 \\
0 \\
0 \\
0 \\
0 \\
0 \\
0 \\
0 \\
0 \\
0 \\
0 \\
0 \\
0 \\
0 \\
0 \\
0 \\
0 \\
0 \\
0 \\
0 \\
0 \\
0 \\
0 \\
0 \\
0 \\
0\end{array}$ & $\begin{array}{l}0 \\
1 \\
2 \\
4 \\
1 \\
0 \\
0 \\
2 \\
3 \\
0 \\
0 \\
0 \\
0 \\
0 \\
1 \\
0 \\
0 \\
0 \\
0 \\
0 \\
0 \\
1 \\
1 \\
2 \\
0 \\
0 \\
0 \\
0 \\
0\end{array}$ & $\begin{array}{l}0 \\
0 \\
0 \\
0 \\
0 \\
0 \\
0 \\
0 \\
0 \\
0 \\
0 \\
0 \\
0 \\
0 \\
0 \\
0 \\
0 \\
0 \\
0 \\
0 \\
0 \\
0 \\
0 \\
0 \\
0 \\
0 \\
0 \\
0 \\
0\end{array}$ \\
\hline
\end{tabular}


Acetone Ret Teratology: Woights (g) and Urine Poramotors for Sperm Positive Fomeles

\begin{tabular}{|c|c|c|c|c|c|c|c|c|c|c|}
\hline & Netno & Pregnant & $\begin{array}{c}\text { Pre-study } \\
\text { Wt (g) }\end{array}$ & $\underset{w t(g)}{d g}$ & $\begin{array}{l}\text { e dg } \\
w t(g)\end{array}$ & $\begin{array}{l}10 d \theta \\
W t(\theta)\end{array}$ & $\begin{array}{l}14 \underset{d g}{d t} \\
W(g)\end{array}$ & $\begin{array}{l}17 \mathrm{dg} \\
\mathrm{wt}(g)\end{array}$ & $\begin{array}{l}20 d g \\
W t(g)\end{array}$ & $\begin{array}{l}\text { Uter } \\
\text { Wt (g) }\end{array}$ \\
\hline io & $\begin{array}{l}651 \\
865 \\
686 \\
679 \\
794 \\
765 \\
712 \\
719 \\
727 \\
734 \\
735 \\
738 \\
745 \\
789 \\
786 \\
791 \\
799 \\
822 \\
823 \\
834 \\
883 \\
865 \\
867 \\
868 \\
873 \\
879 \\
888 \\
889 \\
891 \\
908 \\
916\end{array}$ & $\begin{array}{l}1 \\
1 \\
1 \\
1 \\
1 \\
1 \\
1 \\
1 \\
1 \\
1 \\
1 \\
1 \\
1 \\
1 \\
1 \\
1 \\
1 \\
1 \\
0 \\
1 \\
1 \\
1 \\
1 \\
1 \\
1 \\
1 \\
1 \\
0 \\
1 \\
1 \\
1\end{array}$ & 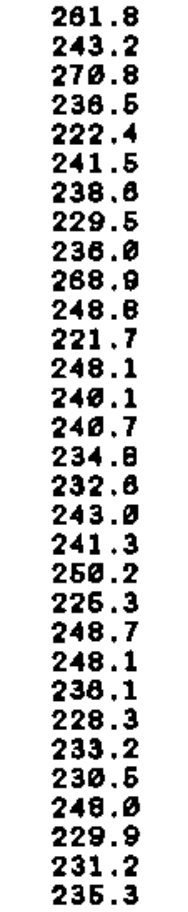 & $\begin{array}{l}366.6 \\
267.8 \\
321.8 \\
273.9 \\
248.4 \\
283.2 \\
249.1 \\
242.9 \\
275.9 \\
396.6 \\
283.7 \\
267.6 \\
292.8 \\
259.7 \\
268.7 \\
286.3 \\
289.1 \\
275.9 \\
281.6 \\
287.7 \\
264.1 \\
288.6 \\
296.1 \\
273.1 \\
253.6 \\
274.8 \\
257.8 \\
294.9 \\
254.1 \\
273.9 \\
263.8\end{array}$ & 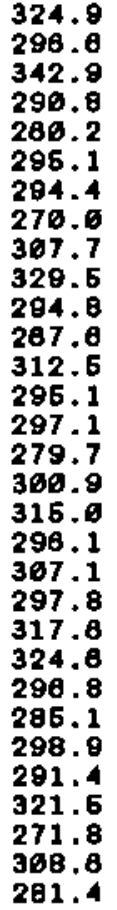 & $\begin{array}{l}334.1 \\
368.7 \\
366.5 \\
369.2 \\
282.2 \\
313.9 \\
365.9 \\
286.9 \\
331.9 \\
351.6 \\
324.1 \\
282.1 \\
328.6 \\
314.6 \\
311.6 \\
298.1 \\
316.9 \\
326.6 \\
316.8 \\
318.2 \\
368.6 \\
329.4 \\
343.2 \\
323.9 \\
307.9 \\
363.2 \\
314.2 \\
324.3 \\
274.4 \\
332.6 \\
303.1\end{array}$ & $\begin{array}{l}348.2 \\
332.3 \\
388.6 \\
327.1 \\
363.1 \\
342.7 \\
327.7 \\
364.7 \\
364.4 \\
372.4 \\
361.6 \\
366.3 \\
345.6 \\
336.1 \\
326.3 \\
311.7 \\
339.3 \\
348.5 \\
317.5 \\
334.1 \\
326.2 \\
339.2 \\
362.7 \\
364.3 \\
326.7 \\
321.7 \\
335.4 \\
327.6 \\
263.3 \\
368.6 \\
318.1\end{array}$ & $\begin{array}{l}359.1 \\
356.0 \\
417.1 \\
368.9 \\
323.2 \\
369.2 \\
344.4 \\
323.9 \\
388.0 \\
383.4 \\
384.9 \\
317.8 \\
372.7 \\
357.7 \\
353.3 \\
334.9 \\
366.8 \\
373.3 \\
316.2 \\
382.8 \\
362.6 \\
370.6 \\
382.7 \\
368.7 \\
364.1 \\
369.8 \\
368.1 \\
317.7 \\
363.1 \\
383.7 \\
342.8\end{array}$ & $\begin{array}{l}401.7 \\
380.8 \\
464.4 \\
383.6 \\
354.2 \\
395.6 \\
387.1 \\
343.4 \\
422.7 \\
415.3 \\
416.1 \\
341.5 \\
463.1 \\
386.7 \\
461.4 \\
363.0 \\
388.4 \\
395.6 \\
310.9 \\
396.8 \\
396.9 \\
391.6 \\
416.9 \\
431.7 \\
395.7 \\
391.4 \\
389.7 \\
316.8 \\
327.2 \\
421.6 \\
372.3\end{array}$ & $\begin{array}{r}84.39 \\
78.67 \\
68.86 \\
73.93 \\
76.83 \\
88.23 \\
56.11 \\
67.24 \\
167.66 \\
38.57 \\
84.65 \\
52.16 \\
81.64 \\
74.41 \\
86.28 \\
81.83 \\
46.52 \\
61.31 \\
6.73 \\
62.48 \\
82.26 \\
67.97 \\
71.68 \\
98.14 \\
83.86 \\
78.32 \\
81.38 \\
6.66 \\
63.82 \\
86.41 \\
71.71\end{array}$ \\
\hline
\end{tabular}


Acetone Ret Toretology Study: Woight: (g) and Urine Peremeter for Sperm-positive Fomelos

\begin{tabular}{|c|c|c|c|c|c|c|c|c|c|}
\hline Metno & $\begin{array}{l}\text { Liver } \\
\text { Wt (g) }\end{array}$ & $\begin{array}{c}\text { Kidnoy } \\
\text { wt (o) }\end{array}$ & pH & $\begin{array}{l}\text { Protein } \\
(\mathrm{mg} / \mathrm{dL})\end{array}$ & $\begin{array}{l}\text { Glucose } \\
(\mathrm{mg} / \mathrm{dL})\end{array}$ & $\begin{array}{l}\text { Ketone } \\
(\mathrm{mg} / \mathrm{dL})\end{array}$ & $\begin{array}{c}\text { Bilirubin } \\
(0-3)\end{array}$ & $\begin{array}{l}\text { Blood } \\
(B-4)\end{array}$ & $\begin{array}{l}\text { Urobilinogen } \\
\text { (Ehrlich units/dL) }\end{array}$ \\
\hline $\begin{array}{l}861 \\
655 \\
688 \\
679 \\
704 \\
705 \\
712 \\
719 \\
727 \\
734 \\
736 \\
736 \\
746 \\
789 \\
780 \\
791 \\
799 \\
922 \\
823 \\
834 \\
983 \\
685 \\
867 \\
868 \\
673 \\
979 \\
889 \\
989 \\
981 \\
968 \\
916\end{array}$ & 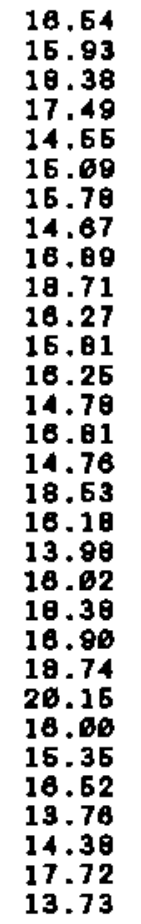 & $\begin{array}{l}2.16 \\
2.56 \\
2.30 \\
2.70 \\
1.97 \\
2.07 \\
2.32 \\
1.91 \\
2.18 \\
2.29 \\
2.42 \\
2.09 \\
2.22 \\
2.28 \\
2.39 \\
2.16 \\
2.46 \\
2.21 \\
2.27 \\
2.03 \\
2.47 \\
2.28 \\
2.20 \\
2.60 \\
2.13 \\
2.03 \\
2.20 \\
2.46 \\
2.07 \\
2.69 \\
2.10\end{array}$ & 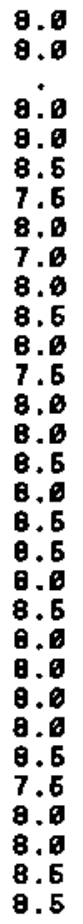 & $\begin{array}{r}15 \\
0 \\
\dot{b} \\
0 \\
30 \\
0 \\
15 \\
30 \\
0 \\
30 \\
6 \\
0 \\
15 \\
15 \\
106 \\
36 \\
36 \\
36 \\
15 \\
36 \\
15 \\
15 \\
16 \\
15 \\
0 \\
0 \\
0 \\
0 \\
30 \\
30\end{array}$ & $\begin{array}{l}0 \\
0 \\
\dot{0} \\
0 \\
0 \\
0 \\
0 \\
0 \\
0 \\
0 \\
0 \\
0 \\
0 \\
0 \\
0 \\
0 \\
0 \\
0 \\
0 \\
0 \\
0 \\
0 \\
0 \\
0 \\
0 \\
0 \\
0 \\
0 \\
0 \\
0\end{array}$ & $\begin{array}{r}0 \\
0 \\
\dot{0} \\
0 \\
0 \\
0 \\
0 \\
0 \\
0 \\
0 \\
0 \\
0 \\
10 \\
0 \\
0 \\
0 \\
0 \\
0 \\
0 \\
0 \\
0 \\
0 \\
0 \\
0 \\
0 \\
0 \\
0 \\
0 \\
0 \\
0\end{array}$ & $\begin{array}{l}0 \\
0 \\
\dot{0} \\
0 \\
0 \\
0 \\
0 \\
0 \\
0 \\
0 \\
0 \\
0 \\
1 \\
0 \\
0 \\
0 \\
0 \\
0 \\
0 \\
0 \\
0 \\
0 \\
0 \\
0 \\
0 \\
0 \\
0 \\
0 \\
0 \\
0\end{array}$ & $\begin{array}{l}0 \\
0 \\
\dot{2} \\
0 \\
4 \\
0 \\
0 \\
0 \\
0 \\
0 \\
0 \\
0 \\
0 \\
0 \\
0 \\
2 \\
0 \\
0 \\
0 \\
1 \\
0 \\
0 \\
0 \\
0 \\
0 \\
0 \\
0 \\
0 \\
0 \\
0\end{array}$ & $\begin{array}{l}0 \\
0 \\
\dot{0} \\
0 \\
0 \\
0 \\
0 \\
0 \\
0 \\
0 \\
0 \\
0 \\
0 \\
0 \\
0 \\
0 \\
0 \\
0 \\
0 \\
0 \\
0 \\
0 \\
0 \\
0 \\
0 \\
0 \\
0 \\
0 \\
0 \\
0 \\
0\end{array}$ \\
\hline
\end{tabular}


Acotone Rat Toratology: Weighta (g) and Urine Parameters for Sporm Positive Fomeles

\begin{tabular}{|c|c|c|c|c|c|c|c|c|c|c|}
\hline & Watno & Pregnant & $\begin{array}{c}\text { Pro-study } \\
\text { Wt (g) }\end{array}$ & $\begin{array}{l}g d g \\
W t(g)\end{array}$ & $\begin{array}{l}\qquad d g \\
W t(g)\end{array}$ & $\begin{array}{l}10 d g \\
W t(g)\end{array}$ & $\begin{array}{l}14 d g \\
w t(g)\end{array}$ & $\begin{array}{l}17 d g \\
w t(g)\end{array}$ & $\begin{array}{l}2 \theta d g \\
w t(\theta)\end{array}$ & $\begin{array}{l}\text { Uter } \\
\text { Wt }(g)\end{array}$ \\
\hline$\stackrel{\rho}{E}$ & $\begin{array}{l}864 \\
667 \\
679 \\
693 \\
697 \\
698 \\
711 \\
738 \\
742 \\
765 \\
771 \\
778 \\
781 \\
782 \\
917 \\
818 \\
826 \\
828 \\
831 \\
942 \\
886 \\
869 \\
878 \\
684 \\
904 \\
966 \\
911\end{array}$ & $\begin{array}{l}1 \\
1 \\
1 \\
1 \\
1 \\
1 \\
1 \\
1 \\
1 \\
1 \\
1 \\
1 \\
1 \\
1 \\
1 \\
1 \\
1 \\
1 \\
1 \\
6 \\
1 \\
1 \\
1 \\
1 \\
1 \\
1 \\
1\end{array}$ & $\begin{array}{l}239.7 \\
242.8 \\
269.8 \\
245.3 \\
263.3 \\
243.5 \\
214.3 \\
244.6 \\
231.8 \\
249.8 \\
239.2 \\
219.7 \\
233.7 \\
246.2 \\
239.2 \\
232.4 \\
269.8 \\
239.8 \\
283.9 \\
245.1 \\
233.4 \\
268.3 \\
233.6 \\
238.1 \\
233.2 \\
215.3 \\
232.1\end{array}$ & 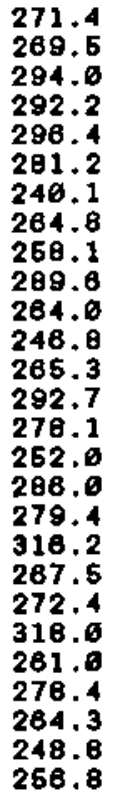 & $\begin{array}{l}291.6 \\
287.0 \\
369.6 \\
315.3 \\
332.8 \\
369.3 \\
268.6 \\
268.3 \\
281.5 \\
338.2 \\
294.6 \\
264.0 \\
297.3 \\
313.6 \\
297.6 \\
260.1 \\
318.0 \\
316.6 \\
366.6 \\
282.6 \\
286.9 \\
338.7 \\
294.3 \\
314.2 \\
282.7 \\
277.1 \\
286.7\end{array}$ & $\begin{array}{l}316.6 \\
299.2 \\
324.2 \\
323.9 \\
396.0 \\
365.2 \\
263.5 \\
256.9 \\
294.3 \\
341.8 \\
292.7 \\
269.2 \\
362.7 \\
336.8 \\
396.9 \\
286.8 \\
298.6 \\
318.1 \\
368.8 \\
285.6 \\
369.5 \\
398.8 \\
368.9 \\
296.4 \\
296.6 \\
287.2 \\
297.1\end{array}$ & $\begin{array}{l}330.1 \\
317.1 \\
346.6 \\
348.8 \\
351.7 \\
335.6 \\
290.6 \\
228.2 \\
306.8 \\
367.6 \\
316.2 \\
286.8 \\
328.2 \\
344.8 \\
326.8 \\
399.1 \\
318.3 \\
331.6 \\
373.7 \\
288.6 \\
320.3 \\
346.7 \\
322.9 \\
310.4 \\
364.0 \\
363.1 \\
311.6\end{array}$ & $\begin{array}{l}366.2 \\
336.6 \\
366.6 \\
373.8 \\
379.6 \\
368.3 \\
317.2 \\
294.6 \\
334.1 \\
398.4 \\
346.2 \\
289.4 \\
359.6 \\
369.9 \\
347.5 \\
334.8 \\
354.4 \\
363.2 \\
397.5 \\
296.4 \\
353.4 \\
367.7 \\
342.6 \\
328.4 \\
327.4 \\
325.1 \\
362.7\end{array}$ & $\begin{array}{l}391.0 \\
348.8 \\
395.8 \\
468.8 \\
398.6 \\
393.3 \\
336.1 \\
328.1 \\
365.8 \\
410.9 \\
349.1 \\
298.5 \\
377.5 \\
383.9 \\
366.4 \\
367.5 \\
364.4 \\
389.8 \\
417.6 \\
289.7 \\
383.6 \\
410.0 \\
352.4 \\
351.0 \\
342.8 \\
354.3 \\
379.8\end{array}$ & $\begin{array}{r}75.18 \\
62.25 \\
62.85 \\
75.03 \\
66.23 \\
88.71 \\
62.27 \\
62.45 \\
69.44 \\
67.21 \\
65.11 \\
29.67 \\
77.18 \\
62.71 \\
71.62 \\
76.87 \\
74.48 \\
76.01 \\
77.85 \\
6.66 \\
63.57 \\
78.29 \\
36.46 \\
63.47 \\
62.17 \\
62.77 \\
83.96\end{array}$ \\
\hline
\end{tabular}


Acetone Rat Teratology Study: Woighte (g) ond Urine Perameters for Sperm-positive Fomolea

\begin{tabular}{|c|c|c|c|c|c|c|c|c|c|c|}
\hline & Metno & $\begin{array}{l}\text { Liver } \\
w t(g)\end{array}$ & $\begin{array}{l}\text { Kidney } \\
w t(g)\end{array}$ & $\mathrm{pH}$ & $\begin{array}{l}\text { Protein } \\
\text { (mg/dL) }\end{array}$ & $\begin{array}{l}\text { Glucowe } \\
(\mathrm{mg} / \mathrm{dL})\end{array}$ & $\underset{(m o / d L)}{\text { Ketone }}$ & $\begin{array}{c}\text { Bilirubin } \\
(\theta-3)\end{array}$ & $\begin{array}{l}B \operatorname{lood} \\
(0-4)\end{array}$ & $\begin{array}{l}\text { Urobilinogon } \\
\text { (Ehrlich unitg/dL) }\end{array}$ \\
\hline in & $\begin{array}{l}854 \\
857 \\
878 \\
893 \\
897 \\
898 \\
711 \\
736 \\
742 \\
786 \\
771 \\
776 \\
781 \\
782 \\
817 \\
818 \\
820 \\
828 \\
831 \\
842 \\
860 \\
669 \\
878 \\
684 \\
964 \\
968 \\
911\end{array}$ & $\begin{array}{r}18.74 \\
16.22 \\
18.69 \\
21.18 \\
17.89 \\
26.83 \\
14.68 \\
14.81 \\
17.81 \\
16.90 \\
13.92 \\
13.69 \\
18.68 \\
18.48 \\
14.16 \\
18.68 \\
16.29 \\
17.81 \\
17.63 \\
8.63 \\
18.76 \\
18.80 \\
18.41 \\
16.86 \\
14.87 \\
18.83 \\
14.74\end{array}$ & $\begin{array}{l}2.31 \\
2.18 \\
2.68 \\
2.68 \\
2.51 \\
3.61 \\
2.65 \\
2.19 \\
2.34 \\
2.41 \\
2.11 \\
2.61 \\
2.46 \\
2.74 \\
2.16 \\
2.43 \\
2.26 \\
2.39 \\
2.82 \\
3.62 \\
2.18 \\
2.42 \\
2.49 \\
2.44 \\
2.16 \\
2.49 \\
2.28\end{array}$ & $\begin{array}{l}0.0 \\
6.0 \\
8.6 \\
8.0 \\
8.0 \\
8.0 \\
8.0 \\
8.0 \\
8.6 \\
8.0 \\
8.0 \\
8.6 \\
8.0 \\
8.0 \\
8.0 \\
9.0 \\
8.0 \\
8.0 \\
8.0 \\
8.0 \\
8.0 \\
8.6 \\
8.0 \\
8.6 \\
8.6 \\
8.6\end{array}$ & $\begin{array}{r}0 \\
15 \\
30 \\
30 \\
16 \\
0 \\
\dot{0} \\
16 \\
6 \\
16 \\
30 \\
30 \\
0 \\
0 \\
30 \\
0 \\
0 \\
0 \\
0 \\
0 \\
16 \\
0 \\
15 \\
30 \\
160 \\
16\end{array}$ & $\begin{array}{l}0 \\
0 \\
0 \\
0 \\
0 \\
0 \\
0 \\
0 \\
0 \\
0 \\
0 \\
0 \\
0 \\
0 \\
0 \\
0 \\
0 \\
0 \\
0 \\
0 \\
0 \\
0 \\
0 \\
0 \\
0 \\
0 \\
0\end{array}$ & $\begin{array}{l}0 \\
0 \\
5 \\
0 \\
0 \\
0 \\
\dot{0} \\
0 \\
0 \\
0 \\
5 \\
0 \\
0 \\
0 \\
0 \\
0 \\
0 \\
0 \\
0 \\
0 \\
0 \\
0 \\
0 \\
0 \\
0 \\
0\end{array}$ & $\begin{array}{l}0 \\
0 \\
0 \\
0 \\
0 \\
0 \\
\dot{0} \\
0 \\
0 \\
0 \\
0 \\
0 \\
0 \\
0 \\
0 \\
0 \\
0 \\
0 \\
0 \\
0 \\
0 \\
0 \\
0 \\
0 \\
0 \\
0 \\
0\end{array}$ & $\begin{array}{l}0 \\
0 \\
0 \\
0 \\
1 \\
0 \\
\dot{0} \\
1 \\
0 \\
0 \\
0 \\
0 \\
0 \\
1 \\
2 \\
0 \\
3 \\
0 \\
0 \\
0 \\
0 \\
1 \\
0 \\
0 \\
0 \\
1\end{array}$ & $\begin{array}{l}0 \\
0 \\
0 \\
0 \\
0 \\
0 \\
\dot{0} \\
0 \\
0 \\
0 \\
0 \\
0 \\
0 \\
0 \\
0 \\
0 \\
0 \\
0 \\
0 \\
0 \\
0 \\
0 \\
0 \\
0 \\
0 \\
0\end{array}$ \\
\hline
\end{tabular}


Acetone Rat Ketone Teratology Study: Body Woights (g) for Sperm-positive Femaleo

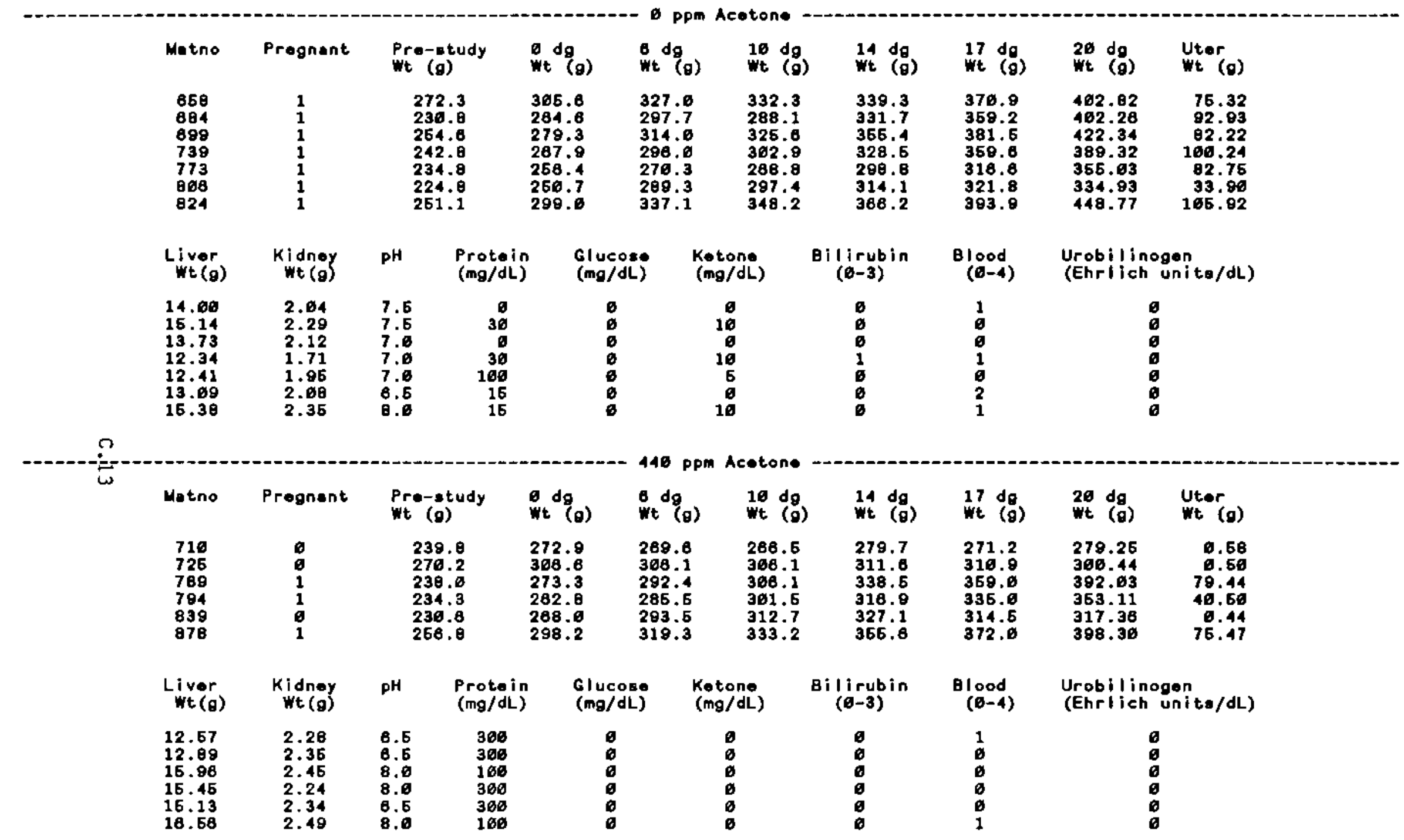


Acetone Ret Kotone Teratology Study: Body Woighte (g) for Sperm-positive Femaleo

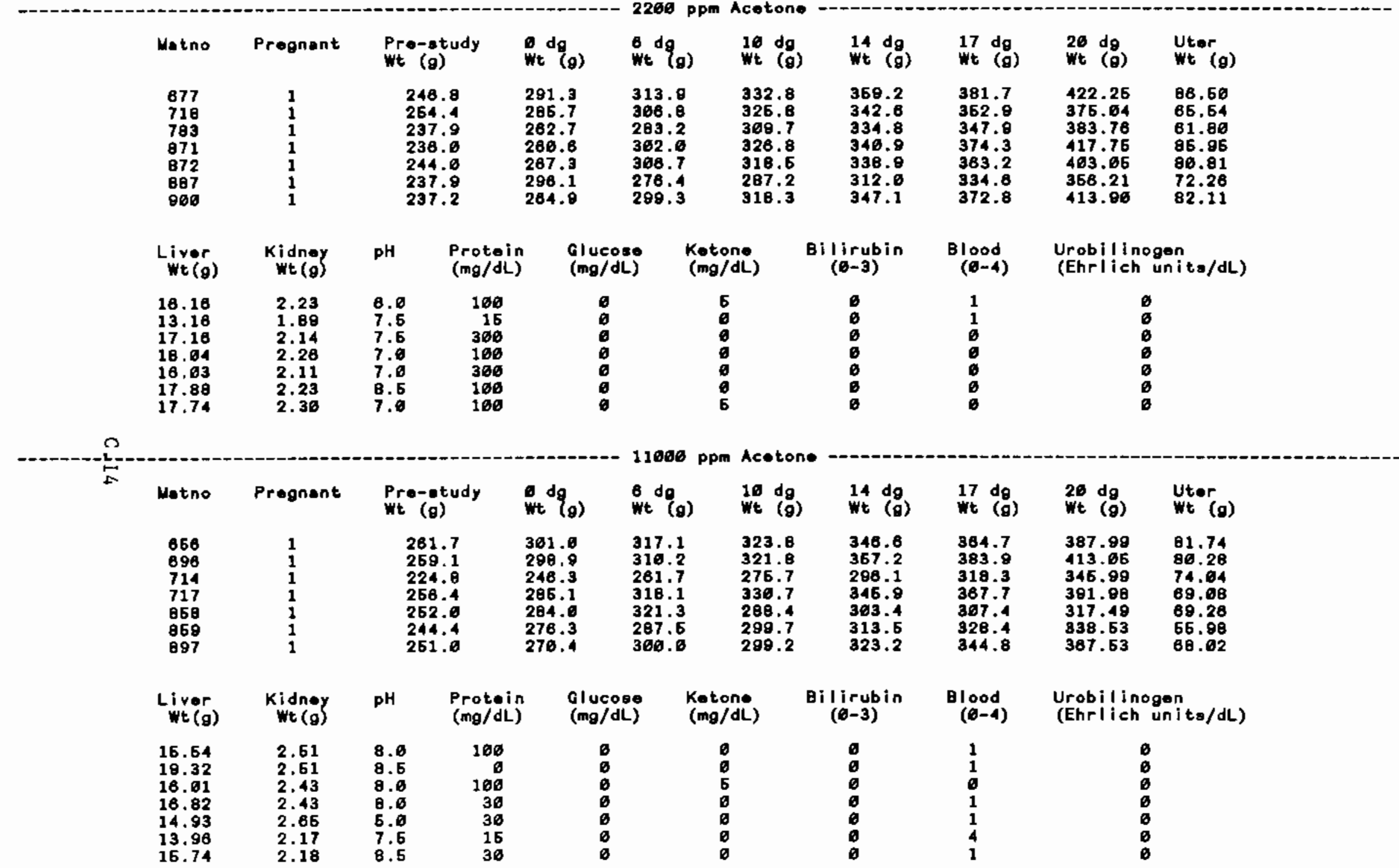


SAS

Acotone Rot Teratology Study: Raw Fotol Deto

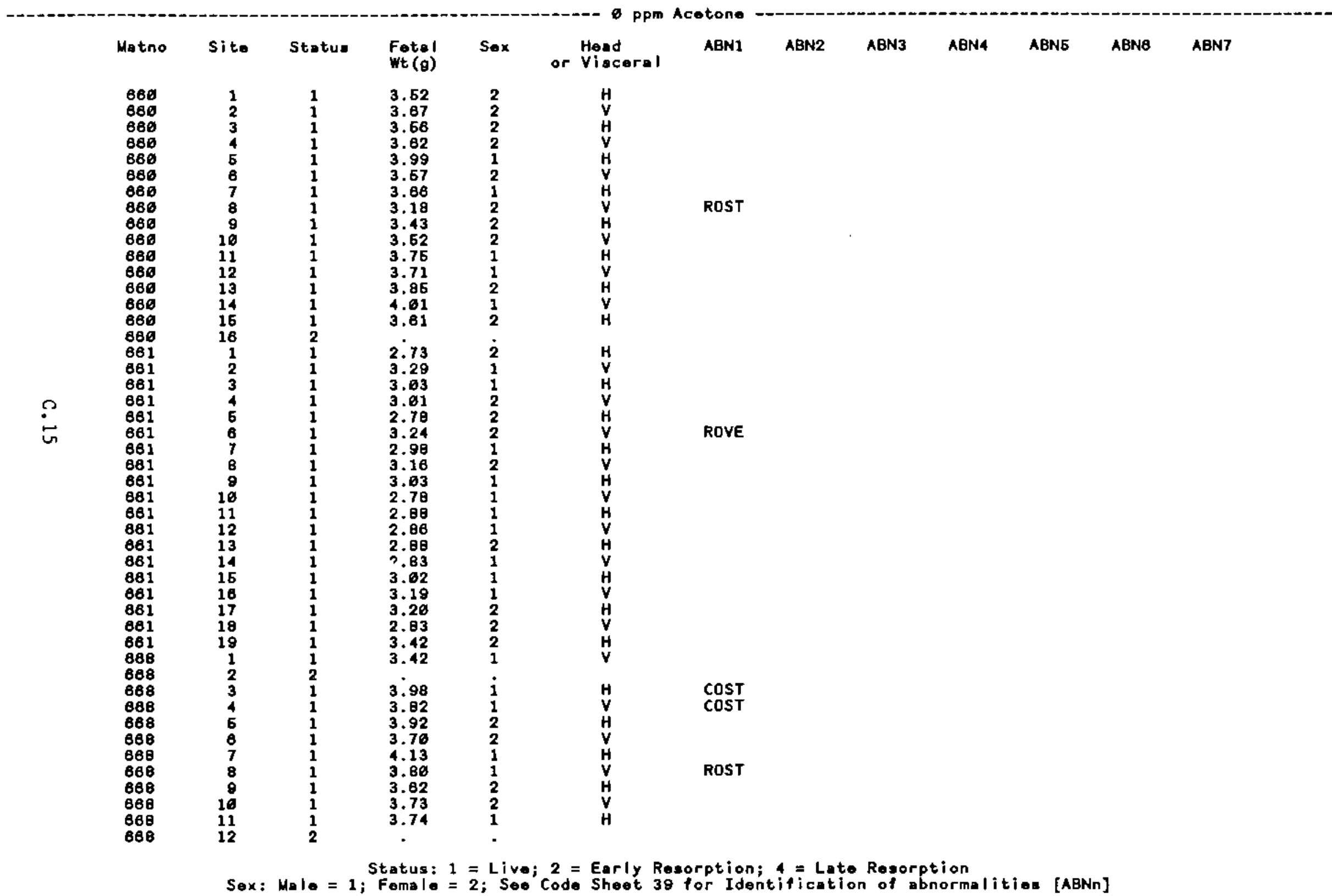


Acetone Rat Teretology Study: Raw Fotal Data

\begin{tabular}{|c|c|c|c|c|c|c|c|c|c|c|c|c|c|}
\hline & Matno & site & Status & $\begin{array}{l}\text { Fetal } \\
\text { Wt }(g)\end{array}$ & Sex & $\begin{array}{l}\text { Head } \\
\text { or Visceral }\end{array}$ & ABN1 & ABN2 & ABN3 & ABN4 & ABNE & ABNB & ABN7 \\
\hline 苟 & $\begin{array}{l}668 \\
688 \\
668 \\
694 \\
694 \\
694 \\
694 \\
694 \\
694 \\
694 \\
694 \\
694 \\
694 \\
694 \\
694 \\
694 \\
694 \\
694 \\
701 \\
761 \\
761 \\
701 \\
761 \\
701 \\
701 \\
761 \\
701 \\
761 \\
701 \\
701 \\
761 \\
701 \\
761 \\
701 \\
701 \\
703 \\
703 \\
703 \\
703 \\
703 \\
703 \\
703 \\
703 \\
703 \\
703 \\
703 \\
703\end{array}$ & $\begin{array}{r}13 \\
14 \\
15 \\
1 \\
2 \\
3 \\
4 \\
5 \\
8 \\
7 \\
8 \\
9 \\
19 \\
11 \\
12 \\
13 \\
14 \\
15 \\
1 \\
2 \\
3 \\
4 \\
5 \\
8 \\
7 \\
8 \\
9 \\
18 \\
11 \\
12 \\
13 \\
14 \\
15 \\
16 \\
17 \\
1\end{array}$ & $\begin{array}{l}1 \\
1 \\
2 \\
1 \\
1 \\
1 \\
1 \\
1 \\
1 \\
1 \\
1 \\
1 \\
1 \\
1 \\
1 \\
1 \\
1 \\
1 \\
1 \\
1 \\
1 \\
1 \\
1 \\
1 \\
1 \\
1 \\
1 \\
1 \\
1 \\
1 \\
1 \\
1 \\
2 \\
1 \\
2 \\
1 \\
1 \\
1 \\
1 \\
1 \\
1 \\
1 \\
1 \\
1 \\
1\end{array}$ & $\begin{array}{l}3.79 \\
3.96 \\
3.17 \\
3.11 \\
3.16 \\
3.39 \\
3.47 \\
3.39 \\
3.49 \\
3.28 \\
2.71 \\
3.06 \\
2.73 \\
3.28 \\
3.44 \\
3.28 \\
3.52 \\
3.68 \\
3.89 \\
3.49 \\
3.68 \\
3.58 \\
3.21 \\
3.28 \\
3.13 \\
3.46 \\
3.57 \\
3.82 \\
3.86 \\
4.02 \\
3.83 \\
3.71 \\
3.14 \\
3.89 \\
3.49 \\
3.32 \\
3.38 \\
3.31 \\
3.48 \\
3.47 \\
3.37 \\
2.89 \\
3.40 \\
3.46\end{array}$ & $\begin{array}{l}1 \\
1 \\
2 \\
2 \\
2 \\
1 \\
1 \\
1 \\
1 \\
1 \\
1 \\
2 \\
1 \\
1 \\
2 \\
2 \\
1 \\
1 \\
1 \\
1 \\
1 \\
2 \\
1 \\
2 \\
2 \\
2 \\
1 \\
1 \\
2 \\
2 \\
2 \\
2 \\
1 \\
1 \\
1 \\
2 \\
2 \\
1 \\
2\end{array}$ & $\begin{array}{l}V \\
H \\
V \\
Y \\
Y \\
H \\
H \\
Y \\
H \\
V \\
H \\
V \\
H \\
V \\
H \\
V \\
H \\
V \\
H \\
V \\
H \\
V \\
H \\
V \\
H \\
V \\
H \\
V \\
H \\
V \\
H \\
V \\
H \\
H \\
V \\
H \\
V \\
H \\
V \\
H \\
V \\
H \\
V \\
H \\
V \\
H\end{array}$ & $\begin{array}{l}\text { SURB } \\
\text { DIUR } \\
\text { ROST } \\
\text { SURB } \\
\text { SURB }\end{array}$ & SUR日 & & & & & \\
\hline
\end{tabular}


Acotone Rat Teratology Study: Rel Fotal Data

\begin{tabular}{|c|c|c|c|c|c|c|c|c|c|c|c|c|c|}
\hline & Metno & site & Stotus & $\begin{array}{l}\text { Fotol } \\
w t(g)\end{array}$ & Sex & $\begin{array}{l}\text { Head } \\
\text { or Viscorel }\end{array}$ & ABN1 & ABN2 & ABN3 & ABN4 & ABN5 & ABNB & ABN7 \\
\hline$\frac{0}{2}$ & 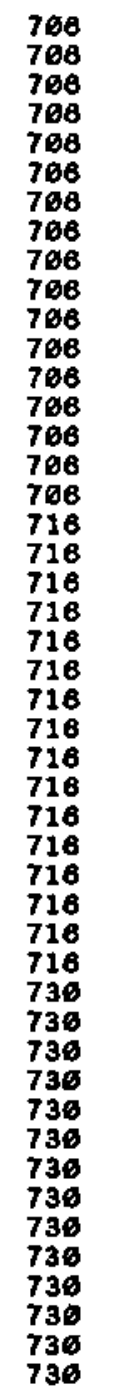 & 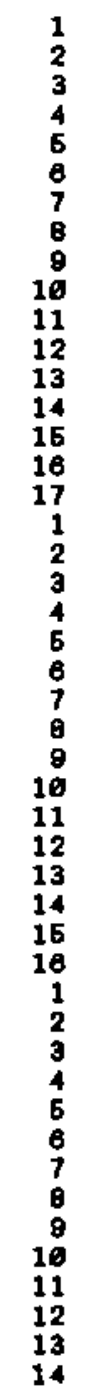 & $\begin{array}{l}1 \\
1 \\
1 \\
1 \\
1 \\
1 \\
1 \\
1 \\
1 \\
1 \\
1 \\
1 \\
1 \\
1 \\
1 \\
1 \\
1 \\
1 \\
1 \\
1 \\
1 \\
1 \\
1 \\
1 \\
1 \\
1 \\
1 \\
1 \\
1 \\
1 \\
1 \\
1 \\
1 \\
2 \\
1 \\
2 \\
1 \\
1 \\
1 \\
2 \\
1 \\
1 \\
1 \\
1 \\
1 \\
1 \\
1\end{array}$ & $\begin{array}{l}3.25 \\
3.84 \\
3.89 \\
3.49 \\
3.79 \\
3.80 \\
3.61 \\
3.96 \\
3.37 \\
3.86 \\
3.44 \\
3.33 \\
3.86 \\
3.95 \\
3.69 \\
3.93 \\
3.85 \\
3.80 \\
3.48 \\
3.53 \\
3.42 \\
3.96 \\
3.87 \\
3.81 \\
3.85 \\
3.67 \\
3.71 \\
3.75 \\
3.81 \\
3.98 \\
3.84 \\
3.38 \\
3.60 \\
3.16 \\
3.24 \\
3.63 \\
2.82 \\
2.49 \\
3.38 \\
3.30 \\
3.35 \\
3.67 \\
3.36 \\
3.41\end{array}$ & $\begin{array}{l}2 \\
1 \\
1 \\
2 \\
1 \\
1 \\
1 \\
1 \\
2 \\
2 \\
2 \\
2 \\
2 \\
1 \\
2 \\
1 \\
1 \\
2 \\
2 \\
2 \\
2 \\
2 \\
2 \\
1 \\
1 \\
1 \\
1 \\
1 \\
2 \\
1 \\
1 \\
2 \\
2 \\
1 \\
1 \\
2 \\
1 \\
1 \\
1 \\
2 \\
1 \\
1 \\
1 \\
2 \\
2\end{array}$ & 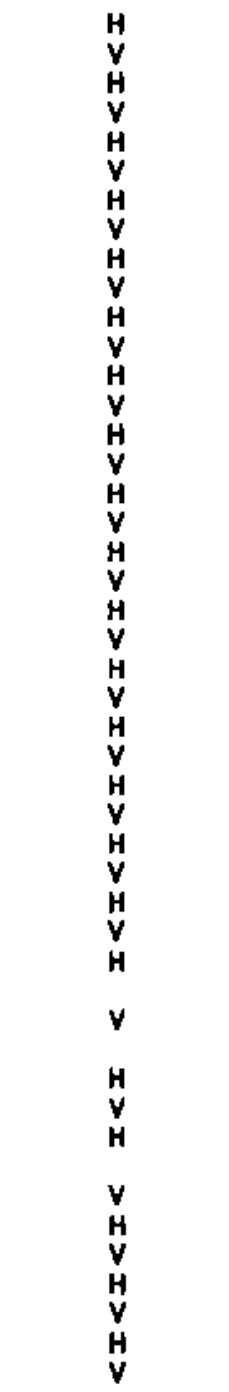 & $\begin{array}{l}\text { ROVE } \\
\text { SURB } \\
\text { SURB } \\
\text { ROST } \\
\text { SURB } \\
\text { SURB } \\
\text { SURB } \\
\text { SURB } \\
\text { SURB } \\
\text { ROST } \\
\text { DIUR } \\
\text { ROST } \\
\text { ROST } \\
\text { ROST } \\
\text { ROST }\end{array}$ & $\begin{array}{l}\text { SURB } \\
\text { SURB } \\
\text { COST }\end{array}$ & $\begin{array}{l}\text { ROPH } \\
\text { ROPH }\end{array}$ & & & & \\
\hline
\end{tabular}


Acetone Ret Teratology Study: Raw Fetal Date

\begin{tabular}{|c|c|c|c|c|c|c|c|c|c|c|c|c|c|}
\hline & Matno & site & status & $\begin{array}{l}\text { Fetal } \\
w t(g)\end{array}$ & $S=x$ & $\begin{array}{l}\text { Hood } \\
\text { or Viseceral }\end{array}$ & ABN1 & ABN2 & ABN3 & ABNA & ABNE & ABN6 & ABN7 \\
\hline $\begin{array}{l}\infty \\
\infty \\
\infty\end{array}$ & $\begin{array}{l}730 \\
736 \\
731 \\
731 \\
731 \\
731 \\
731 \\
731 \\
731 \\
731 \\
731 \\
731 \\
731 \\
731 \\
731 \\
731 \\
731 \\
731 \\
732 \\
732 \\
732 \\
732 \\
732 \\
732 \\
732 \\
732 \\
732 \\
732 \\
732 \\
732 \\
732 \\
732 \\
732 \\
732 \\
741 \\
741 \\
741 \\
741 \\
741 \\
741 \\
741 \\
741 \\
741 \\
741 \\
741 \\
741 \\
741\end{array}$ & 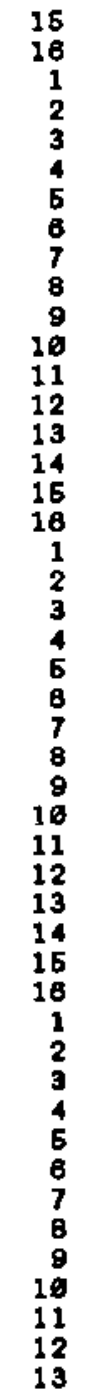 & $\begin{array}{l}1 \\
1 \\
1 \\
4 \\
1 \\
4 \\
1 \\
1 \\
1 \\
1 \\
1 \\
1 \\
4 \\
1 \\
1 \\
1 \\
1 \\
1 \\
1 \\
1 \\
1 \\
1 \\
1 \\
1 \\
1 \\
1 \\
1 \\
1 \\
1 \\
1 \\
1 \\
1 \\
1 \\
1 \\
1 \\
1 \\
1 \\
1 \\
1 \\
1 \\
1 \\
1 \\
1 \\
1 \\
1 \\
1\end{array}$ & $\begin{array}{l}3.28 \\
3.36 \\
1.72 \\
3.63 \\
3.81 \\
2.71 \\
3.37 \\
3.41 \\
3.54 \\
3.68 \\
3.29 \\
3.64 \\
3.68 \\
3.61 \\
3.48 \\
2.63 \\
3.84 \\
3.61 \\
3.66 \\
3.62 \\
3.68 \\
3.26 \\
3.31 \\
3.28 \\
3.72 \\
3.78 \\
3.64 \\
3.86 \\
3.99 \\
3.42 \\
3.96 \\
3.39 \\
4.65 \\
4.63 \\
3.96 \\
3.62 \\
3.61 \\
3.83 \\
3.64 \\
3.68 \\
4.68 \\
3.81 \\
3.86 \\
3.60\end{array}$ & $\begin{array}{l}2 \\
2 \\
2 \\
2 \\
2 \\
1 \\
1 \\
1 \\
2 \\
2 \\
1 \\
2 \\
2 \\
1 \\
2 \\
1 \\
2 \\
2 \\
1 \\
2 \\
1 \\
1 \\
2 \\
2 \\
2 \\
1 \\
1 \\
1 \\
1 \\
2 \\
2 \\
2 \\
1 \\
1 \\
1 \\
1 \\
1 \\
2 \\
2 \\
2 \\
2 \\
1 \\
1 \\
2 \\
2 \\
2\end{array}$ & 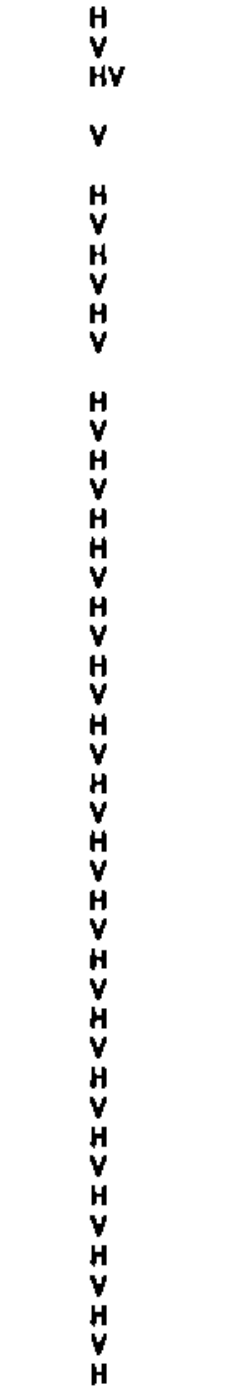 & $\begin{array}{l}\text { EXCE } \\
\text { ROST } \\
\text { ROST } \\
\text { ROST } \\
\text { ROST } \\
\text { COST } \\
\text { COST } \\
\text { SURB } \\
\text { ROST }\end{array}$ & $\begin{array}{l}\text { AOPT } \\
\text { ROPB } \\
\text { MAST }\end{array}$ & RACH & FURB & & & \\
\hline
\end{tabular}


Acotone Rat Teratology Study: Row Fotel Doto

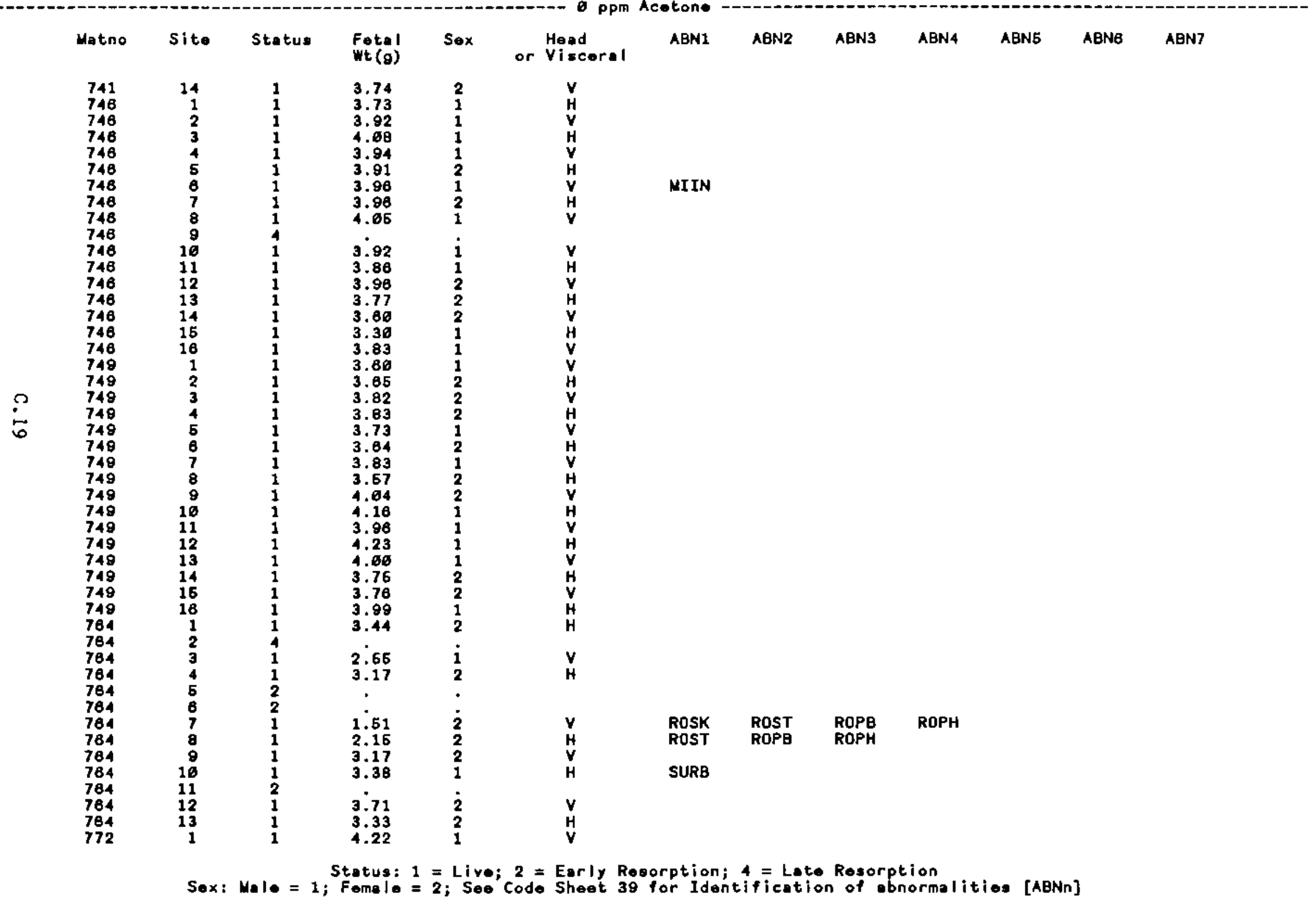


Acotone Rat Teratology Study: Raw Fetal Data

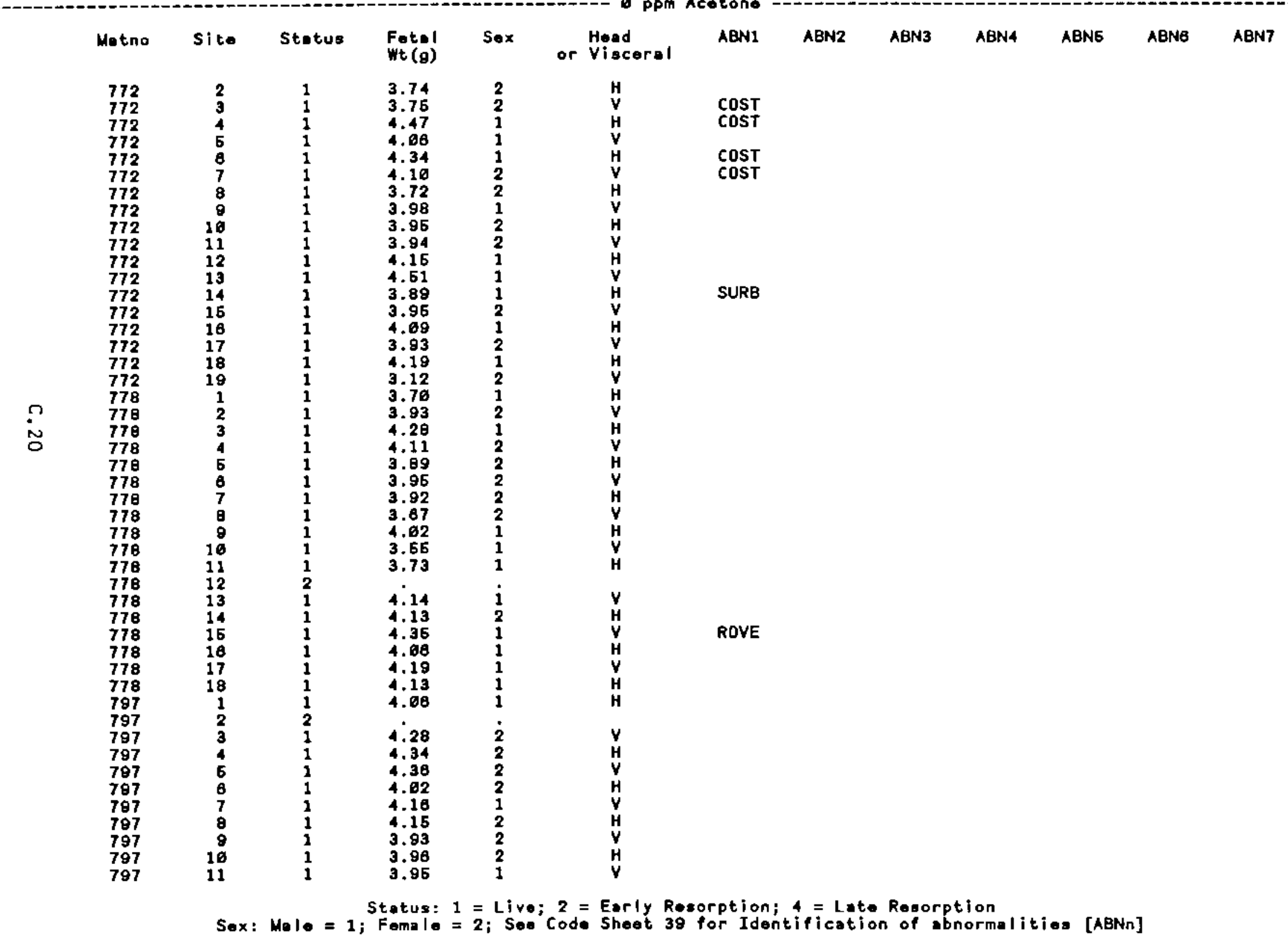


Acetone Ret Toratology Study: Raw Fotal Dete

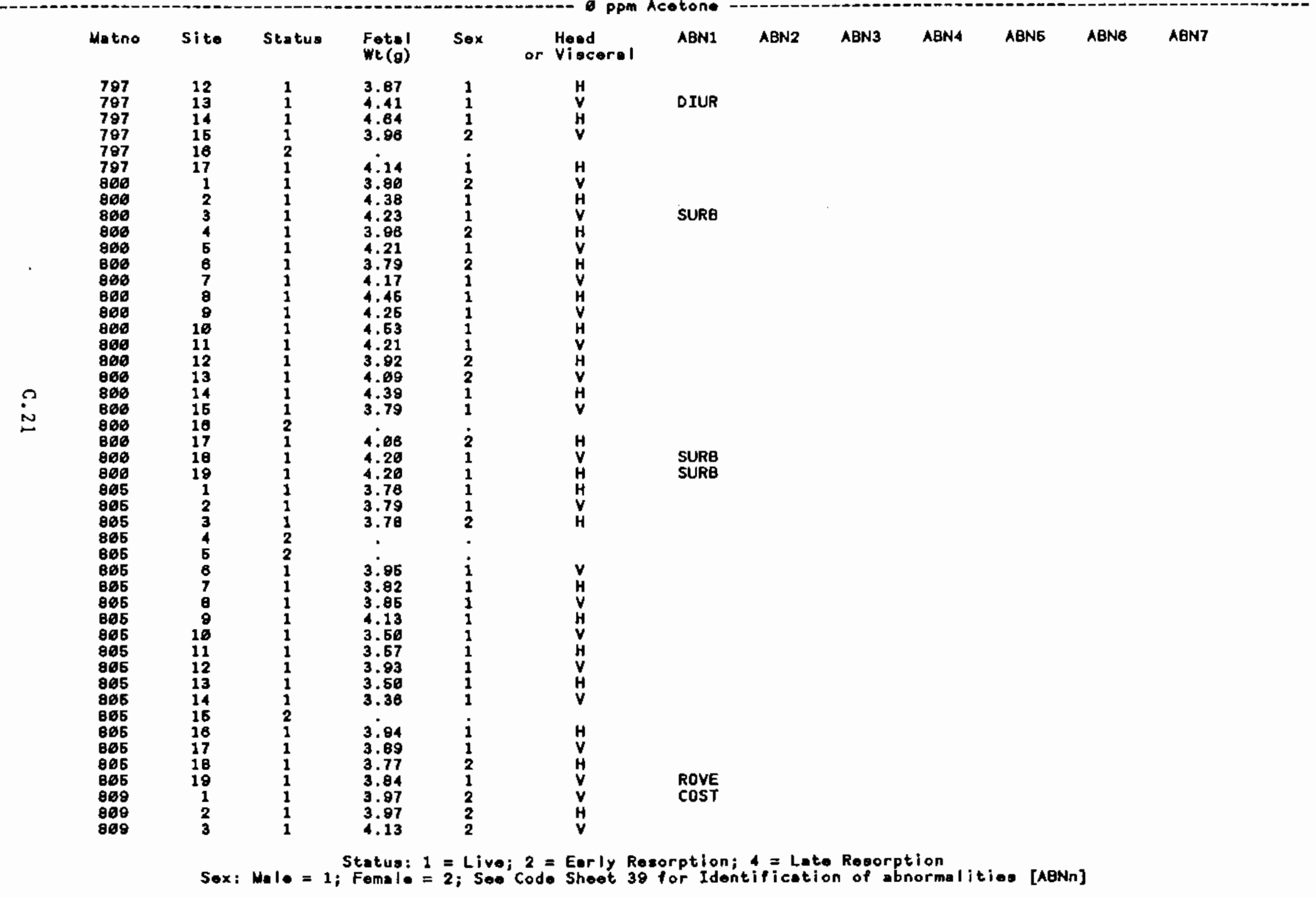


Acetone Ret Toratology Study; Raw Fotal Data

\begin{tabular}{|c|c|c|c|c|c|c|c|c|c|c|c|c|c|}
\hline & Metno & site & Status & $\begin{array}{l}\text { Fet: } 1 \\
\text { wt (g) }\end{array}$ & Sex & $\begin{array}{l}\text { Mead } \\
\text { or Visceral }\end{array}$ & ABN1 & ABN2 & ABN3 & ABN4 & ABN5 & ABNB & ABN7 \\
\hline ' & 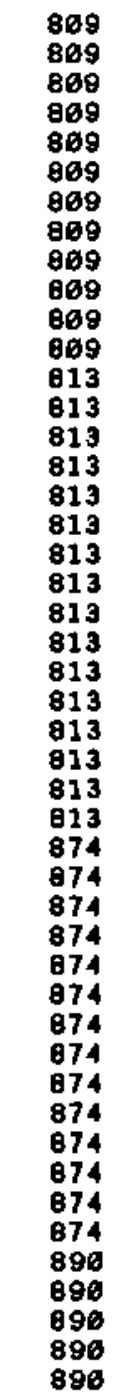 & $\begin{array}{r}4 \\
5 \\
6 \\
7 \\
9 \\
9 \\
19 \\
11 \\
12 \\
13 \\
14 \\
15 \\
1 \\
2 \\
3 \\
4 \\
5 \\
6 \\
7 \\
8 \\
9 \\
10 \\
11 \\
12 \\
13 \\
14 \\
15 \\
16 \\
1 \\
2 \\
3 \\
4 \\
5 \\
8 \\
7 \\
8 \\
9 \\
10 \\
11 \\
12 \\
13 \\
14 \\
1 \\
2 \\
3 \\
4 \\
5\end{array}$ & $\begin{array}{l}1 \\
2 \\
1 \\
1 \\
1 \\
1 \\
1 \\
1 \\
1 \\
1 \\
1 \\
1 \\
1 \\
1 \\
1 \\
1 \\
1 \\
1 \\
1 \\
1 \\
1 \\
1 \\
1 \\
1 \\
2 \\
1 \\
1 \\
1 \\
1 \\
1 \\
1 \\
1 \\
1 \\
1 \\
1 \\
1 \\
1 \\
1 \\
1 \\
1 \\
1 \\
1 \\
1 \\
1 \\
1 \\
1\end{array}$ & $\begin{array}{l}4.18 \\
4.22 \\
4.38 \\
3.84 \\
4.19 \\
4.24 \\
4.38 \\
4.26 \\
4.18 \\
4.63 \\
3.18 \\
3.66 \\
3.88 \\
3.43 \\
3.60 \\
3.17 \\
3.18 \\
2.42 \\
3.93 \\
3.47 \\
2.86 \\
3.47 \\
3.14 \\
3.52 \\
3.71 \\
3.36 \\
3.71 \\
3.76 \\
3.41 \\
3.66 \\
3.96 \\
3.81 \\
3.47 \\
3.73 \\
3.37 \\
3.65 \\
3.84 \\
3.71 \\
3.84 \\
3.67 \\
3.65 \\
3.76 \\
3.47 \\
3.87\end{array}$ & $\begin{array}{l}2 \\
\dot{2} \\
1 \\
2 \\
2 \\
1 \\
1 \\
\dot{2} \\
2 \\
1 \\
2 \\
1 \\
1 \\
1 \\
2 \\
1 \\
2 \\
1 \\
2 \\
2 \\
2 \\
1 \\
1 \\
1 \\
1 \\
2 \\
2 \\
2 \\
2 \\
1 \\
1 \\
1 \\
2 \\
2 \\
2 \\
1 \\
1 \\
2 \\
1 \\
1 \\
2 \\
2 \\
2 \\
1\end{array}$ & 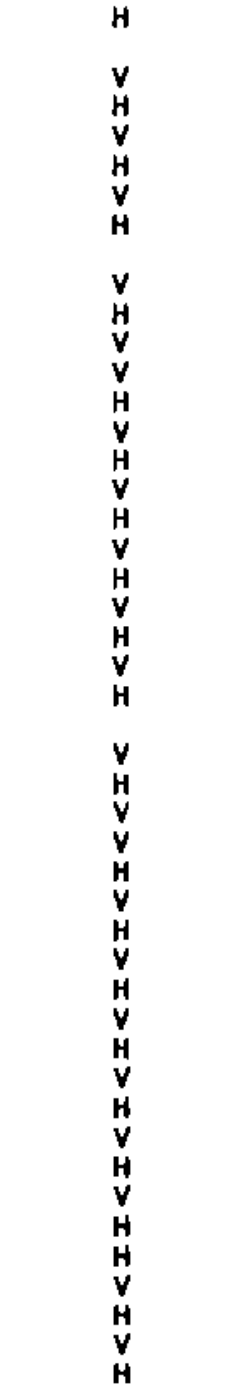 & $\begin{array}{l}\text { ROST } \\
\text { ROST } \\
\text { MAST } \\
\text { SURB }\end{array}$ & & & & & & \\
\hline
\end{tabular}


Acotone Rat Toratology Study: Re= Fotal Dato

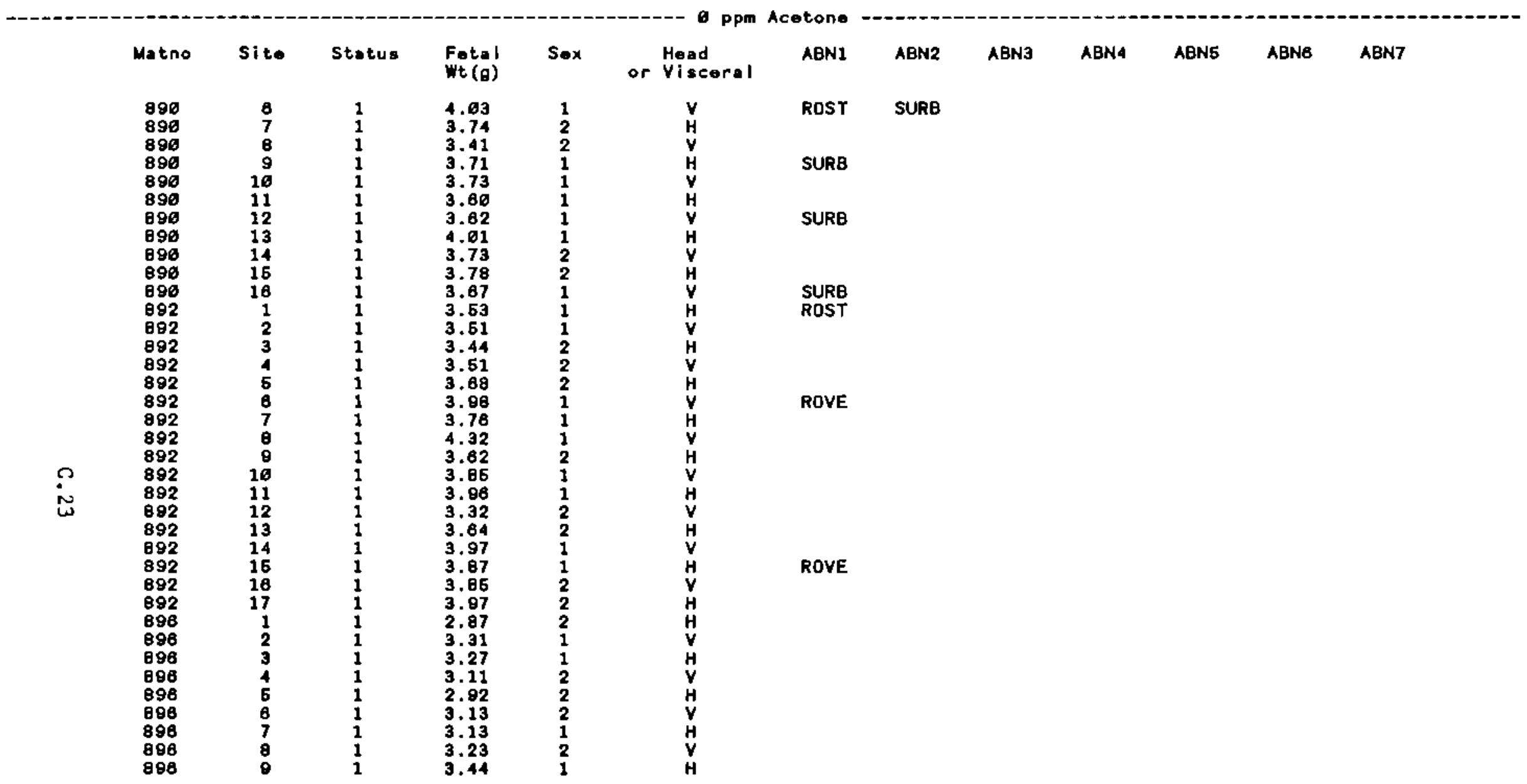


Acetone Rat Teratology Study: Raw Fetal Data

\begin{tabular}{|c|c|c|c|c|c|c|c|c|c|c|c|c|c|}
\hline & Matno & Site & Status & $\begin{array}{l}\text { Fetal } \\
\text { Wt (g) }\end{array}$ & Sox & $\begin{array}{l}\text { Head } \\
\text { or Visceral }\end{array}$ & AEN1 & ABN2 & $A B N 3$ & ABN4 & AENE & ABNB & ABN7 \\
\hline$\stackrel{D}{\sim}$ & $\begin{array}{l}662 \\
662 \\
682 \\
662 \\
662 \\
662 \\
682 \\
662 \\
662 \\
662 \\
682 \\
682 \\
662 \\
662 \\
682 \\
662 \\
662 \\
682 \\
663 \\
683 \\
683 \\
683 \\
683 \\
683 \\
683 \\
683 \\
683 \\
683 \\
683 \\
683 \\
863 \\
863 \\
863 \\
863 \\
864 \\
664 \\
664 \\
684 \\
664 \\
684 \\
684 \\
684 \\
684 \\
684 \\
684 \\
684 \\
684\end{array}$ & 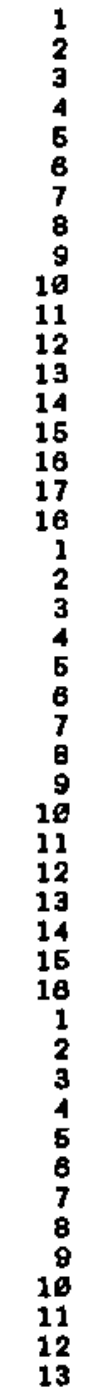 & $\begin{array}{l}2 \\
1 \\
1 \\
1 \\
1 \\
1 \\
1 \\
1 \\
1 \\
1 \\
1 \\
1 \\
1 \\
1 \\
1 \\
1 \\
1 \\
1 \\
1 \\
2 \\
1 \\
1 \\
1 \\
1 \\
1 \\
1 \\
1 \\
1 \\
1 \\
1 \\
1 \\
1 \\
1 \\
2 \\
2 \\
1 \\
1 \\
1 \\
1 \\
1 \\
1 \\
1 \\
1 \\
1 \\
1 \\
1 \\
1\end{array}$ & $\begin{array}{l}3.69 \\
3.55 \\
3.54 \\
3.88 \\
3.74 \\
4.67 \\
3.83 \\
3.68 \\
3.62 \\
3.58 \\
3.56 \\
3.51 \\
3.69 \\
3.71 \\
4.61 \\
3.79 \\
3.94 \\
3.11 \\
3.68 \\
3.63 \\
3.37 \\
3.29 \\
3.37 \\
3.15 \\
3.06 \\
3.26 \\
3.84 \\
3.27 \\
3.83 \\
3.44 \\
3.66 \\
.6 \\
3.40 \\
3.38 \\
3.58 \\
3.57 \\
2.89 \\
3.82 \\
3.42 \\
3.36 \\
3.42 \\
3.35 \\
3.52 \\
3.53\end{array}$ & $\begin{array}{l}1 \\
1 \\
1 \\
2 \\
2 \\
2 \\
1 \\
2 \\
1 \\
1 \\
2 \\
2 \\
2 \\
1 \\
2 \\
2 \\
2 \\
2 \\
1 \\
1 \\
1 \\
2 \\
2 \\
2 \\
2 \\
2 \\
1 \\
1 \\
1 \\
1 \\
2 \\
1 \\
2 \\
2 \\
2 \\
1 \\
2 \\
2 \\
1 \\
2 \\
2 \\
1 \\
2 \\
1 \\
2\end{array}$ & $\begin{array}{l}\mathbf{V} \\
H \\
\mathbf{V} \\
\mathbf{H} \\
\mathbf{V} \\
\mathbf{H} \\
\mathbf{V} \\
\mathbf{H} \\
\mathbf{V} \\
\mathbf{H} \\
\mathbf{V} \\
\mathbf{H} \\
\mathbf{V} \\
\mathbf{H} \\
\mathbf{V} \\
\mathbf{H} \\
\mathbf{V} \\
\mathbf{V} \\
\mathbf{H} \\
\mathbf{V} \\
\mathbf{H} \\
\mathbf{V} \\
\mathbf{H} \\
\mathbf{V} \\
\mathbf{H} \\
\mathbf{V} \\
\mathbf{H} \\
\mathbf{V} \\
\mathbf{H} \\
\mathbf{V} \\
\mathbf{H} \\
\\
\mathbf{H} \\
\mathbf{V} \\
\mathbf{H} \\
\mathbf{V} \\
\mathbf{H} \\
\mathbf{V} \\
\mathbf{H} \\
\mathbf{V} \\
\mathbf{H} \\
\mathbf{V} \\
\mathbf{H} \\
\mathbf{V}\end{array}$ & $\begin{array}{l}\text { ROST } \\
\text { SURB } \\
\text { ROST } \\
\text { SURB } \\
\text { ROST } \\
\text { ROST } \\
\text { MAST } \\
\\
\text { RORB } \\
\text { ROST } \\
\text { DIUR } \\
\text { SURB } \\
\text { ROST } \\
\text { DIUR } \\
\text { SURE } \\
\text { DIUR }\end{array}$ & $\begin{array}{l}\text { SURB } \\
\text { SURB } \\
\end{array}$ & & & & & \\
\hline
\end{tabular}


Acetone Ret Teratology Study: Raw Fatal Data

\begin{tabular}{|c|c|c|c|c|c|c|c|c|c|c|c|c|c|}
\hline & Matno & sito & Status & $\begin{array}{l}\text { Fetal } \\
\text { Wt (g) }\end{array}$ & Sox & $\begin{array}{l}\text { Hoad } \\
\text { or Visceral }\end{array}$ & ABN1 & ABN2 & ABN3 & ABN4 & ABN5 & $A B N B$ & ABN7 \\
\hline$\stackrel{\Omega}{N}$ & $\begin{array}{l}864 \\
664 \\
684 \\
675 \\
676 \\
676 \\
675 \\
676 \\
675 \\
675 \\
675 \\
675 \\
675 \\
675 \\
676 \\
676 \\
676 \\
676 \\
675 \\
675 \\
729 \\
720 \\
729 \\
726 \\
729 \\
726 \\
720 \\
726 \\
726 \\
726 \\
726 \\
726 \\
726 \\
720 \\
720 \\
726 \\
723 \\
723 \\
723 \\
723 \\
723 \\
723 \\
723 \\
723 \\
723 \\
723 \\
723\end{array}$ & $\begin{array}{r}14 \\
15 \\
18 \\
19 \\
2 \\
3 \\
4 \\
5 \\
7 \\
7 \\
99 \\
16 \\
11 \\
12 \\
13 \\
14 \\
15 \\
16 \\
17 \\
1 \\
2 \\
3 \\
4 \\
5 \\
8 \\
7 \\
8\end{array}$ & $\begin{array}{l}1 \\
1 \\
1 \\
1 \\
1 \\
1 \\
1 \\
1 \\
1 \\
1 \\
1 \\
1 \\
1 \\
1 \\
1 \\
1 \\
1 \\
1 \\
1 \\
1 \\
1 \\
1 \\
1 \\
2 \\
1 \\
1 \\
1 \\
2 \\
1 \\
1 \\
1 \\
1 \\
1 \\
2 \\
1 \\
2 \\
1 \\
1 \\
1 \\
2 \\
2 \\
1 \\
1 \\
1 \\
1 \\
1 \\
1\end{array}$ & $\begin{array}{l}3.42 \\
3.48 \\
3.75 \\
3.76 \\
4.68 \\
4.64 \\
4.17 \\
4.02 \\
3.87 \\
3.95 \\
3.66 \\
3.42 \\
3.73 \\
3.99 \\
4.26 \\
4.62 \\
3.82 \\
4.16 \\
3.98 \\
4.61 \\
3.51 \\
3.78 \\
3.81 \\
4.67 \\
3.93 \\
3.87 \\
3.64 \\
3.72 \\
3.63 \\
3.65 \\
3.95 \\
3.17 \\
3.74 \\
3.86 \\
4.69 \\
.0 \\
3.87 \\
4.22 \\
3.94 \\
4.30 \\
3.90 \\
3.98\end{array}$ & $\begin{array}{l}2 \\
2 \\
1 \\
1 \\
1 \\
1 \\
1 \\
2 \\
1 \\
2 \\
1 \\
2 \\
2 \\
1 \\
1 \\
1 \\
2 \\
1 \\
1 \\
2 \\
1 \\
1 \\
2 \\
i \\
1 \\
1 \\
\dot{2} \\
1 \\
1 \\
1 \\
1 \\
2 \\
2 \\
2 \\
1 \\
2 \\
1 \\
1 \\
2 \\
1 \\
2 \\
1\end{array}$ & 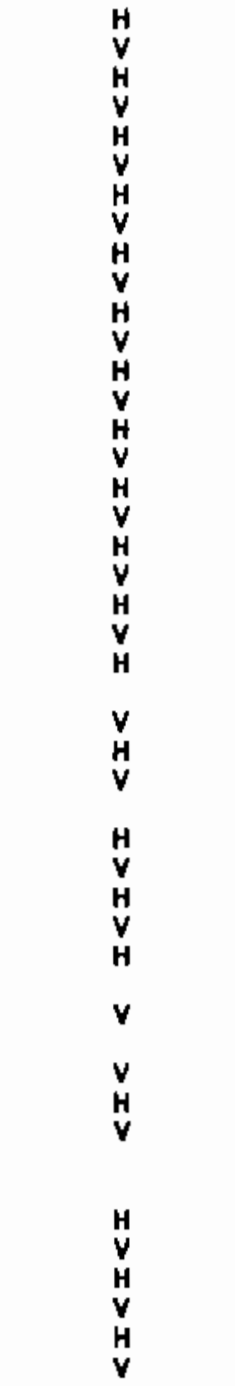 & $\begin{array}{l}\text { SURB } \\
\text { ROVE } \\
\text { ROVE } \\
\text { COST } \\
\text { COST }\end{array}$ & & & & & & \\
\hline
\end{tabular}


Acetone Rat Toratology Study: Raw Fotal Data

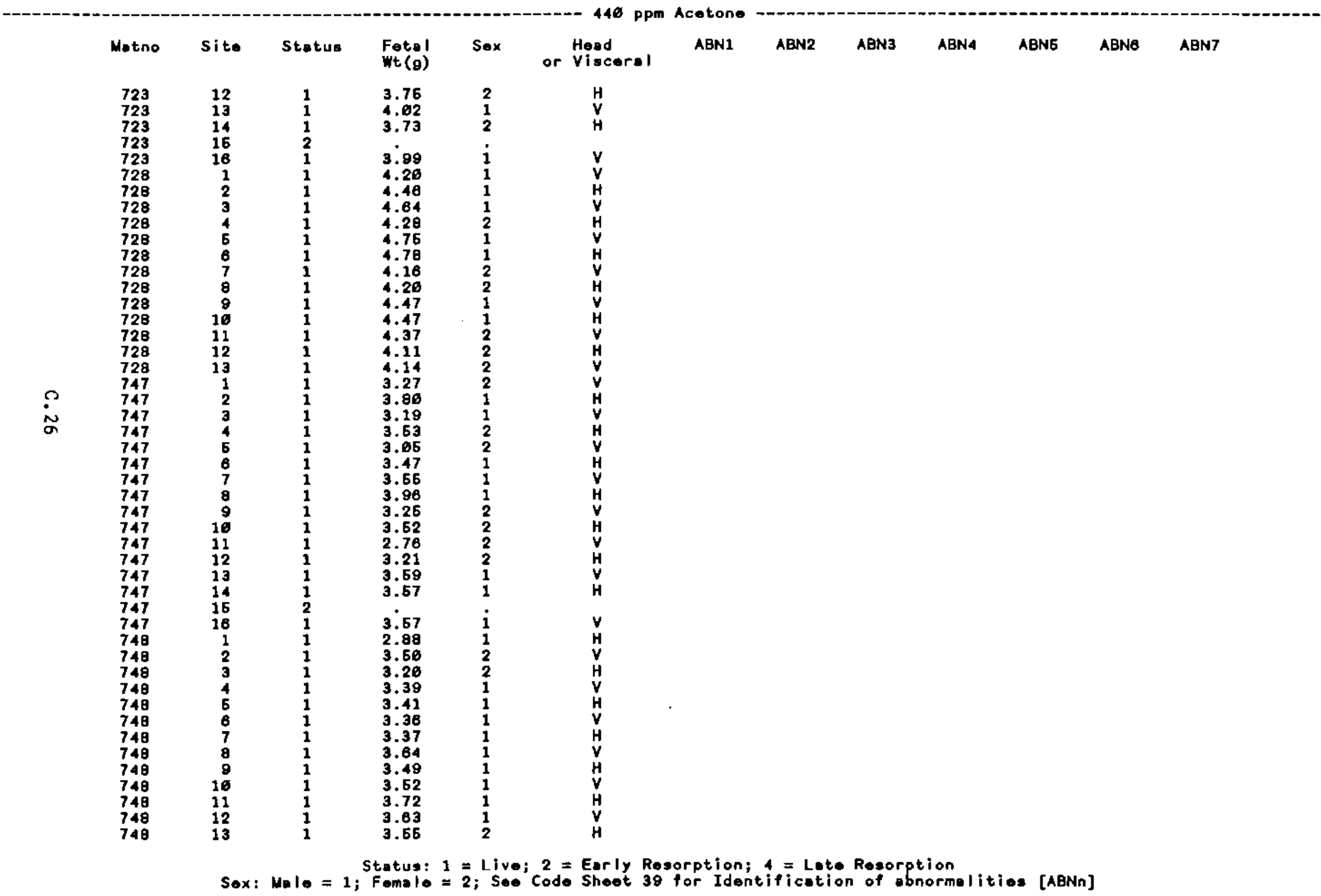


Acetone Ret Yeratology Study: Raw Fotal Data

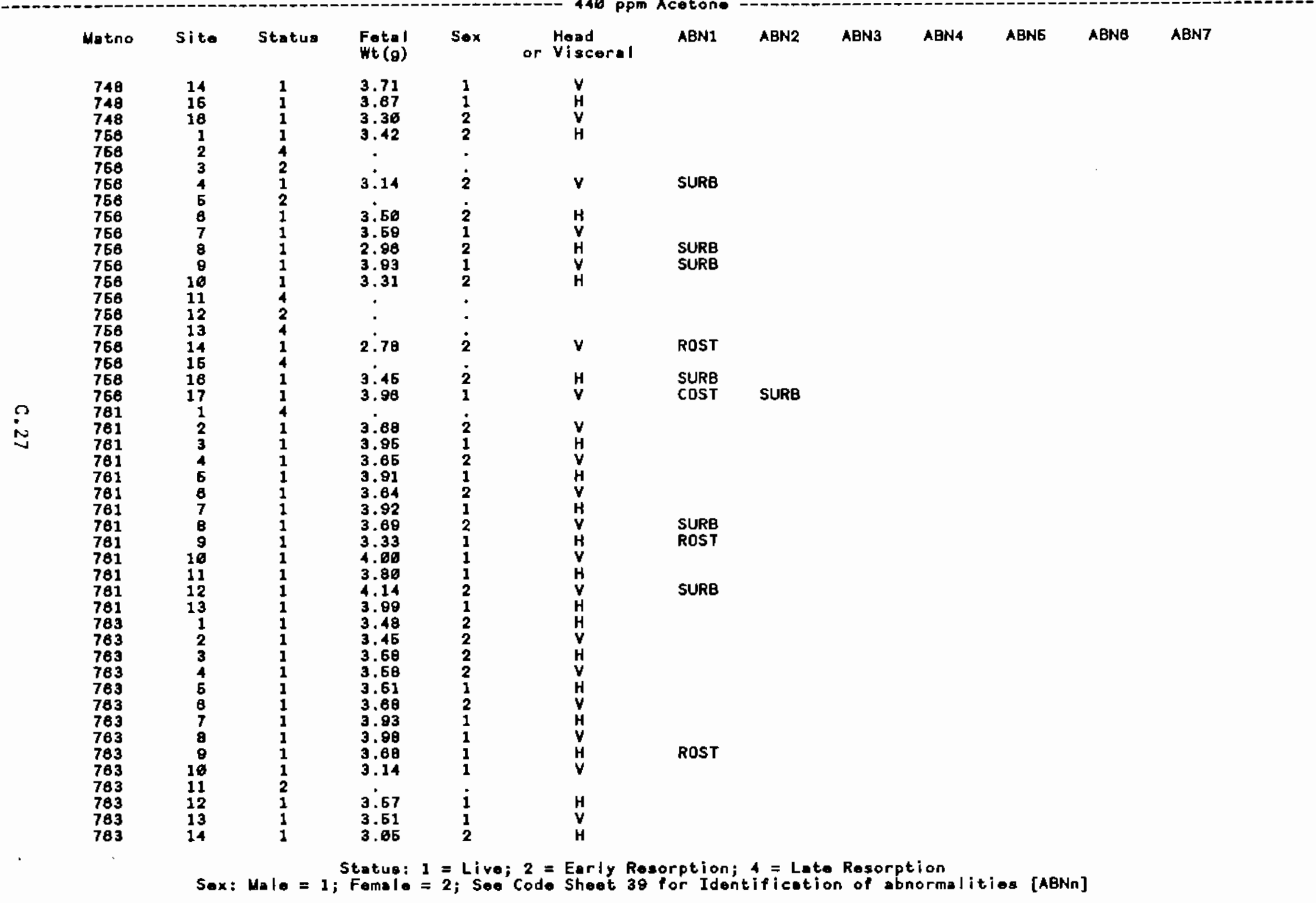


Acetone Rat Teratology Study: Rav Fetal Dato

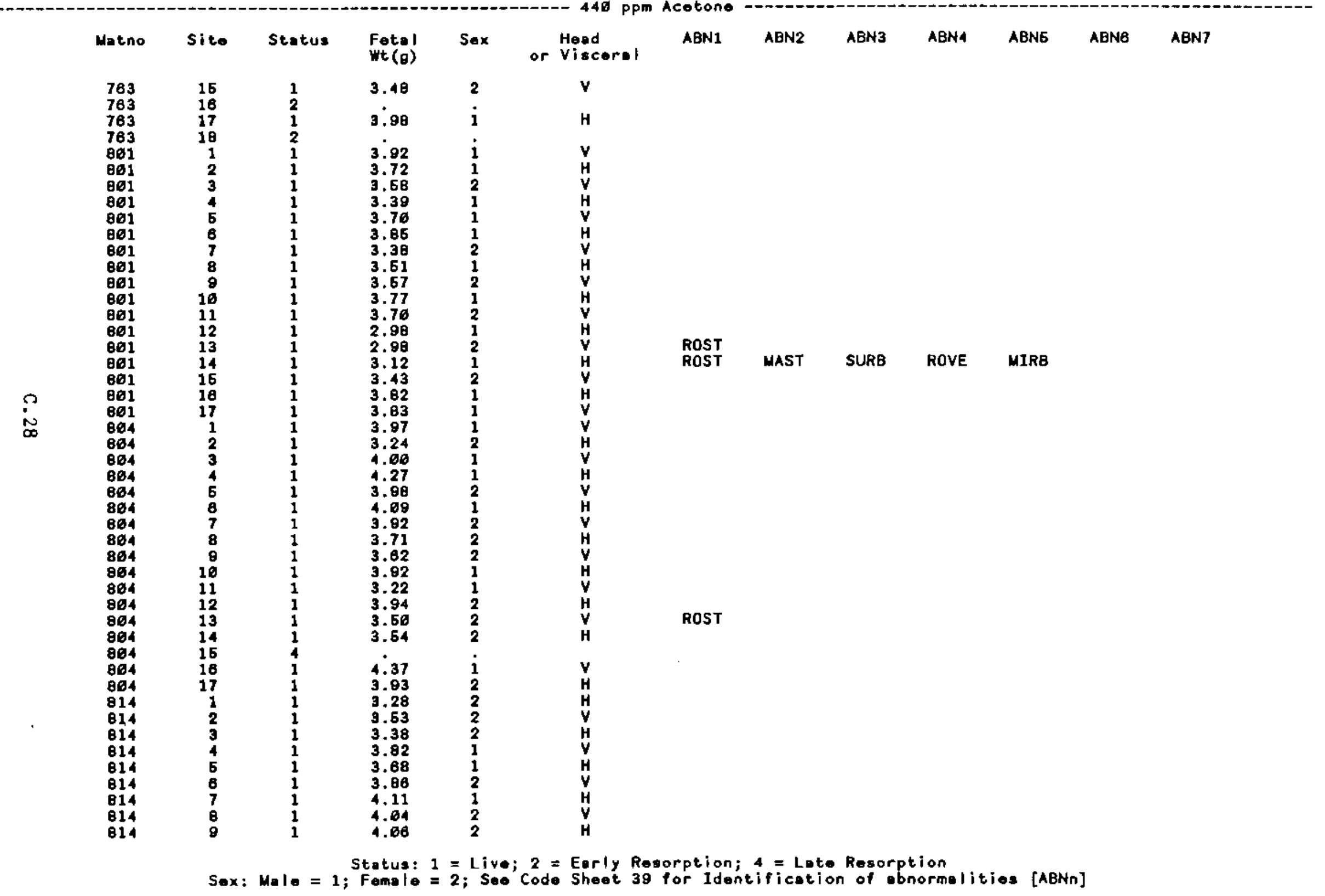


Acetone Rat Terotology Study: Raw Fotal Data

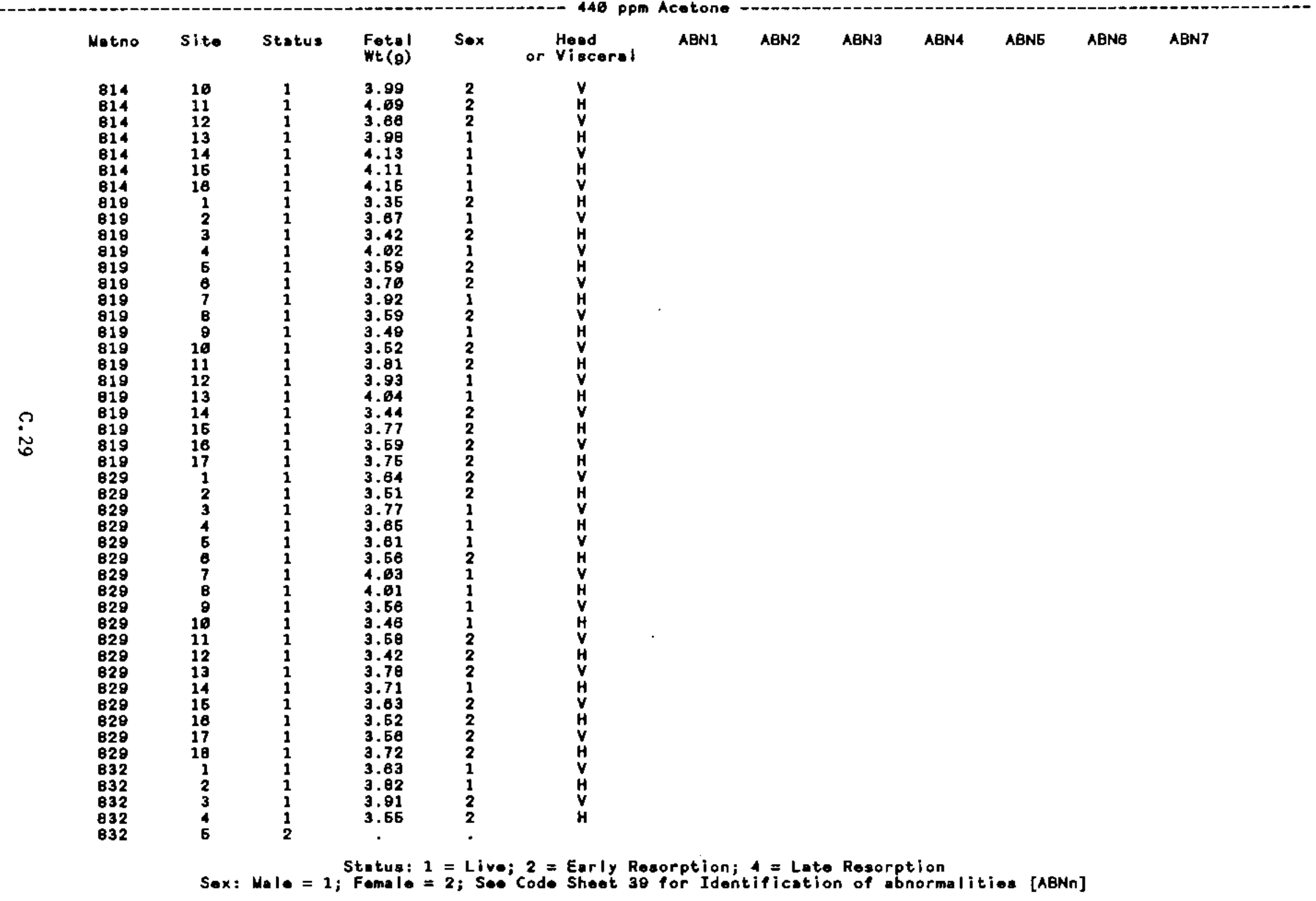


Acotone Rat Teratology Study: Raw Fetal Data

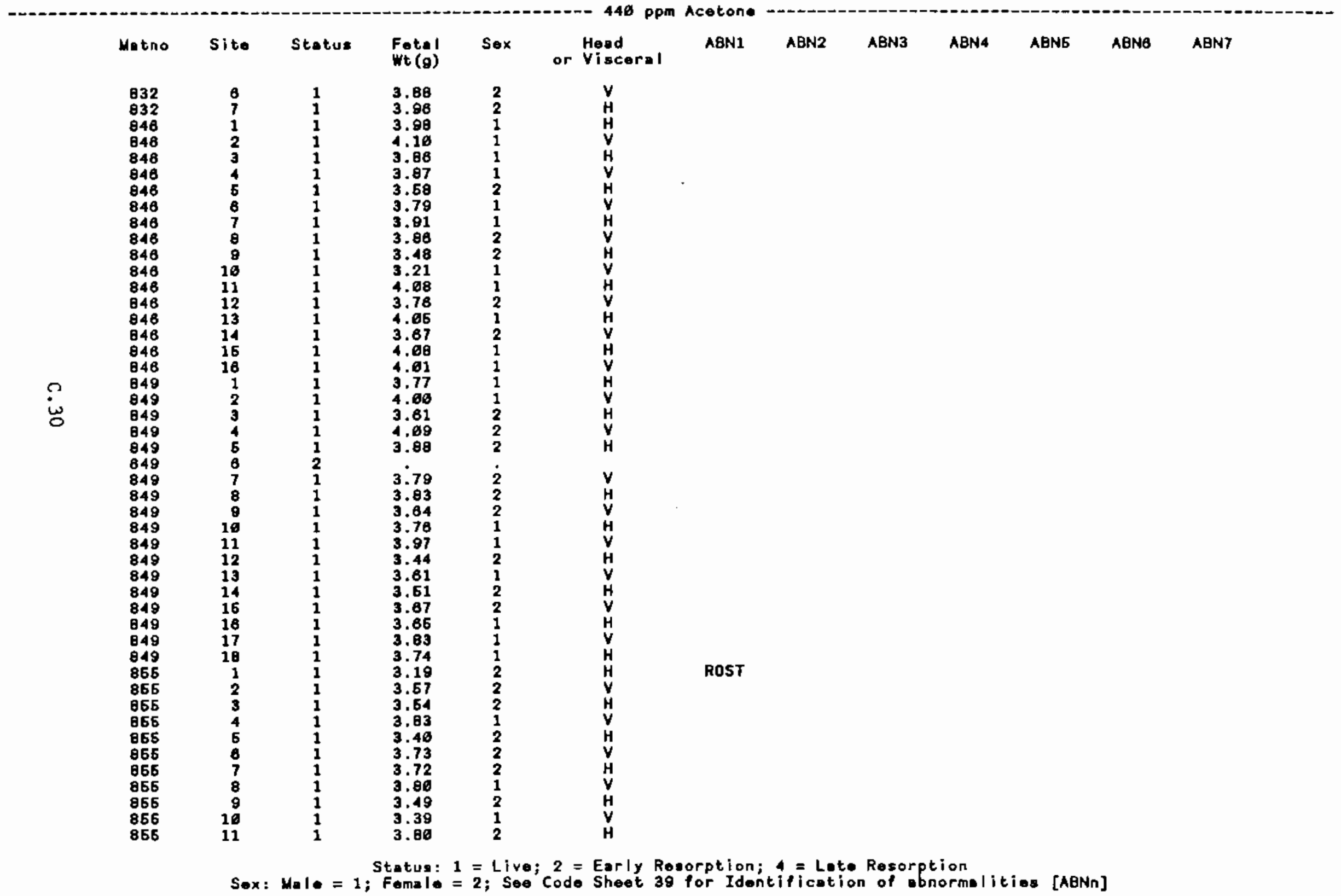


Acetone Rat Teratology Study: Row Fotel Data

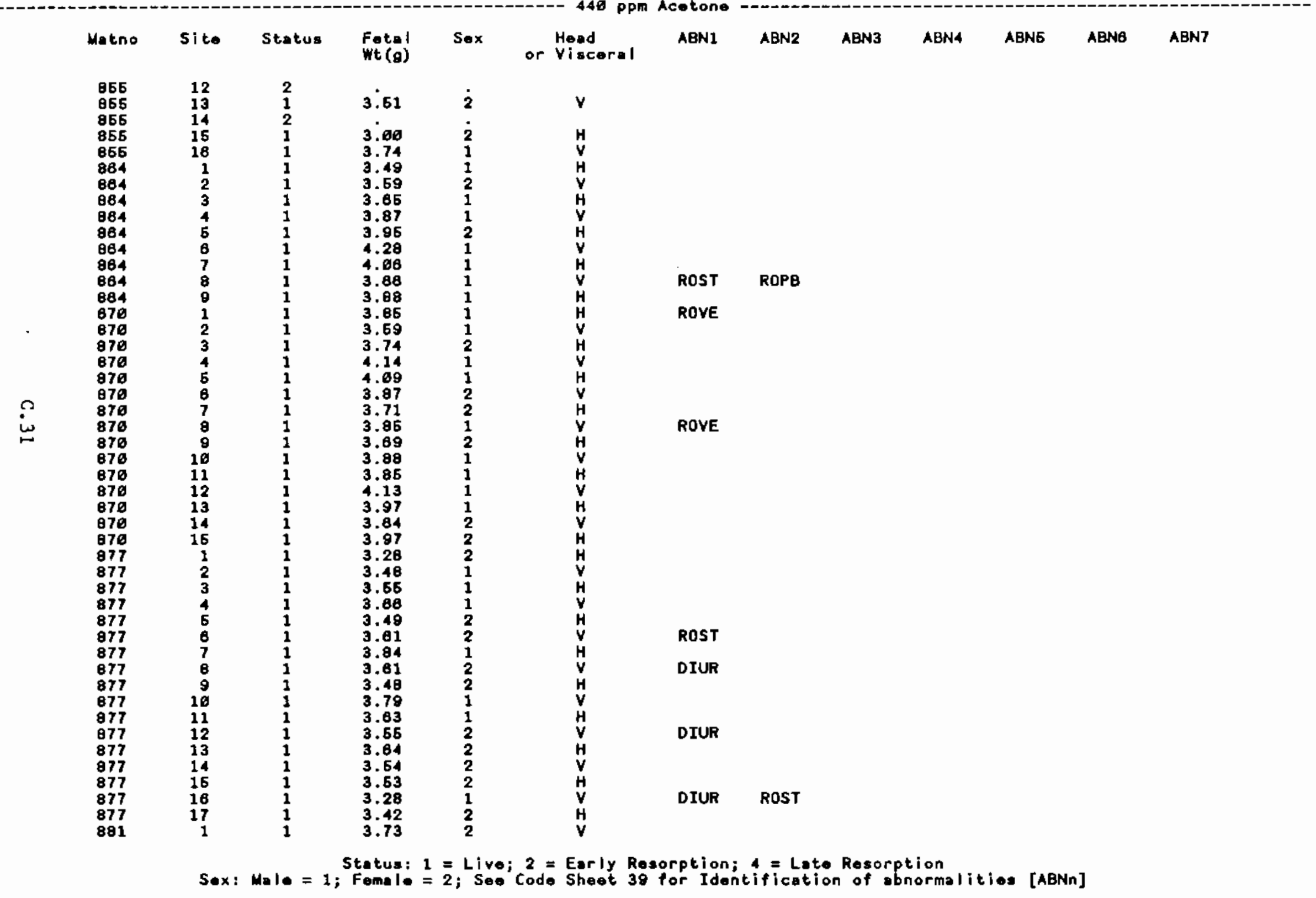


Acetone Rat Teretology Study: Raw Fotal Date

\begin{tabular}{|c|c|c|c|c|c|c|c|c|c|c|c|c|c|}
\hline & Matno & site & Status & $\begin{array}{l}\text { Fetal } \\
\text { Wt }(g)\end{array}$ & Sex & $\begin{array}{l}\text { Head } \\
\text { or Visceral }\end{array}$ & ABN1 & ABN2 & $A B N 3$ & ABN4 & ABNE & ABNB & ABN7 \\
\hline$\cdot$ & 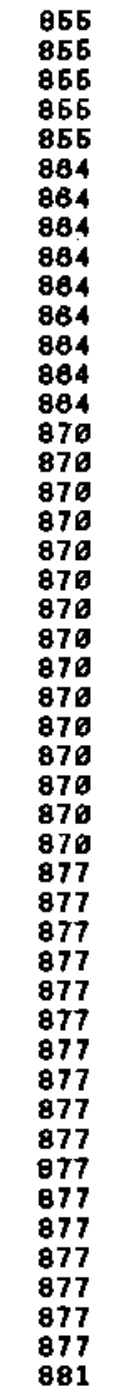 & 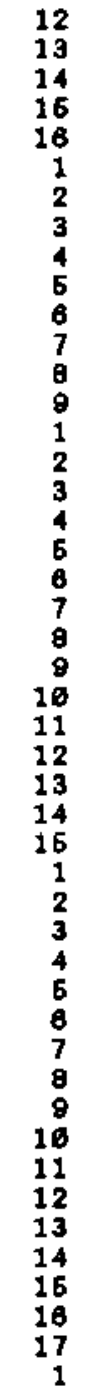 & $\begin{array}{l}2 \\
1 \\
2 \\
1 \\
1 \\
1 \\
1 \\
1 \\
1 \\
1 \\
1 \\
1 \\
1 \\
1 \\
1 \\
1 \\
1 \\
1 \\
1 \\
1 \\
1 \\
1 \\
1 \\
1 \\
1 \\
1 \\
1 \\
1 \\
1 \\
1 \\
1 \\
1 \\
1 \\
1 \\
1 \\
1 \\
1 \\
1 \\
1 \\
1 \\
1 \\
1 \\
1 \\
1 \\
1\end{array}$ & 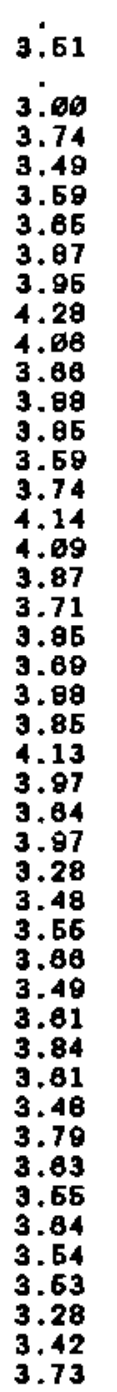 & $\begin{array}{l}\dot{2} \\
\dot{2} \\
1 \\
1 \\
2 \\
1 \\
1 \\
2 \\
1 \\
1 \\
1 \\
1 \\
1 \\
1 \\
2 \\
1 \\
1 \\
2 \\
2 \\
1 \\
2 \\
1 \\
1 \\
1 \\
1 \\
2 \\
2 \\
2 \\
1 \\
1 \\
1 \\
2 \\
2 \\
1 \\
2 \\
2 \\
1 \\
1 \\
2 \\
2 \\
2 \\
2 \\
1 \\
2 \\
2\end{array}$ & $\begin{array}{l}V \\
H \\
\mathbf{V} \\
H \\
V \\
H \\
V \\
H \\
\mathbf{V} \\
\mathbf{H} \\
\mathbf{V} \\
\mathbf{H} \\
\mathbf{H} \\
\mathbf{V} \\
\mathbf{H} \\
\mathbf{V} \\
\mathbf{H} \\
\mathbf{V} \\
\mathbf{H} \\
\mathbf{V} \\
\mathbf{H} \\
\mathbf{V} \\
\mathbf{H} \\
\mathbf{V} \\
\mathbf{H} \\
\mathbf{V} \\
\mathbf{H} \\
\mathbf{H} \\
\mathbf{V} \\
\mathbf{H} \\
\mathbf{V} \\
\mathbf{H} \\
\mathbf{V} \\
\mathbf{H} \\
\mathbf{V} \\
\mathbf{H} \\
\mathbf{V} \\
\mathbf{H} \\
\mathbf{V} \\
\mathbf{H} \\
\mathbf{V} \\
\mathbf{H} \\
\mathbf{V} \\
\mathbf{H} \\
\mathbf{V}\end{array}$ & $\begin{array}{l}\text { ROST } \\
\text { ROVE } \\
\text { ROVE } \\
\text { ROST } \\
\text { DIUR } \\
\text { DIUR } \\
\text { DIUR }\end{array}$ & ROST & & & & & \\
\hline
\end{tabular}


Acetone Rat Teratology Study: Ran Fetel Date

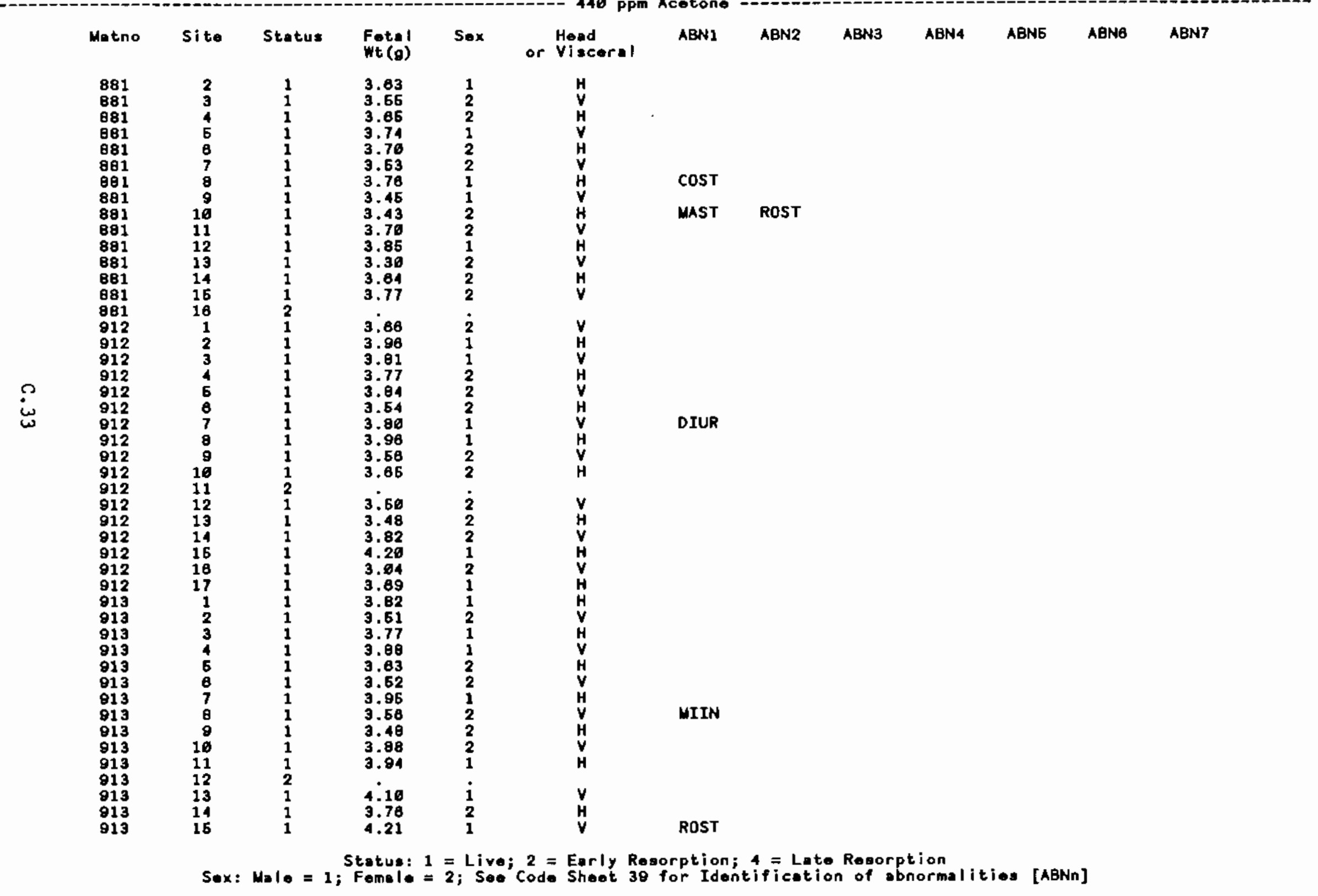


Acetone Rat Teratology Study: Rav Fotal Data

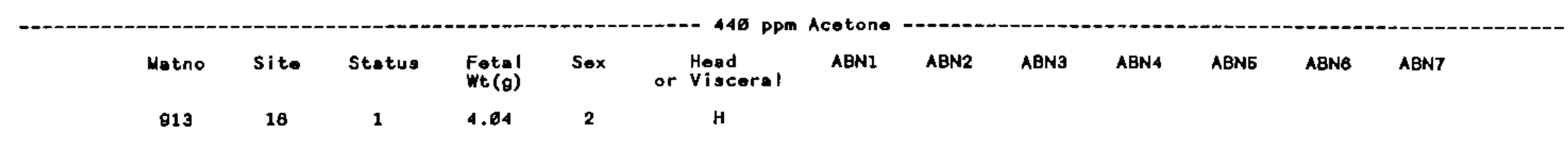


SAS

Acetone Rat Toratology Study: Raw Fotal Dato

\begin{tabular}{|c|c|c|c|c|c|c|c|c|c|c|c|c|}
\hline Matno & site & Status & $\begin{array}{l}\text { Fetal } \\
\text { wt (g) }\end{array}$ & Sex & $\begin{array}{l}\text { Head } \\
\text { or Visceral }\end{array}$ & ABN1 & ABN2 & ABN3 & ABN4 & ABN5 & ABNB & ABN7 \\
\hline $\begin{array}{l}651 \\
651 \\
651 \\
651 \\
651 \\
651 \\
651 \\
651 \\
851 \\
651 \\
651 \\
651 \\
651 \\
661 \\
651 \\
651 \\
651 \\
651 \\
655 \\
655 \\
655 \\
655 \\
665 \\
656 \\
656 \\
655 \\
656 \\
655 \\
655 \\
655 \\
655 \\
655 \\
665 \\
665 \\
655 \\
668 \\
666 \\
686 \\
668 \\
686 \\
866 \\
666 \\
688 \\
688 \\
666 \\
668 \\
688\end{array}$ & $\begin{array}{r}1 \\
2 \\
3 \\
4 \\
5 \\
6 \\
7 \\
8 \\
9 \\
16 \\
11 \\
12 \\
13 \\
14 \\
15 \\
16 \\
17 \\
18 \\
1 \\
2 \\
3 \\
4 \\
5 \\
6 \\
7 \\
8 \\
9 \\
10 \\
11 \\
12 \\
13 \\
14 \\
16 \\
18 \\
17 \\
1 \\
2 \\
3 \\
4 \\
5 \\
6 \\
7 \\
8 \\
8 \\
10 \\
11 \\
12\end{array}$ & $\begin{array}{l}1 \\
1 \\
1 \\
1 \\
1 \\
1 \\
1 \\
1 \\
1 \\
1 \\
1 \\
1 \\
1 \\
1 \\
1 \\
1 \\
1 \\
1 \\
1 \\
1 \\
1 \\
1 \\
1 \\
1 \\
1 \\
1 \\
1 \\
2 \\
1 \\
1 \\
1 \\
1 \\
1 \\
1 \\
1 \\
1 \\
1 \\
1 \\
1 \\
1 \\
1 \\
1 \\
1 \\
1 \\
1 \\
1\end{array}$ & $\begin{array}{l}2.79 \\
3.02 \\
2.70 \\
3.60 \\
3.34 \\
3.27 \\
3.82 \\
3.37 \\
3.21 \\
3.08 \\
3.30 \\
3.02 \\
3.16 \\
3.24 \\
3.32 \\
3.06 \\
2.92 \\
3.07 \\
3.52 \\
3.98 \\
2.97 \\
3.31 \\
3.38 \\
3.86 \\
3.64 \\
3.16 \\
3.25 \\
3.37 \\
3.23 \\
3.60 \\
3.19 \\
3.14 \\
3.62 \\
3.43 \\
2.69 \\
2.99 \\
3.36 \\
3.11 \\
3.37 \\
3.15 \\
3.43 \\
3.16 \\
3.48 \\
3.60 \\
3.26 \\
3.45\end{array}$ & $\begin{array}{l}2 \\
2 \\
2 \\
2 \\
1 \\
1 \\
2 \\
1 \\
2 \\
1 \\
1 \\
2 \\
1 \\
1 \\
2 \\
2 \\
2 \\
2 \\
1 \\
1 \\
2 \\
1 \\
1 \\
2 \\
1 \\
1 \\
1 \\
2 \\
2 \\
1 \\
2 \\
2 \\
1 \\
2 \\
1 \\
1 \\
2 \\
2 \\
1 \\
1 \\
1 \\
2 \\
1 \\
2 \\
2 \\
1\end{array}$ & 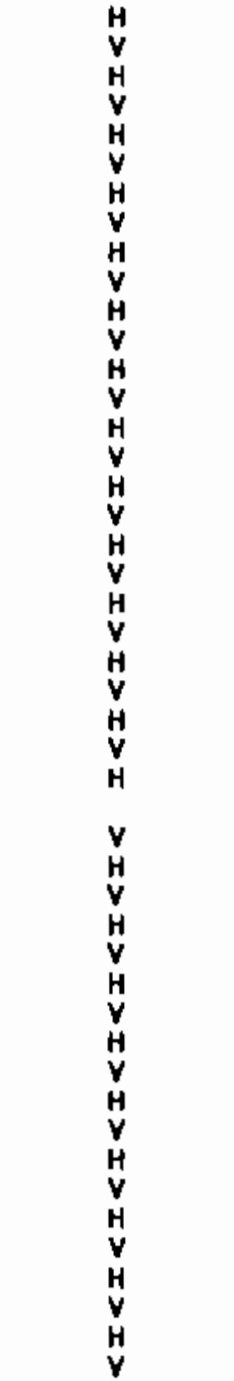 & $\begin{array}{l}\text { SURB } \\
\text { ROST } \\
\text { SURB } \\
\text { SURB } \\
\text { SURB } \\
\text { SURB } \\
\text { SURB } \\
\text { SURB } \\
\text { ROSK } \\
\text { ROST } \\
\text { ROST } \\
\text { ROST } \\
\text { ROST }\end{array}$ & ROST & 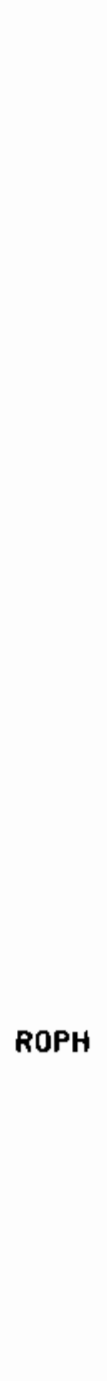 & & & & \\
\hline
\end{tabular}


Acotone Rat Teratology Study: Raw Fotal Date

\begin{tabular}{|c|c|c|c|c|c|c|c|c|c|c|c|c|c|}
\hline & Metno & site & Status & $\begin{array}{l}\text { Fetal } \\
\text { Wt (g) }\end{array}$ & Sex & $\begin{array}{l}\text { Head } \\
\text { or Visceral }\end{array}$ & ABN1 & ABN2 & ABN3 & ABN4 & ABN5 & ABNB & ABN7 \\
\hline i & 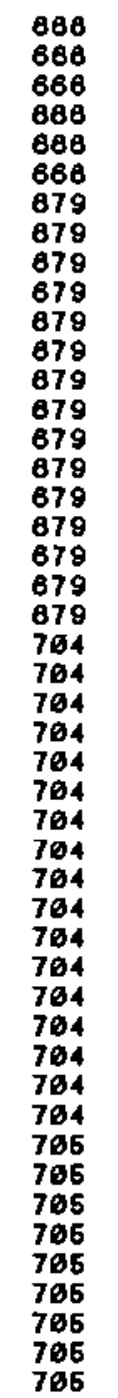 & $\begin{array}{r}13 \\
14 \\
15 \\
18 \\
17 \\
18 \\
1 \\
2 \\
3 \\
4 \\
6 \\
6 \\
7 \\
8 \\
9 \\
16 \\
11 \\
12 \\
13 \\
14 \\
15 \\
1 \\
2 \\
3 \\
4 \\
6 \\
6 \\
7 \\
8 \\
9 \\
10 \\
11 \\
12 \\
13 \\
14 \\
15 \\
16 \\
17 \\
1 \\
2 \\
3 \\
4 \\
6 \\
6 \\
7 \\
8 \\
9\end{array}$ & $\begin{array}{l}1 \\
1 \\
1 \\
1 \\
1 \\
1 \\
1 \\
1 \\
1 \\
2 \\
1 \\
1 \\
1 \\
1 \\
1 \\
1 \\
1 \\
1 \\
1 \\
1 \\
1 \\
1 \\
2 \\
1 \\
1 \\
2 \\
2 \\
1 \\
1 \\
1 \\
1 \\
1 \\
1 \\
1 \\
1 \\
1 \\
1 \\
1 \\
1 \\
1 \\
1 \\
1 \\
1 \\
2 \\
1 \\
1 \\
1\end{array}$ & $\begin{array}{l}3.19 \\
3.18 \\
3.86 \\
3.68 \\
3.38 \\
3.88 \\
3.14 \\
3.58 \\
3.16 \\
3.59 \\
3.89 \\
3.78 \\
3.41 \\
3.48 \\
3.70 \\
3.69 \\
3.62 \\
3.89 \\
3.91 \\
3.62 \\
3.04 \\
3.64 \\
3.39 \\
.5 \\
3.64 \\
3.49 \\
3.31 \\
3.41 \\
3.31 \\
3.34 \\
3.14 \\
3.26 \\
3.54 \\
3.46 \\
2.44 \\
3.74 \\
3.86 \\
3.76 \\
4.84 \\
3.54 \\
3.40 \\
3.91 \\
4.08\end{array}$ & $\begin{array}{l}1 \\
2 \\
1 \\
2 \\
2 \\
2 \\
1 \\
2 \\
2 \\
\dot{2} \\
1 \\
1 \\
1 \\
2 \\
1 \\
1 \\
2 \\
1 \\
1 \\
2 \\
2 \\
1 \\
2 \\
2 \\
i \\
1 \\
2 \\
1 \\
2 \\
2 \\
2 \\
2 \\
2 \\
2 \\
1 \\
1 \\
1 \\
1 \\
2 \\
1 \\
1\end{array}$ & 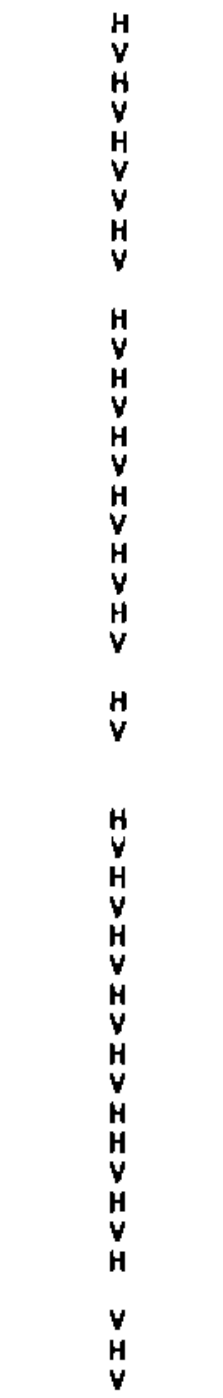 & $\begin{array}{l}\text { SURB } \\
\text { ROST } \\
\text { ROST } \\
\text { ROPB } \\
\text { ROPB } \\
\text { ROST }\end{array}$ & MAST & & & & & \\
\hline
\end{tabular}


Acetone Rat Toratology Study: Row Fotal Dote

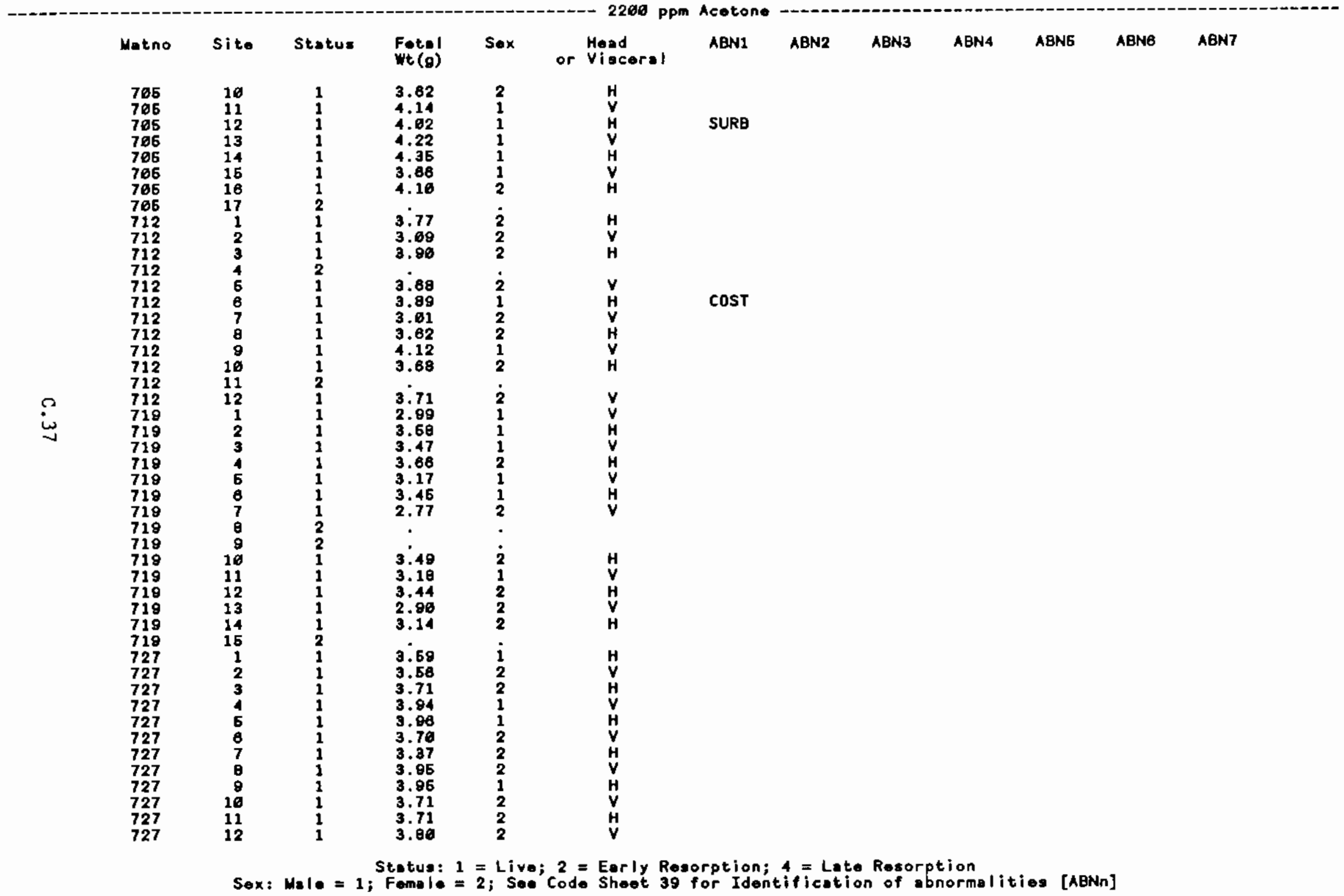


Acetono Rot Teratology Study: Raw Fetal Data

\begin{tabular}{|c|c|c|c|c|c|c|c|c|c|c|c|c|c|c|}
\hline & Matno & site & Status & $\begin{array}{l}\text { Fotel } \\
\text { wt (g) }\end{array}$ & Sex & or & $\begin{array}{l}\text { Head } \\
\text { visceral }\end{array}$ & ABN1 & ABN2 & ABN3 & ABN4 & ABN5 & ABNB & $A B N 7$ \\
\hline$\stackrel{?}{\omega}$ & $\begin{array}{l}727 \\
727 \\
727 \\
727 \\
727 \\
727 \\
727 \\
727 \\
734 \\
734 \\
734 \\
734 \\
734 \\
734 \\
734 \\
734 \\
734 \\
734 \\
734 \\
734 \\
734 \\
734 \\
736 \\
736 \\
735 \\
735 \\
735 \\
736 \\
736 \\
736 \\
736 \\
735 \\
735 \\
736 \\
736 \\
736 \\
736 \\
736 \\
736 \\
736 \\
736 \\
736 \\
736 \\
736 \\
736 \\
736 \\
736\end{array}$ & $\begin{array}{r}13 \\
14 \\
16 \\
16 \\
17 \\
18 \\
19 \\
26 \\
1 \\
2 \\
3 \\
4 \\
6 \\
8 \\
7 \\
8 \\
9 \\
16 \\
11 \\
12 \\
13 \\
14 \\
1 \\
2 \\
3 \\
4 \\
5 \\
6 \\
7 \\
9 \\
9 \\
16 \\
11 \\
12 \\
13 \\
14 \\
16 \\
16 \\
17 \\
1 \\
2 \\
3 \\
4 \\
6 \\
6 \\
7 \\
9\end{array}$ & $\begin{array}{l}1 \\
1 \\
1 \\
1 \\
1 \\
1 \\
1 \\
2 \\
2 \\
2 \\
2 \\
1 \\
2 \\
2 \\
1 \\
1 \\
1 \\
2 \\
2 \\
2 \\
1 \\
2 \\
1 \\
1 \\
1 \\
1 \\
1 \\
1 \\
1 \\
1 \\
1 \\
1 \\
1 \\
1 \\
1 \\
1 \\
1 \\
1 \\
1 \\
1 \\
1 \\
1 \\
1 \\
1 \\
1 \\
1 \\
1\end{array}$ & $\begin{array}{c}3.71 \\
3.96 \\
3.74 \\
3.99 \\
4.16 \\
1.69 \\
4.36 \\
: \\
: \\
4.63 \\
: . \\
2.62 \\
3.74 \\
2.72 \\
: \\
: . \\
3.68 \\
3.31 \\
2.63 \\
3.61 \\
3.43 \\
3.77 \\
3.91 \\
3.62 \\
3.44 \\
3.68 \\
3.39 \\
3.16 \\
3.66 \\
3.26 \\
3.56 \\
3.62 \\
3.14 \\
3.54 \\
3.68 \\
3.76 \\
3.63 \\
3.62 \\
3.65 \\
3.82 \\
3.19 \\
3.29\end{array}$ & $\begin{array}{l}2 \\
1 \\
2 \\
1 \\
1 \\
2 \\
1 \\
: \\
: \\
i \\
: \\
2 \\
1 \\
1 \\
: \\
\vdots \\
i \\
i \\
1 \\
2 \\
2 \\
1 \\
1 \\
2 \\
1 \\
2 \\
1 \\
2 \\
2 \\
1 \\
1 \\
2 \\
2 \\
1 \\
2 \\
1 \\
2 \\
1 \\
1 \\
2 \\
1\end{array}$ & & $\begin{array}{l}H \\
Y \\
V \\
H \\
V \\
H \\
V \\
H \\
V \\
H \\
V \\
H \\
V \\
H \\
V \\
H \\
V \\
H \\
V \\
V \\
H \\
V \\
H \\
V \\
H \\
V \\
H \\
V\end{array}$ & $\begin{array}{l}\text { SURB } \\
\text { ROST } \\
\text { SUR日 } \\
\text { ROST } \\
\text { ROST } \\
\text { RORB } \\
\text { COST } \\
\text { SURB }\end{array}$ & ROPB & & & & & \\
\hline
\end{tabular}


Acetone Rat Terotology Study: Raw Fotel Data

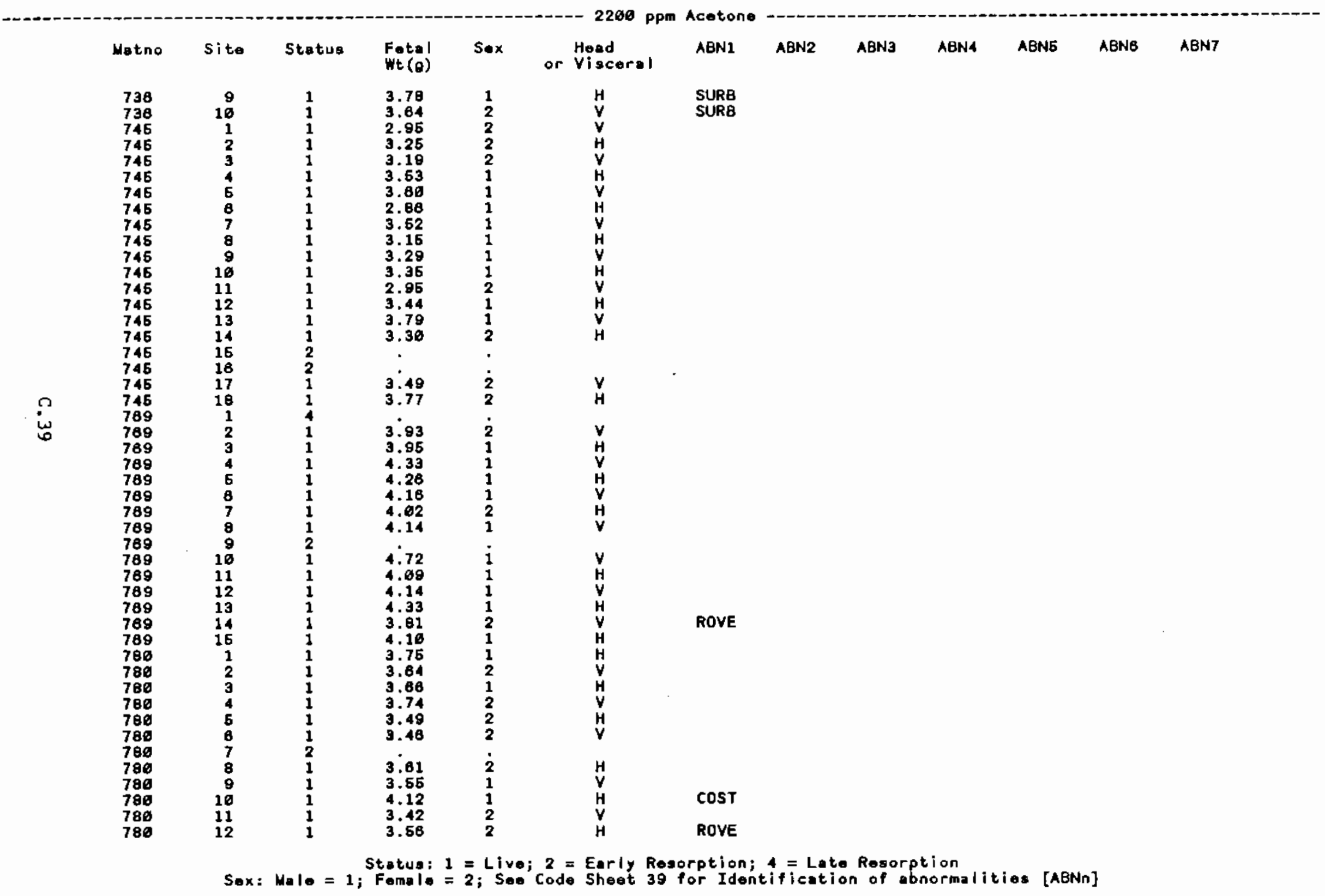


Acetone Ret Teratology Study: Raw Fotel Data

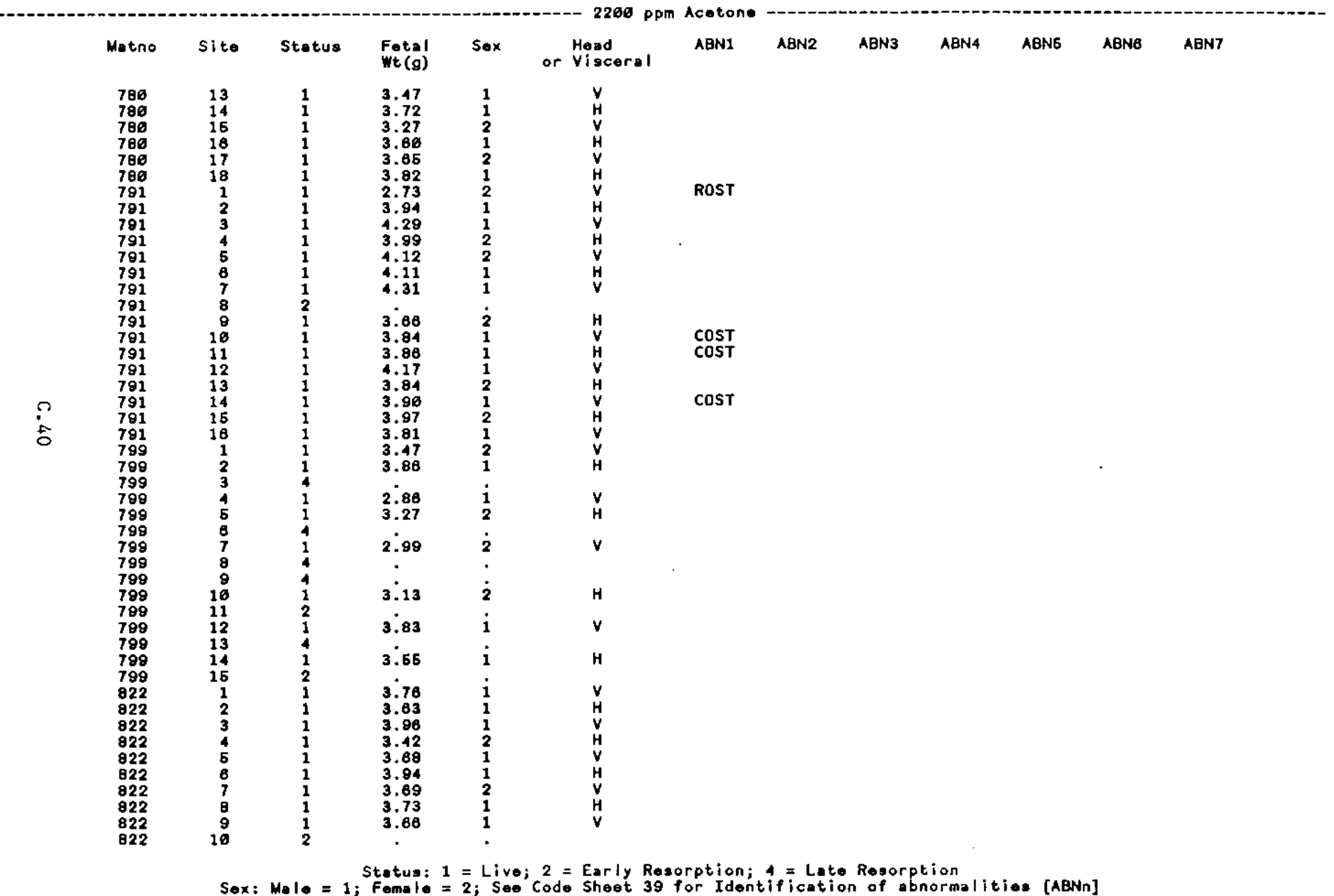

Sex: Mole = 1; Female = 2; See Code Sheet 39 for Identification of abnormalitios [ABNn] 
Acetone Rat Teratology Study: Raw Fetal Data

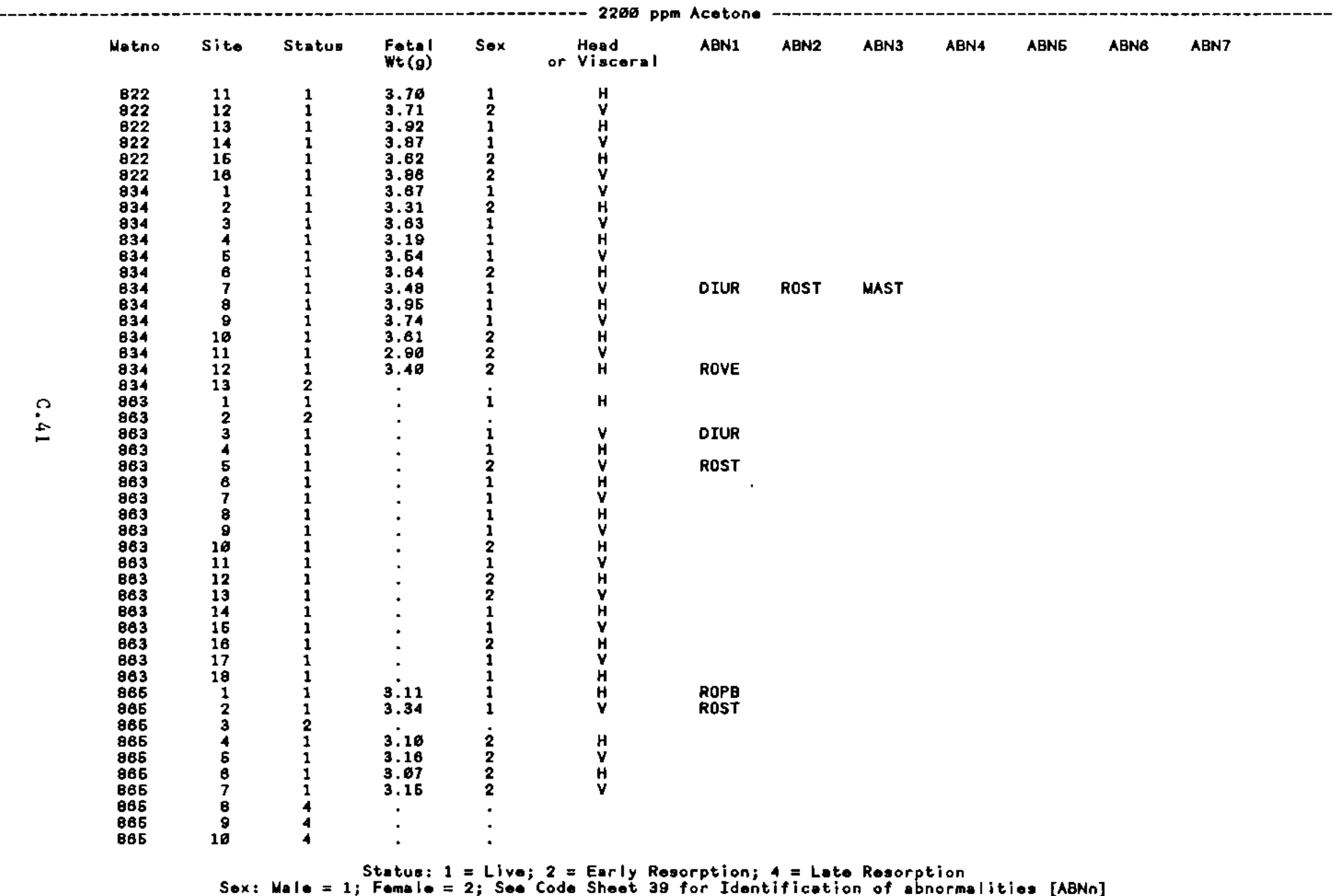


Acotone Rat Terotology Study: Raw Fotal Dete

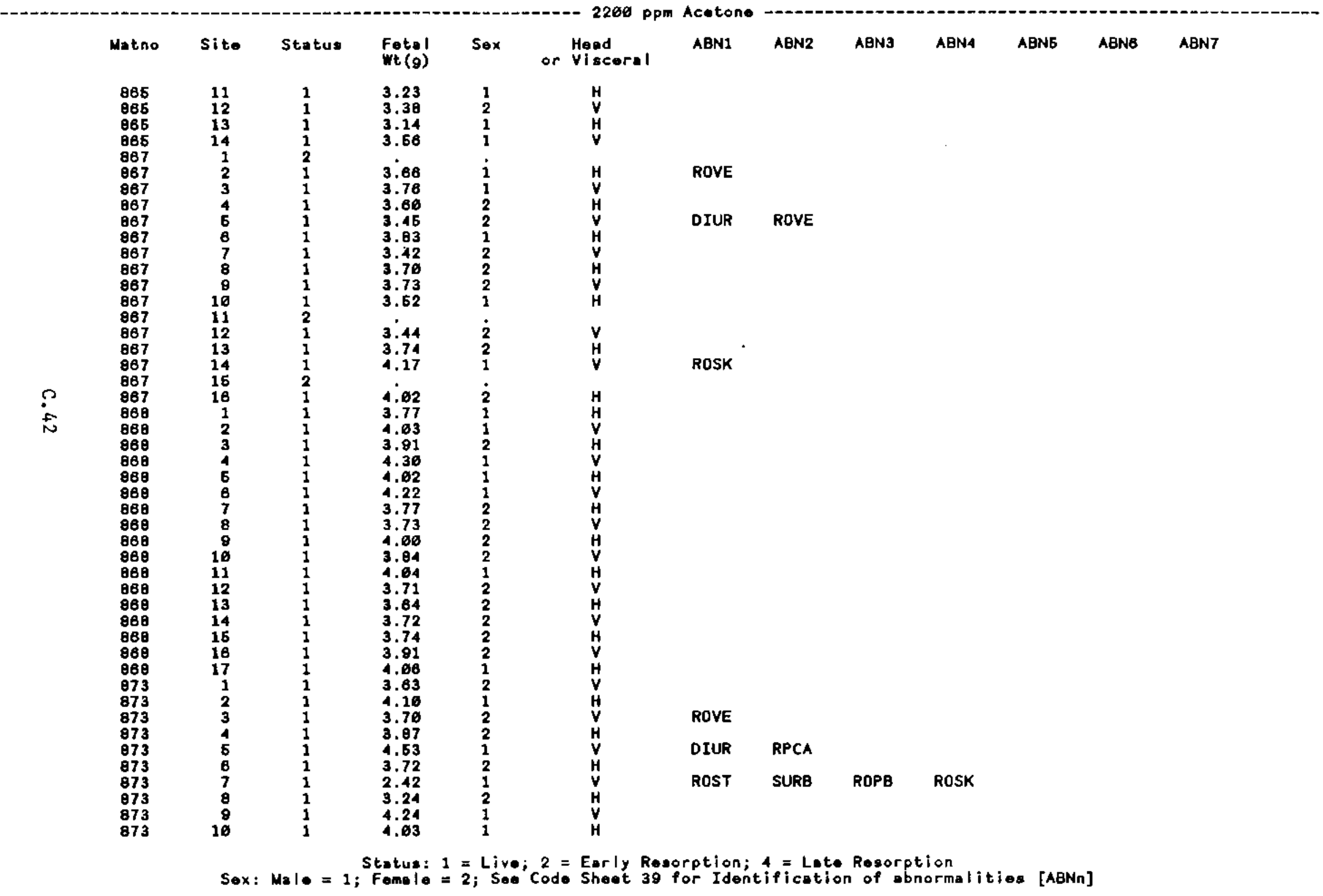


Acetone Rat Teretology Study: Raw Fotal Data

\begin{tabular}{|c|c|c|c|c|c|c|c|c|c|c|c|c|c|c|}
\hline & Metno & site & Status & $\begin{array}{l}\text { Fetal } \\
\text { Wt (g) }\end{array}$ & $S=x$ & or & $\begin{array}{l}\text { Head } \\
\text { viscerel }\end{array}$ & ABNI & ABN2 & ABN3 & ABN4 & ABNE & ABNO & AEN7 \\
\hline $\begin{array}{l}\Omega \\
\stackrel{\omega}{\omega}\end{array}$ & $\begin{array}{l}873 \\
873 \\
873 \\
873 \\
673 \\
879 \\
679 \\
879 \\
879 \\
879 \\
879 \\
879 \\
879 \\
879 \\
879 \\
879 \\
679 \\
879 \\
879 \\
879 \\
888 \\
888 \\
888 \\
888 \\
688 \\
888 \\
688 \\
888 \\
686 \\
689 \\
888 \\
888 \\
888 \\
888 \\
888 \\
888 \\
891 \\
891 \\
891 \\
691 \\
891 \\
891 \\
891 \\
891 \\
891 \\
891 \\
891\end{array}$ & 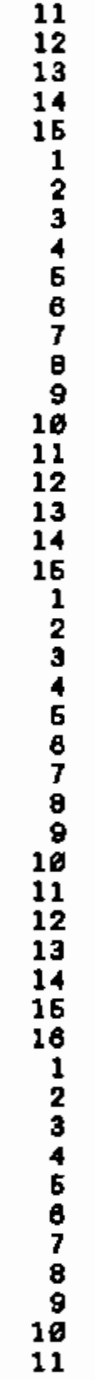 & $\begin{array}{l}1 \\
1 \\
1 \\
1 \\
1 \\
1 \\
1 \\
1 \\
1 \\
1 \\
1 \\
1 \\
1 \\
1 \\
1 \\
1 \\
1 \\
1 \\
1 \\
1 \\
1 \\
1 \\
1 \\
1 \\
1 \\
2 \\
1 \\
1 \\
1 \\
1 \\
1 \\
1 \\
1 \\
1 \\
1 \\
1 \\
1 \\
1 \\
1 \\
1 \\
1 \\
1 \\
1 \\
1 \\
1 \\
1 \\
1\end{array}$ & $\begin{array}{l}4.22 \\
4.07 \\
4.67 \\
3.73 \\
4.61 \\
3.48 \\
3.91 \\
3.46 \\
3.77 \\
3.69 \\
3.66 \\
3.62 \\
3.66 \\
3.72 \\
3.32 \\
2.97 \\
3.75 \\
3.56 \\
3.36 \\
3.94 \\
3.61 \\
3.68 \\
3.77 \\
3.41 \\
3.82 \\
3.39 \\
3.58 \\
3.68 \\
3.67 \\
3.65 \\
3.72 \\
3.36 \\
3.51 \\
3.84 \\
3.63 \\
3.14 \\
3.25 \\
3.16 \\
3.25 \\
3.16 \\
3.48 \\
3.56 \\
3.64 \\
3.36 \\
3.39 \\
3.65\end{array}$ & 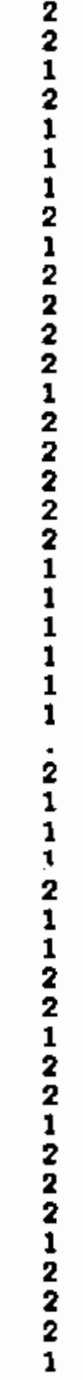 & & 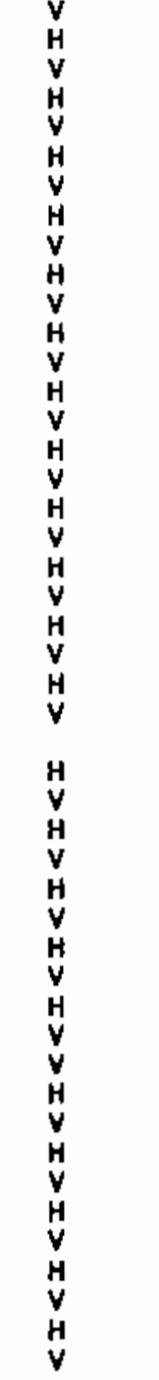 & $\begin{array}{l}\text { DIUR } \\
\text { ROST } \\
\text { ROVE } \\
\text { ROST }\end{array}$ & & & & & & \\
\hline
\end{tabular}


Acetone Rot Teratology Study: Raw Fetel Data

\begin{tabular}{|c|c|c|c|c|c|c|c|c|c|c|c|c|c|}
\hline & Matno & site & Status & $\begin{array}{l}\text { Fotel } \\
W t(\theta)\end{array}$ & Sex & $\begin{array}{l}\text { Head } \\
\text { or Viscerel }\end{array}$ & ABN1 & ABN2 & ABN3 & ABN4 & ABN6 & $A B N B$ & ABN7 \\
\hline$\stackrel{8}{\&}$ & $\begin{array}{l}908 \\
908 \\
908 \\
908 \\
908 \\
908 \\
908 \\
908 \\
908 \\
908 \\
908 \\
908 \\
908 \\
908 \\
908 \\
968 \\
916 \\
916 \\
910 \\
916 \\
910 \\
910 \\
916 \\
910 \\
916 \\
910 \\
916 \\
916 \\
910 \\
916 \\
910\end{array}$ & $\begin{array}{r}1 \\
2 \\
3 \\
4 \\
6 \\
8 \\
7 \\
8 \\
9 \\
16 \\
11 \\
12 \\
13 \\
14 \\
15 \\
16 \\
1 \\
2 \\
3 \\
4 \\
5 \\
6 \\
7 \\
6 \\
9 \\
16 \\
11 \\
12 \\
13 \\
14 \\
16\end{array}$ & $\begin{array}{l}1 \\
1 \\
1 \\
1 \\
1 \\
1 \\
1 \\
1 \\
1 \\
1 \\
1 \\
1 \\
1 \\
1 \\
1 \\
1 \\
1 \\
1 \\
2 \\
1 \\
1 \\
1 \\
1 \\
1 \\
1 \\
1 \\
1 \\
1 \\
1 \\
1 \\
1\end{array}$ & $\begin{array}{l}3.37 \\
3.38 \\
3.46 \\
3.66 \\
3.64 \\
3.76 \\
3.36 \\
3.69 \\
3.52 \\
3.68 \\
3.98 \\
3.46 \\
3.69 \\
2.97 \\
3.28 \\
3.24 \\
3.32 \\
2.96 \\
3.82 \\
3.48 \\
3.86 \\
3.41 \\
3.49 \\
3.17 \\
2.86 \\
3.29 \\
3.94 \\
3.39 \\
3.32 \\
3.68\end{array}$ & $\begin{array}{l}2 \\
2 \\
2 \\
1 \\
1 \\
1 \\
1 \\
2 \\
1 \\
2 \\
1 \\
2 \\
2 \\
1 \\
2 \\
2 \\
2 \\
2 \\
i \\
1 \\
1 \\
2 \\
2 \\
1 \\
2 \\
2 \\
1 \\
2 \\
2 \\
2\end{array}$ & $\begin{array}{l}H \\
V \\
H \\
V \\
H \\
V \\
H \\
V \\
H \\
V \\
H \\
V \\
H \\
V \\
H \\
V \\
H \\
V \\
H \\
H \\
V \\
H \\
V \\
H \\
V \\
H \\
V \\
H \\
V \\
H \\
V\end{array}$ & $\begin{array}{l}\text { ROST } \\
\text { ROSK } \\
\text { RORB } \\
\text { ROST }\end{array}$ & SURB & ROST & & & & \\
\hline
\end{tabular}


Acotone Ret Teratology Study: Raw Fotal Dete

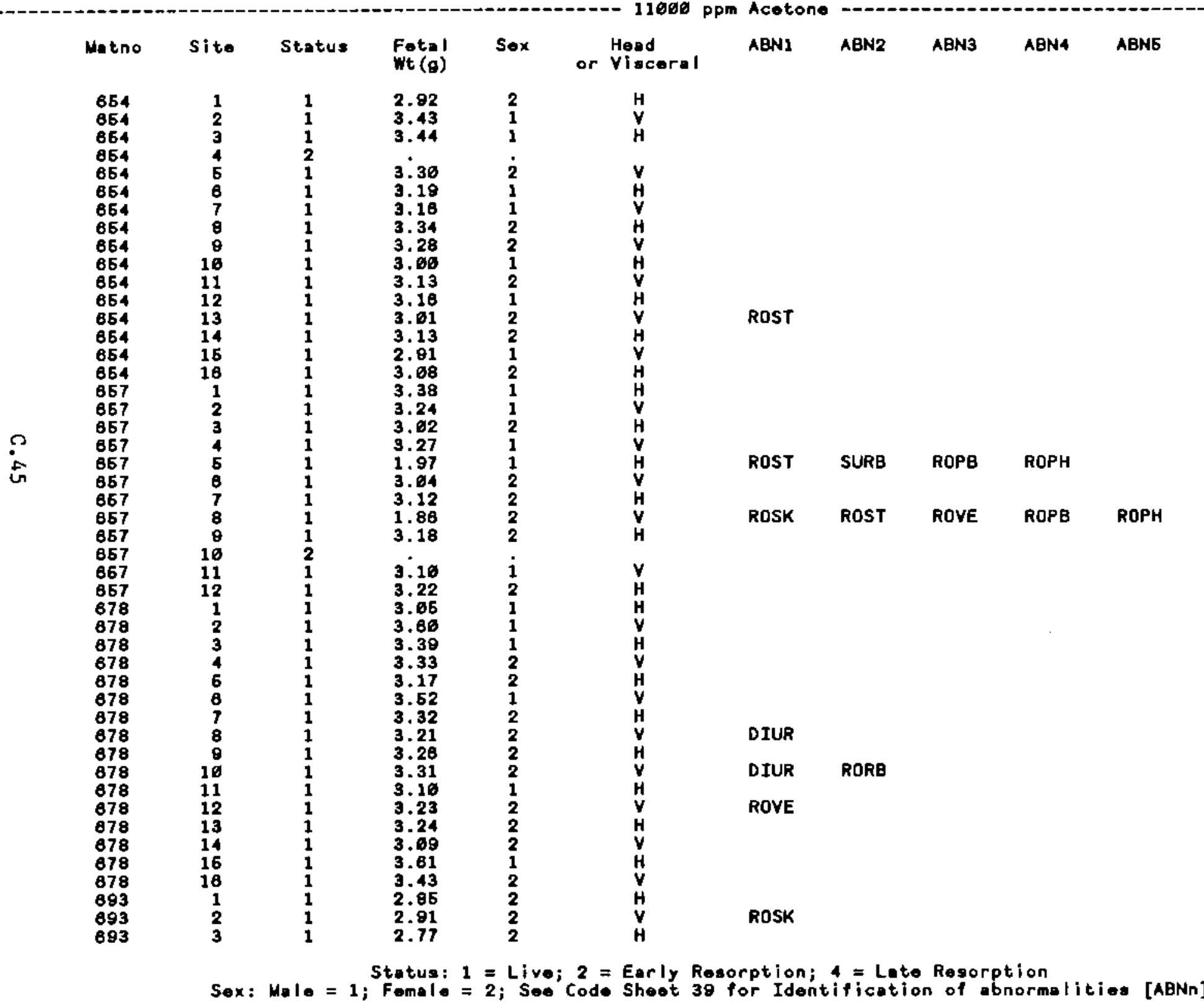


Acetone Rat Toratology Study: Row Fetal Dota

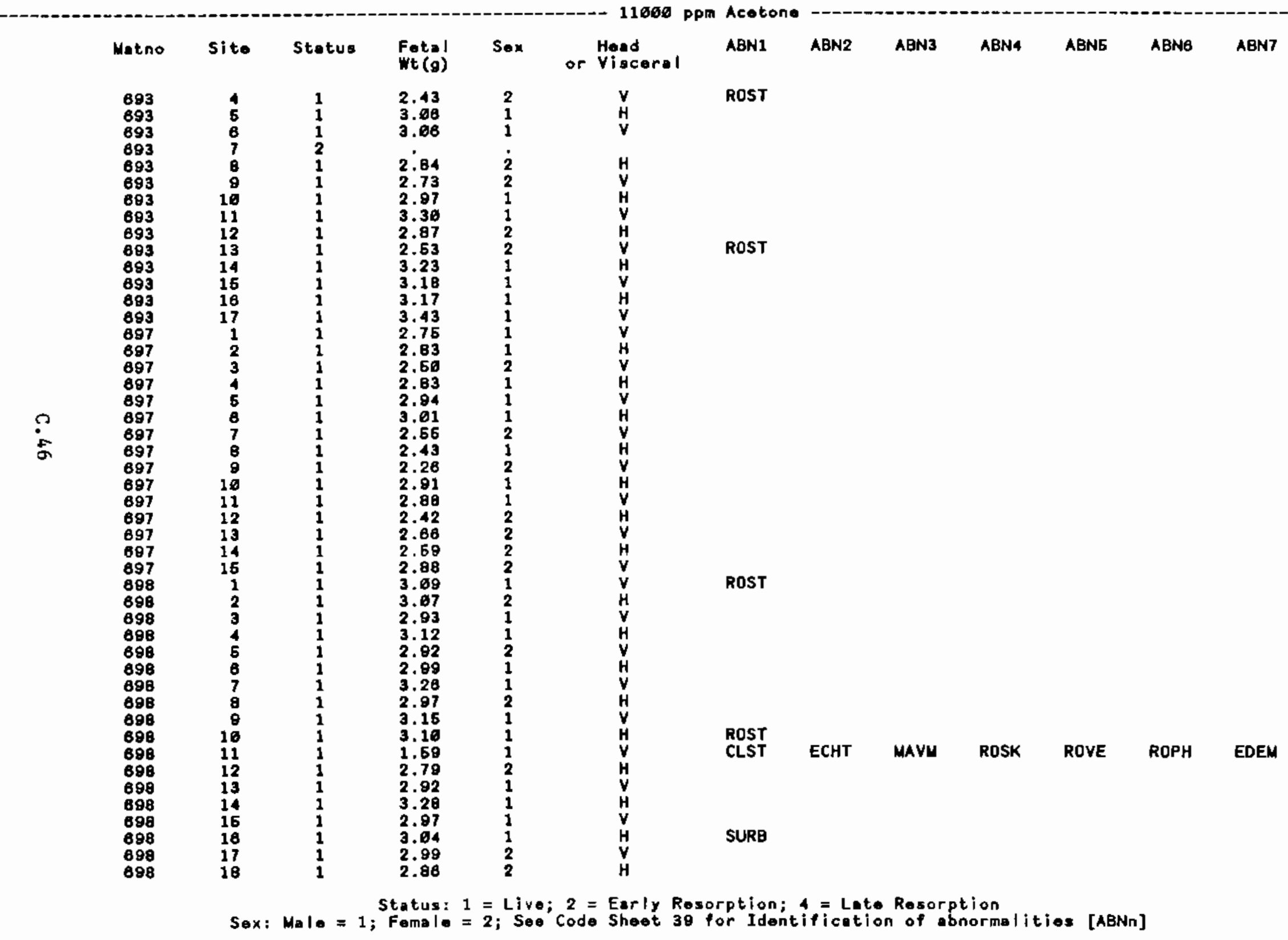


Acetone Rat Teratology Study: Rer Fotal Dete

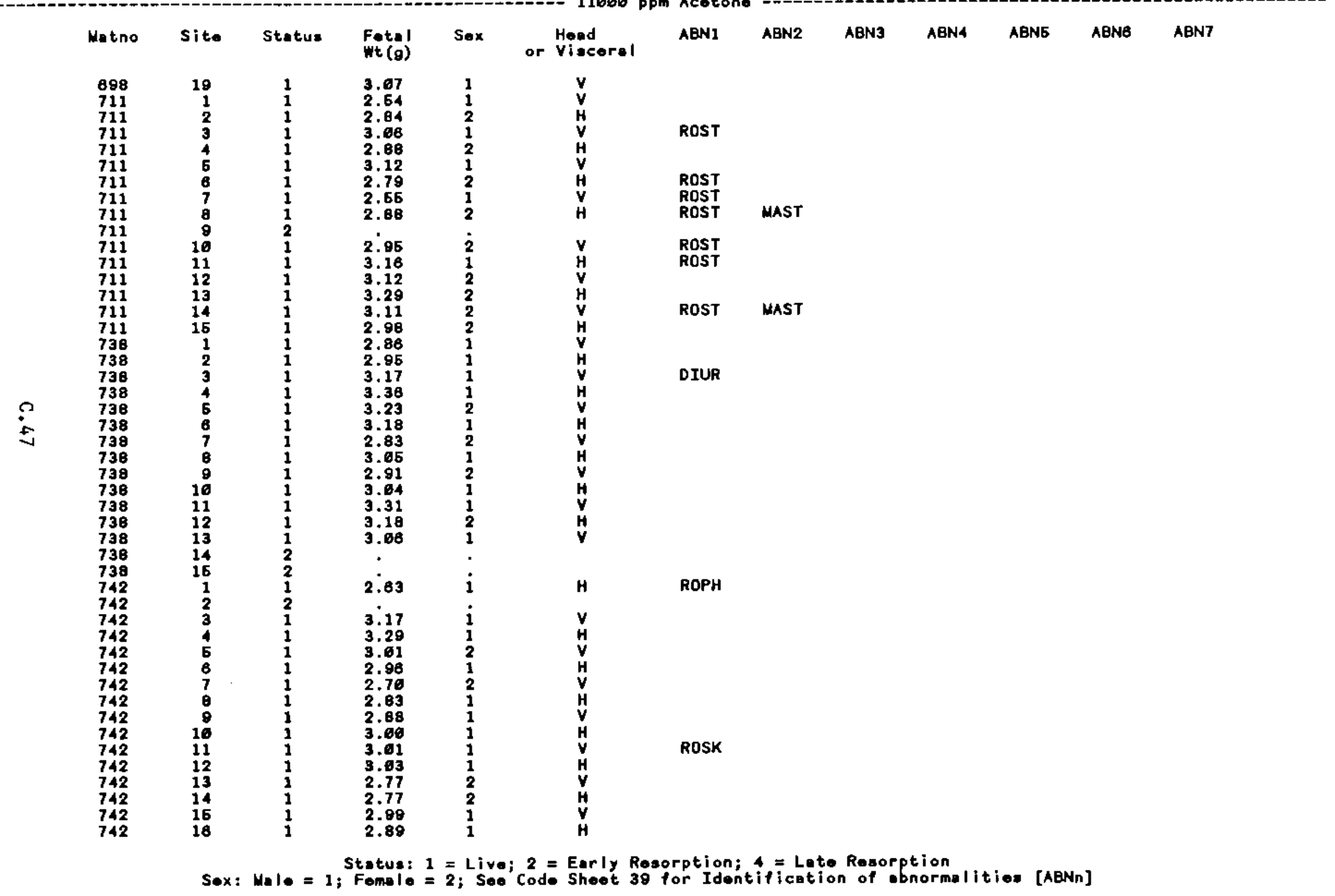


Acetone Rat Teratology Study: Raw Fotal Data

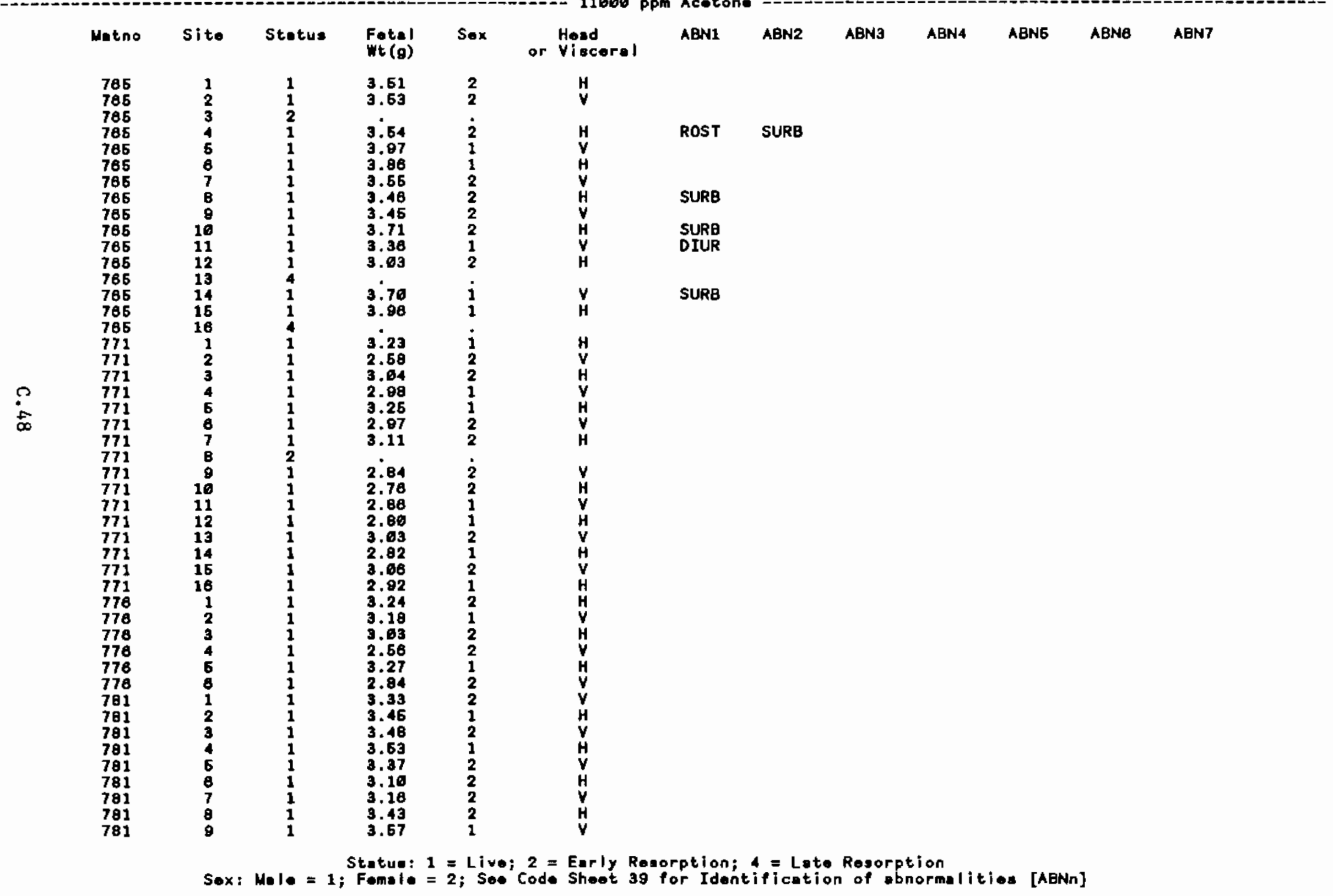


Acetone Ret Terstology Study: Rew Fotel Date

\begin{tabular}{|c|c|c|c|c|c|c|c|c|c|c|c|c|c|}
\hline & Matno & site & Stetus & $\begin{array}{l}\text { Fotel } \\
\text { wt }(g)\end{array}$ & Sex & $\begin{array}{l}\text { Heod } \\
\text { or Viscerel }\end{array}$ & ABN1 & ABN2 & $A B N 3$ & $A B N_{4}$ & ABNE & ABNG & ABN7 \\
\hline 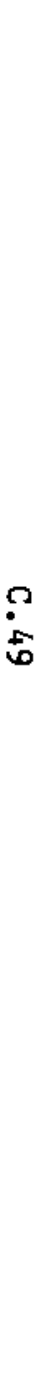 & $\begin{array}{l}781 \\
781 \\
781 \\
781 \\
781 \\
781 \\
781 \\
782 \\
782 \\
782 \\
782 \\
782 \\
782 \\
782 \\
782 \\
782 \\
782 \\
782 \\
782 \\
782 \\
782 \\
782 \\
782 \\
782 \\
817 \\
817 \\
817 \\
817 \\
817 \\
817 \\
817 \\
817 \\
817 \\
817 \\
817 \\
817 \\
617 \\
817 \\
617 \\
817 \\
819 \\
618 \\
818 \\
819 \\
816 \\
818 \\
818\end{array}$ & $\begin{array}{r}10 \\
11 \\
12 \\
13 \\
14 \\
15 \\
16 \\
1 \\
2 \\
3 \\
4 \\
5 \\
6 \\
7 \\
6 \\
8 \\
16 \\
11 \\
12 \\
13 \\
14 \\
16 \\
16 \\
17 \\
1 \\
2 \\
3 \\
4 \\
5 \\
6 \\
7 \\
8 \\
9 \\
16 \\
11 \\
12 \\
13 \\
14 \\
16 \\
16 \\
1 \\
2 \\
3 \\
4 \\
5 \\
6 \\
7\end{array}$ & $\begin{array}{l}1 \\
1 \\
1 \\
1 \\
1 \\
1 \\
2 \\
2 \\
4 \\
1 \\
1 \\
1 \\
1 \\
1 \\
2 \\
2 \\
1 \\
2 \\
1 \\
1 \\
1 \\
1 \\
1 \\
2 \\
1 \\
1 \\
1 \\
2 \\
1 \\
1 \\
1 \\
1 \\
1 \\
1 \\
1 \\
1 \\
1 \\
1 \\
1 \\
1 \\
1 \\
1 \\
1 \\
1 \\
1 \\
1 \\
1\end{array}$ & $\begin{array}{c}3.48 \\
3.38 \\
3.17 \\
3.34 \\
3.67 \\
3.48 \\
: \\
3.06 \\
2.66 \\
2.61 \\
3.22 \\
3.65 \\
. \\
2.97 \\
2.82 \\
3.61 \\
3.15 \\
3.32 \\
3.61 \\
3.19 \\
3.69 \\
3.22 \\
3.46 \\
2.94 \\
3.32 \\
2.96 \\
3.23 \\
3.32 \\
3.66 \\
2.89 \\
3.12 \\
3.34 \\
3.38 \\
3.49 \\
3.35 \\
3.69 \\
3.41 \\
3.26 \\
2.81 \\
3.26 \\
3.63\end{array}$ & $\begin{array}{l}2 \\
1 \\
2 \\
2 \\
1 \\
2 \\
: \\
\dot{2} \\
2 \\
2 \\
1 \\
1 \\
: \\
i \\
\dot{2} \\
2 \\
2 \\
1 \\
1 \\
\dot{2} \\
1 \\
2 \\
i \\
1 \\
1 \\
1 \\
1 \\
1 \\
2 \\
1 \\
1 \\
2 \\
1 \\
1 \\
1 \\
1 \\
2 \\
2 \\
1 \\
2\end{array}$ & 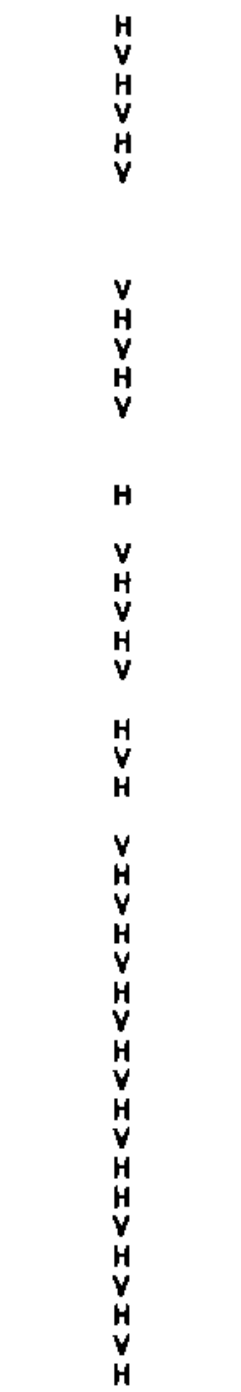 & $\begin{array}{l}\text { DIUR } \\
\text { ANUR } \\
\text { ANUR } \\
\text { ROSK } \\
\text { ROST }\end{array}$ & $\begin{array}{l}\text { SURB } \\
\text { ROVE }\end{array}$ & MIVE & SURB & & & \\
\hline
\end{tabular}


Acetone Rat Toratology Study: Rew Fotel Data

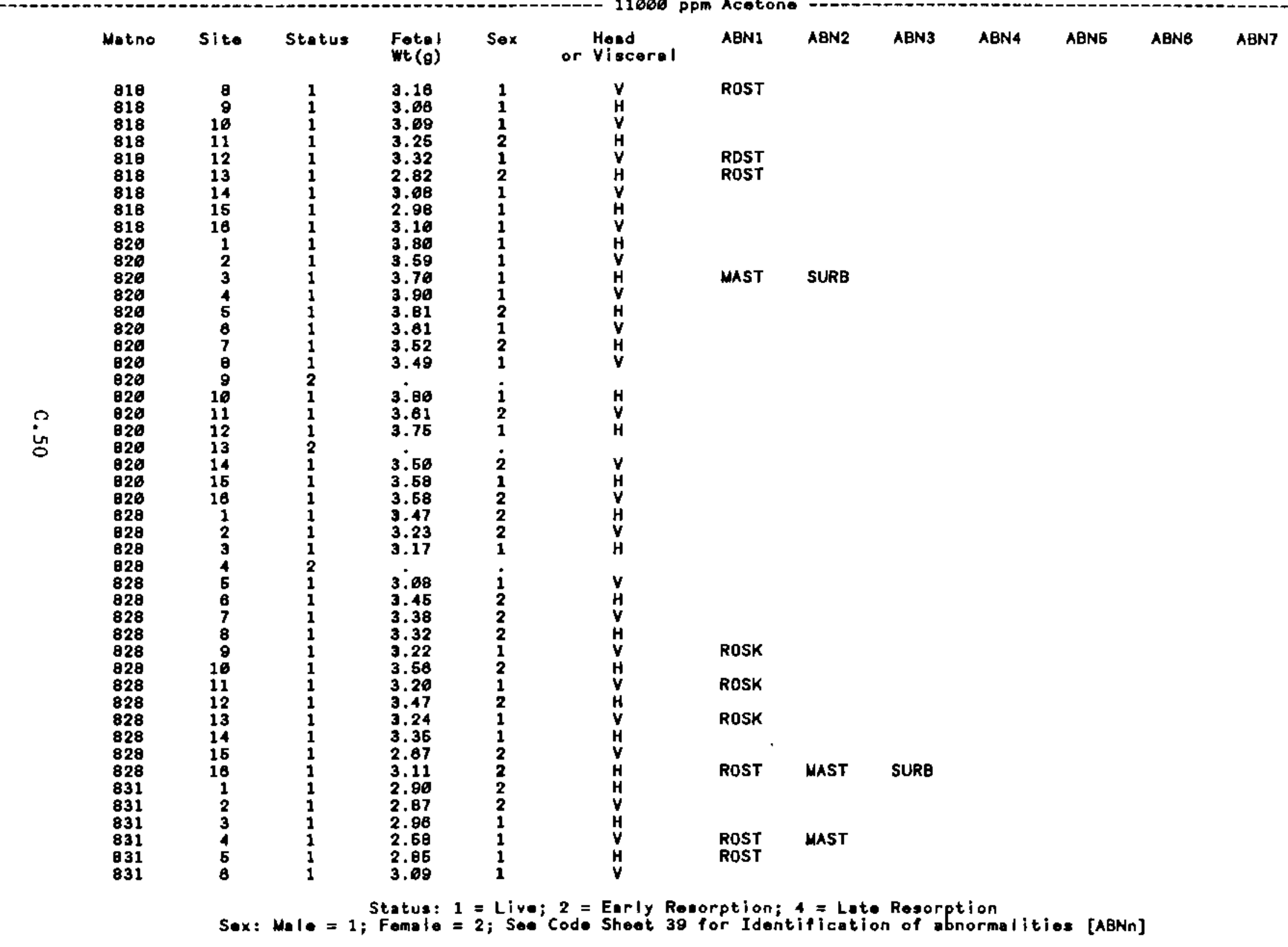


Acotone Ret Teretology Study: Row Fetel Date

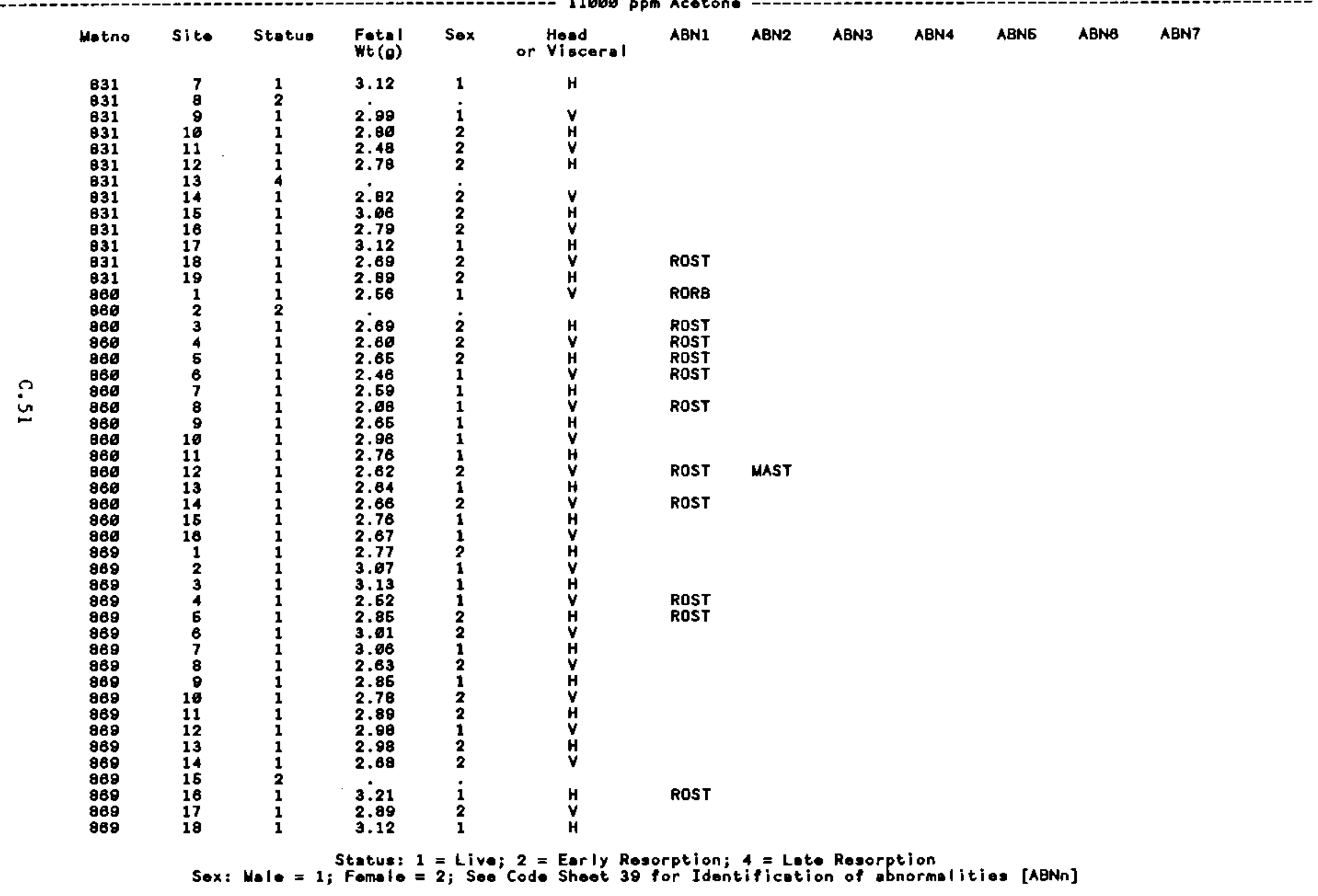


Acetone Rat Teratology Study: Raw Fotel Dote

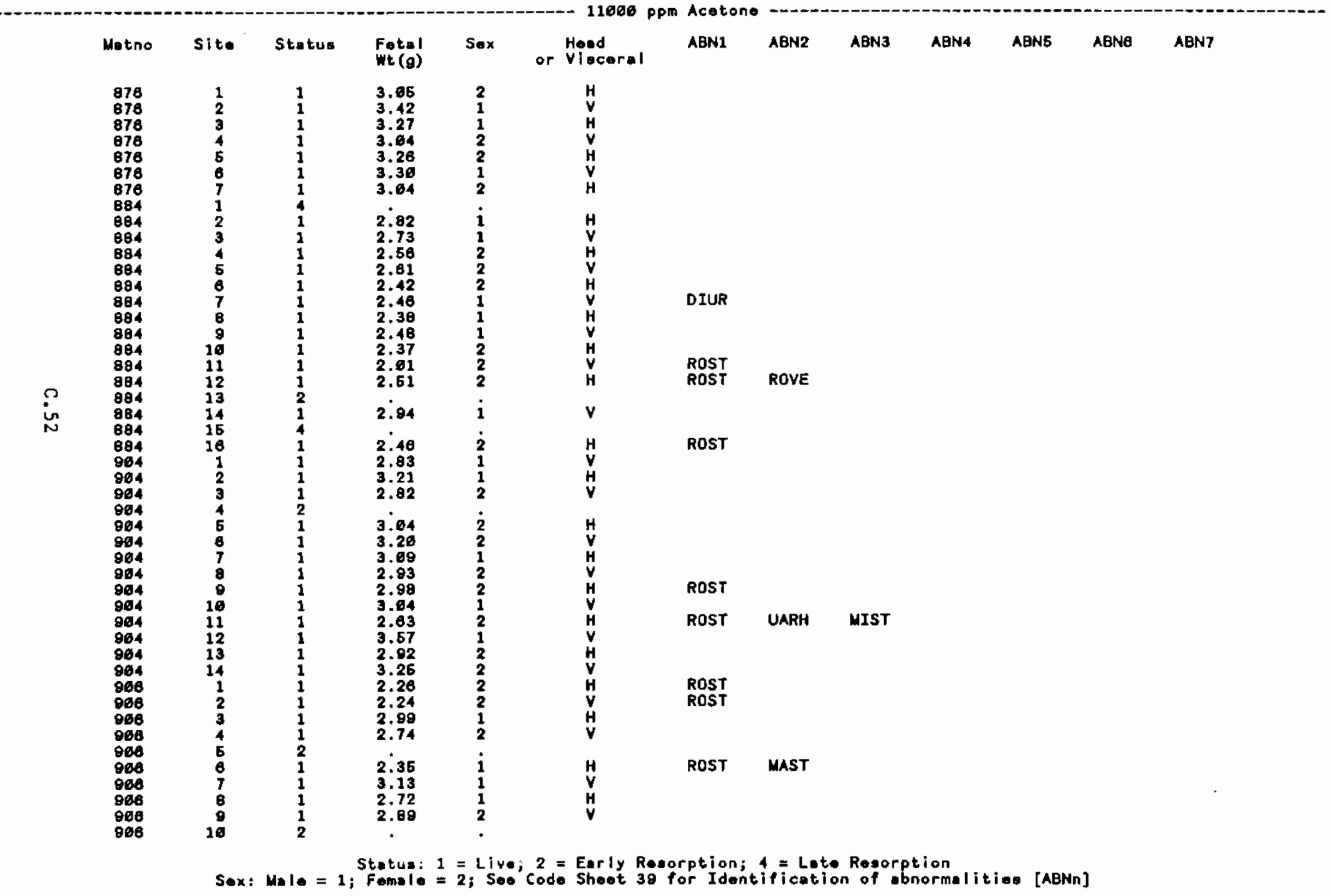


Acetone Ret Teretology Study: Rew Fetel Data

\begin{tabular}{|c|c|c|c|c|c|c|c|c|c|c|c|c|c|}
\hline & Metno & site & Status & $\begin{array}{l}\text { Fetal } \\
\text { wt (g) }\end{array}$ & Sox & $\begin{array}{l}\text { Head } \\
\text { or Viscerel }\end{array}$ & ABN1 & ABN2 & ABN3 & ABN4 & ABNG & ABNB & ABN7 \\
\hline $\begin{array}{l} \\
\vdots \\
\omega\end{array}$ & $\begin{array}{l}996 \\
906 \\
906 \\
906 \\
906 \\
906 \\
911 \\
911 \\
911 \\
911 \\
911 \\
911 \\
911 \\
911 \\
911 \\
911 \\
911 \\
911 \\
911 \\
911 \\
911 \\
911 \\
911\end{array}$ & $\begin{array}{r}11 \\
12 \\
13 \\
14 \\
16 \\
18 \\
1 \\
2 \\
3 \\
4 \\
6 \\
6 \\
7 \\
8 \\
8 \\
16 \\
11 \\
12 \\
13 \\
14 \\
15 \\
16 \\
17\end{array}$ & $\begin{array}{l}1 \\
1 \\
1 \\
1 \\
1 \\
1 \\
1 \\
1 \\
1 \\
1 \\
1 \\
1 \\
1 \\
1 \\
1 \\
1 \\
1 \\
1 \\
1 \\
1 \\
1 \\
4 \\
1\end{array}$ & $\begin{array}{l}3.19 \\
2.91 \\
3.00 \\
2.81 \\
2.82 \\
2.82 \\
3.67 \\
3.44 \\
3.68 \\
3.67 \\
3.43 \\
3.83 \\
3.41 \\
3.33 \\
3.49 \\
3.87 \\
3.64 \\
3.29 \\
2.90 \\
2.44 \\
3.41 \\
3.40\end{array}$ & $\begin{array}{l}1 \\
2 \\
1 \\
2 \\
2 \\
2 \\
1 \\
2 \\
2 \\
2 \\
2 \\
1 \\
1 \\
2 \\
1 \\
1 \\
1 \\
2 \\
2 \\
2 \\
2 \\
2 \\
2\end{array}$ & $\begin{array}{l}H \\
V \\
H \\
V \\
H \\
V \\
V \\
H \\
\mathbf{V} \\
\mathbf{H} \\
\mathbf{V} \\
\mathbf{H} \\
\mathbf{V} \\
\mathbf{H} \\
\mathbf{V} \\
\mathbf{H} \\
\mathbf{V} \\
\mathbf{H} \\
\mathbf{V} \\
\mathbf{H} \\
\mathbf{V} \\
\mathbf{H}\end{array}$ & $\begin{array}{l}\text { MIIN } \\
\text { ROST } \\
\text { DIUR } \\
\text { SURB } \\
\text { ROST }\end{array}$ & MAST & & & & & \\
\hline
\end{tabular}


Acetone Ret Teratology Study: Raw Fotal Data

Code Sheot for Identification of Fotal Abnormalitiog

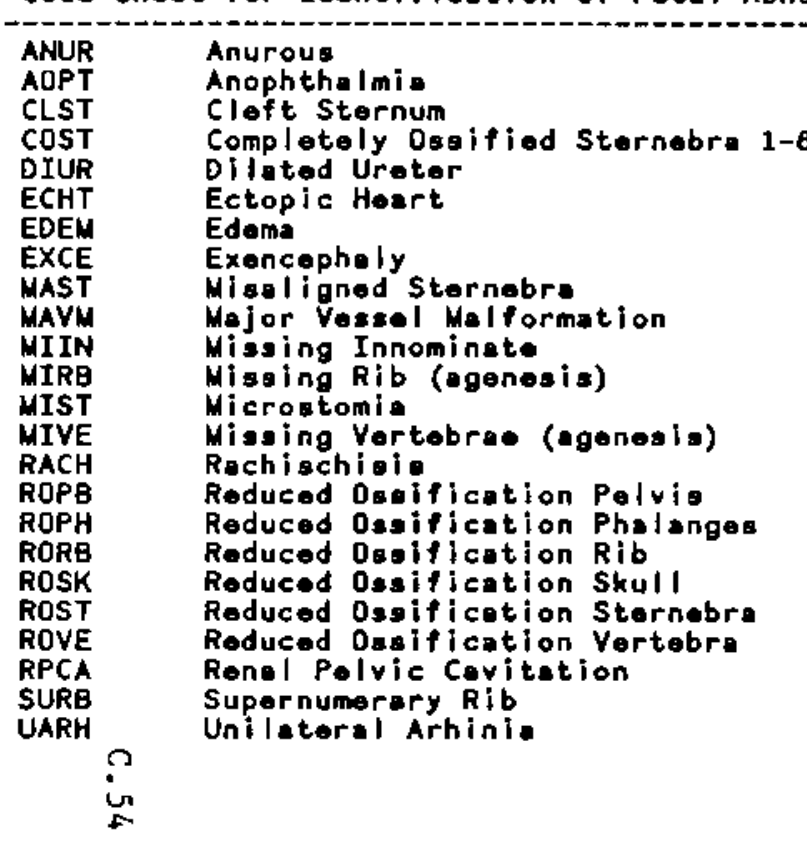


Acetone Rat Teratology Study: Calendar of Events

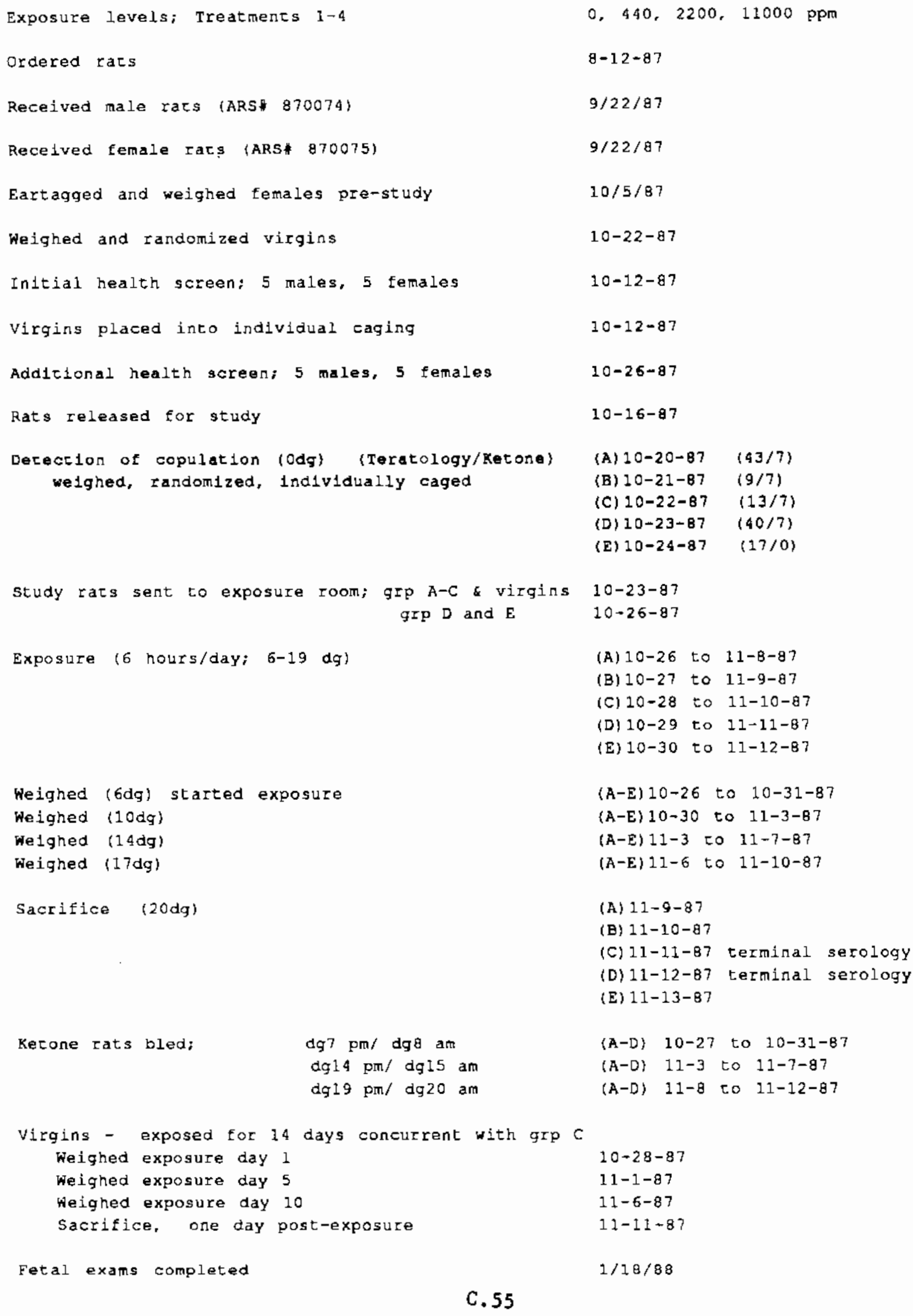


ACETONE RAT TERATOLOGY STUDY DISPOSTTION

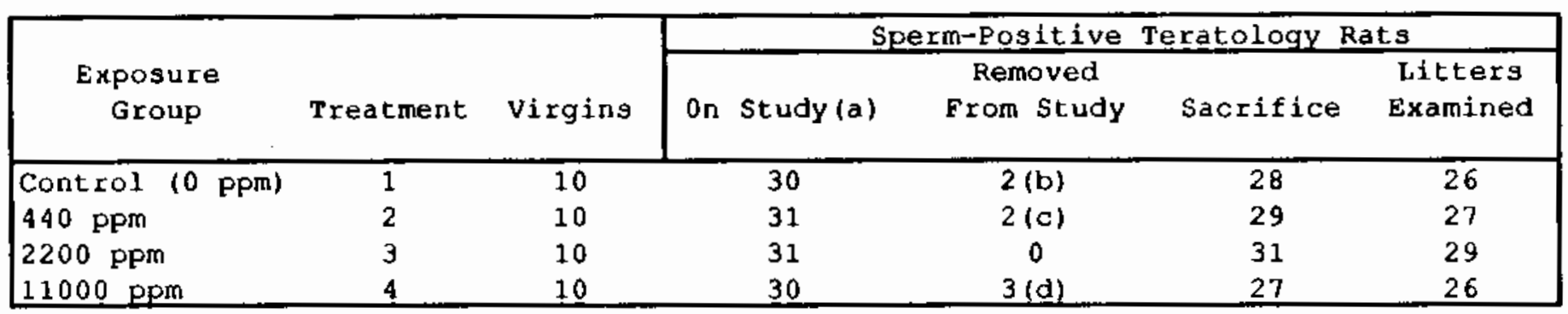

(a) The study protocol required a minimum of 30 sperm-positive females (to obtain 20 pregnant females).

(b) 1 dam - umbilical hernia

1 litter $\$ 2$ implants

(c) 1 dam - weight loss, moribund due to dental problem

1 Iitter $\leq 2$ implants

(d) 1 dam - dental problems

2 litters $\leq 2$ implants

ACETONE RAT TERATOLOGY (KETONE) STUDY DISPOSITION

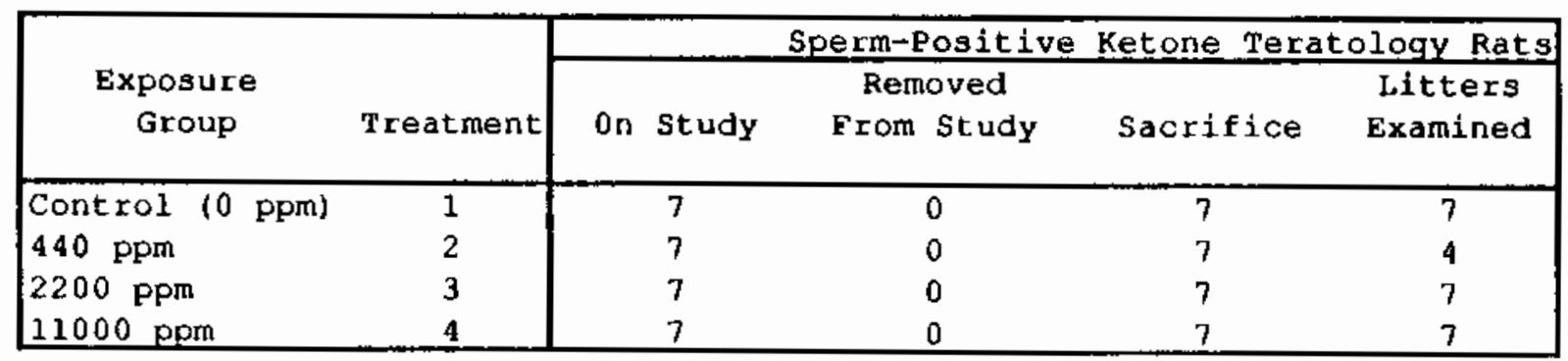


Acetone Mouse Teratology Study: Body Woight: (g) for Virgin Femeles

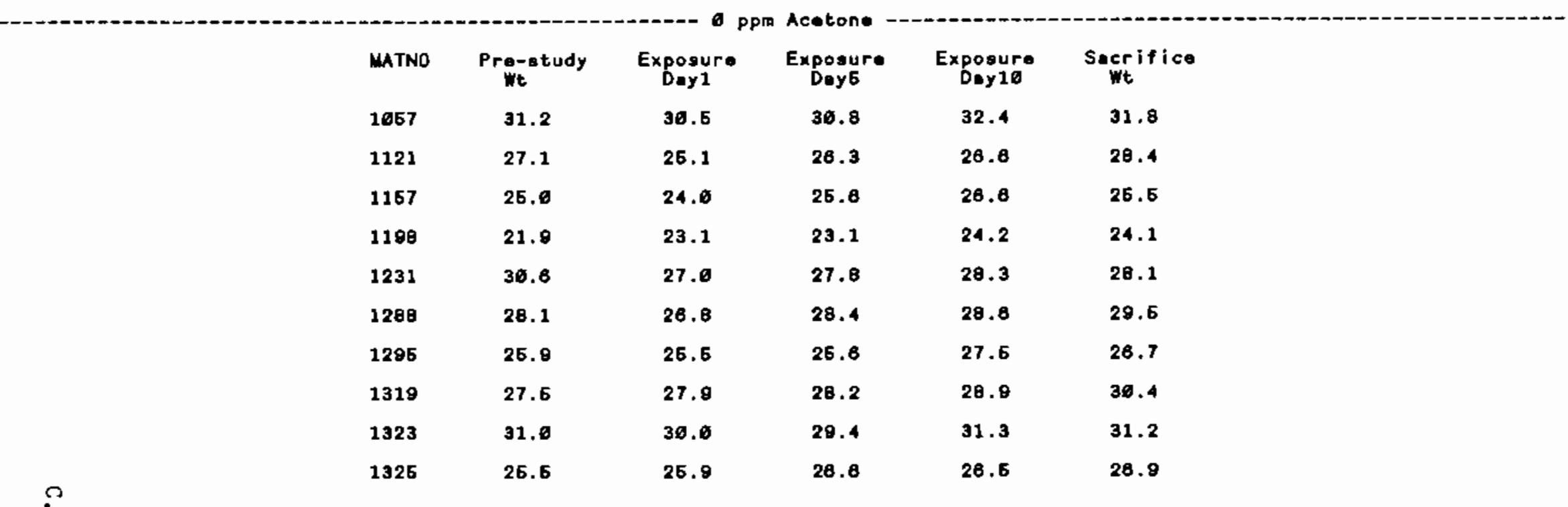


Acetone Mouso Teratology Study: Body Woights (g) for Virgin Females

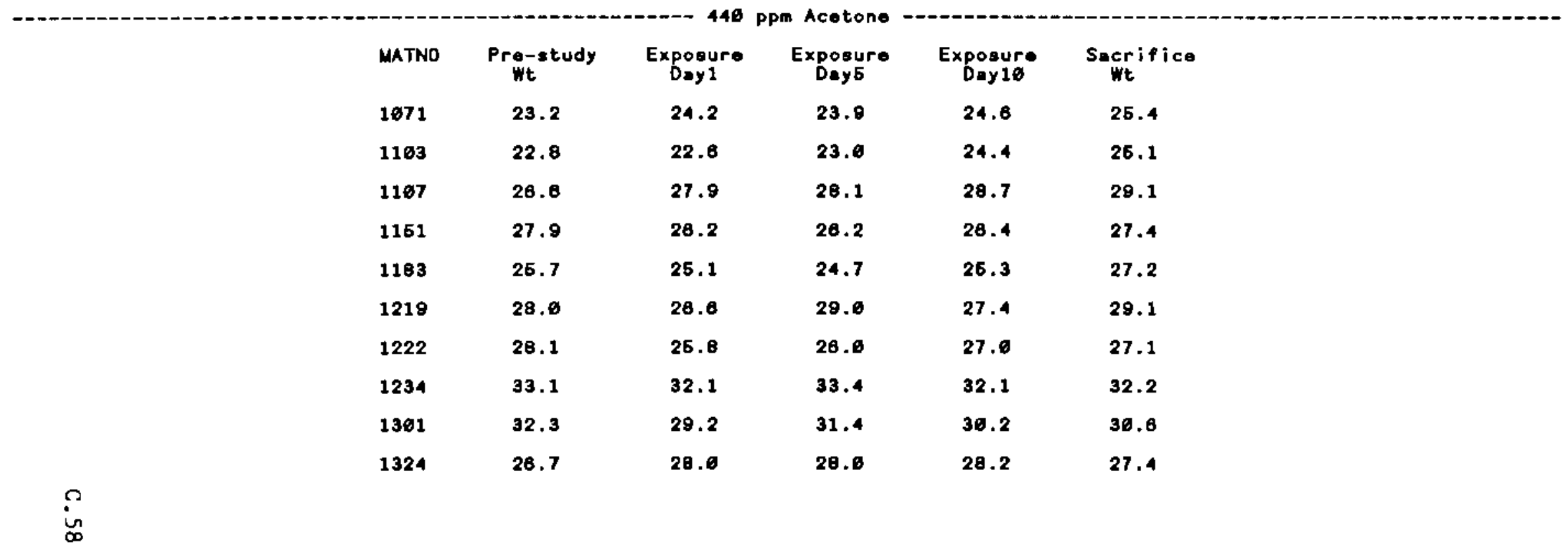


Acetone Mouse Teretology Study: Body Woights (g) for Virgin Fomsleo

\begin{tabular}{|c|c|c|c|c|c|c|}
\hline & MATNO & $\underset{w t}{\text { Pre-study }}$ & $\begin{array}{c}\text { Exposure } \\
\text { Day } 1\end{array}$ & $\begin{array}{c}\text { Exposure } \\
\text { Dey } 6\end{array}$ & $\begin{array}{c}\text { Exposure } \\
\text { Day } 16\end{array}$ & $\underset{w t}{\text { Secrifice }}$ \\
\hline & 1041 & 29.7 & 29.0 & 30.6 & 30.0 & 30.6 \\
\hline & 1082 & 27.2 & 28.2 & 27.6 & 26.8 & 28.8 \\
\hline & 1672 & 34.2 & 34.6 & 34.6 & 35.4 & 36.1 \\
\hline & 1695 & 23.4 & 21.0 & 22.2 & 23.1 & 22.9 \\
\hline & 1124 & 27.1 & 26.8 & 26.8 & 27.5 & 28.8 \\
\hline & 1148 & 23.3 & 24.9 & 26.8 & 26.1 & 26.8 \\
\hline & 1188 & 23.5 & 24.6 & 24.7 & 24.4 & 28.6 \\
\hline & 1210 & 26.8 & 28.1 & 27.4 & 28.9 & 28.1 \\
\hline & 1266 & 24.8 & 27.7 & 27.8 & 27.6 & 27.6 \\
\hline & 1278 & 27.8 & 26.4 & 28.8 & 26.7 & 27.7 \\
\hline
\end{tabular}


Acotone Mouse Teratology Study: Body Woighto (g) for Virgin Fomalos $6800 \mathrm{ppm}$ Acetone

\begin{tabular}{|c|c|c|c|c|c|}
\hline MATNO & $\underset{W t}{\operatorname{Pres}}$ & $\begin{array}{c}\text { Exposure } \\
\text { Day } 1\end{array}$ & $\begin{array}{c}\text { Exposure } \\
\text { Day6 }\end{array}$ & $\begin{array}{c}\text { Expoeure } \\
\text { Day } 10\end{array}$ & $\underset{w t}{\text { Secrifice }}$ \\
\hline 1631 & 29.8 & 27.8 & 28.8 & 28.4 & 29.5 \\
\hline 1070 & 29.0 & 28.4 & 28.7 & 32.0 & 34.1 \\
\hline 1154 & 26.1 & 28.3 & 26.4 & 27.6 & 27.6 \\
\hline 1186 & 30.6 & 27.9 & 29.7 & 30.4 & 30.3 \\
\hline 1189 & 26.0 & 28.2 & 27.2 & 28.0 & 29.3 \\
\hline 1182 & 25.1 & 26.3 & 26.6 & 27.2 & 28.2 \\
\hline 1287 & 23.7 & 24.2 & 24.8 & 26.3 & 26.4 \\
\hline 1264 & 24.8 & 22.9 & 24.1 & 25.6 & 25.8 \\
\hline 1314 & 26.2 & 26.5 & 26.6 & 28.9 & 28.3 \\
\hline 1322 & 33.4 & 31.4 & 30.1 & 31.8 & 31.9 \\
\hline
\end{tabular}


Acetone Mouse Teretology Study: Body Woights (g) for Plug-positive Femeles

\begin{tabular}{|c|c|c|c|c|c|c|c|c|c|c|c|}
\hline MATNO & Pregnent & $\begin{array}{l}\text { Pro-study } \\
W_{t}(\theta)\end{array}$ & ${ }_{w t}^{o} d g$ & $\underset{w t}{6} d g$ & $\stackrel{9}{w_{t}} \stackrel{d g}{(g)}$ & $\begin{array}{l}12 d g \\
W t(g)\end{array}$ & $\begin{array}{ll}16 & \text { dg } \\
W t & (g)\end{array}$ & $\underset{W t}{18} \stackrel{d g}{(g)}$ & $\begin{array}{l}\text { Uter } \\
\text { wt (g) }\end{array}$ & $\begin{array}{l}\text { Liver } \\
\text { (g) }\end{array}$ & $\begin{array}{c}\text { Kidney } \\
\text { (g) }\end{array}$ \\
\hline $\begin{array}{l}1006 \\
1016 \\
1015 \\
1036 \\
1045 \\
1062 \\
1064 \\
1078 \\
1079 \\
1089 \\
1123 \\
1126 \\
1131 \\
1164 \\
1168 \\
1176 \\
1179 \\
1185 \\
1193 \\
1202 \\
01209 \\
11212 \\
1213 \\
1225 \\
1239 \\
1249 \\
1254 \\
1272 \\
1289 \\
1293 \\
1306\end{array}$ & $\begin{array}{l}1 \\
1 \\
1 \\
0 \\
1 \\
1 \\
1 \\
1 \\
6 \\
1 \\
1 \\
1 \\
1 \\
1 \\
0 \\
1 \\
0 \\
1 \\
1 \\
1 \\
1 \\
1 \\
1 \\
1 \\
1 \\
1 \\
1 \\
0 \\
1 \\
1 \\
1\end{array}$ & $\begin{array}{l}27.5 \\
27.9 \\
29.1 \\
29.2 \\
25.4 \\
32.9 \\
36.6 \\
28.5 \\
29.1 \\
25.7 \\
25.7 \\
36.7 \\
22.6 \\
26.0 \\
22.8 \\
25.5 \\
22.1 \\
26.6 \\
27.3 \\
24.4 \\
28.3 \\
34.4 \\
28.4 \\
27.2 \\
27.0 \\
36.8 \\
24.8 \\
26.7 \\
36.6 \\
30.9 \\
31.1\end{array}$ & $\begin{array}{l}28.3 \\
25.4 \\
29.6 \\
29.8 \\
25.8 \\
32.6 \\
38.4 \\
26.2 \\
27.5 \\
24.9 \\
25.0 \\
31.0 \\
22.0 \\
26.0 \\
23.4 \\
25.7 \\
23.5 \\
28.0 \\
27.4 \\
24.4 \\
28.9 \\
31.9 \\
28.9 \\
25.6 \\
27.0 \\
38.1 \\
25.1 \\
27.5 \\
30.3 \\
27.7 \\
31.1\end{array}$ & $\begin{array}{l}29.1 \\
27.4 \\
31.3 \\
30.4 \\
27.8 \\
34.5 \\
32.8 \\
28.7 \\
30.3 \\
28.2 \\
27.8 \\
33.3 \\
25.6 \\
28.9 \\
26.8 \\
27.5 \\
23.1 \\
36.8 \\
28.4 \\
28.5 \\
31.1 \\
33.7 \\
31.6 \\
26.8 \\
30.3 \\
32.4 \\
28.8 \\
29.2 \\
32.9 \\
31.8 \\
32.2\end{array}$ & $\begin{array}{l}30.8 \\
28.6 \\
31.8 \\
32.3 \\
28.7 \\
36.3 \\
34.2 \\
31.0 \\
27.9 \\
28.2 \\
29.6 \\
37.4 \\
26.2 \\
31.4 \\
26.0 \\
29.1 \\
24.4 \\
32.4 \\
36.1 \\
26.9 \\
33.2 \\
36.9 \\
32.4 \\
26.6 \\
36.7 \\
33.3 \\
36.4 \\
27.3 \\
34.4 \\
33.8 \\
33.2\end{array}$ & $\begin{array}{l}36.3 \\
33.8 \\
37.2 \\
31.1 \\
34.6 \\
41.6 \\
41.3 \\
37.6 \\
29.6 \\
33.6 \\
33.6 \\
41.6 \\
32.4 \\
36.1 \\
26.5 \\
34.2 \\
24.3 \\
38.7 \\
33.6 \\
33.6 \\
38.7 \\
41.1 \\
39.6 \\
34.0 \\
36.7 \\
38.7 \\
37.6 \\
28.3 \\
41.5 \\
41.2 \\
38.6\end{array}$ & $\begin{array}{l}39.4 \\
41.4 \\
44.6 \\
31.3 \\
48.8 \\
56.2 \\
48.6 \\
46.4 \\
29.2 \\
48.3 \\
38.9 \\
49.8 \\
37.9 \\
44.8 \\
28.2 \\
41.3 \\
24.8 \\
48.1 \\
41.2 \\
42.1 \\
46.3 \\
48.8 \\
46.7 \\
46.8 \\
46.4 \\
46.3 \\
46.7 \\
29.1 \\
56.8 \\
51.8 \\
46.8\end{array}$ & $\begin{array}{l}44.47 \\
49.17 \\
52.01 \\
36.69 \\
47.92 \\
60.59 \\
58.86 \\
64.12 \\
27.23 \\
46.26 \\
46.31 \\
58.32 \\
44.21 \\
51.76 \\
25.94 \\
47.06 \\
24.16 \\
57.40 \\
47.97 \\
60.22 \\
53.84 \\
57.35 \\
54.98 \\
47.46 \\
54.31 \\
63.38 \\
54.95 \\
17.58 \\
61.46 \\
57.96 \\
54.26\end{array}$ & $\begin{array}{r}11.378 \\
18.678 \\
17.688 \\
6.167 \\
16.871 \\
22.107 \\
26.189 \\
19.832 \\
6.127 \\
18.473 \\
14.386 \\
26.224 \\
13.652 \\
19.113 \\
6.110 \\
18.126 \\
6.684 \\
23.683 \\
16.716 \\
19.878 \\
18.899 \\
20.116 \\
22.397 \\
16.682 \\
22.841 \\
16.968 \\
21.843 \\
6.165 \\
22.684 \\
26.763 \\
19.663\end{array}$ & $\begin{array}{l}6.472 \\
2.843 \\
2.989 \\
2.085 \\
2.833 \\
3.120 \\
3.343 \\
3.145 \\
1.719 \\
2.441 \\
2.592 \\
3.121 \\
2.863 \\
2.812 \\
1.812 \\
2.391 \\
1.618 \\
3.115 \\
2.639 \\
2.484 \\
2.893 \\
3.781 \\
2.649 \\
3.046 \\
2.792 \\
3.463 \\
2.768 \\
1.799 \\
3.537 \\
3.296 \\
2.587\end{array}$ & 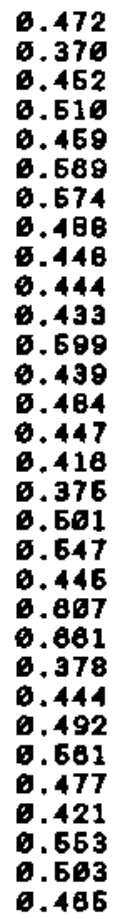 \\
\hline
\end{tabular}


Acetone Mouse Teratology Study: Body Woighte (g) for Plug-positive Femeles

\begin{tabular}{|c|c|c|c|c|c|c|c|c|c|c|c|}
\hline MATNO & Pregnant & $\begin{array}{l}\text { Pre-tudy } \\
\text { Wt (g) }\end{array}$ & ${ }_{w t}^{b} d g$ & $\underset{w t}{g} d g$ & $\underset{w t}{g} d g$ & $\begin{array}{l}12 \mathrm{dg} \\
\text { Wt }(9)\end{array}$ & $\begin{array}{ll}15 & d g \\
w t & (g)\end{array}$ & $\begin{array}{l}19 \mathrm{dg} \\
\text { Wt }(g)\end{array}$ & $\begin{array}{l}\text { Uter } \\
\text { Wt (g) }\end{array}$ & $\begin{array}{l}\text { Liver } \\
\text { (g) }\end{array}$ & $\begin{array}{c}\text { Kidney } \\
\text { (a) }\end{array}$ \\
\hline $\begin{array}{l}1001 \\
1682 \\
1629 \\
1632 \\
1633 \\
1634 \\
1642 \\
1666 \\
1669 \\
1693 \\
1164 \\
1128 \\
1132 \\
1147 \\
1149 \\
1168 \\
1161 \\
1171 \\
1182 \\
01199 \\
1129 \\
1216 \\
1238 \\
1261 \\
1281 \\
1270 \\
1271 \\
1274 \\
1279 \\
1297 \\
1294 \\
1308 \\
1317 \\
1321\end{array}$ & $\begin{array}{l}1 \\
1 \\
1 \\
1 \\
1 \\
1 \\
0 \\
1 \\
1 \\
0 \\
1 \\
1 \\
1 \\
1 \\
0 \\
1 \\
1 \\
1 \\
1 \\
1 \\
0 \\
1 \\
1 \\
1 \\
1 \\
1 \\
1 \\
1 \\
1 \\
1 \\
1 \\
1 \\
0\end{array}$ & $\begin{array}{l}21.7 \\
26.4 \\
27.7 \\
29.5 \\
31.2 \\
28.6 \\
26.7 \\
27.1 \\
25.7 \\
23.2 \\
24.4 \\
22.6 \\
36.0 \\
31.9 \\
26.7 \\
24.4 \\
36.5 \\
24.4 \\
32.1 \\
24.3 \\
28.6 \\
29.0 \\
24.0 \\
26.9 \\
23.1 \\
31.3 \\
36.2 \\
27.9 \\
28.7 \\
28.6 \\
24.6 \\
26.6 \\
32.4\end{array}$ & $\begin{array}{l}23.5 \\
26.2 \\
27.5 \\
29.2 \\
29.3 \\
28.7 \\
27.5 \\
27.7 \\
28.4 \\
23.5 \\
24.8 \\
22.6 \\
29.1 \\
36.5 \\
27.9 \\
25.6 \\
28.4 \\
24.6 \\
32.8 \\
24.5 \\
27.6 \\
38.3 \\
28.4 \\
28.4 \\
23.8 \\
36.6 \\
31.9 \\
27.2 \\
29.1 \\
25.1 \\
23.5 \\
26.9 \\
38.2\end{array}$ & $\begin{array}{l}25.3 \\
39.1 \\
29.8 \\
28.1 \\
34.7 \\
31.1 \\
29.2 \\
31.6 \\
26.5 \\
23.9 \\
27.3 \\
25.7 \\
28.8 \\
33.2 \\
27.6 \\
29.3 \\
36.5 \\
27.6 \\
33.5 \\
27.8 \\
29.9 \\
33.2 \\
28.7 \\
36.5 \\
26.2 \\
34.6 \\
32.4 \\
36.4 \\
31.7 \\
28.4 \\
25.6 \\
29.2 \\
32.1\end{array}$ & $\begin{array}{l}28.8 \\
33.9 \\
32.1 \\
31.7 \\
36.9 \\
33.9 \\
29.7 \\
33.9 \\
29.6 \\
23.9 \\
29.8 \\
27.1 \\
36.3 \\
35.2 \\
29.9 \\
31.3 \\
32.9 \\
28.6 \\
34.8 \\
31.1 \\
28.6 \\
33.8 \\
31.3 \\
31.8 \\
27.3 \\
36.6 \\
34.0 \\
32.8 \\
34.3 \\
29.9 \\
27.4 \\
31.7 \\
32.7\end{array}$ & $\begin{array}{l}32.6 \\
38.9 \\
37.7 \\
36.2 \\
42.6 \\
38.4 \\
28.2 \\
39.2 \\
34.7 \\
23.7 \\
36.2 \\
32.6 \\
34.9 \\
39.6 \\
29.6 \\
37.2 \\
39.2 \\
34.7 \\
39.3 \\
34.3 \\
28.9 \\
39.4 \\
34.4 \\
37.5 \\
32.6 \\
44.6 \\
38.8 \\
37.9 \\
41.2 \\
36.8 \\
32.3 \\
36.9 \\
31.6\end{array}$ & $\begin{array}{l}37.1 \\
47.2 \\
44.9 \\
42.8 \\
62.6 \\
46.9 \\
29.0 \\
47.6 \\
42.4 \\
24.8 \\
41.2 \\
37.8 \\
39.7 \\
48.6 \\
28.7 \\
46.0 \\
46.9 \\
43.2 \\
45.9 \\
41.0 \\
36.1 \\
47.8 \\
41.6 \\
44.6 \\
46.4 \\
63.3 \\
45.4 \\
46.6 \\
61.9 \\
44.7 \\
39.6 \\
44.2 \\
31.7\end{array}$ & 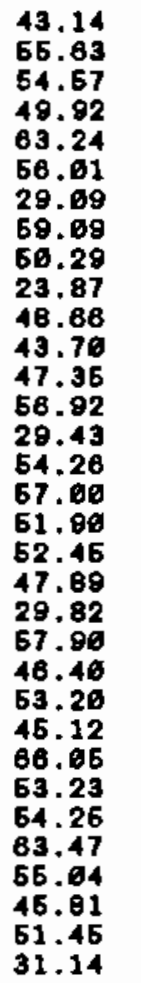 & 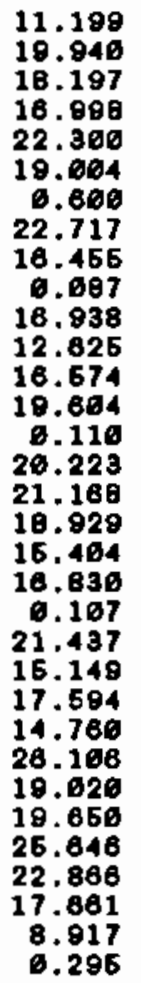 & $\begin{array}{l}2.917 \\
2.823 \\
3.163 \\
3.164 \\
3.420 \\
6.614 \\
2.069 \\
3.280 \\
3.274 \\
1.711 \\
3.167 \\
2.869 \\
2.678 \\
3.163 \\
1.889 \\
2.987 \\
3.291 \\
2.646 \\
2.993 \\
2.771 \\
2.320 \\
3.697 \\
2.367 \\
2.861 \\
1.936 \\
3.763 \\
2.821 \\
2.619 \\
3.069 \\
2.481 \\
2.302 \\
2.682 \\
2.167\end{array}$ & 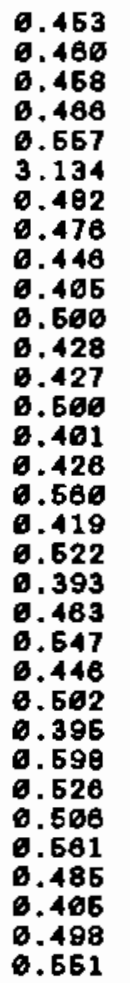 \\
\hline
\end{tabular}


Acetone Mouse Toratology Study: Body Weighte (o) for Plug-positive Femeles

\begin{tabular}{|c|c|c|c|c|c|c|c|c|c|c|c|}
\hline MATNO & Pregnant & $\begin{array}{l}\text { Pre-tudy } \\
\text { wt (g) }\end{array}$ & $\underbrace{b}_{t t} d g$ & $\underset{w t}{6} d g(g)$ & $\stackrel{\theta}{w t} d g$ & $\begin{array}{ll}12 \stackrel{d g}{d} \\
w t\end{array}$ & $\begin{array}{l}15 \text { dg } \\
\text { wt }(g)\end{array}$ & $\begin{array}{l}18 \mathrm{dg} \\
w t \quad(o)\end{array}$ & $\begin{array}{l}\text { Uter } \\
w t(g)\end{array}$ & $\begin{array}{l}\text { Liver } \\
\text { (g) }\end{array}$ & $\begin{array}{c}\text { Kidney } \\
\text { (g) }\end{array}$ \\
\hline 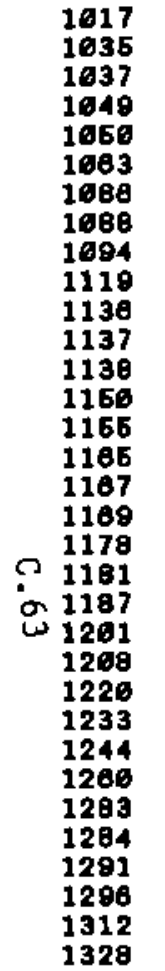 & $\begin{array}{l}1 \\
0 \\
1 \\
1 \\
1 \\
1 \\
1 \\
1 \\
1 \\
1 \\
1 \\
0 \\
1 \\
1 \\
1 \\
1 \\
0 \\
0 \\
1 \\
1 \\
1 \\
1 \\
1 \\
1 \\
1 \\
1 \\
1 \\
1 \\
1 \\
1 \\
1 \\
1 \\
1\end{array}$ & $\begin{array}{l}34.6 \\
38.6 \\
29.6 \\
26.4 \\
27.1 \\
28.6 \\
31.7 \\
34.8 \\
27.7 \\
28.3 \\
23.2 \\
22.8 \\
23.4 \\
24.4 \\
30.6 \\
23.8 \\
29.4 \\
28.1 \\
34.6 \\
30.6 \\
28.2 \\
24.6 \\
26.6 \\
27.6 \\
23.8 \\
29.0 \\
27.4 \\
28.4 \\
24.4 \\
34.4 \\
28.6 \\
21.8 \\
28.4\end{array}$ & $\begin{array}{l}34.8 \\
28.8 \\
29.7 \\
28.6 \\
25.9 \\
27.2 \\
31.6 \\
34.6 \\
27.5 \\
27.6 \\
22.8 \\
22.8 \\
22.4 \\
25.2 \\
29.8 \\
25.8 \\
31.2 \\
27.8 \\
32.4 \\
28.8 \\
27.5 \\
24.2 \\
26.3 \\
27.7 \\
24.7 \\
29.2 \\
27.8 \\
28.9 \\
24.5 \\
32.3 \\
27.1 \\
22.3 \\
25.2\end{array}$ & $\begin{array}{l}38.0 \\
31.5 \\
31.7 \\
30.0 \\
29.4 \\
31.2 \\
33.2 \\
36.2 \\
30.6 \\
29.7 \\
28.4 \\
23.4 \\
24.9 \\
26.9 \\
32.4 \\
27.2 \\
29.0 \\
26.4 \\
37.1 \\
31.3 \\
28.1 \\
24.9 \\
26.9 \\
28.1 \\
27.4 \\
33.2 \\
28.1 \\
31.2 \\
27.7 \\
36.1 \\
36.1 \\
26.2 \\
29.2\end{array}$ & $\begin{array}{l}39.8 \\
32.2 \\
32.2 \\
32.7 \\
32.8 \\
33.6 \\
38.8 \\
37.7 \\
32.7 \\
32.3 \\
28.3 \\
24.2 \\
27.1 \\
29.2 \\
33.8 \\
29.8 \\
29.6 \\
28.8 \\
39.2 \\
33.7 \\
32.2 \\
27.3 \\
27.7 \\
36.1 \\
29.4 \\
36.8 \\
36.4 \\
32.8 \\
29.5 \\
37.7 \\
32.6 \\
28.2 \\
29.8\end{array}$ & $\begin{array}{l}44.7 \\
31.3 \\
37.2 \\
38.6 \\
37.8 \\
38.6 \\
41.4 \\
43.2 \\
37.4 \\
38.8 \\
34.3 \\
24.3 \\
29.3 \\
32.8 \\
39.6 \\
36.4 \\
31.1 \\
28.7 \\
46.2 \\
39.2 \\
98.8 \\
31.8 \\
31.6 \\
36.4 \\
38.6 \\
42.8 \\
38.6 \\
39.6 \\
34.9 \\
44.8 \\
38.8 \\
32.2 \\
38.6\end{array}$ & $\begin{array}{l}61.8 \\
31.9 \\
45.8 \\
47.6 \\
46.2 \\
48.8 \\
66.4 \\
68.3 \\
46.3 \\
43.4 \\
11.7 \\
24.7 \\
33.1 \\
38.9 \\
45.6 \\
43.6 \\
36.2 \\
27.7 \\
63.1 \\
47.3 \\
12.9 \\
37.2 \\
38.0 \\
43.8 \\
43.5 \\
62.0 \\
43.3 \\
48.3 \\
43.5 \\
64.4 \\
46.6 \\
39.1 \\
43.7\end{array}$ & 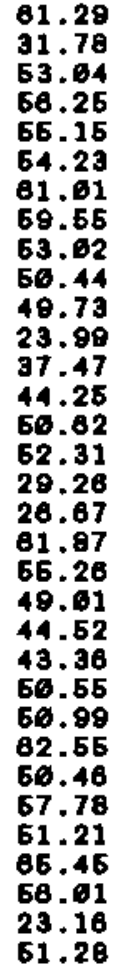 & 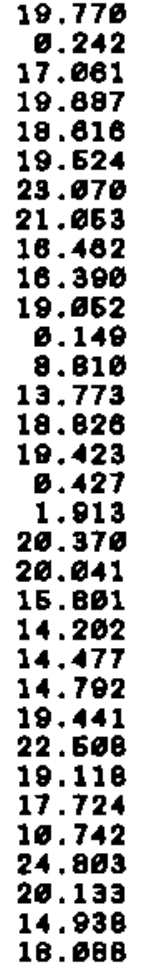 & $\begin{array}{l}3.304 \\
2.667 \\
2.894 \\
3.639 \\
2.628 \\
2.976 \\
3.386 \\
3.422 \\
2.993 \\
3.691 \\
3.128 \\
1.861 \\
2.668 \\
2.866 \\
2.986 \\
2.886 \\
2.267 \\
9.699 \\
3.436 \\
2.710 \\
3.283 \\
2.618 \\
2.346 \\
3.386 \\
2.586 \\
3.583 \\
2.488 \\
3.383 \\
2.847 \\
3.216 \\
2.796 \\
2.659 \\
2.948\end{array}$ & 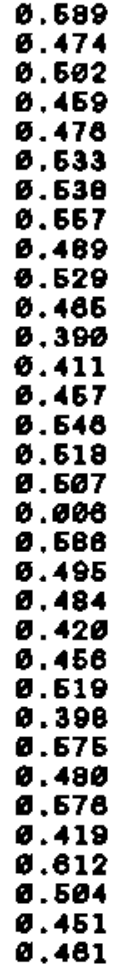 \\
\hline
\end{tabular}


Acetone Mouse Toratology Study: Body Woighte (g) for Plug-positive Females

\begin{tabular}{|c|c|c|c|c|c|c|c|c|c|c|c|}
\hline MATNO & Pregnant & $\begin{array}{l}\text { Pre-atudy } \\
\text { wit (g) }\end{array}$ & $\stackrel{g}{\text { wt }}(g)$ & $\left.w_{t}^{6} d g\right)$ & ${ }_{w t}^{g} d g$ & $\begin{array}{l}12 \text { dg } \\
w t(o)\end{array}$ & $\underset{w t}{16} \stackrel{d g}{(g)}$ & $\begin{array}{l}18 \mathrm{dg} \\
w t(g)\end{array}$ & $\begin{array}{l}\text { Uter } \\
\text { wt (a) }\end{array}$ & $\begin{array}{l}\text { Liver } \\
\text { (g) }\end{array}$ & $\begin{array}{c}\text { Kidney } \\
\text { (g) }\end{array}$ \\
\hline $\begin{array}{l}1009 \\
1611 \\
1614 \\
1019 \\
1622 \\
1623 \\
1624 \\
1026 \\
1026 \\
1636 \\
1648 \\
1668 \\
1061 \\
1197 \\
1698 \\
1118 \\
1142 \\
1144 \\
1168 \\
01172 \\
11174 \\
1126 \\
1264 \\
1232 \\
1236 \\
1241 \\
1248 \\
1266 \\
1269 \\
1263 \\
1286 \\
1292 \\
1297 \\
1336\end{array}$ & $\begin{array}{l}1 \\
1 \\
1 \\
1 \\
1 \\
1 \\
1 \\
1 \\
1 \\
0 \\
1 \\
1 \\
1 \\
1 \\
1 \\
1 \\
1 \\
1 \\
1 \\
1 \\
1 \\
6 \\
1 \\
1 \\
1 \\
1 \\
1 \\
1 \\
1 \\
1 \\
1 \\
1 \\
1\end{array}$ & $\begin{array}{l}31.7 \\
26.7 \\
29.0 \\
31.3 \\
29.1 \\
28.3 \\
28.6 \\
29.9 \\
34.6 \\
32.6 \\
26.2 \\
36.8 \\
28.5 \\
28.9 \\
28.3 \\
26.7 \\
26.1 \\
24.6 \\
23.4 \\
23.1 \\
26.7 \\
23.1 \\
30.2 \\
25.3 \\
29.4 \\
24.6 \\
31.6 \\
23.6 \\
26.2 \\
23.9 \\
28.1 \\
25.9 \\
24.6\end{array}$ & $\begin{array}{l}32.3 \\
26.7 \\
29.8 \\
31.8 \\
29.1 \\
27.9 \\
28.9 \\
29.2 \\
33.1 \\
31.6 \\
26.6 \\
36.9 \\
26.9 \\
27.2 \\
27.2 \\
28.4 \\
25.8 \\
25.8 \\
24.3 \\
24.0 \\
26.4 \\
23.6 \\
36.8 \\
29.6 \\
27.8 \\
25.4 \\
36.7 \\
24.8 \\
24.9 \\
24.8 \\
27.2 \\
26.8 \\
24.9\end{array}$ & 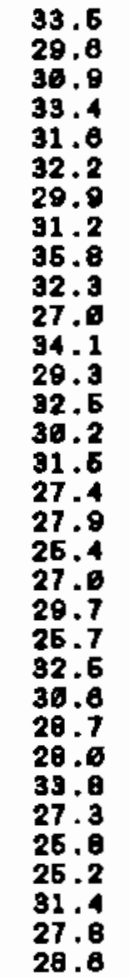 & $\begin{array}{l}36.6 \\
32.1 \\
32.7 \\
36.7 \\
33.6 \\
34.6 \\
32.8 \\
35.6 \\
36.6 \\
33.1 \\
29.8 \\
36.2 \\
32.4 \\
33.5 \\
33.6 \\
33.2 \\
29.7 \\
28.8 \\
28.4 \\
28.6 \\
31.6 \\
28.8 \\
34.6 \\
32.6 \\
36.9 \\
36.4 \\
38.4 \\
28.8 \\
27.3 \\
27.2 \\
33.2 \\
39.6 \\
31.6\end{array}$ & $\begin{array}{l}41.6 \\
37.7 \\
37.8 \\
43.6 \\
39.8 \\
37.8 \\
38.3 \\
39.1 \\
41.8 \\
34.2 \\
34.2 \\
43.8 \\
37.7 \\
40.2 \\
39.1 \\
34.3 \\
36.7 \\
35.7 \\
29.8 \\
35.1 \\
36.3 \\
24.8 \\
40.1 \\
49.8 \\
38.2 \\
37.6 \\
46.7 \\
33.8 \\
32.7 \\
31.9 \\
40.5 \\
36.5 \\
35.4\end{array}$ & $\begin{array}{l}60.6 \\
46.1 \\
43.5 \\
53.6 \\
46.6 \\
47.1 \\
46.8 \\
47.3 \\
66.1 \\
33.8 \\
42.8 \\
69.7 \\
47.6 \\
47.8 \\
48.0 \\
46.4 \\
41.7 \\
46.7 \\
39.8 \\
43.4 \\
44.4 \\
25.3 \\
49.4 \\
48.9 \\
44.6 \\
46.8 \\
48.8 \\
42.3 \\
38.9 \\
38.5 \\
48.4 \\
44.6 \\
41.8\end{array}$ & $\begin{array}{l}61.42 \\
64.86 \\
51.44 \\
84.85 \\
57.19 \\
54.89 \\
53.46 \\
55.72 \\
58.95 \\
36.10 \\
49.61 \\
61.18 \\
56.84 \\
56.67 \\
69.61 \\
63.84 \\
48.17 \\
44.85 \\
44.52 \\
58.16 \\
24.96 \\
57.25 \\
68.56 \\
62.65 \\
65.99 \\
65.85 \\
49.71 \\
46.21 \\
43.28 \\
57.57 \\
51.68 \\
31.46\end{array}$ & $\begin{array}{r}19.656 \\
18.676 \\
14.269 \\
23.031 \\
20.668 \\
18.360 \\
18.316 \\
19.399 \\
18.322 \\
6.228 \\
16.144 \\
26.224 \\
18.614 \\
17.831 \\
18.067 \\
17.399 \\
18.823 \\
13.636 \\
14.619 \\
19.296 \\
13.849 \\
6.095 \\
19.185 \\
19.939 \\
18.381 \\
20.685 \\
18.832 \\
18.679 \\
14.069 \\
13.516 \\
18.613 \\
18.686 \\
10.386\end{array}$ & 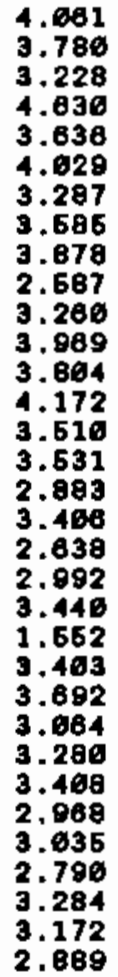 & 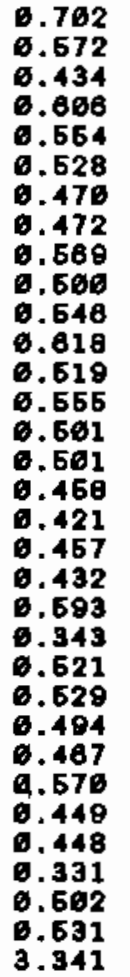 \\
\hline
\end{tabular}


Acetone Mouse Toratology Study: Raw Fotel Dota

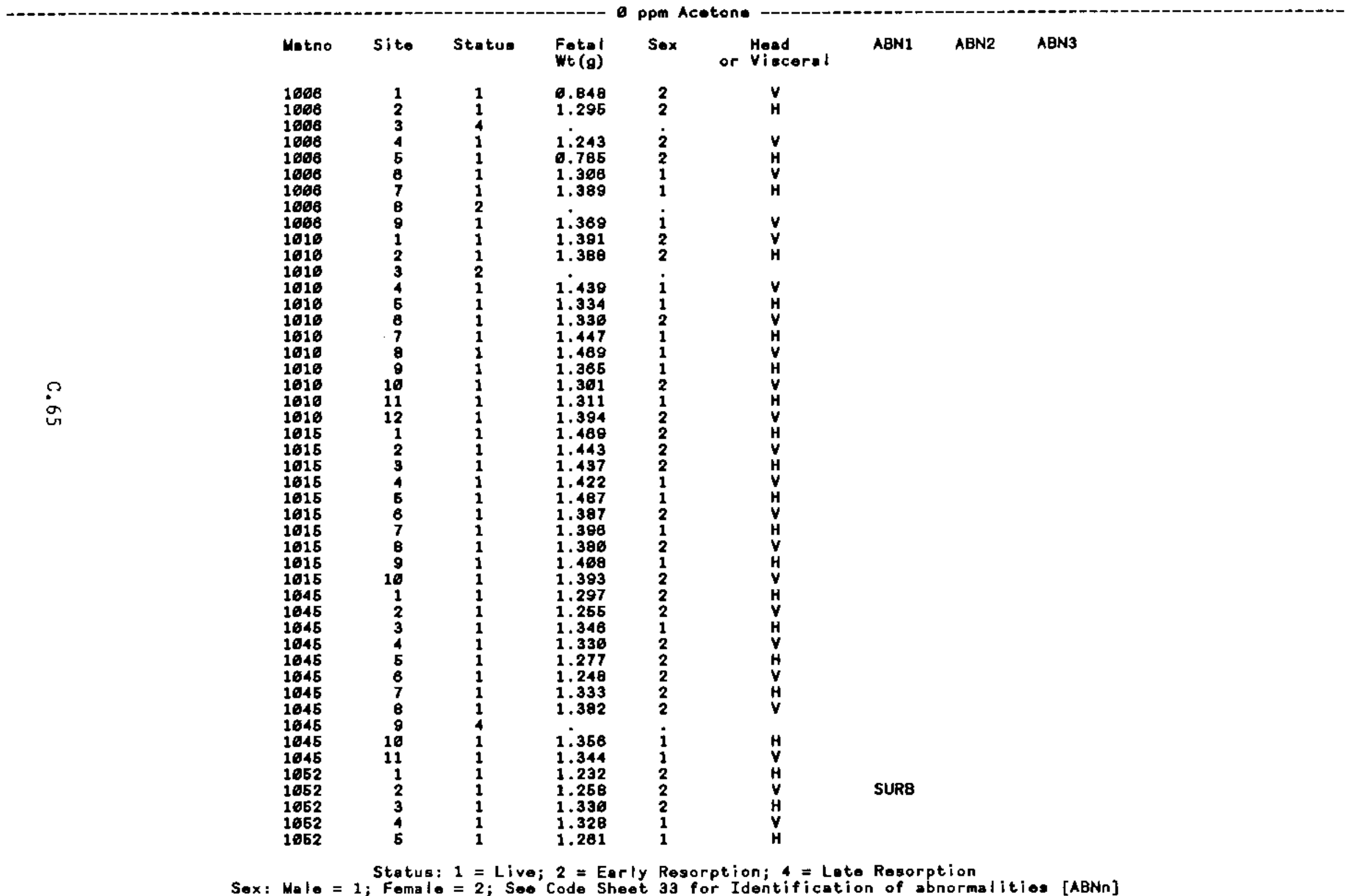

Sex: Male = 1; Female = 2; Seo Code Sheet 33 for Identification of abnormalitios [ABNn] 
Acetone Mouse Teratology Study: Rew Fotal Dete

\begin{tabular}{|c|c|c|c|c|c|c|c|c|c|}
\hline & Metno & Site & Status & $\begin{array}{l}\text { Fet.l } \\
W t(g)\end{array}$ & Sex & $\begin{array}{l}\text { Head } \\
\text { or Vieceral }\end{array}$ & ABN1 & ABN2 & ABN3 \\
\hline $\begin{array}{l}\Omega \\
\text { on }\end{array}$ & 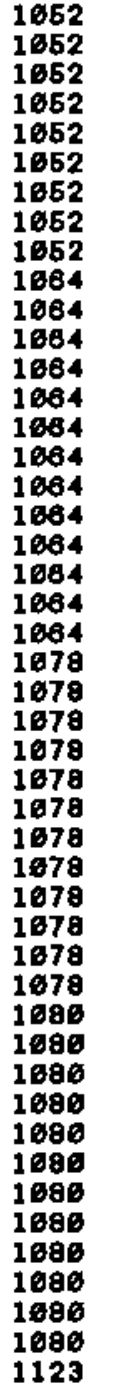 & $\begin{array}{r}8 \\
7 \\
6 \\
9 \\
10 \\
11 \\
12 \\
13 \\
14 \\
1 \\
2 \\
3 \\
4 \\
5 \\
8 \\
7 \\
8 \\
9 \\
16 \\
11 \\
12 \\
13 \\
1 \\
2 \\
3 \\
1 \\
5 \\
6 \\
7 \\
9 \\
9 \\
16 \\
11 \\
12 \\
1 \\
2 \\
3 \\
4 \\
5 \\
6 \\
7 \\
8 \\
9 \\
16 \\
11 \\
12 \\
1\end{array}$ & $\begin{array}{l}1 \\
1 \\
1 \\
1 \\
1 \\
4 \\
1 \\
1 \\
1 \\
1 \\
1 \\
1 \\
1 \\
1 \\
1 \\
1 \\
4 \\
1 \\
1 \\
1 \\
1 \\
1 \\
1 \\
1 \\
1 \\
1 \\
1 \\
1 \\
1 \\
1 \\
1 \\
1 \\
1 \\
1 \\
1 \\
1 \\
1 \\
1 \\
1 \\
1 \\
1 \\
1 \\
1 \\
1 \\
1 \\
1 \\
1\end{array}$ & $\begin{array}{l}1.386 \\
1.349 \\
1.331 \\
1.391 \\
1.466 \\
1.319 \\
1.509 \\
1.404 \\
1.377 \\
1.368 \\
1.331 \\
1.413 \\
1.496 \\
1.436 \\
1.299 \\
1.424 \\
1.353 \\
1.260 \\
1.250 \\
1.411 \\
1.364 \\
1.462 \\
1.365 \\
1.414 \\
1.337 \\
1.329 \\
1.467 \\
1.248 \\
1.271 \\
1.342 \\
1.468 \\
1.414 \\
1.182 \\
1.267 \\
1.331 \\
1.372 \\
1.235 \\
1.613 \\
1.163 \\
1.319 \\
1.235 \\
1.346 \\
1.251 \\
1.468 \\
1.378\end{array}$ & $\begin{array}{l}1 \\
2 \\
1 \\
1 \\
1 \\
i \\
1 \\
2 \\
1 \\
1 \\
2 \\
1 \\
1 \\
1 \\
2 \\
1 \\
2 \\
2 \\
2 \\
1 \\
1 \\
1 \\
1 \\
1 \\
2 \\
2 \\
2 \\
2 \\
2 \\
1 \\
2 \\
1 \\
2 \\
1 \\
1 \\
2 \\
1 \\
2 \\
2 \\
2 \\
2 \\
1 \\
2 \\
1 \\
2\end{array}$ & $\begin{array}{l}V \\
H \\
V \\
H \\
V \\
H \\
V \\
H \\
V \\
H \\
V \\
H \\
V \\
H \\
V \\
H \\
\mathbf{V} \\
H \\
V \\
H \\
V \\
H \\
V \\
H \\
V \\
H \\
V \\
H \\
V \\
H \\
V \\
H \\
V \\
H \\
V \\
H \\
V \\
H \\
V \\
H \\
V \\
H \\
V \\
H \\
H\end{array}$ & $\begin{array}{l}\text { LMFL } \\
\text { SURB } \\
\\
\text { LMFL } \\
\\
\text { SURB } \\
\text { SURB } \\
\text { SURB } \\
\text { SURB } \\
\text { SURB } \\
\text { SURB } \\
\text { SURB } \\
\\
\text { SURB } \\
\text { SURB } \\
\text { SURB } \\
\text { SUR日 } \\
\text { SURB } \\
\text { SURB } \\
\text { SURB }\end{array}$ & 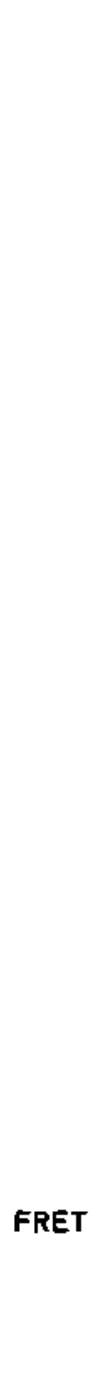 & \\
\hline
\end{tabular}


Acotone Mouse Teratology Study: Rew Fotel Data

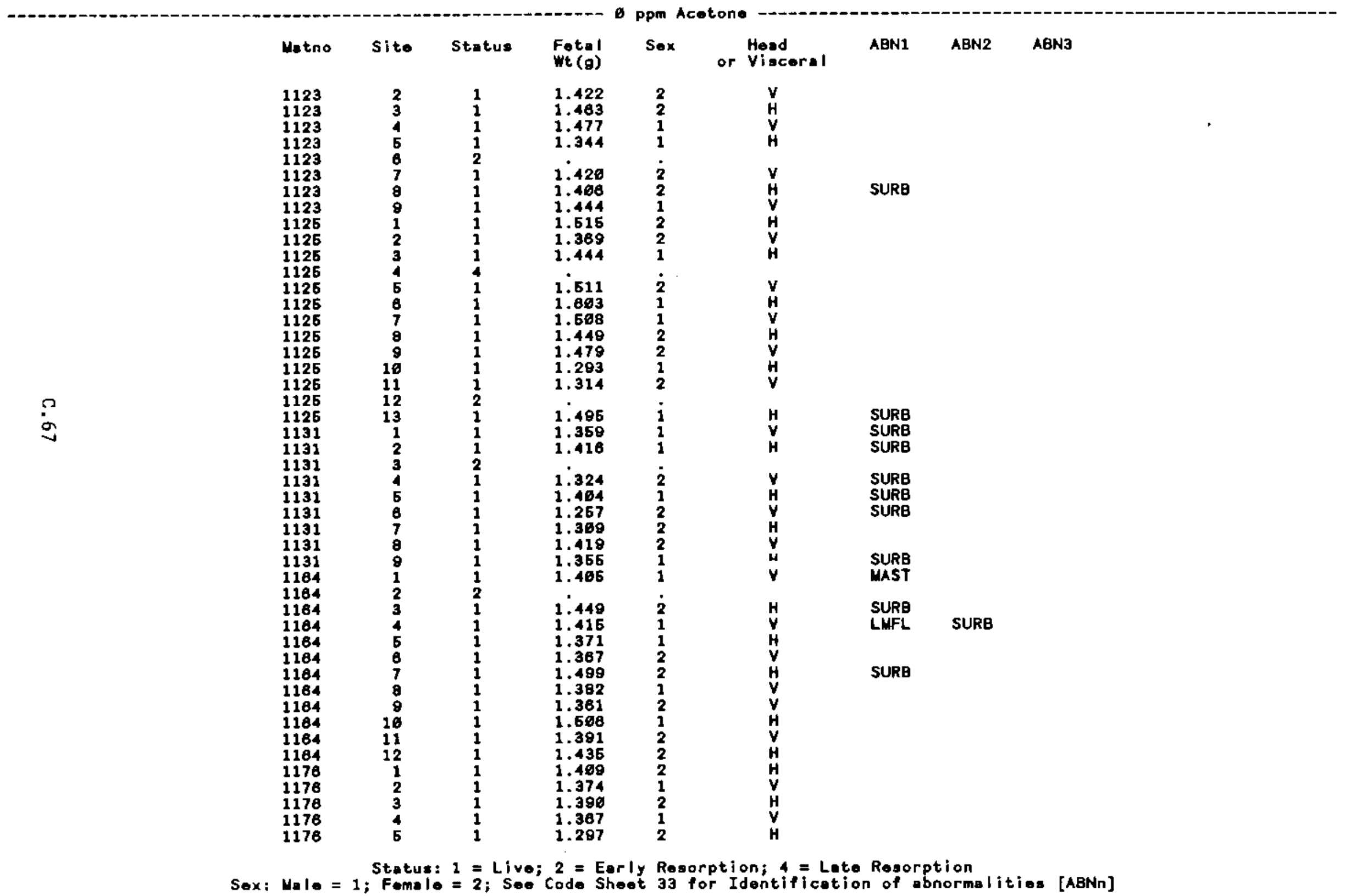


Acetone Mouse Teretology Study: Rew Fetal Date

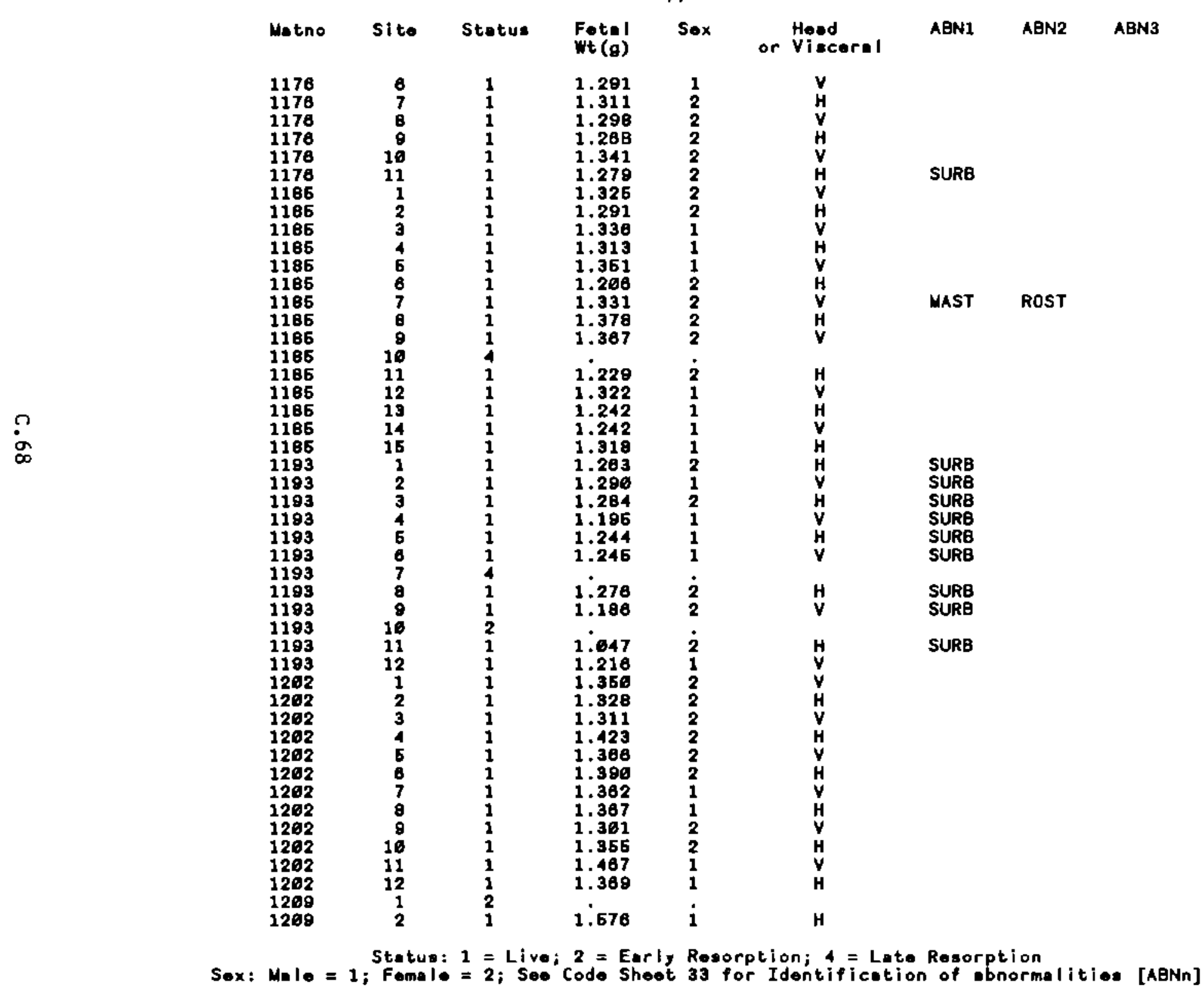


Aceton* Mouse Teretology Study: Raw Fotel Data

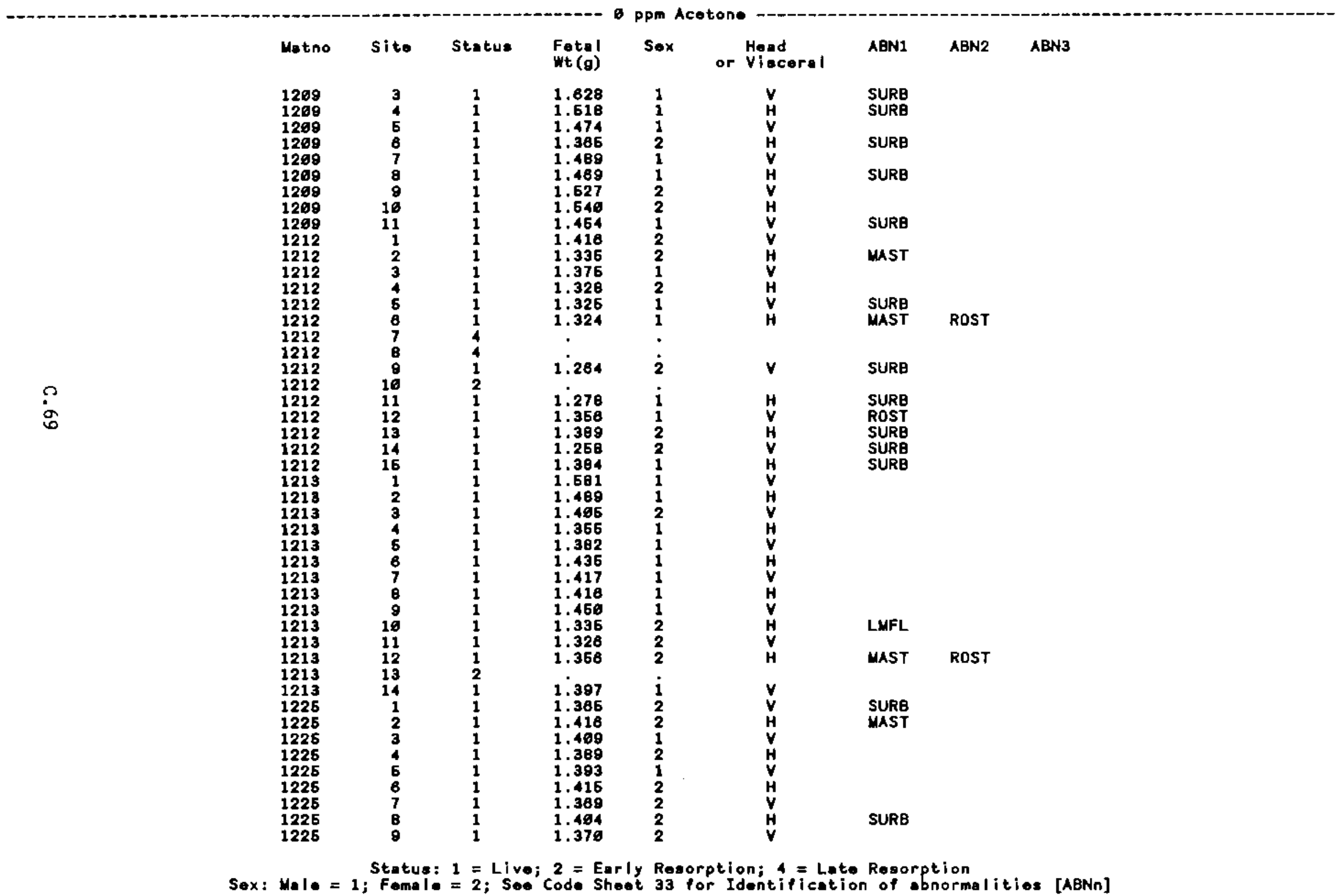


Acetone Mouse Terotology Study: Raw Fetal Date

\begin{tabular}{|c|c|c|c|c|c|c|c|c|c|}
\hline & Wotno & site & Stotua & $\begin{array}{l}\text { Fotal } \\
\text { we(o) }\end{array}$ & Sex & or Head & ABN1 & ABN2 & ABN3 \\
\hline 8 & $\begin{array}{l}1239 \\
1239 \\
1239 \\
1239 \\
1239 \\
1239 \\
1239 \\
1239 \\
1239 \\
1239 \\
1239 \\
1239 \\
1239 \\
1249 \\
1249 \\
1249 \\
1249 \\
1249 \\
1249 \\
1249 \\
1249 \\
1249 \\
1249 \\
1249 \\
1249 \\
1249 \\
1254 \\
1254 \\
1254 \\
1264 \\
1254 \\
1254 \\
1254 \\
1264 \\
1264 \\
1254 \\
1254 \\
1254 \\
1254 \\
1254 \\
1289 \\
1289 \\
1289 \\
1289 \\
1289 \\
1289 \\
1289\end{array}$ & $\begin{array}{r}1 \\
2 \\
3 \\
4 \\
5 \\
8 \\
7 \\
8 \\
9 \\
16 \\
11 \\
12 \\
13 \\
1 \\
2 \\
3 \\
4 \\
5 \\
6 \\
7 \\
8 \\
9 \\
16 \\
11 \\
12 \\
13 \\
1 \\
2 \\
3 \\
4 \\
5 \\
6 \\
7 \\
8 \\
9 \\
16 \\
11 \\
12 \\
13 \\
14 \\
1 \\
2 \\
3 \\
4 \\
5 \\
6 \\
7\end{array}$ & $\begin{array}{l}1 \\
1 \\
1 \\
1 \\
1 \\
1 \\
1 \\
1 \\
1 \\
1 \\
1 \\
1 \\
1 \\
1 \\
1 \\
1 \\
1 \\
2 \\
1 \\
2 \\
2 \\
1 \\
1 \\
1 \\
1 \\
1 \\
1 \\
1 \\
1 \\
1 \\
1 \\
1 \\
1 \\
1 \\
1 \\
1 \\
1 \\
1 \\
1 \\
1 \\
1 \\
1 \\
1 \\
2 \\
1 \\
1 \\
1\end{array}$ & $\begin{array}{l}1.417 \\
1.163 \\
1.390 \\
1.461 \\
1.391 \\
1.263 \\
1.361 \\
1.381 \\
1.391 \\
1.286 \\
1.376 \\
1.355 \\
1.346 \\
1.433 \\
1.369 \\
1.349 \\
1.631 \\
1.461 \\
1 . \\
1.419 \\
1.348 \\
1.382 \\
1.372 \\
1.356 \\
1.398 \\
1.355 \\
1.268 \\
1.242 \\
1.316 \\
1.197 \\
1.285 \\
1.148 \\
1.169 \\
1.239 \\
1.264 \\
1.221 \\
1.242 \\
1.196 \\
1.391 \\
1.122 \\
1.298 \\
1.227 \\
1.237 \\
1.118\end{array}$ & $\begin{array}{l}2 \\
2 \\
1 \\
2 \\
2 \\
2 \\
2 \\
2 \\
1 \\
2 \\
2 \\
2 \\
2 \\
2 \\
1 \\
2 \\
1 \\
i \\
1 \\
1 \\
1 \\
1 \\
1 \\
2 \\
1 \\
1 \\
2 \\
2 \\
1 \\
1 \\
1 \\
2 \\
2 \\
1 \\
1 \\
2 \\
1 \\
2 \\
2 \\
2 \\
1 \\
2 \\
1 \\
2\end{array}$ & 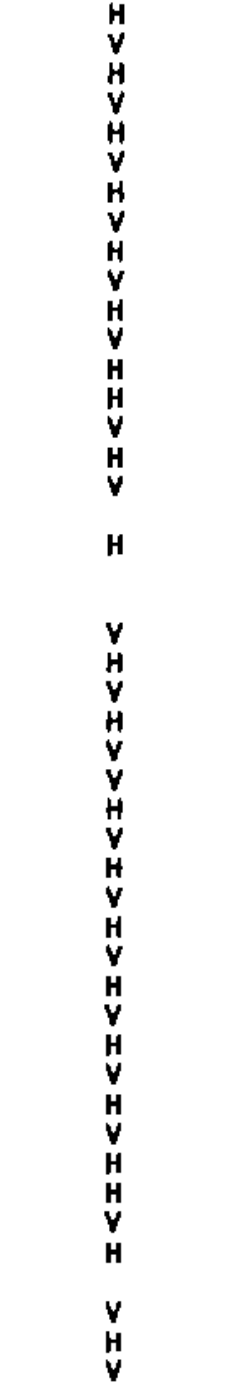 & $\begin{array}{l}\text { SURB } \\
\text { SURB } \\
\text { SURB } \\
\text { MAST } \\
\text { SURB } \\
\text { MAST } \\
\text { SURB } \\
\text { SURB } \\
\text { SURB } \\
\text { OSST } \\
\text { SURB }\end{array}$ & $\begin{array}{l}\text { SURB } \\
\text { SURB }\end{array}$ & \\
\hline
\end{tabular}


Acotone Mouse Toretology Study: Raw Fotal Data

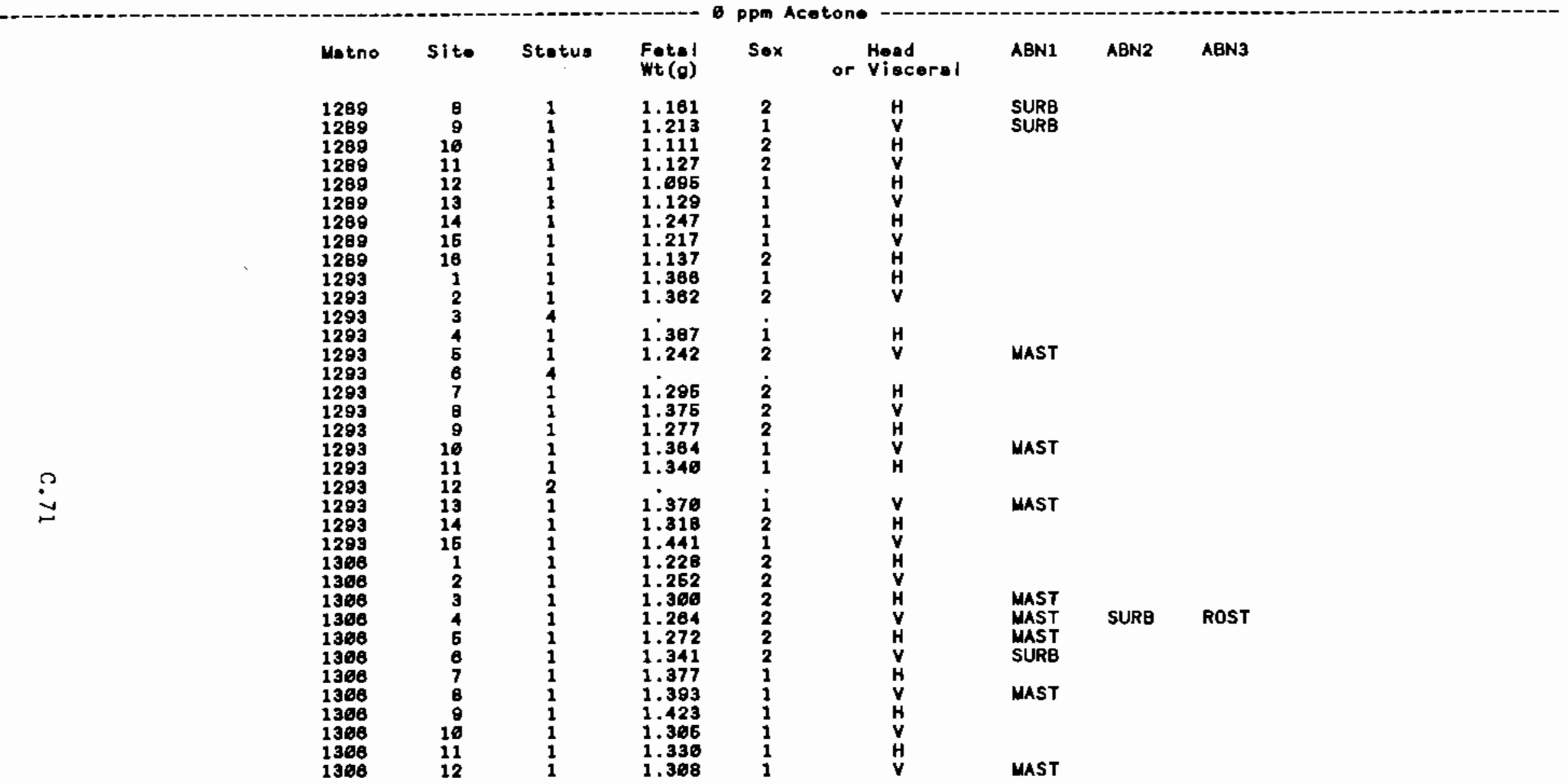


Acetone Mouse Toretology Study: Rer Fotel Dete

\begin{tabular}{|c|c|c|c|c|c|c|c|c|}
\hline & Metno & site & Stetus & $\begin{array}{l}\text { Fotal } \\
\text { Wt }(g)\end{array}$ & Sox & $\begin{array}{l}\text { Head } \\
\text { or Vieceral }\end{array}$ & ABN1 & ABN2 \\
\hline$\stackrel{0}{N}$ & 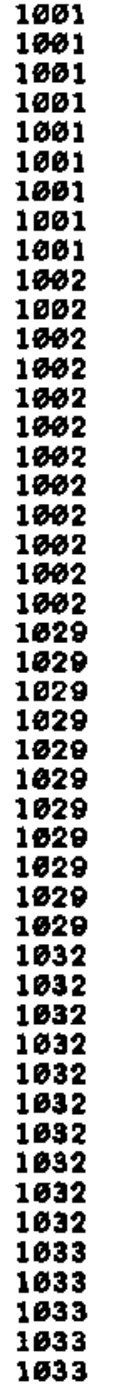 & 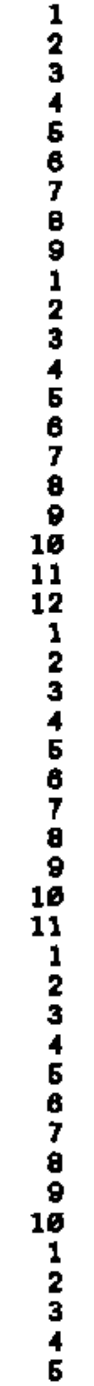 & $\begin{array}{l}1 \\
1 \\
1 \\
1 \\
2 \\
1 \\
1 \\
2 \\
2 \\
1 \\
1 \\
1 \\
1 \\
1 \\
1 \\
1 \\
1 \\
1 \\
1 \\
1 \\
1 \\
1 \\
1 \\
1 \\
1 \\
1 \\
1 \\
1 \\
1 \\
1 \\
1 \\
1 \\
1 \\
1 \\
1 \\
1 \\
1 \\
1 \\
1 \\
1 \\
1 \\
1 \\
1 \\
1 \\
1\end{array}$ & $\begin{array}{c}1.477 \\
1.364 \\
1.523 \\
1.419 \\
1.633 \\
1.641 \\
0 \\
1.448 \\
1.261 \\
1.453 \\
1.391 \\
1.386 \\
1.392 \\
1.265 \\
1.363 \\
1.292 \\
1.285 \\
1.295 \\
1.473 \\
1.377 \\
1.474 \\
1.413 \\
1.338 \\
1.351 \\
1.292 \\
1.466 \\
1.369 \\
1.311 \\
1.219 \\
1.339 \\
1.337 \\
1.346 \\
1.346 \\
1.347 \\
1.346 \\
1.337 \\
1.339 \\
1.359 \\
1.964 \\
1.441 \\
1.467 \\
1.514 \\
1.461 \\
1.461 \\
1.573\end{array}$ & 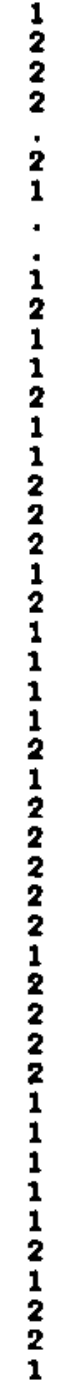 & 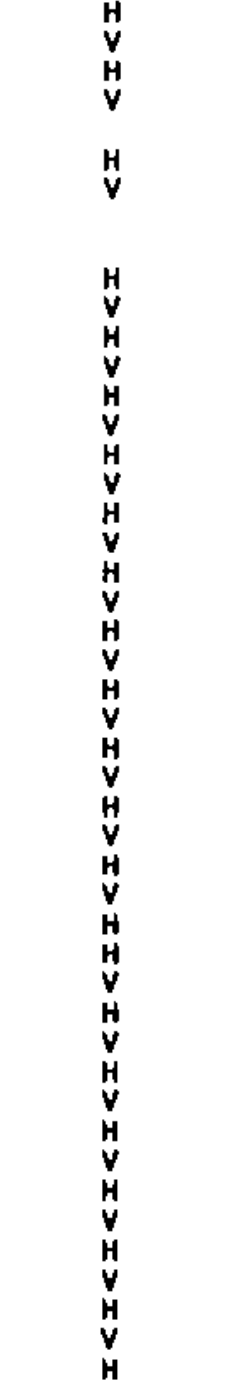 & $\begin{array}{l}\text { SURB } \\
\text { SURB } \\
\text { SURB } \\
\text { LMFL } \\
\text { LMFL } \\
\text { SURB } \\
\text { SURB }\end{array}$ & SURB \\
\hline
\end{tabular}

Sex: Male = 1; fomale 1 = 2; See; Code Sheot 33 for Identification of obnormalitios [ABNn] 
Acetone Mouse Teratology Study: Raw Fotel Date

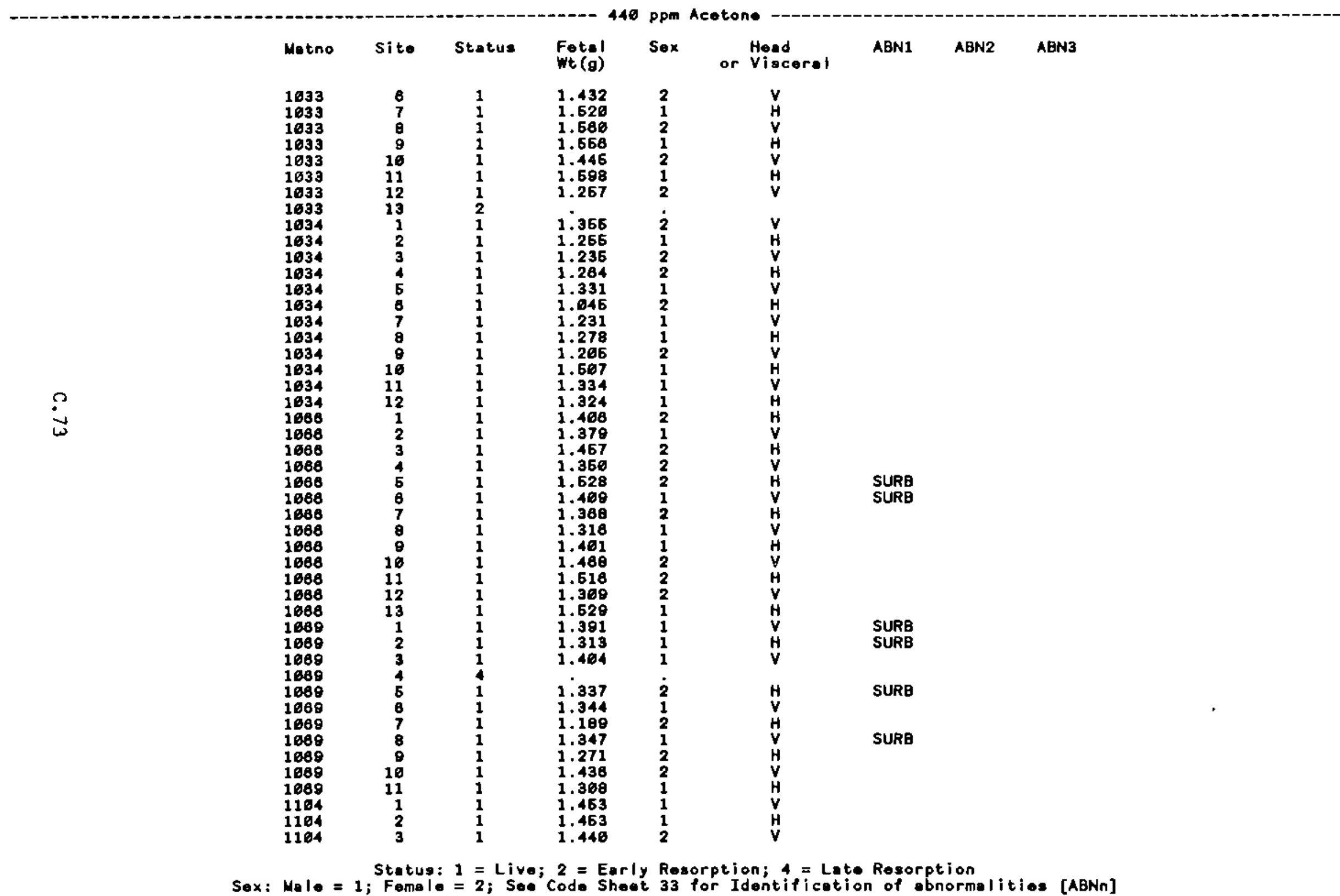


Acetone Mouse Teratology Study: Raw Fetel Data

\begin{tabular}{|c|c|c|c|c|c|c|c|c|}
\hline & Matno & site & Status & $\begin{array}{l}\text { Fetel } \\
\text { wt (o) }\end{array}$ & Sex & $\begin{array}{l}\text { Hesed } \\
\text { or Vi oceral }\end{array}$ & ABN1 & ABN2 \\
\hline$\stackrel{0}{5}$ & $\begin{array}{l}1164 \\
1184 \\
1164 \\
1164 \\
1164 \\
1164 \\
1184 \\
1128 \\
1128 \\
1128 \\
1128 \\
1128 \\
1126 \\
1128 \\
1132 \\
1132 \\
1132 \\
1132 \\
1132 \\
1132 \\
1132 \\
1132 \\
1132 \\
1132 \\
1147 \\
1147 \\
1147 \\
1147 \\
1147 \\
1147 \\
1147 \\
1147 \\
1147 \\
1147 \\
1147 \\
1168 \\
1166 \\
1168 \\
1156 \\
1158 \\
1168 \\
1168 \\
1168 \\
1168 \\
1168 \\
1156 \\
1156\end{array}$ & $\begin{array}{r}4 \\
5 \\
6 \\
7 \\
8 \\
8 \\
16 \\
1 \\
2 \\
3 \\
4 \\
6 \\
6 \\
7 \\
1 \\
2 \\
3 \\
4 \\
5 \\
8 \\
7 \\
8 \\
9 \\
10 \\
1 \\
2 \\
3 \\
4 \\
6 \\
6 \\
7 \\
8 \\
9 \\
10 \\
11 \\
1 \\
2 \\
3 \\
4 \\
5 \\
6 \\
7 \\
9 \\
8 \\
16 \\
11 \\
12\end{array}$ & $\begin{array}{l}4 \\
1 \\
1 \\
1 \\
1 \\
1 \\
1 \\
1 \\
1 \\
1 \\
1 \\
1 \\
1 \\
1 \\
1 \\
1 \\
1 \\
1 \\
1 \\
1 \\
1 \\
1 \\
1 \\
1 \\
1 \\
4 \\
1 \\
1 \\
1 \\
1 \\
1 \\
1 \\
2 \\
1 \\
1 \\
1 \\
1 \\
1 \\
1 \\
2 \\
1 \\
1 \\
1 \\
1 \\
1 \\
1 \\
1\end{array}$ & 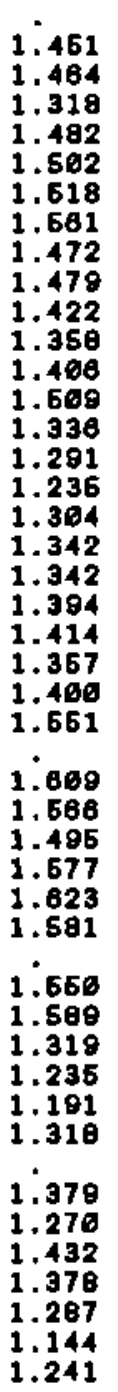 & $\begin{array}{l}2 \\
1 \\
2 \\
2 \\
1 \\
2 \\
2 \\
1 \\
1 \\
1 \\
2 \\
1 \\
2 \\
1 \\
1 \\
2 \\
2 \\
1 \\
2 \\
1 \\
1 \\
2 \\
2 \\
2 \\
i \\
1 \\
2 \\
1 \\
2 \\
2 \\
i \\
1 \\
2 \\
2 \\
2 \\
2 \\
i \\
2 \\
1 \\
1 \\
2 \\
2 \\
1\end{array}$ & $\begin{array}{l}H \\
V \\
H \\
V \\
H \\
V \\
H \\
V \\
H \\
V \\
H \\
V \\
H \\
H \\
V \\
H \\
V \\
H \\
V \\
H \\
V \\
H \\
V \\
H \\
V \\
H \\
V \\
H \\
V \\
V \\
H \\
V \\
H \\
V \\
H \\
V \\
H \\
V \\
H \\
V \\
H \\
V \\
H\end{array}$ & $\begin{array}{l}\text { SURB } \\
\text { SURB } \\
\text { SURB } \\
\text { SURB } \\
\\
\text { SURB } \\
\text { OSST } \\
\text { OSST } \\
\text { OSST } \\
\text { OSST } \\
\text { OSST } \\
\text { OSST } \\
\text { OSST } \\
\text { OSST } \\
\text { KITA } \\
\text { SURB } \\
\text { SURB } \\
\text { SURB } \\
\\
\text { SURB } \\
\text { SURB } \\
\text { SURB } \\
\text { SURB }\end{array}$ & $\begin{array}{l}\text { SURB } \\
\text { SURE } \\
\text { SURB } \\
\text { SURB }\end{array}$ \\
\hline
\end{tabular}

Stetus: 1 = Live; 2 = Early Rosorption; 4 = Leto Rosorption
Sox: Mote = 1; Fomale = 2 ; Soe Code Sheot 33 for Identification of abnormalitios [ABNn] 
Acetone Mouse Toretology Study: Rav Fotel Data

440 ppm Acetone

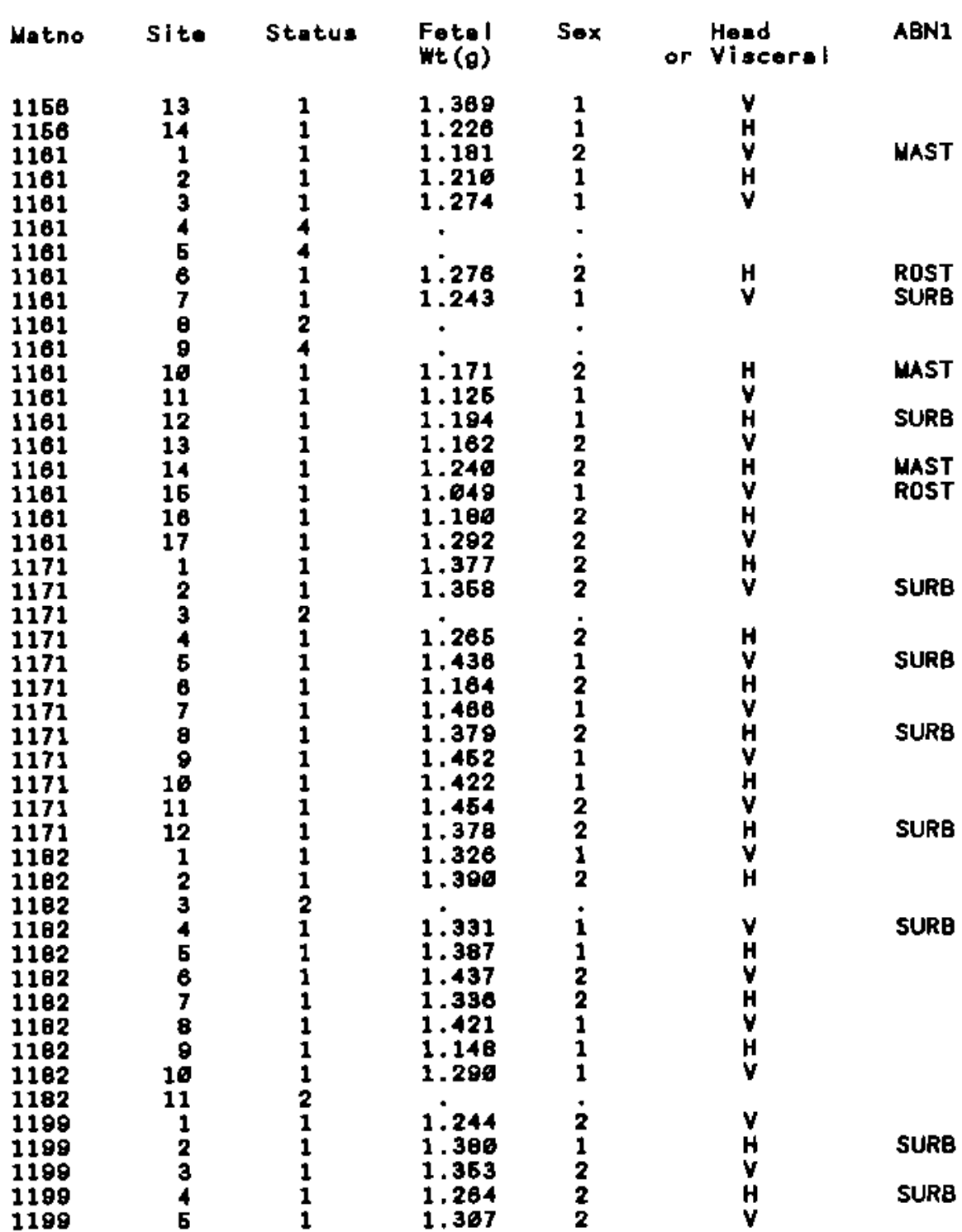

Sox: Male = 1; Fomalo = 2 ; Seo Code Shoet 33 for Identificotion of abnormalities [ABNn] 
Acetone Mouse Toretology Study: Rew Fetel Date

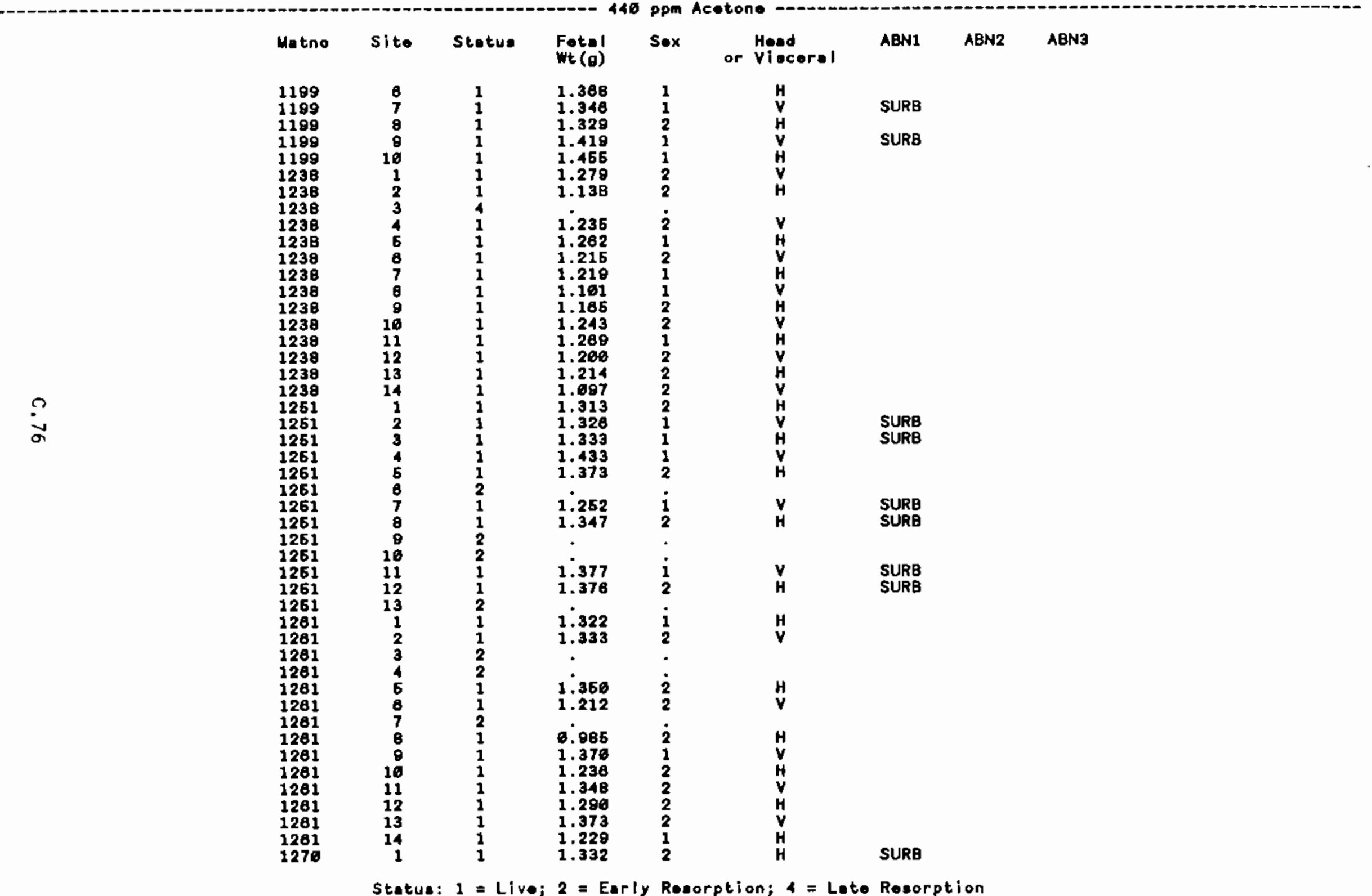

Sox: Male = 1; Fomele = 2; Soe Code Shoet 33 for Identification of abnormalities [ABNn] 
Acetone Mouso Teratology Study: Row Fotel Data

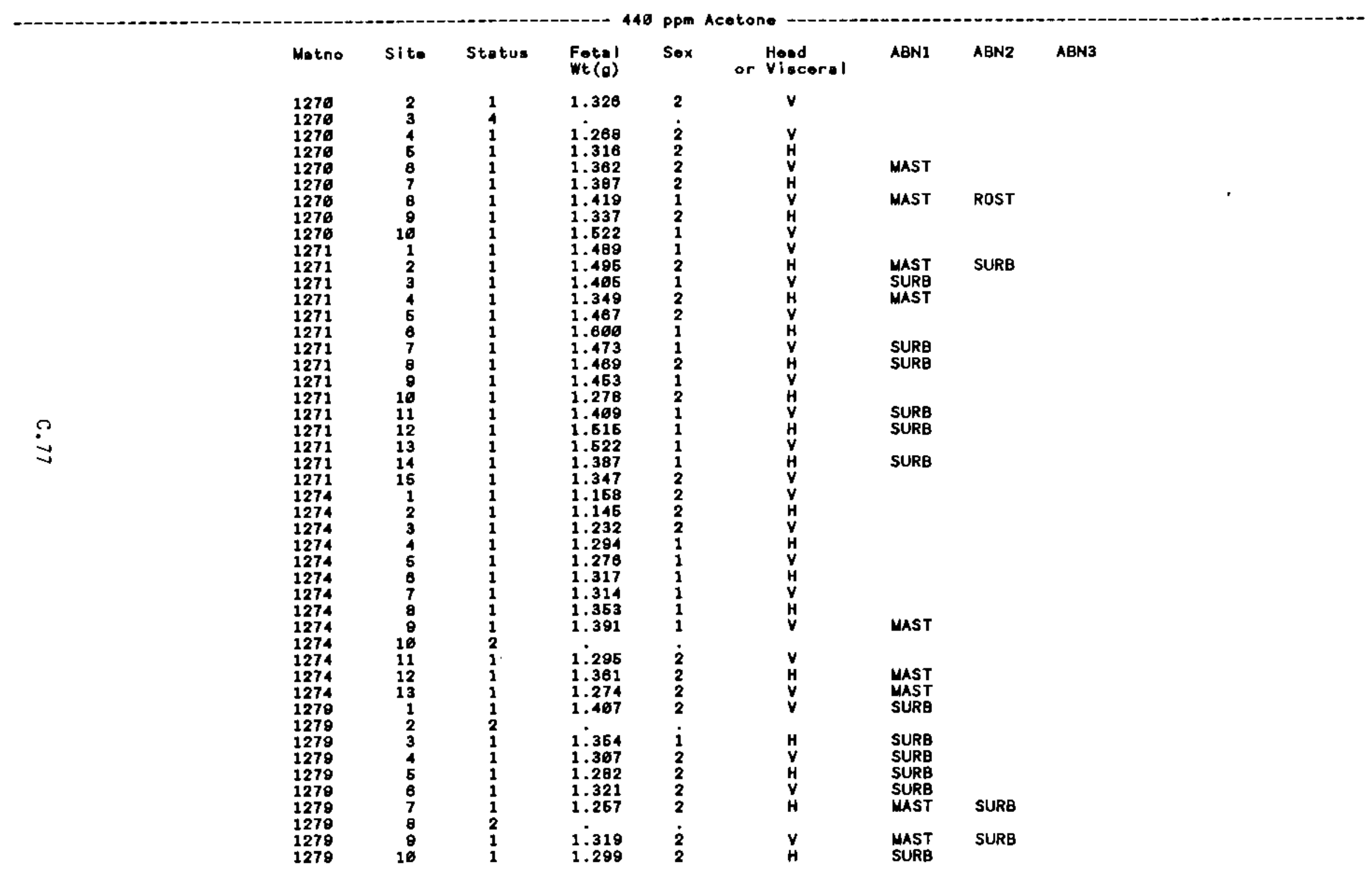

Statua: 1 = Live; 2 = Early Resorption; 4 = Lote Resorption

Sox: Male = 1; Female = 2; See Code Sheot 33 for Identification of ebnormalities [ABNn] 
Acetone Houee Terotology Study: Rew Fetal Date

\begin{tabular}{|c|c|c|c|c|c|c|c|c|c|}
\hline & Matno & site & Statua & $\begin{array}{l}\text { Fotal } \\
W t(g)\end{array}$ & Sex & $\begin{array}{l}\text { Hoed } \\
\text { or Visceral }\end{array}$ & ABN1 & ABN2 & ABN3 \\
\hline$\stackrel{?}{\infty}$ & $\begin{array}{l}1279 \\
1279 \\
1279 \\
1279 \\
1287 \\
1287 \\
1287 \\
1297 \\
1287 \\
1287 \\
1297 \\
1287 \\
1287 \\
1287 \\
1287 \\
1287 \\
1297 \\
1287 \\
1297 \\
1294 \\
1294 \\
1294 \\
1294 \\
1294 \\
1294 \\
1294 \\
1294 \\
1294 \\
1294 \\
1294 \\
1294 \\
1294 \\
1294 \\
1308 \\
1308 \\
1308 \\
1308 \\
1308 \\
1308 \\
1308 \\
1308 \\
1308 \\
1308 \\
1398 \\
1308 \\
1317 \\
1317\end{array}$ & $\begin{array}{r}11 \\
12 \\
13 \\
14 \\
1 \\
2 \\
3 \\
4 \\
5 \\
8 \\
7 \\
6 \\
9 \\
10 \\
11 \\
12 \\
13 \\
14 \\
15 \\
1 \\
2 \\
3 \\
4 \\
5 \\
6 \\
7 \\
6 \\
9 \\
16 \\
11 \\
12 \\
13 \\
14 \\
1 \\
2 \\
3 \\
4 \\
5 \\
6 \\
7 \\
6 \\
9 \\
10 \\
11 \\
12 \\
1 \\
2\end{array}$ & $\begin{array}{l}1 \\
1 \\
1 \\
1 \\
1 \\
1 \\
1 \\
1 \\
1 \\
1 \\
1 \\
2 \\
1 \\
1 \\
1 \\
1 \\
1 \\
1 \\
1 \\
1 \\
1 \\
1 \\
1 \\
1 \\
1 \\
1 \\
1 \\
1 \\
1 \\
1 \\
1 \\
1 \\
1 \\
1 \\
1 \\
1 \\
4 \\
1 \\
1 \\
1 \\
1 \\
1 \\
1 \\
1 \\
1 \\
1 \\
1\end{array}$ & $\begin{array}{l}1.220 \\
1.289 \\
1.382 \\
1.465 \\
1.563 \\
1.493 \\
1.579 \\
1.573 \\
1.538 \\
1.457 \\
1.433 \\
1.393 \\
1.564 \\
1.459 \\
1.446 \\
1.492 \\
1.441 \\
1.433 \\
1.426 \\
1.328 \\
1.348 \\
1.467 \\
1.382 \\
1.373 \\
1.342 \\
1.246 \\
1.343 \\
1.355 \\
1.365 \\
1.289 \\
1.246 \\
1.224 \\
1.286 \\
1.191 \\
1.360 \\
1.248 \\
1.164 \\
1.268 \\
1.144 \\
1.287 \\
1.167 \\
1.226 \\
1.142 \\
1.659 \\
1.679\end{array}$ & $\begin{array}{l}2 \\
2 \\
1 \\
1 \\
2 \\
2 \\
2 \\
1 \\
1 \\
2 \\
1 \\
\dot{2} \\
1 \\
2 \\
1 \\
1 \\
1 \\
1 \\
1 \\
2 \\
1 \\
1 \\
1 \\
2 \\
2 \\
2 \\
1 \\
1 \\
2 \\
1 \\
2 \\
2 \\
2 \\
1 \\
1 \\
1 \\
2 \\
1 \\
2 \\
1 \\
2 \\
1 \\
2 \\
1 \\
1\end{array}$ & $\begin{array}{l}V \\
H \\
V \\
H \\
V \\
H \\
V \\
H \\
V \\
H \\
V \\
H \\
V \\
H \\
V \\
H \\
V \\
H \\
V \\
H \\
V \\
H \\
V \\
H \\
V \\
H \\
V \\
H \\
V \\
H \\
V \\
H \\
V \\
H \\
V \\
H \\
V \\
H \\
V \\
H \\
V \\
H \\
V \\
V \\
H\end{array}$ & $\begin{array}{l}\text { MAST } \\
\text { MAST } \\
\text { SURB } \\
\text { SURB } \\
\text { SURB } \\
\text { SURB } \\
\text { SURB } \\
\text { SURB } \\
\text { SURB } \\
\text { SURB } \\
\text { SURB } \\
\text { ROST } \\
\text { MAST } \\
\text { SURB } \\
\text { SURB } \\
\text { SURB } \\
\text { SURB } \\
\text { SURB } \\
\text { SURB } \\
\text { MAST } \\
\text { MAST } \\
\text { SURB } \\
\text { MAST } \\
\text { SURB } \\
\text { MAST } \\
\text { SURB } \\
\text { MAST } \\
\text { SURB } \\
\text { MAST } \\
\text { MAST } \\
\text { SURB } \\
\text { MAST } \\
\text { SURB } \\
\text { SURB } \\
\text { SURB }\end{array}$ & $\begin{array}{l}\text { ROST } \\
\text { SURB } \\
\text { ROST } \\
\text { ROST } \\
\text { SURB }\end{array}$ & \\
\hline
\end{tabular}


Acetone Mouse Teretology Study: Rew Fotal Date

446 Ppm Acetone

\begin{tabular}{|c|c|c|c|c|c|c|c|c|}
\hline Metno & site & Stetus & $\begin{array}{l}\text { Fetel } \\
W t(\theta)\end{array}$ & Sox & $\begin{array}{l}\text { Heod } \\
\text { or Vieceral }\end{array}$ & ABN1 & ABN2 & ABN3 \\
\hline $\begin{array}{l}1317 \\
1317 \\
1317 \\
1317 \\
1317 \\
1317 \\
1317 \\
1317\end{array}$ & $\begin{array}{r}3 \\
4 \\
6 \\
6 \\
7 \\
8 \\
9 \\
10\end{array}$ & $\begin{array}{l}1 \\
1 \\
1 \\
1 \\
1 \\
1 \\
1 \\
1\end{array}$ & $\begin{array}{l}1.489 \\
1.451 \\
1.418 \\
1.818 \\
1.477 \\
1.488 \\
1.955 \\
1.488\end{array}$ & $\begin{array}{l}2 \\
1 \\
2 \\
1 \\
2 \\
1 \\
2 \\
2\end{array}$ & $\begin{array}{l}\mathbf{V} \\
\mathbf{H} \\
\mathbf{V} \\
\mathbf{H} \\
\mathbf{V} \\
\mathbf{H} \\
\mathbf{V} \\
\mathbf{H}\end{array}$ & $\begin{array}{l}\text { MAST } \\
\text { SURB } \\
\text { MAST }\end{array}$ & ROST & \\
\hline
\end{tabular}


Acetone Mouse Teretology Study: Rew Fotal Dota

\begin{tabular}{|c|c|c|c|c|c|c|c|c|c|}
\hline & Motno & site & Statu: & $\begin{array}{l}\text { Fetal } \\
w t(g)\end{array}$ & Sox & $\begin{array}{l}\text { Head } \\
\text { or Viscerel }\end{array}$ & ABN1 & ABN2 & ABN3 \\
\hline $\begin{array}{l}\Omega \\
\infty\end{array}$ & 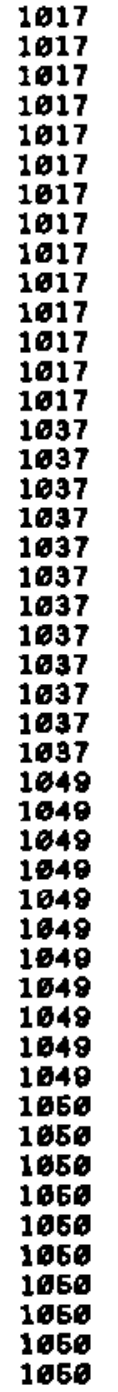 & $\begin{array}{r}1 \\
2 \\
3 \\
4 \\
5 \\
8 \\
7 \\
8 \\
8 \\
16 \\
11 \\
12 \\
13 \\
14 \\
1 \\
2 \\
3 \\
4 \\
5 \\
6 \\
7 \\
8 \\
8 \\
16 \\
11 \\
12 \\
1 \\
2 \\
3 \\
4 \\
5 \\
6 \\
7 \\
8 \\
8 \\
16 \\
11 \\
1 \\
2 \\
3 \\
4 \\
5 \\
6 \\
7 \\
8 \\
9 \\
10\end{array}$ & $\begin{array}{l}1 \\
2 \\
1 \\
1 \\
1 \\
1 \\
1 \\
1 \\
1 \\
1 \\
1 \\
1 \\
1 \\
1 \\
1 \\
1 \\
1 \\
1 \\
1 \\
1 \\
4 \\
1 \\
2 \\
1 \\
1 \\
1 \\
1 \\
1 \\
1 \\
1 \\
1 \\
1 \\
1 \\
1 \\
1 \\
1 \\
1 \\
1 \\
1 \\
1 \\
1 \\
1 \\
1 \\
4 \\
1 \\
1\end{array}$ & $\begin{array}{l}1.404 \\
1.332 \\
1.138 \\
1.368 \\
1.263 \\
1.276 \\
1.326 \\
1.238 \\
1.212 \\
1.312 \\
1.374 \\
1.446 \\
1.378 \\
1.293 \\
1.234 \\
1.287 \\
1.246 \\
1.278 \\
1.223 \\
1.214 \\
1.280 \\
1.296 \\
1.420 \\
1.542 \\
1.414 \\
1.376 \\
1.479 \\
1.489 \\
1.489 \\
1.931 \\
1.420 \\
1.439 \\
1.624 \\
1.424 \\
1.198 \\
1.481 \\
1.386 \\
1.342 \\
1.393 \\
1.416 \\
1.489 \\
1.433\end{array}$ & $\begin{array}{l}1 \\
i \\
1 \\
1 \\
1 \\
2 \\
2 \\
2 \\
1 \\
2 \\
1 \\
i \\
2 \\
2 \\
1 \\
2 \\
2 \\
2 \\
1 \\
2 \\
2 \\
2 \\
2 \\
2 \\
1 \\
2 \\
1 \\
2 \\
2 \\
1 \\
1 \\
2 \\
2 \\
2 \\
1 \\
1 \\
2 \\
2 \\
1 \\
1 \\
2 \\
2 \\
2 \\
1 \\
1\end{array}$ & $\begin{array}{l}H \\
V \\
H \\
V \\
H \\
V \\
H \\
V \\
H \\
V \\
H \\
V \\
H \\
V \\
H \\
V \\
H \\
V \\
H \\
V \\
V \\
H \\
V \\
V \\
H \\
V \\
H \\
V \\
H \\
V \\
H \\
V \\
H \\
V \\
V \\
H \\
V \\
H \\
V \\
H \\
V \\
H \\
V\end{array}$ & $\begin{array}{l}\text { SURB } \\
\text { SURB } \\
\text { SURB } \\
\text { SURB }\end{array}$ & & \\
\hline
\end{tabular}


Acetone Mouse Teratology Study: Raw Fetol Date

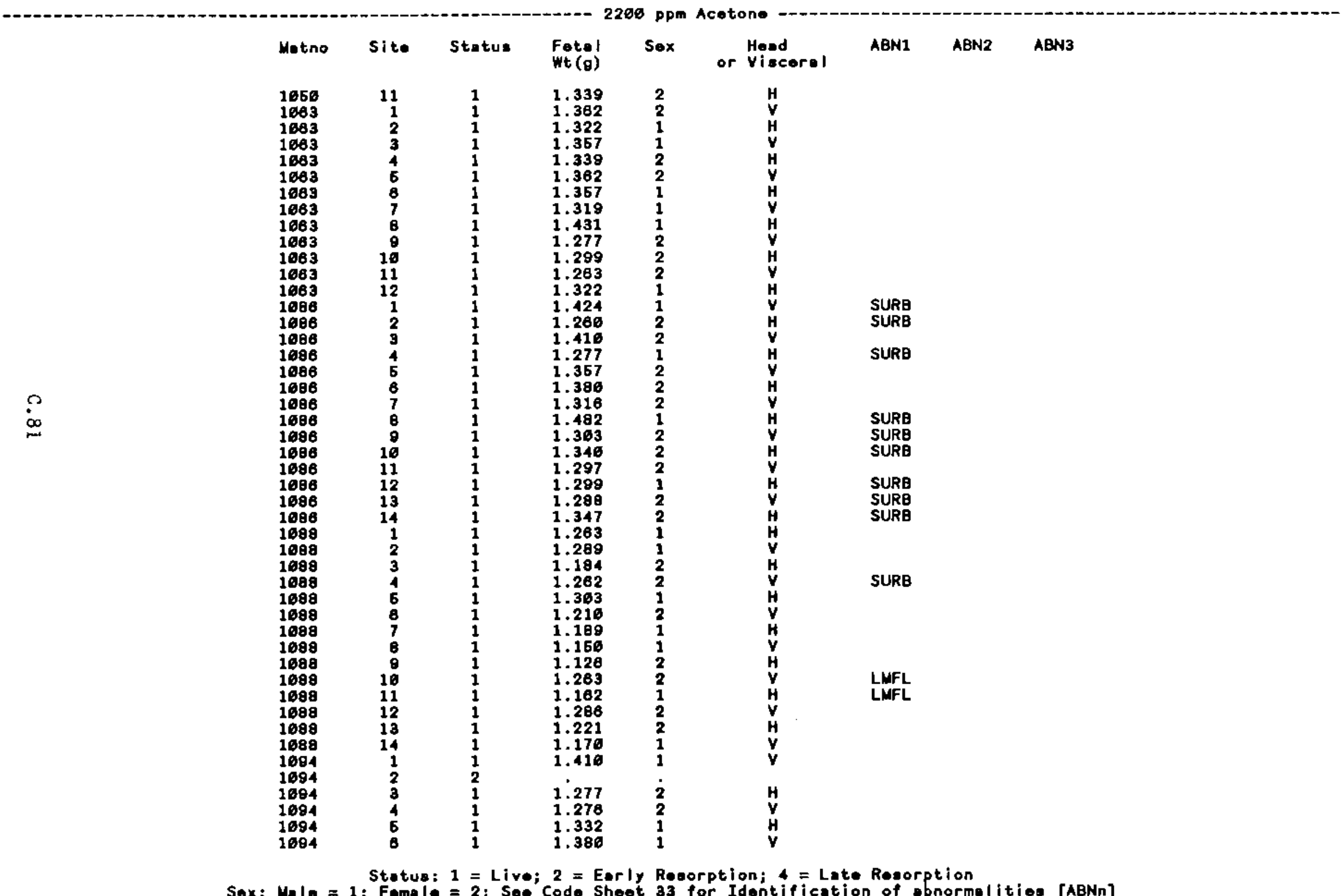


Acetone Nouse Toratology Study: Raw Fetel Data

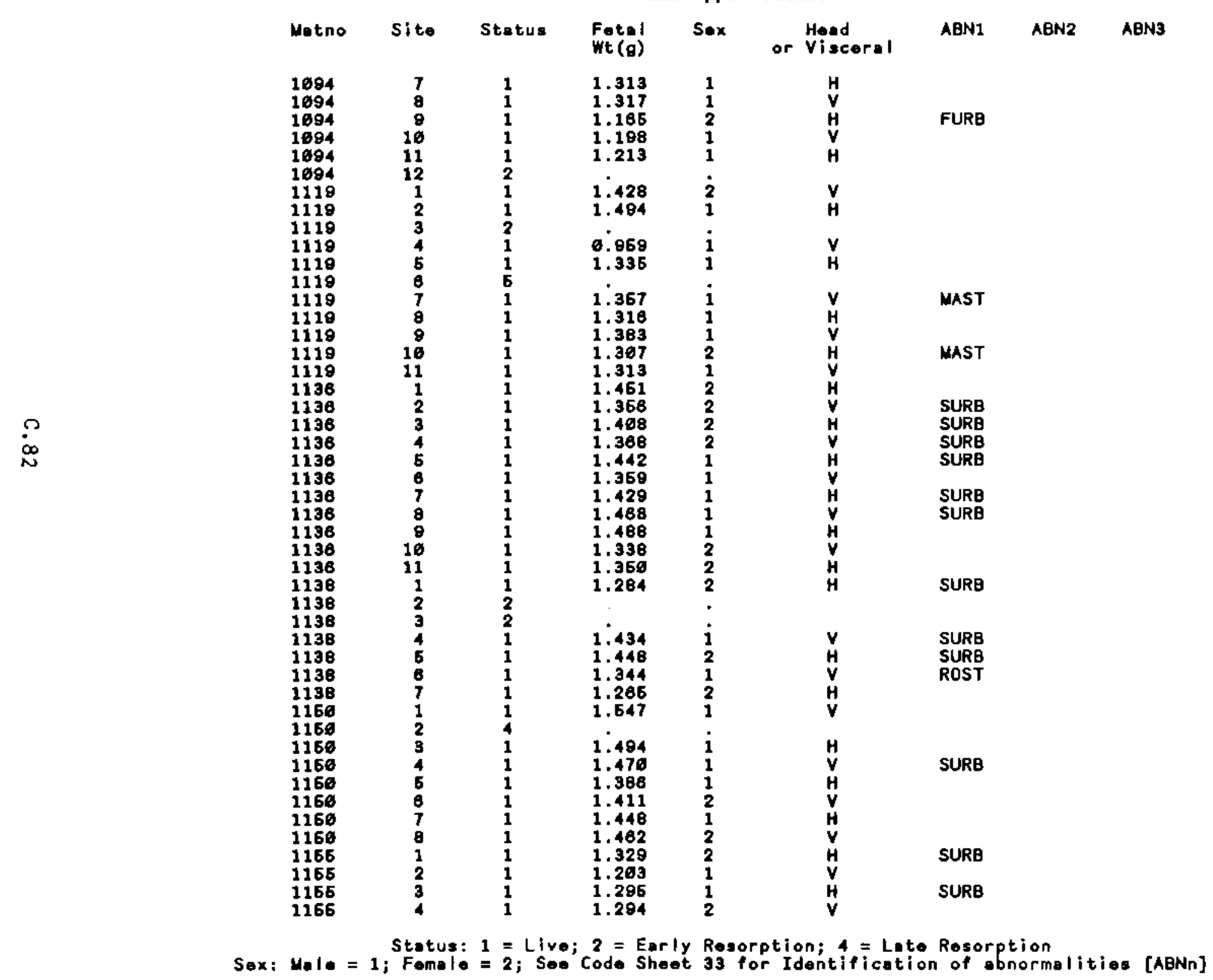


SAS

Acetone Mouse Teratology Study: Raw Fotel Deta $2200 \mathrm{ppm}$ Acetone

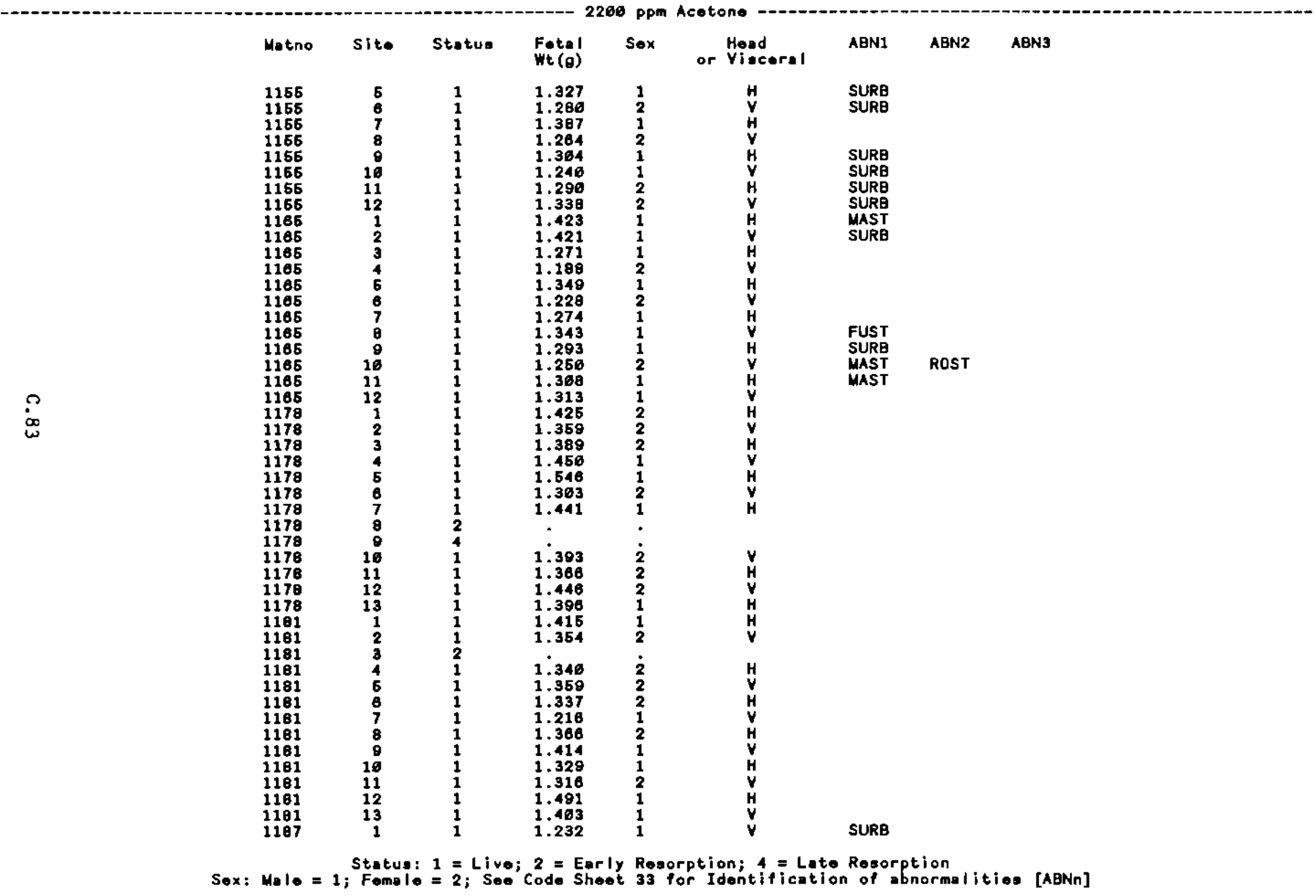


Acetone Mouse Teretology Study: Ren Fotel Dato

\begin{tabular}{|c|c|c|c|c|c|c|c|c|c|}
\hline & Matno & Site & Status & $\begin{array}{l}\text { Fetal } \\
\text { wt (g) }\end{array}$ & Sox & $\begin{array}{l}\text { Head } \\
\text { or Viscersel }\end{array}$ & $A B N 1$ & ABN2 & ABN3 \\
\hline $\begin{array}{l}? \\
\infty \\
\infty\end{array}$ & 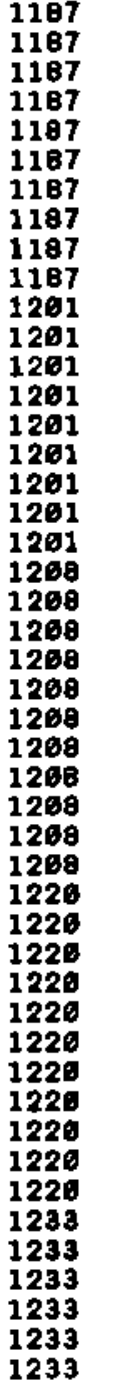 & $\begin{array}{r}2 \\
3 \\
4 \\
6 \\
6 \\
7 \\
8 \\
8 \\
18 \\
11 \\
1 \\
2 \\
3 \\
4 \\
5 \\
6 \\
7 \\
8 \\
8 \\
1 \\
2 \\
3 \\
4 \\
5 \\
8 \\
7 \\
6 \\
9 \\
16 \\
11 \\
1 \\
2 \\
3 \\
4 \\
5 \\
6 \\
7 \\
8 \\
9 \\
10 \\
11 \\
1 \\
2 \\
3 \\
4 \\
5 \\
6\end{array}$ & $\begin{array}{l}4 \\
1 \\
1 \\
1 \\
1 \\
1 \\
1 \\
1 \\
1 \\
1 \\
1 \\
1 \\
4 \\
1 \\
2 \\
1 \\
1 \\
1 \\
1 \\
1 \\
4 \\
1 \\
1 \\
1 \\
1 \\
1 \\
1 \\
1 \\
1 \\
1 \\
1 \\
1 \\
1 \\
2 \\
1 \\
1 \\
1 \\
1 \\
1 \\
1 \\
1 \\
1 \\
1 \\
1 \\
1 \\
1 \\
1\end{array}$ & 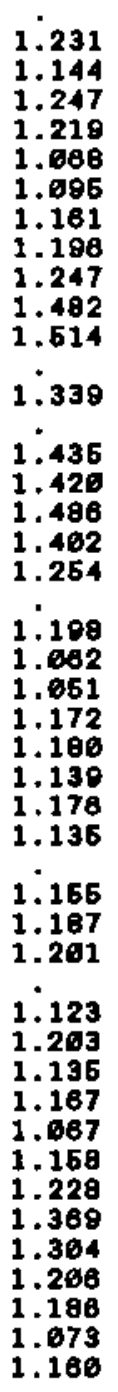 & $\begin{array}{l}2 \\
2 \\
2 \\
2 \\
2 \\
2 \\
2 \\
2 \\
2 \\
2 \\
1 \\
2 \\
2 \\
i \\
2 \\
2 \\
2 \\
1 \\
i \\
1 \\
2 \\
2 \\
2 \\
1 \\
2 \\
1 \\
2 \\
i \\
1 \\
1 \\
i \\
1 \\
2 \\
2 \\
2 \\
1 \\
1 \\
1 \\
1 \\
2 \\
2 \\
2 \\
1\end{array}$ & 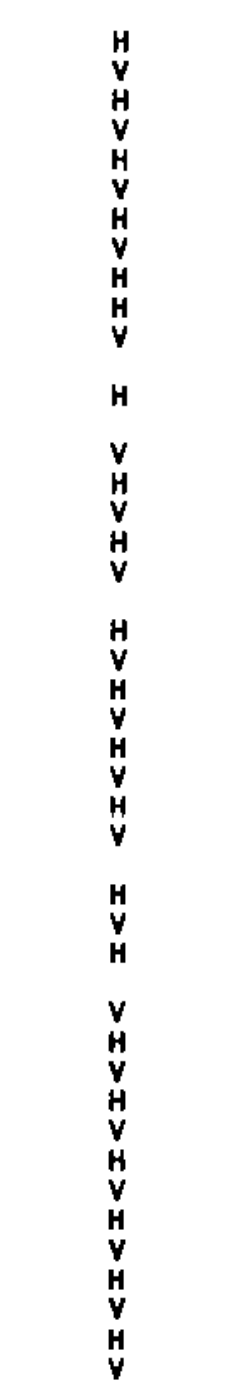 & $\begin{array}{l}\text { SURB } \\
\text { SURB } \\
\text { ROST } \\
\text { MAST } \\
\text { SURB } \\
\text { SURB } \\
\text { SURB } \\
\text { SURB } \\
\text { ROST } \\
\text { MAST } \\
\text { SURB } \\
\\
\text { SURB }\end{array}$ & ROST & \\
\hline
\end{tabular}


Acetone Mouse Terotology Study: Rew Fotal Date

2200 ppm Acotone

$\stackrel{\infty}{\infty}$

\begin{tabular}{|c|c|c|c|c|}
\hline $\begin{array}{l}\text { Fetel } \\
W t(g)\end{array}$ & Sox & or Visecoral & ABN1 & ABN2 \\
\hline $\begin{array}{l}1.138 \\
1.699 \\
1.168 \\
1.268 \\
1.317 \\
1.250 \\
1.312 \\
1.341 \\
1.648 \\
1.364 \\
1.396 \\
1.372 \\
1.346 \\
1.366 \\
1.263 \\
1.378 \\
1.297 \\
1.396\end{array}$ & $\begin{array}{l}2 \\
2 \\
2 \\
1 \\
1 \\
1 \\
1 \\
1 \\
1 \\
2 \\
1 \\
2 \\
2 \\
2 \\
2 \\
1 \\
2 \\
2\end{array}$ & 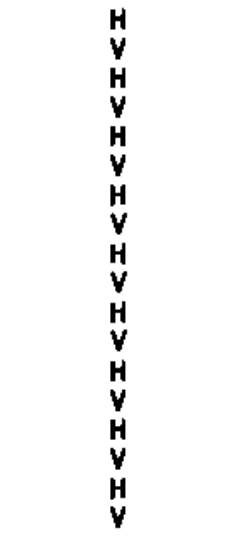 & $\begin{array}{l}\text { SURB } \\
\text { SURB } \\
\text { SURE } \\
\text { SURB } \\
\text { SURB }\end{array}$ & \\
\hline $\begin{array}{l}1.386 \\
1.476 \\
1.364 \\
1.296 \\
1.186\end{array}$ & $\begin{array}{l}\dot{2} \\
1 \\
1 \\
2 \\
2\end{array}$ & $\begin{array}{l}H \\
V \\
V \\
H \\
V\end{array}$ & & \\
\hline 1.256 & $i$ & H & SURB & \\
\hline $\begin{array}{l}1.141 \\
1.296 \\
1.342 \\
1.313 \\
1.349 \\
1.339 \\
1.369 \\
1.292 \\
1.375 \\
1.428 \\
1.395 \\
1.372 \\
1.397 \\
1.284 \\
1.389 \\
1.388 \\
1.349 \\
1.345 \\
1.465 \\
1.357\end{array}$ & $\begin{array}{l}2 \\
2 \\
2 \\
2 \\
1 \\
2 \\
1 \\
1 \\
1 \\
1 \\
2 \\
2 \\
1 \\
2 \\
1 \\
2 \\
1 \\
1 \\
1 \\
2\end{array}$ & $\begin{array}{l}V \\
H \\
V \\
H \\
V \\
V \\
H \\
V \\
H \\
H \\
V \\
H \\
V \\
H \\
H \\
y \\
y \\
V \\
H \\
V \\
H \\
V\end{array}$ & $\begin{array}{l}\text { MAST } \\
\text { SURB } \\
\text { MAST } \\
\text { SURB } \\
\text { SURB }\end{array}$ & \\
\hline
\end{tabular}

Stetus: 1 = Live; 2 = Early Resorption; 4 = Late Resorption

Sox; Mole = 1; Fomelo = 2; See Code Shoet 33 for Identification of obnormalities [ABNn] 
Acetone Mouse Teratology Study: Rew Fotel Data

\begin{tabular}{|c|c|c|c|c|c|c|c|c|c|}
\hline & Matno & site & Statua & $\begin{array}{l}\text { Fetol } \\
\text { Wt }(g)\end{array}$ & Sex & $\begin{array}{l}\text { Head } \\
\text { or Visceral }\end{array}$ & ABN1 & ABN2 & ABN3 \\
\hline 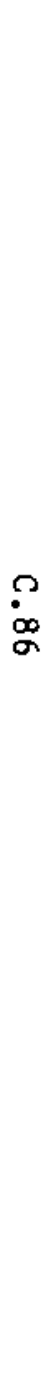 & $\begin{array}{l}1283 \\
1284 \\
1284 \\
1284 \\
1284 \\
1284 \\
1284 \\
1284 \\
1284 \\
1284 \\
1284 \\
1284 \\
1291 \\
1291 \\
1291 \\
1291 \\
1291 \\
1291 \\
1291 \\
1291 \\
1291 \\
1291 \\
1291 \\
1291 \\
1291 \\
1291 \\
1296 \\
1296 \\
1296 \\
1296 \\
1296 \\
1296 \\
1296 \\
1296 \\
1296 \\
1296 \\
1296 \\
1296 \\
1312 \\
1312 \\
1312 \\
1312 \\
1312 \\
1312 \\
1312 \\
1312 \\
1312\end{array}$ & $\begin{array}{r}13 \\
1 \\
2 \\
3 \\
4 \\
6 \\
6 \\
7 \\
8 \\
9 \\
16 \\
11 \\
1 \\
2 \\
3 \\
4 \\
6 \\
6 \\
7 \\
6 \\
8 \\
16 \\
11 \\
12 \\
13 \\
14 \\
1 \\
2 \\
3 \\
4 \\
5 \\
6 \\
7 \\
8 \\
8 \\
16 \\
11 \\
12 \\
1 \\
2 \\
3 \\
4 \\
6 \\
6 \\
7 \\
8 \\
8\end{array}$ & $\begin{array}{l}1 \\
1 \\
1 \\
1 \\
1 \\
1 \\
1 \\
1 \\
1 \\
1 \\
1 \\
1 \\
1 \\
1 \\
1 \\
1 \\
1 \\
1 \\
1 \\
1 \\
1 \\
1 \\
1 \\
1 \\
1 \\
1 \\
1 \\
1 \\
1 \\
1 \\
1 \\
1 \\
1 \\
1 \\
1 \\
1 \\
1 \\
1 \\
1 \\
1 \\
1 \\
2 \\
1 \\
1 \\
1 \\
1 \\
1\end{array}$ & $\begin{array}{l}1.366 \\
1.483 \\
1.389 \\
1.327 \\
1.468 \\
1.342 \\
1.396 \\
1.468 \\
1.637 \\
1.461 \\
1.662 \\
1.311 \\
1.689 \\
1.449 \\
1.665 \\
1.499 \\
1.381 \\
1.466 \\
1.425 \\
1.426 \\
1.617 \\
1.416 \\
1.486 \\
1.479 \\
1.323 \\
1.448 \\
1.311 \\
1.381 \\
1.368 \\
1.348 \\
1.261 \\
1.332 \\
1.340 \\
1.461 \\
1.312 \\
1.468 \\
1.283 \\
1.366 \\
1.419 \\
1.375 \\
1.289 \\
1.187 \\
1.369 \\
1.313 \\
1.212 \\
1.467\end{array}$ & $\begin{array}{l}2 \\
2 \\
1 \\
1 \\
1 \\
2 \\
1 \\
1 \\
1 \\
2 \\
1 \\
2 \\
1 \\
2 \\
2 \\
2 \\
2 \\
2 \\
2 \\
2 \\
1 \\
2 \\
2 \\
1 \\
2 \\
1 \\
2 \\
1 \\
2 \\
2 \\
2 \\
2 \\
2 \\
1 \\
2 \\
1 \\
2 \\
2 \\
1 \\
2 \\
2 \\
2 \\
1 \\
1 \\
2 \\
1\end{array}$ & $\begin{array}{l}H \\
H \\
V \\
H \\
V \\
H \\
V \\
H \\
V \\
H \\
V \\
H \\
H \\
V \\
H \\
V \\
H \\
V \\
H \\
V \\
H \\
V \\
H \\
V \\
H \\
V \\
V \\
H \\
V \\
H \\
V \\
H \\
V \\
H \\
V \\
H \\
V \\
H \\
H \\
V \\
H \\
V \\
H \\
V \\
H \\
V\end{array}$ & $\begin{array}{l}\text { MAST } \\
\text { MAST } \\
\text { MAST } \\
\text { SURB } \\
\text { SURB } \\
\text { SURB } \\
\text { SURB } \\
\text { SURB } \\
\text { SURB } \\
\text { SURB }\end{array}$ & $\begin{array}{l}\text { SURB } \\
\text { OSST }\end{array}$ & \\
\hline
\end{tabular}


Acetone Mouse Toratology Study: Raw Fotel Data

\begin{tabular}{|c|c|c|c|c|c|c|c|c|}
\hline Metno & site & Status & $\begin{array}{l}\text { Fotal } \\
\operatorname{wt}(\theta)\end{array}$ & Sox & $\begin{array}{l}\text { Head } \\
\text { or Víceral }\end{array}$ & ABN1 & ABN2 & ABN3 \\
\hline $\begin{array}{l}1312 \\
1328 \\
1328 \\
1328 \\
1328 \\
1328 \\
1328 \\
1328 \\
1328 \\
1328 \\
1328 \\
1328 \\
1328\end{array}$ & $\begin{array}{r}10 \\
1 \\
2 \\
3 \\
4 \\
6 \\
8 \\
7 \\
8 \\
9 \\
10 \\
11 \\
12\end{array}$ & $\begin{array}{l}1 \\
1 \\
1 \\
1 \\
1 \\
1 \\
1 \\
4 \\
1 \\
1 \\
1 \\
1 \\
1\end{array}$ & $\begin{array}{l}1.360 \\
1.243 \\
1.670 \\
1.321 \\
1.367 \\
1.318 \\
1.261 \\
1.150 \\
1.112 \\
1.110 \\
1.214 \\
1.287\end{array}$ & $\begin{array}{l}1 \\
2 \\
1 \\
1 \\
2 \\
1 \\
2 \\
\vdots \\
1 \\
2 \\
2 \\
1 \\
1\end{array}$ & $\begin{array}{l}H \\
H \\
V \\
H \\
V \\
H \\
V \\
\\
H \\
V \\
H \\
V \\
H\end{array}$ & $\begin{array}{l}\text { ROST } \\
\text { MAST } \\
\text { MAST }\end{array}$ & & \\
\hline
\end{tabular}


Acetone Mouse Teratology Study: Row Fotel Data

\begin{tabular}{|c|c|c|c|c|c|c|c|c|c|}
\hline & Matno & Sito & Stetus & $\begin{array}{l}\text { Fot } 01 \\
\text { wt (g) }\end{array}$ & Sex & $\begin{array}{l}\text { Head } \\
\text { or Viaceral }\end{array}$ & ABN1 & ABN2 & ABN3 \\
\hline $\begin{array}{l}\Omega \\
\infty \\
\infty \\
.\end{array}$ & 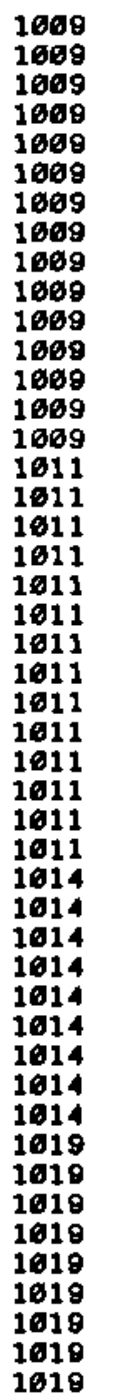 & $\begin{array}{r}1 \\
2 \\
3 \\
4 \\
6 \\
8 \\
7 \\
8 \\
9 \\
16 \\
11 \\
12 \\
13 \\
14 \\
15 \\
1 \\
2 \\
3 \\
4 \\
5 \\
6 \\
7 \\
8 \\
9 \\
16 \\
11 \\
12 \\
13 \\
14 \\
1 \\
2 \\
3 \\
4 \\
5 \\
8 \\
7 \\
8 \\
9 \\
1 \\
2 \\
3 \\
4 \\
5 \\
8 \\
7 \\
8 \\
9\end{array}$ & $\begin{array}{l}1 \\
1 \\
1 \\
1 \\
1 \\
1 \\
1 \\
1 \\
1 \\
2 \\
2 \\
1 \\
1 \\
1 \\
1 \\
1 \\
2 \\
1 \\
1 \\
1 \\
1 \\
1 \\
1 \\
4 \\
1 \\
1 \\
1 \\
1 \\
1 \\
1 \\
1 \\
1 \\
1 \\
1 \\
1 \\
1 \\
1 \\
1 \\
1 \\
1 \\
1 \\
1 \\
1 \\
1 \\
1 \\
1 \\
1\end{array}$ & 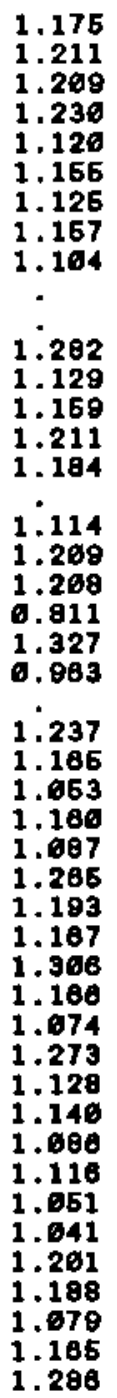 & $\begin{array}{l}2 \\
1 \\
2 \\
2 \\
2 \\
2 \\
1 \\
1 \\
2 \\
\vdots \\
i \\
2 \\
2 \\
1 \\
2 \\
i 2 \\
2 \\
1 \\
1 \\
2 \\
1 \\
i \\
1 \\
2 \\
1 \\
2 \\
1 \\
1 \\
1 \\
1 \\
2 \\
2 \\
1 \\
2 \\
1 \\
2 \\
2 \\
2 \\
2 \\
1 \\
1 \\
1 \\
1 \\
1\end{array}$ & $\begin{array}{l}\mathbf{V} \\
\mathbf{H} \\
\mathbf{V} \\
\mathbf{H} \\
\mathbf{H} \\
\mathbf{V} \\
\mathbf{H} \\
\mathbf{V} \\
\\
\mathbf{H} \\
\mathbf{V} \\
\mathbf{H} \\
\mathbf{V} \\
\mathbf{V} \\
\mathbf{H} \\
\mathbf{V} \\
\mathbf{H} \\
\mathbf{V} \\
\mathbf{H} \\
\mathbf{V} \\
\mathbf{H} \\
\mathbf{V} \\
\mathbf{V} \\
\mathbf{H} \\
\mathbf{H} \\
\mathbf{U} \\
\mathbf{H} \\
\mathbf{V} \\
\mathbf{H} \\
\mathbf{V} \\
\mathbf{H} \\
\mathbf{V} \\
\mathbf{H} \\
\mathbf{H} \\
\mathbf{V} \\
\mathbf{H} \\
\mathbf{V} \\
\mathbf{H} \\
\mathbf{V} \\
\mathbf{H} \\
\mathbf{V} \\
\mathbf{H}\end{array}$ & $\begin{array}{l}\text { SURB } \\
\text { SURB }\end{array}$ & & \\
\hline
\end{tabular}


Acetone Mouse Teratology Study: Ra- Fotal Data

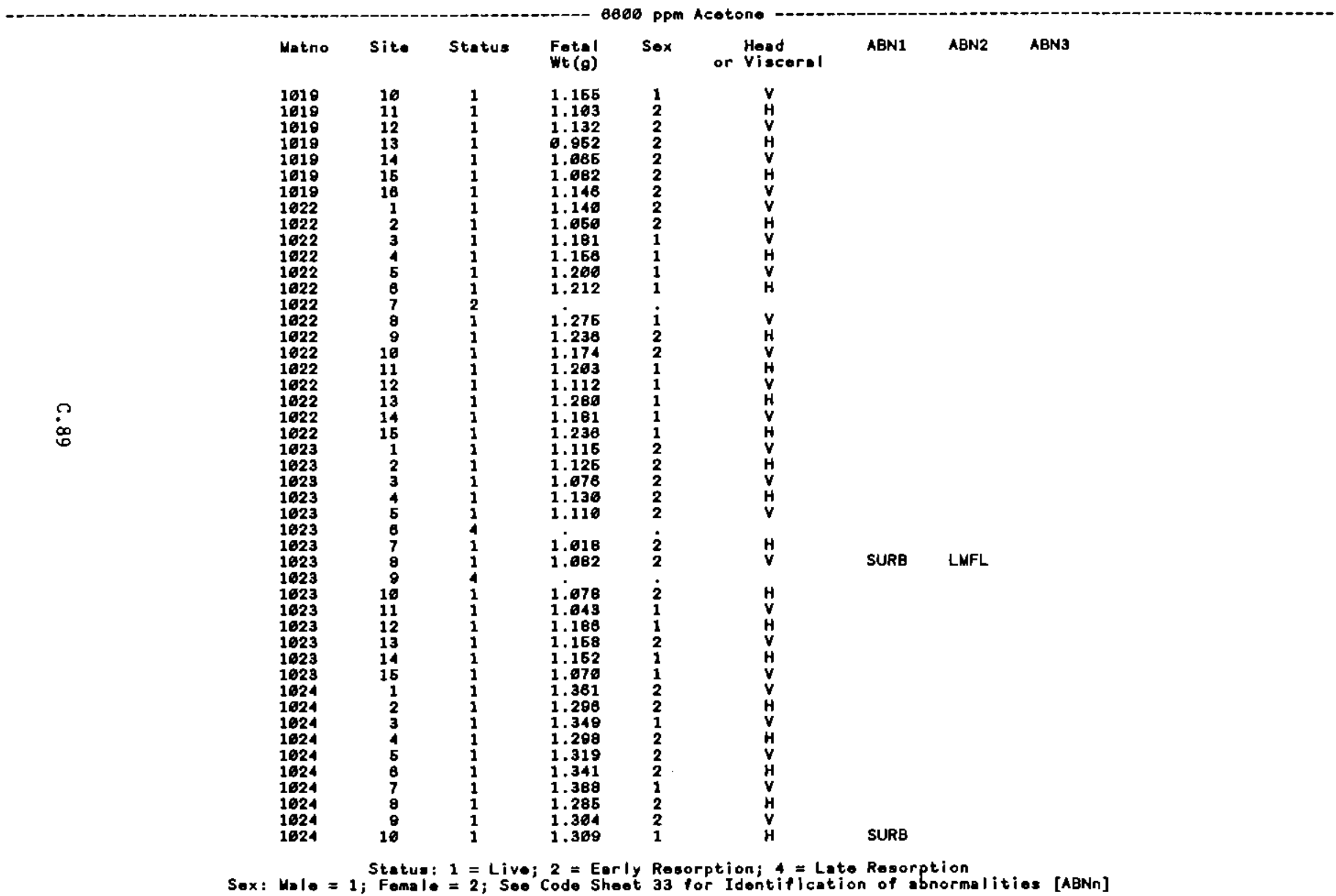


Acetone House Terotology Study: Raw Fotal Data

\begin{tabular}{|c|c|c|c|c|c|c|c|c|c|}
\hline & Metno & Site & Status & $\begin{array}{l}\text { Fetal } \\
\text { wt (g) }\end{array}$ & Sox & $\begin{array}{l}\text { Heed } \\
\text { or Viscerel }\end{array}$ & ABN1 & ABN2 & ABN3 \\
\hline $\begin{array}{l}\Omega \\
\stackrel{\circ}{\circ}\end{array}$ & 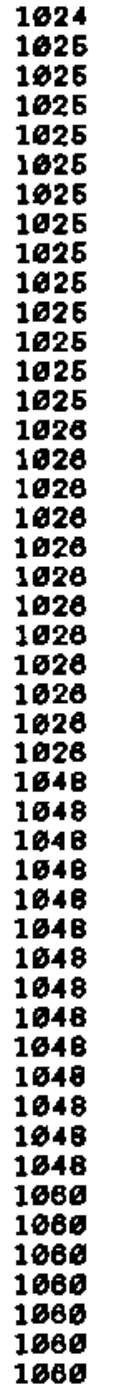 & 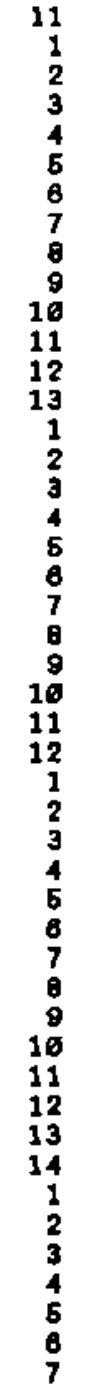 & $\begin{array}{l}1 \\
1 \\
1 \\
1 \\
1 \\
1 \\
1 \\
1 \\
1 \\
1 \\
1 \\
1 \\
1 \\
1 \\
1 \\
1 \\
1 \\
1 \\
1 \\
1 \\
1 \\
1 \\
1 \\
1 \\
1 \\
1 \\
1 \\
1 \\
1 \\
1 \\
1 \\
1 \\
1 \\
1 \\
2 \\
1 \\
1 \\
1 \\
1 \\
2 \\
1 \\
1 \\
1 \\
1 \\
1\end{array}$ & $\begin{array}{l}1.306 \\
1.113 \\
1.173 \\
1.277 \\
1.262 \\
1.186 \\
1.238 \\
1.249 \\
1.061 \\
1.223 \\
1.168 \\
1.234 \\
1.196 \\
1.236 \\
1.343 \\
1.216 \\
1.114 \\
1.231 \\
1.361 \\
1.286 \\
1.278 \\
1.355 \\
1.406 \\
1.399 \\
1.428 \\
1.048 \\
1.612 \\
0.989 \\
6.826 \\
6.942 \\
1.011 \\
1.031 \\
6.914 \\
1.617 \\
1.061 \\
6.056 \\
6.562 \\
1.423 \\
1.363 \\
1.363 \\
1.258 \\
1.127 \\
1.326\end{array}$ & $\begin{array}{l}1 \\
2 \\
2 \\
1 \\
1 \\
2 \\
1 \\
1 \\
2 \\
1 \\
2 \\
1 \\
2 \\
1 \\
2 \\
1 \\
2 \\
1 \\
1 \\
i \\
1 \\
1 \\
1 \\
2 \\
1 \\
1 \\
2 \\
2 \\
1 \\
2 \\
1 \\
1 \\
2 \\
1 \\
i \\
2 \\
1 \\
i \\
2 \\
1 \\
2 \\
1 \\
2\end{array}$ & $\begin{array}{l}V \\
V \\
H \\
V \\
H \\
V \\
H \\
V \\
H \\
V \\
H \\
V \\
H \\
V \\
H \\
V \\
H \\
V \\
H \\
V \\
H \\
V \\
H \\
V \\
H \\
V \\
H \\
V \\
H \\
V \\
H \\
V \\
H \\
V \\
Y H \\
V \\
H \\
H \\
V \\
H \\
V \\
H \\
V\end{array}$ & $\begin{array}{l}\text { DIUR } \\
\text { ROST } \\
\text { ROST } \\
\text { ROST } \\
\text { MAST } \\
\text { ROST } \\
\text { MAST } \\
\text { MAST } \\
\text { MAST } \\
\\
\text { SURB } \\
\text { SURB }\end{array}$ & $\begin{array}{l}\text { MAST } \\
\text { SURB } \\
\text { ROST } \\
\text { ROST } \\
\text { ROST }\end{array}$ & SURB \\
\hline
\end{tabular}

Sox: Mele = 1 ; Femele $=2$; Seo Code Sheot 33 for Identification of obnormalities [ABNn] 
Acetone Mouse Toratology Study: Raw Fotel Dato

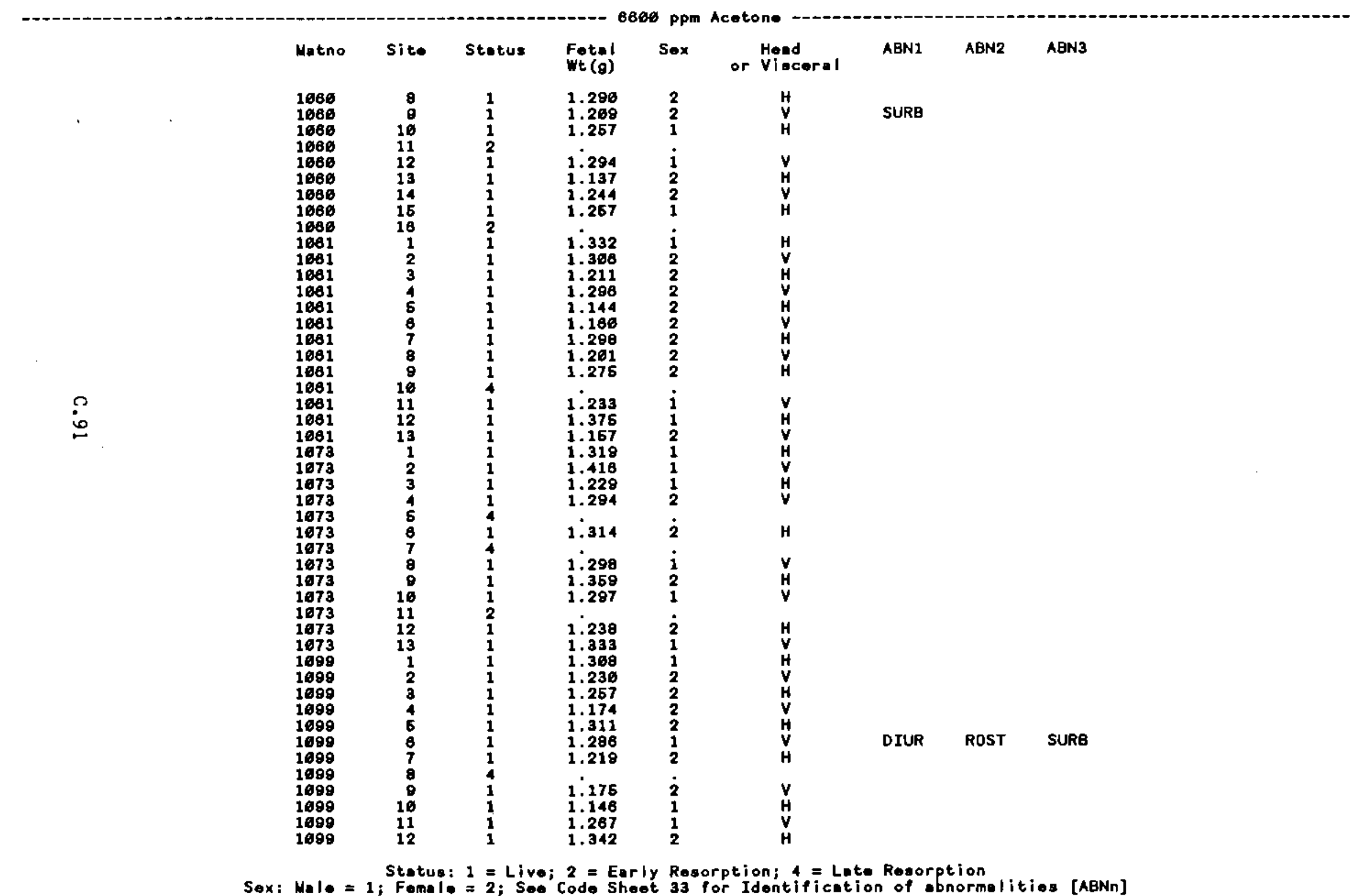


Acotone Mouse Teratology Study: Raw Fotel Dete

\begin{tabular}{|c|c|c|c|c|c|c|c|c|c|}
\hline & Matno & site & Stetus & $\begin{array}{l}\text { Fetal } \\
\text { wt (g) }\end{array}$ & Sex & $\begin{array}{l}\text { Head } \\
\text { or Vioceral }\end{array}$ & ABN1 & ABN2 & ABN3 \\
\hline م & $\begin{array}{l}1118 \\
1118 \\
1118 \\
1118 \\
1118 \\
1118 \\
1118 \\
1118 \\
1118 \\
1118 \\
1118 \\
1118 \\
1118 \\
1142 \\
1142 \\
1142 \\
1142 \\
1142 \\
1142 \\
1142 \\
1142 \\
1142 \\
1142 \\
1142 \\
1144 \\
1144 \\
1144 \\
1144 \\
1144 \\
1144 \\
1144 \\
1144 \\
1144 \\
1144 \\
1168 \\
1168 \\
1168 \\
1168 \\
1168 \\
1168 \\
1168 \\
1168 \\
1168 \\
1168 \\
1172 \\
1172 \\
1172\end{array}$ & $\begin{array}{r}1 \\
2 \\
3 \\
4 \\
5 \\
6 \\
7 \\
8 \\
9 \\
10 \\
11 \\
12 \\
13 \\
1 \\
2 \\
3 \\
4 \\
5 \\
6 \\
7 \\
8 \\
9 \\
16 \\
11 \\
1 \\
2 \\
3 \\
4 \\
6 \\
6 \\
7 \\
0 \\
0 \\
10 \\
1 \\
2 \\
3 \\
4 \\
6 \\
8 \\
7 \\
8 \\
9 \\
10 \\
1 \\
2 \\
3\end{array}$ & $\begin{array}{l}4 \\
1 \\
1 \\
4 \\
1 \\
1 \\
1 \\
1 \\
1 \\
4 \\
1 \\
4 \\
1 \\
1 \\
1 \\
1 \\
1 \\
1 \\
1 \\
1 \\
1 \\
1 \\
4 \\
1 \\
1 \\
1 \\
1 \\
1 \\
1 \\
1 \\
1 \\
2 \\
1 \\
1 \\
1 \\
1 \\
1 \\
1 \\
1 \\
1 \\
1 \\
4 \\
4 \\
1 \\
1 \\
1 \\
1\end{array}$ & $\begin{array}{r}1.166 \\
1.268 \\
1.186 \\
1.132 \\
1.116 \\
1.182 \\
1.183 \\
1.165 \\
1.166 \\
1.182 \\
1.210 \\
1.248 \\
1.314 \\
1.224 \\
1.274 \\
1.295 \\
1.282 \\
1.185 \\
1.296 \\
1.163 \\
1.229 \\
1.262 \\
1.219 \\
1.264 \\
1.199 \\
1.330 \\
1.124 \\
1.696 \\
1.288 \\
1.236 \\
1.207 \\
1.225 \\
1.246 \\
1.261 \\
1.211 \\
.2 \\
1.197 \\
1.237 \\
1.229 \\
1.162\end{array}$ & $\begin{array}{l}\dot{2} \\
2 \\
i \\
2 \\
1 \\
1 \\
2 \\
i \\
\dot{2} \\
1 \\
1 \\
1 \\
1 \\
2 \\
1 \\
1 \\
2 \\
1 \\
1 \\
2 \\
2 \\
2 \\
1 \\
1 \\
2 \\
1 \\
\dot{2} \\
1 \\
1 \\
1 \\
2 \\
2 \\
1 \\
2 \\
1 \\
\dot{2} \\
2 \\
1 \\
1 \\
1\end{array}$ & 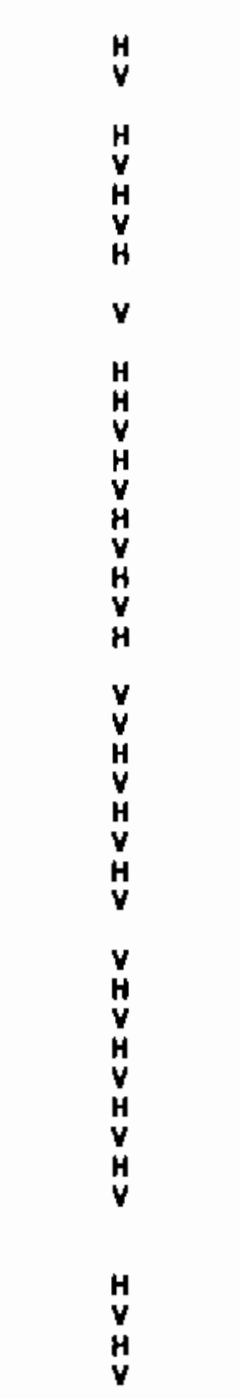 & $\begin{array}{l}\text { MAST } \\
\text { ROST } \\
\text { ROST } \\
\text { MAST } \\
\text { ROST } \\
\text { MAST } \\
\text { MAST } \\
\text { MAST } \\
\text { ROST } \\
\text { ROST } \\
\text { ROST }\end{array}$ & $\begin{array}{l}\text { ROST } \\
\text { ROST } \\
\text { MAST } \\
\text { SURB }\end{array}$ & \\
\hline
\end{tabular}


SAS

Acetone Mouse Torotology Study: Raw Fetal Data

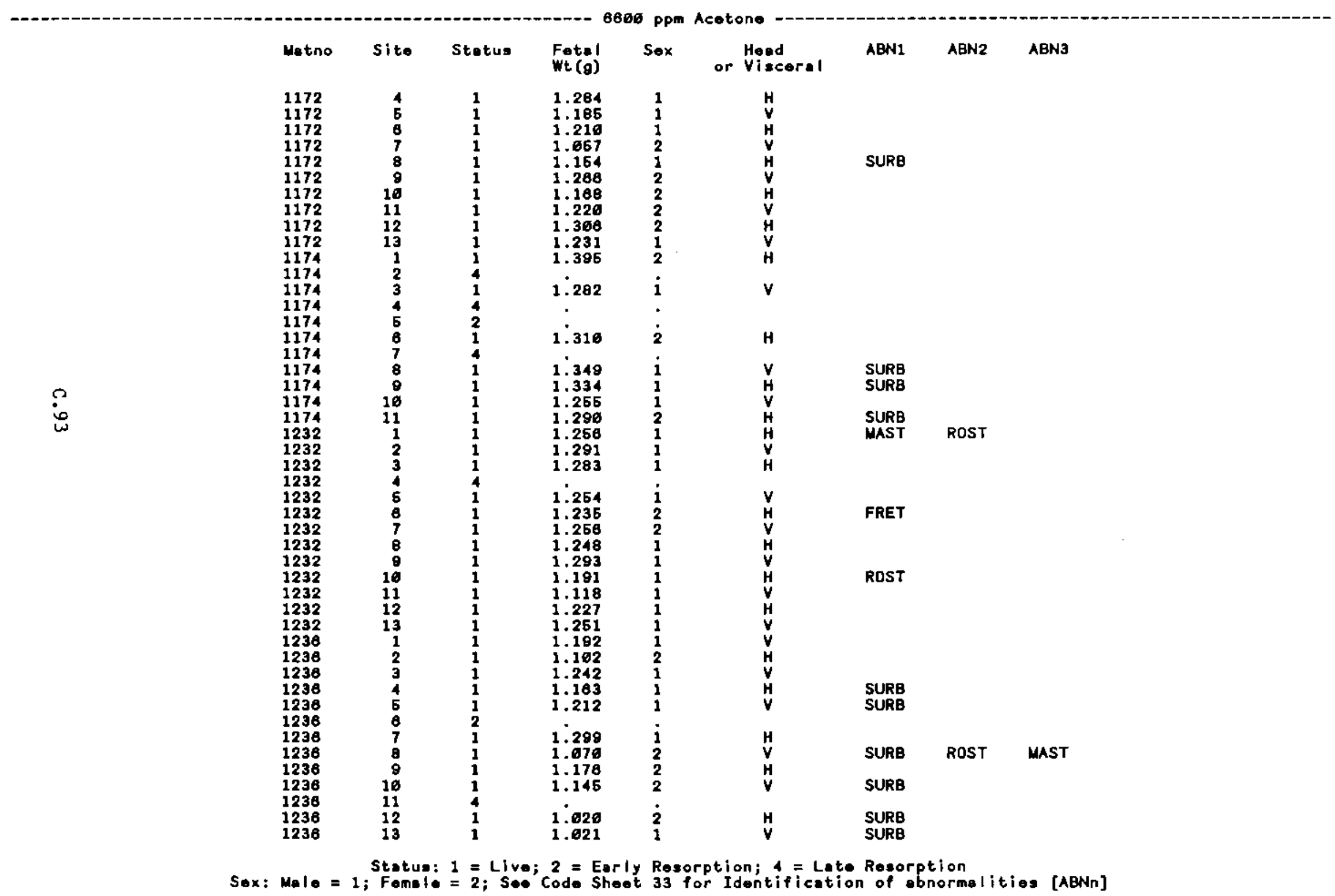


Acetone Mouse Teratology Study: Row Fotel Dota

6800 ppm Acetone

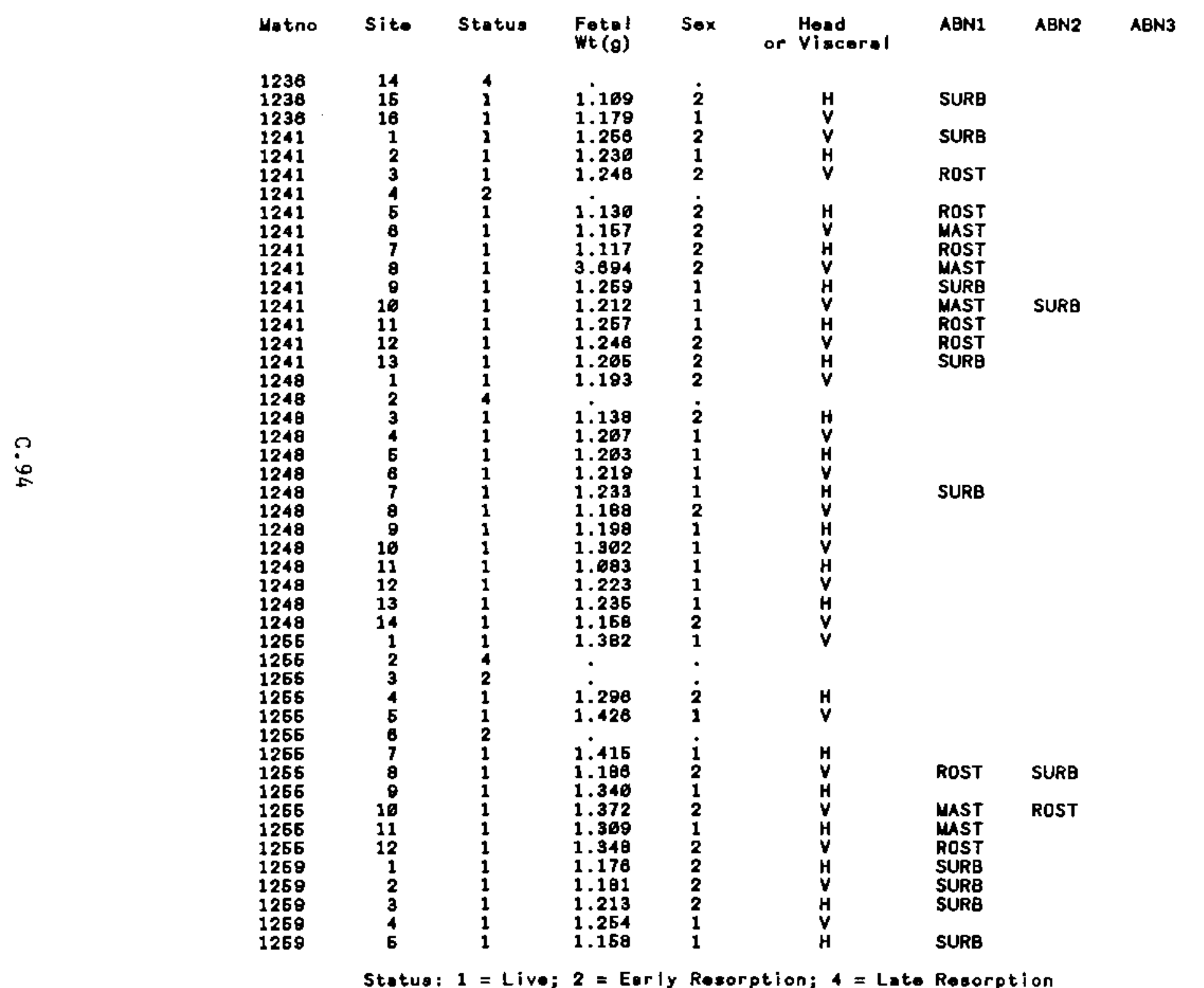

Sox: Mole = 1; Fomale = 2; Seo Code Sheot 33 for Identification of abnormalitios [ABNn] 
SAS

Acotone Mouse Terstology Study: Rew Fotal Data

\begin{tabular}{|c|c|c|c|c|c|c|c|c|}
\hline Matno & Site & Status & $\begin{array}{l}\text { Fotol } \\
\text { Wt (g) }\end{array}$ & Sex & $\begin{array}{l}\text { Heed } \\
\text { or Vieceral }\end{array}$ & ABN1 & ABN2 & ABN3 \\
\hline 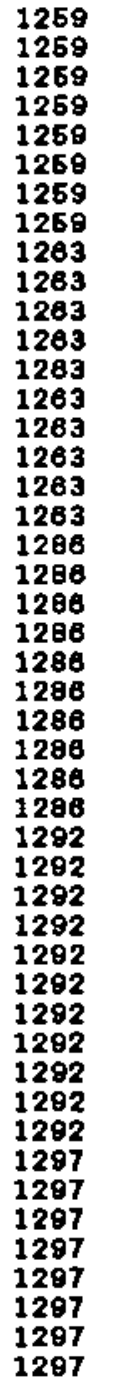 & $\begin{array}{r}8 \\
7 \\
8 \\
8 \\
10 \\
11 \\
12 \\
13 \\
1 \\
2 \\
3 \\
4 \\
5 \\
6 \\
7 \\
8 \\
9 \\
16 \\
1 \\
2 \\
3 \\
4 \\
5 \\
8 \\
7 \\
8 \\
9 \\
10 \\
1 \\
2 \\
3 \\
4 \\
6 \\
6 \\
7 \\
8 \\
9 \\
10 \\
11 \\
1 \\
2 \\
3 \\
4 \\
5 \\
6 \\
7 \\
8\end{array}$ & $\begin{array}{l}2 \\
4 \\
1 \\
1 \\
1 \\
1 \\
1 \\
1 \\
1 \\
1 \\
1 \\
2 \\
1 \\
1 \\
4 \\
1 \\
1 \\
1 \\
1 \\
1 \\
1 \\
1 \\
1 \\
1 \\
1 \\
1 \\
1 \\
1 \\
1 \\
1 \\
1 \\
1 \\
1 \\
1 \\
1 \\
1 \\
1 \\
1 \\
1 \\
1 \\
1 \\
1 \\
1 \\
1 \\
1 \\
1 \\
1\end{array}$ & $\begin{array}{l}1 \\
1.284 \\
1.158 \\
1.298 \\
1.462 \\
1.118 \\
1.158 \\
1.258 \\
1.151 \\
1.196 \\
1.063 \\
1.146 \\
1.164 \\
1.229 \\
1.194 \\
1.244 \\
1.192 \\
1.168 \\
1.216 \\
1.127 \\
1.196 \\
1.277 \\
1.177 \\
1.644 \\
1.313 \\
1.296 \\
1.382 \\
1.384 \\
1.338 \\
1.338 \\
1.337 \\
1.313 \\
1.298 \\
1.426 \\
1.389 \\
1.938 \\
1.188 \\
1.179 \\
1.123 \\
1.131 \\
1.128 \\
1.011 \\
1.072\end{array}$ & 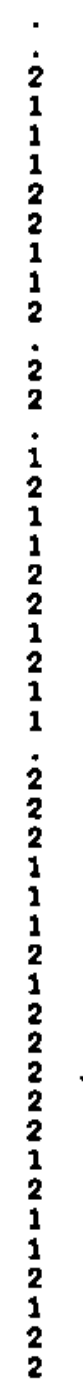 & 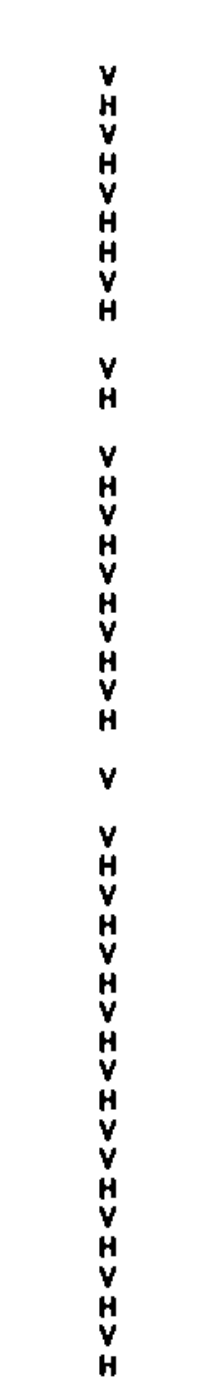 & $\begin{array}{l}\text { EXCE } \\
\text { MAST } \\
\text { MAST } \\
\text { MAST } \\
\text { SURB }\end{array}$ & ROST & ROST \\
\hline
\end{tabular}

Sex: Male = 1 ; Femel: = 2 ; See Code Sheet 33 for Identification of obnormalities [ABNn] 
Acetone Mouse Toratology Study: Rew Fotal Date

6806 ppm Acotone

\begin{tabular}{|c|c|c|c|c|c|c|c|}
\hline Metno & site & Statue & $\begin{array}{l}\text { Fotel } \\
\text { Wt (g) }\end{array}$ & Sox & $\begin{array}{l}\text { Head } \\
\text { or Visecerel }\end{array}$ & ABN1 & ABN2 \\
\hline $\begin{array}{l}1297 \\
1297 \\
1297 \\
1297 \\
1297 \\
1297 \\
1330 \\
1330 \\
1336 \\
1336 \\
1330 \\
1330 \\
1330 \\
1330 \\
1330 \\
1336\end{array}$ & $\begin{array}{r}9 \\
16 \\
11 \\
12 \\
13 \\
14 \\
1 \\
2 \\
9 \\
4 \\
6 \\
8 \\
7 \\
6 \\
9 \\
10\end{array}$ & $\begin{array}{l}4 \\
1 \\
1 \\
4 \\
1 \\
1 \\
1 \\
1 \\
1 \\
1 \\
1 \\
4 \\
1 \\
1 \\
1 \\
2\end{array}$ & $\begin{array}{l}1.685 \\
1.040 \\
0.892 \\
1.025 \\
1.348 \\
1.356 \\
1.444 \\
1.283 \\
1.236 \\
1.289 \\
1.231 \\
1.622 \\
.\end{array}$ & $\begin{array}{l}\text { i } \\
2 \\
\dot{2} \\
2 \\
2 \\
2 \\
1 \\
2 \\
2 \\
\dot{2} \\
2 \\
1\end{array}$ & $\begin{array}{l}\mathbf{V} \\
H \\
\mathbf{V} \\
\mathbf{H} \\
\mathbf{V} \\
\mathbf{H} \\
\mathbf{H} \\
\mathbf{V} \\
\mathbf{H} \\
\mathbf{V} \\
\mathbf{H}\end{array}$ & $\begin{array}{l}\text { MAST } \\
\text { MAST } \\
\text { MAST } \\
\text { MAST } \\
\text { MAST }\end{array}$ & $\begin{array}{l}\text { ROST } \\
\text { SURB }\end{array}$ \\
\hline
\end{tabular}

$\stackrel{?}{2}$ 
Acetone Mouse Teratology Study: Raw Fotal Data

Code Sheot for Identification of Fotel Abnormalities

$\begin{array}{ll}\text { DIUR } & \text { Diloted Ureter } \\ \text { EXCE } & \text { Exencephaly } \\ \text { FRET } & \text { Foldod Retina } \\ \text { FURB } & \text { Fused Ribs } \\ \text { FUST } & \text { Fused Starnebrae } \\ \text { KITA } & \text { Kinked Teil } \\ \text { LMFL } & \text { Limb Flexure } \\ \text { MAST } & \text { Migelignod Stornebra } \\ \text { OSST } & \text { Osaification Site Botween Sternobre } \\ \text { ROST } & \text { Reduced Oesification Sternobra } \\ \text { SURB } & \text { Supernumerary Rib }\end{array}$




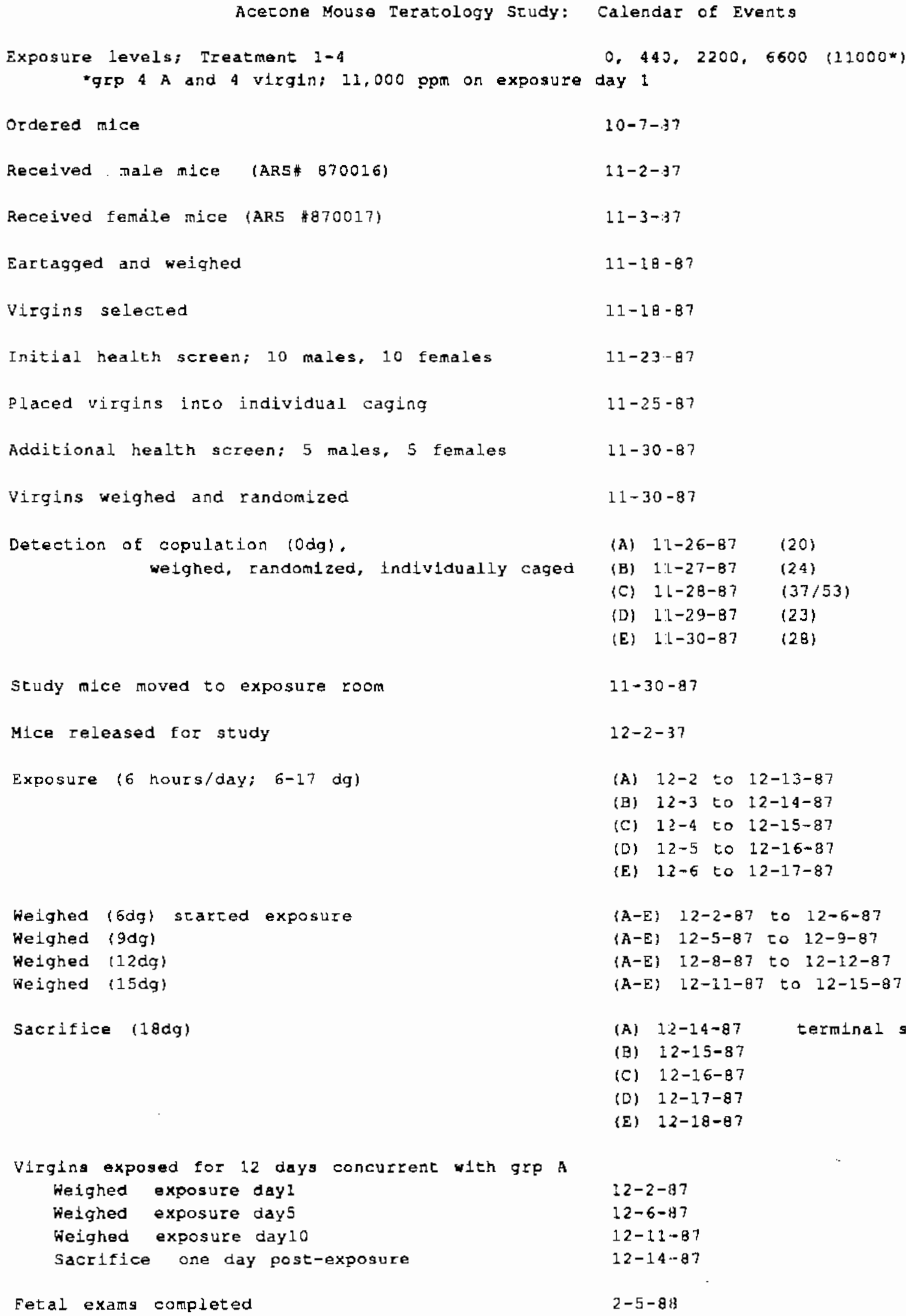


ACETONE MOUSE TERATOLOGY STUDY DISPOSITION

\begin{tabular}{|c|c|c|c|c|c|c|}
\hline \multirow{3}{*}{$\begin{array}{c}\text { Exposure } \\
\text { Group }\end{array}$} & \multirow[b]{3}{*}{ Treatment } & \multirow[b]{3}{*}{ Virgins } & \multicolumn{4}{|c|}{ Plug-Positive Teratology Mice } \\
\hline & & & & Removed & & Litters \\
\hline & & & on Study (a) & From Study & Sacrifice & Examined \\
\hline 440 ppm & 2 & 10 & 33 & 0 & 33 & 28 \\
\hline $2200 \mathrm{ppm}$ & 3 & 10 & 33 & 0 & 33 & 29 \\
\hline
\end{tabular}

(a) The study protocol required a minimum of 33 plug-positive females (to obtain 20 pregnant females).

(b) Breeding group $4 \mathrm{~A}$ and virgin mice were exposed at 11000 ppm on exposure day 1. Due to narcosis, the exposure level was thereafter reduced to $6600 \mathrm{ppm}$.

(c) Premature delivery of litter; not treatment related. 
. 


\section{APPENDIX D}

ANIMAL REALTE SCREEN 
ARC RODENT HEALTH SCREEN REROE:

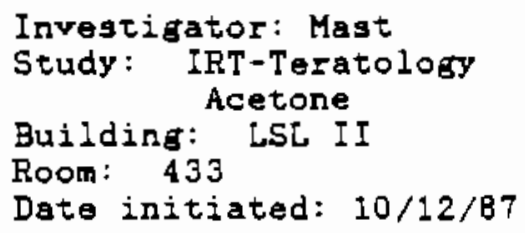

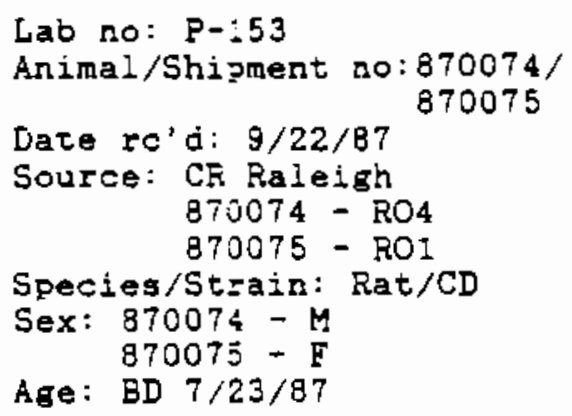

Statug: Received ten rats ( 5 males, $\$ 1-5 ; 5$ females, \#6-10) for pre-exposure health screen

\section{Gross Necropsy}

No significant lesions

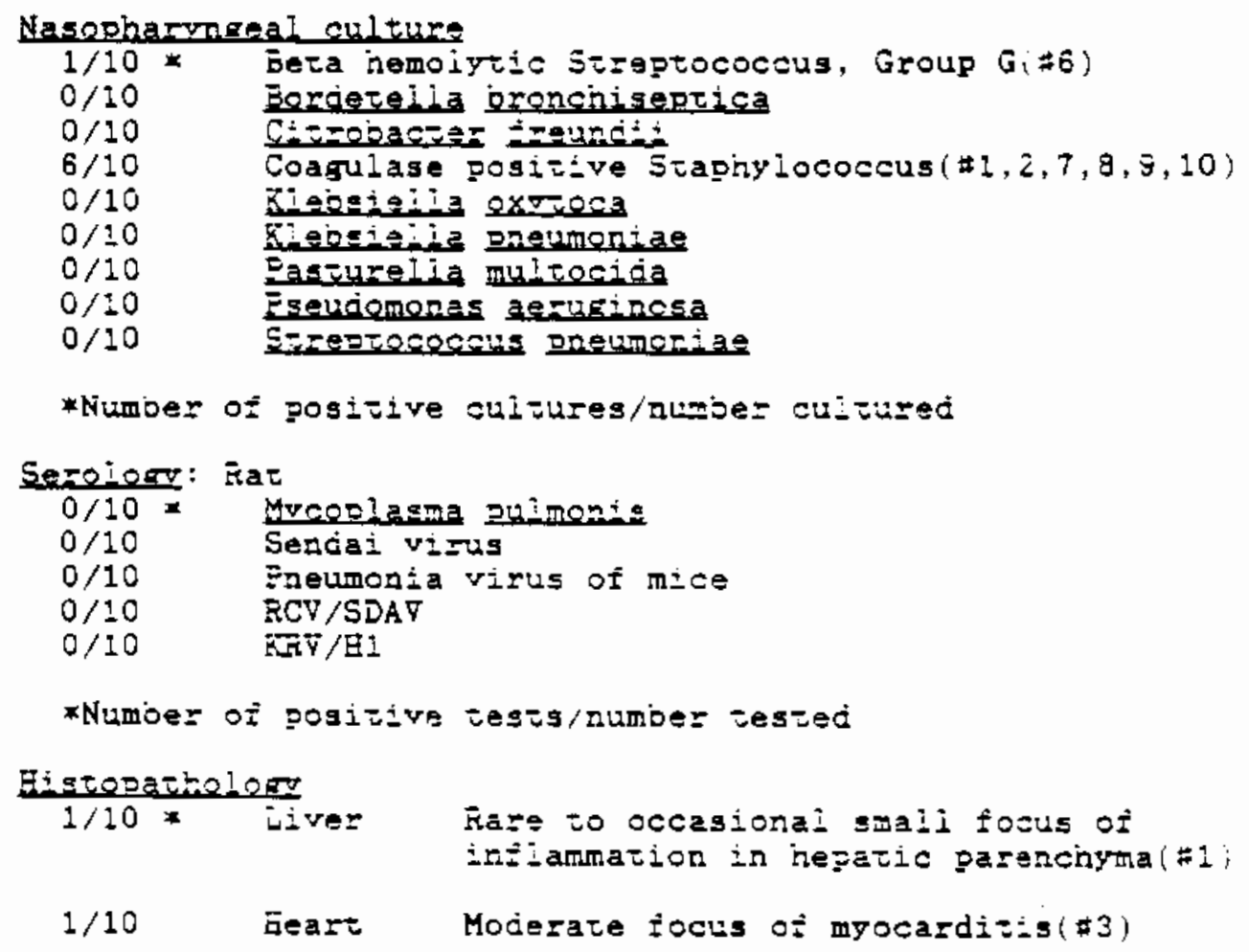


1/10 Lung Eocai aree with perivascular cuizing witis FMN'S( 14 )

1/10 Lung Occusional paravascuiar aggregate of mixed inziammatory ceils(75)

$3 / 10$ Liver Fazo tiny Eocug of inilammation in hepatic parencingma $(=5,7,10)$

*Numider af̌ecred/numider examized

\section{Cormelation/SummarT}

Tine Group G Streptococcus has deer found greviously in rats from RO1. Fis have reportad tiig to Charies River. They have seen no eviesnce of signiticane infectior asgociated with tinis organigm noz have we. The miczoscopic legiong ars of no particular concezo but since some ثocai intlammation was seen, ten additional rass wili be evaluased to assure that thers has been no progression of lesions. The joilow-up Hill inciude culture and geroiosy. Rars are not to de reieased from guarantine until the soliow-ue is compieted.

$$
\text { Released For Study on } 10 / 16 / 87 \text {. }
$$

$\frac{\text { QEfonee } 10 / 23 / 87}{\text { Tecinologist }}$

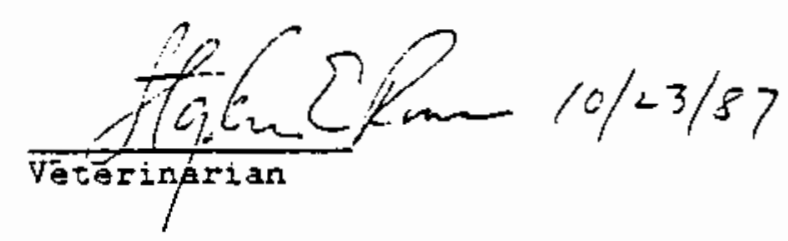


ARC RODENT HEALTE SCEEEN RLEFORT

Invesigator: Mage

Study: $i R T$-icetone

Building: LSi II

Room: 433

Date initiatad: $10 / 26 / 87$
Lab no: $F \rightarrow 160$

Animal/Sinipment no:870074/

870075

Daze rc'à $9 / 22 / 87$

Source: CR Raieigh

870074 - R04

870075 - RO1

Species/Strain: Rat/CD

Sex: 870074 -

$870075-7$

Age: BD $7 / 23 / 87$

Starin: Recoived ten rats ( $\$ 1-5$, males; $16-10$, Ėmales) for follow-up health scroen of $F-153$

Serology: Rat

$0 / 10 *$ Meoplasma pulmonis

$0 / 10 \quad$ Sendai virug

$0 / 10$ Pneumonia virus of mice

$0 / 10 \quad \mathrm{RCV} / \mathrm{SDAV}$

$0 / 10 \quad \mathrm{KRV} / \mathrm{HI}$

* Number of positive tests/number tested

\author{
Nasopharyngeal oulture \\ $2 / 10 *$ Beta hemolytic Streptococcus, Group $G y(\neq 8,9)$ \\ $0 / 10$ \\ Bordetella bronchisegtica \\ $0 / 10$ \\ Citrobacter ireundij \\ $8 / 10$ \\ Coapulase positive Staphy lococcus ( $\$ 1,2,3,5,7,8,9,10)$ \\ $0 / 10$ \\ $0 / 10$ \\ Clebsiella exvtoca \\ Klebsialla pneumonize \\ $0 / 10 \quad$ Easturella multocida \\ $0 / 10$ Pseudomonas aeruginesa \\ $0 / 10$ Streptococcus preumoniae \\ * Number or positive cultures/number cultured
}

Histopatholory

$2 / 10$ t Hard. gl. Rare tiny focus of inflammation $(\$ 1,5)$ 


\begin{tabular}{|c|c|c|}
\hline $5 / 10$ & Liver & $\begin{array}{l}\text { Rare to occasional tiny focus of } \\
\text { inflammation in hepatic parenchyma } \\
(\sharp 1,2,3,5,6)\end{array}$ \\
\hline $3 / 10$ & Heart & $\begin{array}{l}\text { Rare tiny focus of inflammation in } \\
\text { myocardium }(\sharp 1)\end{array}$ \\
\hline $3 / 10$ & Lung & $\begin{array}{l}\text { Occasional ting subpleural focus of } \\
\text { inflammation }(\# 2,4,10)\end{array}$ \\
\hline $2 / 10$ & Kidney & $\begin{array}{l}\text { Rare tiny focus of taflammation in } \\
\text { interstitium }(\$ 2,5)\end{array}$ \\
\hline $1 / 10$ & $\begin{array}{l}\text { Subman. } \\
\text { Lyenph }\end{array}$ & Slight to moderate hyperplasia $(\neq 6)$ \\
\hline
\end{tabular}

* Number affected/number examined

Correlation/Summan

A fen incidental microscopic lesions were geen in these rats. The digtribution and geverity are similar to that found in the first rats examined from this group ( $P-153$ ). Since there has been no significant progression of the lesions seen previously and since serologic teats for antibodtes to common parhogens remain negative, tigese leaiong are not consibered to be an indication of significant tnfection or disease.

On the same day tiat tiris heal th screen was initiazed $(10 / 26 / 87)$, a fow female rats assignod to this study were noted to be mairing poor woight gaing (or to have wetaj: iosses). S.I.Rowe examined these animais on $10 / 27$ p.m. anc agais on $10 / 28$ a.t. Some of thoge witi the poor weigit gaing resistes handisng while the normal weigint gain zats were easy to handie. Excepr for being underweight and having gomewhat roughened hais coats, no physical abnormaities wero found in ine poor weigis gain rats. A pathological evaluation rili be made of a fes of tinese animals at reminal sacritice.

Dr. Tom Dayis from Crarles River sas concacted about tire weight/handling proilem as veil as ine izcidenval iesions. be reported no inowledge of any disease or denaviozal probiem in - tiner Raleigir RO1 or RO4 but is to checir furtier and call back. These animals will be heid in quarantine status for tine duration of the study. This is a precautionary measure winicin should not impact on the cost of running ine siudy.
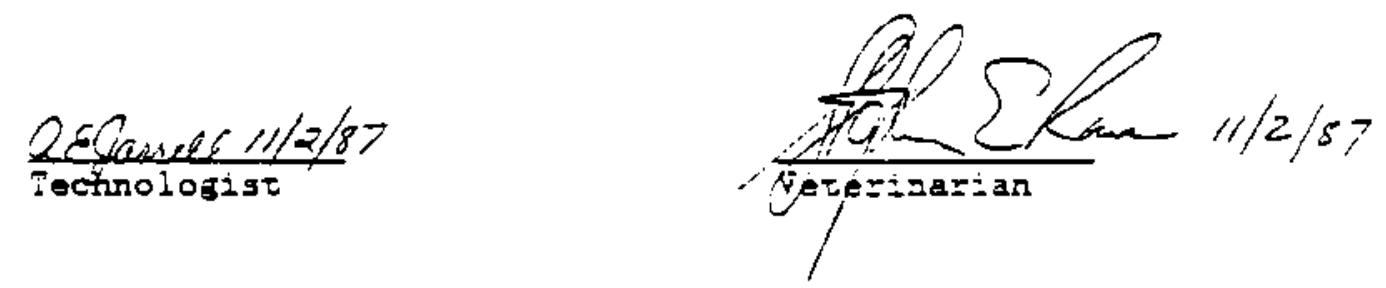
ARC RODENT GEALTE SCREEN REPORT

Inyestigator: Mast Sruiy: IRT-Acetone Building: LSL II Foom: 433

Daze iniziated: $10 / 29 / 87$
Lai no: P-I65

Animal/Sipipment no:870074/

Date ro'd: $9 / 22 / 87$

Source: CR Raieigin 87007s - RO4 870075 - EO1

Species/Strain: Rat/CD

Sex: $870074-H$ $870075-E$

Age: BD $7 / 23 / 87$

Statua: Seven anal tape preps were taken from rats in the 440 pom cinamoer and tinree from the conirol chanoer to examine for pinworm ora.

\section{Encoparasite/Ectoparasite exam}

$0 / 10$ * Anai tape preps for pinworm ova

* Number positive/number examined

\section{Comments/Summary}

No ova were iound. If any pinworss are pregent in these animals, they are sexually immature. It is considered unliueiy that there has been any exposure to or infection by pinworms in this group of rats.
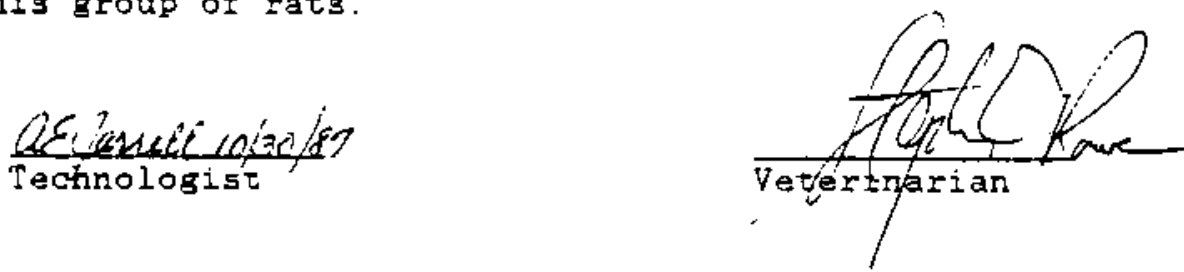
Investigator: Mast

Study: IRT-Acetone

Building: LSL II

Koom: 433

Date initiated: $11 / 9 / 87$
Lab no: $\mathrm{P}-168$

Animal/Shipment no:870074/

870075

Dase rc'd: $9 / 22 / 87$

Source: CR Rajeigh RO1

Species/Strain: Rat/CD

Sex: F Age: BD 7/23/87

Status: Received eight rats (Animal \#5 728, 747, 771, 776, 809, 820,684 , and 773 ) from gestation group A which had snown weight loss prior to exposure. Blood was obtained from all rats with the exception of $\sharp 728$ and 747 .

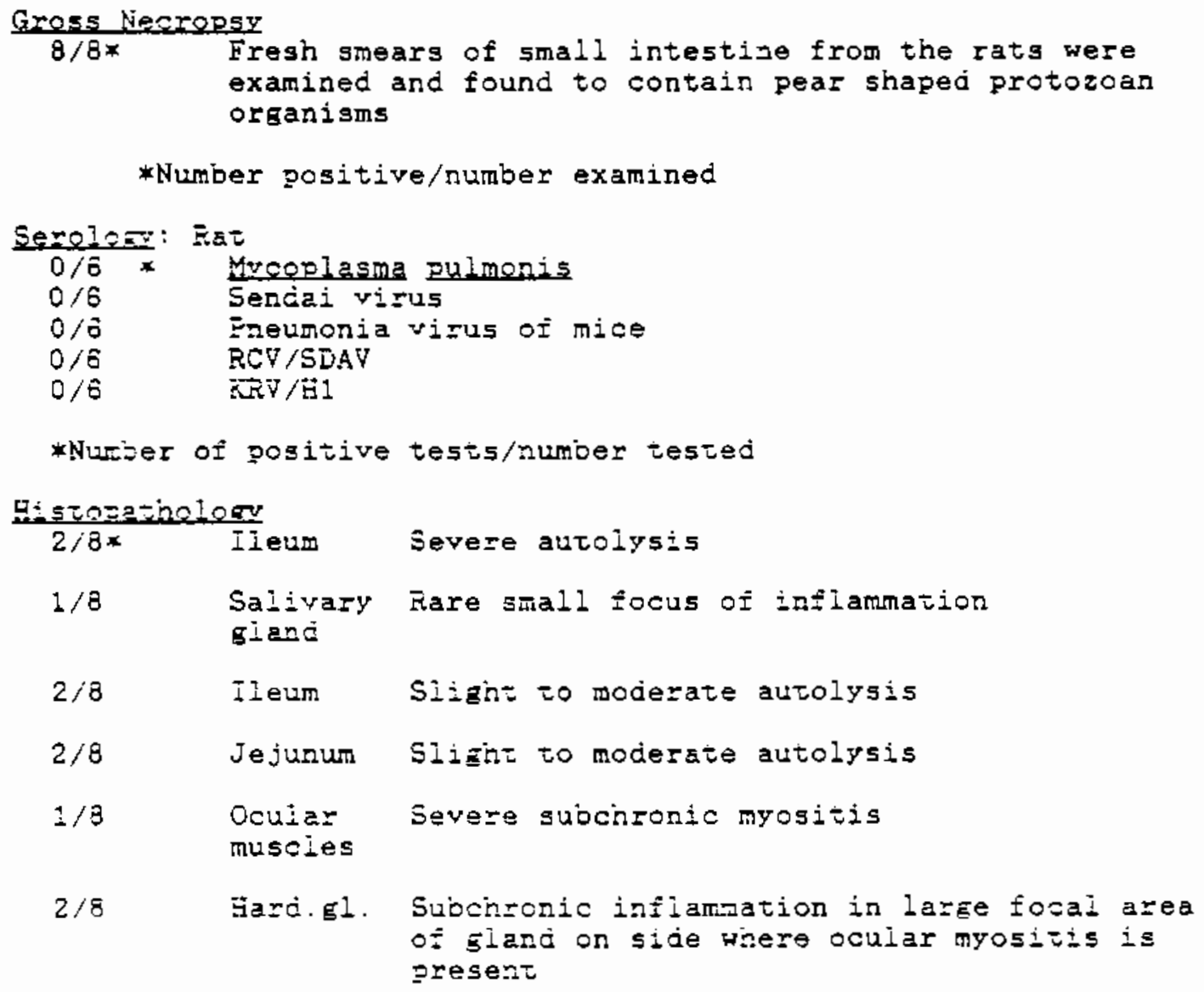




\begin{tabular}{|c|c|c|}
\hline $1 / 8$ & $\begin{array}{l}\text { Ocuiar } \\
\text { mugeies }\end{array}$ & $\begin{array}{l}\text { Sligint to moderate focai iemorriags and } \\
\text { intiammation }\end{array}$ \\
\hline $1 / 8$ & Livar & 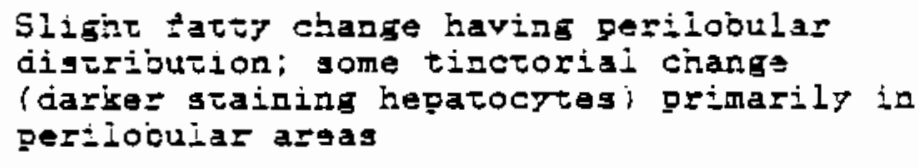 \\
\hline & Kiċey & Sligit autoiysis in focai araas of mecuila \\
\hline
\end{tabular}

*Numier ఏffected/aumber examined

\section{Comelation/sumbare}

There was no signizicant evidence of inzectious jigegae in any of the animaig examined nor wers trere any tindings winich would explain as earlier weight 10s3. Some unidentified protozoan organisms (possibly Tritrichomonas muris) were found on direct smears from gmall integtines but tinese woro not associated with any lesions. There was evidence of trauma to the ocular mugcies and Garterian gland in the two rats of the group winich were retro-orijilily bled ( $\$ 684,773)$. Rat $\$ 773$ had silght focal hepatocellular Eatty changes which wero presumabiy caused by exposure to ace:one. These rats were not evaluated criticaily sor losions caused by acetone toxicity.

Qcousci: 1/4:87

Technologist

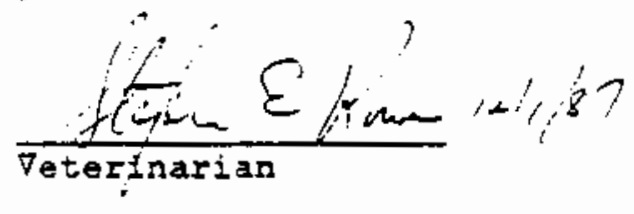




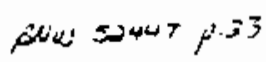

\section{ARC RODENT EALIE SCREIN REEORT}

Inyegtigazor: Mast Stucy: IFr-Acetone Euildiag: [N5 I:

Room: 433

Date initiazed: $11 / 11 / 67$
Las no: $\equiv-170$

Animai/Sinifment no:370074/ 870075

Date re'd: $5 / 22 / 87$

Source: CA Taieigh 리 Specteg/Sirain: Rat/CD Sex: $\bar{F}$ Age: $\overline{\text { JD }} 7 / 23 / 87$

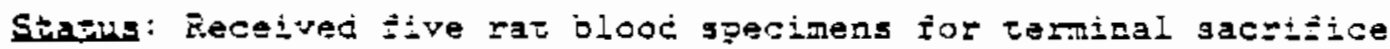
soroiogy (Animai 7694, 697, 700, 738 , and 8.3)

Serolos: Rat

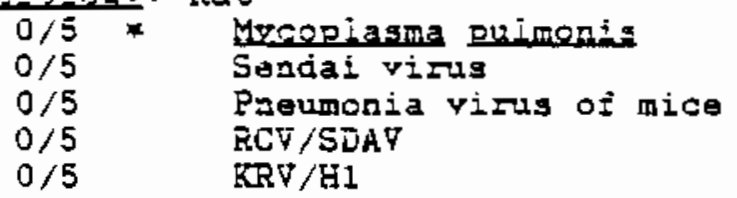

* Number of positive testg/numier tested

Corpelation/Stmman

There was no gerological evidence of infection by any of the above named organisms in any of the rive rats tested.

QE(kuserilso/p)

Tectinologist

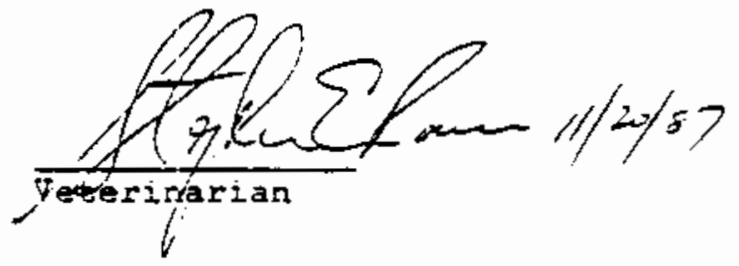


AFC RIDENT HEALTH SCREEN REPORT

Investigator: Mast Study: IRT - Acetone

Building: LSL II

Room: 433

Date initiated: $11 / 12 / 07$
Lai no: $F-171$

Animal/Shipment no: 870075

Date rc'd: $9 / 22 / 87$

Source: CR Raleigh RO1

Species/Strain: Rat/CD

Sex: F Age: BD 7/23/87

Status: Recelved five raz carcasses and blood specimens from gestation group D, a grolip that appeared to have nomai reight gain, for comparison with E-168

\section{Gross Necrepsy}

No significant lesions

\section{Endoparasite/Fotoparasite_exam}

$5 / 5 *$ Intestinal protozoans

*Number positive/nurjer examined

Serolory: Fat

$0 / 5 *$ Mreopiasma Dinimonia

$0 / 5$ Sexcai virug

$0 / 5 \quad$ Eneumoria vizas of mice

$0 / 5 \quad \operatorname{RCV} / 5 D A Y$

$0 / 5 \quad \mathrm{KRV} / \mathrm{B} 1$

*Numider of positive rests/numier tested

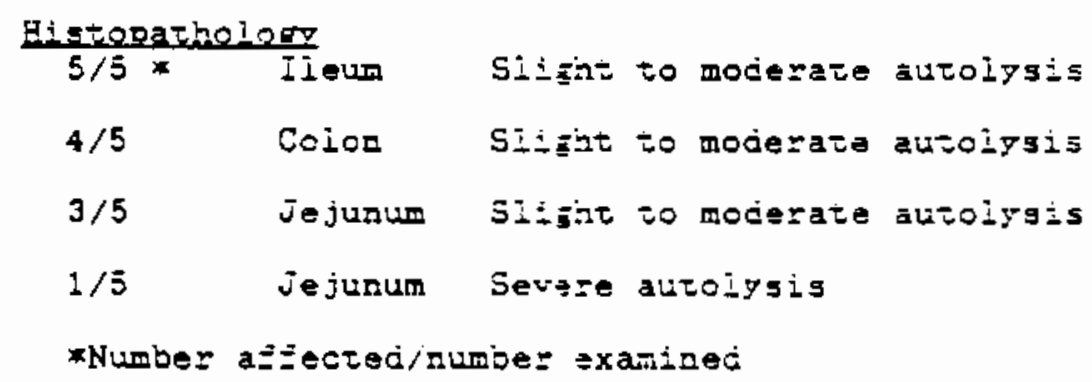




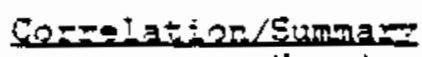

No sigmificant lesions or other significant evidence of infecitous digesse rere iousd in these rats. The intesinal protozoang seen weze not identified (possibly ici-richomonas murig). Altiougi evaiuation of their significance was ooscured ip tie autoissis gresent in intestinal sections irom these ratg, no lesions or evidence of invasion of the mucosa wers seen in other Acetone Siudz rais with tise same organigms. Tissues irom thege rats were not evailuaed criticaily for acgtone toxiciti.

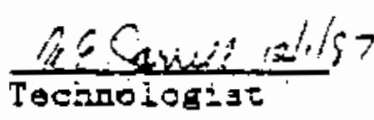

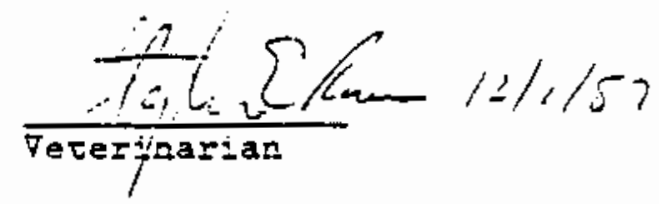


ARC RODENT UEALTF SCEEEN REPORT

Invegrigator: Hast

Scucy: IRT ACezone

Euilding: LSL IE

Room: 433

Date initiated: $11 / 30 / 67$

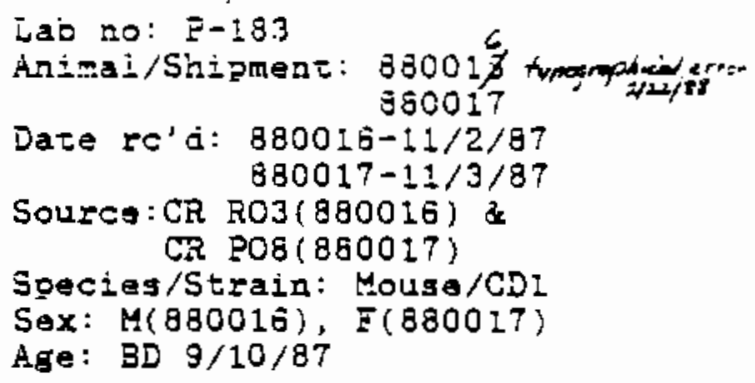

Statug: Received ten mice ( 5 male. $1-5 ; 5 \bar{s}, \neq 6-10$ ) for Foljow up healin screen on P-180

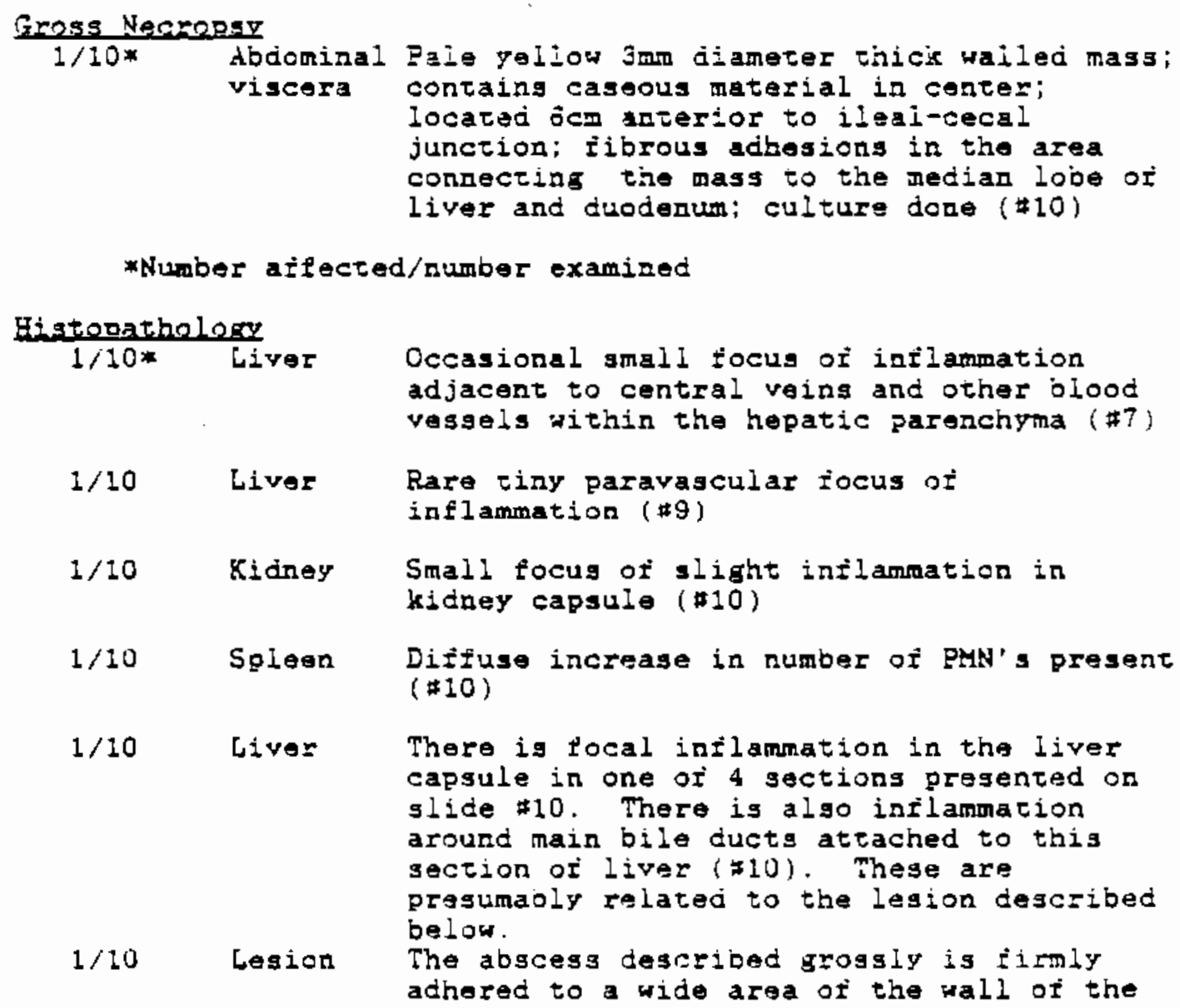




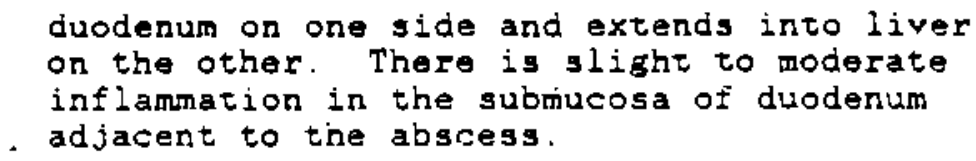

* Number affectej/number examined

\section{Culture results:}

Abeceas oulturs

Direct smesr: NOS

Culture: Etza hemoiytic coaguìge positive Staphyococcus s?. from brotin subculture oniy

Liver sultures $1 / 10 *$

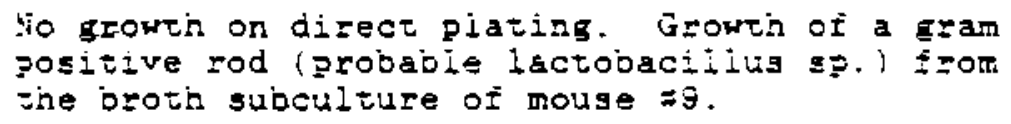

* Number ci-tured/number of positive culzurss

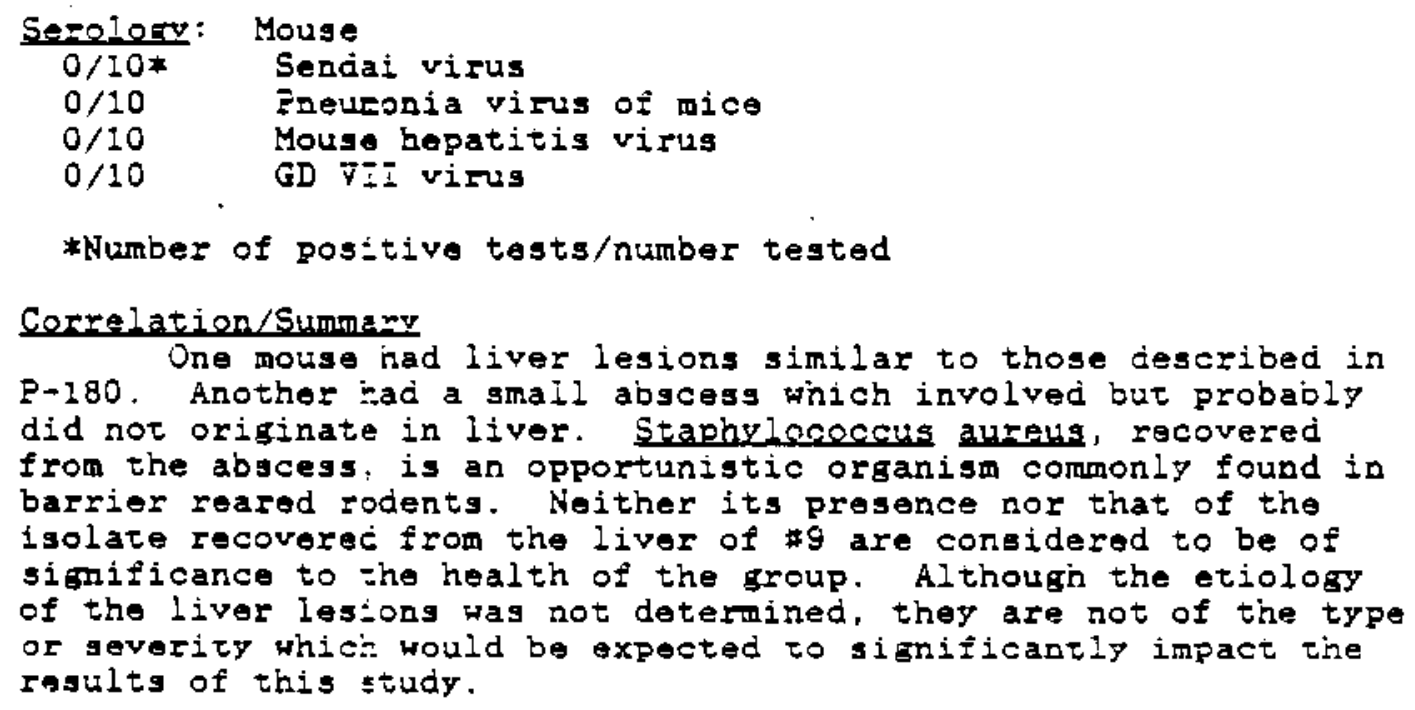

Releaged for Siudy on $12 / 2 / 87$.

\section{$\frac{\text { QEburet 12/s\}? }}{\text { Tecknologist }}$}
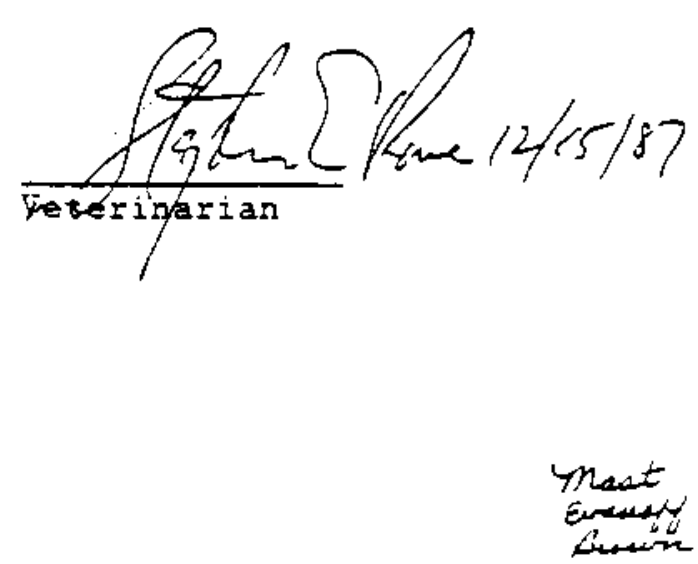


\section{ARC RODENT HEALTH SCREEN REFORT}

Investigator: Mas:
Study: IRT Acetcue

Lab no: P-194

Animal/Shipment: 880017

Building: LSL I:

Room: 436

Date initiated: $12 / 14 / 87$

Date IC'd: $11 / 3 / 87$

Source: CR PO8

Species/Strain: Mouse/CD1

Sex: I Age: BD $9 / 10 / 87$

Status: Ten mouse blood samples submitted for terminal sacrifics serology ( $\# 1011, \$ 123,1131,1118,1158,1070,1006,1157,1064$, 1048)

\section{Serology: Mouse}

\begin{tabular}{|c|c|}
\hline $\begin{array}{l}/ 10 \\
/ 10 \\
10\end{array}$ & 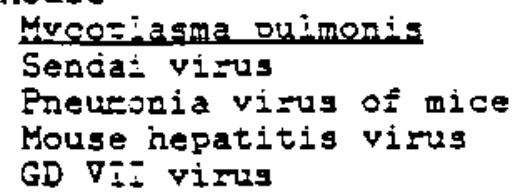 \\
\hline
\end{tabular}

*Numier of posisive testg/number tested

Correlatien/Summaxy

The 10 sera submitted were negative for antibodies to thoge common rodezt pathogens listed above. This is good evidence that no study animals wore infocted by any of these pathogens.
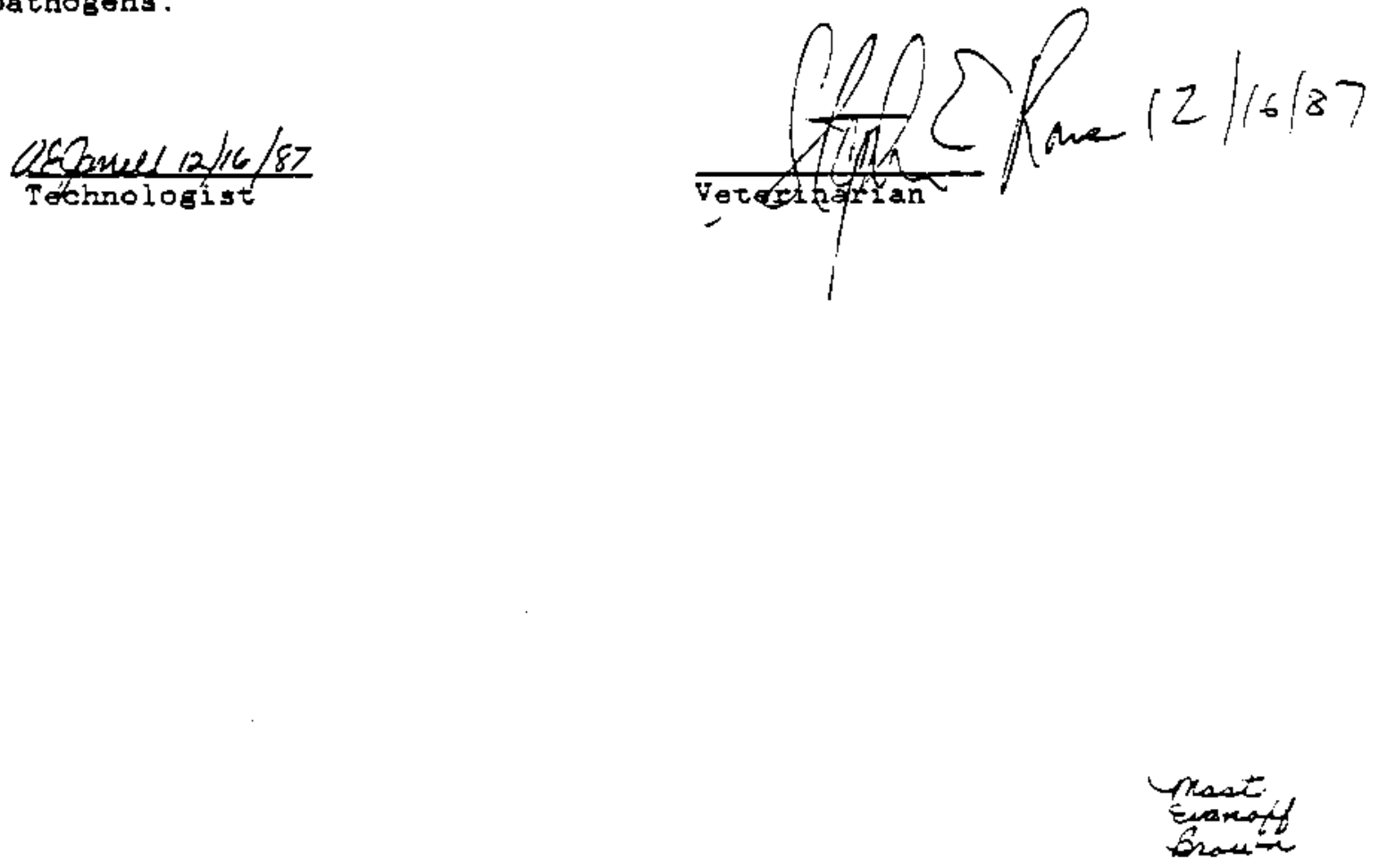

D. 14 


\section{APPENDIX $\mathbf{E}$}

QUALITY ASSURANCE STATEMENT 


\title{
TERATOLOGY STUDY OF ACETONE IN MICE AND RATS
}

\author{
Quality Assurance Statement
}

Listed below are the phases and/or procedures included in the study described in this report which were reviewed by the Quality Assurance Unit during the period, 9/15/87 - 1/30/88, or specifically for this study and the dates the reviews were performed and findings reported to management. (All findings were reported to the study director or his designee at the time of the review.)

Date Findings Submitted in Writing to

Phase/Ptocedure Reviewed

Animal Receipt
Animal Identification
Health Screen
Body Weights
Animal Receipt
Dosing
Data
Plasma Analysis
Necropsy
Health Screen
Dosing
Data
Data
Data
Data
Final Report

Review Date

$$
\text { 9/22/87* }
$$

$10 / 06 / 87$

$10 / 12 / 87^{*}$

$10 / 19 \& 22 / 87$

$11 / 03 / 87^{*}$

$11 / 05 / 87^{*}$

$12 / 07 / 87^{*}$

$1104 / 87^{*}$

$11 / 13 \& 12 / 16 / 87 *$

$11 / 23 / 87^{*}$

$12 / 13 / 87^{*}$

$1 / 13$ \& $5 / 31 / 88^{*}$

$1 / 15 / 88^{*}$

$1 / 20-21 / 88^{*}$

$3 / 15-17 / 88^{*}$

$11 / 15-18 / 88^{*}$
$9 / 22 / 87$

$10 / 06 / 87$

$10 / 13 / 87$

$10 / 24 / 87$

$11 / 06 / 87$

$11 / 09 / 87$

$1 / 05 / 88$

$1 / 11 / 88$

$1 / 12 / 88$

$1 / 12 / 88$

$1 / 12 / 88$

$6 / 20 / 88$

$5 / 03 / 88$

$3 / 08 / 88$

$3 / 29 / 88$

$11 / 21 / 88$

*Reviewed specifically for this study.

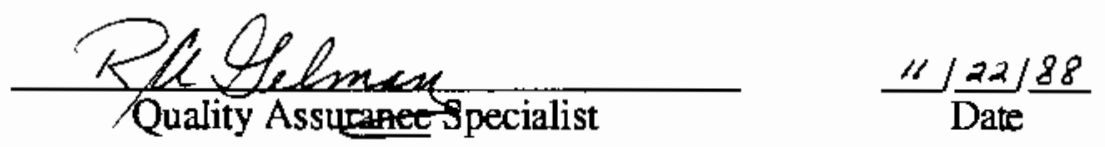




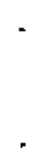


APPENDIX $F$

PROTOCOL AND CAGE MAPS 


\title{
STUDY PROTOCOL
}

\section{Inhalation Teratology Study of Acetone}

\author{
in Mice and Rats
}

Submitted to:

Dr. Bernard Schwetz

Dr. Richard Morrissey

National Tosicology Program

National Institute Environmental Health Sciences

Research Triangle Park, NC

Submitted by:

Dr. Terryl J. Mast

Battelle - Pacific Northwest Laboratory

Richland, WR 99352

September 14, 1987

Dctober 15, 1987 - Revision A

F.1 
I. TITLE Teratology study of Acetone in Mice and Rats ........

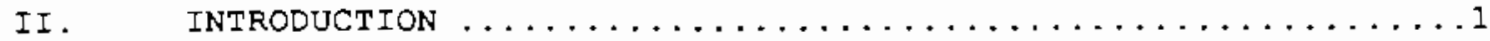

II. $\quad$ SPONSOR AND SPONSOR'S REPRESENTATIVE $\ldots \ldots \ldots \ldots \ldots \ldots \ldots \ldots \ldots$

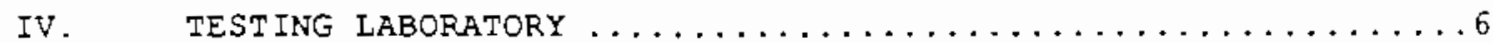

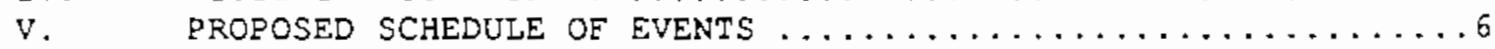

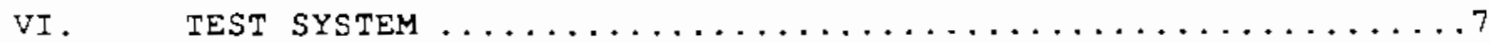

VII. EXPERIMENTAL DESIGN AND DOSE LEVELS . . . . . . . . . . . .

VIII. TEST SYSTEM HOUSING, HANDLING AND ENVIRONMENTAL CONDITIONS ..8

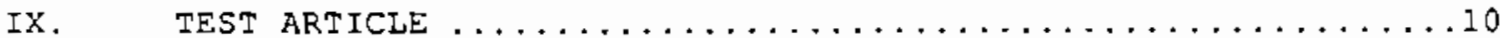

$\mathrm{X}$. DESCRIPTION OF INHALATION EXPOSURE SYSTEM ............

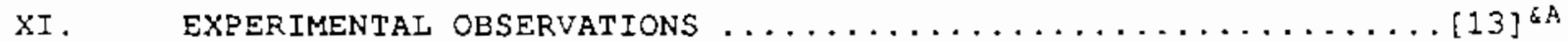

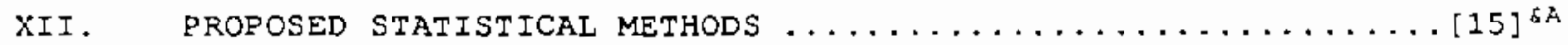

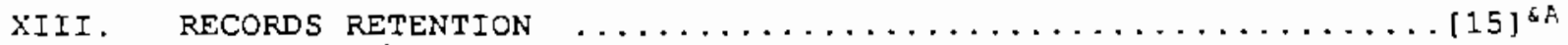

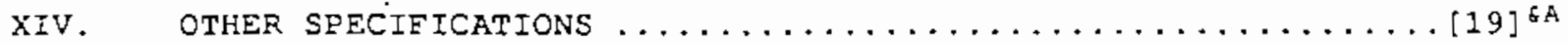

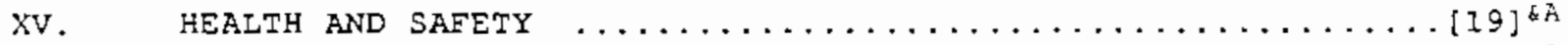

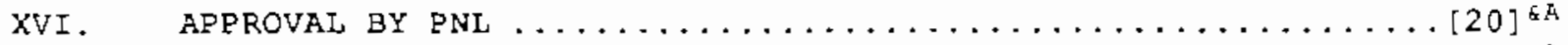

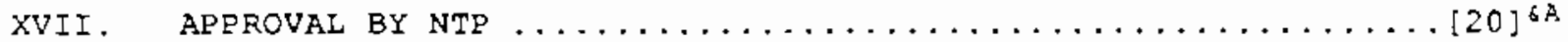

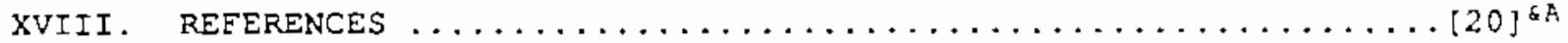

[XVIX. CHANGES AND/OR REVISIONS TO THE PROTOCOL............. $\ldots 22]^{+A}$

ATTACHMENT 1 SOP IIST

FTTACHMENT 2 INHALATION EXPOSURE SYSTEM

6 A Changed $10 / 15 / 87$ by Revision $A$.

$+A$ Added $10 / 15 / 87$ by Revision $A$. F.2 
ACETONE

MOUSE AND RAT TERATOLOGY
$G B-D T-1=Q M-D 0-0192$

Page: 1 of 22

\title{
INEALATION REPRODUCTIVE TOXICOLOGY STUDY PROTOCOL
}

\author{
ACETONE \\ I. IIIE:Teratology study of Acetone in Mice and Rats \\ II. INTRODUCTION
}

Acetone, an aliphatic ketone, is a ubiquitous industrial solvent and chemical incermediate, consequently, the opportunity for human exposure is higk. Acetone production in the United states alone reached nearly one milition metric tons in 1974 and world manufacturing capacity was predicted to be greater than 3 million metric cons per year by 1980 (Nelson and webb 1978 ). The primary use for acetone is in the synthesis of methacrylates, followed by use as a multi-purpose solvent and chemical intermediate. The combination of its high volatility (bp $56.2^{\circ} \mathrm{C}$ ) and extensive use creates a significant possibility for human exposure to acecone via irhalation, especialiy in the incustrial environment. Acetone is also present in many hazardous waste sizes and may reach the groundwater.

The National Insticuce of occupational Safezy and Health (NIOSH IS78) recommends an exposure limit of $250 \mathrm{ppm}\left(590 \mathrm{mg} / \mathrm{m}^{3}\right)$ for acetone. The osis siandard for acezone is 1000 ppm averaged over an $8-h$ work ghitt. The American Conference of Governmental Industrial Hygienists (ACGIH 1980) recomends a tireshold linit value cime-weighted average (TrV-Twa) cf 750 DEx $\left(1,780 \mathrm{mg} / \mathrm{m}^{3}\right)$ over each $8-\mathrm{h}$ period of a 40-h work week, and a short term

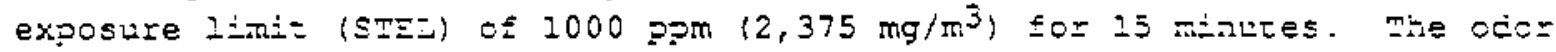
inzeshcld is repszied to be between 200 and $400 \mathrm{gpm}$.

Roetone is considered to be one of the lezst toxic crganic solverzs lised in injustry, bozh in zems of acute and of chronic coxicity. The inhaied vapor is abscrbed trto the blood stream, and is present in expired air and urine, es the parent compound and/or metabolices. Although no pezanert effects have been obsezved from shozt-zem exposures to low concentzations ct acezone vapors $(* 1000 \mathrm{pDm})$, sujjects exposed to these levels have ctuslatres

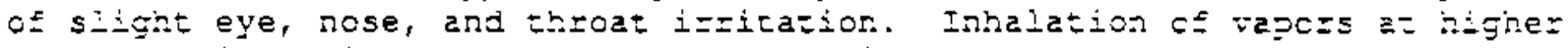
concenzrations (in excess of 10,000 pom) is likely to procuce certazl nervous syszen depression and nezcosis (Claycon and Claytor 1982). Drojonged cr repeazed skin contact with the liquid may cause cruness or defatzing of the skin coliowed by exychema and dexatizis. It has been zeported aret omiy a

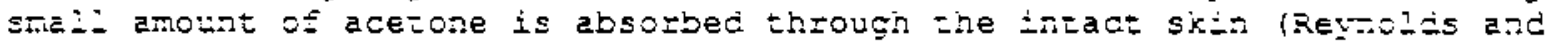
Ezasad 7982$)$. Howevez, these resuits are in conzass to those of another s=usy where Eukabori $\in t$ al. (1979) applied acetone to the skin end susequenty detected elevated concentrations of acetcne in the blood, alveoier air and urine. The skin penerration of acetone was rapis and apsozition of acetone increased difectly with the frequency and ine extent ct exposure. No chronic toxicity has been reported for acecone in the literature, although exposure to acetone coincident with chiorinazed hycrocarbons has been shown to potentiate the hepatocoxicity of the latter (Iza-ger and Plaa I972; and others).

Studies in experimenta? arimals have shown that expostre to ar aceicne concentzazion of 52,200 ppr for $i$ h produced narcosis in razs, anj inet

\section{BATIELLE - PACIFIC NORTHWEST LABORATORY}


ACETONE

MOUSE AND RAT TERATOLOGY
$Q B-D T-1 F Q M-B D-Q 192$

Page: 2 of 22

exposure to 126,000 ppm for 1 h was fatal (Rowe 1963). The minimum lethal concentration for rats exposed to acecone vapors has been reported as 16,000 pom for a $4 \mathrm{~h}$ exposure (Smyth et al. 1962), and 46,000 ppm for mice exposed for $I h$ (Flury and Wirth 1934). Another report gave the minimum lethal concentration for rats as 126,000 ppm following a 2-h exposure period (Verschueren 1977). Rats exposed to 3,000, 6,000, 12,000, and 16,000 pom of acetone, $4 \mathrm{~h} /$ day for 10 days, showed some behavioral changes, particularly a: the higher levels, e.g., the inability to climb a pole within 2 seccnds of receiving a scimulus (Goldberg et al. 1964). Tolerance developed afrer adcitional exposures. Rats exposed to $19,000 \mathrm{ppm}$ of acetone $3 \mathrm{~h} / \mathrm{day}$, 5 days/week for $B$ weeks, and sacrificed at $2,4,8,10$ weeks of exposure exhibited no evidence of toxic effects (Bruckner and peterson $1981 \mathrm{~b}$ ). The $3-h$ $L_{50}$ in zats was detexmined to be 55,700 ppm, approximately 6.5 times that of toluene (Bruckner ec al. 1981a).

Male volunceers exposed to either 300 or $500 \mathrm{ppm}$ acetone under various recimers of exercise and rest demonstraced that about $45 \%$ of the acetone adminiscered was absorbed regardless. of state cf exercise or exposure concentration (Wigeaus et al. 1981). There was no sign of attainment of an equizibrium between blood, alveolat air, and irspired air. The haif-rife of acetone in alveolar air, arcerial blood, and venous blood in the hunan was 4.3 $\pm 1.1 \mathrm{~h}, 3.9 \pm 0.7 \mathrm{~h}$, and $6.1 \pm 0.7 \mathrm{~h}$, respecivively.

in another study, maie volunteers were exposed to ioo or 500 pem acetone vapor for 2 - or $4-h$ pefiods (Divincenzo et al. 1973). Exposure to the vepor caused no untoward effects, nor eny changes in cinical chemiscry or hematological values in the human subjects. Not suzprisingly, exezcise curing exposure increased the amounc of acetone absorbed and recained by the subjezt. Body burders of acetone in this, as th the previousiy mentioned sucy, weze rot observed to epproach steady stace ccncertrations. Disappearance cf

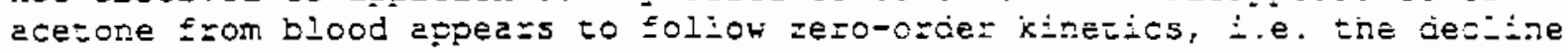
zate is not concentzation depercient.

Subchrcicic exposize of zats to 19,000 gpan acecone, $3 \mathrm{~h} / \mathrm{day}, 5 \mathrm{day} / \mathrm{wk}, 8$ weeks cid not result in any staciscicaly sigrizicant changes in the cingical chemistry parameters monitorec, in gross pathoiogy cr histopathology, o= in

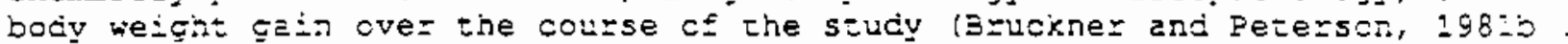
There was a siggh elevation in serun glutaniamoxaloacetic transaninase (Socr) leveis in azerche-exposed animals et 2, 4, as. 8 weeks; however, lactere cenycrogenase (Di) and biood urea nitrogen (SUN) levels were not

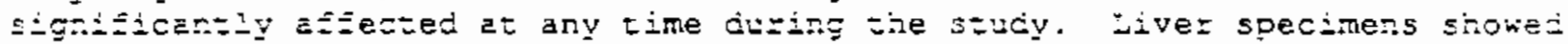
littie sign of Iipid vacuolation and liver tziglycezice levels were not cifferent from controls. body weight gain in acecone-exposed rass wies s-ict:ly redused as compated co controls, but the cifference was not sこaこisticklly significan, Eazin anc kicney weights weze also rediced in animals witin iowerec body weigics, howevez, liver weights remeined ccmparaie to contzols. MLis Ejncing is consiscent with the known ability cf acetone zo

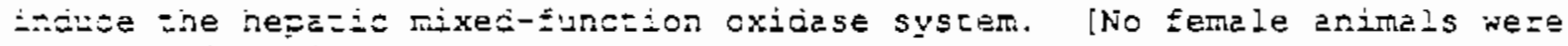
inciuged in tris study.]

The metabolism of acetone was weli-charattezized by the jate lo50's with several groups making significant contributions to the developing bocy cf knowledge (Mourkides et ai. 205\%; Sakami et al. 1950; Pzice and Ritcerbezg -950; and Rudney 1950). Acezone was shown to de eininaced in expirec aiz, mosily as carion dioxide, but also as the parent compound if the initial dose exceeded the merabolic capability of ine test anima. Exoretion of paren and 


\section{ACETONE}

MOUSE AND RAT TERATOLOGY
$Q \bar{E}-2 T-1 F Q M-00-0192$

Page: 3 of 22

metabolices into the urine was also determined to be a significant route of elimination. Acetone was found to be converted to acetate, formate, and a three-carbon intermediace which entered the glycolytic cycle llacer identified as the 1,2-diol), acetoaceric acid, and B-hydroxybutyrate in vivo.

Acrinistration of ${ }^{14} \mathrm{C}-1$-acetone in the intact rat demonstrated the utilization of the methyl group in the synthesis of cholesterol and several amino acids, i.e. serine and the methyl groups of choline and methionine (Sakami 1950). Since this author had previously shown the same compounds to contain a methyl group derived from administered formate (Sakami, 1948) it is presumed that a: least one metabolic pathway of acetone proceeds via formic acid.

Acetone administered to male rats in drinking water ( $18 \mathrm{v} / \mathrm{v}$ for 5 days) increased plasma free fatty acid concentrations from $408.0 \pm 40.9$ ueq/1 to 473 \pm 37.3 veq $/ 1$ (Eurner et al. 1972). Measurements of hepatic Mro activity demonstrated no difference in the ability of microsomal preparations from treated animals to $\mathrm{N}$-demethylate ethylmorphine; however, the ability of preparations from treated animals to p-hydroxylate aniline or to o-deethylate p-nicroanisole was significantly increased as compared to controls. These changes were similar to MFO activity changes found following scarvacion and physical stress.

When male Sprague-Dawley rats were exposec to $19,000 \mathrm{ppm}$ acetone for a $3-\mathrm{h}$ period whole brain, liver and blood were found to contain, $2.7 \mathrm{mg} / \mathrm{g}, 2.5$ $\mathrm{mg} / \mathrm{g}$, and $2.3 \mathrm{mg} / \mathrm{ml}$, respectively (Bruckner and Peterson i9BIb). Although this exposure is highet than would be used in a developmental toxicity study the restits demonstrate that acetone is distributed more of less nomogeneorsly in the fissues examined and that blood levels are significant. Since aceione is one of the "ketone bodies" nomally found in the blood, levels of this magnitudie could resilt in ketosis and the symptoms ccrexrzer: bith thet mesecoliz disorder. This is of sigrificant impact where deveicpmertal studies aze concezned as kerosis is a concition present in Dieberes meinzirs, a cisease suspected of havirg aciverse effects an pregrancy.

The incezacticns of maternal metabolic distu=bences with fetal development are extremely complex as evicenced by the fact that ketonemi during the emszyonic period may result in retarded development of the emisyo while tine same disturbance in laze pregnancy results in excessive fetal growth, maczoscmie (Freirikei 1985). The latrer may be due in pazt to eievaced

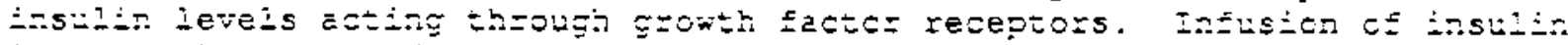
ir.co fetai beboons in utero zecreetes the mezabolic and growth abnomeitilies

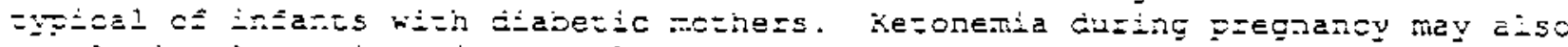
resii in alterations ir nomal deveicpment of the central nervous system and causes such actomalities as opea nelral tube, faulty neural zube fusich,

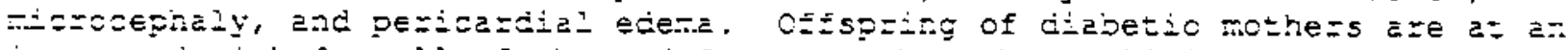
ircreased Iisk fct all of these dejects. Other abnormalizies, ail associcted hitin the eazly organogenic period, are aiso linked to ciabe=ic fregnarcies and incilode tzansposizion of the grear vesseis end sacral dysgenesis (Gebie i977).

Zasting has been snown co proouce kezosis in rats duling late precharcy fascer than it does in nonpregnent animals and, fuzhezmore, inat primparous zess developed a more severe kezosis after l day of fasing than did mitiparous dams (Cheng and Yang 1970). Adrenal corticoic secretions were aiso Envoived in the merabolic changes winich increased the susceptibilizy io ketosis duzing pregnancy. Adcitionally, increased levels of progesterone or estzoge:. contzibuzed co these changes. 


\section{ACETONE}

MOUSE AND RAT TERATCLOGY

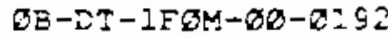

Page: 4 of 22

Several in vitro studies have been conducted in attempts to detemine the teracogenic pocential of acecone and have yielded negative results. No evidence of teratogenicity was found when 39 or $78 \mathrm{mg}$ of acetone was injected into the yolk sacs of fertile chick eggs prior to incubation (Mclaughil et ai. 1964). Dipaolo et al. (1969) adoed 0.2 percent acetone to the growth medium of cultured Syrian hamster embryonic celis and detected no evidence of cellular transformacion. Guntakatta et al. (1984) assayed acetone for tezatogenic potential in an in vitro mouse embryo limb bud cell culture system designed to decect perturbations in the synthesis of extracellular matrix components and found no effects attributable to acetone. Acerone was not mutagenic in the Salmonella/microsome test (McCann et al. 1975).

Although these in vitro studies did not indicate a significant teracogenic potential for acetone, such studies conducted on another ketone body, $\beta$-hydroxybutyrate $(\beta-H B)$, indicated an involvement in fetal abnomalities. Horton and sadler (1983) exposed mouse embryos in vitro to $\beta$ HB, the most common ketone body, at either the $i-4$ or 4-5 somite stage. The concentrations of $\beta-\mathrm{HB}$ employed encompassed ketcne body levels in blood reported in severe ketosis in the human and ranced from $1-4 \mathrm{mg} / \mathrm{ml}$. Embryos cultured in the presence of $\beta$-HB exhibited neural tube defects whose incionce wes age- and dose-related with the youngez embryos being the more sensitive. The abnomalities were chazacterized by inhibition or delay of neural tube clostre primarily involving tine cranial region.

Acetone is listed as causing birth defects (Scharcein 1985; Table 21-2, pp. 572-572), however, no reference source for this infomation is giver too is any specific abromality mentioned. At a latez point (p.650) the sane author stazes that "zepozis cE acetone testing in tezatogenesis cr reprocuctive coxicology zopzze:=ly have not been puilished." Howevez, Itis autroz coes refez to e repcro (Kucera 1968) in which saczal agenesis was associated with a history of expostre of women to tat selvents du=ing Fregnancy. The solvents to wich these women were exposed includec ryiene, z=ichicroethyiene, mesnyi dilozide, acezone, and petrol. Anotjez report, by the same authox (Kuceza and Senesove 1962) was mertioned "in winich a case cE campomelic synarome [sic] in an infant was associaced with close cortact witi acezone (and othez chemicals) curing the sitsh to eight gestationz: weeks of pregràcy."

The oniy other mention found in the published itcerzture regarding the

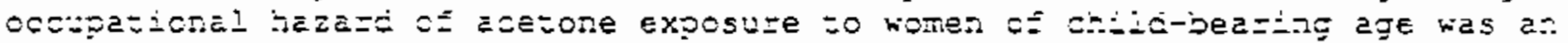

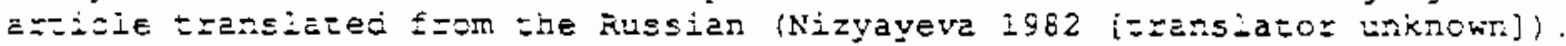

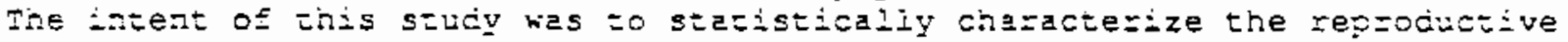

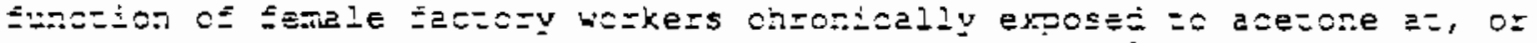

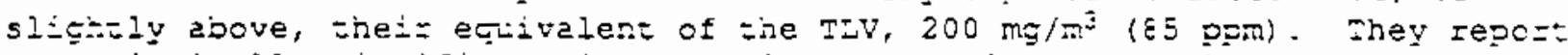
a siaristicaliy significant increese in pregnancies atcog these worke=s inciuding an increasec fireat of abortion $(p<0.031)$, foxicoses $(s i c)$ during the second half of stegnency $(p<0.02)$, and diminisnec hemogicin ievel and hypozension $(p<0.001$ ). A significent recuction in the bizh weigte end size of trants cf the chemical fibez-factcry wcrkezs relazive to a controi group was aiso repoztec $(p<0.00 i)$. They viewed these compications of pregnency as betng seccndary to chenges in general body function, notably "acjojosis, distuzbed cazbohydrate and tat metabolism, and distuzbed neuroendoczine regulation." Furthenore, shey associated these parhologic conditions cirectiy with exposure to reietively iow levels of acerone. 
ACETONE

MOUSE AND RAT TERATOZOGY
$Q B-D T-2 F Q M-D z-9192$

Page: 5 of 22

In addition to the human epidemiological data presented by Nizyayeva (1982), an inhalation teratology study was performed in [rats?]. Animals were exposed to 30 and $300 \mathrm{mg} / \mathrm{m}^{3}$ acetone for either $1-13$ days of gestation (dg) or 1-20 dg. [Details of the daily duration of exposure were not given.] $\mathrm{A}$ statisticaliy significant, but not concentration-related, reduction in the percentage of live embryos was reported for both exposure concentrations in animals exposed from $1-20 \mathrm{dg}$. Percent embryonal deaths for the control and 30 and $300 \mathrm{mg} / \mathrm{m}^{3}$ groups were $11.3 \pm 1.3,28.44 \pm 5.92$, and $23.04 \pm 3.8$, respectively. Fetal weights were not given. They also reported "disorders of the placental barrier", apparently discerned from morphological changes. This reviewer believes that caution is required when considering the data and results presented in the report of Nizyayeva (1982); however, the toxic effects referred to are consistent with those which could be precicted following exposure to a volatile ketone during pregnancy.

In 5 ummary:

- Acetone is a relatively non-coxic solvent whose only esiablished hazard at relatively low exposure levels is its ability to potentiate chlorinated hydrocarbon hepatotoxicity.

- Exposize to relatively high levels of acetone results in an increase in blood ketones and may therefore mimic deleierious effects on pregnancy known to be caused by metabolic ketosis resuliing from starvation or Diabetes mellitus.

- Acetone has not been show to exijist a teratogenic eftect in vitro; howevez, other kezone bodies, especiajly $\beta$-hydzoxybuzyzace have exibiced such a poreniial.

- Acerche has been intirectry linxed 0 several cases of ntich. teratogenesis exi one repozt presencs hunan epicemiological evionece, as weil as experinerial evidence, that eceione exposure may have deletezious effecss on pregnancy and ine ofzspring (Nizyayeve, Igs2).

RECOMENDATIONS

In light of the known abilizy of acetone vepozs to cause ketosis, tho stzongly suspectec efłecis of meceznal ketcsis tijing pregnancy ch the

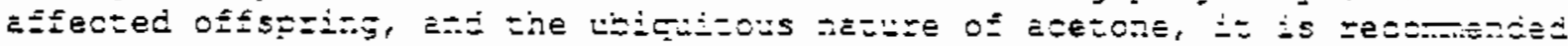

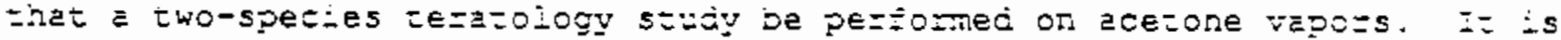

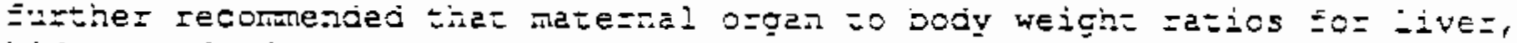

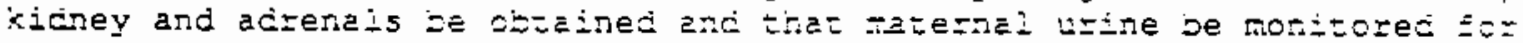

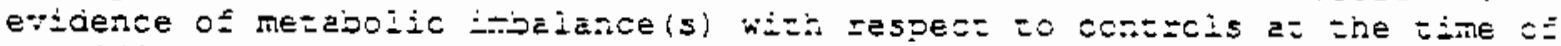

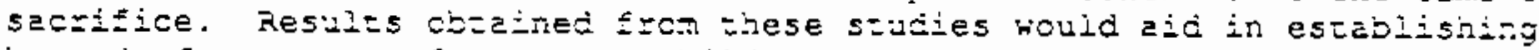
hazarc of exposure of women of itidi-deening age to acetone vapors. 


\section{SRONSOR AND SPONSOR'S RERRESENTATIVE}

A. Sponsor:

National Ingtitute of Environmental Health Sciences

National Toxicology Program (NTP)

P.O. Box 12233:

Research Triangle Park, N.C. 27709

B. Sponsor's Representatives:

Dr. Bernard Schwetz

Dr. Richard Morrissey

IV. TESTING IABORARORY

A. Facility

Battelle - Pacific Northwest Laboratory (PNL)

P.O.Box 999; Richland, Washington 99352

B. Study Director:

Dr. Terryl J. Mast

V. RROROSED SCHERULE OF EVENTS (This proposed schedule may be altered. All changes will be appended to the protocol.)

Bats Mice
A. Animals arrive week of:
$9 / 21 / 87$
$11 / 4 / 87$
B. Identification of females:
$10 / 5 / 87$
$11 / 18 / 87$
c. Health screen :
$10 / 12 / 87$
$11 / 25 / 87$
D. Prestart audit for GLP compliance:
$[10 / 216 / 87]^{\& A}$
$11 / 25 / 87$
E. Initiate breeding procedures:
$[10 / 7219 / 87]^{8 A}$
$11 / 25 / 87$
F. Initiate exposure :
$[10 / 2926 / 87]^{\& A}$
$12 / 2 / 87$
G. Initiate necropsy:
$[11 / 29 / 87]^{d A}$
$12 / 14 / 87$
H. Evaluate fetal specimens:
$[11 / 916 / 87]^{8 A}-1 / 25 / 87$
combined
I. Submit draft report:
$2 / 15 / 88$
J. Submit final report:
$\Xi / 28 / 88$

tA Changed 10/15/87 by Revision A. 
ACETONE

MOUSE AND RAT TERATOLOGY $\oslash B-D T-1 F \varnothing M-\varnothing \varnothing-\varnothing 192$

Armended Page: 7 of 22

VI. TEST SYSTEN

A. Species: mouse and rats

B. Strain: Mice: CrI:CD-1(ICR)BR; rats: Sprague-Dawley [CrI:CD (SD)BR]

C. Number of Animals and Supplier: Charles River Breeding Laboratories, Raleigh, NC.

Mice: 85 males

310 females

Rats: 55 males

245 fernales

D. Age of Animals Upon Arrival: Mice: $7-8$ weeks

Rats: $8-9$ weeks

E. Experimental Animals (Eemales: 40 virgin female mice or rats will be randonly selected and assigned to four dose groups (10/group) from the total fernale pool (10B-DT-3BøB). The remaining females will be mated by placing at least two females with one male overnight in a breeding cage ( $\varnothing \mathrm{B}-\mathrm{DT}-3 \mathrm{~B} \varnothing \mathrm{D})$. Nine $\mathrm{AM}$ of the day that copulation is established will be designated as 0 dg (ØB-DT-3BøD).

F. Number of Animals in study: A minimum of 33 plug-positive female mice or [437] \&A sperm-positive rats (to obtain [25] áA pregnant [ rats and 20 pregnant mice] ${ }^{2}$ ) will comprise each of the four treatment groups; the minimum number of mated females to be exposed will be 132 mice or $[2148]^{\text {fA }}$ rats. There will also be 10 virgins (females) of each species per exposure level.

VII. EXPERTMENTAI DESIGN AND DOSF IEVELS

A. Experimental Design: Four groups of mated female mice will be exposed to the test chemical on 12 consecutive days (6 dg - $17 \mathrm{dg}$ ). The animals will be necropsied on $18 \mathrm{dg}$ for maternal and fetal evaluations.

Eour groups of mated female rats will be exposed to the rest chemical on 14 consecutive days $(6-19 \mathrm{dg})$. The rats will be necropsied on 20 dg for maternal and fetal evaluations.

In addition, 10 virgin females of each species will be added to each exposure group for the purpose of obtaining ovaries to be used for quantitative ovarian follicle counts. These animals will be exposed concurrently with the mated females and sacrificed immediately after the last exposure period.

A A Changed 10/15/87 by Revision A. 
B. Exposure Regimen: Chamber atmospheric concentrations of acetone will. be 0 (filtered air), 440, 2200, and 11,000 ppm. Plug-positive and virgin mice will be exposed for 6 hrs/day for 12 consecutive days 16 dg - $17 \mathrm{dg}) ;$ sperm-positive and virgin rats for 14 consecutive days ( $6 \mathrm{dg}-19 \mathrm{dg}$ ), $6 \mathrm{hr} / \mathrm{day}$. The exposure chamber doors will be closed throughout the exposure and non-exposure periods, except during 
ACETONE

MOUSE AND RAT TERATOLOGY
$Ф B-D T-1 F \emptyset M-\emptyset \varnothing-\emptyset 192$

Ammended Page: 8 of 22

animal care procedures. Exposure chamber temperatures will be maintained at $75 \pm 3^{\circ} \mathrm{F}$ and relative humidities at $55 \pm 15 \%$. Air flow will be maintained at $15 \pm 3$ cfm and the chamber pressure at approximately l" water negative with respect to room pressure.

C. Selection of Atmospheric concentrations: Exposure chamber concentrations are based partly on information obtained from previously published reports on inhalation toxicology studies of acetone and partly on safety considerations. Safety considerations limit the maximum exposure concentration to $50 \%$ of the lower explosion limit $(=22,000 \mathrm{ppm}\}$ which is $11,000 \mathrm{ppm}$.

[D. Measurement of Ketone Body Levels in plasma: Ketone body levels in rat plasma (acetone, acetoacetate, and $\beta$-hydroxybutyrate) will be monitored three times during gestation--7, 14 , and $19 \mathrm{dg}$. Seven of the 35 sperm-positive rats in each exposure group will be selected for this task. These animals will not be used in the teratology evaluations due to the added stress of blood collection during pregnancy. $]^{+A}$

VIII. TEST SYSTEM HOUSING HANDIING AND ENYTRONMENMAI. CONDITIONS

A. Quarantine and Acclimatization $(Q B-A R-3 E Q 3)$

1. Animal shipping crates will be examined upon arrival for evidence of conditions likely to permit exposure to pathogens (soiled, wet or otherwise damaged).

2. The uncrating will be conducted at the door of the quarantine room. While being removed from the crates the animals will be examined for evidence of shipping stress.

3. The animals will be quarantined and acclimatized in the ISL-II Building for 3-4 weeks prior to the start of the study.

4. During part of the quarantine/acclimatization period the animals will be housed by sex, approximately $10 \mathrm{mice}$ or 5 rats per cage in wire cages on flush racks. The cage space will meet tine requirements stated in the NIH "Guide for Care and Use of Laboratory Animals".

5. During the breeding period the animals will be housed in the quarantine room.

6. Plug-positive mice or sperm-positive rats will be acclimated from $0 \mathrm{dg}$ in individual compartments of wire-mesh cages within exposure chambers (with chamber doors open). Virgin females will be acclimated for approximately 1 week prior to exposure under the same conditions.

$+\mathrm{A}$ Added 10/15/87 by Revision A.

BATTELLE - PACIFIC NORTHEEST LABOAATORY

F.11 
7. Room temperature during the acclimatization and exposure periods will be maintained at $72 \pm 3^{\circ} \mathrm{F}$ and relative humidity at $50 \pm 15{ }^{\circ}$. These measurements will be recorded at least twice daily.

8. Twelve hours light and twelve hours cark will be maintained with light starting at 0600 .

9. Eive male and five female animals will be randomly selected for pre-exposure health screening (OB-AR-3Eø2). They will be examinec by gross necropsy, histopathology and nasopharyngeal culture for evidence of disease and the presence of potentially pathogenic organisms. 
10. The clinical veterinarian will make a visual inspection of the animals to be used in the study just prior to their release for the study (documented on the last quarantine/ acclimatization record).

11. As an added screen for viral infection, 5 animals from the control group and 5 animals from the highest dose group will be tegted promptly after sacrifice at $B N W$ for viral pathogens (ØB-AR3BIR).

12. Females not selected for the study or health screen will be discarded during the first exposure week. The disposition of these females will be recorded on the Animal Disposition Record and retained in the study files (GB-AR-3F93). Males, (they are not individually identified) will also be discarded.

B. Eeed $(O B-A R-3 E Q 5)$

1. NTP pre-approved NIH-07 Open Formula Diet (pellets) from Ziegler Bros., Inc., Gardner, PA will be used during the quarantine/acclimatization periods and throughout the duration of the experiment.

2. Feed will be provided ad libitum in slot feeders during the experiment, except during exposure hours.

C. Water

1. Fresh softened water (ion exchange softener, Illinois water Treatment Company, Model 2R-2240, Rockford, IL) will be supplied ad libitum at all times. The hardness of the water will be checked approximately once every week. Records will be retained in the LSL-II Building Engineer's office.

2. The automatic watering system (Edstrom Indugtries, Waterford, WI) will be used for the quarantine/acclimatization period and throughout the duration of the study.

3. A representative sample of animal drinking water from one of the NTP study rooms will be analyzed for contaminants at least once each calendar year.

D. Randemization: Virgin females will be randomly chosen from the pool of female animals based on the first body weight (taken at the time of eartagging). During the week prior to the gtart of exposure virgins will be weighed and randomly assigned to a treatment group by means of a computer-assisted randomization program which is based on a single blocking factor, body weight (GB-DT-3BøB).

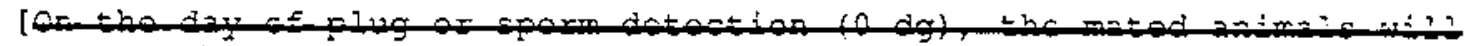

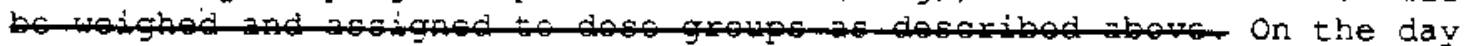
of plug or sperm detection ( $0 \mathrm{dg}$ ), the mated animals will be weigned. Seven animals will be randomaly selected, designated for blood collection, and assigned to a specific exposure group (Eor example, animals from the first day of breeding, Ges Grp A, will be assigned to Exposure Group 1, etc.). The remaining sperm-positive animals in 
each gestation group will be randomly assigned to exposure groups as described above. $]^{\text {\&A }}$

IA Changed $10 / 15 / 87$ by Revision $A$. 
E. Identificication:

1. All female animals will be individually identified by metal ear tags during the first weighing session (GB-DT-3FøC)

2. Cage maps (OB-DT-3Bø3) showing placement of individual animais ir. each cage unit of the exposure chamber will be prepared and updated as needed. Each exposure chamber will be identified by chamber number and exposure level. The proposed arrangement of the exposure chambers is included in Figure 1.

IX. $\mathrm{BEST}$ ARTIGLE

A. Chemical name: acetone

B. Formula: $\mathrm{C}_{2} \mathrm{H}_{6} \mathrm{O}$

C. CAS No.: 67-64-1

D. Manufacturer: Ashland Chemical Co. P.O. Box 2219

Columbus, $\mathrm{OH} 43216$

シ. BNW LOT NO.: $52446-6-(1-10)$

RTI No.: 5597-66-23; Manufactures Lot No: 0618B75 (Additichal test material fzom this lot will be received during the study in 5 j-calion dizins.

$F$. The velicie cort=0l kili be filcered $a i=$

G. Scorage concitions: A zeacy reserve is meinteined in a fietubie stcrage caijnet at rocm cempezulue in the IsI-II Euilding. The

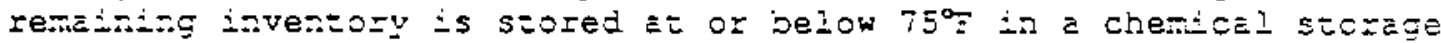
facility acjacent to the LSI-IZ. The bulk tese mazezial is meintained in 5 -geilion metal drums with a nitrogen heasspace.

BNW Iot No. 52466-6-(2 - 10) consisced cE 10 cre-geilon giess boztles. This simpment wili be used foz tes genezation puzposes.

\#. Aratyzical viemsezy

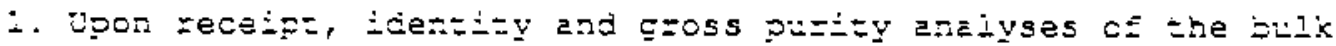

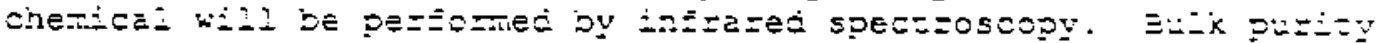

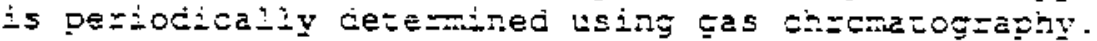

2. Acetone concentzations within the exposure chembers will be

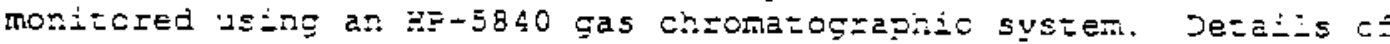
the calibacicr. method are given in htuachment 2.

I. Aralysis Scheciule

i. Puzity analysis will be performed on the bulk chemica: voon receipe, and till be perfomec once between mice and gat scudies. 
ACETONE

MOUSE AND RAT TERATOLOGY
BB-DT-IEQM-DD-Z192

Page: 11 of 22

X. DESCRIPTION OF TNHATARION EXPOSURE SYSTEN

The inhalation chambers will be located in room 436 of the isL-II building. A decailed description of che inhalacion exposure sysrex to be used in this study is included in Atcachment 2 of chis protocol. The location of the exposure room and chamber layout are shown in Eigure 1.

A. Exiroomental Mocitoping

i. Air filcration: HEPA and charcoal Eiters will be used for intake air, and a HEPA filter will be used for exhaust air.

2. Temperatures will be monitored by R'TS multiplexed to a digital thermometer with computer data acquisition at aporoximately $4-$ inou cycles for 24 hours per day. The cortrol range is $75 \div 2^{\circ}$ Fin critical 2 imits, $<70$ or $>80^{\circ} \mathrm{g}$. Any chamber cemperature excursion beyond the critical limits $\mathrm{rill}$ be recorded and alazmed automaticaily.

3. Relative humidity will be monitored by a single dew point hygzometez in conjunction $\mathrm{kth}$ a multiplexed sampling system hith computer data acouisition at epproximately 4 -hour cycles, 24 hcuss per day. The control range is $55 \pm 15 \%$ with critical limits of <3 oz >75f. Fry zelarive numicicy excursion beyond the critical lirits wijl be recorded and alamed autotaticelly.

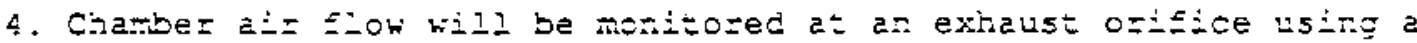

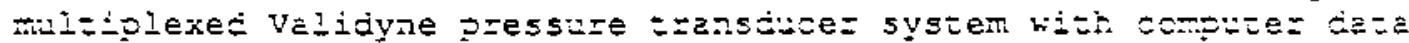

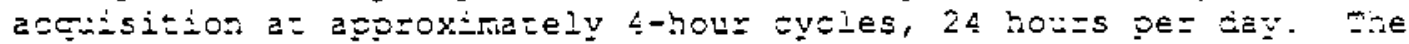

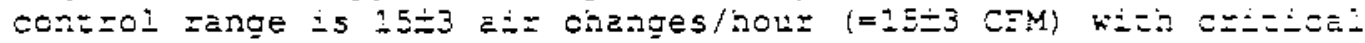

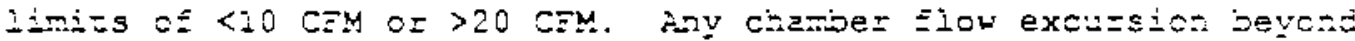

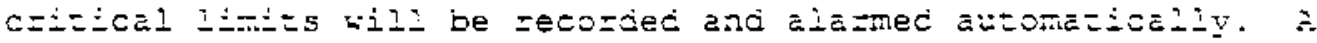

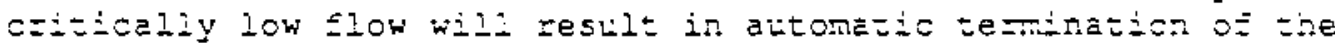
exposure. haecone concertzafions in tie chamders wili be

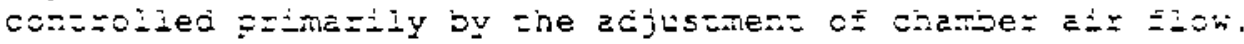

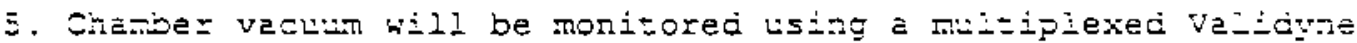

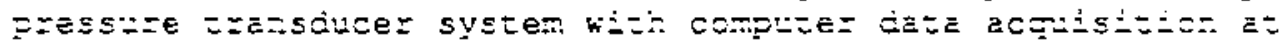

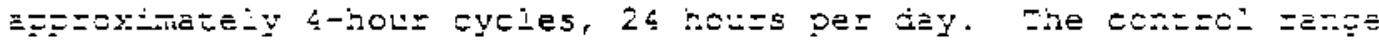

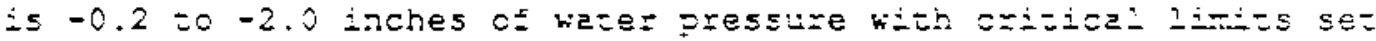
at ine sane ralues. ary chamez vacuun excussion beycrid gie ここえこここえ

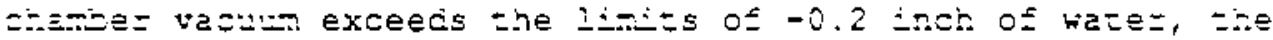
exposize wili be autorazicaily zemisateci.

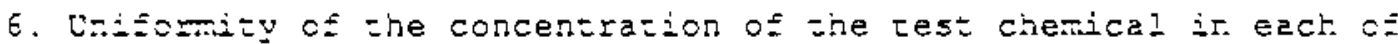
zhe chambers will be dezemined duzing the development of exposize generation hitholt erimels. Chember unitomity wili be veriziec within zine tizst week of the ras teracology study and again wizhir. the first week of the mouse study. F becween port and tishin port veziability of S 5\% RSD wizl be considered acceptable.

7. The exposire chambers test chemical builcup and decay jime wi: i be

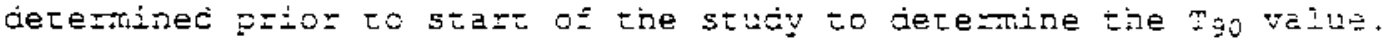




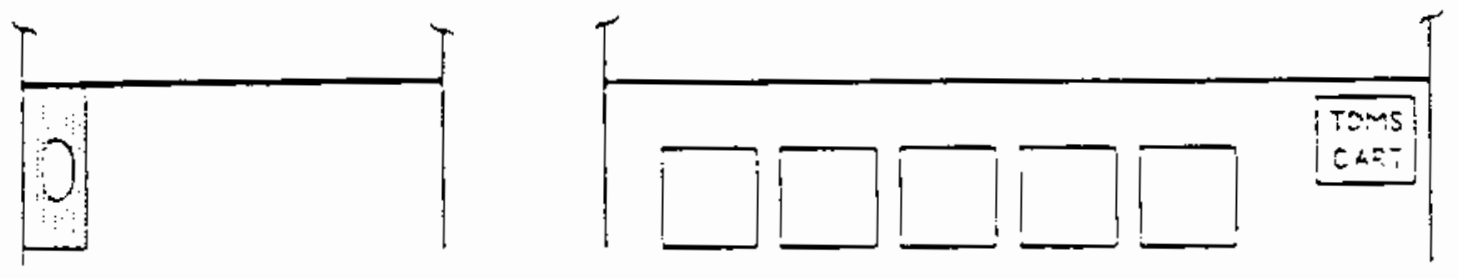

ROOM 327

HOT USED

ROOM 428
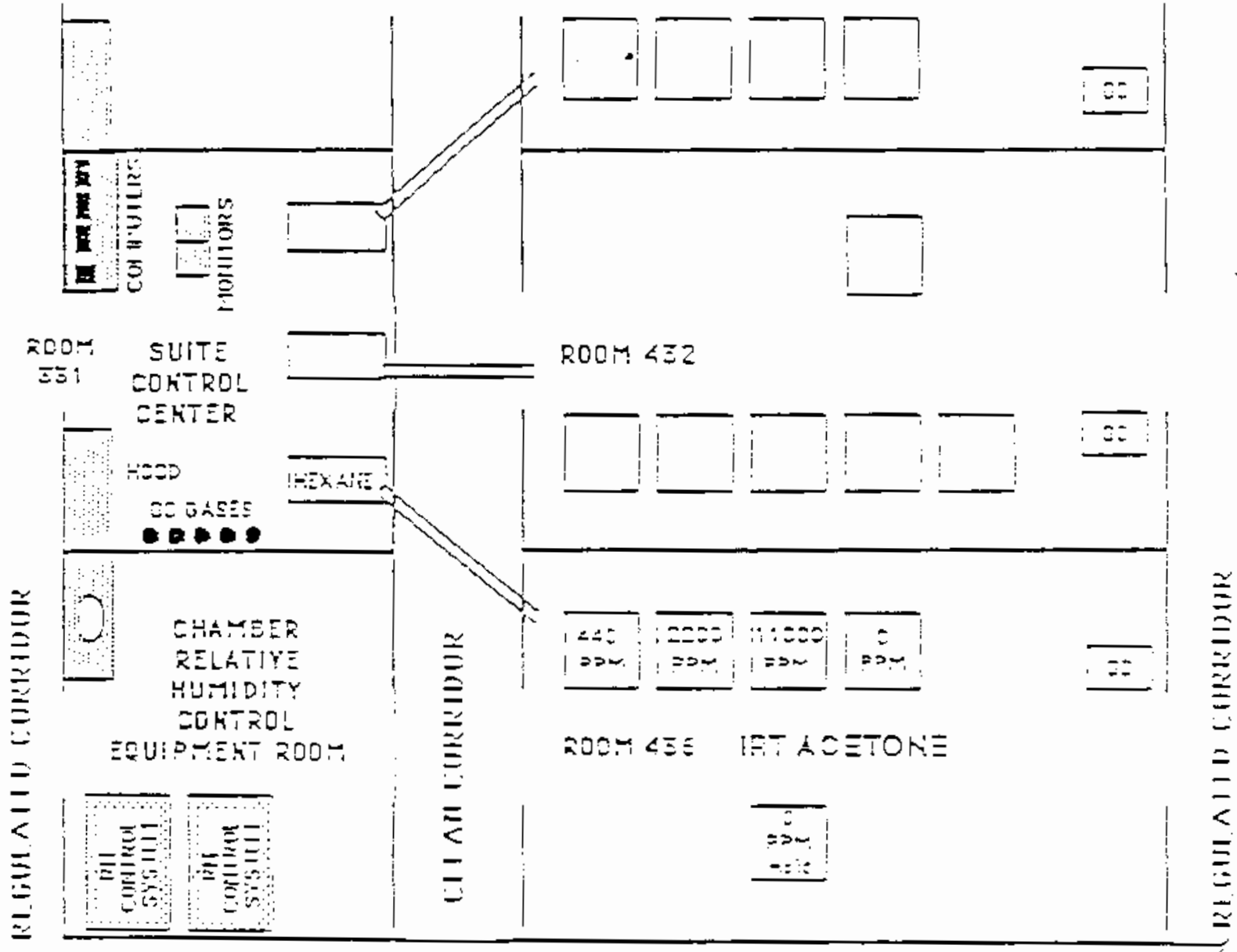

Figure i. Leyouz c: exposure room and exposure chambers ior tiosecone. 
ACETONE

MOUSE AND RAT TERATOLOGY $\varnothing \mathrm{B}-D \mathrm{DT}-1 \mathrm{~F} O \mathrm{M}-\$ 0-\varnothing 192$

Rage: i3 of 22

These curves will be verified withir. the first week of the rat study and again within the first week of the mouse study.

8. Prior to the start of the study and once in the high level charber during the rat study, samples will te taken from ail chambers using a Garciner condensation nuclei counter to assure that the vapor generation does not produce ar. aerosol of acetone.

9. A study of test material stabiitty in the exposure chambers and in the generator reservoir will conducted during the developmenta: work without animals in the chambers and once during the first week of the mouse exposures. The chamber samples will be taken from the high and low dose chambers during the last hour of exposure. A generator reservoir sample will be taxen at the end of an exposure day.

B. Effluent mreatment

Chamber exhaust will be diluted to comply with applicable state and Federal Regulaticns prioz to release from the building exinast stack.

XI . EXTERTHENTEI OREERVZTIONS

A. Clinimal Ohserwinins: The animals will be observed daily for mottalicy, mczbidizy, and signs of tcxicity (OB-DT-3Br3). The date anc time of deeth $c$ r euchanasia of mozibuno animals will be reccriec and tine aritais will be necropsied accorcing to (BS-DT-3505).

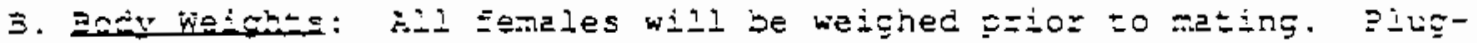

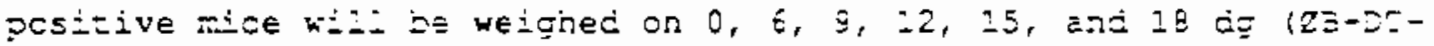

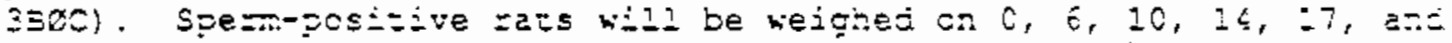

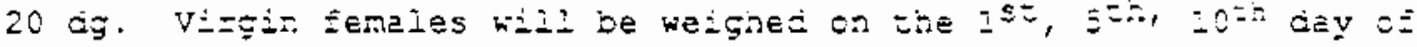
exposuze end at sacrisice.

c. Shembled ivenasy: The mice are scheculec to be eutharized with Ch

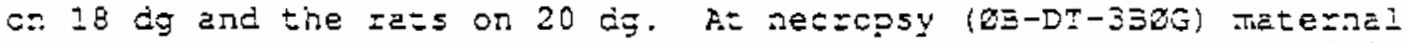

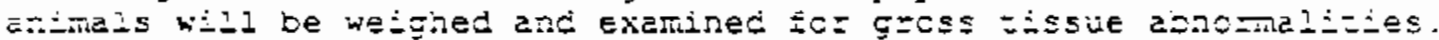

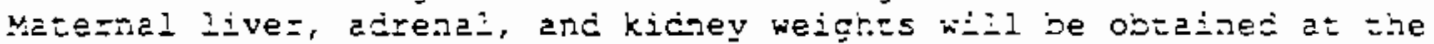

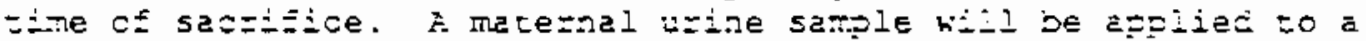

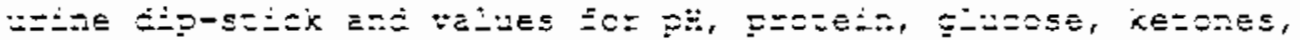

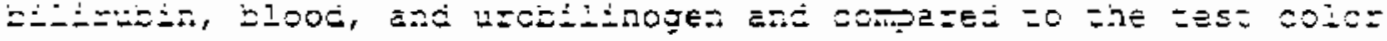

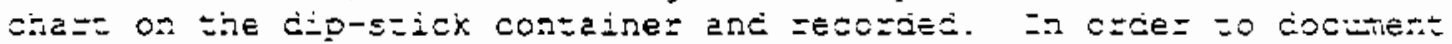

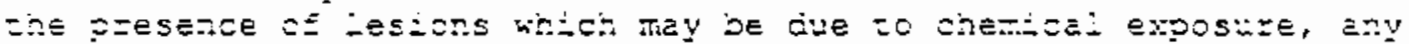

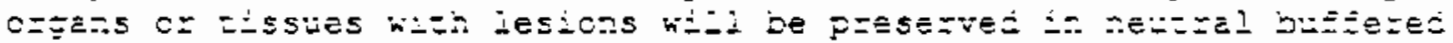

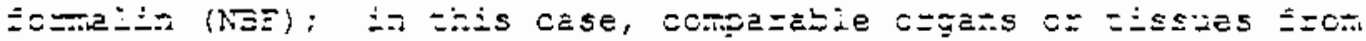

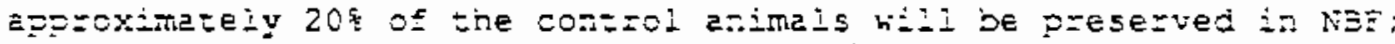

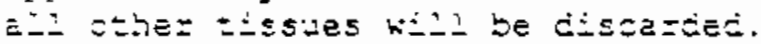

The userus hili be removed and weifhed, and the numbe, posinion and status of inglezs wil be recorcied. The placenas fill be exarinec.

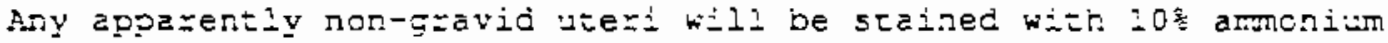

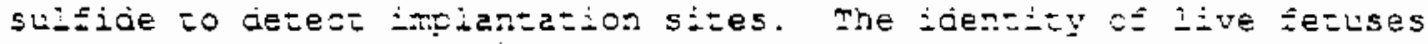
(by szudy, dan ringos and wterine pcsition) wili bo retained

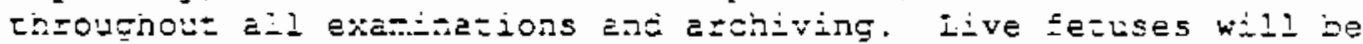
exaninec Ecr gross jefects and weighed. s compiere risceral

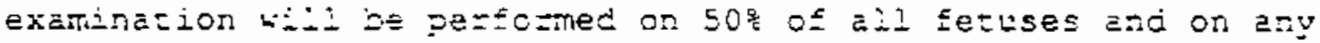

BRTELLE - PRCIFIC NORTHUEST LABOARTORY

F. 18 
ACETONE

MOUSE AND RAT TERATOLOGY

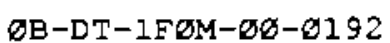

Ammended Page: 14 of 22

fetuses with gross abnormalities, (סB-DT-3BGG) Sex will be determined on all fetuses by internal examination. All skeletons will be double-stained and examined for cartilage formation and centers of ossification ( $\boxminus B-D T-3 B \oslash G$ ); however, $=50$ \& of these will have had their heads removed. These fetal heads will be examined by razor-blade sectioning fixation in Bouin's fluid (Wilson, 1965; [ØB-DT-3BØI]). Records of morphologic lesions observed in gross and visceral examinations will include photographs (ØB-DT-3BØJ) of representative lesions.

Both ovaries from the virgin females and one ovary from each of the pregnant females will be collected at the time of sacrifice. (бB-DT3BDG). Collected ovaries will be fixed for 24 hr in Bouin's fluid then transferred to 708 ethanol and sent to Dr. Donald Mattison at the National Center for Toxicological Research for sectioning and quantitative follicle counts.

[Ca. Measurement of Ketone Rodies in Rat Plasma: Plasma will be collected from seven animals in each of the four exposure groups on the 7, 14, and $19^{\text {th }}$ day of gestation and analyzed for ketone body levels (acetone, acetoacetate, and $\beta$-hydroxybutyrate). The same seven animals in each exposure group will be used for this purpose throughout the study. At the time of sacrifice these animals will be weighed, their gestational status recorded, uterine and fetal weights obtained and the status of the fetuses recorded. These fetuses will not be subject to a teratological evaluation except for a gross examination.

Blood will be collected from specified animals into heparinized vacuum tubes 30 minures post-exposure on each of the designated gestation days and again one hour prior to the start of exposure on the following day. Plasma will be collected following centrifugation at $4^{\circ} \mathrm{F}$. Three $125-u l$ will be placed in each of three headspaceanalysis viais, one for each of the three ketone bodies. Plasma samples will be subjected to headspace analysis by gas chromatography according to the methods of Lopez-Soriano and Argiles (1985).

Briefly, free acetone will be determined after the addicion of $0.025 \mathrm{ml}$ of $4 \mathrm{~N}$ sodium hydroxide to one of the 125-ul aliquots to prevent spontaneous decarboxylation of acetoacetate. The second aliquot will be treated with $0.025 \mathrm{ml}$ of $0.6 \mathrm{M}$ perchloric acid to enhance quantitative decarboxylation of acetoacetate co acetone and the third plasma aliquot will be treated with $0.025 \mathrm{ml}$ of an oxidative reagent $\left(0.2 \mathrm{M} \mathrm{K} \mathrm{Cr}_{2} \mathrm{O}_{7}\right.$ in $5 \mathrm{M}$ phosphoric acid). The second and third samples will be kept in a $100^{\circ} \mathrm{C}$ water bath for 90 minutes. The oxidative treatment of the third sample converts all kecone bodies to acetone; thus, $\beta$-nydroxybutyrate will be decemined by subtracting the amount of acetone and acetoacetate from the value obtained for the total ketone body level. All samples will be quantified by headspace gas chromatographic analysis on a $1 / 8$ " o.d. $x$ 10' nickel colum loaded with 3\% Carbowax 1500 on Chromosorb WAW, $60 / 80$ mesh, operated isothermally at $45^{\circ} \mathrm{C}$. The retention time of acetone on this system is $=1.5$ minutes $(0 B-A C-3 A 1 M-O D).]^{-A}$

\footnotetext{
+A Added 10/15/87 by Revigion A.
} 
D. Indices of Effects: The following parameters, expressed as mean \pm STD, when appropriate, will be computed from data for inseminated animals and their litters and will be presented in the Final Report for each treatment group:

- Number of dead maternal animals, animals removed from the study and reason for removal

- Sumnary of maternal toxicity, including incidence of changes detected during clinical observationg

- Number and percent pregnant

- Maternal body weights:

Mice on $0,6,9,12,15$ and $18 \mathrm{dg}$

Rats on $0,6,10,14,17$, and $20 \mathrm{sg}$

- Weight of gravid uterus

- Maternal liver, adrenal, and kidney weights

- Maternal urine parameters (dg 20): pH, protein, glucose, ketone, bilirubin, blood, and urobilinogen

- Extragestational weight and weight gain

- Number of implantation sites/litter

- Number of litterg with live fetuses

- Number and percent of live fetuses/litter

- Body weight of live fetuges/litter

- Body weight of male and female fetuses/litter

- Sex ratio of fetuses/litter

- Number and percent of early and late resorptions/litter 
- Number and percent of non-live/litter learly and late resorptions and dead fetuses)

- Listing of malformations and variations observed in fetuses/litters

- Number and percent of malformed fetuses

- Number and percent of litters with malformed fetuses

[- Ketone body levels in plasma ${ }^{+A}$

\section{PROPOSED STATISTICAI METHODS}

The methods proposed for the statistical analyses of representative maternal, reproductive and fetal indices of effects are: summary statistics, $N$, mean, standard deviation, with accompanying ANOVA based on multiple comparisons where appropriate. Arc sin transformations will be performed on data presented as percent incidence. Further statistical analyses may be performed at discretion of sponsor.

\section{XIII.RECORDS RETENTION}

Records that accumulate during the study will be retained at BNW until requested and shipped to NTP archives. Some of these records may be presented as part of the protocol or reports. These will include but not be limited to the following records:

A. Rersonnel Records

1. List of BNW personnel participating in the study.

2. Name, address, and function of any outside consultant (s)

3. Record of removal of any individual from direct contact of the test system due to illness.

B. Health and Safety Records (original records and five copies of microfiche will be submitted to NTP within approximately two months after the end of each fiscal year). Chemical specific records will be submitted with the study. Facility specific records will be submitted annually.

1. Medical records of all personnel participating in the study. These records will be retained by Hanford Environmental Health Foundation (HEHF), P.O. Box 100, Richland, WA 99352 for a minimum of 40 years. A letter verifying this arrangement will be retained for each test material file.

2. Records and results of any biological monitoring on laboracory personnel (if applicable). 
3. NTP Health and Safety package for acetone.

4. BNW biohazard protocols and BNW Health and Safety Plan.

5. Chemical specific health and safety training records. 
ACETONE

MCUSE RND RAT TERATOLOGY
BB-DM-1FQM-GD-Q192

Page: 16 of 22

6. Waste disposal records.

7. Respiratory protection program with documentation cf usez trairing (specific fit testing if needed) for each type of respirator.

8. Building ventilation system, hoods and exhausting system monitoring records (pertinent co NTP studies).

9. Health and Safety Section of the Monthly Progress Reports.

10. Accident/injury reports for personnel involved in this study.

11.NTP site visit reports, attention items and related ccrrespondence on health and safery.

C. Drotocols

1. Approved and dared BNW study protocol.

2. Protocol amencments including NTP technical contract modificaticns which affect the study.

3. Documentation of any deviation from the protocol.

4. Documenting any unforeseen circunstances that may affect the integricy of the study and corrective acrions taker.

J. Pest $M= \pm 0-i a l$ Recoris

1. Test materiel identity records including manufactuzez, cientĩy, lot nuber $(s)$, puzity grade and cate(s), Etc.

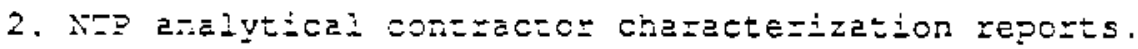

3. Naz anelytical contuactor buik stajiltty reports.

4. NTP analytical contactor shipment recoris (It avaijabie).

5. 3Nw rest chemicai receist records.

E. Jnit storage recorts inclucing szcage concitions.

7. ENx bulk a-ajysis a:d degradazion zecords.

E. E:Th method devel apmer: recorts.

o. Chemical exposure generation system description and pzocesures.

20. Chamber concentuation monitcring recorcs, inciucing Go

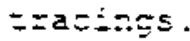

‥ Unizomizy (onemior baience) recorcis.

12. Gas chromatogzaph celibrarion reccrds.

13. Generetion and chambet degradation study recoris.

14. ENK Lest mezeriel inventory and usage zecoris. 
ACETONE

MOUSE AND RAT TERATOLOGY
QE-DT-1EQM-BQ-0:92

Page: $i 7$ of 22

15. Records of shipment to NTP repository of any unused test material.

16. Gas chromatograph maintenance records.

17. Aerosol determination records.

18. Chamber concentration buildup, decay, and overnight moritorinç records.

19. Exposure generation operating paramerer records.

E. Arimal Recerds_- eretest

1. Animal receiving records including supplier, species, strain, birch week, sex, number of animals ior each sex, receiving date and receiving conditions (photocopy of a representarive animiz shipping crate label).

2. Quarantine and acclimatization fecosds.

3. Pretest health screening records and animal health notebook.

4. Randomization records.

5. Animal identification records.

6. Writien reiease records from clinical vererinazian.

7. Disposal of excess animis.

a. seding type.

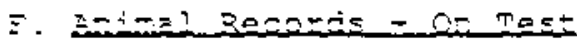

1. Exposure room locaticn and chember ieyout fecoris.

2. Chambez cage meo.

3. Cage zype, zack type and the zorazion scheme duriag stuly.

4. Cegejoerd =ype.

5. mye of wiatezing syszem.

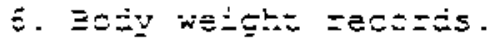

7. Deijy oiservation records

E. Cíñci sigrs of coxicity records.

9. Sezology deta and zeports.

\$0.Pachological specinen inventory recorcs.

G. Eenci

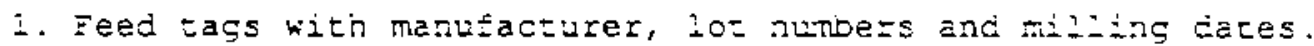


ACETONE

NOUSE AND RAT TERAFOLOGY
$Q \mathrm{~B}-\mathrm{DT}-1 \mathrm{FOM}-\$ Q-Q 192$

Page: 18 of 22

2. Feed analysis records as provided by NaP analytical contract laboracory.

H. hater

1. Annual water analysis.

2. Heekly water hardness check (records will be maintained in building engineer and/or building manager's officel.

I. Quarantine Room. Exposure Boom and Tohalation Evpesure Chamber Recerds

2. Exposure chamber description.

2. Exposure suite control center description.

3. Temperature raw daca and daily and monthiy summation reports.

4. Relative humidity raw data and daily and monthly sumation reports.

5. ñ flow naw deta and daily and monthly sumation repozcs.

6. Charber vaculm raw data and deily and monthly sumaticn reports.

7. Ixposuze system monitors celibration and maintenance zecozis.

8. Description of the lighting system and light/dirk zeginen.

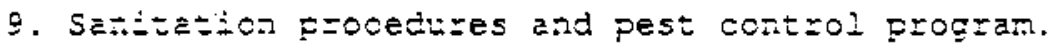

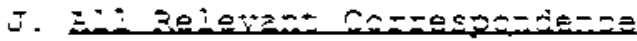

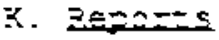

1. Monthiy ?zogress Report.

2. Specizl stusy zepo=ss iz 2uy:

3. Incident repozts (iz eppícable).

․ Ėna- Teza:oiogy Regozこ.

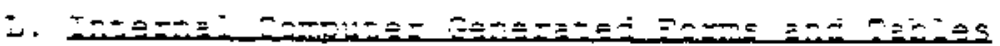

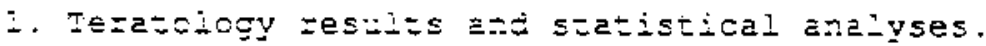

2. Injiyzicai gine-isszy resuizs.

3. Exposure suize conzzol center compliter printouts.

4. XYBION prin:OLts (if any). 
ACETONE

MOUSE AND RAT TERATOLOGY
QS-D年-1FBM-BB-E:92

Page: 19 of 2 in

XIV. ONHER SPECTETCATIONS

A. This study will be performed in compliance with the FDA Good Laboratory Practice Regulations for Non-Clinical Laboratory Studies (21 CFR 58) except where deviations are required by the NTP January, 1984 General Statement of Work and subsequent modifications.

B. This Protocol will be the controlling document in case of discrepancies between the Protocol and sops. If this occurs the Study Director is to be notified imnediately for clarification.

C. A list of all relevant Standard operating Procedures (SOPs) for this study are present in Attachment 1 .

XV. HERIME AND SAEETY

3Nh's Health and Safety Plan (GE-HS-3SIC) has been approved by NTP. In adiiticn, a respiratory program is instituted. This is suppiemented by using supiled-air respirators (63-45-35i9) which wil- be worn by pezsonel duzing periocs of animai care while the chambers are open and by having available self-contained breathing apparatus for use when entering a zoom uncier enezgency concitions foliowing a leak. 
ACETONE

MOUSE AND RAT TERATOLOGY

XVI APPROVAL DY PHI

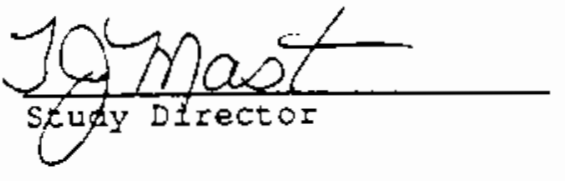

PRthencere

Quality Assurance Auditor

XVII. APPROVAL BY NIP

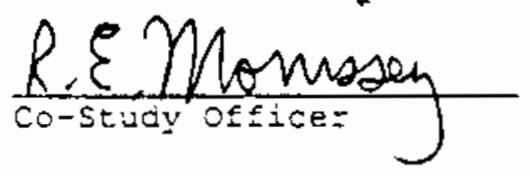

$\frac{\beta A S c l u e t z}{\text { co-stuy officer }}$
$Q B-D T-1 F B M-Q 2-Q 292$

Page: 20 of 22

Date: $9 / 18 / 87$

Date: $\quad 9 / 18 / 27$

Dare: 28 Sept .87

Daze: 28 Sept 87

BATTELLE - PACIFIC NORTHWEST LABORATORY

F. 27 
ACETONE

MOUSE AND RAT TERATOLOGY $\varnothing B-D T-1 F \varnothing M-\varnothing \varnothing-\varnothing 192$

Ammended Page: 21 of 22

XVIII . BEFERENCES

American Conference of Governmental Industrial Hygienists. Docunentation of the Threshold Limit Values, 4th Edition. Lincinnati: ACGIH, 1980.

Bruckner, TV and RG Feterson. Evaluation of toljene and acetone inhalant abuse: phamacology and pharmacodynamics. Toxicol. Appl. Pharmacol. $61: 27-38,1981 \mathrm{a}$.

Bruckner, JV and RG Peterson. Evaluation of toliene and acetone inhalant abuse: model development and toxicology. Toxicol. Appl. Pharmacol. $61: 302-312,1981 b$.

Cheng, KK and MP Yang. Study of pregnancy ketosis in the rat. Q. J. Experim. Physiol. 55:83-92, 1970 .

Clayton, GD and FE Clayton. Ratty's Industrial Hyoiene and Toxicolegy, 3 rd Rev'sd Edition. Vol. 2C. pp 4720-4727, 1982.

Dipaolo, JA, $P$ Donovan, and R Nelson. Quantitative studies of in vitro transformation by chemical carcinogens. J. Natl. Cancer Int. 42:867$874,1969$.

Divincenzo, GD, FJ Yanno and BD Astill. Exposure of man and dog to low concentrations of acetone vapor. Ar. Ind. Hyg. Assoc. J. 34:329-336, 1973 .

Flury, F and w Wirth. Arch. Gewerbepathol. Gewerbehyg. 5:1, 1934.

Ereinkel, N. Metabolic Changes in Pregnancy. In: Textbook of Endocrinology $7^{\text {th }}{ }_{E d}$, JD Wilson and DW Eoster, Eds. WB Saunders Co., Philadelphia, PP. $438-451,1985$.

Eukabori, S, K Nakaaki, and O Taga. Cutaneous absorption of acetone. Rodo Kagaku 55:525-532, 1979.

Eurner, RI, ED Neville, KS Talarico, and DB Feller. A comon modality of action of simulated space stresses on the oxidative metabolism of ethylmorphine, aniline and p-nitroanisole by male rat liver. roxicol. Appl. Phasmacol. 21:569-581, 1972.

Gabbe, SG. Congenical malformations in infants cf diabetic mothers. Obstet. Gynecol. Surv. 32:125-132, 1977.

Goldberg, ME, HE Johnson, UC Pozzani, and HE Smyth. Effect of repeated inhalacion vapors of industrial solvents cn animal behavior. Am. Ind. Hyg. Assoc. J. 25:369-375, 1964 .

Guntakatta, M, EJ Matthews, and Jo Rundell. Development of a mouse embryo limb bud cell culture system for the estimation of chemical teratogenic potential. Teratog. Carcinog. Mutagen. 4:349-364, 1984.

Horton, WE and TW Sadler. Effects of maternal ciabetes on early embryogenesis: alteration in morphogenesis produced by the ketone body, B-hydroxybutyrate. Diabetes $32: 610-616,1983$.

Kucera, J. Exposure to fat solvents: a possible cause of sacral agenesis in man. J. Pediatr. 72:857-859, 1968.

Kucera, J and D Benasova. Poruchy nitrodelozniro vyroje cloveka zpusobene pokusem o potrat. Cesk. Pediatr. 17:483-489, 1962.

[Lopez-Soriano, FJ, and JM Argiles. Simultaneovs determination of ketone bodies in biological samples by gas chrometographic headspace analysis. J. Chromatog. Sci. 23:120-123, 1985. $]^{+A}$

Mccann, J, E Choi, E Yamasaki, and BN Ames. "Detection of Carcinosens as mutagens in the Salmonelda/microsome test: Assay of 300 chemicals., Proc. Natl. Acad. Sci. 72:5135-5139, 1975.

Mclaughlin, J, JP Marliac, MJ Verrett, MK Mutchler and OG Eitzhugh. Toxicity of 14 volatile chemicals as measured by the chick embryo mechod. Am. Ind. Hyg. Assoc. J. 25:282-284, 1964 . 
ACETONE

MOUSE AND RAT TERATOLOGY
G-DT-1FØM-ØØ-Ø192

Amended Page: 21 a of 22

Mourkides, GA, DC Hobbs, and RE Koeppe. The metabolism of acetone-2-Cl4 by intact rats. J. Biol. Chem. 234:27-30, 1959.

Nelson, DL, and BP webb. Acetone. In: Kirk-othmer Encyclopedia, of chemical Technology, $3^{\text {rd }}$ Ed. HE Mark, DF Othmer, CG Overberger and GT Seaborg, Eds. Wiley and Sons, NY, pp 1:179-191, 1978 . 
ACETONE

MOUSE ANS RAT TERATOLOGY
$Q \bar{B}-2 T-1 F O M-D Q-D 192$

Page: 22 of 22

NIOSH, Criteria for a recommended standaxd for occupational exposure to ketones. US Dept of Health, Education and weifare, National Institute for Occupational Safety and Health DHEW (NIOSH) Publication No. 78-173, 1978 .

Nizyayeva, IV. On hygienic assessment of acetorie. Gig. truda i. prof. zabol. (Russian) June, pP 24-28, 1982.

Price, TD and D Rittenberg. The metabolism of acetone: I. Gross aspects of catabolism and excretion. J. Eiol. Chem. 185:449-459, 1950.

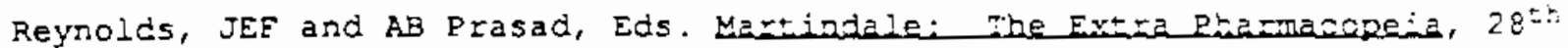
Edition. The Pharmaceutical press, London, 1982.

Rowe, VK. Indistrial hyciere arcimexicelegy, 2nd Ed, Vol II, Interscience, NY, 1963 .

Rudney, H. The metabolism of 1,2-propanediol. Arch. Biochem., 29:231-232, 1950 .

Sakami, $W$ and JM Lasaye. Fomation of formate and labiie methyl groups fzom acetone in the intact rat. J. Biol. Chem. 287:369-378, :950.

Sakami, kJ. Biol. Chem. 176:995, 1948.

Schazdein, II. Chemicaliy todired Eizih Deferts, Marcel Dekker, 1985.

Snyth, HE, CP Carpenter, CS Heil, and UC Rozzani. Range finding toxicity data: list VI. An. Ind. Hyg. Assoc. J., 23:95-107, 2962.

Traiger, GJ and GI Plat. Relationship of alcohol metabolisn to the petentiation ef Colq hepatotoxicity induced by aliphatic alcohcls. J. Phazmacol. Exp. Ther. 183:481-488, 2972.

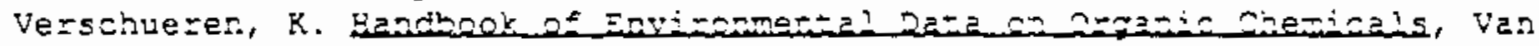
Nostrand Reinhold, New York, 1977.

Wigeaus, I, S Holm, and I Astzand. Exposuze to acezone: lozake and

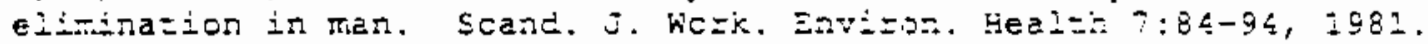


ACETONE

MOUSE AND RAT TERATOLOGY $\emptyset \mathrm{B}-\mathrm{DT}-1 \mathrm{~F} \emptyset \mathrm{M}-\emptyset \square-\emptyset 192$

Ammended Page: $22 \mathrm{a}$ of 22

XVIX. CHANGES AND/OR_REVTSIONS TO MHE PROROCOI

Revision A: Rage i

Corrected erroneous page number references in Table of Contents. Added page number reference to section XVIIa.

Reagon: Rectify Table of Conterts.

Page $6 . V$. Proposed Schedule of Events

Initiation of breeding and health screen delayed one week.

Reason: Late arrival of test material.

Page 7. VI. Test System.

Number of sperm-positive rats on study increased.

Reason: Addition of task to measure ketone body levels in plasma.

Page 8. VII. Experimental Design and Dose Level.

Addition of Part D. Measurement of Ketone Body Levels in Plasma.

Reason: Addition of this task at request of Rroject officers.

Page $9 . \mathrm{VIII}$. Test System,....

Change in Part D. Randomization. Changed to accomnodate additional animals required for blood collection.

Reason: Addition of task at request of Project officers.

Page 14. XI. Experimental observations.

Addition of Eart Ca. Measurement of Ketone Bodies in Rat Plasma.

Reason: Addition of task at request of Project Officers.

Page 25. XI. Expeximental observations.

Addition of effect.

Reason: Addition of task at request of Project officers.

Rage 20.XVIIa, Changes and/or Revisions to the Rrotocol.

Addition of section.

Reason: To accommodate protocol revisions. 


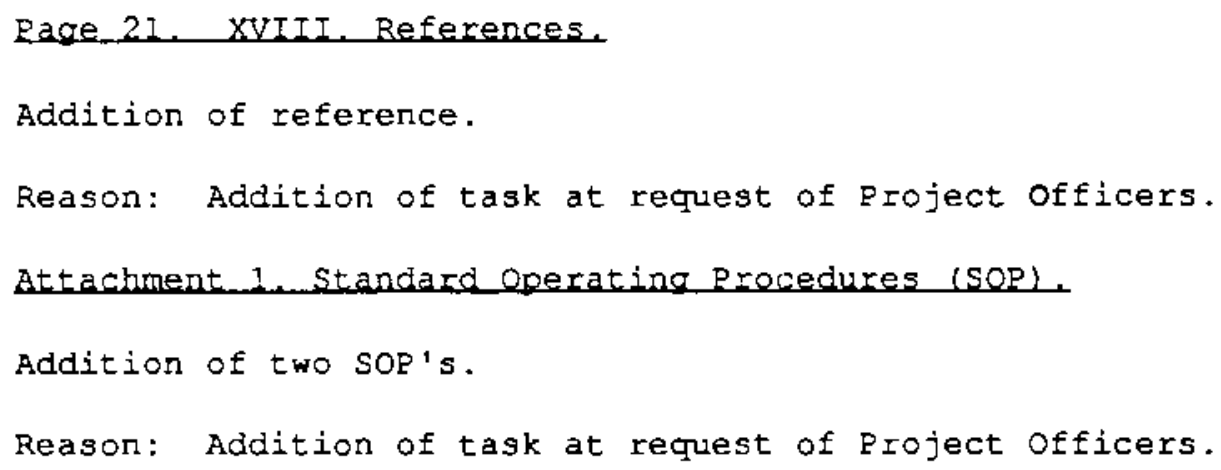


ACETONE

MOUSE AND RAT TERATOLOGY $\emptyset \mathrm{B}-\mathrm{DT}-1 \mathrm{~F} Q \mathrm{M}-0 \varnothing-\emptyset 192$

Armended Page: 22 of 22

XVX. ORIGINAT PAGES THAT HAVE BEEN REVTSED 
I. Time Teratology Study of Acetone in Mice and Rats ........

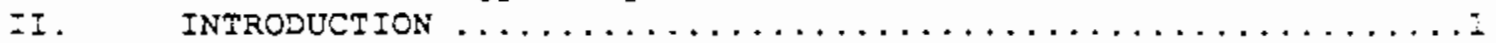

III. $\quad$ SPONSOR AND SPONSOR'S REPRESENTATIVE .............6

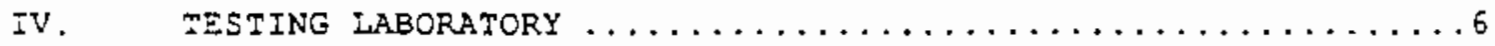

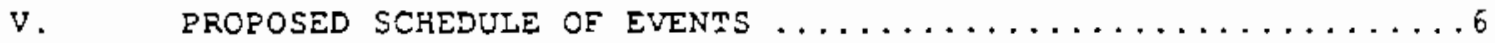

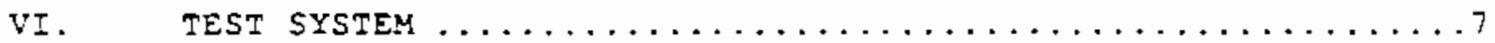

VII. EXPERIMENTAL DESIGN AND DOSE LEVELS $\ldots \ldots \ldots \ldots \ldots \ldots \ldots \ldots \ldots$

VIII. TEST SYSTEM HOUSING, HANDIING AND ENVIRDNMENTAL CONDITYONS ..8

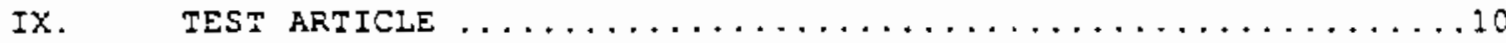

$X$. DESCRIPTION OE INHALATION EXPOSURE SYSTEM .............

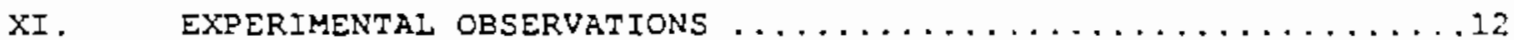

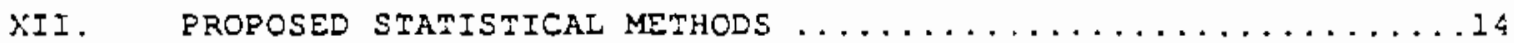

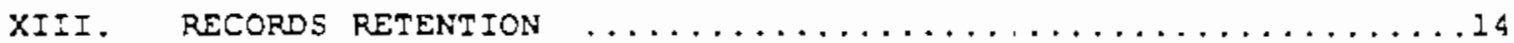

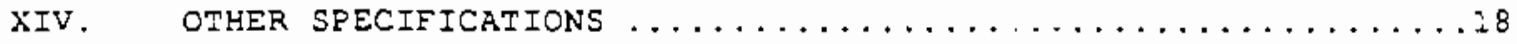

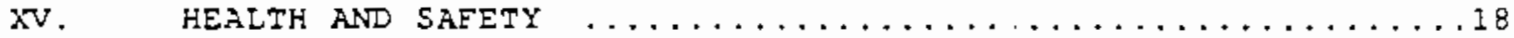

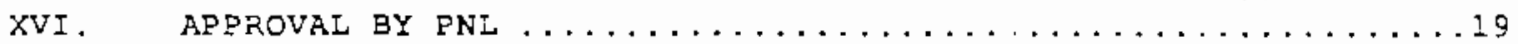

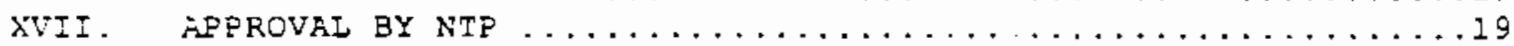

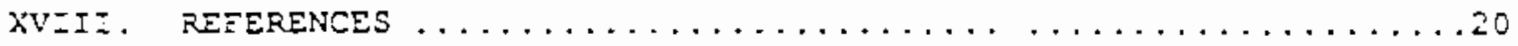

ATTACHMENT 1 SOP IIST

AMTACHMENT 2 INHALATION EXPOSURE SYSTEM 


\section{SPONSOR AND SPONSOR'S RERBESENMAIIVE}

A. Spenser:

National Institute of Environmental Health Sciences

National Toxicology Program (NTP)

P.O. BOX 12233;

Research Triangle Park, N.C. 27709

B. Seonsor's Recresertatives:

$D x$. Bernard Schwetz

Dr. Richard Morrissey

\section{MESTING IABORARORY}

a. Facisicy

Batcelle - Pacific Northwest Laboratory (PNL)

P.0.30x 999; Richland, Washington 99352

B. Study Director:

Dr. Terryl J. Mast

v. ZROPOSER SCHEDUTE OF EVENTS (This proposed schedule may be attered. All changes will be appended to the protocol.)
$B a=5$ Nice
A. Arimals azzive week of:
$9 / 21 / 87 \quad 21 / 4 / 87$
3. Icentification of Eemales:
$10 / 5 / 87 \quad: 1 /: 9 / 87$
C. Health screen :
$10 / 22 / 87 \quad 11 / 25 / 87$
D. Pzestart audit for GiP compliance:
$10 / 22 / 37 \quad 21 / 25 / 87$

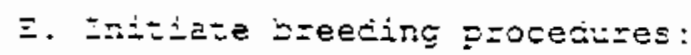
$20 / 22 / 87 \quad 21 / 25 / 87$
I. Initicte exposuze :
$10 / 29 / 87 \quad 22 / 2 / 57$
G. Inisiate necropsy:
$21 / 2 / 87$
$22 / i 4 / 87$
シ. Eveluate fetal specimens:
$51 / 9 / 87-1 / 25 / 87$
samined
I. Submiz drast report:
$2 / 25 / 88$
¿. Submiz Einal report:
$3 / 28 / 88$ 
ACETONE

MOUSE AND RAT TERATOLOGY
OB-2T-IFOM-OQ-O:92

Page: 7 of 22

VI. $\quad \operatorname{TEST}$ SYSTEM

A. Speries: mouse and rats

B. Strain: Mice: CII:CD-1(ICR)BR; rats: Sprague-Dawley [CrI:CD(SD)BR]

c. Number of Brimals and Sucphier: Charles River Breeding Laboratories, Raleigh, NC.

Mice: 85 males 310 females

Rats: 55 males 245 females

D. Age of enimzls inco Arrival:

Mice: $7-8$ weeks

Rats: $\quad$ i-9 weeks

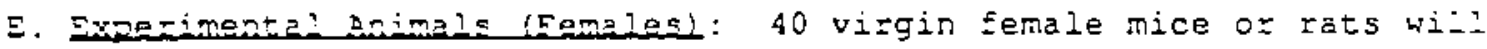
be ranciomly selected and assigned to four dose grcups (10/group) $\mathrm{f}$ an. the total female pool (BB-DT-3BOB). The remaining femaies will be mared by placing at least two females with one mele overnight in breeding cage (O3-DT-3BOD). Nine AM of the day that copuiation is eszablisined will be designated as 0 dg (BE-ZT-3BZD).

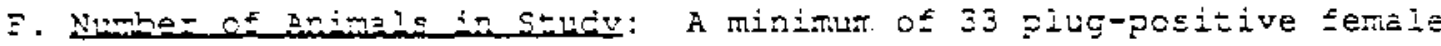

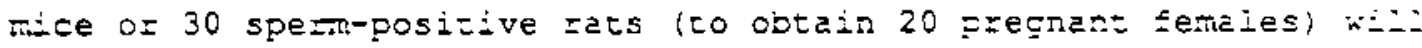
comprise eaci of the four rreacment groups; the minimin rumer ct

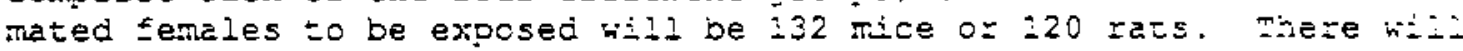
also be 10 vizgins (femeles) of eech species per exposize jeve:.

VII. EXERTMENTE RESIGN AND DOSE TEVETS

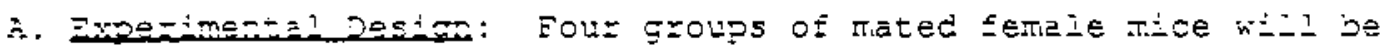

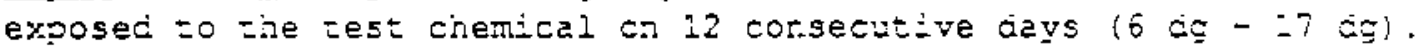

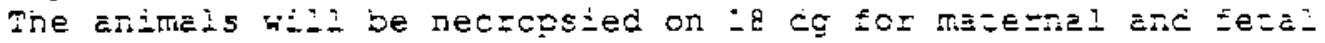
evá่uaziars.

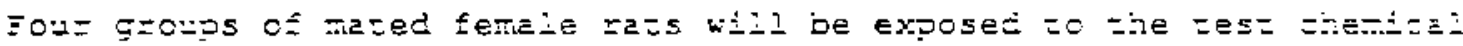

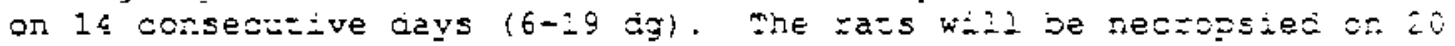
dg fcr meこezni anc fetal eveiuetions.

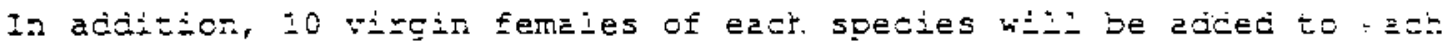
exposuze Groug for the purpose cf obtaining ovazies to be used

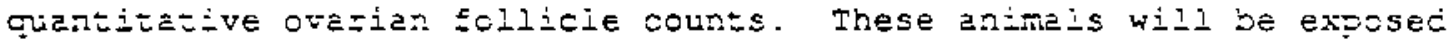

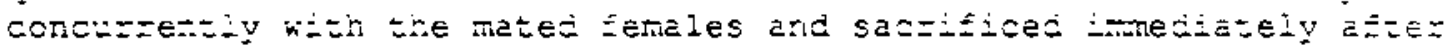
the iast exposure period.

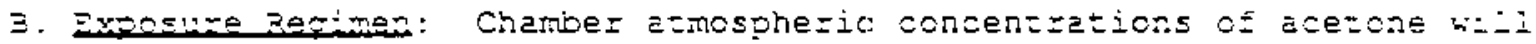

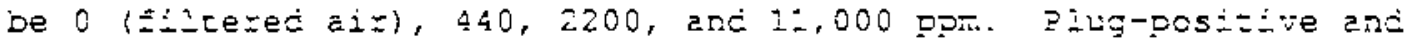
virgir mice wili be exposed for o hrsiday for 12 consecutive days is

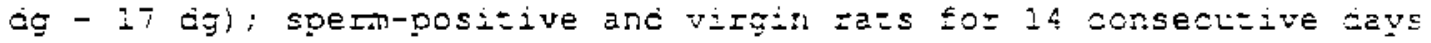

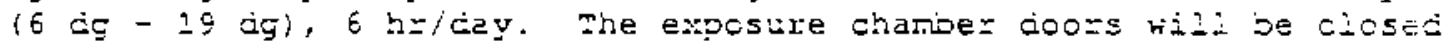
throughout ine expostre and nor-exposure periods, except during 
ACETONE

MOUSE AND RAT TERATOLOGY $\theta \mathrm{B}-2 \mathrm{~T}-1 \mathrm{D} \sigma \mathrm{M}-60-0292$

Page: 8 of 22

animal care procedures. Exposure chamber temperatures will be maintained at $75 \pm 3^{\circ} \mathrm{F}$ and relative humidities ac $55 \pm 15 \%$. fir flow will be maintained at $15 \pm 3$ cfm and the chambe= pressure at approximately I" water negative with respect to room pressure.

C. Selection of Atmospheric concentrations: Exposure chamber concentrations are based partly on information obtained from previously published reports on inhalation toxicology studies of acetone and partly on safety considerations. Safety considerations limit the maximum exposure concentration to $50 \%$ of the lower explosion limit $(-22,000 \mathrm{ppm})$ which is $11,000 \mathrm{ppm}$.

VIII.

\section{TEST SYSTEM HOUSTNG, HANOUING AND ENVIRONMENTAL} CONDITIONS

A. Ouarantine and Acoiniatizatico (0a-2R-3502)

2. Animal shipping crates wizl be examined upon arrival for evidence of concitions likely to permit exposure to pathogens (soiled, wet or otherwise damaged).

2. The lincrating will be conducred at the door of the guarartine zoom. While being removed frcm the crafes the animais will be examined for evidence of shipping stress.

3. The animals will be quazanined and acclinarized in the ISi-iz Euilcing for i-4 weeks prior to the start oi the study.

4. Duzing part ce the ouarantine/acelimazization petiod the animais Hili be housed jy sex, approximately io mice of 5 rats per cage in wize ages or. Elush zacks. The cage space will meet the requizements sated in the $\mathrm{NIH}$ "Guide for Care and Use cE Ladorazo:Y Ariziels".

5. Duzing che breecing peziod the arimals will be noused in tie

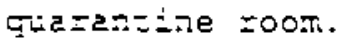

6. Plug-positive rice or sperm-posizive rats will de actímzed frcm 0 dg in inciviciel compaztments of wize-mesi cages within exposize

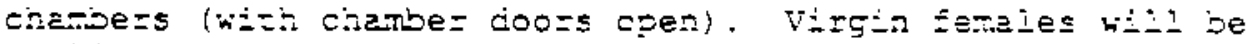
accimaled for epproximately 1 week $0=i o r$ to emposure lnder ine same cancitzons.

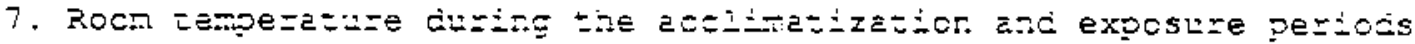
nili be Ha These measuzemexs bill de recomed at least trice daily.

8. Twelve hours itght and tweive hours däk wili be maintained wis: ígint stazing

9. Five male and five female animals wil de randomiy selected fcr pre-exposure health screening (GS-AR-3FQ2). They will be examined by gross necropsy, histopazhology and nasopinzyngeal culcure for evidence of cisease and the sresence of potertiaiiy pachogenic organisms. 
ACETONE

MOUSE RND RAT TERATOLOGV
GB-DT-ZEOM-OB-E192

Page: 9 of 22

10. The clinical veterinarian will make a visual inspection of the animals to be used in the study just prior to their release for the study (documented on the last cuarantine/ acclimatization record).

11. As an adced screen for viral infection, 5 animals from the control group and 5 animals from the highest dose group wiil be tested promptly after sacrifice at BNW for viral pathogens (OS3BIR).

12. Females not selected for the study or health screen wizl be discarded during the first exposure week. The disposition of these females will be recorded on the Animal Disposition Record and retained in the study files (OE-AR-3Fb3). Males, (they are not individually identified) will also be discarded.

B. Easd (OEA-AR-3505)

1. NiP pre-approved NIH-07 Open Formula Diet (pellers) frot ziegler Bros., Inc., Gardner, PA will be used during the cuarantine/acclimatization periocis and throughout the duzatica ce the experiment.

2. Feed will be provided ad libitur in slot feeciers curing the experiment, except curing exposure hours.

C. $h \geq \pm e r$

1. Eresh scttened water (ion exchange softenez, Illinois Water rreatment Company, Model 2k-2240, Fockford, IL) will be sippliec ad libicin at all zines. The tazcless cf the water kili be

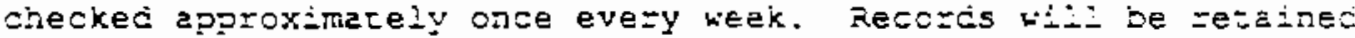
in the LSI-II Juiling Enginee='s c=tice.

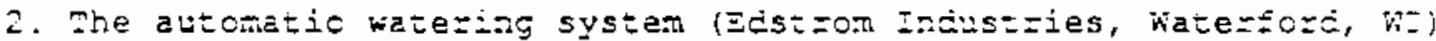
will be used fcr the grizrantine/acclimetizacion period and infoughout the dufation of the siucy.

3. A representative sample of animal dinking watez tzon cne ct lie

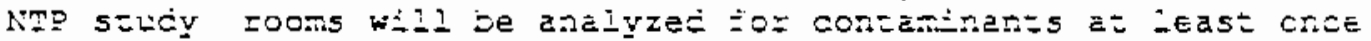
eazh calerciar yeaz.

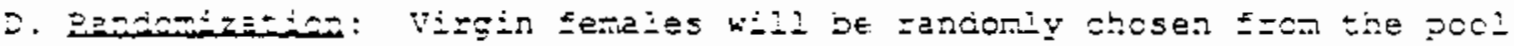

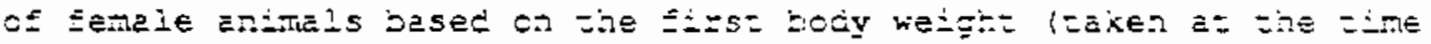

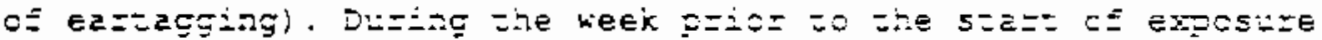

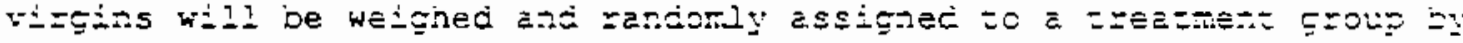

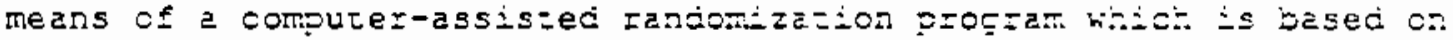

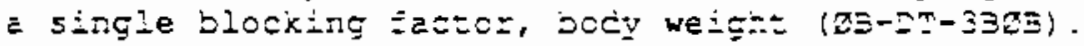

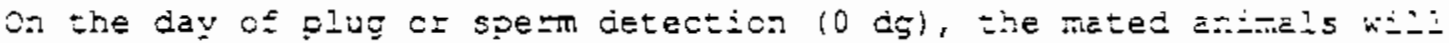
be weighed and essigned to cose groups as descridec above. 
ACETONE

MOUSE AND FAT TERATOZOGY
$Q 3-D T-1 F O M-3 \nabla-\varepsilon 192$

Page: 14 of 22

fetuses with gross abnomalities. (BB-DT-3BBG) Sex will be determined on all fetuses by internal examination. All skeletons wili be double-stained and examined for cartilage formation and centers cf ossification ( $6 \mathrm{~B}-D T-3 B O G$ ); however, $=50$ of these will have had their heads removed. These fetal heads will be examined by razor-blade sectioning fixation in Bouin's fluid (Wilson, 2965; (0E-DT-3BOI)). Records of morphologic lesions observed in gross and viscera: examinations wiIl include photographs (BB-DT-3BOJ) of representative lesions.

Both ovaries from the virgin females and one ovary from each of the pregnant females will be collected at the time of sacrifice. 10B-DT3BWG). Collected ovaries will be fixed for 24 hr in Bouin's fluid then transferred to 70 ethanol and sent to Dr. Donald Mattison at the National Center for Toxicological Research for sectioning and quantitative follicle counts.

D. Indices of Effeats: The following parameters, expressed as mean = STD, when appropriate, will be computed from data for inseninated animals and their litters and will be presented in the Final Report for each treacment group:

- Numer of dead maternal animals, asimais removed from the study and reason for removal

- Sumazy of maternal toxicity, including incidence of changes detected dirzing cinicical obsezvarions

- Numer and percent pregnant

- Mateznal bocy weigits:

Mice on $0,6,9,12, \quad 25$ a:d 16 cg

Razs on $0,6,10,-4, \pm 7$, and 20 :

- Weighi of gravid uterus

- Mateziel livez, aizenel, asc kidney wejghts

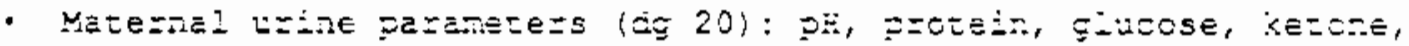
bilizukin, bisos, enci wasilinoges.

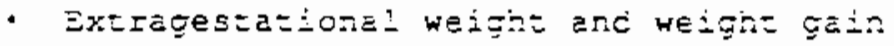

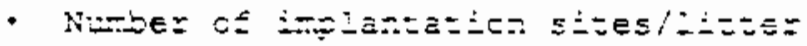

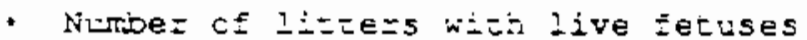

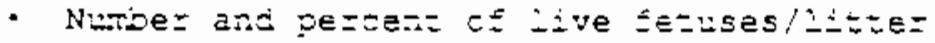

- Bocy weigit cE Iive Eetuses/litzez

- Body weight of maie ano female fetuses/litrez

- Sex zazio of zetuses/iiztez

- Number and percent of early and late zescrpions/liteter

\section{BATTELLE - PACIFIC NORTHUEST LABORATORY}


ACETONE

MOUSE AND RAT TERATCLOGY
QB-DT-1FOM-QZZ-Q2:92

Page: 15 of 22

- Number and percent of non-live/licter (early and late regorftions and dead fetuses)

- Listing of malformacions and variations observed in fecuses/litters

- Number and percent of malformed fetrses

- Number and percent of litters with nalformed fetuses

\section{RROPOSER STATISTICAT METHORS}

The methods proposed for the statistical analyses of representative maternal, reproductive and fetal indices of effects are: sumnary statistics, N, mean, standard deviation, with accompanying ANOVA based on multiple comparisons where appropriate. Arc sin tzansfomacions will be performec on data presented as percent incidence. Further statistical analyses may be performed at ciscretion of sponsor.

\section{BECORDS RETENTION}

Records that accumulate during the stujy $t$ ill be retained at aNk lintil requested and sinipped to NTP zuchives. Some ct these resoris may be presented as pazt of the protocol cr repozss. These $1:=1$ include but nct be limited to the foilowing recozis:

A. Dorsonged zecosis

2. Iist of BNW pezgonel participating in the szidy.

2. Neme, adicess, and funcion of any ousside consuiten: (s)

3. Record of removal of any individiel from dizest conzeco of the test sysien dive to ininess.

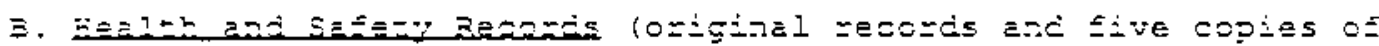

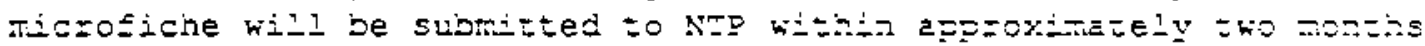

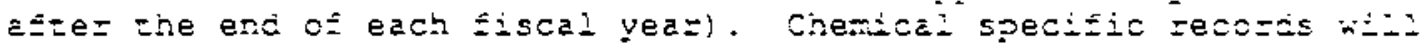

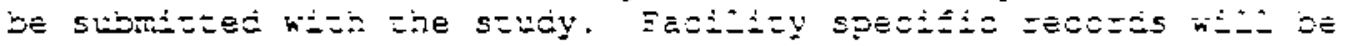

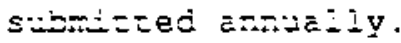

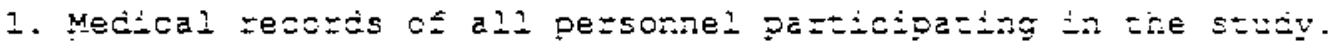

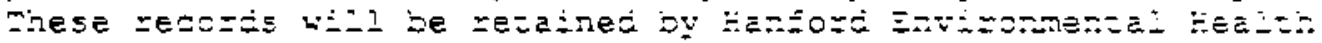

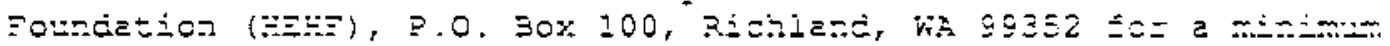

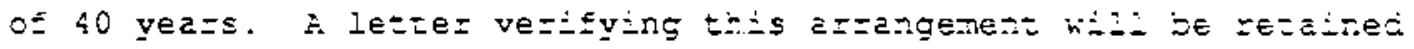
Ł̃x eaci zest material file.

2. Kecorcis and zesults of any diologice: monifozing on jabozetory personnel (if apelicaile).

3. NTP Health and Safery package for acetone.

4. BNW Dionazard prococols and BNw Health anc sezezy Zlar..

5. Chemical specifio heelth and safety tzaining records. 


\section{ACETONE}

MOUSE AND RAT TERATOLOGY
$Q B-2 T-1 F D M-B Z-2192$

Page: 21 of 22

\section{BEEERENCES}

Aterican Conference of Governmental Industrial Hygienists.. Denumentaticn of the Threshold Itmit Values, 4th Edition. Cincinnati: ACGIH, 1980.

Bruckner, $N$ and RG Peterson. Evaluation of tolvene and acetone inhalant abuse: pharmacology and phamacodynamics. Toxicol. Appl. Phamacol. $61: 27-38,1981 \mathrm{a}$.

Bruckner, $J V$ and RG Peterson. Evaluation of toluene and acetone inhalant abuse: model development and toxicology. Toxicol. Appl. Pharmacol. $62: 302-312,1981 \mathrm{~b}$.

Cheng, KK and MP Yang. Study of pregnancy ketosis in the rat. Q. J. Experim. Physiol. 55:83-92, 1970.

Clayton, GD and EE Clayton. Patty's Industeial Hyciene and woxicolocy, 3rd Rev'sd Edition. Vol. 2C. pp 4720-4727, 1982.

Dipaoio, JA, P Donovan, and R Nelson. Quantitative studies of in vitro transformation by chemical carcinogens. J. Natl. Cancer Int. 42:867874,1969 .

DiVincenzo, GD, EJ Yanno and BD Astill. Exposure cf man and dog to low concentzations of acetone vapor. An. Ind. Hyg. Assoc. J. 34:339-336, 2973.

Eluzy, $z$ and $W$ Wirth. Arch. Gewezbepathol. Gewezbehyg. 5:2, 1934.

Ereinkel, N. Metabolic Changes in Pregnency. In: Textbook of Enconzinciogy

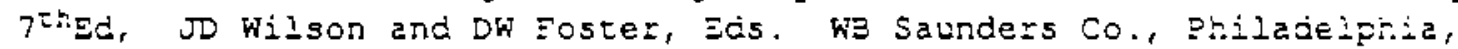
PP. $438-451,1985$.

Eukabori, S, K Nakaaki, ans O Taga. Cltaneous absorption of acetone. Roso Kagaku 55:525-532, 1979 .

Funez, Ri, ED Neville, KS Talaziso, and 23 Eellez. A conon modaijzy cE action of simulazed space szzesses ca the oxidarive mezajo:ist os ethyinorphine, aniine and p-nitroarisoie by male zaz livez. poxisci. AE:l. Pha maccl. 21:569-581, 1972 .

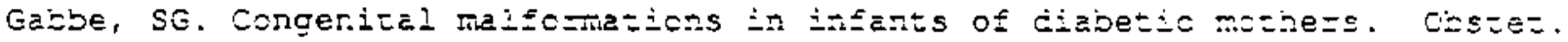
Gynecol. Suzv. $32: 225-132,1977$.

Goliberg, ME, ra Johnson, UC pozzan, and tE Styth. Iffect

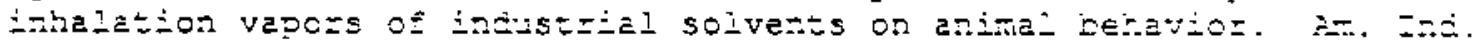
ثyg. Assoc. I. 25:369-375, :964.

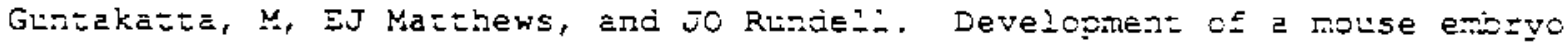

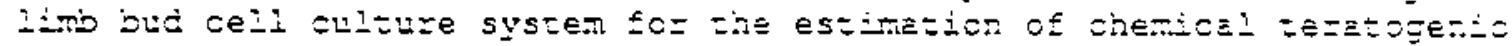
poterziz1. rezatog. Cezcinog. M:tagen. 4:345-364, -984.

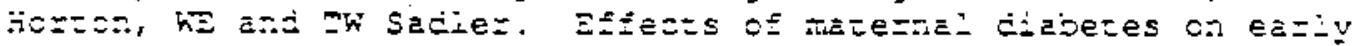
eminyogenesis: elzeration in morphogenesis produced by fhe kezone bosy,

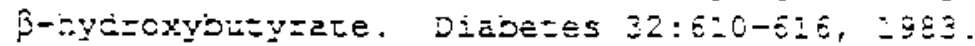

Kuceze, $J$. Exposure ro fat solveñs: a possible cause oz saczaj agenesis í man. J. Eecietr. 72:857-85s, 1958 .

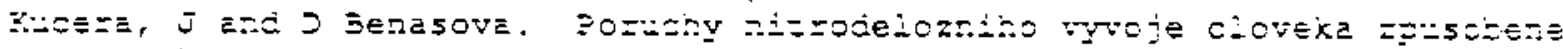
pokusem o potzat. Cesk. Fecisur. 17:483-489, 1962.

Mcつzan, J, E Choi, E Yamasaki, end BN Ames. "Detection oE Cazcinogens as muagens in the Sämonella/microsome test: Assay cf 200 cremiads.,

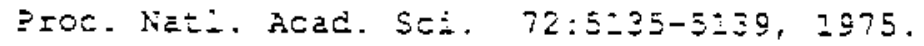

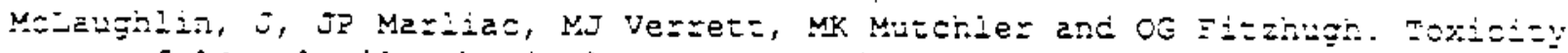

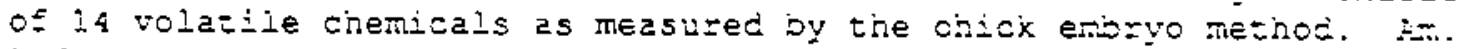
Inc. Hyg. Assoe. J. Z5:282-284, 1964 .

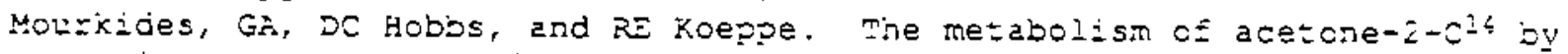
intact rats. J. Bioj. Chet. $234: 27-30,1959$.

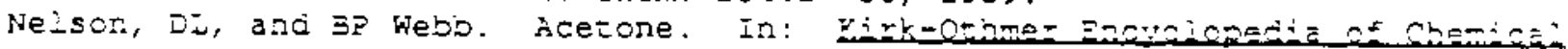

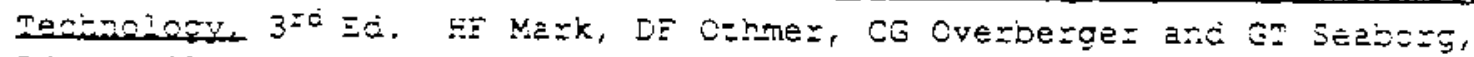
Eds. Wiley and Sons, NY, PP : :179-191, 2978 .

BRTELLE - PRCIFIC NORTHWEST LABORATORY 
ACETONE

MOUSE AND RAT TERATOLOGY

ATTACHMENT 1 $\triangle B-D T-1 F O M-D \sigma-0192$

Page: 1 of 3

ATTACHMENT 1

\section{STANDARD OPERATING PROCEDURES FOR INHALATION REPRODUCTIVE TOXICOLOGY STUDIES}

\section{REPBODUCTEVE_AND REIEIORMENTAI_TOXICOLOGY}

$6 B-D T-3 B O 3$

Cage Locarion Maps and Daily observations

$9 B-D T-3 B B B$

Randomizacion of Animals

$B B-D T-3 B Q C$

Animal Body Weights

$6 E-D T-3 B O D$

Rodent Mating Proceduzes

GB-DT-3BEE

Necropsies for Health Evaluation and of pead or Moribund Animals

$Q S-D T-3.96 G$

Developmental Evaluations for Teratology Studies

$93-5 T-330 I$

Examination of Fetal heads Eixed in Bouin's Solutior

$B \equiv-D T-350 \mathrm{~J}$

Photography

$\square \equiv-D T-33 x I$

Data Hancling end Storage

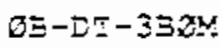

Sample storage/Sirinent

$8 \overline{S-2 T-35 \propto Y}$

Exanination of Doubie-stained Detal Ret and Mouse Sixelezons.

BS-DT-351

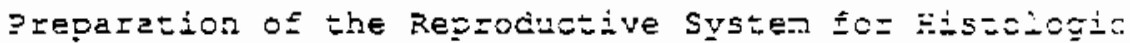
जvaluacion

$\not S-S I-\Sigma \Xi \emptyset 1$

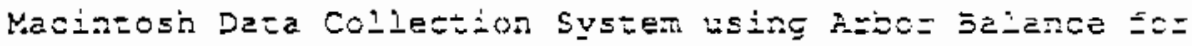
Tezatclogy enc Dcriañ iezhai Saczizice.

$2 \Xi-S I-3 \Xi Q 3$

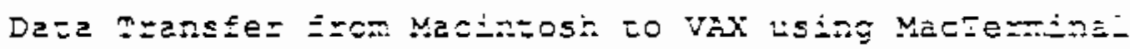

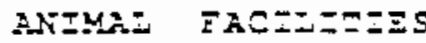

$2 \Xi-x R-3 \Xi 23$

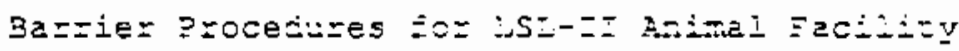

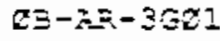

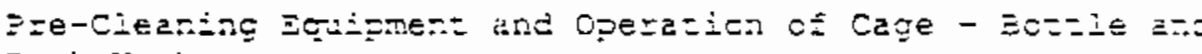
Reck Washe $=5$

のースミー 3テも:

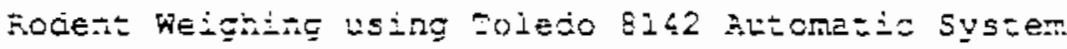

$8 \Xi ー ミ ス-3 \Xi Z 3$

Handling enc Changing ou Exposute Chambers and Cage Units

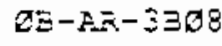

Hending Escaped stail joimels

$Z \bar{B}-F=-3 \equiv C 2$

Pze-Exposure Healti Screering of Roder:s

ZS-2E-3EZ3

Quzzantine of Arimais 


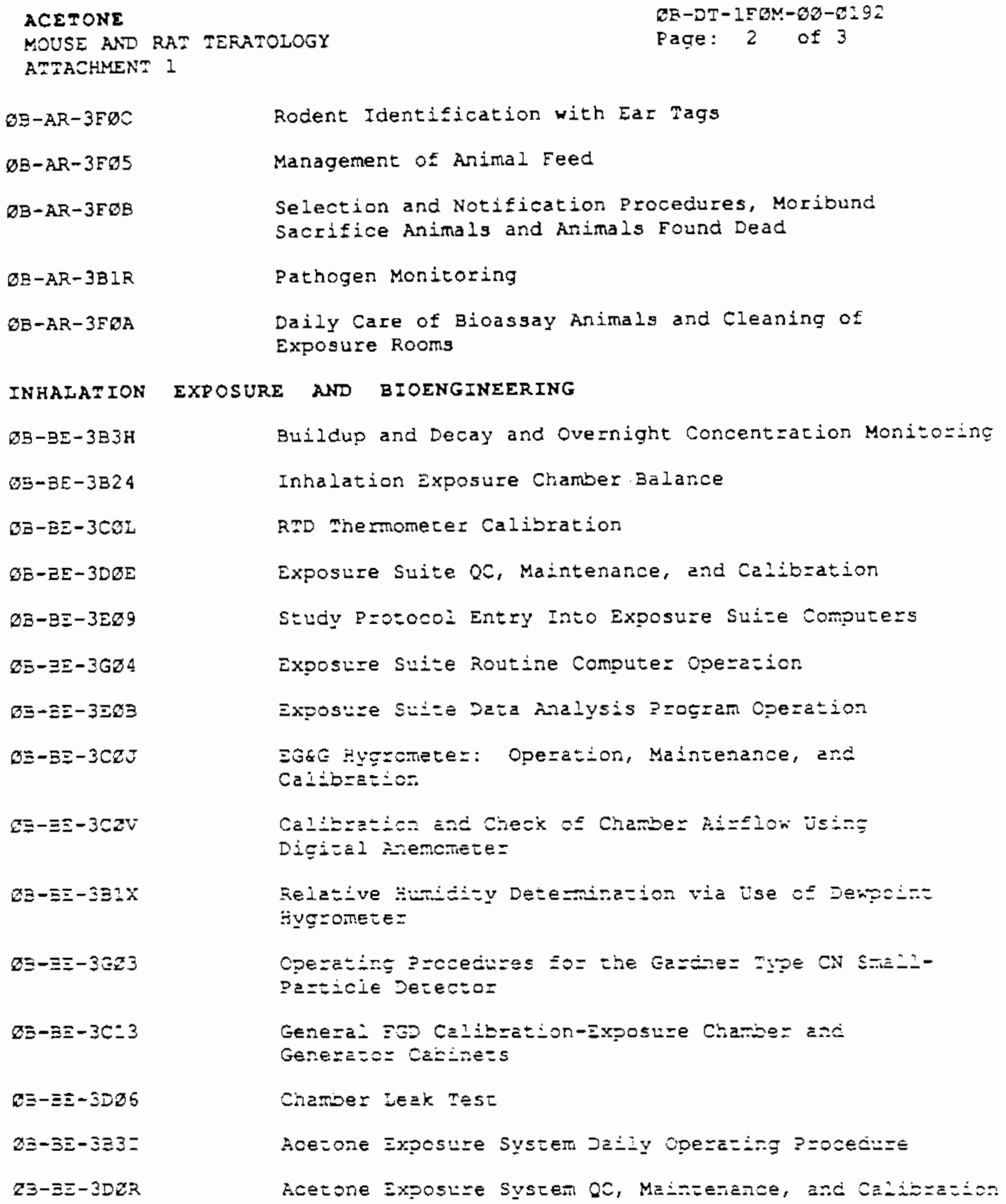

RNAIYICAL CHEMISTRY

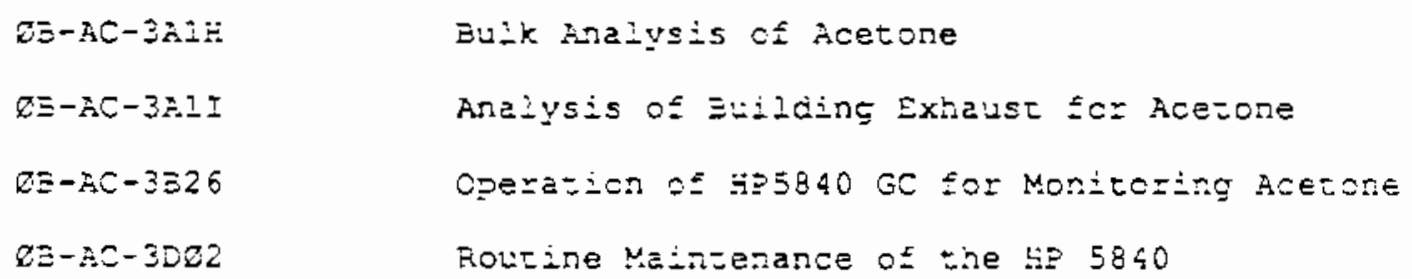


ACETONE

MOUSE AND RAT TERATOLOGY

ATTACHMEN' 1 $\emptyset \mathrm{B}-\mathrm{DT}-1 \mathrm{~F} \emptyset \mathrm{M}-\emptyset \varnothing-\emptyset 192$

Armended Page: 1 of 3

ATTACHMENT 1

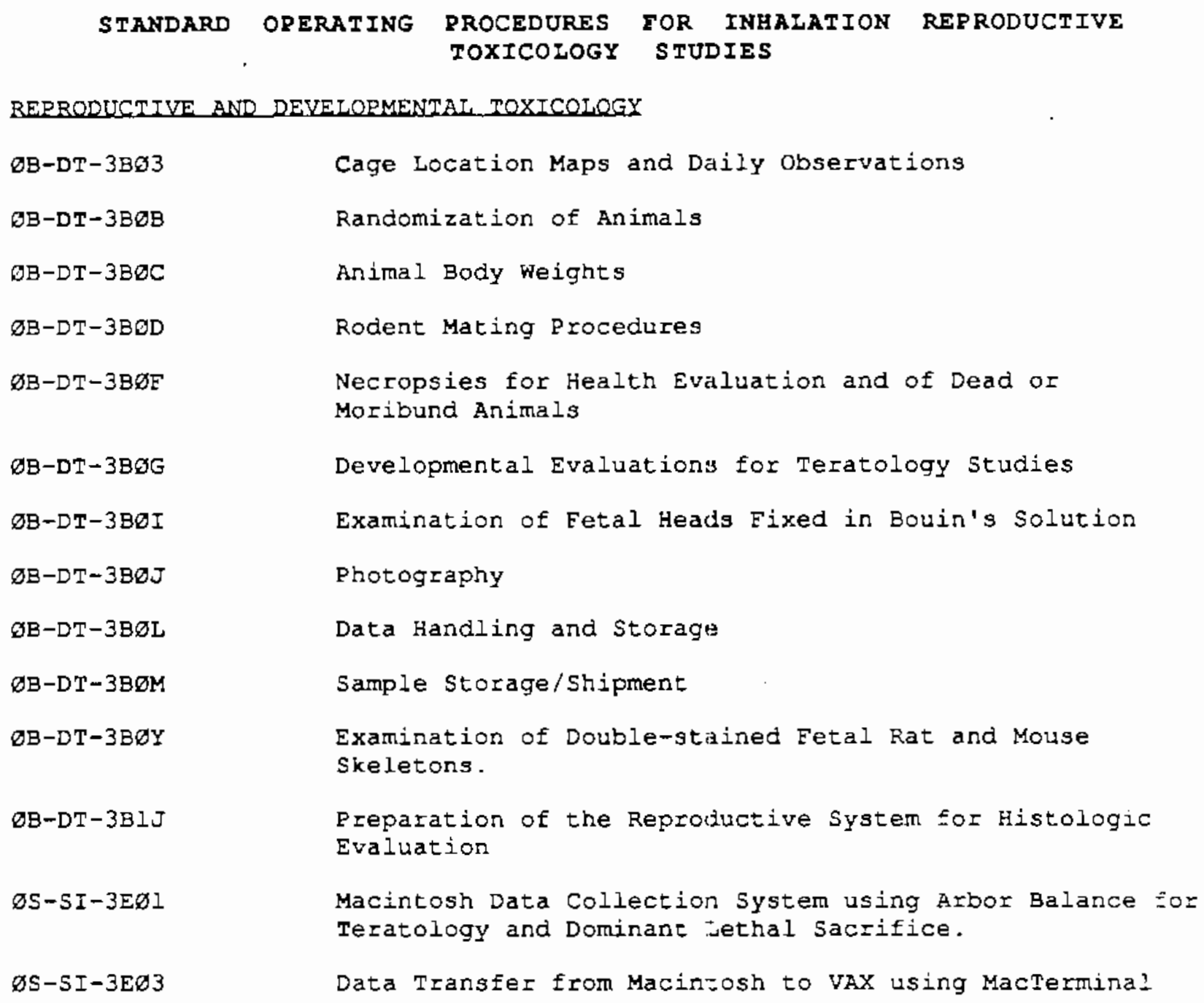

ANIMAZ FACIZITIES

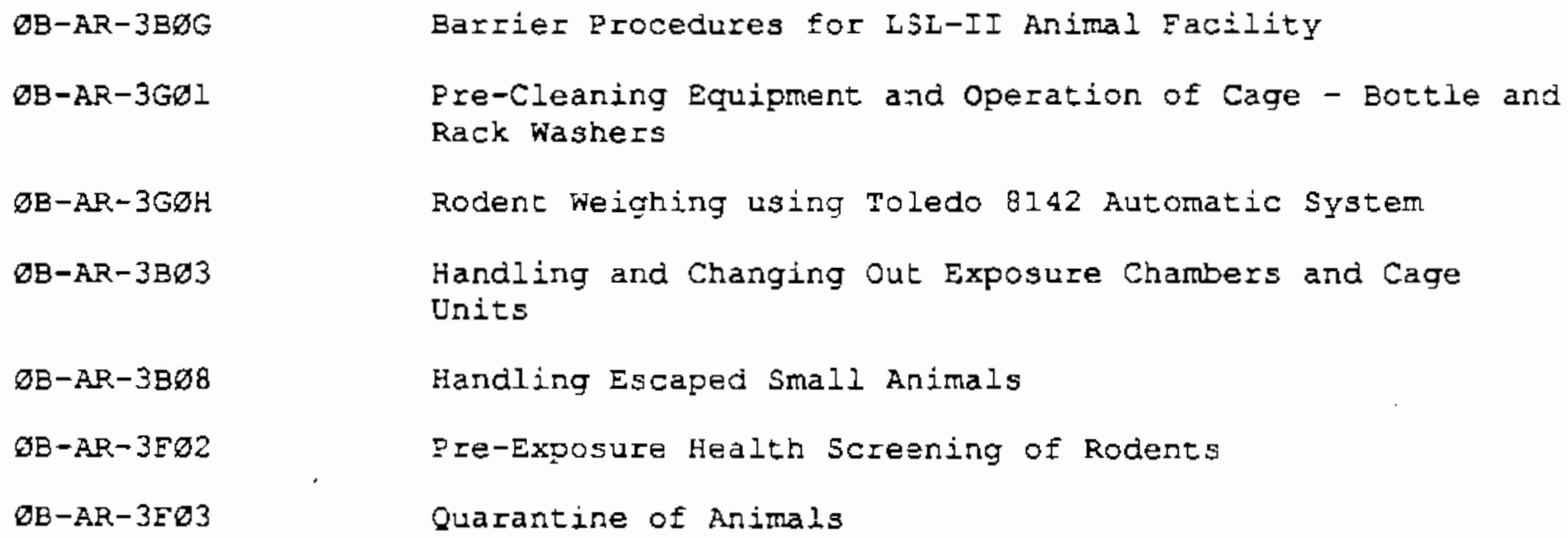


ACETONE

MOUSE AND RAT TERATOLOGY

ATTACHMENT 1

$B B-C P-3 E D 1$ $\emptyset \mathrm{B}-\mathrm{DT}-1 F O M-\emptyset \emptyset-0192$

Arumended Page: la of 3

Daily Operating Procedure-Specimen Handling 
ACETONE

MOUSE AND RAT TERATOLOGY

ATTACHMENT 1
$D B-D T-1 F O M-O D-0192$

Ammended Page: 2 of 3

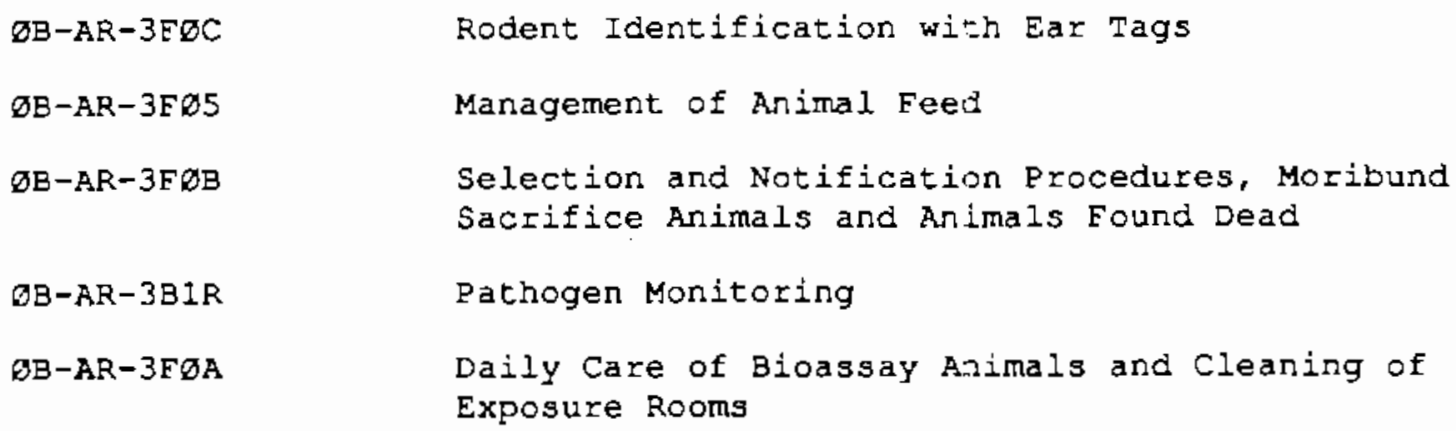

\section{INHALATION}

$6 B-B E-3 B 3 H$

$\Xi \mathrm{B}-\mathrm{BE}-3 \mathrm{~B} 24$

$6 B-B E-3 C Q L$

$G B-B E-3 D G E$

$9 B-B E-3 E \sigma 9$

$B B-B E-3 G O 4$

$B B-B E-3 E \sigma B$

$O B-B E-3 C D J$

$B D-B E-3 C g V$

$Q B-B E-3 B 1 X$

GB-BE-3G@3

BB-BE-3C13

$9 B-B E-3 B 3 I$

GB-BE-3DER
$0 B-B E-3 D 06$

\section{EXPOSURE AND BIOENGINEERING}

Buildup and Decay and Overnight Concentration Monitoring Inhalation Exposure Chamoer Balance

RTD Thermometer Calibration

Exposure Suite QC, Maintenance, and Calibration

Study Protocol Entry Into Exposure Suite Computers

Exposure Suite Routine Computer Operation

Exposure Suite Data Analysis Program Operation

EG\&G Hygrometer: Operation, Maintenance, and Calibration

Calibration and Check of Chamber Airflow Using Digital Anemometer

Relative Humidity Detemination via Use of Dewpoint Hygrometer

Operating Procedures for the Gardner Type CN SmallParticle Detector

General FGD Calibration-Exposure Chamber and Generator Cabinecs

Chamber Leak Test

Acetone Exposure System Daily Operating Procedure

Acetone Exposure System QC, Maintenance, and Calibration

ANALYTICAL CHEMISTRY

$9 B-A C-3 A 1 H$

Bulk Analysis of Acetone

$G B-A C-3 A I I$

Analysis of Building Extaust for Acetone

$B B-A C-3 B 26$
Operation of HP5840 GC for Monitoring Acetone 
ACETONE

MOUSE AND RAT TERATOLOGY

ATTACHMENT 1

$\varnothing B-A C-3 A 1 M$ $\varnothing \mathrm{B}-\mathrm{DT}-1 \mathrm{~F} \not \mathrm{M}-\varnothing \varnothing-\varnothing 192$

Ammended Page: 2 a of 3

Detemination of Ketone Bodies in Rat Plasma by Headspace Analysis 
ACETONE

MOUSE AND RAT TERATOLOGY

ATTACHMENT 1

$\mathrm{QB}-\mathrm{AC}-3 \mathrm{C} \perp \mathrm{Z}$

Calibration of the Acetone Chamber Monitor

\section{SAFETY}

QE-HS-3SI9

QB-HS-3S1C

QB-HS-3SIA

$9 \mathrm{~B}-\mathrm{HS}-3 \mathrm{~S} 2 \mathrm{~B}$

פ- $\mathrm{H} S-3 \mathrm{~S} 2 \mathrm{D}$
ZB-DT-1FQM- $02-E 192$

Page: 3 of 3

NTP PROJECT OFEICE

$03-9 A-3 E 06$

Data Handling and Storaçe of NTP Study Documents and Materials

$Q B-Q A-3 E D A$

Eiling Out Daca Sheets 
I. ANIMAL EXPOSURE CHAMBER

II. EXPOSURE SUITE CONTROL CENTER

III. TEST ARTICLE GENERATION AND MONITORING

A. Acetone Vapor Generation and Distribution System

B. Acetone Vapor Concentration Monitoring

IV. ENVIRONMENTAL MONITORING
A. Temperature Measurements
B. Relative Humidity Measurements
C. Chamber Air Flow Measurements
D. Chamber Vacuum Measurements

V. ENVIRONMENTAI CONTROLS
A. Animal Facility A1r Handling System
B. Animal Room Air Handling Syscem
C. Chamer Relacive Humicicy Control
D. Chamber Air Elow Control
E. Chamer Temperarure Controi

VI. CHAMBER EXHAUST WASTE IREATMENT

VIF. DAIA HANDIING

VIII. EQUIDMENT OR POWER FAILURE PROTECTION SYSTEYS 


\section{ANIMAI EXPOSURE CHAMBER}

The animals will be exposed and mair.tained in inhalation exposure chambers developed at Battelle-Northwest by O.R. Moss and M.G. Brown (U.S. Patent No, 4,261,741, August 12, 1980; Moss, 1980; Brown and Moss, 1981; Moss et al., 1982), and now commercially produced by Harford Division of Lab Products, Inc., Aberdeen, MD. The chamber (Figure 1A) facilitates multiple-tier exposures of various laboratory rodent species to aerosols and vapors. The design permits the use of excreta-collecting pans under each tier of animal cages during exposures, yet keeps variability of exposure concentrations at the different tier levels as low as, or lower than that usually experienced in conventional single-tier exposure chanbers. The total volume of the chamber is $2.3 \mathrm{~m}^{3}$ with an active mixing volume of $1.7 \mathrm{~m}^{3}$, che remainder being the inlet and exhaust volumes wiere animals are not placed. There are three levels of caging, each level split into two tiers which are offset from each other and from the chamber valls (Figure 1B).

Drawer-like stainless-steel cage units composed of individual animal cages are suspended in the space above each tier. Stainless-steel catch pans for the collection of urine and feces are suspended below each cage unit. Catch pans are left in posicion during each exposure period. Cageboard is added to these catchpans during non-exposure periocs to rejuce anmonia leveis.

The chasier was designed so tiat uniform aerosol oz vapoz concentrations can be maintained throughout the chamoer when the catch pans are left in position. Incoding air containing a uniton tiyture of cest material is diverted so that it flows verticaily along the inne: surfaces of tine chamoer. Eddies are formed (Eigure lB) at each tier as the aerosol or vapor fiows past the catch pans. Stagnent zones triat would norgally exist above each pair of catch pans are cleared by exhaust fiow tinrough tie space between the tiezs. Aezoso1 or vapor reaching the lowest level is deflected across the botton tiers by metai

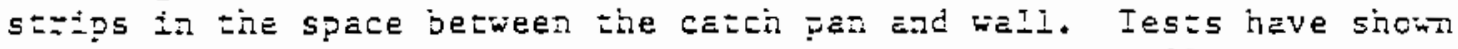
that aerosol or vepor concentrations unifors so witisin $8 \%$ tinrougneu the chamber cat be obrained repeateciy, proviced tie aerosol or vapor is

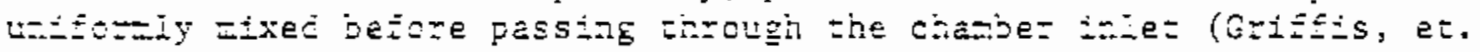
ai., i98i).

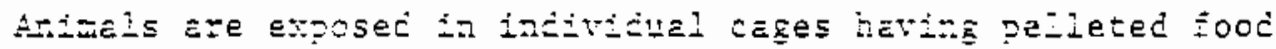
Feecers and automatic watezing. Duzing exposure tie zeecers till be

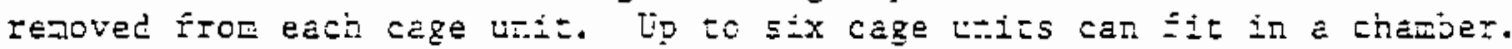

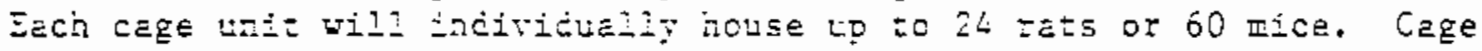

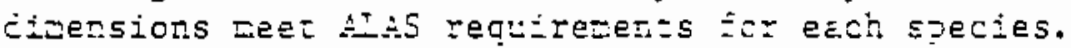

Procedures for entry into an expostre chamoer on study is detailed in $S O P \# \emptyset B-A R-3 B 23$. 

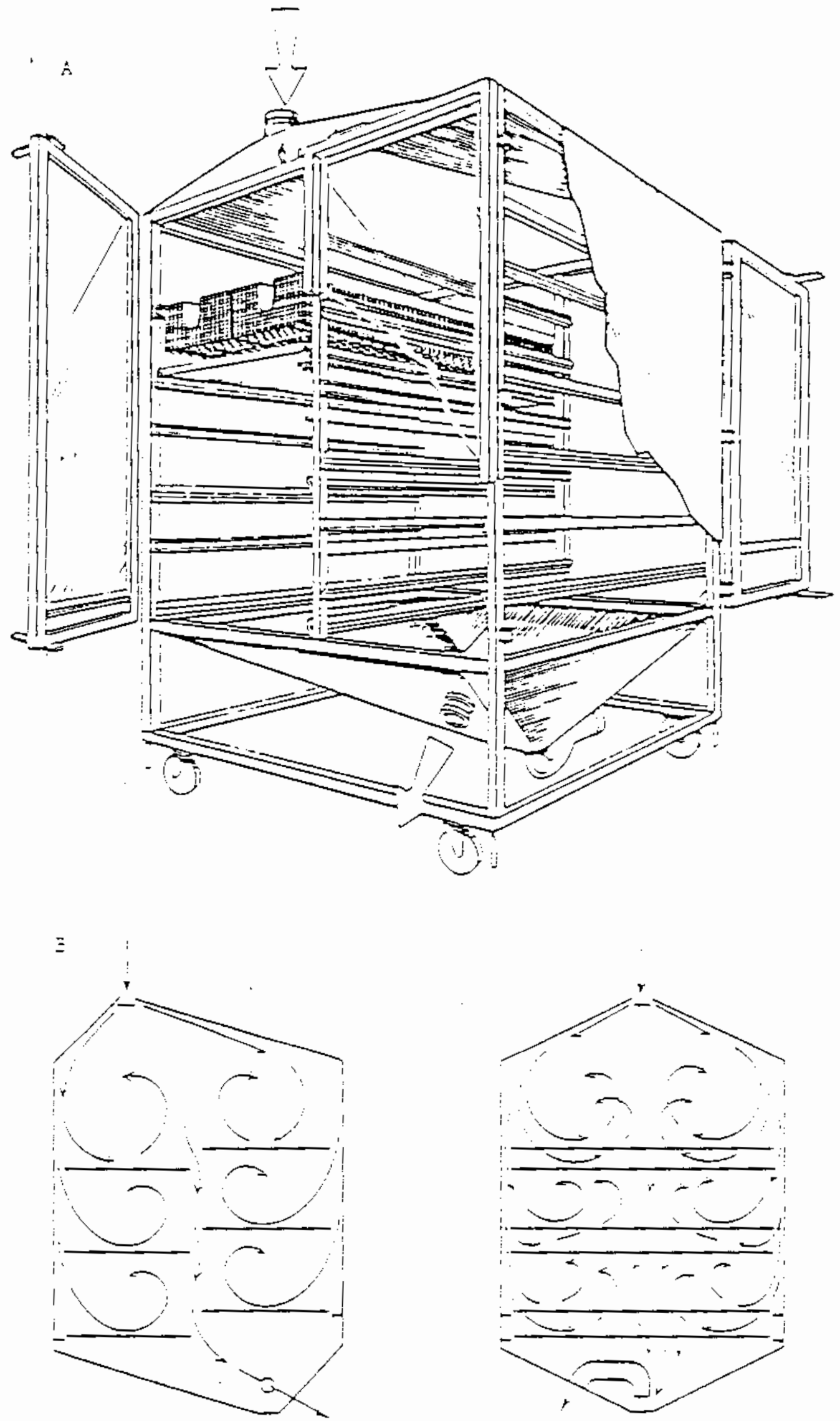

F⿻ON: V:I:A

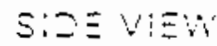

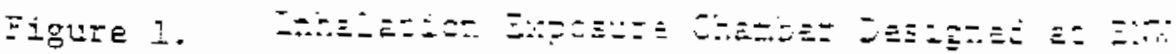

í.

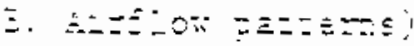

F. 51 


\section{EXPOSURE SUITE CONTROL CENTER}

A computer located in the Suite Control Cencer interfaces with syscem monitors and controls the basic functions of chamber air flow, tesc chemical concentracion, vacuum, temperature and relative humidity in each of three exposure rooms (Figure 2). The arrangement of computer control and interface instrumentation is shown in Figure 3. The executive compucer is an Hewlett Packard Model 9816. All data acquisition and aucomaced syscem concrol originates from chis compucer.

All experimental prococols related to the data acquisition and control system (such as data channel assignmencs, monitoring frequencies, and alarm settings) reside in the execucive compucer and are entered into tables accessed by menuts.

Data input to the executive compute: is accomplished through several incerface instruments. All chemical monitor daca is collected and preconditioned by Hewletc Packard Model $85 B$ compucers, one for each of the exposure rooms. Concitioned data is transferred to the executive computer for analysis, scorage, printing and concentration control.

System control is provided from tine computer by means of cortrol relays in the CDS Incelligent Interface jysten. These relays control such devices as valves, crive motors, auible aiazs, indicator larps, etc.

A complete description of the sottrare for this system is contained in document $\emptyset \bar{E}-B \bar{E}-5 E \emptyset 1$ and $\emptyset \bar{D}-5 E-5 E \emptyset 2$. Miaintenance 0 the system is detailed in SOP! $\emptyset B-3 E-3 D Q E$. Entry of prococol data into tie cotputer is aetailed in SOP $\$ B-B E-3 E \emptyset 9$. Routine operation of the computer syster is cezailed in SOp $Q B-B E-3 G D 4$. Routine daity opezation Oí the systew nardware is detaijed in SOP\# QE-BE-353G.

ZII. TEST AREICIE GENERAEION AND YONZTORIXG

A. Acscone Vepor Generation and Distzijution system

A scietutic diagran of the acetone vapor geneztion and delivery system is shown in Figure 4. The acetore gerezacor is nousec in a vented castue located in the suzte Control Center.

The acetone to de vaporized hill de transiezred from the original container in wich it was sinpped to a !9 liter stainiess steel zeservoir. The reservoir wi be retilied every othez exposure der. The ziling procecure is designed to prevent explosion. Ail oxyer in the reservotr is cisplaced with aitroger tirough a purge port. lisrogen under low pressure is then epplied to the shipping container to force the acetone inrowgi a filter and into the reservoir. The reservoir is placed on an electronic scale during fi..ling so that the correct levei can be readily obtained. All meta: containers are grounded during ire Eili procedure. The Eilled reservoir is transierred and instalied irto the generator cajine:. 
Acetone

Mouse and Rat Teratology

ATTACHMENT II $\emptyset \mathrm{B}-\mathrm{DT}-1 \mathrm{~F} \emptyset \mathrm{M}-\emptyset \emptyset-\emptyset 192$

Page 5 of 27

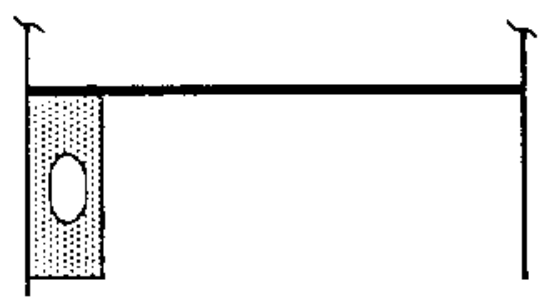

ROOM 327

NOT USED

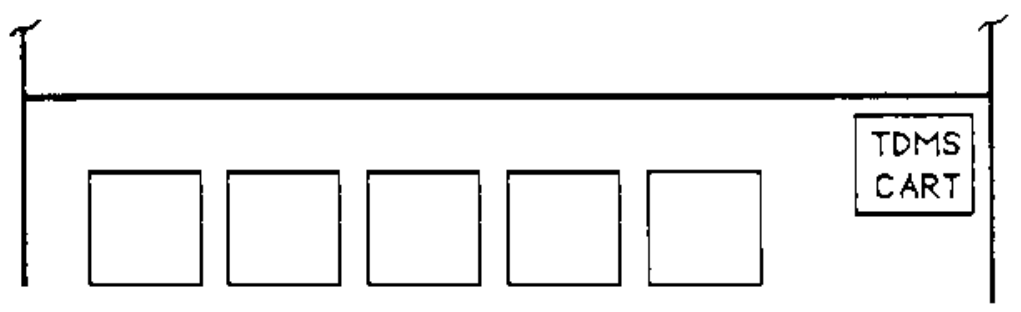

ROOM 428
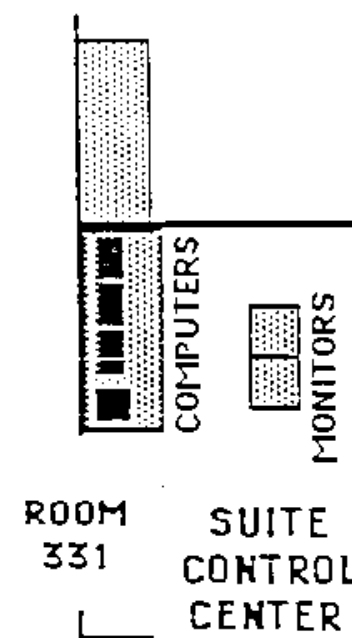

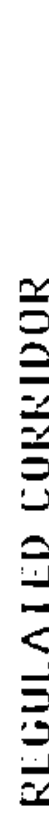
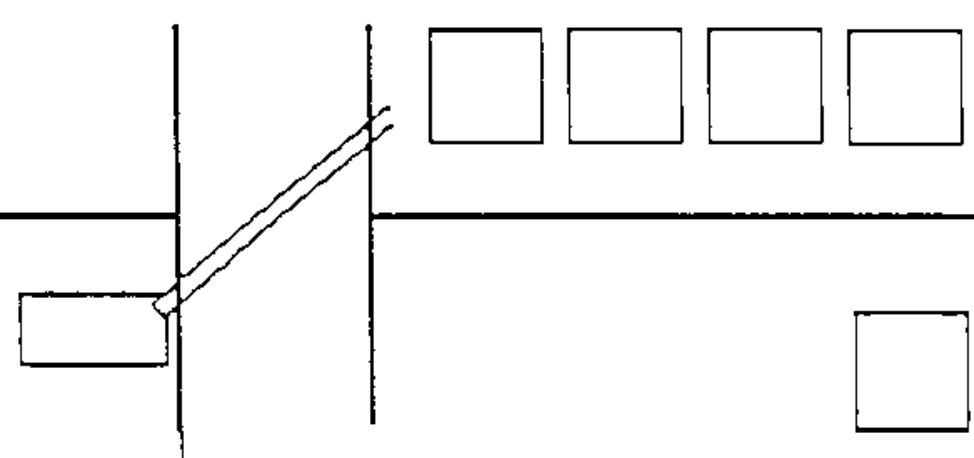

ROOM 432
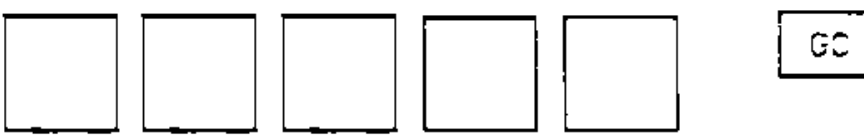

GC GASES

coeo

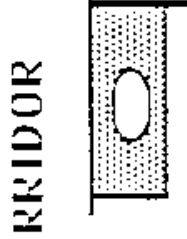

CHAMBER

RELATIYE

HUMIDITY

CONTROL EQUIPMENT ROOM

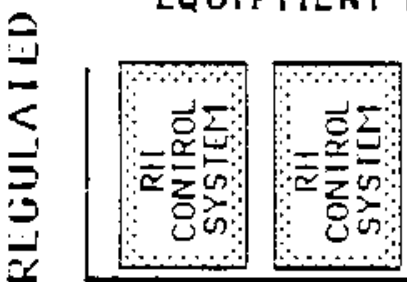

ROOM 436
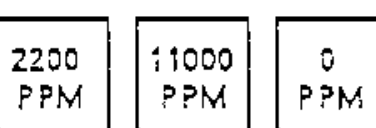

$\theta=$

产

440
P PM

PPM

PYM

NTP (IRT) ACETONE TERATOLOGY

Eigure 2. Arrangemenc of Exposure Rooms for Acezone Study 
COMUUIR SYSTLM

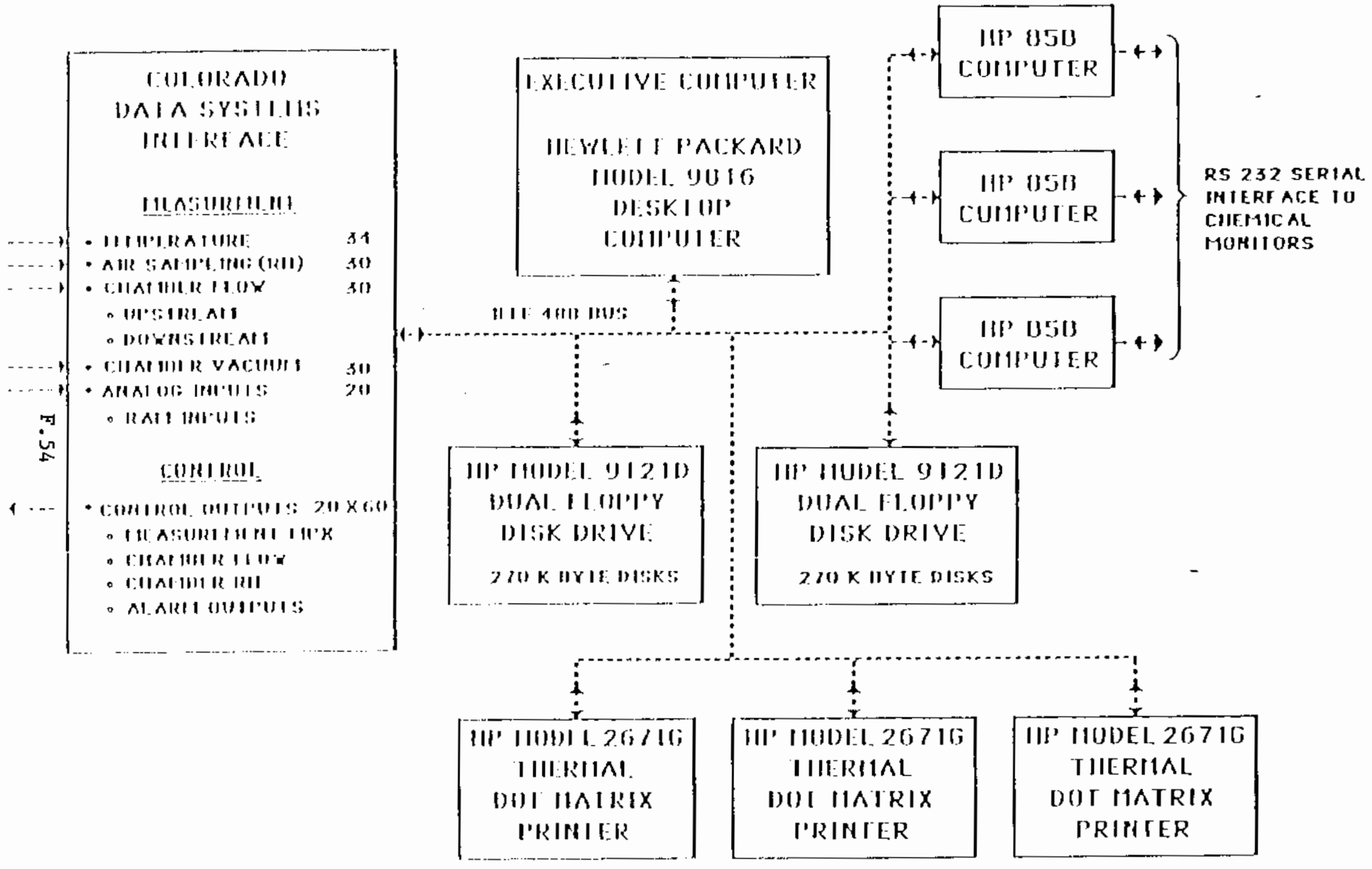

Flate 3. Mlork blaprom of lexposme Sulte Automated Dala Acquisition and

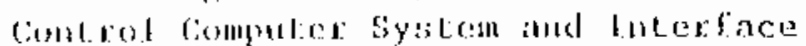




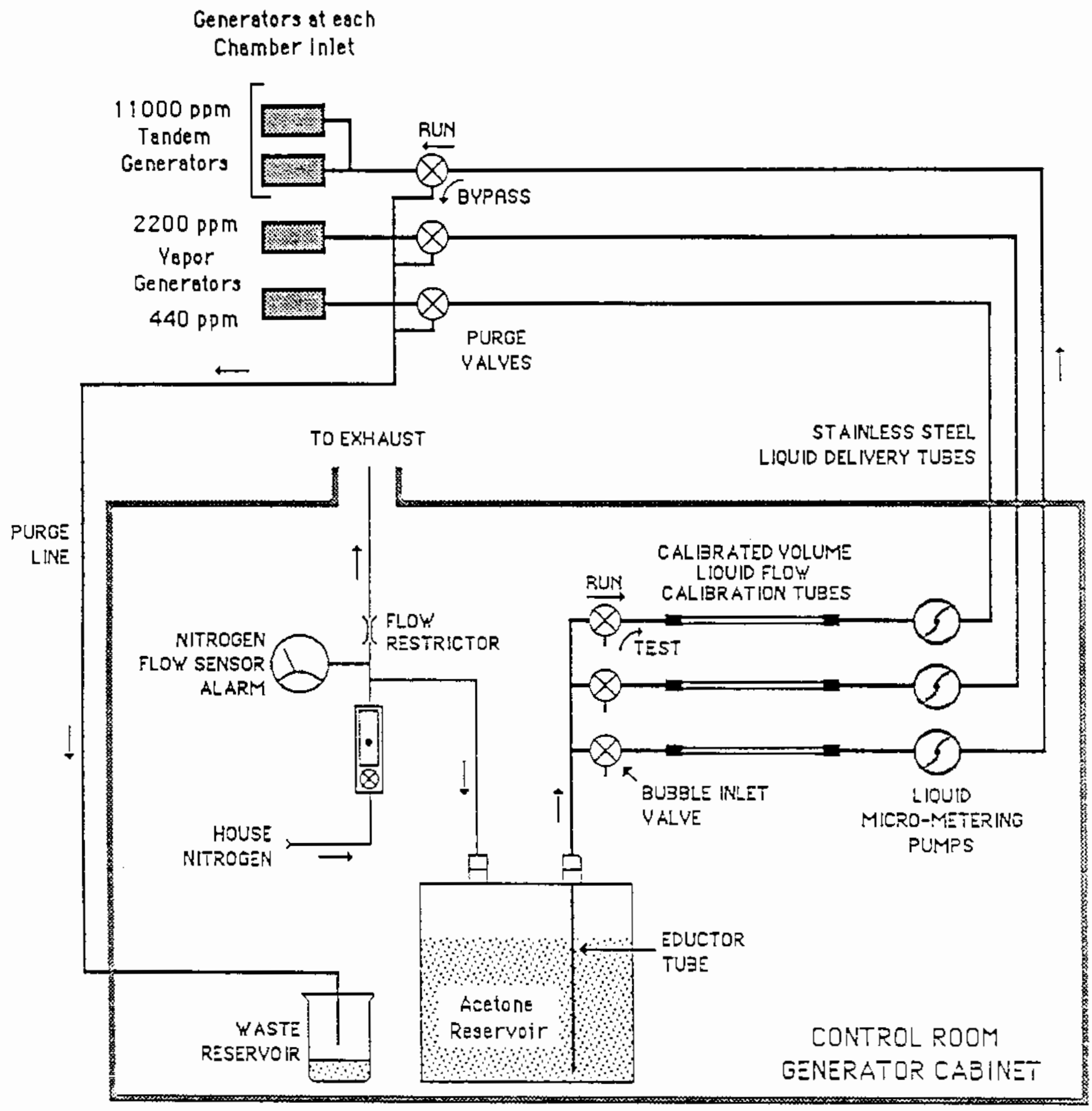

Figure 4. Schematic of the Acetone Generation and Delivery System 
During exposure the acetone is pumped from the stainless steel reservoir through an eductor tube and aelivery tubes to vaporizers located at the fresh air inlet of each arimal exposure chamber. The high concentration chamber will require two vaporizers since the required rate of delivery exceeds the vaforization capacity of a single vaporizer. Stable micrometering pumps with adjustable drift-free pump rates vill be used.

Each vaporizer (Figure 5) comprises a stainless steel cylinder covered with a glass fiber wick from which the liquid is vaporized. The wick can be easily and inexpensively replaced if residue buildup occurs. An 80-vatt heater and a temperature sensing element are incorporated within the cylinder and connected to a remotely located temperature controller. A second temperature monitor is incorporated in the vaporizer allowing the operating temperature to be recorded by the automated data acquisition system. The cperacing cemperature of che vaporizer is maintained belos $50^{\circ} \mathrm{C}$ (the koiling poinc of acecone is about $56^{\circ} \mathrm{C}$ ). The cylindrical vaporizer is positioned in the iresh ai= duct leading directly co the inlet of the exposure chamber.

A clear Teflono tube of measured volume, preceded by a three-way valve is attached downsteam of the purp to facilitate measurement of the flov rate of the vapor generator. Measurement is accomplished by monentarily shicching the inree-vay valve from the run posicion to the test position. A saell bubble of air is pulied by tie pump from the cabinet througin the valve and into the ciear cude. The progress of tis bubble $f=c n$ one end to the other of the tube (calibrated volume) is rimed win a stop watch. Elow rate is caiculated by diviting rine voiuze by the time. The concentration in the exposure chatier can de calculated from the ziow measurements of ilouid and cilution air and is

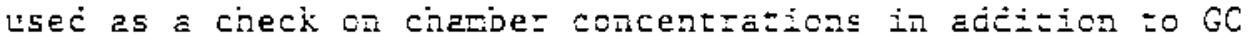
tieasurements.

Al1 genezition equipment which comes in contect tith the acerone is stainless-steel, giass, Teflono or Vizond. All equipeant containet the vented geterator cajinet is explosior. prook.

Detailec operatung instructions for tịs systan are contained in SOP $\# \varnothing B-5 E-3 E 3 I$ and $Q E-B E-3 D Q R$.

\section{E. Ascetone Vapor Concentzation Moritoring}

A singie gas chromacograph (GC) with a ziame ionization detector

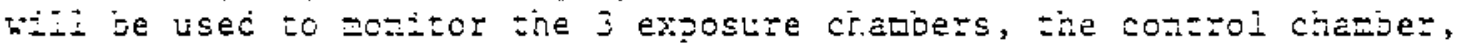
tine roow, a saztisiec stancard vapor of acetone in aitrogen, and a nitzogen blank. Sempling from the muititie posicions wili je accorplished by weans of an autowaced, mitiplexed 8-port stream selec: vaive. The sapling systen (Figure 6) is incorporated into the reiative numidity (RH) sampling system. Samples trom each jocation are contimuously crawn by a vacuun pulp tinrough polytetrafluoroethylene-lined stainiess stee? tubes to e location near the input of the stream select valve. This assures zresi sample at tie Jonitoz. The samie lines witich 


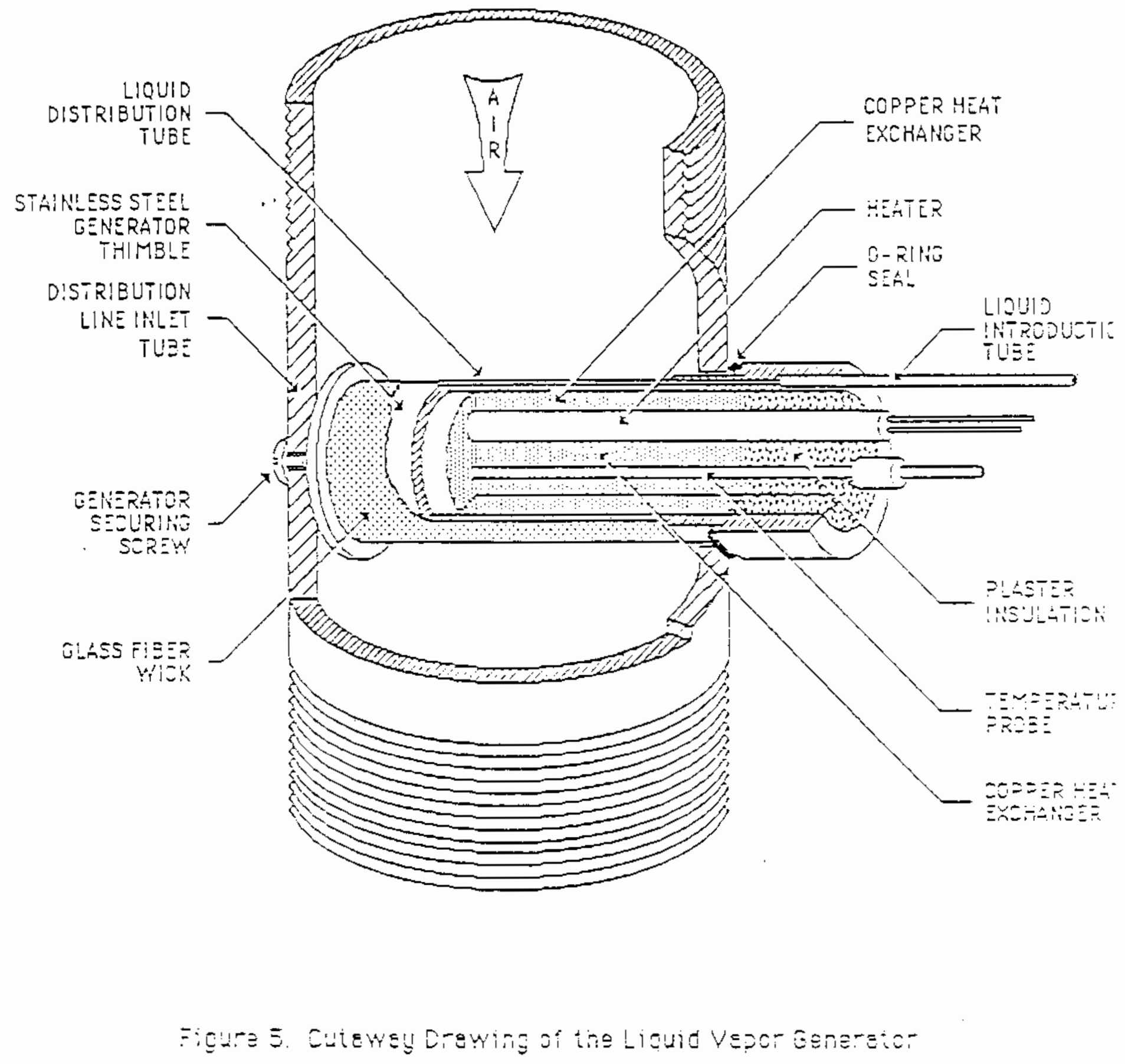




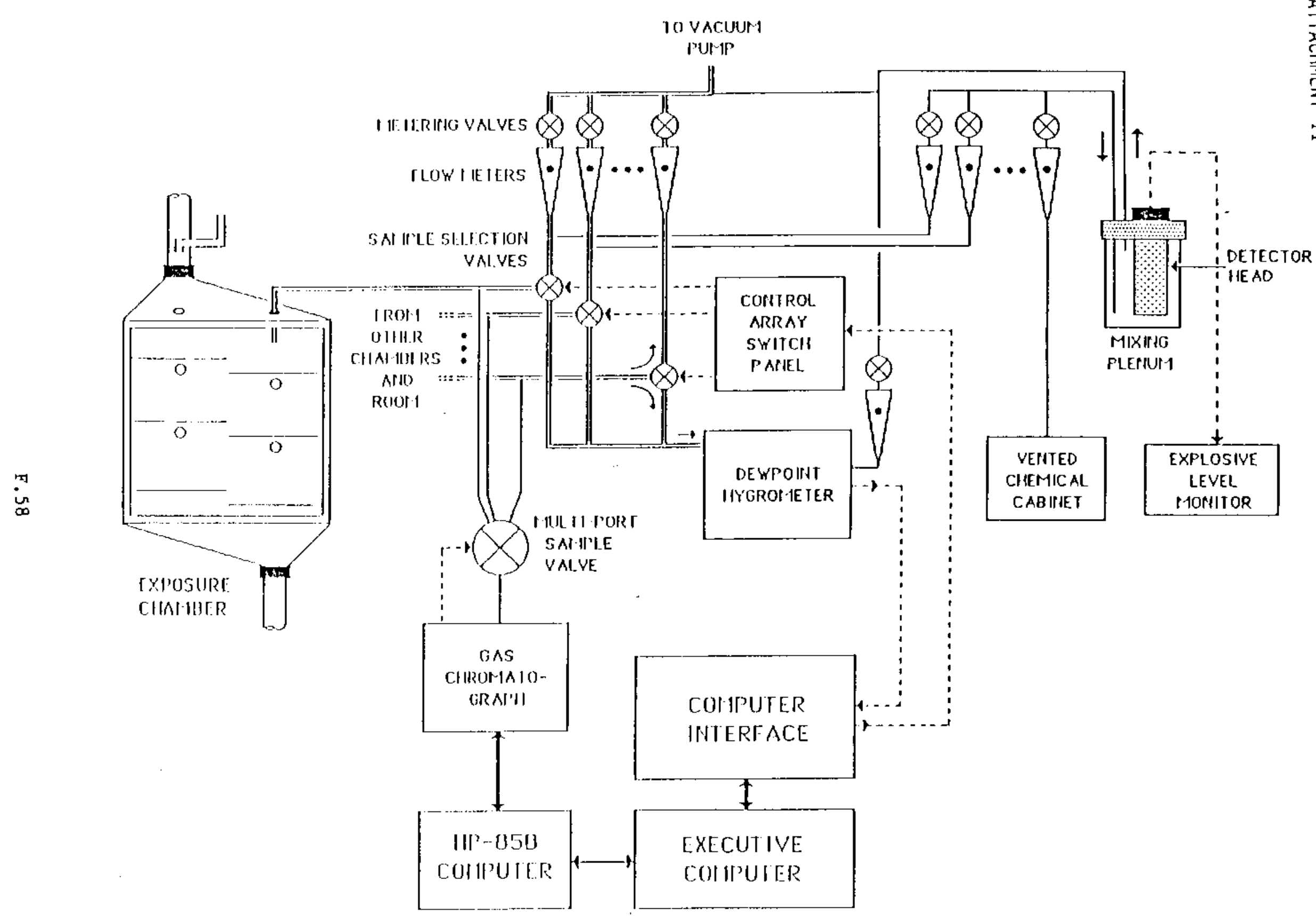

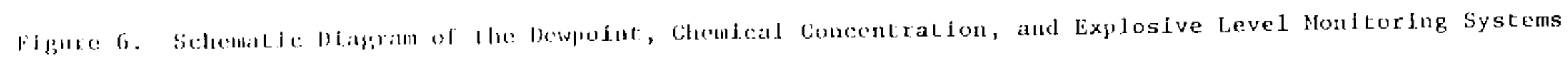


continue from the point where they $T$-off to the stream select vavie to the dewpoint monitor are polytetrafluoroethylene. The sample time per port will be less than 3 minutes assuring rhat all ports are sampled at least once per hour.

Sample values are accumulated from the GC and printed by an $H P$ Model $85 \mathrm{~B}$ computer until samples for all twelve ports of the stream select valve have been measured. These values are then sent to the executive computer for printing and storage. As each value is sent to the HP $85 B$ from the GC, it is compared with limit values for that particular location. If the value is beyond the control limits, the HP $85 \mathrm{~B}$ will immediately send the information to the executive computer which will then take the appropriate action as follow's:

- Concentration $\geq$ non-critical los limit and $\leq$ non-critical high limit:

No action.

- Concentration < non-critical low limit but z critical low linit:

Indicate on daily computer log that concentzation is beyond linits.

- Concentration < critical low limit:

Indicate on daily computer log that concentratica is beyond ligits. Activate aueible alarm.

- Concentration > non-critical high liuit but @ critiall high litis:

Indicate on datly computer log that concentration is Deyond limiss.

- Conceatratich > crizical high inta:

Indicate on daily cospure: Log that concentration zs

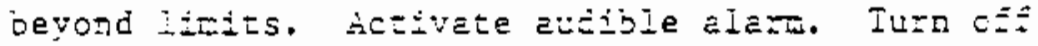
generation syster.

The calibration of the lonitor will be contirued and cozrected jy periodic assay of graj sampies Erom ine ciacibers. Generally, duplicare grab samples will be obtained from each chamer, using bubblers. Samples will be dratn through the bubolers using a vacuum pump at a fiow-rate saintained constant by a caliorated orifice. Samples uil be diann for a specific period, depending on the cinamer concentration. The bubile: contents will tien be analyzed using a calibrated anciyticai gas chronatograpd located in the Anaiyticai Cinemstry iaboracory. 
Additionally, the operation of the chamber-monitoring gas chromatograph will be checked laily against an on-line standard. This check provides a measure of day-to-day instrument drift. When an unacceptable level of drift of the on-line standard response factor is detected, the GC calibration vill be checked by taking bubbler samples.

Daily operating procedures for the concentration monitoring system are concained in SOP $\triangle O B-A C-3 B 1 K$. Routine maintenance and calibracion of the GC is covered in SOP $\$ B-A C-3 C \emptyset S$.

\section{ENVIRONMENTAL MONITORING}

\section{A. Temperature Measurements}

Temperatures of the exposure chambers, exposure rooms and, if necessary, test chenical generators are measured by Resistance Temperature Devices (RTDS). The RTDs will be placed in a representative location in each chamber (a cop sample port on the back side). Eacin RTD can be connected to an Omega Model 412B DigitaI Thermometer by a manual select switch or jy compucer controlled scanner relays in the CDS interface systern (Figure 7). This allows remperature to be read manually or to be recorded autoratically. All temperature measurement equipment except ine RTDs wili be located in the Suite Cchirol Center. Temperatures will ise autodaticaliy recordec at regular periods during each 24 hour dey.

RTDs wiIl be calikrated at least once every two months (oS-BE$3 C \emptyset D$ and $\emptyset B-B E-3 C \emptyset L$ and $Q E-3 E-3 D \emptyset 7)$. Calzbrarion wil1 Esrerate values for offset and slope which $\ddot{x i l l}$ be encered into the couputez zcr each RID. Calibracion data will be included as part of tine stucy erchive.

\section{B. Relative Eutidity Measurezents}

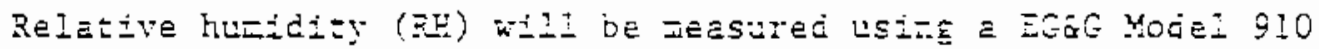
chillei-zirror dewpoint hygrometer iocated in the Suize Conzrol Center.

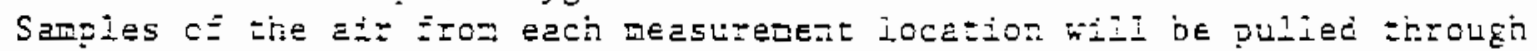

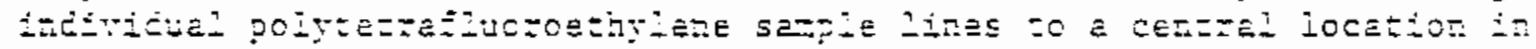
tire suite Cortrcl Cente: (Eigcze 6). This assures a Ezest samie of tie air at the point of measurement. Aiz fron exposuze charders wi i de

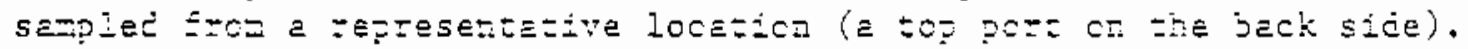

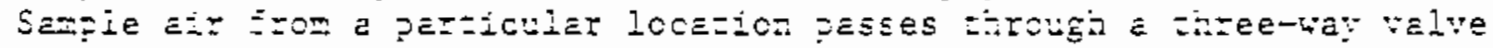
to the syster exhast. Line. the itis to je weastrec at that location,

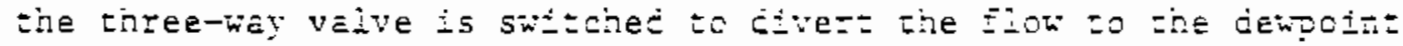

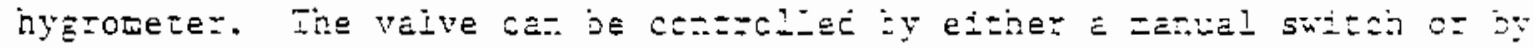

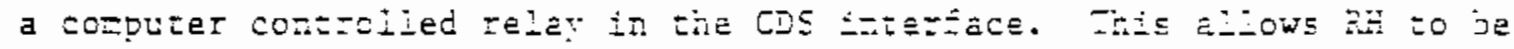
measured manlaliy or autonaticaily. Once the dehpoint has been determined by the hygrometer, the RH is autowaticaily calculatec by the executive compucer using the denpoint value $\left(T_{1}\right)$ anc the dryould temperature $\left(T_{2}\right)$, measured simultaneousiy at that measurenent iocazion. 
Acetone

Mouse and Rat Ieracology

AITACHMENT II $\phi \mathrm{B}-D I-1 F \emptyset \mathrm{M}-\emptyset \phi-\phi 192$

Page 13 of 27

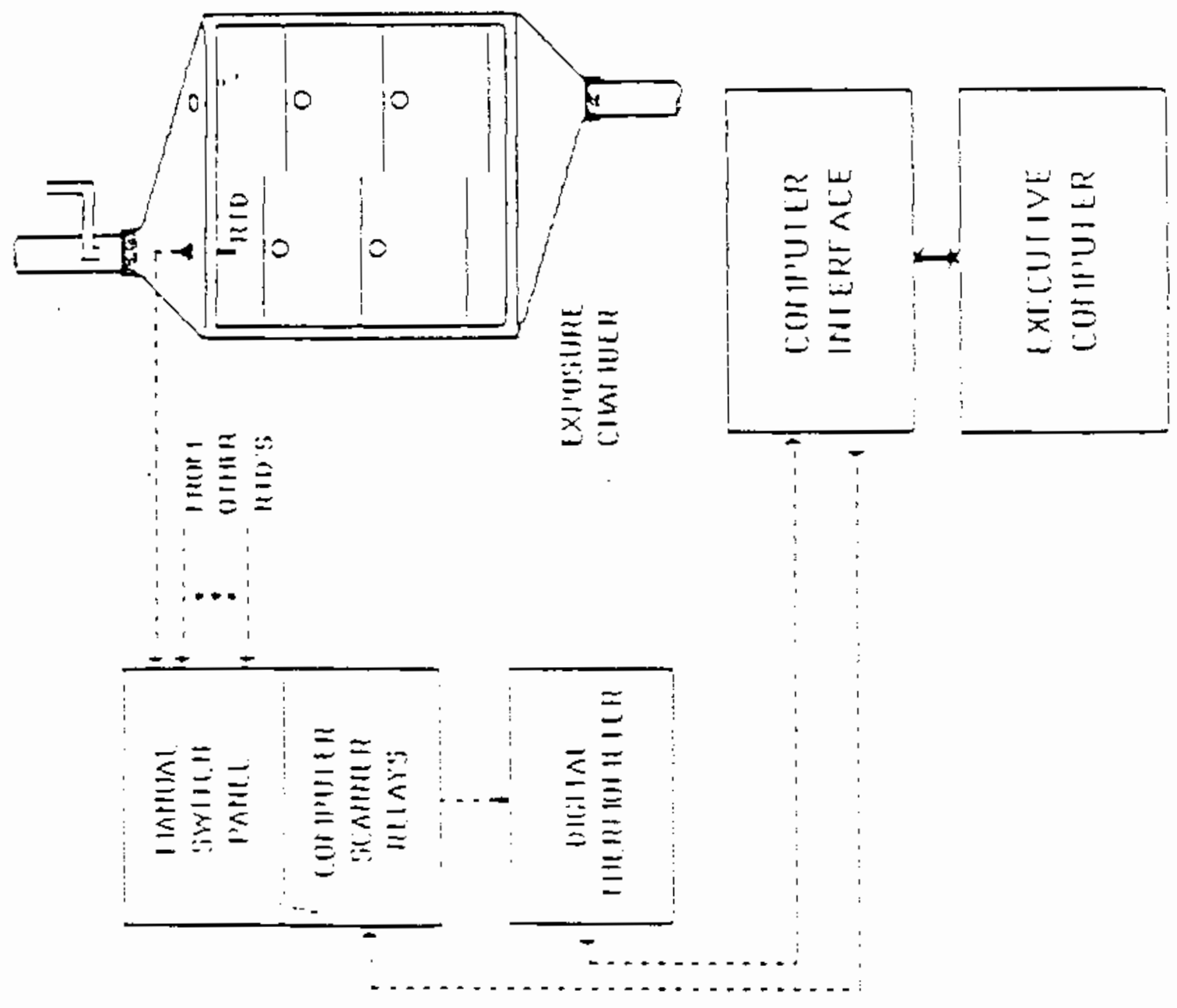

כ

F. 61 


$$
\% \mathrm{RH}=\frac{10\left[9.91-\frac{2714.55}{(5 / 9)\left(\mathrm{T}_{1}-32\right)+293.3}\right]}{10\left[9.91-\frac{2714.55}{(5 / 9)\left(\mathrm{T}_{2}-32\right)+293.3}\right]} \times 100
$$

where: $\quad \begin{aligned} & \mathrm{T}_{1}=\text { dewpoint temperature, }{ }^{\circ} \mathrm{F} \\ & \mathrm{T}_{\mathbf{2}}=\text { drybulb temperature, }{ }^{\circ} \mathrm{F}\end{aligned}$

Calibration of the dewpoint hygrometer will be checked at least once every two months $(\emptyset B-B E-3 C \emptyset J$ and $\emptyset B-B E-3 B 1 X)$. The procedure requires comparison of the $\mathrm{RH}$ calculated by che system monitor to measurements made by calibraced dewpoint hygrometer at che sample location. Calibration of the system monicor can be accomplished by inserting a value for offset and slope in the computer for each measurement location. Calibration daca will be included as part of the study archive. Relative humidity sill be recorded at regular periods during each 24 hour day.

\section{Chamber Air Flow Measurements}

Chamer air fiow is measured by a multiplexed orifice-meter syster. (Figure 8). Calibratei flow orifices are installed at ine inlet and exhaust of each chamber. The desired fiow orifice is atsachec to a Valicyne Model D?-4j pressure transucucer anc CD-18 carrier demodulato: pressure-measurement system through Tygono tubes by means of solencid valves. The valves can be operated either by a nantal sutach or by computer activated relays in tie CDS inteziace. This allows flow to be measured eithez mantally or eutowaticaily. Dzessure is reac gantialy on a Valiayne Model 2x:-12 voltmeter. Lisuaily charder flow wid je measurec using the exhaust flow orifice; however, following closing of the chamber doors, both iniet and exhaust fiow zeasurements wit de made and comparei to detertine if tinere are leaks in the charber. Fi leaks ate present, the executive copputer will notify the operator and üill not ailow erpostres to proceet until the ieak is zepairec.

A11 Elow measurement equipment, except the tultiplexed soieroid

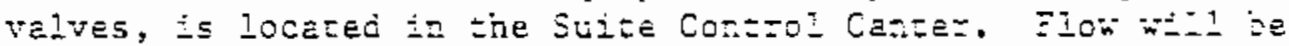

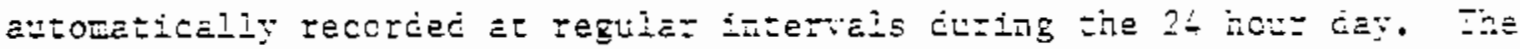
Vaildyne pressure transducer hil be caltorated once each veek

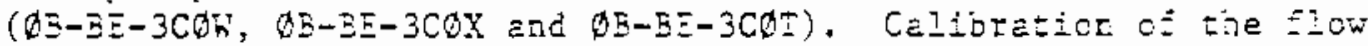

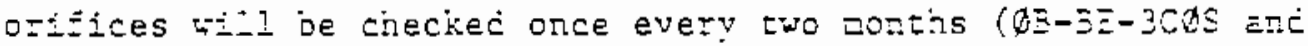

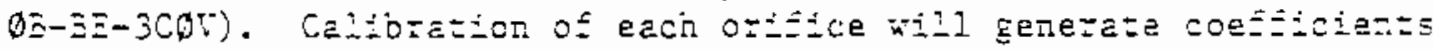
that will be inserted into the computer flow equation for each orizice. 


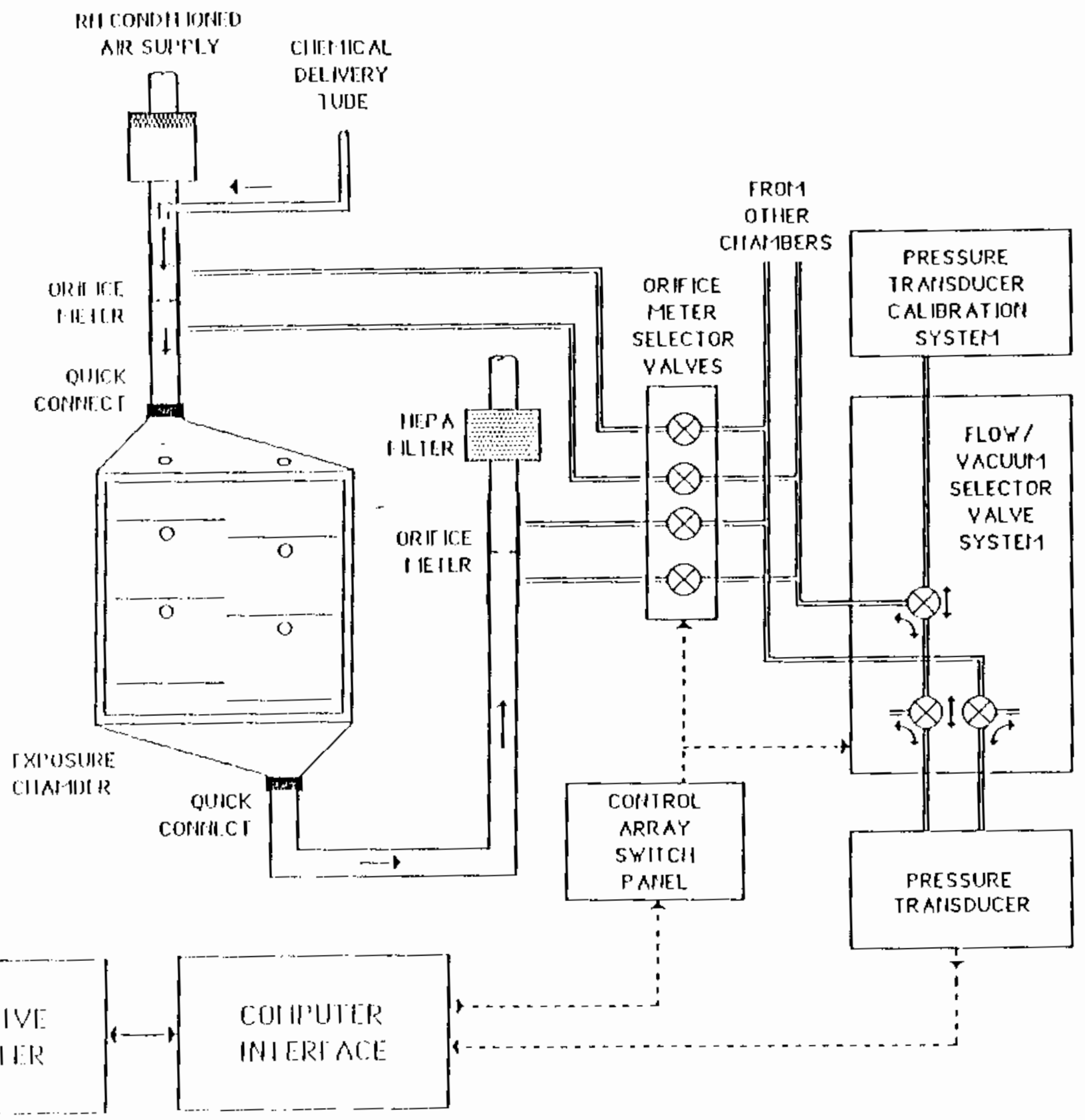

w

T.XICISIVE CUHIUIS
NIERT ACE 


\section{Chamber Vacuum Measurements}

The same Validyne pressure transducer system used to measure chamber flows will be used to measure chamber vacuum (Figure 8). Vacuum in che chamber will be measured relacive to atmospheric pressure in the Suite Control Room. Vacuum will be autonatically recorded at regular intervals during the 24 hour day.

Vacuum will also be continuously monitored by a pressure switch mounted near each chamber. If the chamber should develop a leak (for example, a door inadvertently opened or a sample port stopper jarred loose), the pressure switch will immediately shuc off the flow of compound to the chamber and alert the executive computer of the condition. The computer will activate as audio alarn and print and display a comment for the operator.

\section{ENVIRONMENTAL CONTROLS}

\section{A. Animal Facility Ai: Handling System}

Supply air enters the building through cwo identical parallel ai= handling systems (Figure 9). Each systen consists of a pre-hear coil, a filcer system, a heating coil, a chilling coil, and a supply fan. The pre-heat coil neacs the air to a minimum of $45^{\circ} \mathrm{F}$. The filter system winich includes a roil Eilcer, pre-filter, and a dag filcez - rids the air of wost particies. The heazing and chiliirg coils maintain the cemperature of the air exiting the air concitioning system at ajout $53^{\circ} \mathrm{F}$. The chiling coils aiso dry tie air to a dempoine not greace $\operatorname{tran} 53^{\circ} \mathrm{F}$.

\section{B. Arizal kocm Air Harizing System}

The ait fron the two builiing air hancling systens is then -ired togetier by an air mixing unit and is civided into cwo ducts winich zeed the roozs on East and hiest sices of the anida! quarzers. IE recessary, steam is injected into the air in these jucts to mantain the relative humicity of the room.

\section{Chamber Reîsive Ïüidisy Concro}

Figure 10 sinows a schematic ciagral of the systea used to contro: the rejative numicicy in the exposuze chambers. Equjpert jocated in the at Control Equippent Roca (Roon 335) provides sepazatz cucts of $d z y$ and zoist air to each exposure chambez. A fixing valve, contro-led by tia compurer, mixes the froper proporticns of the roist and $\dot{a r y}$ at: =0 wankain the proper tis is each chabjer.

Eltered air with a meximum dewpoire of about $53^{\circ} \mathrm{F}$ is supplied to the $\mathrm{KF}$ control equiptent by the building air handling systea. This a: is everly deliverec to wo ducts. Air from the first duct passes into a pienum where stean is injectec to bring the air to a dewpoint of about $65^{\circ} \mathrm{E}$. This provides moist air to the gixing valves. Steam is generated Erom city tap wate with no adcitiona: additives. The bir from the 
Acetone

Mouse and Rat Teratology

ATTACHMENT II
OUTSIDE

AIR INTAKE

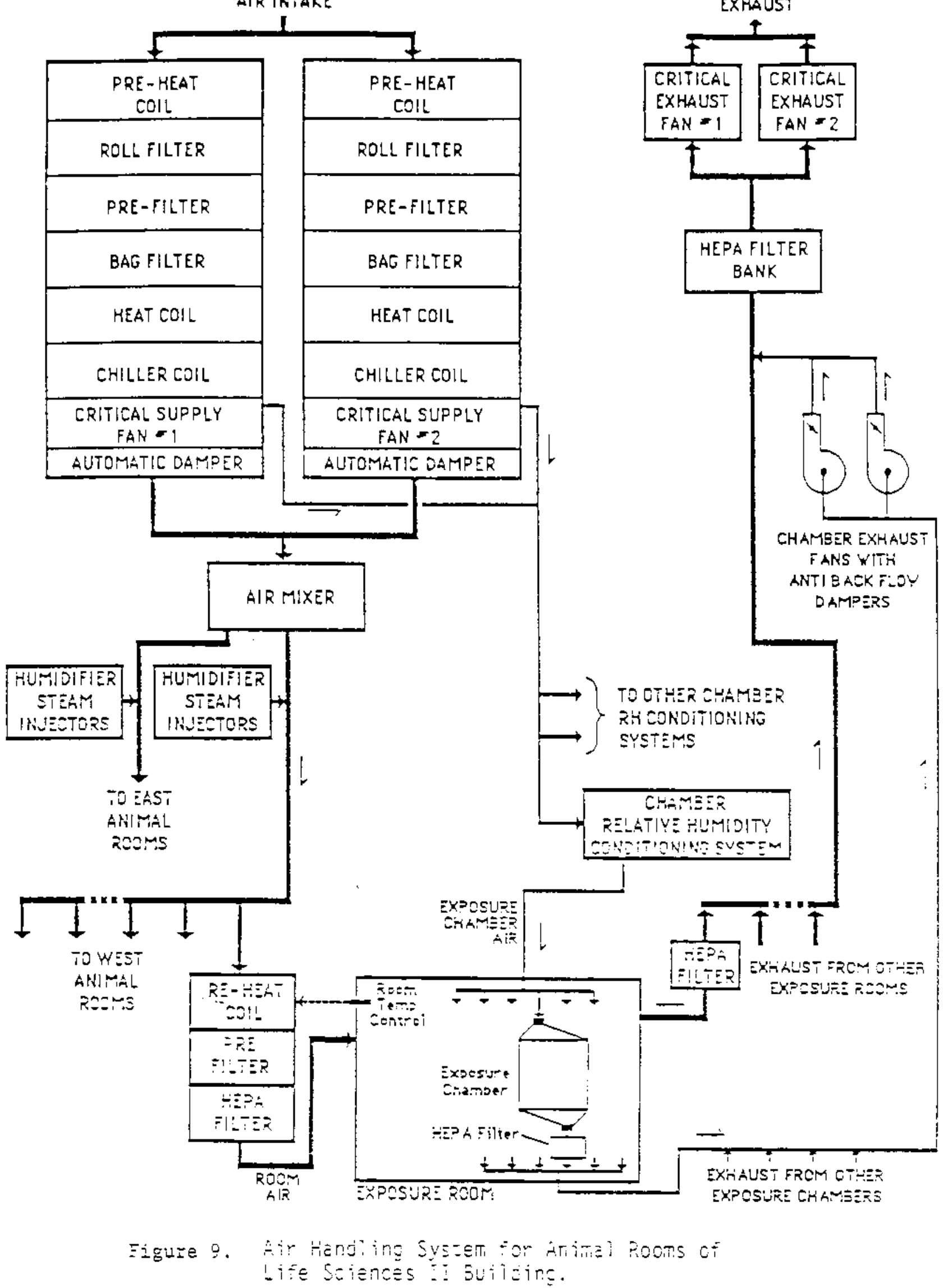

WASTE AIR

EXMAUST

CRITICAL

EXHAUST

(a)

FANS WTTH

ATI BACK FIOU AMPERS 


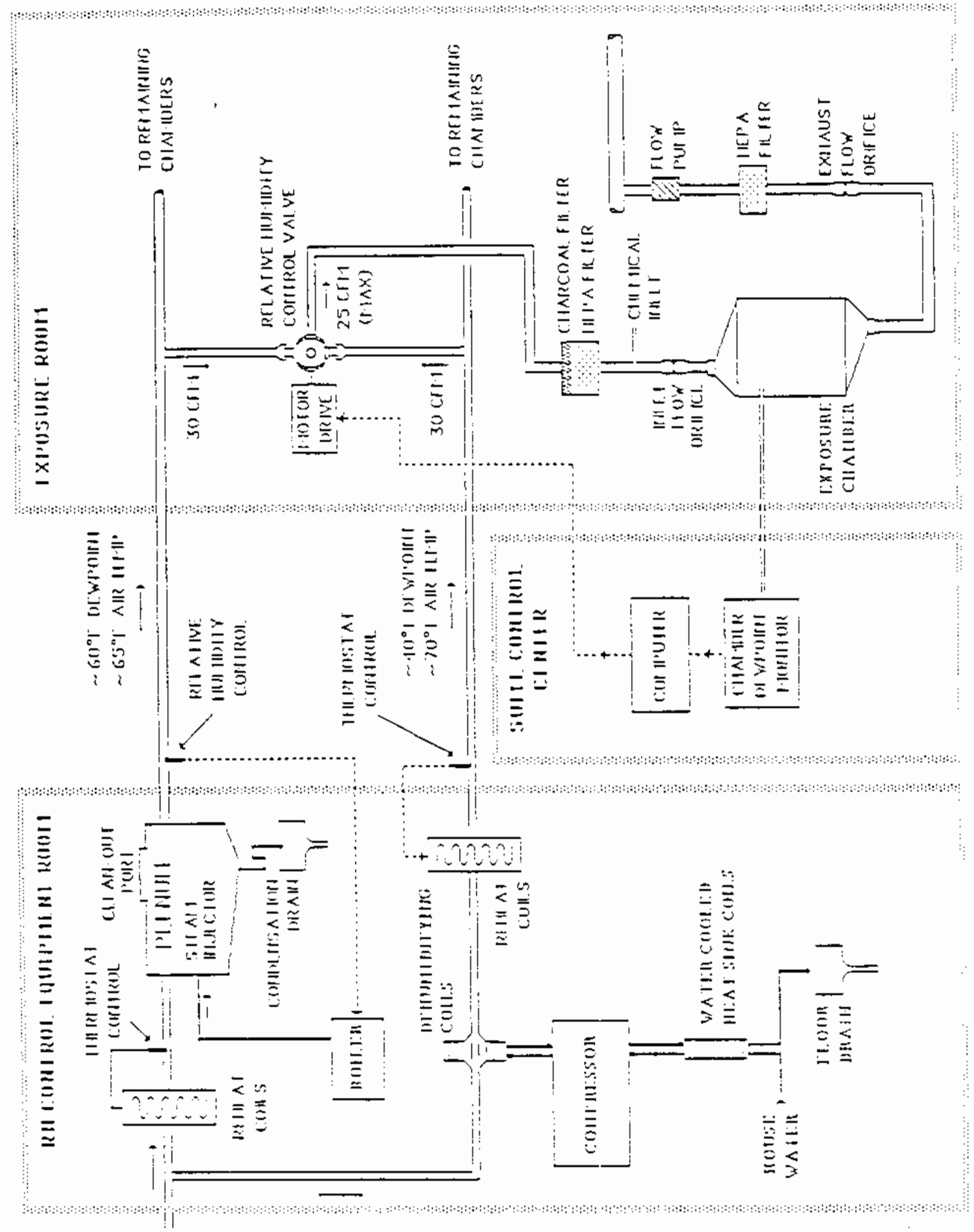


second duct passes through a refrigerarion coil which reduces the moisture content of the air to a derpoint of about $38^{\circ} \mathrm{F}$. This provides "dry" air to the mixing valves.

Chamber RH is measured by the multiplexed dewpoint hygrometer. If the $R H$ is found to be beyond the RH control range, the computer will calculate and make the appropriate adjustment to the mixing valve to bring the chamber RH to the desired target value.

\section{Chamber Air Flow Control}

Flow of air through the chambers is maintained by the vacuum in the central chamber exhaust duct (Figure 11). This vacuum is created by the chamber exhaust flow fans located in the South Equipment Roon of the LSL-II Building. There are two parallel chamber exhaust fans. Only one $f a n$ is operational with the second acting as an automatic backup. Both fans operate from emergency power. Flov is controlled by a gate valve in the chamber exhaust duct. A drive motor, attacied to the stem of this valve, allows the control of chamber flow either by computer or manually from the Exposure Control Center. The exhaust from the chambers is HEPA filtered to remove all particles which may impede the function of this valve. Fine control of exposure concentration can be accompiisined by automatically or manually adjusting tine valve position to control chasder flow witnin the aliowatle flov limits. Gross acjustaent of concentration must be done by wanual adjustment oz the generation system.

Exhaust $f=0 \mathrm{~g}$ aIl chabers is collected inco a central cinaber exhaust duct vizinin she exposure room. The vacuum levei in the certral cuct is automacicaily regulated by a rotor criven íedoack damper to prevent dohstreas presstre variarions in building exhaust pressute $=$ zom affecting chamber air tion rete.

The vacuta level th the central charber exhaust duct is continuousiy monicored anc alamed. If the vacuu levei in this duct Eais $20 \%$ delow rozmai, tire aditor trips the alan which imediately

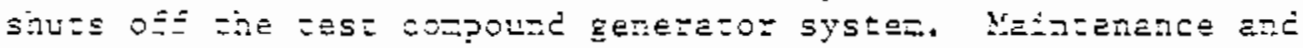

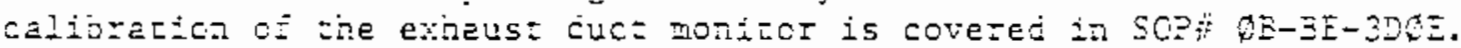

\section{E. Cne⿻jer Inzperature Con:=01}

Nearly all of the heat loac cortributec to the exposure chazoe

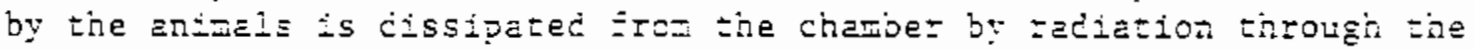
chabez wils. Conseouenty, Lezpezature of the air supplied co the

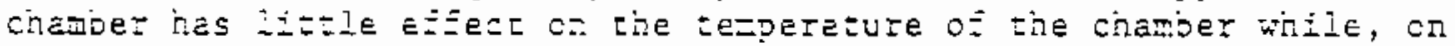
the other hanc, the temperature of the room housing the chamber has a great deat of efiect. For this reason, the major mernod of chamber temperature will be control of the room temperature. 


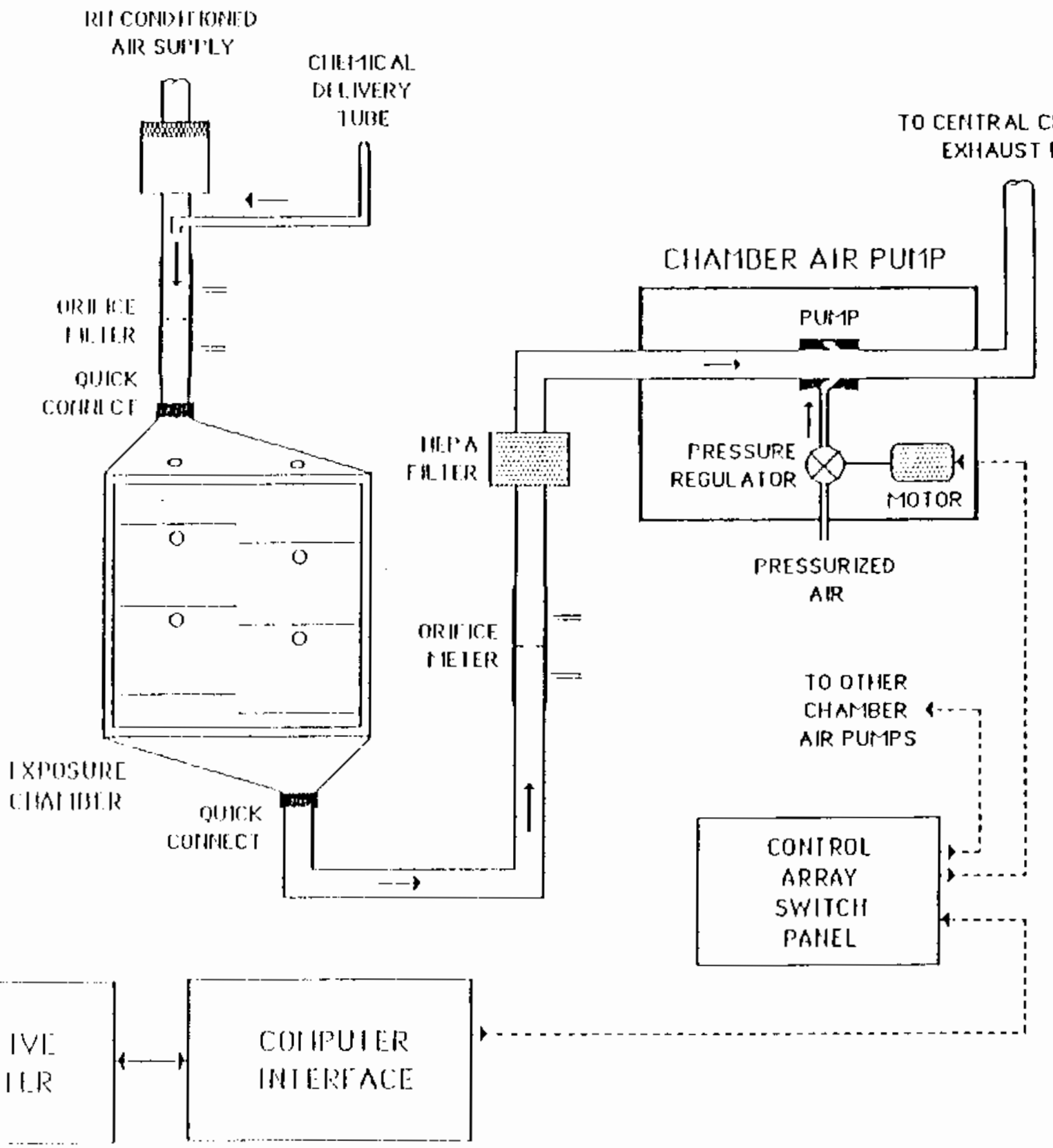




\section{CHAMBER EXHAUST WASTE TREATMENT}

The exhaust from the central chamber exhaust duct is mixed with the exhaust from the entire animal facility $(75,000 \mathrm{cfm})$ prior to being exhausced from the building stack. Dilution of chamber exhaust with building exhaust results in an acceptable stack concentration of less than $1 \%$ of the ACGIH THA TLV of $40 \mathrm{ppm}$.

\section{DATA HANDLING}

Data from each exposure room are stored in the Exposure Suite Control Center on separate magnecic diskettes by Hewletc Packard Model 9121 micro-floppy disk drives. Data and comments from each exposure room are printed on separate thermal dot-matrix printers (Hewlett Packard Model 26716). Data are printed and stored immediately upon completion of the measurement to a Daily Log (example, Figure I2). At the end of che day (24-hour-period), the daily data are analyzed and three sumaries are printed. The first (Figure 13) includes the mean, standard deviation, maximum, minimum target values for eaci set of iata for the 24-hour period. The second (Figure 14) provides a lis of ourliers; that is, all data points which were beyond the defined critical operating limits. This printout allows guick review of probler. areas euring exposure. The final summary (Figure 15) is a printout of all coments macie by the corputer and Exposure Spectalis and Operato: iuring tine 24-hour period. This includes coments on startup time, exposure cerdination, new calibration factors entered and other inforation wici allows a quick review of events that occurred during the day.

Date handing and anaiysis procedures are described in the

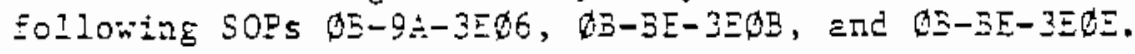

\section{EQUIPMENI OR POKER FAILURE FROIECTION SYSZEXS}

in the event of eguipaent failure, of of a short-term pover failure, two parameters cust be consicered zost important to tie

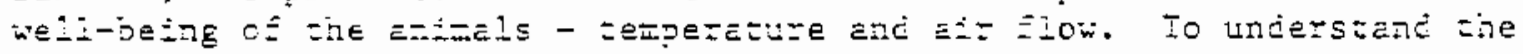

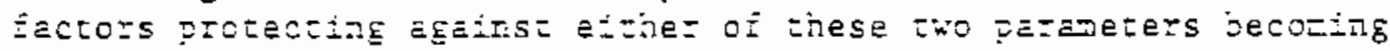

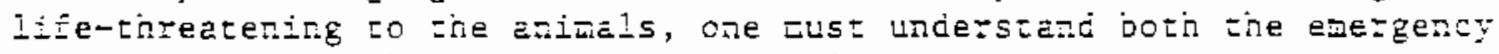

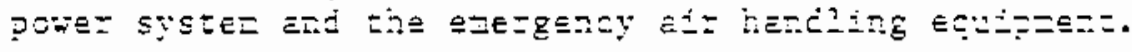

Power is proviced to the Battalie ccupiex ftow two separate cis: substations through en automatic sinccitng device. Inis signizicatiy recuces the possizildty of losing city powez. Fowez Erom the city is routed to ectiplent in LSI-II trrough two types of mosor control centers. One type can switch power to tine ecuipment from eitier city power or emergency power from the LSL-II diesel genezatoz. The orher hes access only to city power. The emergency-power-tye motor control center has a low voliage detector on each leg of the three-pinase input powex. If the city-supplied power should fail or "brown out", these detecrors autoraticaliy start the emergency power diese generator, and route tie energency poter to the equipment supflied by the notor control center. 


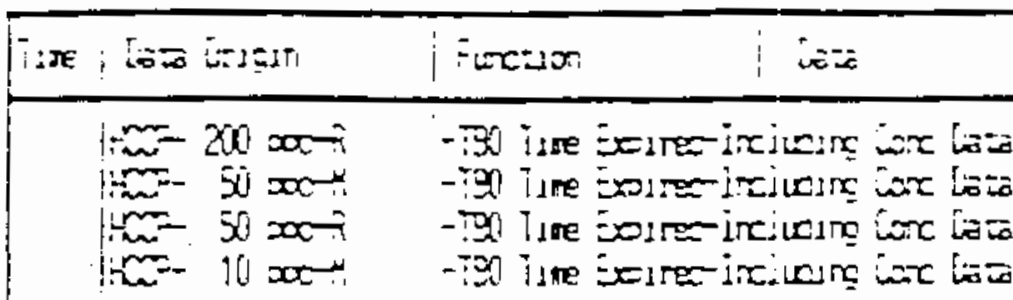

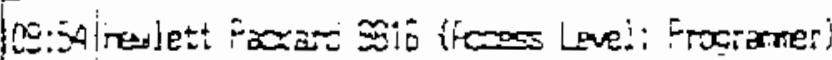

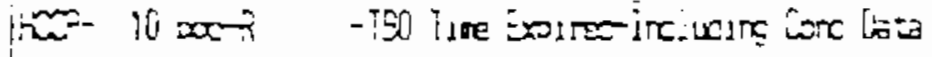

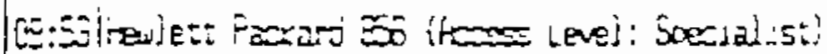

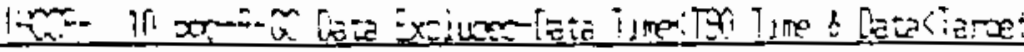

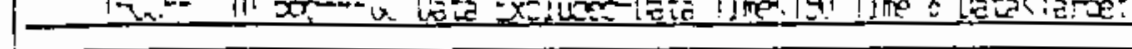

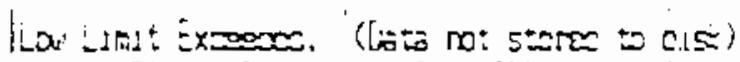

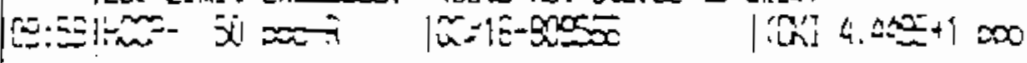

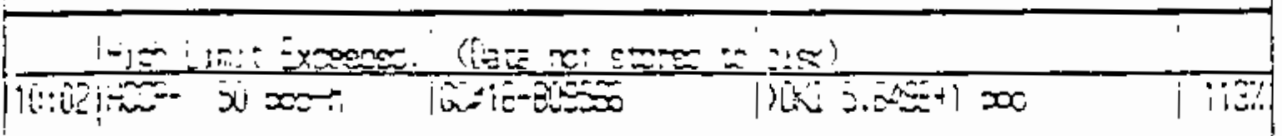

H:

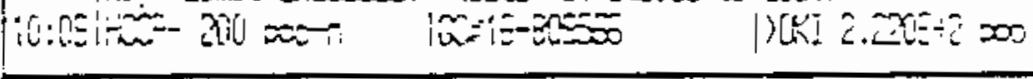

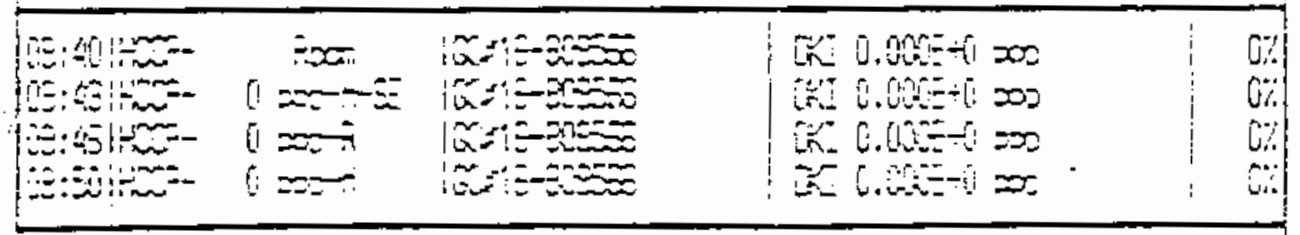

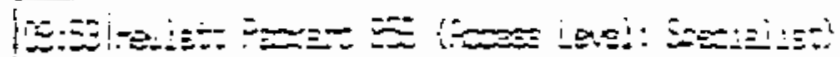

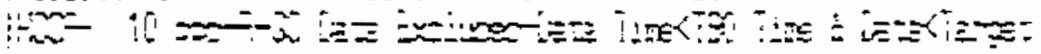

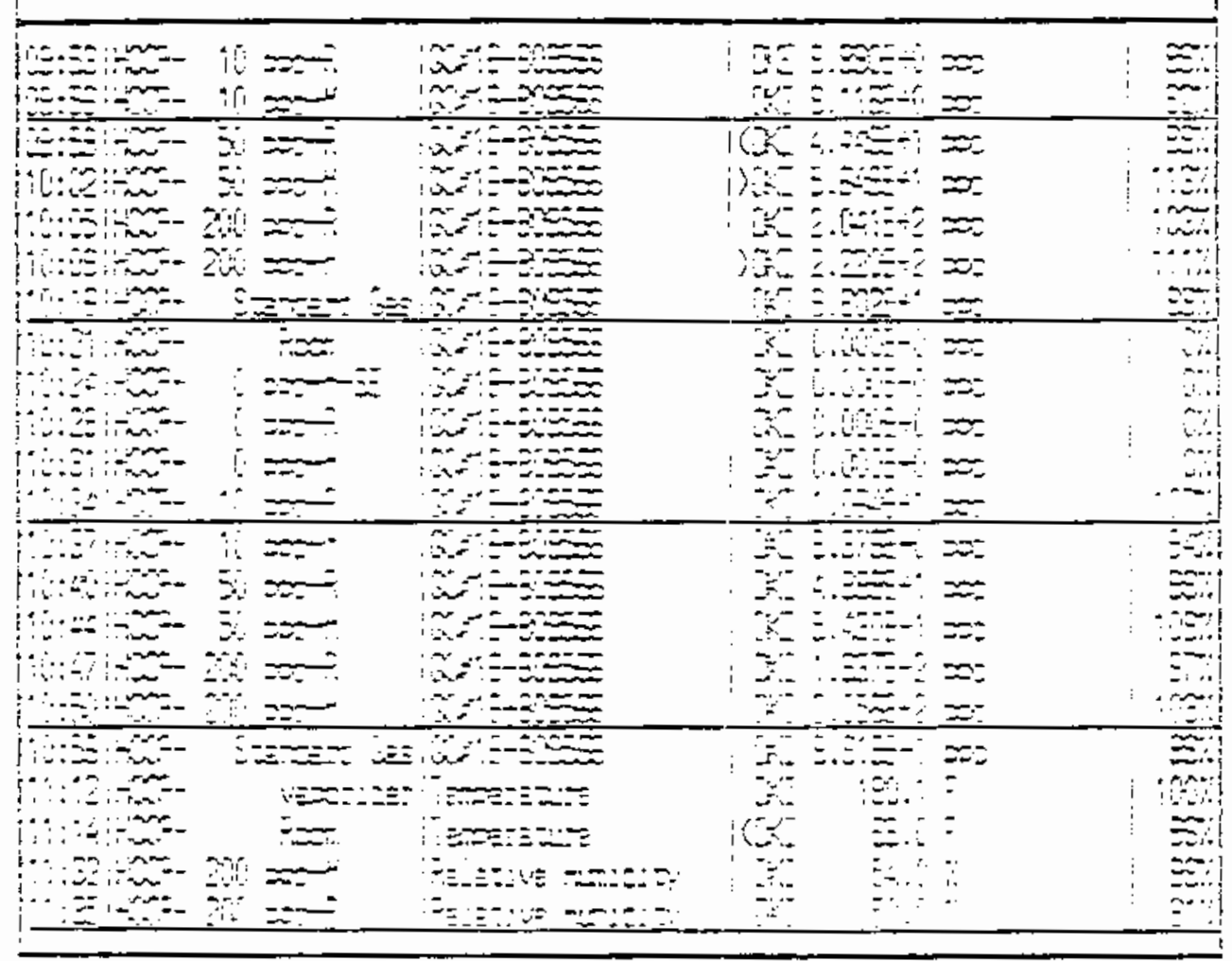

Figure 12. Example of "Daily Log" Printout fron Data Acquisitior. and Control Computer. See followis page for expianation of colums 
The expostre number, exposure name, frogral version and exposure cate vizl he printed at the top of every report page.

Time--inis is the far left colums. Inis is the tame that the measurement vas raken.

Location--This ident1fies where the data came from. Also referred to in the menus as "Location". This column allows for 20 characters.

function--Th1s idencifies which function was used to take the reading. This colum allows for 20 characcers.

Daca--This is the raw dara. Inis coluan inciudes an alaro cooe, a status code, the data value and a unts label.

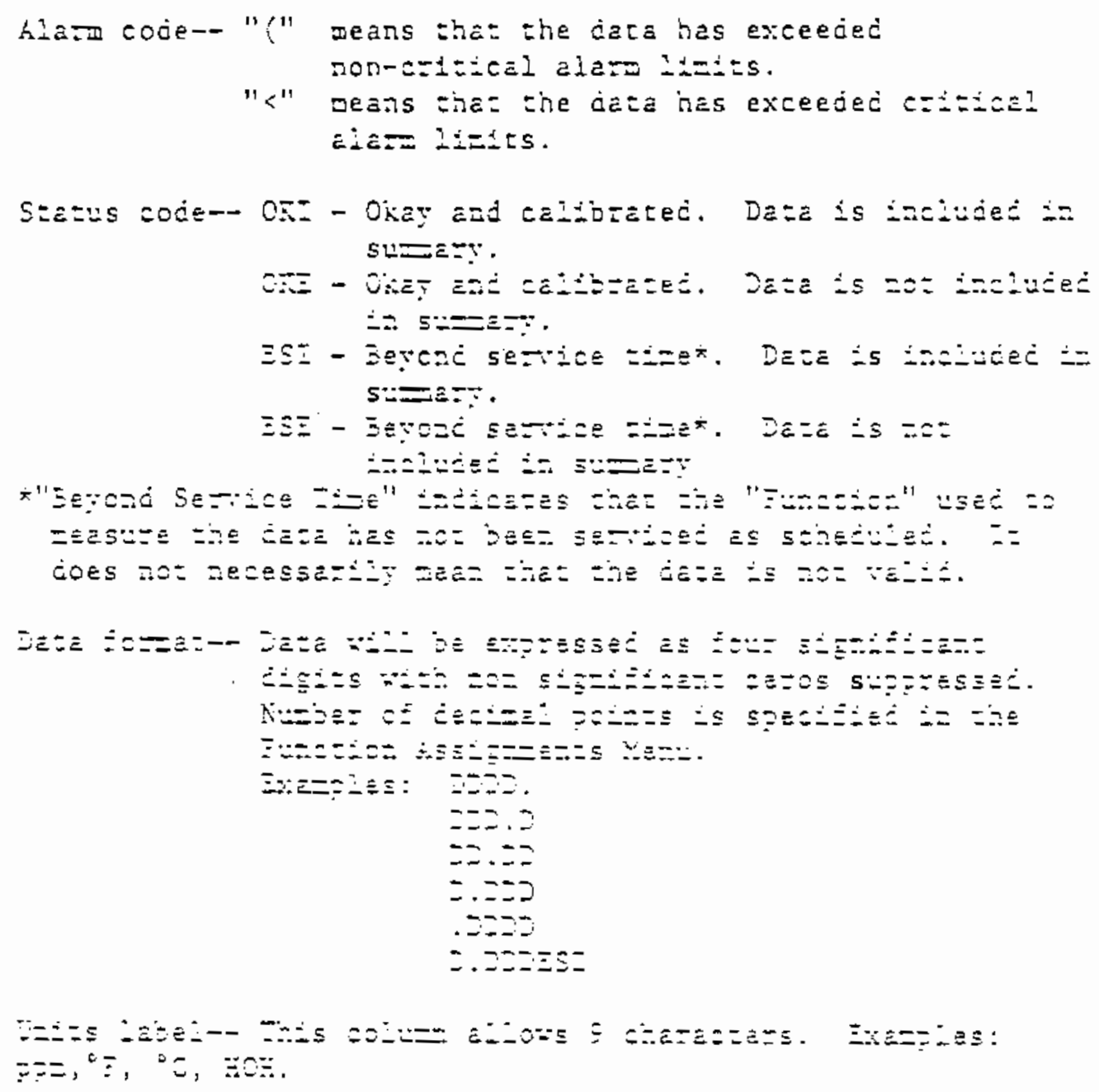




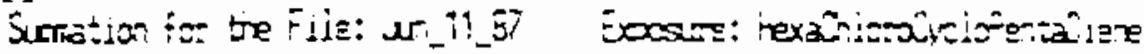

\begin{tabular}{|c|c|c|c|c|c|c|c|c|c|}
\hline$E x a x: 4-7 j$ & ii & $=2 \pi$ & i\% Terot! & 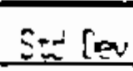 & $\% \approx$ & aximan & $\therefore$ Andar & $2 \pi$ & $x=$ \\
\hline in & 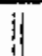 & 14.7 & 5 & .14 & i\% & 15.3 & 14.4 & & $E$ \\
\hline $\lim =200000-3$ & it & 14.9 & $x$ & . .67 & (1) & 15.0 & 14.8 & & $\Xi$ \\
\hline inn $500 x-4$ & 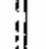 & 14.5 & $5 \%$ & .15 & (\%). & 19.8 & 14.7 & & E. \\
\hline$w_{\infty}^{\infty}=50 x-7$ & & $14 . \hat{\theta}$ & $\Phi \%$ & .12 & $i \%$ & 15.0 & 14.7 & & $\ddot{E}$. \\
\hline in & II & 14.9 & $100 \%$ & .15 & (17) & 15.0 & 14.8 & & $E$ \\
\hline in 10 Doch & $\|$ & 15.6 & $160 \%$ & $\overline{\mathrm{U}}$ & $61 \%$ & 9.1 & $i 4.9$ & & $\hat{\tilde{E}}$. \\
\hline was- $0 p x-4$ & i) & 14.8 & $\approx$ & .19 & $i \%$ & 15.0 & 14.3 & & . \\
\hline $\lim =0$ - $000-\pi$ & & 14.2 & 胥\% & $\approx$ & 5. & 15.1 & 12.5 & & ․ \\
\hline him $0200-5$ & ) & 15.0 & $100 \%$ & .24 & (t) & 15.0 & 19.0 & & $\ddot{E}$. \\
\hline $2 \Omega \pi$ & 1 & hean & 1\% iz-xtil & Sted 0 & 1550 & $\operatorname{axjmax}$ & Hinuax: & & $x=$ \\
\hline$n=200-300-4$ & i. & .9 & 701 & .02 & il. & .5 & .8 & & $\hat{E}$ \\
\hline $\lim _{0}-300 \mathrm{p}$ & 11 & 1.0 & $5 \%$ & $.00^{\circ}$ & $1 \%$ & 1.0 & .3 & & $\hat{\mathrm{S}}$. \\
\hline$H=50=00-1$ & i. & .3 & $\approx$ & . & 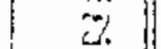 & $\therefore .0$ & $\Xi$ & & :. \\
\hline$y=50=2$ & &.$\overline{0}$ & EN. & .01 & $i \%$ & .3 & .3 & & $=$. \\
\hline ind $10 x$ & $\|$ & 1.2 & 2 & 0 & $i \ddot{i}$ & $\therefore \hat{z}$ & $i .2$ & & 2 \\
\hline$x^{2}-10 x-x$ & 11 & $i .0$ & $\Xi$ & .01 & $\%$ & $\overline{1.6}$ & .2 & & $\pi$ \\
\hline$\forall m=0 x-1$ & . & 1.0 & 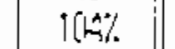 & .02 & $\because$ & 1.1 & 1.0 & & $\ldots$ \\
\hline $\lim =0=x$ & i. & 1.9 & $10 \approx \%$ & .100 & $\%$ & $\therefore .2$ & i.0 & & $\Xi$. \\
\hline $\ln ^{n}=0 x$ & 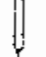 & $i . i$ & $i[\approx$ & .09 & $\%$ & i. & 3.0 & & $\Xi$. \\
\hline I=Lte & 1 & $=-$ & insen & $3=10$ & $\% 3$ & $x$ & 4ninas & & $x^{\prime} \equiv$ \\
\hline$i m-200=-4$ & 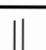 & $\bar{c}$ & 106 & 4.5 & 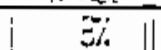 & 20.0 & 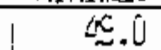 & & $\bar{i}$. \\
\hline$i m-2 n=0$ & & $=2.2$ & $\approx$ & $\equiv \bar{g}$ & 流 & 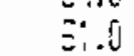 & Si.0 & & v. \\
\hline 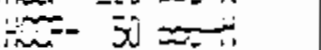 & & 5.5 & $\approx$ & $\therefore 67$ & E. & $=0$ & 47.0 & & E. \\
\hline 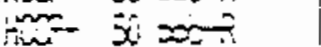 & & $\Sigma 5$ & $\mathrm{i}, \mathrm{i} \%$ & $\equiv .6$ & $\ddot{\mathrm{i} \pi}$ & $\Sigma_{i}$ & $\hat{z} .0$ & & ש. \\
\hline in & il & $\Xi$ & trit ! ! ! & 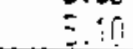 & $\exists$ & $=0$ & $\approx 0$ & & \\
\hline$m^{2} 10 \approx$ & ii & 5.5 & $\pi$ & $\overline{1}$ & i & 5 & $\varepsilon . \overline{\mathrm{j}}$ & & E. \\
\hline Lئ-10 & 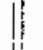 & 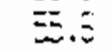 & 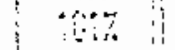 & 5.24 & 2 & $\equiv$ & 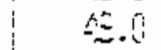 & & $\Xi$ \\
\hline $\lim ^{2} \quad[120$ & is & 3.5 & 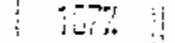 & $\Xi \equiv$ & is: it & $\equiv .0$ & $\approx .0$ & & $\Xi$. \\
\hline 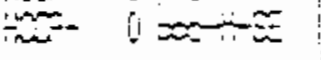 & 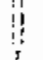 & $\Xi . \vdots$ & ibit & $\equiv$ & $\%$ & $\exists 0$ & $5 i .0$ & & $\Xi$ \\
\hline $\cos =2 \cos$ & 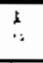 & $\because$ & 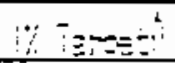 & ias & $7 \times 1$ & ains: & $\operatorname{nin}$ & & $\because " \equiv$ \\
\hline - $\quad 600=$ & 01 & $\hat{2} . \hat{6}$ & Oi. & $\therefore$ & is & 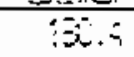 & 50 & & $\Xi$. \\
\hline$\therefore-\quad=\infty$ & 11 & $\Xi$. & $\Xi \because$ & $\equiv$ & \begin{tabular}{l:l}
$\cdots$ \\
\hdashline
\end{tabular} & 7.5 & $\approx 0$ & & E. \\
\hline$m=-2 i j=$ & ii & 75.7 & nis & $\therefore$ & $\cdots \quad \therefore$ & $=2$ & $\Rightarrow 3$ & & E. \\
\hline$m=x-$ & if & $7 \ldots$ & $\cong$ & $\approx$ & $\because$ & $\therefore:$ & $\therefore \equiv$ & & $\vdots$. \\
\hline$\because-\quad=$ & !: & $=$ & 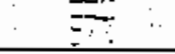 & $\therefore$ & $\therefore$ & $\because$ & $\therefore$ & & $\vdots$ \\
\hline$\therefore$ & i & $\bar{Z}$ & an & 年 & $\%$ & 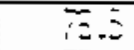 & 7.2 & & 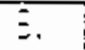 \\
\hline$\therefore=$ & ': & $7 i .3$ & $\approx$ & $\approx$ & $\cdots$ & $\because \therefore$ & $r:{ }_{i}$ & & $=$ \\
\hline$\therefore-$ is & $\therefore$ & 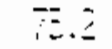 & i & آنة. & $\bar{i} \quad \vdots$ & $\because \ddot{z}$ & 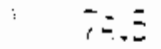 & & $\vdots$ \\
\hline$\approx \quad 6 \approx-$ & 泣 & $7 \div 5$ & 证 & $\therefore$ & $\ddot{i z:}$ & $\because=$ & $7 \div . i$ & & $\vdots$. \\
\hline 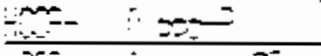 & & $7-3$ & $\approx$ & & 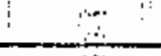 & $\therefore \vdots$ & $\because \ldots$ & & \\
\hline$\therefore \quad \therefore=2 \pi$ & . & $\therefore$ & $\approx$ & 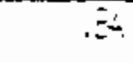 & is. & $\therefore$ & $\therefore$ & & $\vdots$ \\
\hline 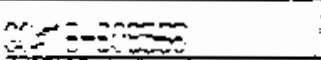 & & $\equiv$ & $=\angle E$ & & $m$ & & 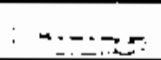 & $=$ & $\because "$ \\
\hline$\therefore \approx-14: \infty$ & & $\approx \approx-2$ & $i$ & & $\tilde{F}$ & 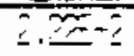 & 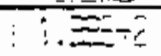 & & 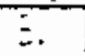 \\
\hline$n=-20$ & & $\hat{x} \div 2$ & ! 10\% & & 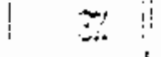 & & .50 & & $\Xi$ \\
\hline
\end{tabular}

Eigure 33. Exazple of hL-Hour Date "Sluation" Pzintolt from Data Accuistion and Cortrol Complizer. Data are organized by dara type. 


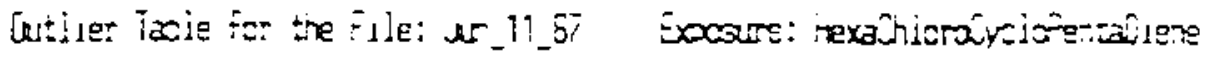

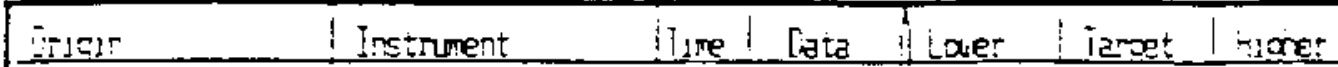

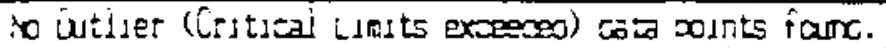




\begin{tabular}{|c|c|}
\hline $\begin{array}{l}\text { Waily Coments } \\
\text { Tuse inerator }\end{array}$ & 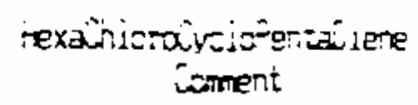 \\
\hline
\end{tabular}

00:14 [avic J. Eailey

0g:14 [avid J. Bäley

0.15 Cavíc J. Earley

0.:15 Lavio j. Eariey

De:16 Davioj. Eailey

00:16 Bavid J. Eariey

00:16 lavid J. Baniey

09:15 Lavió d. Bailey

[0:17 Davió j. Eailey

00:17 Lavid J. Eailey

n::17 Rovid J. Ealiey

$09: 23$ hevlett Pacraro ad

$00: 3$ hediett Pacard os

00:33 fevjett Parar $₫ 15$

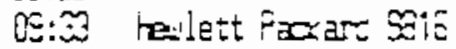

0 c:34 palett Facraro 3816

0.:A hevett Froercosio

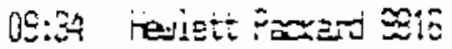

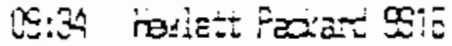

0.:34 hesiett iacors

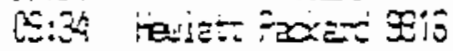

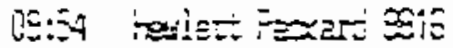

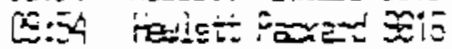

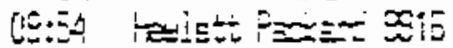

0:34 reis

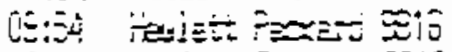

a.

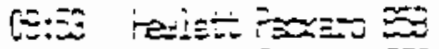

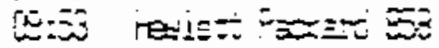

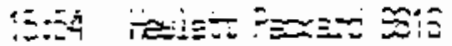

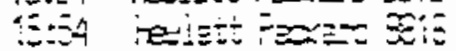

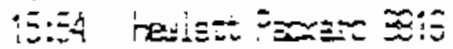

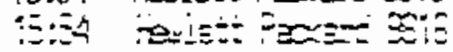

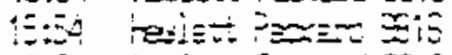

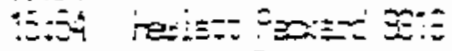

is:-

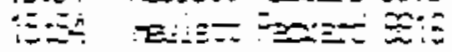

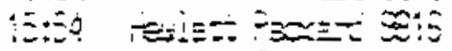

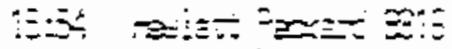

I:

法

:

提

$\therefore: \div$

经:

$1:: \vdots 3$

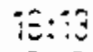

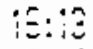

İ:

$::::_{2}^{2}$

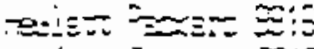

resiz:

reilit

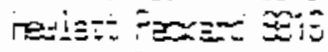

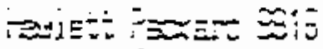

-

raici

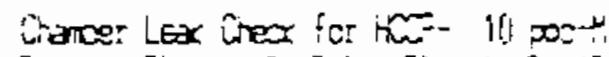

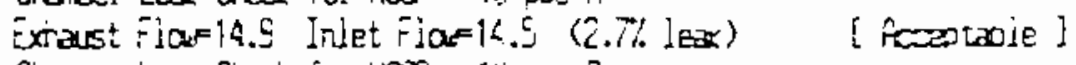

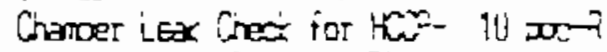

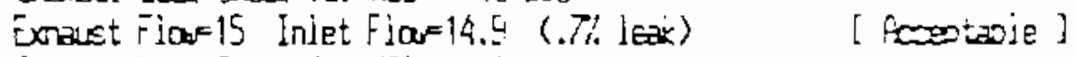

Grander Leax Chex for How- (1) pow

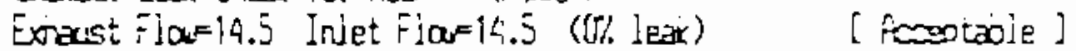

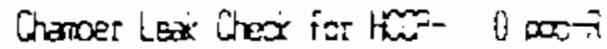

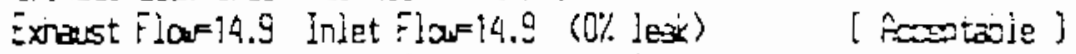

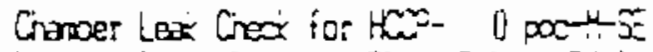

Exraust law 15 inlet Flar $15.3 \quad(-2 \%$ lesix)

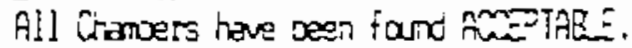

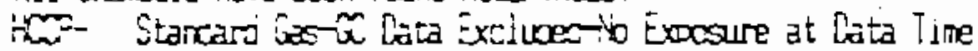

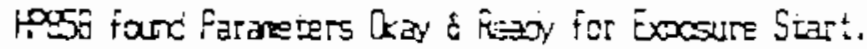

Exocsure Tining siartec.

Generator th

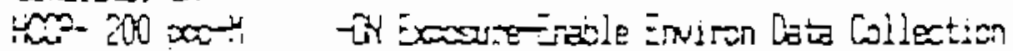

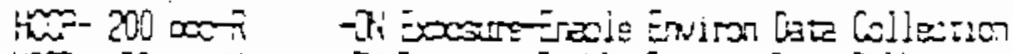

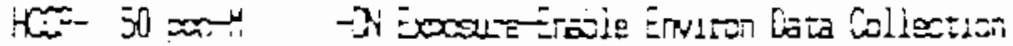

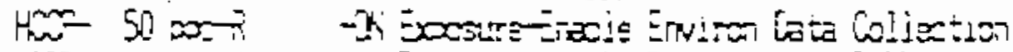

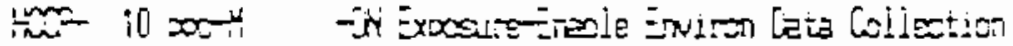

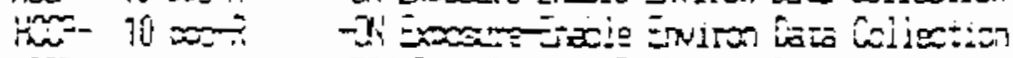

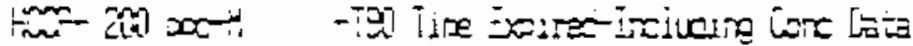

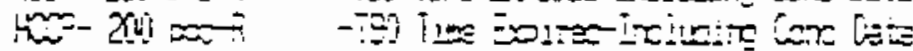

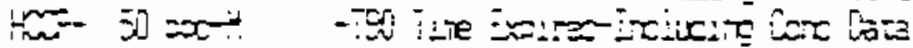

然

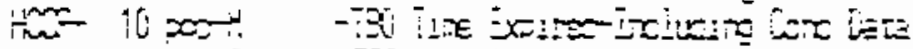

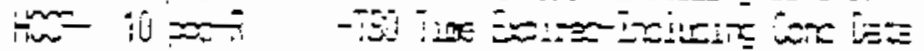

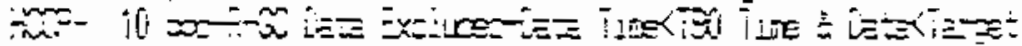

诲

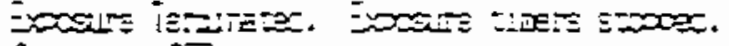

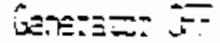

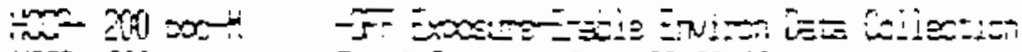

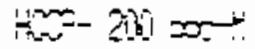

$=20=0$

$\lim _{i \infty} 2 x+2$

$i_{i \infty}=0$

$m=3 i \infty$

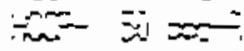

$\therefore-$

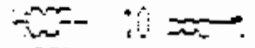

$\operatorname{lin}^{2}-10=0$

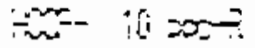

in

EN:

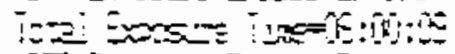

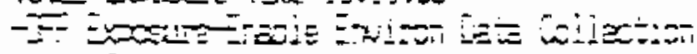

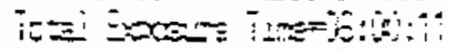

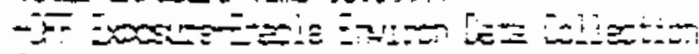

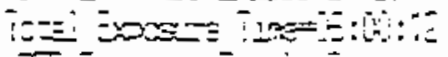

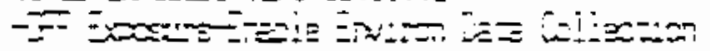

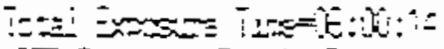

F

it:

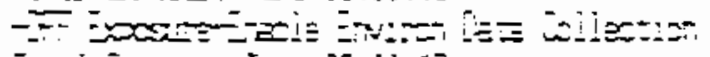

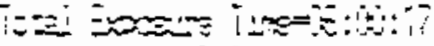

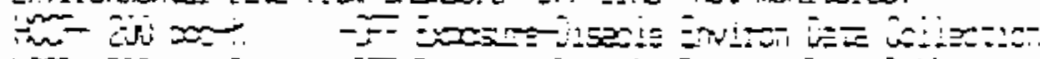

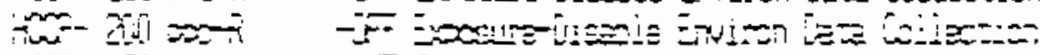

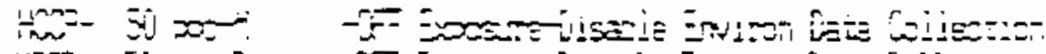

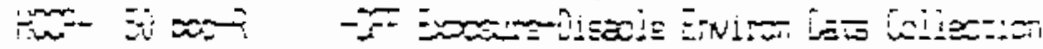

in- id 00 -

保然

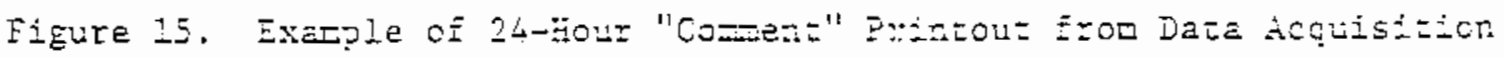
anc Concrol Co=puser 
All equipment critical to the well-being of the animals is connected to the emergency-power-type motor control centers. A list of this equipment is as follows:

- Emergency lighting and electrical outlets

- Chillers $\$ 1$ and $\$ 2$

- Boiler and feedwater pump systems $\# 1$ and $\# 2$

- Air compressors

- Air supply fans $\$ 1$ and $\$ 2$

- Air exhaust fans \#1 and

It should be noted that there are two identical units of all of the equipment that are vital to the well-being of the animals (heating, cooling, supply air, exhaust air, and compressed air). Either of the two units has sufficient capacity to maintain the animal environment within a safe range. In all cases, the emergency power systeri will operate one of the two identical units. If, during a power outage, the unit of equipment that is on emergency power should happen to faji, the other unit of identical equipment can be manually switched to run on emergency power.

All building or chamber systems which are essential to the survival of the animais are alermed. If a system malfunctions, an alarm is tripped in the power operator's office. A power operator is on duty 24 hours/day, 7 days/week. If the power aperator is not autnorized to correct the probien that caused the alarm, he inineciately calls the appropriate personnel, including the Task Leader(s) or the Principa? Investigator(s) of the progran(s) iffected.

\section{Peferences}

Grifijs, L.C., R.K. Wolff, R.L. Beethe, et. àl. (1981). Evaluetion of a mul $i$-tjered innalation exposure chamoer. Fund, Appl. Toxicol. $1: 8-12$.

Bernstein, D.Y. and R.T. Drew. 2980. The major parameters a fifecting temperzture inside inhaiation chambers. AiHAJ, (4i) $6 / 80, p 2,420-426$. 

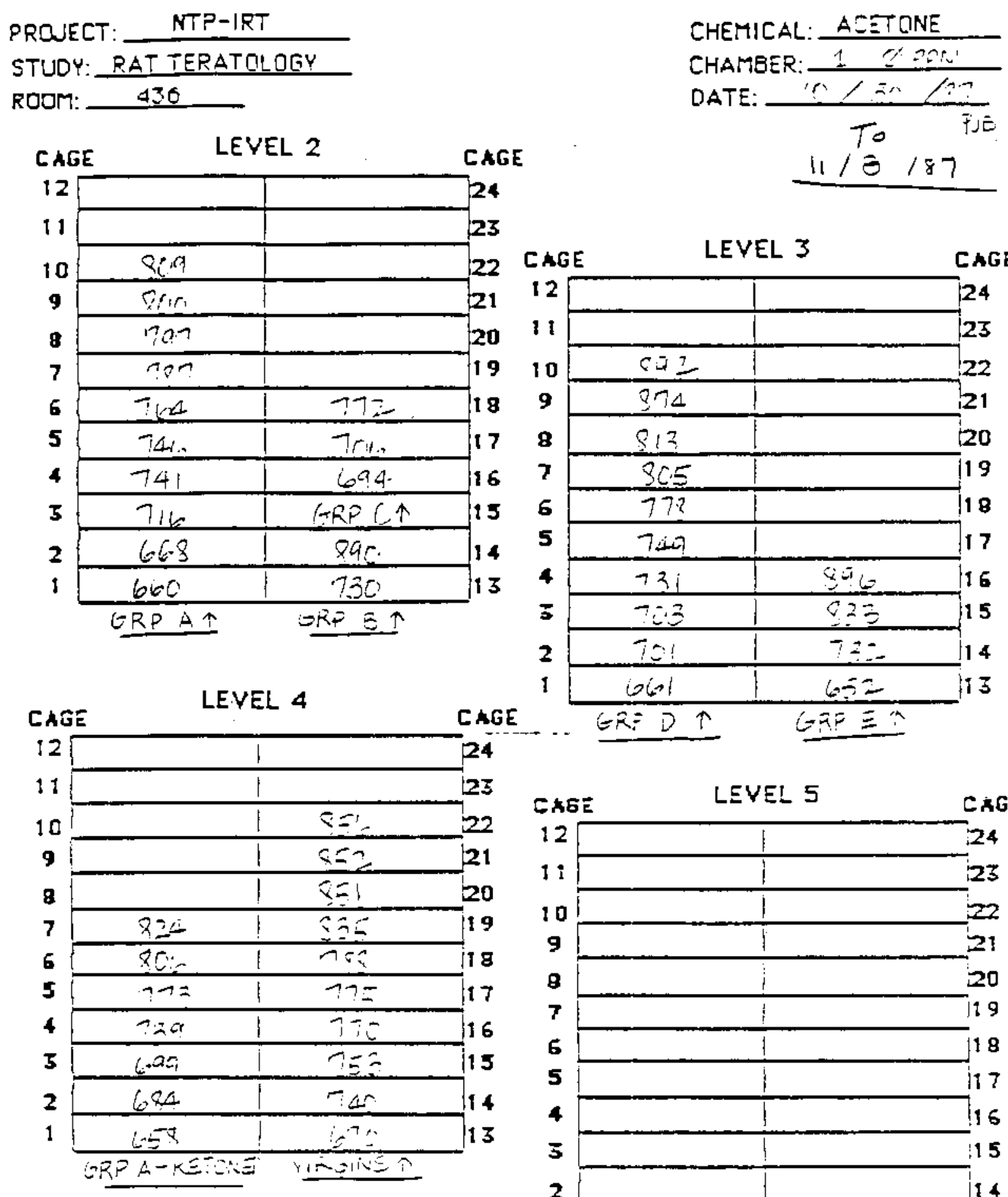

EOMMENTS

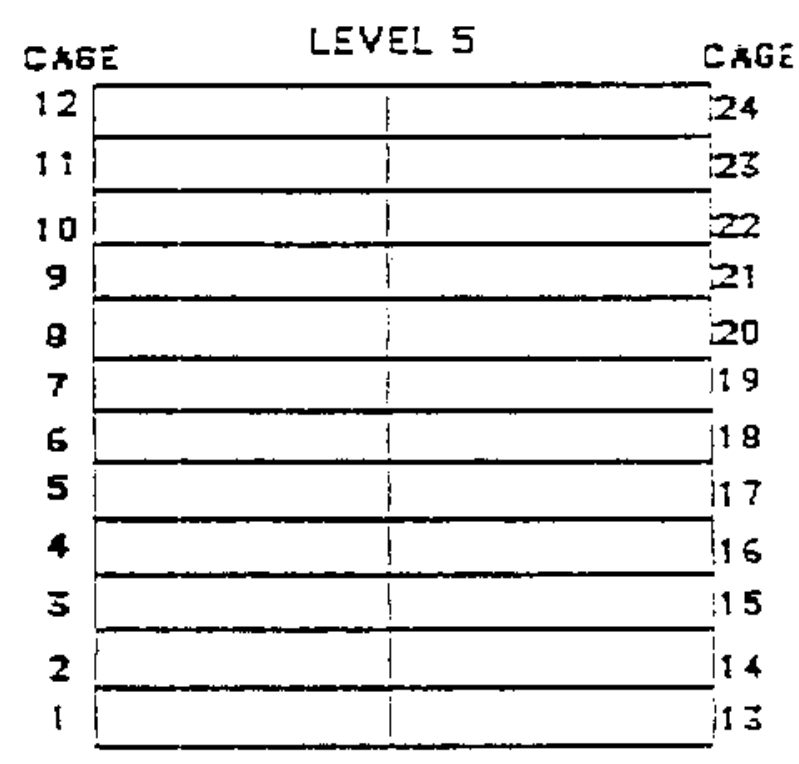



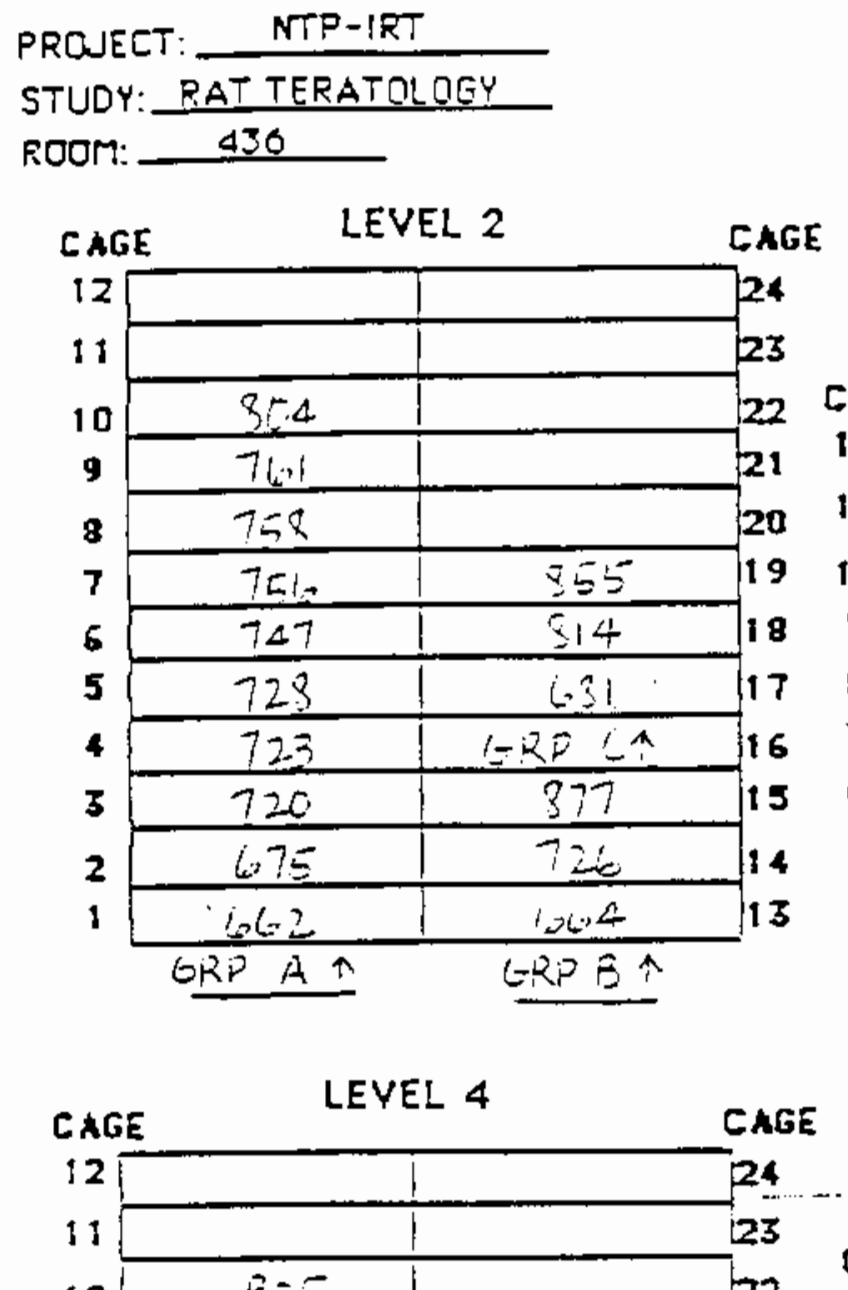

\section{:DMHENTS}

22

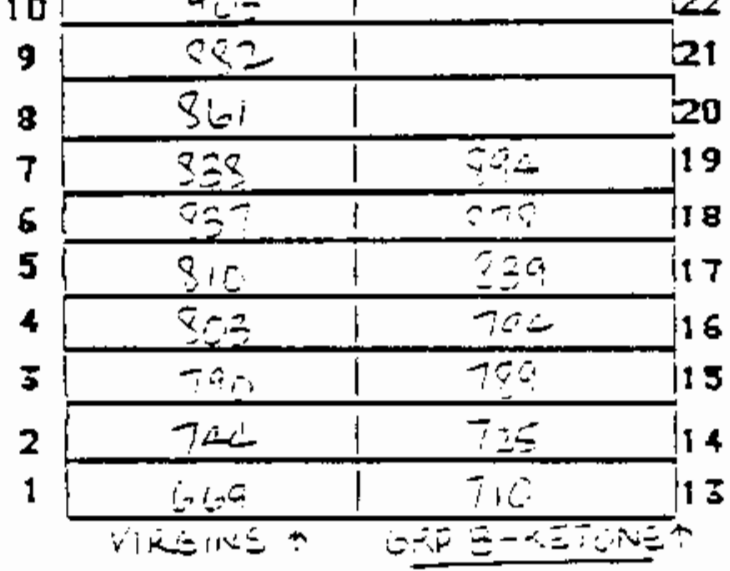

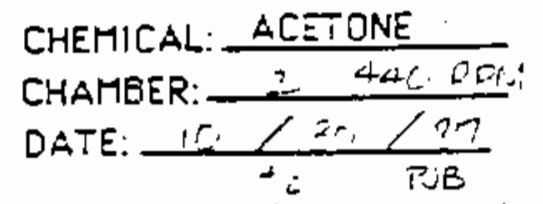

$11 / 8 / 87$

\section{LEVEL 3}

CAGE
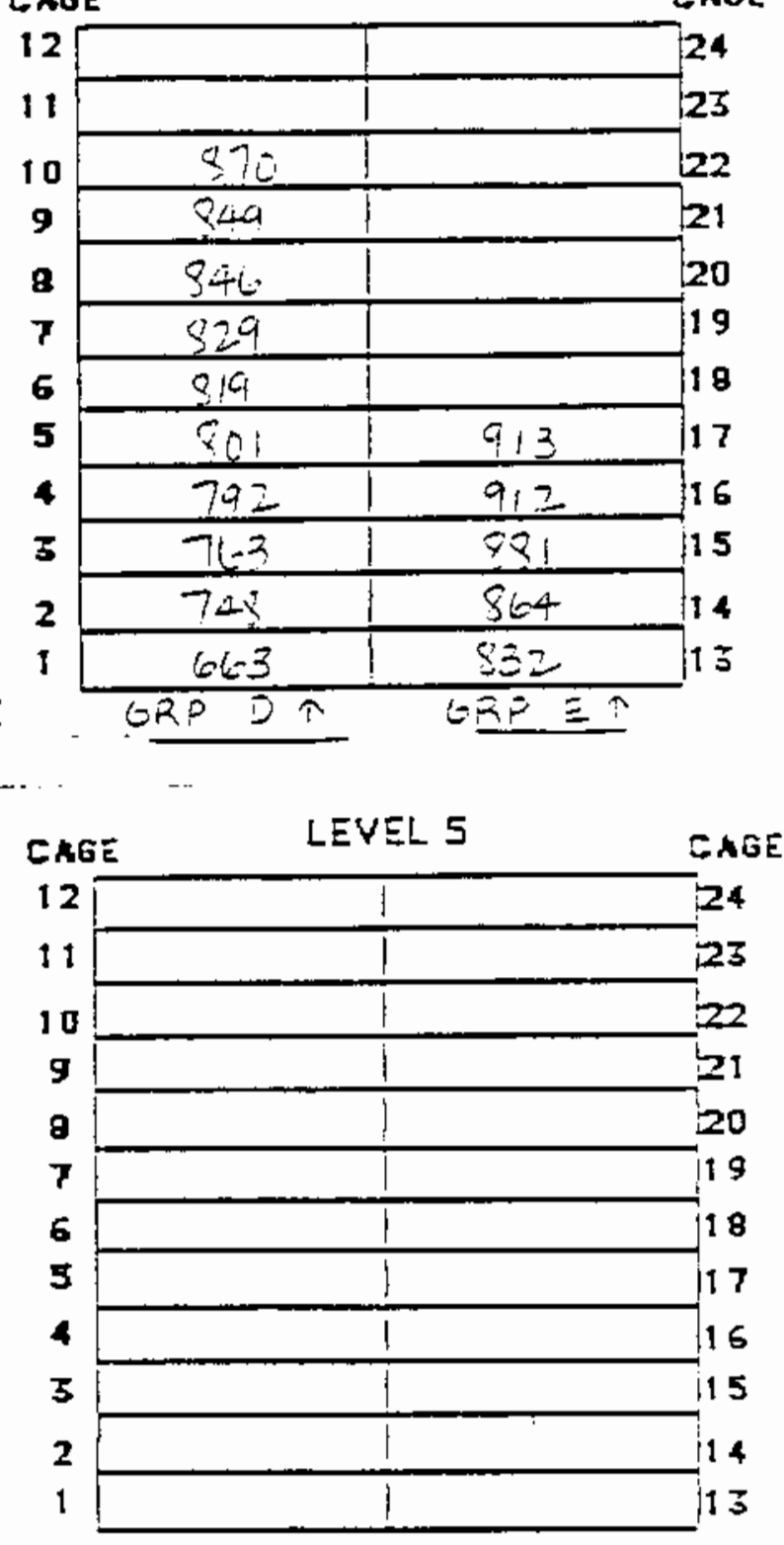


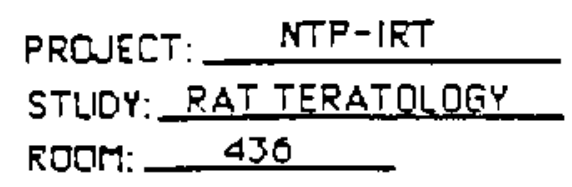

CAGE LEVEL 2
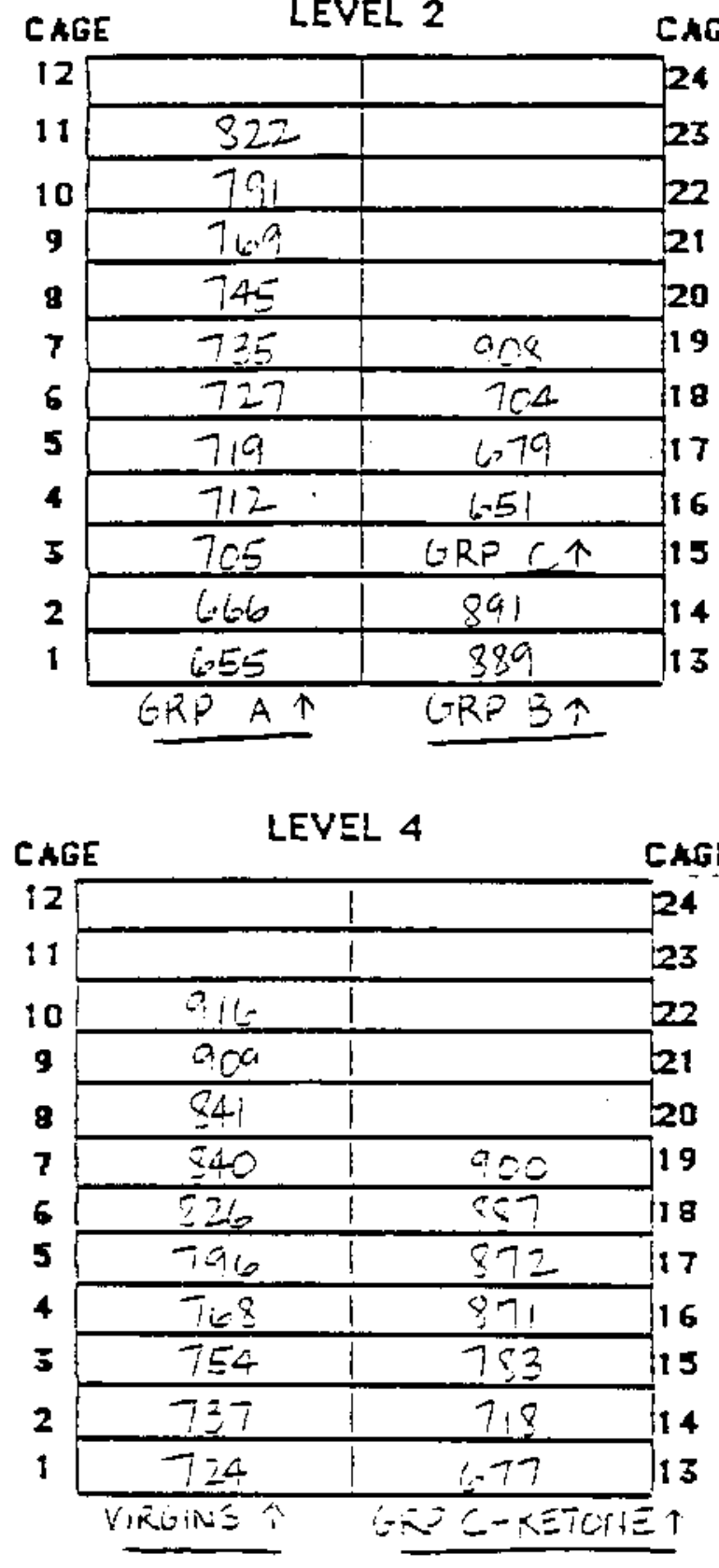

:OMMENTS

24

24
CHEMICAL: ACETONE

CHAMBER: $\frac{3 \quad 22 C C D P R}{2}$

DATE: $\frac{1 M / 2 n / 17}{70}$

$11 / 8 / 87$
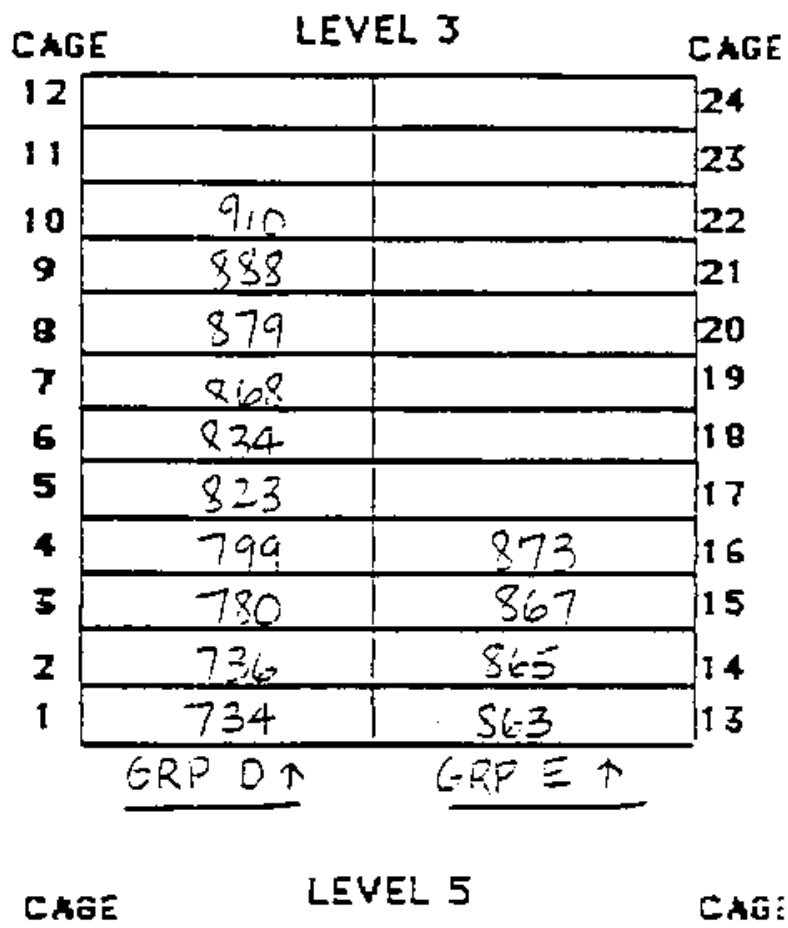

CAu:

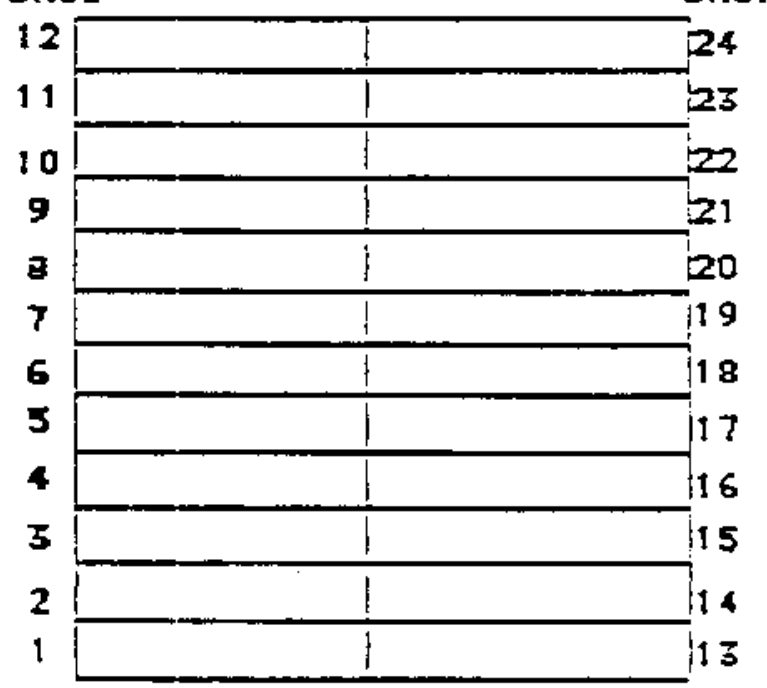



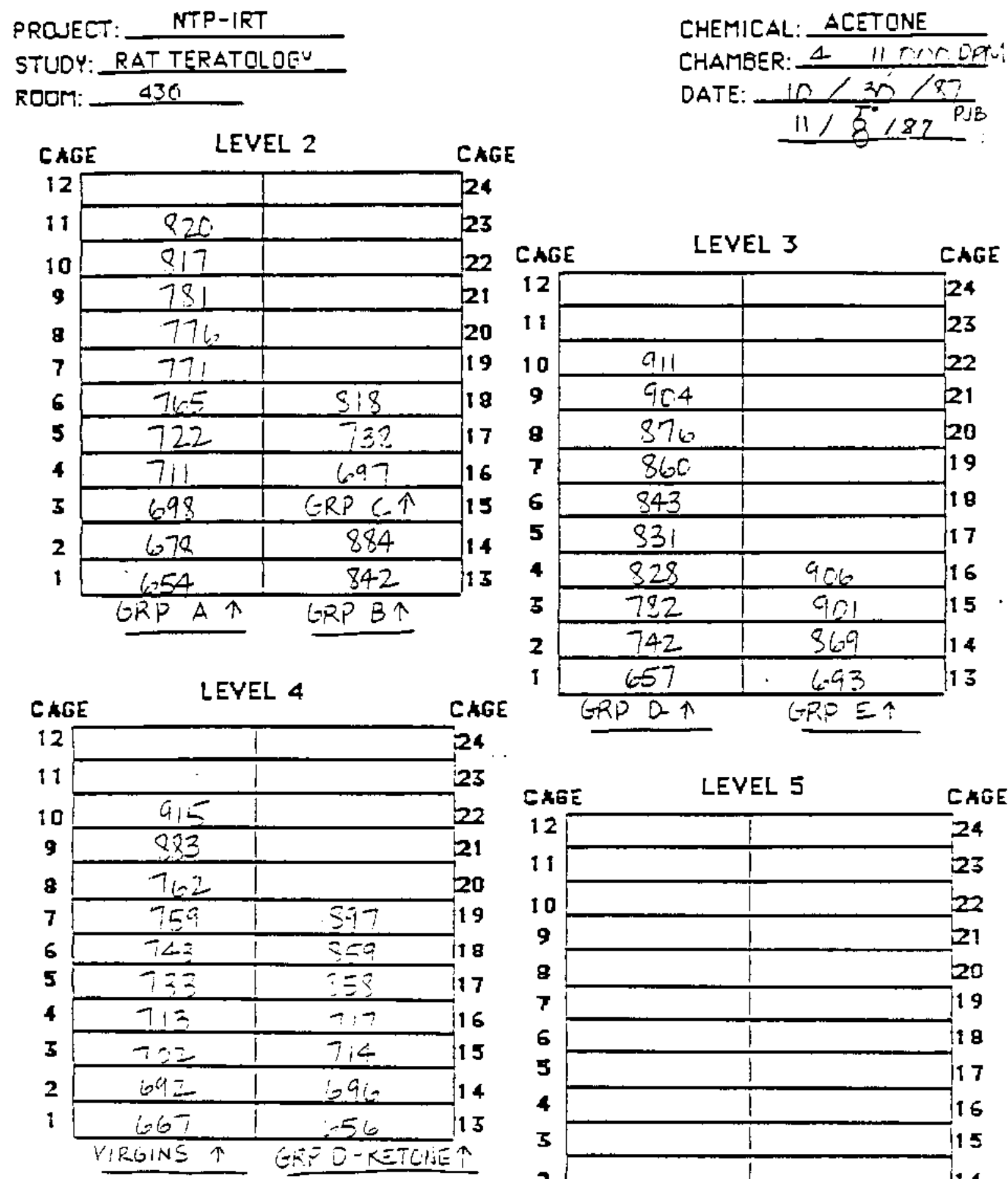

-DMMENTS

CHEMICAL: ACETONE

CHAMBER: 4 UIOCOAA:

DATE: $10 / 20 / 8$ $11 / 8^{6} / 87^{\mathrm{PJB}}$

CAGE

24

24

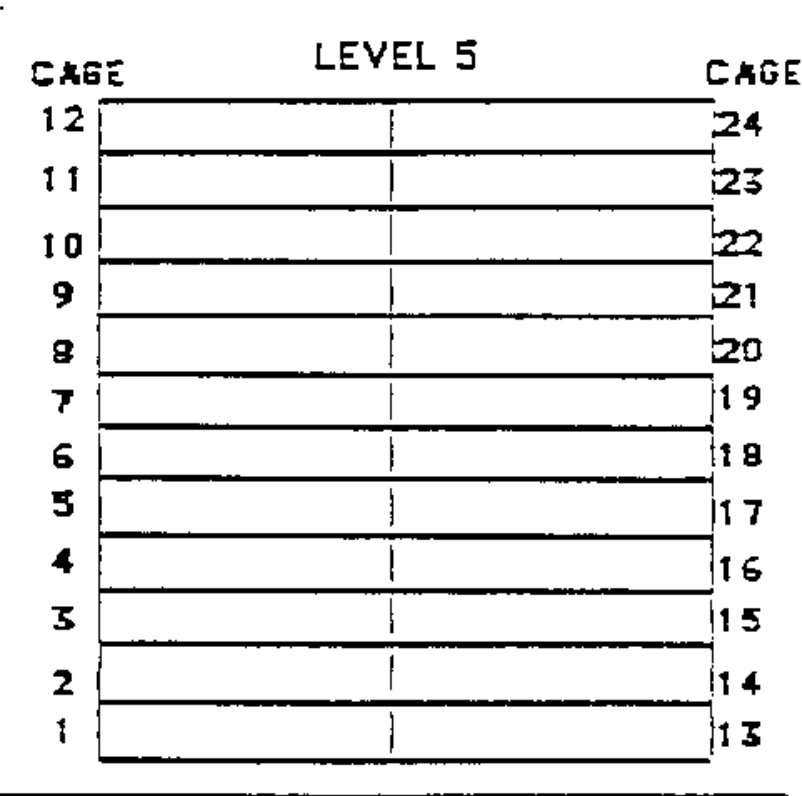


PROJKCT: NTP-IRT

STUDT: HOUSE TRRATOLOGT

ROOI:

436

LEVEL 4

\begin{tabular}{|c|c|c|c|}
\hline & 1 & & 1 \\
\hline & $i$ & & 1 \\
\hline & 1 & & $i$ \\
\hline & ! & & $i$ \\
\hline & 1 & & 1 \\
\hline & $\bar{i}$ & 1325 & 1 \\
\hline & $i$ & $12=3$ & $i$ \\
\hline & 1 & 1310 & 1 \\
\hline $13 E^{\prime} 6$ & 1 & 1705 & I \\
\hline 1293 & 1 & 138 & 1 \\
\hline 1289 & 1 & $i 27$ & 1 \\
\hline 1254 & 1 & 1198 & $i$ \\
\hline $1=39$ & 1 & 1157 & 1 \\
\hline 1225 & 1 & 1151 & 1 \\
\hline 1078 & 1 & 1057 & 1 \\
\hline
\end{tabular}

CEEIICAL : $\quad$ LCTONL

CHAmer: $\frac{1 \text { r nom }}{12-601}$

DATE:

\section{LEVEL 3}

\begin{tabular}{|c|c|c|c|c|c|}
\hline & 1 & & , & & 1 \\
\hline & 1 & & $T$ & & 1 \\
\hline & 1 & & $i$ & & 1 \\
\hline & $i$ & & 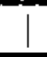 & & 1 \\
\hline & 1 & & 1 & & 1 \\
\hline & 1 & & 1 & & 1 \\
\hline & 1 & & 1 & 1273 & 1 \\
\hline & 1 & & 1 & 1248 & 1 \\
\hline & 1 & & 1 & 1125 & 1 \\
\hline & 1 & 1213 & $i$ & 1179 & $1121=$ \\
\hline 1131 & $i$ & 1120 & $i$ & 1092 & 11269 \\
\hline 1123 & $i$ & $11^{7} \%$ & 1 & 1090 & $1 \quad 12 \hat{15 z}$ \\
\hline 10.74 & $!$ & 1164 & 1 & 1952 & 11193 \\
\hline 1rits & $i$ & 1,1 & i & $10:=$ & 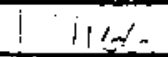 \\
\hline 1656 & 1 & $1=20$ & $i$ & $\therefore 1=$ & $104-$ \\
\hline
\end{tabular}

\section{COMMENTS}


PROJECT: HTP-IRT

STUDT: HOUSE TLRATOLOGT

200I:

436

LEVEL 4

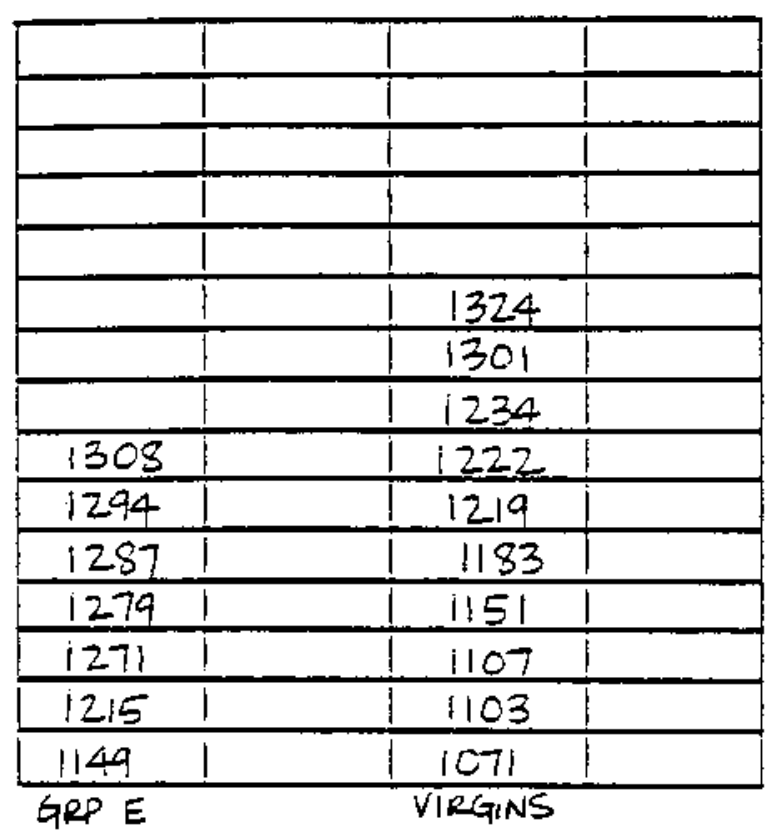

CHIIICAL : ACETONE

CEAMER: $2 \quad 440 \mathrm{cPm}$

DATE: $\frac{12-6-87}{464}$

LEVEL 3

\begin{tabular}{|c|c|c|c|}
\hline & & & \\
\hline & & & \\
\hline & & & \\
\hline & & & \\
\hline & & & \\
\hline & & 1521 & \\
\hline & & 1317 & \\
\hline & & 1274 & \\
\hline & & 1270 & \\
\hline & 1182 & 12001 & \\
\hline 1132 & $116 !$ & 1251 & 1238 \\
\hline 1104 & 1123 & 1171 & 1199 \\
\hline 1042 & 1034 & 1156 & 1147 \\
\hline 1032 & 1029 & 1066 & 1093 \\
\hline 1001 & 1002 & 1033 & 1069 \\
\hline
\end{tabular}

\section{COMMENTS}


PROJECT: HTP-IRT

STUDT: HODSE TLRATOLOGT

200I: 436

LEVEL 4

\begin{tabular}{|c|c|}
\hline & \\
\hline & \\
\hline & \\
\hline & \\
\hline & \\
\hline & 1275 \\
\hline & 1256 \\
\hline & 1210 \\
\hline 1328 & 1168 \\
\hline 1296 & 1143 \\
\hline 1291 & 1124 \\
\hline 1260 & 1095 \\
\hline 1244 & 1072 \\
\hline 1233 & 1062 \\
\hline 1220 & 1041 \\
\hline
\end{tabular}

CHEIICAL: ACFTOH

CHAOEER: 3 2200 pom

DATI: $\frac{12-6-87}{1+i w 19}$

\section{LEVEL 3}

\begin{tabular}{|l|l|l|l|}
\hline & & & \\
\hline & & & \\
\hline & & & \\
\hline & & & \\
\hline & & & \\
\hline & & & \\
\hline & & 1312 & \\
\hline & & 1284 & \\
\hline & & 1253 & \\
\hline & 1208 & 1165 & 1201 \\
\hline 1157 & 1181 & 1155 & 1178 \\
\hline 1167 & 1169 & 1086 & 1138 \\
\hline 1150 & 1137 & 1063 & 1094 \\
\hline 1136 & 1088 & 1049 & 1050 \\
\hline 1119 & 1037 & 1017 & 1035 \\
\hline GRP A & GRP & GRP C & GRP D \\
\hline
\end{tabular}

\section{COMMENTS}


PROJECT: MTP-IRT

STUDT: HOUSE TIRATOLOGT

ROOI:

436

LEVEL 4

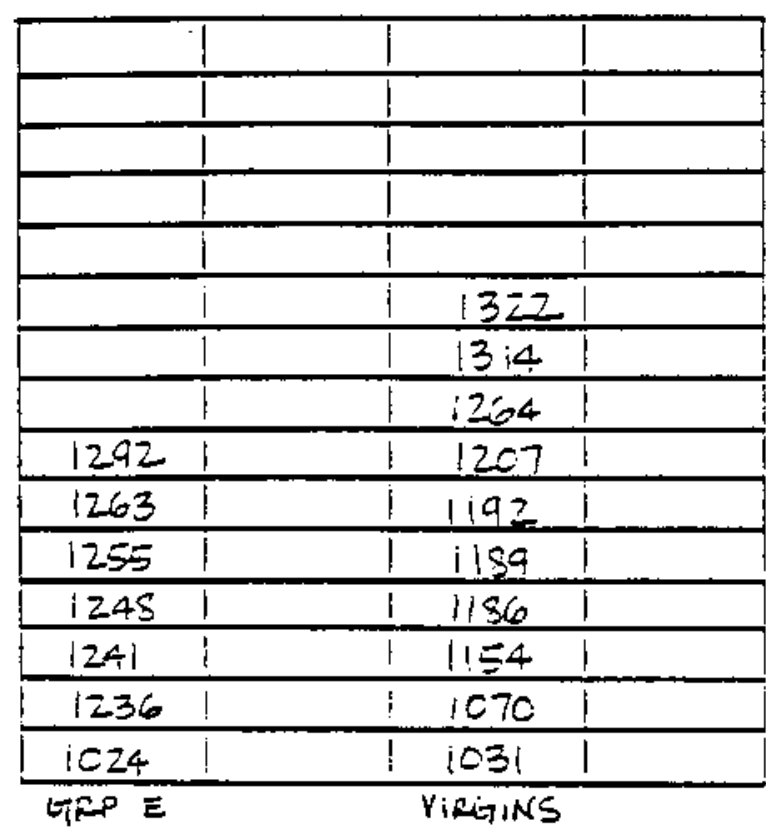

CHIIICAL: ACETORE

CHAMres: 4 Lespon $C$

DATI: $-\frac{12-6-87+i 2-13-5]}{2}$ Whit (1) Dese level change $12,30-5$ ? 级里

LEVEL 3

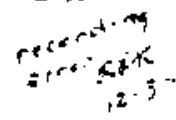

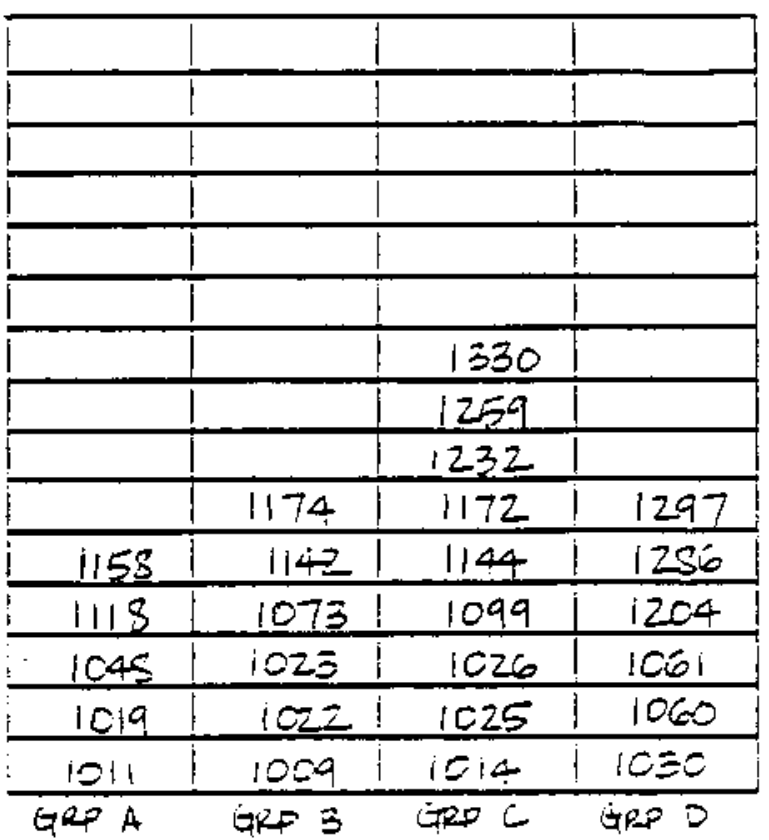

\section{COMMENTS}




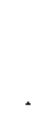




\section{DISTRIBUTION}

No. of

cepies

QEESITE

2 DOE/Office of Scientific and Technical Information

D. Smith

U.S. Department of Energy

ER-72, GTN

Washington, D.C. 20545

10 R.E. Morrissey and

B.A. Schwetz

National Toxicology Program - NIEHS

Alexander Drive

Bldg. 101, Room D440

Research Triangle Park, NC 27709

E.B. Ford

National Institute of Environmental Health Sciences Contracts Management Office, OAM

79 Alexander Drive, Bldg. 4401

P.O. Box 12874

Research Triangle Park, NC 27709

\section{QNSITE}

DOE Richland operations office

E.C. Norman/D.L. Sours

20 Pacific Northwest Iaboratory

E.M. Crow (2)

R.A. Gelman

T.J. Mast (11)

Publishing Coordination

Technical Report Files 
